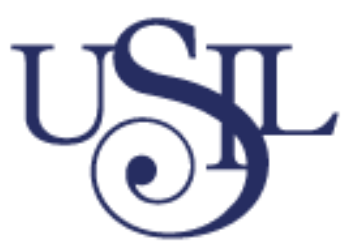

UNIVERSIDAD

SAN IGNACIO

DE LOYOLA

FACULTAD DE ARQUITECTURA

Carrera de Arquitectura, Urbanismo y Territorio

\title{
"MEJORAMIENTO URBANÍSTICO Y EQUIPAMIENTO COMERCIAL - EMPRESARIAL POST PANAMERICANOS ENTORNO DE LA VILLA PANAMERICANA EN VILLA EL SALVADOR"
}

Tesis para optar el Título de Arquitecto

KATHERINE MELISSA OLIVEROS ANDRADE

Asesor:

Arquitecto Carlos Chacón Málaga

(Lima - Perú)

2020 


\section{DEDICATORIA:}

La presente tesis está dedicada a mis PADRES CATALINA Y MARINO que tanto amo, por brindarme siempre su apoyo incondicional desde el comienzo de mi carrera y en cada etapa de mi vida, por implantar en mi ser un profesional y persona con valores, el logro también es de ellos. Gracias por comprender con paciencia la dedicación que se requiere para finalizar esta etapa tan importante de mi vida.

También dedico este logro a mi HERMANO EDGARD al que amo con todo mi corazón por todos sus consejos, aliento y todas sus enseñanzas que me motivaron a continuar hasta el final, de él he aprendido muchas cosas.

A MI ABUELO VICTORINO Y A MIS ABUELOS PANCHO, DOMITILA Y MARIETA QUE ME GUIIAN DESDE EL CIELO. No podía dejar de nombrar a mis compañeros de cuatro patitas que fueron los mejores... acompañándome en todas mis amanecidas de la universidad Roxy, Tyson y Oso los guardo en mi memoria.

AGRADECIDA AHORA Y SIEMPRE CON DIOS... 


\section{AGRADECIMIENTOS:}

Quiero expresar mi sincero agradecimiento principalmente al arquitecto Carlos Chacón Málaga por

ayudarme a perfeccionar las capacidades que adquirí de la carrera para culminar mi tesis. $Y$ a los arquitectos Luis Tagle e Yvan Soto por su apoyo y consejos en este trabajo.

A todos mis profesores de la carrera de los que aprendí enormemente de sus enseñanzas profesionales, a todas las personas y amigos quienes con su aliento en este largo camino a llegar a la meta y motivación me demostraron su confianza en mi muchas gracias. 


\section{$\underline{\text { ÍNDICE }}$}

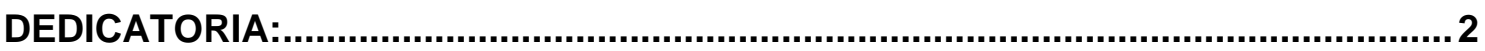

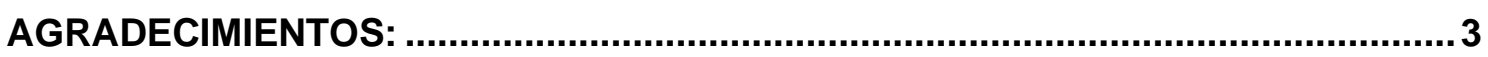

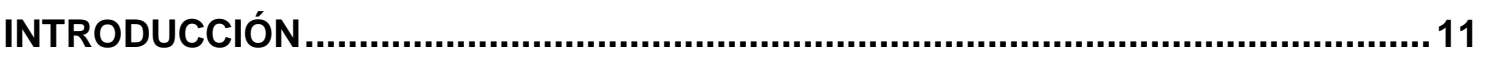

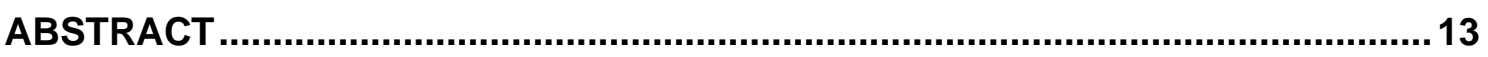

1. Planteamiento del proyecto. .............................................................................. 15

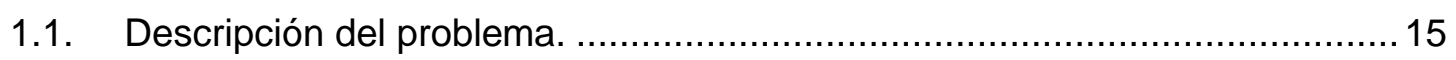

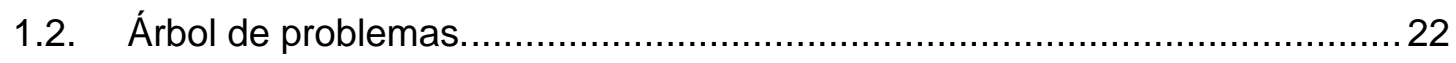

1.2.1. Retrasos en el tiempo para la planificación y ejecución del Plan Maestro

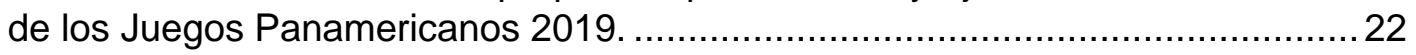

1.2.2. Déficit de áreas urbanas destinadas finalmente para uso comercial que dé soporte a las actividades diarias de la ciudad................................................ 26

1.2.3. Poca participación de los gobiernos locales en el desarrollo del Plan Maestro de los Juegos Panamericanos 2019............................................. 30

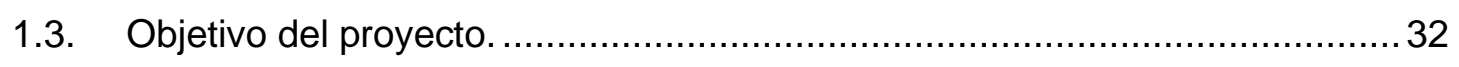

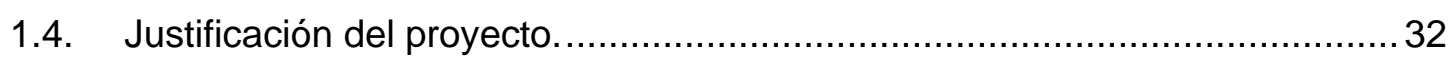

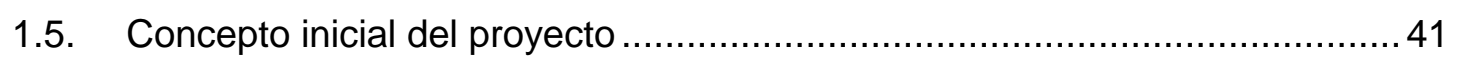

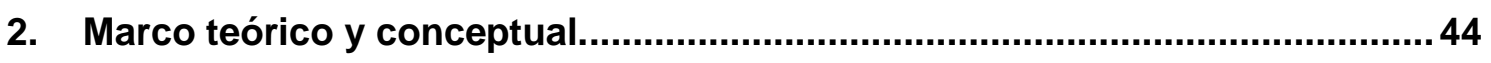

2.1. Ejemplos arquitectónicos referenciales.................................................. 44

2.1.1. Referentes nacionales. .......................................................... 44

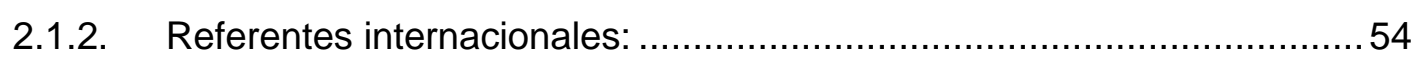

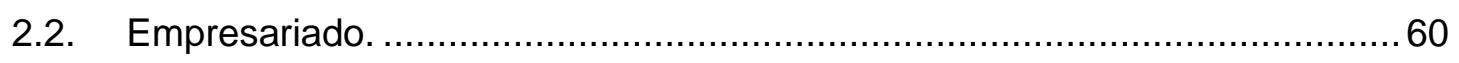

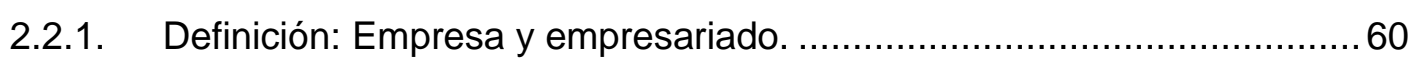

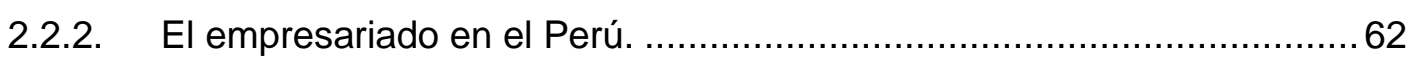

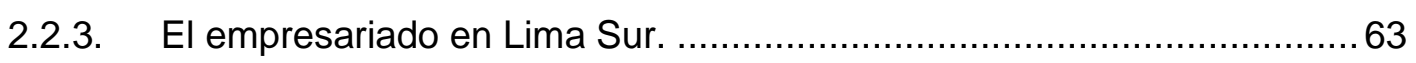

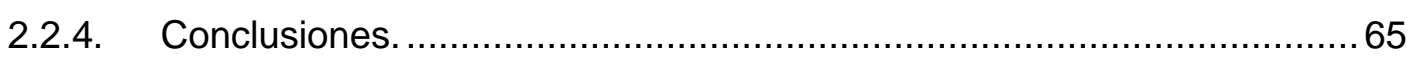

2.3. Servicios complementarios a la actividad empresarial. ...............................65

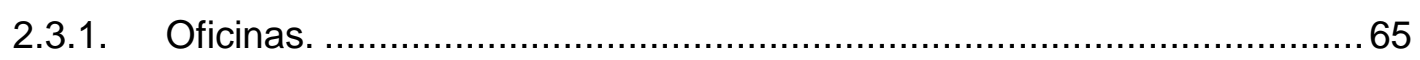

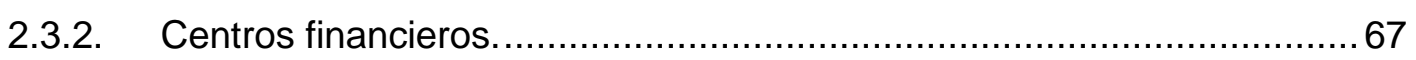

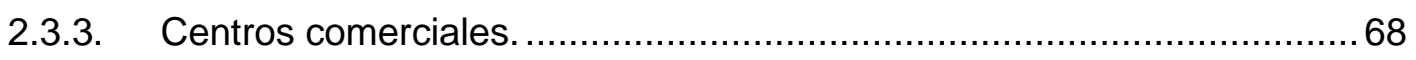

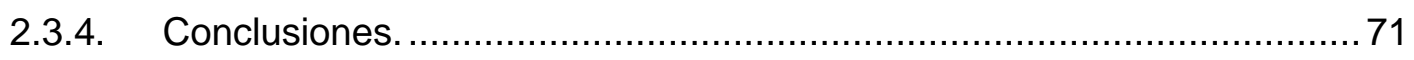

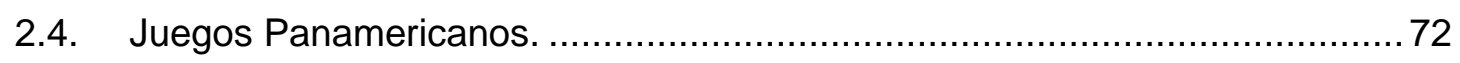

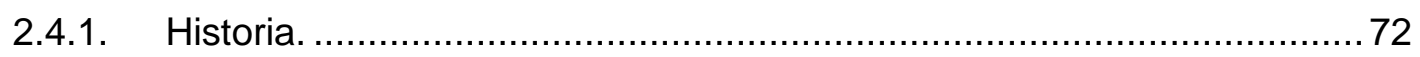

2.4.2. Impacto de los Juegos Panamericanos en la historia. ......................... 73

2.4.3. Lima como sede para los Juegos Panamericanos y Paramericanos 2019. 78 


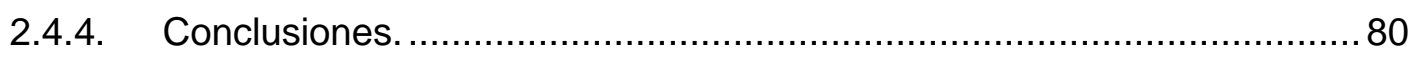

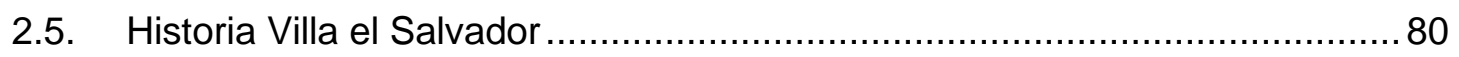

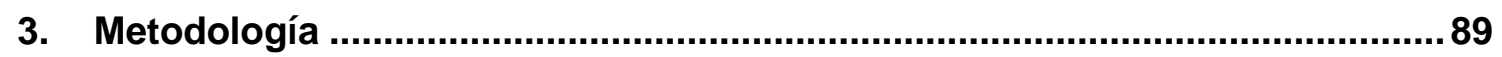

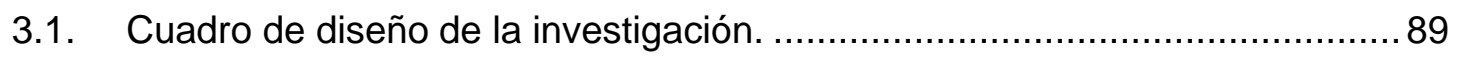

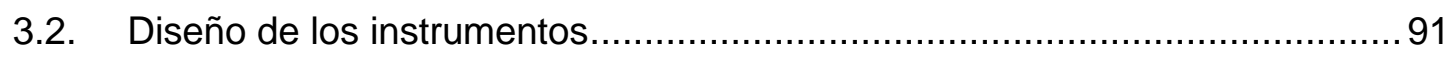

3.2.1. Aspectos Físicos y Territoriales: .................................................... 91

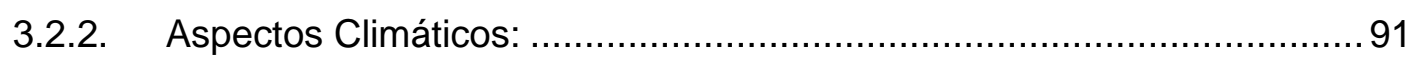

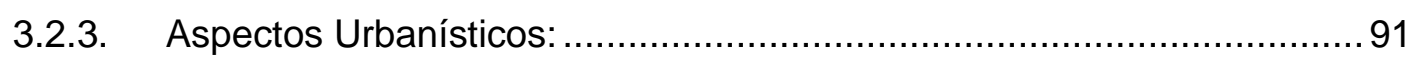

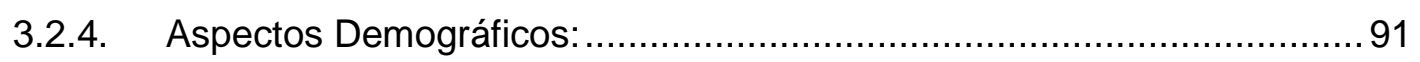

3.2.5. Aspectos Socio-Económicos: ...................................................... 91

3.2.6. Aspectos Normativos y Legales:.................................................. 91

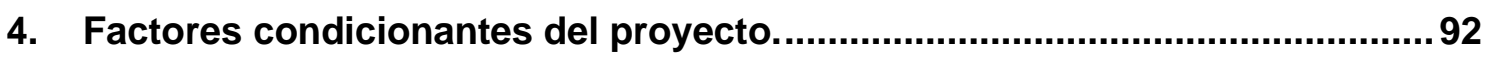

4.1. Aspectos Físicos y Territoriales ......................................................... 92

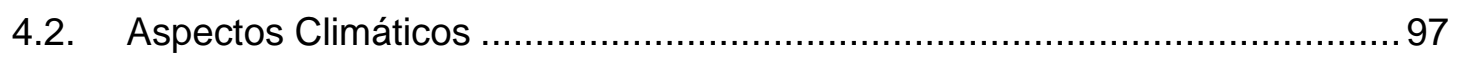

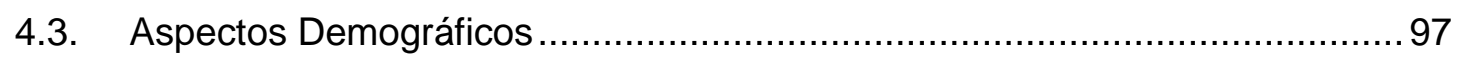

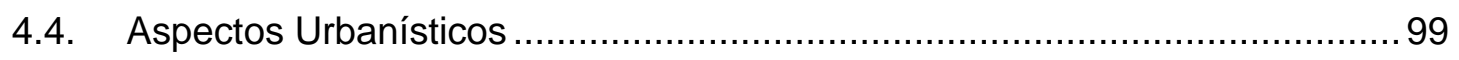

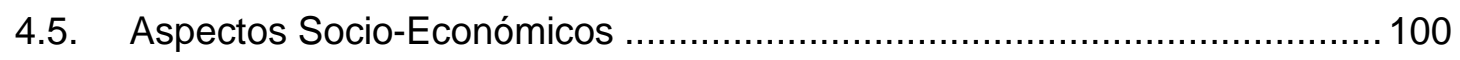

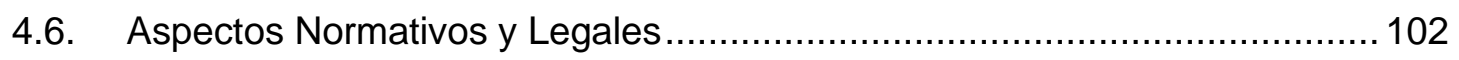

5. Equipamiento Comercial y Empresarial entorno a la Villa Panamericana en Villa el Salvador. .............................................................................................. 103

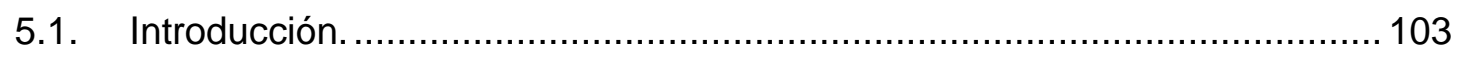

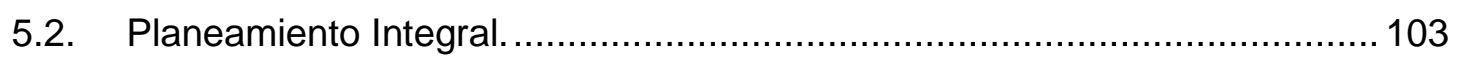

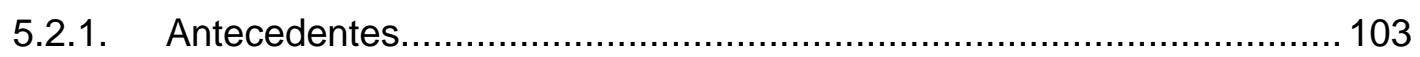

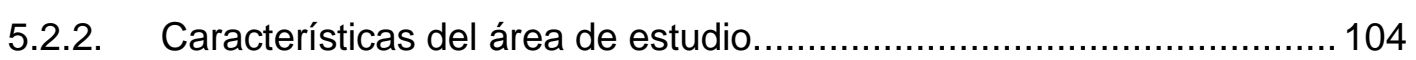

5.2.3. Propuesta de Planeamiento Integral............................................. 110

5.3. Equipamiento Comercial y Empresarial entorno a la Villa Panamericana, en Villa en Salvador. ........................................................................................ 117

5.3.1. Planificación de la propuesta....................................................... 117

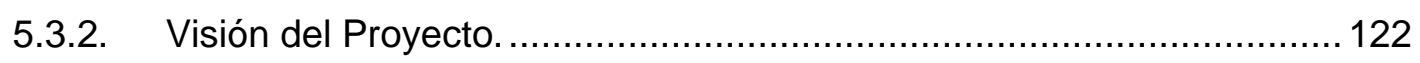

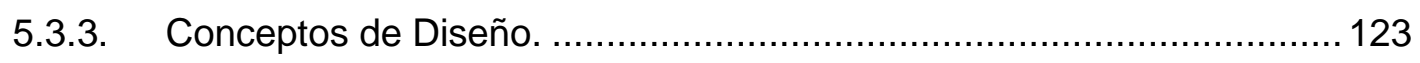

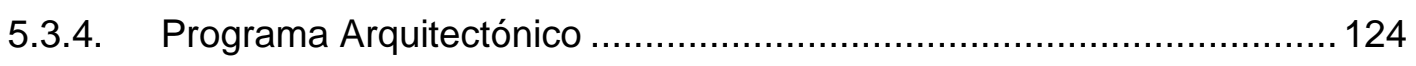

5.3.5. Descripción de Áreas del Proyecto .................................................. 127

5.3.6. Cuadro de Áreas del Proyecto ..................................................... 143

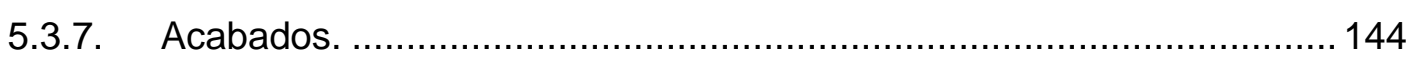

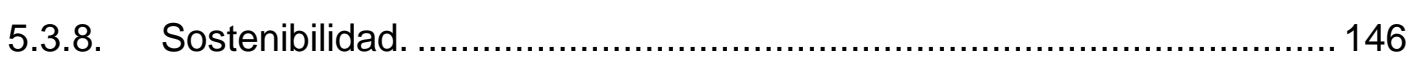

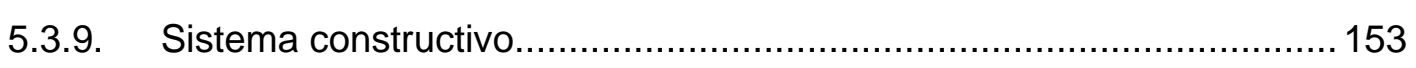




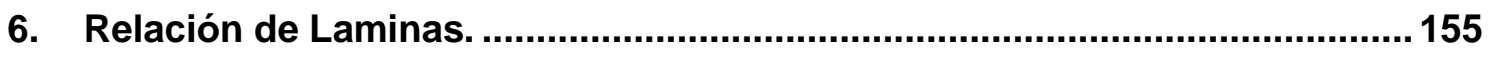

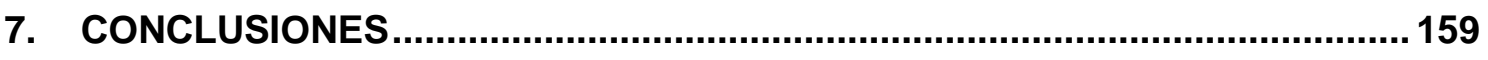

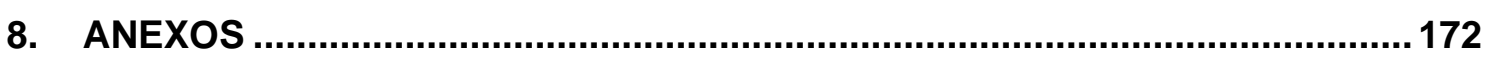

\section{ÍNDICE DE FIGURAS}

Figura 1. Traslado desde Pamplona a las pampas de la Tablada de Lurín - Nace Villa El

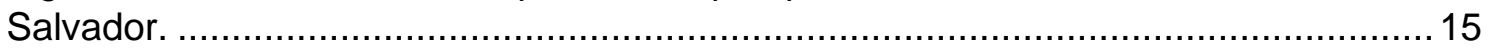

Figura 2. Villa Panamericana en Villa el Salvador................................................. 17

Figura 3. Diseño inicial sede Villa Panamericana..................................................... 18

Figura 4. Diseño final sede Villa Panamericana...................................................... 19

Figura 5. Edificios de 19 y 20 pisos en la Villa Panamericana de Lima.......................20

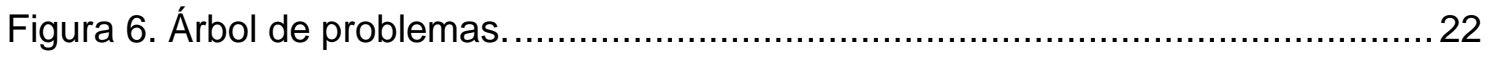

Figura 7. Zonificación del distrito de Villa el Salvador vigente..................................26

Figura 8. Usos actuales del suelo (por predominancia)........................................27

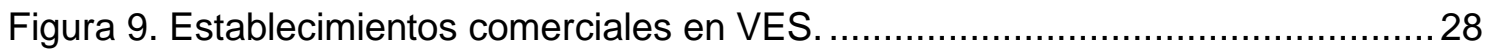

Figura 10. Zonificación actual del distrito de Villa el Salvador .....................................33

Figura 11. Zonificación del distrito de Villa el Salvador vigente vs Usos actuales del suelo

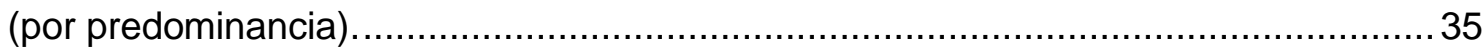

Figura 12. Ruta y paraderos de transporte público de Alimentadores Metropolitano y

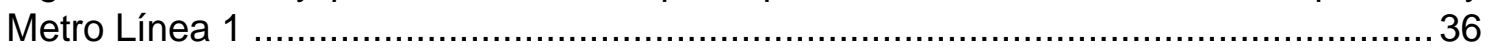

Figura 13. Ruta ciclovía existente, en ejecución y proyectada ....................................37

Figura 14. Núcleos de áreas verdes Villa el Salvador .................................................38

Figura 15. Áreas verdes por distrito en Lima........................................................... 38

Figura 16. Variaciones de zonificación del distrito de Villa el Salvador ........................39

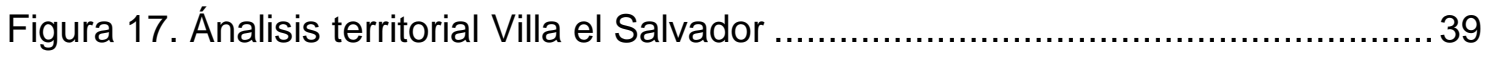

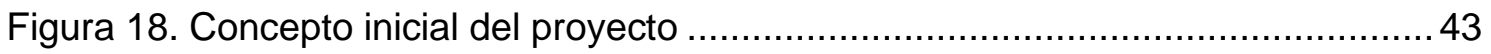

Figura 19. Ubicación Jockey Plaza, Lima............................................................... 44

Figura 20.Centro Comercial Jockey Plaza ........................................................... 46

Figura 21.Centro Comercial Jockey Plaza .......................................................... 47

Figura 22.Centro Comercial Jockey Plaza ....................................................... 47

Figura 23. Ubicación Centro Comercial La Rambla San Borja...................................48

Figura 24. Centro Comercial La Rambla San Borja.................................................. 49

Figura 25. Centro Comercial La Rambla San Borja................................................... 49

Figura 26. Centro Comercial La Rambla San Borja................................................. 50

Figura 27. Centro Comercial La Rambla San Borja..............................................50

Figura 28. Centro Comercial Mega Plaza Lima Norte, Lima......................................51 
Figura 29. Centro Comercial Mega Plaza Lima Norte, Lima....................................52

Figura 30. Centro Comercial Mega Plaza Lima Norte, Lima......................................53

Figura 31. Centro Comercial Mega Plaza Lima Norte, Lima.....................................53

Figura 32. Centro Comercial Mega Plaza Lima Norte, Lima.....................................54

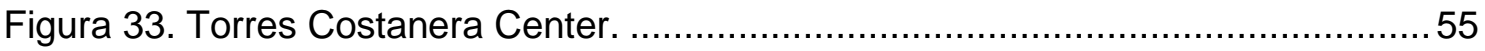

Figura 34. Sistema estructural de la Costanera Center ............................................56

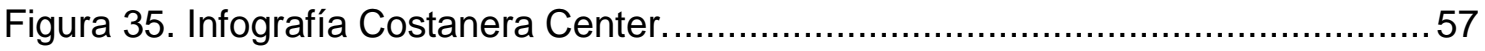

Figura 36. Ubicación Boulevard Piedra Roja, Chile.............................................. 58

Figura 37. Emplazamiento del Boulevard Piedra Roja, Chile. ..................................58

Figura 38. Fachada del Boulevard Piedra Roja, Chile..............................................59

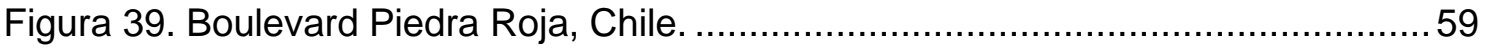

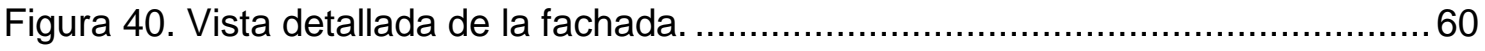

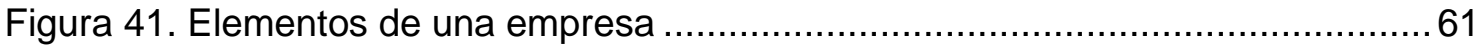

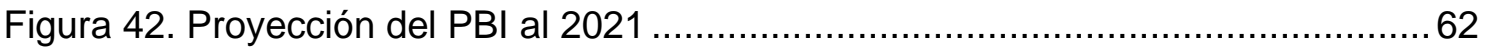

Figura 43. Densidad empresarial (empresas / mil hab.), Lima Sur............................ 63

Figura 44. Densidad empresarial (empresas / km2), Lima Sur................................64

Figura 45. Densidad empresarial de Villa el Salvador .................................................64

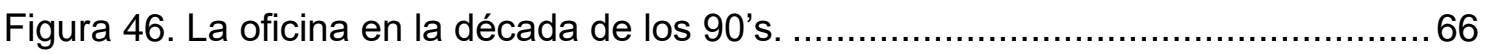

Figura 47. La oficina flexible, un lugar de trabajo para la reunión y comunicación. ......66

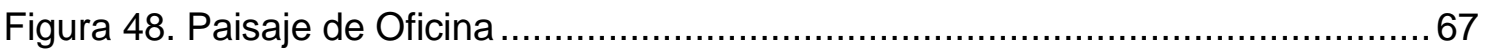

Figura 49. Centro Empresarial Cronos. Uso de concreto expuesto y vidrios...............68

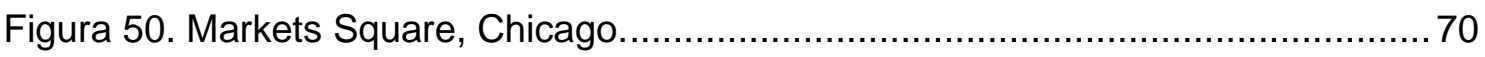

Figura 51. Centro Comercial Larcomar, distrito de Miraflores. ................................. 71

Figura 52. Primer cartel de los Juegos Panamericanos .......................................... 72

Figura 53. Estadio Panamericano en la actualidad. ............................................... 75

Figura 54. Intervención del Parque de los Deportes en 1995 ....................................75

Figura 55. Infraestructura que dejaron los Juegos Panamericanos en 2003 y 2007 ...76

Figura 56. Villa Panamericana en Guadalajara .................................................... 77

Figura 57. La Villa de los Atletas en Toronto, Canadá ............................................... 78

Figura 58. Distribución de sedes Juegos Panamericanos Lima 2019. ....................... 79

Figura 59. Intervenciones viales, Juegos Panamericanos Lima 2019 ........................ 80

Figura 60. Inicio de ocupación en Villa el Salvador. ................................................... 82

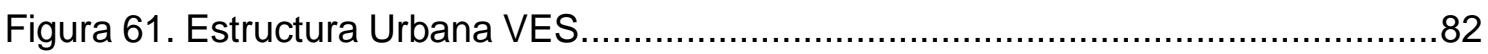

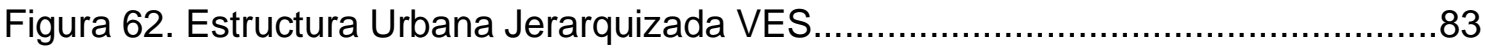

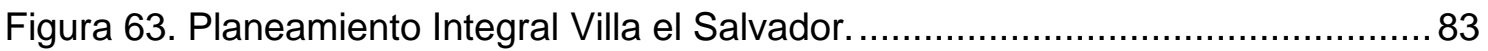


Figura 64. Ocupación actual Villa el Salvador.

Figura 65. Plan vial 1989 de Villa el Salvador.

Figura 66. Sistema Vial Metropolitano de Lima.

Figura 67. Sistema Vial Metropolitano de Lima Sur.....

Figura 68. Red vial actual Villa el Salvador. 88

Figura 69. Mapa distrital de Lima Metropolitana................................................... 92

Figura 70. Mapa áreas interdistritales de Lima Metropolitana y Callao ......................93

Figura 71. Identificación de los sectores VES ................................................... 94

Figura 72. Villa deportiva Panamericana en el distrito Villa el Salvador ...................... 94

Figura 73. Villa deportiva Panamericana en el terreno........................................... 95

Figura 74. Plano de Zonificación del terreno ubicado en Villa el Salvador ...................95

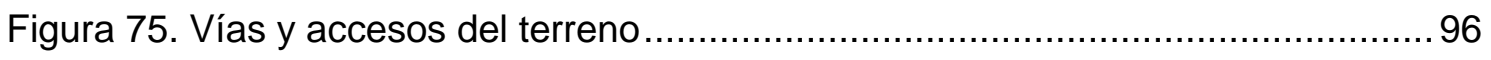

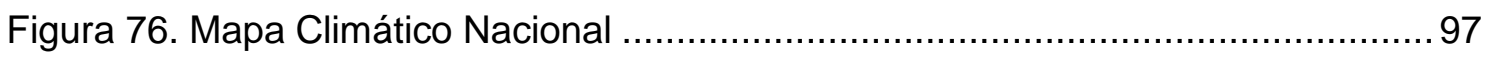

Figura 77. Unidades Económicas según rama de actividades económicas ................98

Figura 78. Situación poblacional de los distritos de Lima Sur.....................................98

Figura 79. Densidad Poblacional en distritos de Lima Metropolitana ......................... 99

Figura 80. Modificación el Plano de Zonificación del distrito de Villa El Salvador ....... 100

Figura 81. Segmentos distritales en Lima Metropolitana según IDH 2019 ................. 101

Figura 82. Distribución de Niveles Socioeconómicos en Lima ................................. 101

Figura 83. La nueva Lima policéntrica. .......................................................... 105

Figura 84. Nuevas centralidades en el área Metropolitana. ................................... 106

Figura 85. Desarrollo de centralidades PLAM 2035............................................. 107

Figura 86. Proceso del suelo urbano en Villa el Salvador 1969-2018. ....................... 108

Figura 87. Evolución de la zonificación de Villa El Salvador....................................... 109

Figura 88. Zonificación de Villa El Salvador a la actualidad ................................... 110

Figura 89. Accesibilidad vial actual y a futuro ..................................................... 111

Figura 90. Accesibilidad vial actual y a futuro ................................................. 112

Figura 91. Plano Sistema de transporte púlico(propuesta integral). ........................113

Figura 92. Plano ciclovía y propuesta(propuesta integral) ...................................114

Figura 93. Plano corredores verdes(propuesta integral) ...................................... 115

Figura 94. Plano de nueva zonificación propuesta............................................... 116

Figura 95. Master Plan Urbano(propuesta integral) ........................................... 117

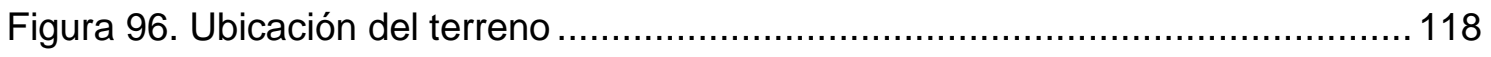

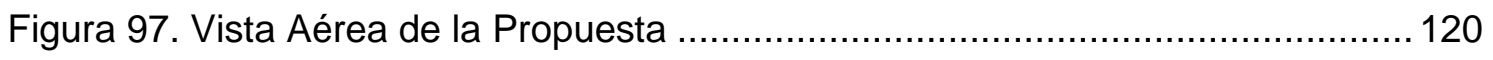

Figura 98. Zonificación actual y existente ..................................................... 121 
Figura 99. Secciones de vías del proyecto

Figura 100. Vista aérea del centro comercial

Figura 101. Analogía entre la arquitectura incaica de Ollantaytambo y la del proyecto. 123

Figura 102. Paisajismo orgánico en el proyecto. .124

Figura 103. División del programa arquitectónico 124

Figura 104. Vista de la zona comercial 125

Figura 105. Vista aérea de la zona empresarial. 125

Figura 106. Vista aérea de la zona residencial...... 126

Figura 107. Vista aérea de la zona recreativa. 126

Figura 108. Plano del primer piso del centro comercial... 127

Figura 109. Plano del segundo piso del centro comercial 128

Figura 110. Plano del tercer piso del centro comercial. 128

Figura 111. Elevación y corte longitudinal del centro comercial. 129

Figura 112. Hall de ingreso, tiendas comerciales y supermercado en el primer piso 130

Figura 113. Pasadizo típico y zona de stands en el primer piso............................... 130

Figura 114. Zona de restaurantes en el segundo piso ........................................... 131

Figura 115. Hall común en tercer piso ........................................................... 131

Figura 116. Patio de comidas en el tercer piso ...................................................... 132

Figura 117. Tienda por departamento típica en el primer piso. ................................ 132

Figura 118. Local de entretenimiento en el segundo piso. ...................................... 133

Figura 119. Hall entrada de cine y boletería....................................................... 133

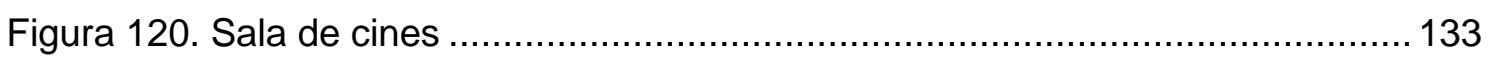

Figura 121. Planta del primer piso y mezanine del gimnasio.................................. 134

Figura 122. Cortes arquitectónicos del gimnasio............................................... 135

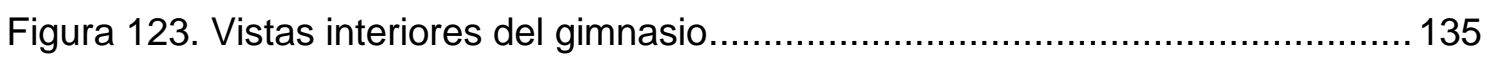

Figura 124. Vistas interiores del gimnasio..................................................... 136

Figura 125. Vistas interiores del gimnasio..................................................... 136

Figura 126. Vistas interiores baño típico del gimnasio ......................................... 136

Figura 127. Hall típico del centro comercial ..................................................... 137

Figura 128. Vista exterior del Centro Comercial. ............................................... 137

Figura 129. Vista nocturna del Centro Comercial.................................................. 138

Figura 130. Planta del primer piso de la zona empresarial.................................... 139

Figura 131. Cortes y planta típica de edificio empresarial. ...................................... 139

Figura 132. Cortes y planta típica de edificio empresarial. ................................... 140

Figura 133. Relación de pisos en bloques residenciales. ........................................ 140 
Figura 134. Planta del Parque Temático en el proyecto. 141

Figura 135. Cortes de parque temático.

Figura 136. Vistas de proyecto integral............................................................ 142

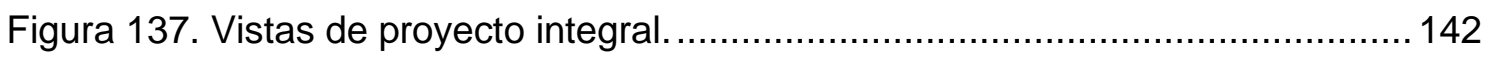

Figura 138. Conceptualización de proyecto sostenible. .......................................... 146

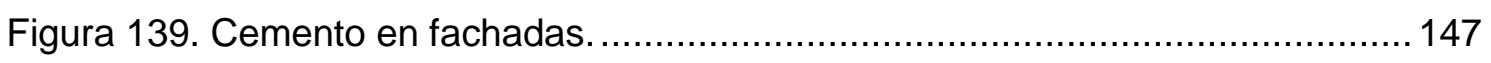

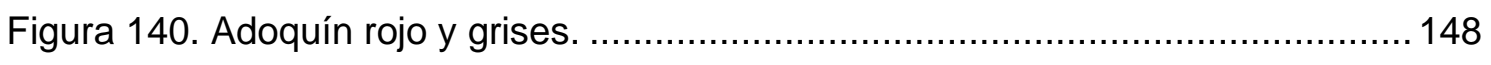

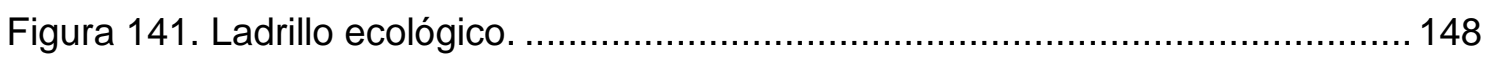

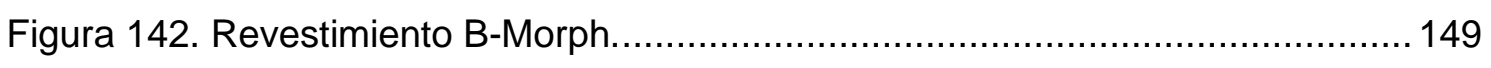

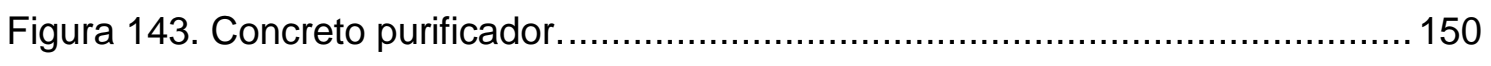

Figura 144. Ciclovía con aplicación de pavimento solar........................................ 150

Figura 145. Pintura ECO de American Colors....................................................... 151

Figura 146. Luces LED. ........................................................................... 152

Figura 147. Planta de tratamiento de agua residual. ............................................ 152

Figura 148. Corte longitudinal del Mejoramiento Urbanístico y Equipamiento Comercial - Empresarial Post Panamericanos entorno de la Villa Panamericana en Villa el

Salvador. 153

Figura 149. Corte trasversal del Mejoramiento Urbanístico y Equipamiento Comercial Empresarial Post Panamericanos entorno de la Villa Panamericana en Villa el Salvador. 154

\section{ÍNDICE DE TABLAS}

Tabla 1. Usos del suelo en Villa el Salvador. 16

Tabla 2. Población actual. 21

Tabla 3. Avances de obras de los XVIII Juegos Panamericanos y VI Paramericanos 2019.

Tabla 4. Principales indicadores sobre la evolución de los centros comerciales en el Perú

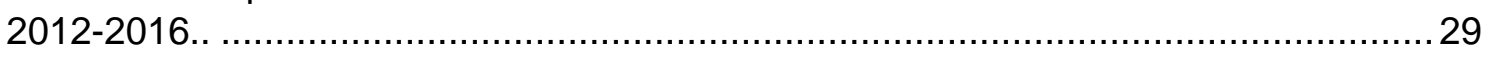

Tabla 5. Establecimientos comerciales actuales y proyectados. ..............................40

Tabla 6. Déficit de viviendas actuales y proyectados. .......................................... 40

Tabla 7. Empresariado actual y proyectado. .................................................... 41

Tabla 8. Datos estadísticos generales del Jockey Plaza Shopping Center. ................46 46

Tabla 8. Datos estadísticos generales del Jockey Plaza Shopping Center. .................46

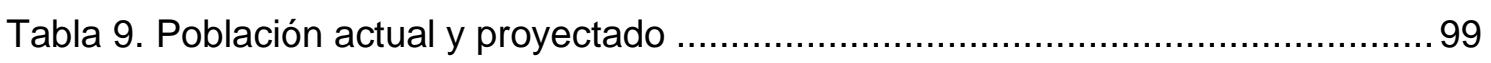

Tabla 10. Áreas conjuntas del proyecto. .......................................................... 143

Tabla 11. Acabados presentes en el diseño......................................................144

Tabla 12. Relación de Láminas proyecto de Tesis.................................................. 155 


\section{INTRODUCCIÓN}

El Mejoramiento Urbanístico y Equipamiento Comercial - Empresarial Post Panamericanos entorno de la Villa Panamericana en Villa el Salvador es un proyecto de desarrollo urbano a nivel de Lima Metropolitana ubicado en el distrito de Villa el Salvador, en la provincia de Lima, en el departamento de Lima, específicamente en los lotes colindantes dentro del terreno designado para la reciente Villa Panamericana realizada para los Juegos Panamericanos y Parapanamericanos 2019.

Asimismo, el territorio de Villa el Salvador desde sus inicios en 1970 diseñado por el arquitecto Miguel Eugenio Romero Sotelo refleja un legado de una gran planificación urbanística modular por sus avenidas y calles de gran dimensión y, el ordenamiento urbano de acuerdo a un patrón de diseño de módulos residenciales. Si bien aquel ordenamiento integral urbano adelantado a su época que se proyectaba ya en ese entonces a un territorio futuro sostenible, debido al aumento de población y dinámica social ha ido cambiando.

Actualmente, el distrito de Villa el Salvador ha crecido exponencialmente en estos últimos años, su crecimiento y desarrollo económico ha sido por sus zonas industriales; sin embargo, ahora de acuerdo a su plan de desarrollo local concertado 2017-2021(2016) y con el PLAM 2035 este distrito al ser considerado como un nuevo nodo de centralidad, tiene una visión para incentivar el aspecto comercial, siendo este un gran factor económico para revitalizar el distrito.

Por ello, este planteamiento de proyecto busca recuperar el propósito de ese diseño y repotenciarlo de acuerdo a lo existente y, sobre todo a las necesidades actuales de la población.

Asimismo, analizando la reciente construcción de la Villa Panamericana y el desaprovechamiento en los espacios de los lotes colindantes del terreno donde se ubica, surge la idea de este proyecto integral para cubrir las actuales necesidades de déficit de comercial, de vivienda y empresarial.

Al realizarse los Juegos Panamericanos en cualquier parte del mundo, los países seleccionados para este evento tan importante no solo deben de invertir para ello, tienen la oportunidad de repotenciar el territorio post evento, por ello este 
proyecto de desarrollo integral genera un eje comercial-empresarial e intervenciones viales en el distrito para mejorar su articulación y conectividad con toda la provincia de Lima. La propuesta principal se enmarca en el diseño de un centro comercial llamado "Mall de Villa" a nivel metropolitano y propuestas complementarias de un centro empresarial, bloques residenciales para viviendas sociales y áreas recreativas. Donde a nivel de propuesta arquitectónica es de carácter sostenible por sus elementos y sistemas constructivos eco amigables y reciclados promoviendo una alternativa de realizar arquitectura sostenible para mejorar el hábitat, calidad de vida y el medio ambiente.

Finalmente, también para mejorar la relación entorno-ciudad se plantea al incentivar patrones urbanos más sostenibles mediante equipamientos adecuados para una mayor integración territorial, convirtiendo a Villa el Salvador en un distrito de identidad comercial, empresarial, inclusivo, con nuevas oportunidades de desarrollo, seguro, resiliente, con visión de alcanzar el nuevo paradigma modelo de una ciudad sostenible.

A partir de este análisis se decidió tratar el tema como proyecto de tesis a desarrollar. 


\begin{abstract}
The Post-Pan American Urban Development and Commercial - Business Equipment Improvement around the Pan American Village in Villa el Salvador is an urban development project at the level of Metropolitan Lima, specifically in the adjoining lots within the land designated for the recent Pan American Village held for the 2019 Pan American and Parapan American Games.

The intervention is based on the potentialities that exist in the territory of the district and the proximity of the connectivity of its important national road axis, which is the South Pan-American highway, which is interconnected to the north.

Likewise, the territory of Villa el Salvador since its inception in 1970 which was designed by the architect, Miguel Eugenio Romero Sotelo, reflects a legacy of a great modular urban planning for its avenues and streets of great dimension, and the urban planning made according to a pattern of residential modules. Although, that comprehensive urban planning ahead of its time was projected into a future territory, due to the increase in population and social dynamics that have been changing.
\end{abstract}

Currently, the district of Villa el Salvador has grown exponentially in recent years. Its growth and economic development has been due to its industrial zones, however, now according to its 2017-2021 (2016) concerted local development plan, and in the same way with PLAM 2035 this district is considered as a new centrality node, it has a vision to encourage the commercial aspect. This being a great economic factor to revitalize the district.

Therefore, this projects approach seeks to recover the purpose of that design and repower it according to what exists and, above all, to the current needs of the population. From analyzing the recent construction of the Pan American Village and the waste in the spaces of the adjacent lots of the land where it is located, the idea of this comprehensive project arises to cover the current needs of commercial, housing and business deficits.

When the Pan-American Games are held anywhere in the world, the countries selected for this important event must not only invest for it, but they have the opportunity to repower the post-event territory. Therefore, this comprehensive 
development project generates a commercial-business axis and road interventions in the district to improve its articulation and connectivity with all of Lima. The main proposal is part of the design of a shopping center called "Mall de Villa" located at the metropolitan level. As well as complementary proposals for a business center, residential blocks for social housing and recreational areas. Where at the architectural proposal level, it is sustainable in nature due to its ecofriendly and recycled construction elements and systems. This promotes an alternative to make sustainable architecture to improve the habitat, quality of life, and the environment.

Finally, to improve the environment-city relationship, adequate facilities are proposed for a greater territorial integration performance. Like turning Villa el Salvador into a district with a commercial, business, inclusive, safe, and resilient identity. All this with a vision of a sustainable city.

Based on this analysis, it was decided to treat the subject as a thesis project to be developed. 


\section{Planteamiento del proyecto.}

\subsection{Descripción del problema.}

Villa el Salvador se encuentra ubicado en la Costa Central del departamento de Lima a $20 \mathrm{~km}$ del centro histórico y es parte de la zona Lima Sur, actualmente limita por el norte con el distrito de San Juan de Miraflores, con el este con el distrito de Villa María del Triunfo, con el sur con el distrito de Lurín y por el Oeste con el distrito de Chorrillos y el Océano Pacifico, según la Municipalidad Distrital de Villa el Salvador (2006).

Hablar de Villa el Salvador, es hablar sobre su historia empezando en el año 1970 cuando ocurrió el terremoto en Yungay - Huaraz destruyendo casi toda su ciudad dejando más de 75,000 fallecidos desencadeno un gran movimiento migratorio a Lima (OtraMirada, 2020), fue entonces ocupado por la mayoría de las víctimas que nos remonta a abril del año 1971, donde miles de familias a raíz de esa tragedia invadieron propiedades públicas y privadas en los distritos de San Borja, Surco y Pamplona Alta para establecerse en estas zonas. Tras varios intentos de la policía para desalojarlos y la iglesia realizando mediaciones para negociar con el Gobierno, este logra reubicarlos en la tablada de Lurín actualmente llamado Villa el Salvador, según Romero (2006).

Figura 1. Traslado desde Pamplona a las pampas de la Tablada de Lurín - Nace Villa El Salvador.

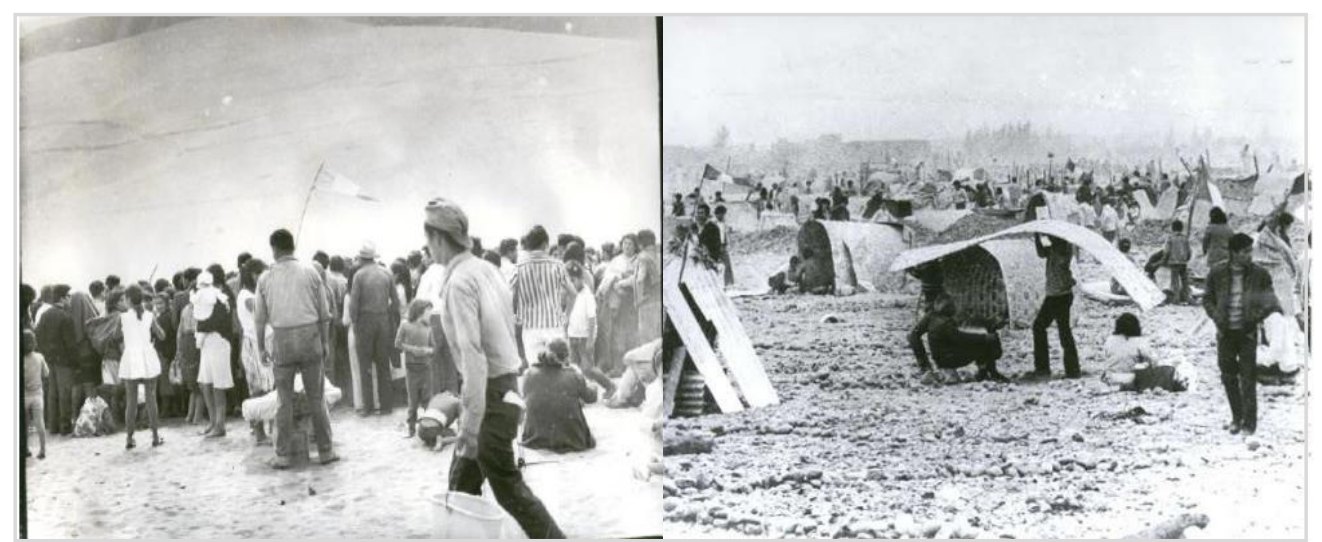

Fuente: Estudios Territoriales de Arq. Miguel Romero Sotelo, 1994. 
Para el mes de abril llegaron a la tablada de Lurín el primer grupo de familias que ascendía a 7,000 familias que se consolidarían en esta área. Cabe mencionar que el $61 \%$ de estas familias provenían de la región de la sierra, $37 \%$ de la región de la costa y el $2 \%$ de la región de la selva, quienes ya vivían en Lima desde hace algunos años en condiciones de precariedad y en zonas tugurizadas, como bien afirma Romero (2006).

Debido a estas migraciones del terremoto el impacto en Lima dio como consecuencia un crecimiento en su expansión territorial de forma desordenada. Sin embargo, el distrito de Villa el Salvador por el aporte de diseño del arquitecto Miguel Eugenio Romero Sotelo se aplicaría un modelo de planificación urbana, donde posteriormente se consolidó como un distrito símbolo de emprendimiento en junio de 1983 en el segundo gobierno del presidente y arquitecto Fernando Belaúnde Terry, pasando de ser un arenal a ser un distrito planificado, gracias a la visión del arquitecto Romero que generó una ciudad planificada, dinámica, viva y dotada de servicios básicos con grandes áreas verdes, según Suyo Urbanistas (2012).

Según Romero (2006), Villa el Salvador es caracterizado por tener 120 módulos residenciales, 16 manzanas y 24 lotes (cada lote de $140 \mathrm{~m} 2$ ); además, de contar con equipamiento sectorial, una trama con trazos ortogonales, regular modulada, una red vial coordinada con el Plan Vial de Lima Metropolitana y según Chong (2009) usos del suelo caracterizados por:

Tabla 1. Usos del suelo en Villa el Salvador.

\begin{tabular}{|l|r|r|}
\hline \multicolumn{1}{c}{ Uso } & Area (has.) & \multicolumn{1}{c|}{ Porcentaje (\%) } \\
\hline Residencial & $1,203.00$ & 33.90 \\
\hline Educación & 422.00 & 11.90 \\
\hline Comercial & 570.00 & 16.00 \\
\hline Industrial & 321.20 & 9.00 \\
\hline Agropecuaria & 525.80 & 14.90 \\
\hline Otros Usos & 147.00 & 4.20 \\
\hline Hab. recreacional & 357.00 & 10.00 \\
\hline Total & $\mathbf{3 , 5 4 6 . 0 0}$ & $\mathbf{1 0 0 . 0 0}$ \\
\hline
\end{tabular}

Fuente: Patrones de Densificación en Villa el Salvador, Gonzalo Chong, 2009. 
En la actualidad, Villa el Salvador ha sido uno de los distritos más visitados por aquellos deportistas que residieron temporalmente en la Villa Panamericana de los Juegos Panamericanos y Parapanamericanos Lima 2019 ubicados en Av. Mariano Pastor Sevilla en el distrito de Villa el Salvador. Como se sabe, el 11 de octubre del 2013, la cincuenta y un Asamblea General de la Organización Deportiva Panamericana - ODEPA, seleccionó a la ciudad de Lima como sede de los XVIII Juegos Panamericanos y Parapanamericanos, según Lima (2019).

Este evento conllevó a que se desarrollen diferentes tipos de equipamientos e infraestructuras como el caso de la Villa Panamericana en Villa el Salvador que cuenta con una edificación inclusiva y eco-eficiente, dotada de servicios básicos y mobiliarios de muy buena calidad, a pesar de los retrasos del proyecto durante su ejecución, así como de la mayoría de proyectos deportivos en el marco del Plan Maestro de los XVIII Juegos Panamericanos y Parapanamericanos, como señala el Diario RPP Noticias (2019).

Figura 2. Villa Panamericana en Villa el Salvador.

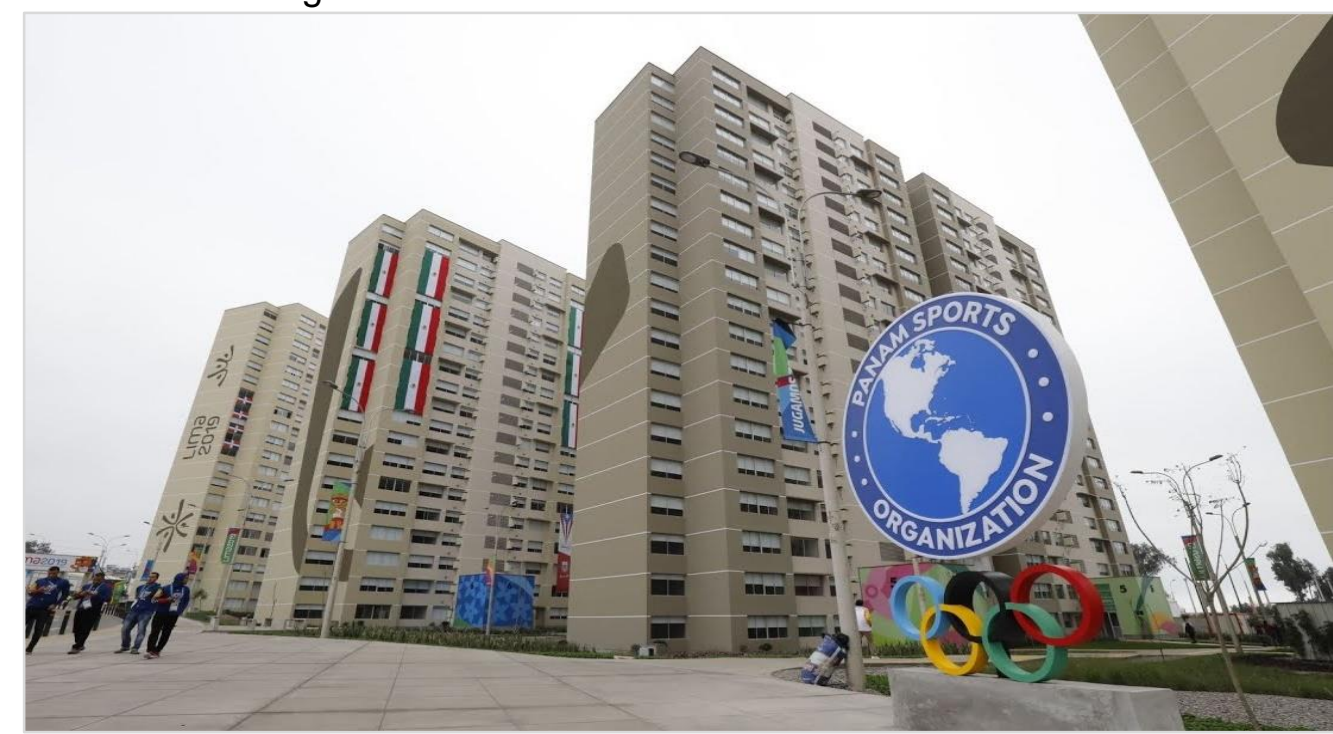

Fuente: Juegos Panamericanos de Lima 2019, tv Noticias, 2020.

El objetivo principal de la Villa Panamericana era desarrollar un proyecto inclusivo en 44 hectáreas para beneficiar el entorno urbanístico de todo Villa el Salvador, mediante una gestión urbana sostenible acorde a los objetivos 
de desarrollo económico, bienestar social y conservación del medio ambiente, aprovechando los recursos naturales y la biodiversidad biológica del terreno, según el Ministerio de Educación (2016).

Esta Villa estaba contemplada para albergar a los atletas durante el evento y posterior a ello, se planteaba que tuviera la finalidad de satisfacer a la población mediante viviendas de carácter social, las cuales se organizarían en 42 bloques residenciales de 10 a 11 pisos, áreas de servicios complementarios y el hall de comida para los atletas que sería desmontable para dar lugar después a dos manzanas adicionales con usos diversos para equipamientos a la futura área residencial, lo cual está establecido en el Plan Conceptual Villa Panamericana 2019, según el Ministerio de Educación (2016), a continuación se muestra el diseño inicial de la Villa Panamericana.

Figura 3. Diseño inicial sede Villa Panamericana.

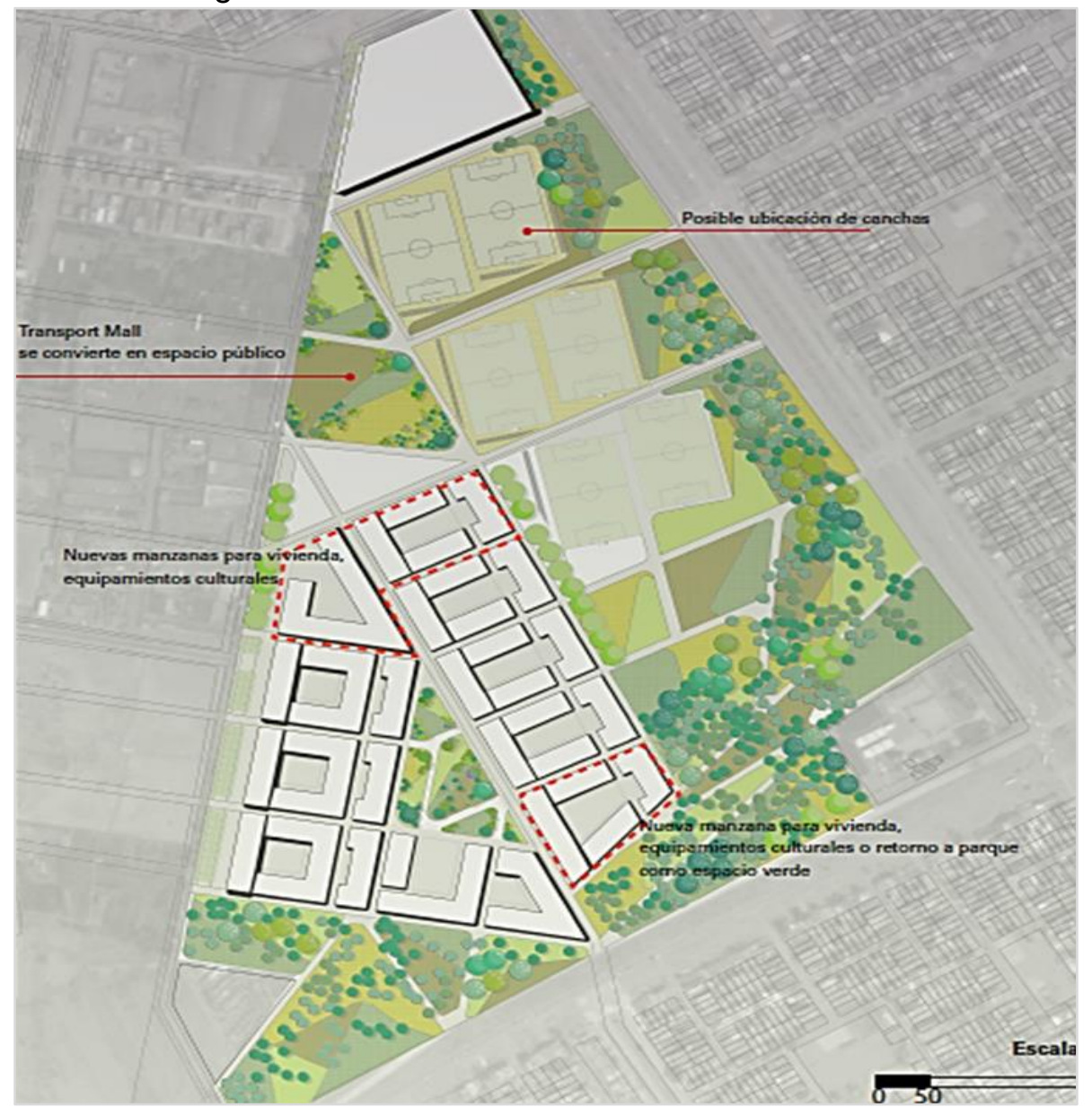

Fuente: Plan Conceptual Villa Panamericana 2019, Ministerio de Educación, 2016. 
Sin embargo, en el año 2017 el proyecto tuvo modificaciones de tal manera que los bloques serian 7 con 1,096 departamentos con áreas de 70 a 75 m2, 4 de ellos con 20 pisos y 3 de ellos con 19 pisos, con áreas sociales de integración y 371 estacionamientos establecidos en un semisótano sobre la superficie siendo un $20 \%$ del área total, como se muestra en la Figura 4 , según el Ministerio de Educación (2016).

Figura 4. Diseño final sede Villa Panamericana.

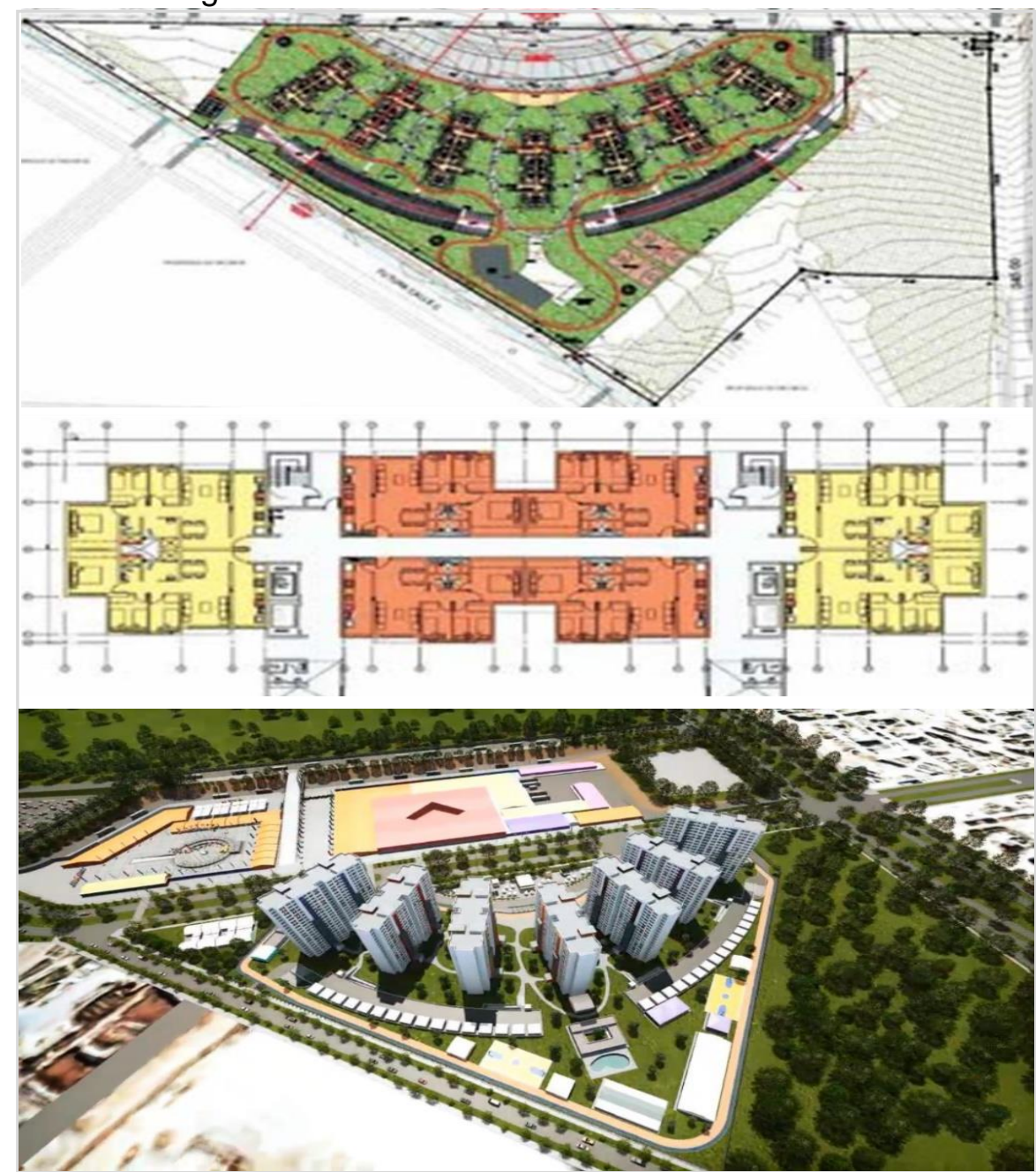

Fuente: Plan Conceptual Villa Panamericana 2019, Ministerio de Educación, 2016.

Según Perú Construye (2018), en la etapa de construcción los sótanos que estaban previstos según proyecto se reubicaron hacia un extremo del terreno lo que permitió que la construcción de estas torres se ejecute más rápido, para luego construir los estacionamientos". 
Esta gran edificación que se encuentra ubicada entre la Avenida el Sol y la Avenida Mariano Pastor Sevilla, donde existen grandes macro lotes con fines industriales, según el diario Gestión (2019) actualmente presentan unas problemáticas, y es que el valor de los departamentos estaría muy elevado para la zona donde se sitúa, ya que el valor del $\mathrm{m}^{2}$ de la Villa Panamericana tendría un costo de 4,900 soles y el valor del $\mathrm{m}^{2}$ en Villa el Salvador tiene un costo de 2,700 soles.

Adicionalmente, según Del Río (2019), las torres con demasiada altura como las de la Villa Panamericana no resultan ser económicas debido al mantenimiento que conllevan, además la demanda de estas viviendas solo recaería en los pisos más bajos por temor a los sismos, los cuales a su vez costarían más, por lo que el concepto de estos departamentos para vivienda de carácter social cada vez se ve más alejado.

Figura 5. Edificios de 19 y 20 pisos en la Villa Panamericana de Lima.

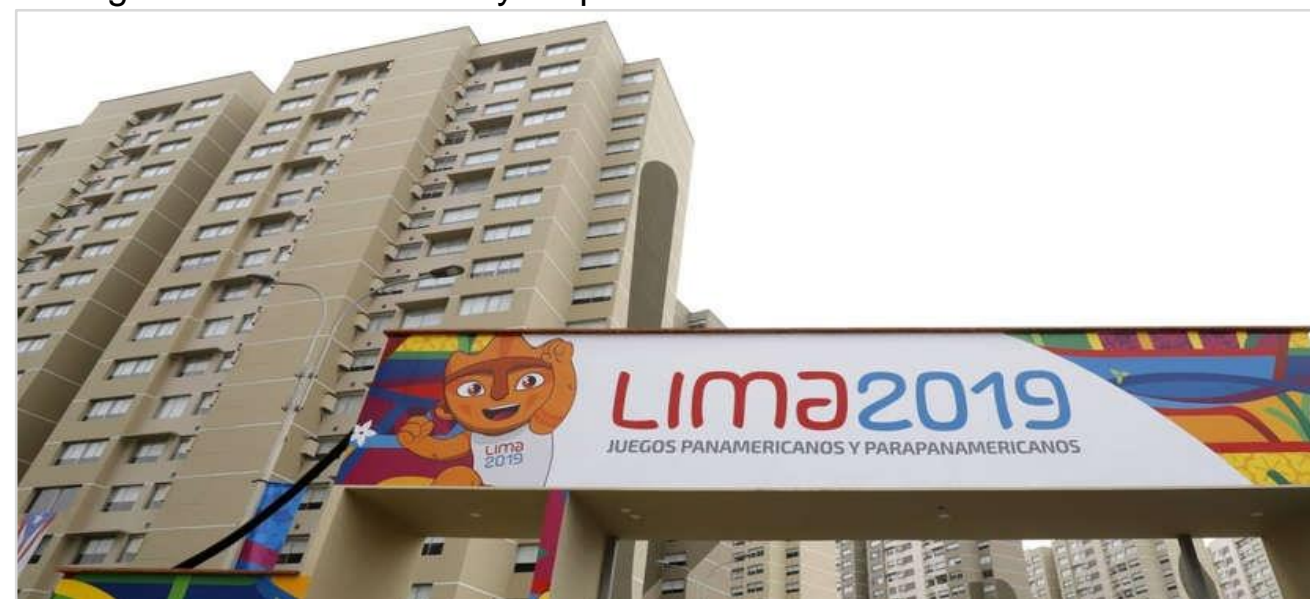

Fuente: ¿Piensas mudarte? Así son y esto costarían los departamentos de la Villa Panamericana, RPP Noticias, 2019.

Una de las razones por las que se percibe que los departamentos de la Villa Panamericana tienen un precio muy elevado para lo que la zona brinda, es debido a que el entorno inmediato no posee servicios complementarios al uso residencial. Si bien es cierto, el proyecto de la Villa Panamericana debió prever esta situación y motivar a la inversión privada a situar servicios complementarios, se sabe que uno de los factores determinantes para esta problemática fue la falta de tiempo para la implementación del Plan Maestro 
que contemplaba el impacto urbano y las estrategias para el post uso de la edificación.

En base al incremento de la población de acuerdo al XII Censo de Población y VII de Vivienda y III de Comunidades Indígenas del año 2017 por incidencias naturales, así como el incremento debido a la densificación de esta área, no se está previniendo estas demandas, además de desperdiciar grandes oportunidades de desarrollo local para el distrito de Villa el Salvador. En la actualidad, Villa el Salvador tiene 423,887 habitantes siendo el $4.7 \%$ de Lima Metropolitana y es parte de los 20 distritos más poblados del mismo. Por ello, se calcula que para el año 2025, llegue a los 506,664 habitantes, según Estimaciones y Proyecciones de población por departamento, provincia y distrito del Instituto Nacional de Estadística e Informática - INEI (2020).

Tabla 2. Población actual.

\begin{tabular}{|c|c|c|}
\hline Población & Hab. 2017 & Proyección 2020 \\
\hline Villa el Salvador & $393,254(4,6) \%$ & $423,887(4,7) \%$ \\
\hline
\end{tabular}

Fuente: Estimaciones y Proyecciones de población por departamento, provincia y distrito del Instituto Nacional de Estadística e Informática - INEI, 2020.

Esta falta de servicios complementarios que no permiten el correcto desarrollo de las actividades humanas de los residentes de las viviendas de la Villa Panamericana se debe también a la falta de participación de los gobiernos locales en el desarrollo del Plan Maestro, ya que su participación hubiese asegurado de alguna manera las demandas actuales y futuras de sus residentes.

Según el Comité Olímpico Peruano (2016), en la Acta de la Cuadragésima Novena Sesión de COPAL - Lima, del 13 de Junio del 2016 donde se aprobó el Plan Maestro de Infraestructura con la participación del representante de Ministerio de Educación, representante del Comité Olímpico Peruano, representante de la Municipalidad de Lima Metropolitana, representante del Ministerio de Vivienda, Construcción y Saneamiento, representante del Ministerio de Economía y Finanzas, representante del Instituto Peruano del Deporte y el representante del Comité Olímpico Internacional; pero no con representantes de las municipalidades locales, como debió llevarse a cabo. 
Por ello a partir de las premisas descritas anteriormente se identifica como problema central: "La deficiente planificación de los espacios urbanos entorno a la Villa Panamericana en Villa el Salvador Post Juegos Panamericanos 2019", el cual se buscará solucionar mediante esta presente tesis, al lograr crear una adecuada y eficiente planificación de los espacios urbanos adyacentes a la Villa Panamericana con adecuados equipamientos para alcanzar un mejoramiento de calidad de vida a través de servicios básicos complementarios, mayor dinámica social y generar a su vez mayor plusvalías del suelo urbano en la zona de estudio.

\section{2. Árbol de problemas.}

Figura 6. Árbol de problemas.

Especulación del suelo generando informalidad, desorden urbano, baja autoestima y calidad de vida de las personas.

Baja calidad en intervención urbana y proyectos específicos ya sea en diseño o ejecución de los Juegos Panamericanos 2019.
Incapacidad de abastecimiento a la demanda de equipamiento comercial y usos complementarios tanto durante como post Juegos Panamericanos 2019.
Limitaciones en el desarrollo de las actividades humanas de la localidad.

DEFICIENTE PLANIFICACIÓN DE LOS ESPACIOS URBANOS ENTORNO A LA VILLA PANAMERICANA EN VILLA EL SALVADOR POST JUEGOS PANAMERICANOS 2019

\section{Retrasos en tiempo para la planificación y ejecución del Plan Maestro de los Juegos Panamericanos 2019.}

Insuficiente equipo de trabajo para el desarrollo organizado de las metas de los Juegos Panamericanos 2019.
Déficit de áreas urbanas destinadas para uso comercial que dé soporte a las actividades diarias de la ciudad.

Falta de un Plan de Desarrollo Metropolitano de Lima

Metropolitana actualizado.

Elaboración Propia.
Poca participación de los gobiernos locales en el desarrollo del Plan Maestro de los Juegos Panamericanos 2019.

Escasa visión de desarrollo por parte de los actores claves durante el desarrollo de los Juegos Panamericanos 2019.

\subsubsection{Retrasos en el tiempo para la planificación y ejecución del Plan} Maestro de los Juegos Panamericanos 2019.

Como se sabe, Lima después de haber ganado la sede de los Juegos Panamericanos 2019 en la asamblea de Guadalajara en México en el año 2013, la Organización Deportiva Panamericana - ODEPA integrada por 42 naciones, encargó a la organización de los XVIII Juegos Panamericanos 2019 el desarrollo total de la planificación para tal evento, mediante un Acuerdo de Responsabilidades y Obligaciones 
para la Organización de los XVIII Juegos Panamericanos del 2019, según Regalado et. al. (2015).

Dos años después en el año 2015 se nombró el Proyecto Especial para la Preparación y Desarrollo de los XVIII Juegos Panamericanos del 2019, que tuvo como fin programar y ejecutar las acciones necesarias para el desarrollo de los Juegos Panamericanos 2019 y Paramericanos del 2019, principalmente los proyectos de inversión pública en infraestructura deportiva en el marco del Plan Maestro y los compromisos con el Comité Organizador - COPAL, según el Decreto Supremo Nº02-2015-MINEDU.

En el mismo año, se encargó el desarrollo del "Plan Maestro de los XVIII Juegos Panamericanos y VI Juegos Paramericanos Lima 2019" al Proyecto Especial para la Preparación y Desarrollo de los XVIII Juegos Panamericanos del 2019, el cual debería incluir la propuesta de escenarios e infraestructuras urbana indetenible en Lima Metropolitana y el Gobierno Regional del Callao; el cual posteriormente fue aprobado mediante el Acta de la Cuadragésima Novena Sesión de COPAL Lima Perú, según Lima 2019 (2019).

A partir de estos acontecimientos se procedió a la fase de iniciación y ejecución de los proyectos, que fueron establecidos en el Plan Maestro de los XVIII Juegos Panamericanos y VI Juegos Paramericanos Lima 2019, ya con dos años de atraso desde que Lima ganó la sede en la asamblea de Guadalajara en México.

Para el año 2017, la Contraloría General de la República acreditó al Grupo de Control de Inversiones - GCl para el seguimiento y monitoreo de los proyectos a cargo del Proyecto Especial para la preparación y desarrollo de los XVIII Juegos Panamericanos del 2019, con el fin de dar cumplimiento al cronograma establecido, según Oficio $\mathrm{N}^{\circ} 00019$ 2017-CG/DC. 
Sin embargo, en diciembre del 2018 la contraloría advirtió mediante el informe de control concurrente 1183-2019-CG/MPROY-CC,1224-2018CG/MPROY-CC y 1149-2018-CG/MPROY-CC, hubieron retrasos en dos proyectos, las sedes deportivas en Punta Negra: Creación del Centro de Alto Rendimiento de Surf en la playa de Punta Roca y en Callao: Mejoramiento de los Servicios de Espectáculo Deportivo de Alta Competencia en el Parque Zonal Yahuar Huaca en Bellavista, las cuales tendrían riesgo de que no se concluyan oportunamente, según Diario América Noticias (2018).

Asimismo, en agosto del 2018, la contraloría advirtió mediante el informe de Control Recurrente $N^{\circ}$ 1336-2018-CG/MPROY-CC, el retraso en las sedes deportivas de Villa el Salvador: La Villa Panamericana que albergó a los deportistas participantes del encuentro deportivo, la cual tenía previsto estar concluida para febrero del 2019; ello se debía a que no contaba con la habilitación de los suministros de los servicios públicos de agua, desagüe, luz y gas por parte de las empresas prestadoras de tales servicios, según Diario Gestión (2019).

Según el Diario El Comercio (2018), las obras de infraestructura de los juegos terminarían 49 días después de iniciado el certamen deportivo que fue el 26 de julio del año 2019, precisamente la Creación del Centro de Alto Rendimiento de Surf en Punta Negra y del Mejoramiento de los Servicios Deportivos de Alta Competencia en el Parque Zonal Yahuar Huaca del Callao, los cuales tuvieron una inversión conjunta de 52 millones de dólares.

Por otro lado, en el portal web oficial de los Juegos Panamericanos y Parapanamericanos 2019, se puede apreciar que el avance del mes de marzo del año 2019, a cuatro meses del inicio de los juegos la mayoría de proyectos estaban próximos a culminar; sin embargo, habían proyectos como el "Centro de alto rendimiento de surf playa Punta Rocas" que tenía un avance físico de $16.97 \%$ y un avance financiero 
de $0.00 \%$ y la "Escuela de equitación del ejército" que tenía un avance físico de $67.09 \%$ y un avance financiero de $63.93 \%$, como se puede apreciar en la Tabla 3.

Tabla 3. Avances de obras de los XVIII Juegos Panamericanos y VI Paramericanos 2019.

\begin{tabular}{|l|c|c|c|}
\hline \multicolumn{1}{|c|}{ Proyecto } & $\begin{array}{c}\text { Monto de } \\
\text { inversión }\end{array}$ & $\begin{array}{c}\text { Avance } \\
\text { Físico }\end{array}$ & $\begin{array}{c}\text { Avance } \\
\text { financiero }\end{array}$ \\
\hline $\begin{array}{l}\text { Villa Panamericana y } \\
\text { Parapanamericana }\end{array}$ & $250,869,129.44$ & $99.00 \%$ & $101.83 \%$ \\
\hline Villa deportiva nacional - Videna & $678,073,024.59$ & $95.88 \%$ & $85.61 \%$ \\
\hline $\begin{array}{l}\text { Complejo deportivo Andrés } \\
\text { Avelino Cáceres }\end{array}$ & $221,877,641.00$ & $98.00 \%$ & $99.29 \%$ \\
\hline Estadio Telmo Carbajo del Callao & $2,380,178.31$ & $91.90 \%$ & $80.50 \%$ \\
\hline $\begin{array}{l}\text { Villa deportiva del Callao y } \\
\text { estadio de la Universidad }\end{array}$ & $152,089,008.00$ & $98.10 \%$ & $100.00 \%$ \\
\hline Nacional Mayor de San Marcos & $1,867,976.57$ & $100.00 \%$ & $100.00 \%$ \\
\hline Escuela militar de Chorrillos & $1,910,641.23$ & $100.00 \%$ & $92.76 \%$ \\
\hline $\begin{array}{l}\text { Polígono de tiro Capitán FAP } \\
\text { José Abelardo Quiñones }\end{array}$ & $90,361,606.85$ & $82.33 \%$ & $82.32 \%$ \\
\hline Gonzales & $29,650,862.91$ & $67.09 \%$ & $63.93 \%$ \\
\hline Polideportivo Villa el Salvador & $32,107,886.43$ & $16.97 \%$ & $0.00 \%$ \\
\hline Escuela de equitación del ejercito & $\begin{array}{l}\text { Centro de alto rendimiento de surf } \\
\text { playa Punta Rocas }\end{array}$ & \multicolumn{2}{|l|}{ Estado de todas las obras: en ejecución al marzo del 2019. } \\
\hline \multicolumn{2}{|l|}{ Fuente: Avances de } \\
\hline
\end{tabular}

Fuente: Avances de obras, Lima 2019, 2019.

Una de las obras que no se concluyó fue el Centro de Alto Rendimiento de Surf en Playa Punta Rocas que tenía un avance físico de 16.97 a marzo cuando los juegos empezaron el 26 de Julio del 2019, es decir a 4 meses de iniciarse las competencias deportivas, por lo que no se cumplió con los compromisos que se asumieron al realizar este proyecto dentro del Plan Maestro de los Juegos Panamericanos 2019.

Como se ha podido apreciar, previamente el planeamiento y la ejecución de los proyectos tuvieron demoras desde el primer día de desarrollo, lo cual se ve reflejado también en la deficiente planificación de los espacios urbanos entorno a la Villa Panamericana en Villa El Salvador Post Juegos Panamericanos 2019. 


\subsubsection{Déficit de áreas urbanas destinadas finalmente para uso}

comercial que dé soporte a las actividades diarias de la ciudad.

Según el Instituto Metropolitano de Planificación (2019), la zonificación urbana de Villa el Salvador posee grandes áreas de Industria Elemental y Complementaria - IE, Industria Liviana - 12, Gran Industria - I3, Residencial de densidad media - RDM y Comercio Zonal - CZ (ver Figura), ya que como hace referencia el Plan de Desarrollo Local Concertado 2017-2021 (2017), la visión del distrito es:

"Villa El Salvador, es un distrito inclusivo, moderno, ordenado, organizado, seguro, productivo, sostenible, comercial, limpio y verde, con todo su territorio debidamente interconectado, accesible y con oportunidades. Se ha consolidado como la capital de la educación superior de calidad de Lima Sur, sus ciudadanos/as y jóvenes son emprendedores/as y comprometidos/as con el distrito, participativos/as y con una fuerte identidad local. Es cuna de deportistas destacados y se ha convertido en una ciudad del turismo vivencial y prestador de servicios para toda Lima Sur". (2016. P. 8)

Figura 7. Zonificación del distrito de Villa el Salvador vigente.

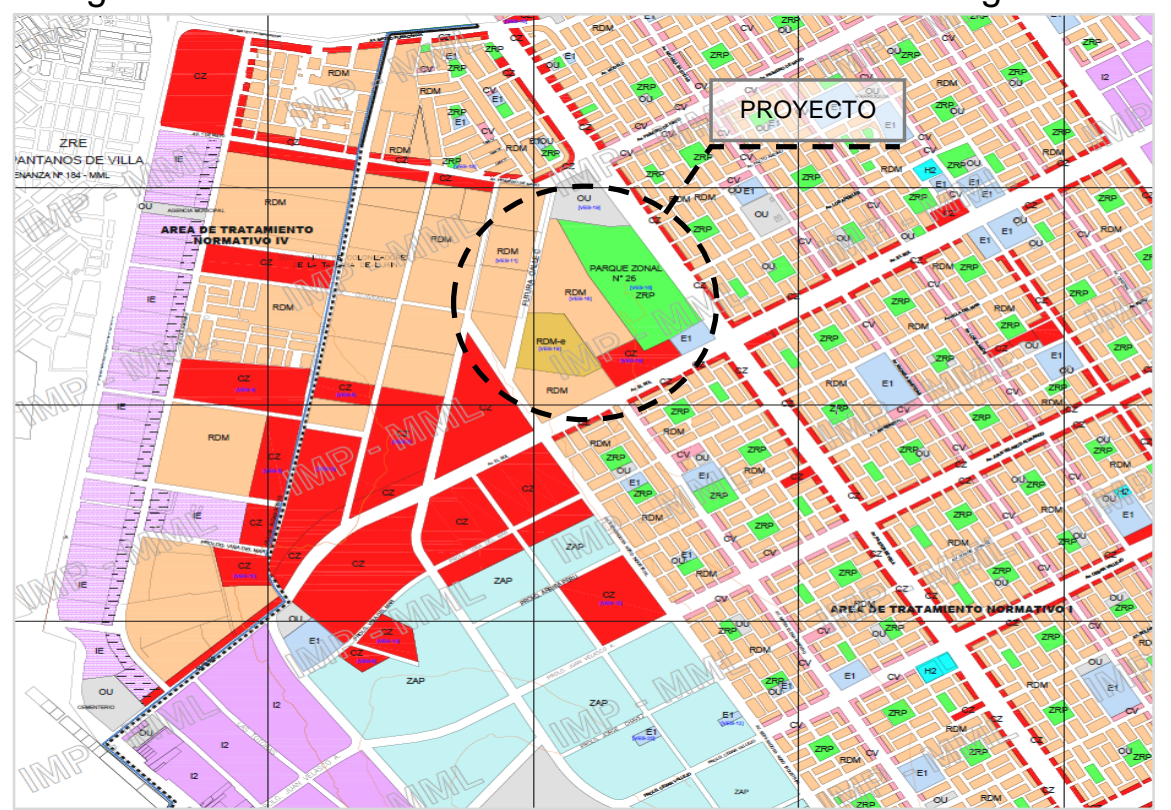

Fuente: Instituto Metropolitano de la Planificación, 2019. 
Por lo que podemos afirmar que el distrito de Villa el Salvador tiene una vocación comercial actualmente dentro del área que corresponde a Lima Sur, sin embargo, cuando se realiza un levantamiento en campo sobre la información actual de usos del suelo, la predominancia del uso del suelo difiere enormemente a la zonificación establecida, como se muestra en la Figura, la imagen urbana del área más próxima al área del terreno, es predominantemente de uso Industrial - I y Residencial de densidad media - RDM.

Figura 8. Usos actuales del suelo (por predominancia).

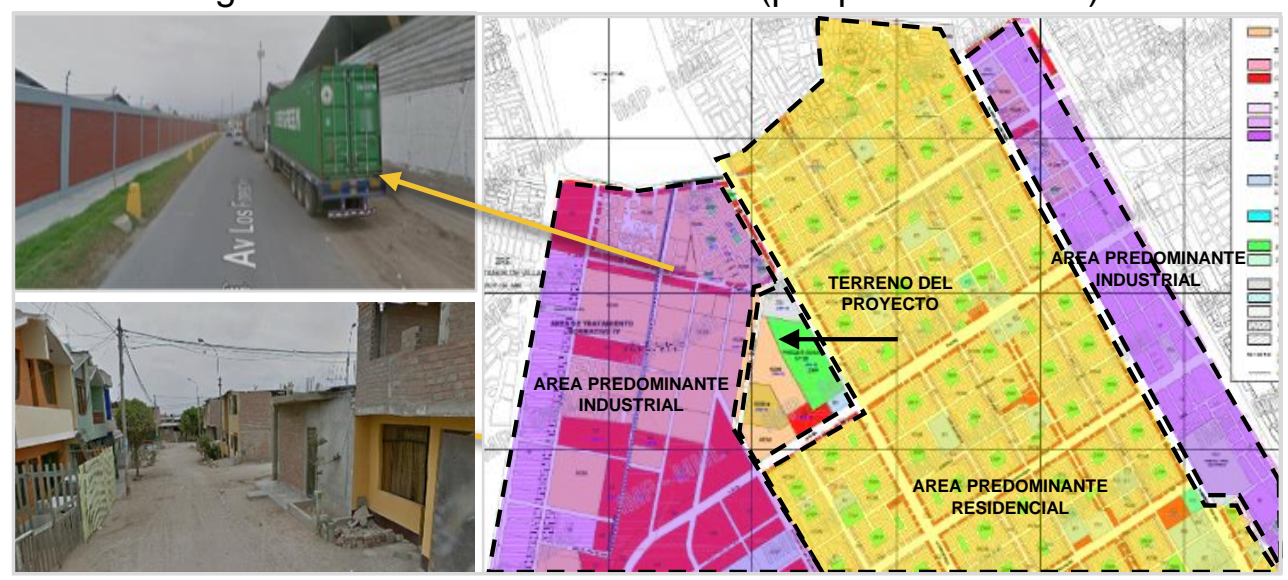

Fuente: Google Earth, 2019. Elaboración Propia.

Asimismo, Villa el Salvador cuenta con una población de 423,887 habitantes según Estimaciones y Proyecciones de población por departamento, provincia y distrito del Instituto Nacional de Estadística e Informática (2020) y una superficie de 35.46 km2 según el Instituto Geográfico Nacional del Perú (2018). Sin bien el distrito cuenta con tres centros comerciales como Megaplaza Villa el Salvador, Megaplaza Villa María del Triunfo y Megaplaza Express estos no son de escala super regional (CSR) y tampoco de zonificación Comercio Metropolitano (CM), sino de escala vecinal (CV) con zonificación comercio Zonal (CZ) que poseen tiendas menores y una pequeña tienda ancla para la atracción de público; por ende, no cubren un gran radio de influencia la demanda de este distrito con gran densidad poblacional, se puede observar en la figura 8 a continuación: 
Figura 9. Establecimientos comerciales en VES.

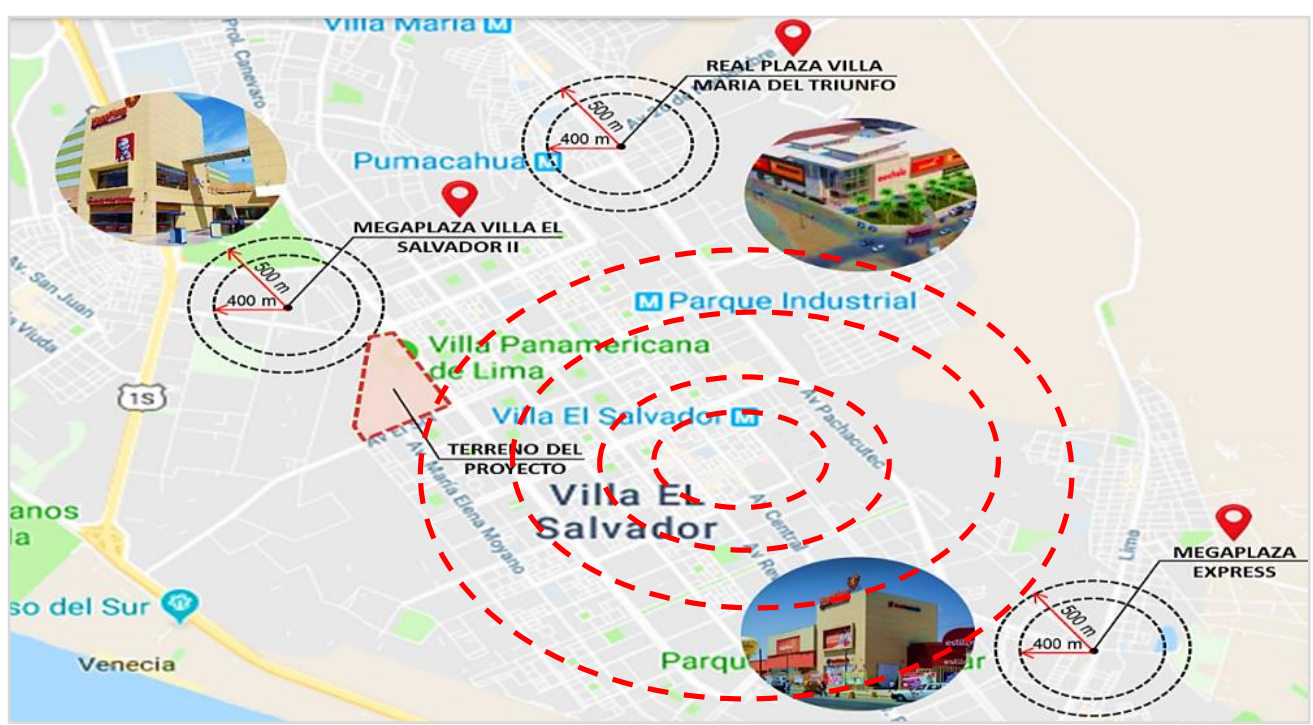

Fuente: Google Earth, 2019. Elaboración Propia.

Como se ha observado, a pesar de estar establecido en la zonificación vigente el uso comercial en el área de transición de la zonificación industrial con la zonificación residencial, el uso real es industria, por lo que finalmente no hay centros comerciales a nivel metropolitano de escala super regional (CSR) en áreas que se desarrollen como comercio Metropolitano (CM) que satisfaga las necesidades de los pobladores del distrito de Villa el Salvador.

Por otro lado, es importante tener conocimiento que cuando un centro comercial se llega a desarrollar en aquellos suelos destinados de forma técnica y normativamente trae consigo buenos indicadores económicos para la localidad, según la Asociación de Centros Comerciales del Perú (2016), asegura que este tipo de equipamientos en el Perú en los últimos años han desencadenado desarrollo ya sea tanto en ventas, empleo local, evolución del área arrendable e incremento de número de visitantes en las zonas emplazadas, como se muestra en la Tabla 4. 
Tabla 4. Principales indicadores sobre la evolución de los centros comerciales en el Perú 2012-2016.

\begin{tabular}{|c|c|c|c|c|c|}
\hline Indicador & 2012 & 2013 & 2014 & 2015 & 2016 \\
\hline $\begin{array}{c}\text { Ventas brutas de los centros } \\
\text { comerciales (millones de } \\
\text { soles) }\end{array}$ & $15,886.1$ & $18,253.2$ & $20,934.4$ & $22,908.5$ & $25,042.8$ \\
\hline $\begin{array}{c}\text { Tasa de crecimiento de las } \\
\text { ventas ** }\end{array}$ & $19.6 \%$ & $14.9 \%$ & $14.7 \%$ & $9.4 \%$ & $9.3 \%$ \\
\hline $\begin{array}{c}\text { Visitas mensuales promedio } \\
\text { a los centros comerciales } \\
\text { (millones de personas) }\end{array}$ & 36.7 & 43.3 & 50.0 & 54.7 & 59.8 \\
\hline $\begin{array}{c}\text { Evolución del área } \\
\text { arrendable (miles de m2) }\end{array}$ & 1,728 & 2,021 & 2,378 & 2,468 & 2,724 \\
\hline $\begin{array}{c}\text { Tasa de vacancia (en } \\
\text { porcentaje) }\end{array}$ & 4.3 & 4.8 & 4.2 & 3.6 & 2.7 \\
\hline $\begin{array}{c}\text { Número de centros } \\
\text { comerciales }\end{array}$ & 48 & 60 & 68 & 73 & 77 \\
\hline Número de tiendas & 5,214 & 5,796 & 5,513 & 7,121 & 8,146 \\
\hline
\end{tabular}

Fuente: Los centros comerciales en el Perú, Asociación de Centros Comerciales y de Entretenimiento del Perú.

Por lo que se está desperdiciando grandes oportunidades de desarrollo local para el distrito de Villa el Salvador, así como también, no se está previniendo las futuras demandas, considerando el incremento de la población por incidencias naturales, así como la cantidad de personas que habitarán en la Villa Panamericana después de los Juegos Panamericanos Lima 2019.

Es por ello que tener una visión de planificación urbana, que incluya equipamiento de rubro comercial como propuesta, sirve de aseguramiento para el territorio con fines de expansión o consolidación urbana enfocada a un aumento de plusvalías del suelo es lo que se necesita como oportunidad de aprovechamiento en el escenario actual Post Panamericanos en el distrito de Villa el Salvador.

Sobre todo, ahora que la Villa Panamericana se habilite residirán gran cantidad de familias, que requerirán de servicios urbanos complementarios al uso residencial como comercio, educación, áreas recreativas, debido a ese número nuevo de residentes y teniendo en cuenta el incremento exponencial de la población y generaciones futuras se repercutirá en nuevas demandas propias del desarrollo de sus actividades. 


\subsubsection{Poca participación de los gobiernos locales en el desarrollo del Plan Maestro de los Juegos Panamericanos 2019.}

Como se ha explicado, Lima oficialmente se convierte en la sede de los Panamericanos en la asamblea de Guadalajara en México en el año 2013, posteriormente se encargó a la Organización de los XVIII Juegos Panamericanos 2019 el desarrollo total de la planificación del evento, es decir tanto el Plan Maestro de Infraestructura como el Plan de Operaciones, según Lima (2019).

Por ser una intervención a nivel metropolitano, se esperaba que los gobiernos locales tuvieran la participación adecuada por ser uno de los principales actores involucrados; sin embargo, cuando se revisa las actas que constituyen el desarrollo del Plan Maestro de Infraestructura y el Plan de Operaciones, estos han sido aprobados sin la participación de los gobiernos distritales, por lo que sus requerimientos especiales o su visión a futuro de acuerdo a las necesidades de los pobladores no han sido considerados.

Según el Comité Olímpico Peruano (2016), en la Acta de la Cuadragésima Novena Sesión de COPAL - Lima, del 13 de Junio del 2016 donde se aprobó el Plan Maestro de Infraestructura con la participación del representante de Ministerio de Educación, representante del Comité Olímpico Peruano, representante de la Municipalidad de Lima Metropolitana, representante del Ministerio de Vivienda, Construcción y Saneamiento, representante del Ministerio de Economía y Finanzas, representante del Instituto Peruano del Deporte y el representante del Comité Olímpico Internacional; pero no con representantes de las municipalidades locales, como debió llevarse a cabo.

Así mismo, el Plan Maestro de Operaciones según el Comité Olímpico Peruano (2016), en el Acta de la Quincuagésima Tercera Sesión del 
COPAL - Lima, del 18 de Julio del 2016 donde se aprobó el Plan Maestro de Operaciones con la participación del representante del Ministerio de Educación, representante del Gobierno Regional del Callao, representante del Instituto Peruano del Deporte, el representante de la Asociación Nacional Paralímpica del Perú, representante del Ministerio de Economía y Finanzas, representante de la Municipalidad Metropolitana de Lima, representante del Ministerio de Transportes y Comunicaciones, representante del Comité Olímpico Peruano, representante de la Asociación Panamericanos y Parapanamericanos Lima 2019, otra vez se constituyó sin la participación de los gobiernos locales involucrados directamente.

La Villa Panamericana de los Juegos Panamericanos Lima 2019 ubicada en Villa el Salvador, estaba contemplada para la residencia temporal de los deportistas durante el evento, pero pasado el evento se decidió que estas infraestructuras se convirtieran en viviendas de carácter social para las familias que no cuenten con una vivienda segura.

Cabe mencionar que, en la actualidad la Villa Panamericana está teniendo un uso coyuntural de salud, debido a la pandemia del COVID19 declarado por la Organización Mundial de la Salud (2020), en el mes de enero del presente año. Es así como, la villa está cumpliendo un rol de centro de aislamiento temporal por COVID19, para pacientes diagnosticados positivos al COVID19, aquellos que estén esperando sus resultados de pruebas y el personal médico. Sin embargo, post pandemia, el uso de esta infraestructura seguirá manteniéndose para uso residencial con carácter social.

Finalmente, entonces se resume que estos acontecimientos señalados no han previsto como intervención urbana entorno a la villa, la dotación de equipamientos urbanos, tales como comercial, educativo o de salud como la oportunidad de desarrollo para la población que vive 
actualmente en Villa el Salvador y sobre todo para las nuevas generaciones que irán llegando.

\subsection{Objetivo del proyecto.}

A nivel urbano diseñar un espacio enfocado a la recreación pública pasiva y activa para el desarrollo humano a través de actividades de entretenimiento, socialización e inclusión social que permitan la integración de la población de Villa el Salvador, diseño acompañado de un planteamiento de recuperación de la estructuración urbana que el distrito posee con gran potencial mediante intervenciones viales, mejoramiento de ciclovías y áreas verdes para una mayor conectividad, habitabilidad, el mejoramiento de calidad de aire, y también en fomentar la participación ciudadana. Hay que tener en cuenta que este distrito posee un gran potencial de emplazamiento por ser considerado nodo de centralidad Lima Sur en el PLAM 2035.

Por ello al aprovechar esta oportunidad de los espacios sin uso específico aledaños de la Villa Panamericana luego de los Juegos Panamericanos 2019 a nivel arquitectónico se propone diseñar un espacio principalmente enfocado a la cobertura con gran demanda y constante de espacios comerciales, además es importante complementar la inexistencia de un espacio para las actividades empresariales que se desarrollen en Villa el Salvador y asimismo disminuir gran parte del déficit residencial del distrito.

Proponer en Villa el Salvador un proyecto de tal envergadura que necesita como nuevo nodo de centralidad creando un nuevo hito comercial en Lima Sur una zona que empieza a tener las mismas características y necesidades de Lima norte.

\subsection{Justificación del proyecto.}

Villa el Salvador es considerado el único distrito de Lima que ha sido planificado a nivel urbano con vías extensas articuladas en todo el distrito, y que ha ganado el premio Príncipe de Asturias de la Concordia, gracias a "La 
práctica ejemplar para organizar un tipo de ciudad solidaria y económicamente productiva". Sin embargo, hoy en día debido al crecimiento de la población, cambios de zonificación y otros factores, Villa el Salvador presenta algunos problemas.

Los usos de suelo en todo el distrito difieren de la zonificación actual dada por la Municipalidad de Villa el Salvador, que se muestra a continuación:

Figura 10. Zonificación actual del distrito de Villa el Salvador.

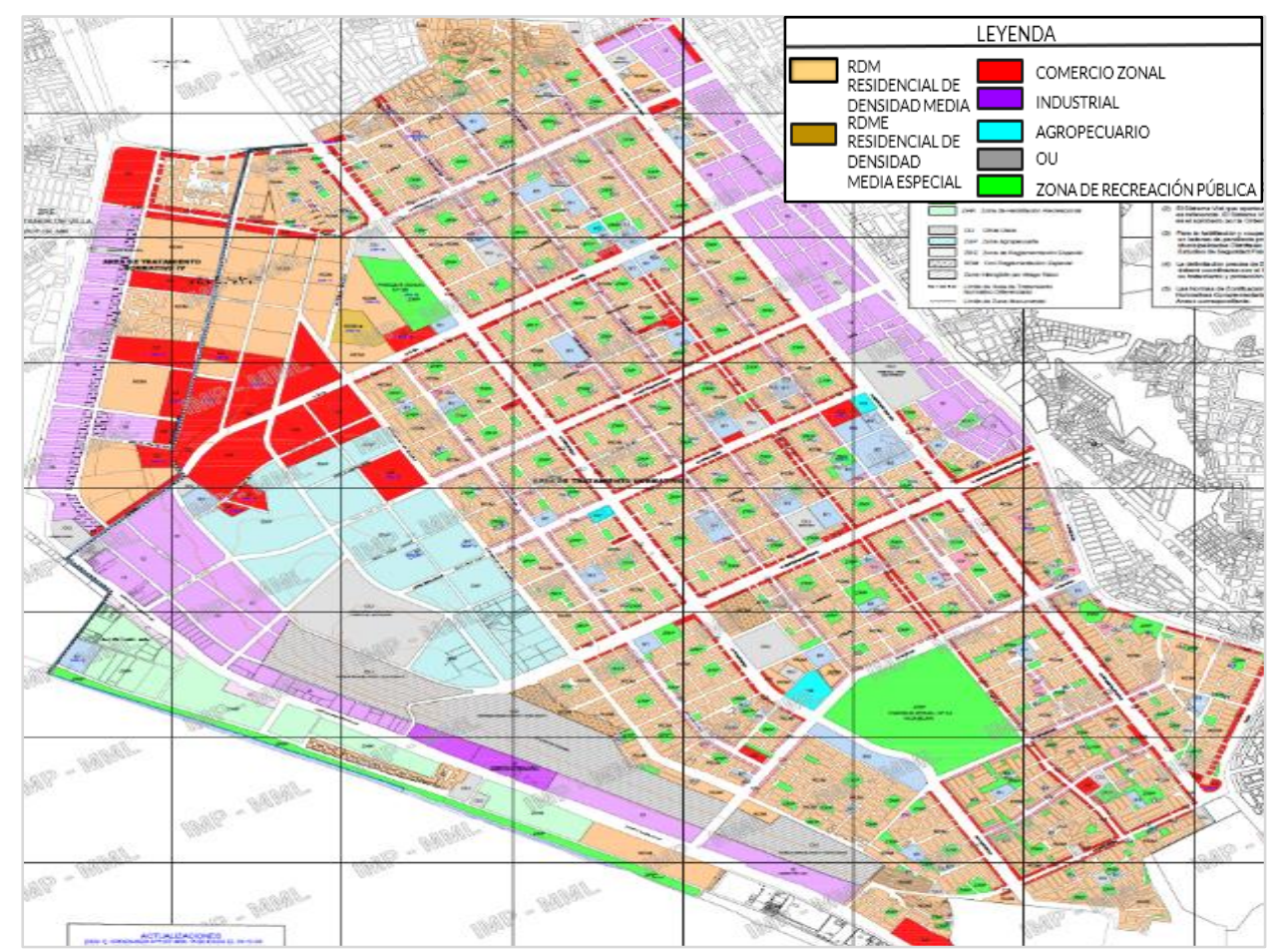

Fuente: Municipalidad Villa el Salvador, 2019.

El territorio a pesar de su diseño inicial ordenado a nivel urbano, a través de los años por el crecimiento exponencial y constante de la población y, dinámica social dieron lugar a cambios de la estructura del suelo, en muchas zonas se distorsionó los ejes principales viales y se perdió la continuidad de estos fomentando desarticulación del mismo territorio y en las zonas de playas.

Los principales problemas actuales de Villa el Salvador es que a pesar de regirse de una zonificación establecida por la Municipalidad de Villa el 
Salvador previamente vista, como zonificación urbana se distribuye mayormente en áreas de Industria Elemental y Complementaria - IE Industria Liviana - 12, Gran Industria - 13, Residencial de densidad media, Comercio Zonal - CZ, zonas Agropecuarias - ZAP y cuenta con dos parques zonales, sin embargo, todos estos lineamientos no se cumplen en su totalidad.

Se ve reflejado en la observación de campo que la misma dinámica social e informalidad han dado consecuencia que los usos reglamentarios de los suelos infieran por otros que no corresponden, desvalorizando los terrenos del distrito. La predominancia del uso del suelo difiere enormemente a la zonificación comercial establecida por VES de acuerdo a la visión actual del distrito, donde se busca que Villa el Salvador sea un distrito con muchas cualidades, pero sobre todo comercial, productivo, verde, accesible, integrado, entre otros.

La imagen urbana del área más próxima al área del terreno es predominantemente de uso Industrial - I y de residencial de densidad media - RDM con bastante comercio zonal - CZ en casi todas las calles de forma difusa sin ningún núcleo ordenado. Es por ello, que se puede afirmar que no hay áreas que se desarrollen como comercio a una mayor escala y planificado que cubra las necesidades del distrito, lo que sería adecuado modificar la zonificación actual para ordenar las nuevas necesidades resaltando las potencialidades del distrito.

A continuación, se muestra las diferencias de las zonificaciones actuales y los usos predominantes del suelo generados por los diversos acontecimientos descritos anteriormente. 
Figura 11. Zonificación del distrito de Villa el Salvador vs Usos actuales del suelo (por predominancia).

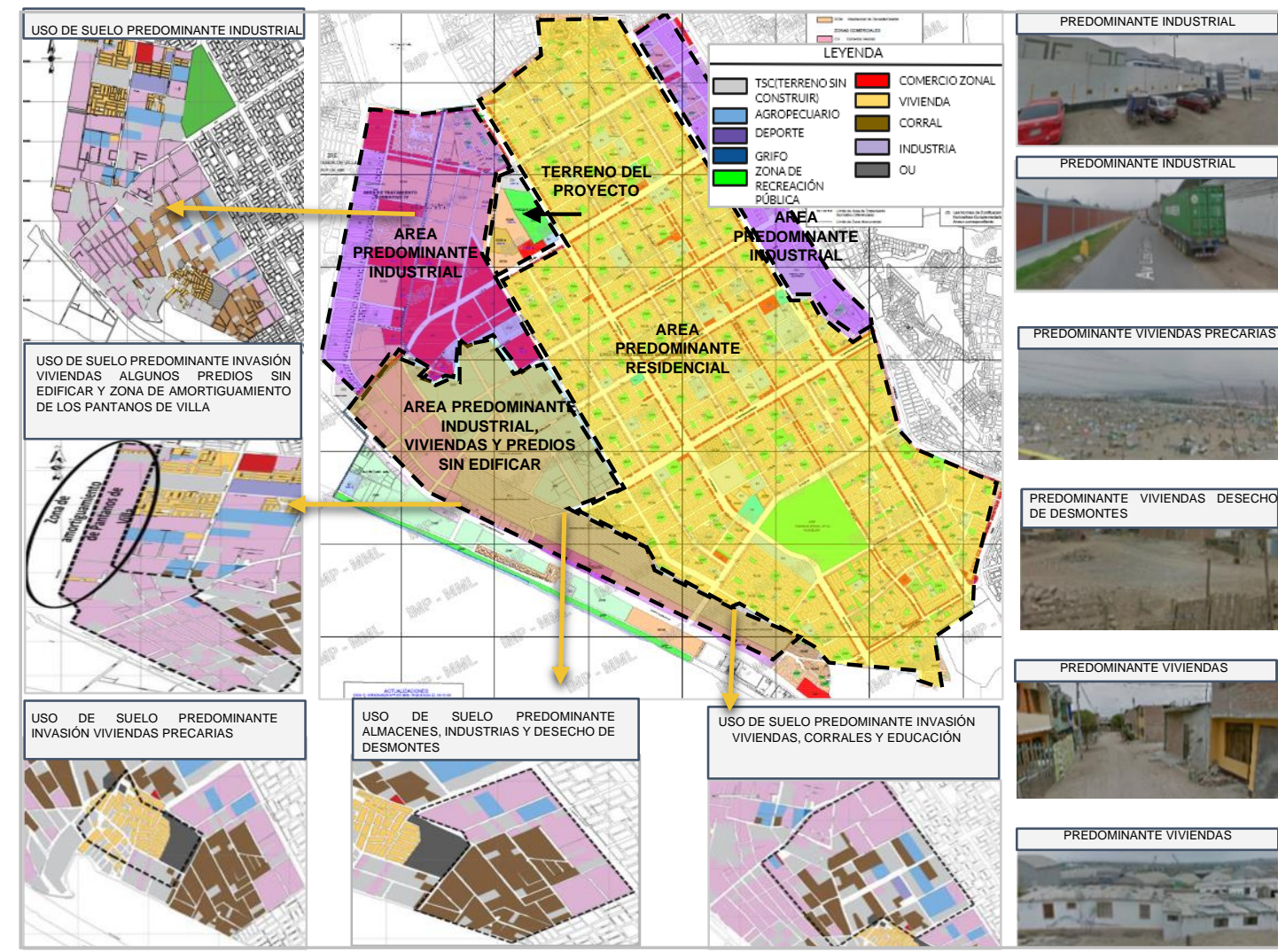

Fuente: Instituto Metropolitano de la Planificación, Google Earth y Municipalidad Villa el salvador, 2019. Elaboración Propia.

Lo que respecta, en transporte existente ya sea el público y el sostenible a través de ciclovías, actualmente el distrito de Villa el Salvador cuenta con buses alimentadores de Metropolitano que parten desde la estación Mantellini en Chorrillos y llegan al distrito con diferentes paradas y también pasa la línea del Metro 1 donde se remata un punto final en av. Separadora Industrial antes de llegar a la av. Jorge Chávez. 
Figura 12. Ruta y paraderos de transporte público de Alimentadores Metropolitano y Metro Línea 1.

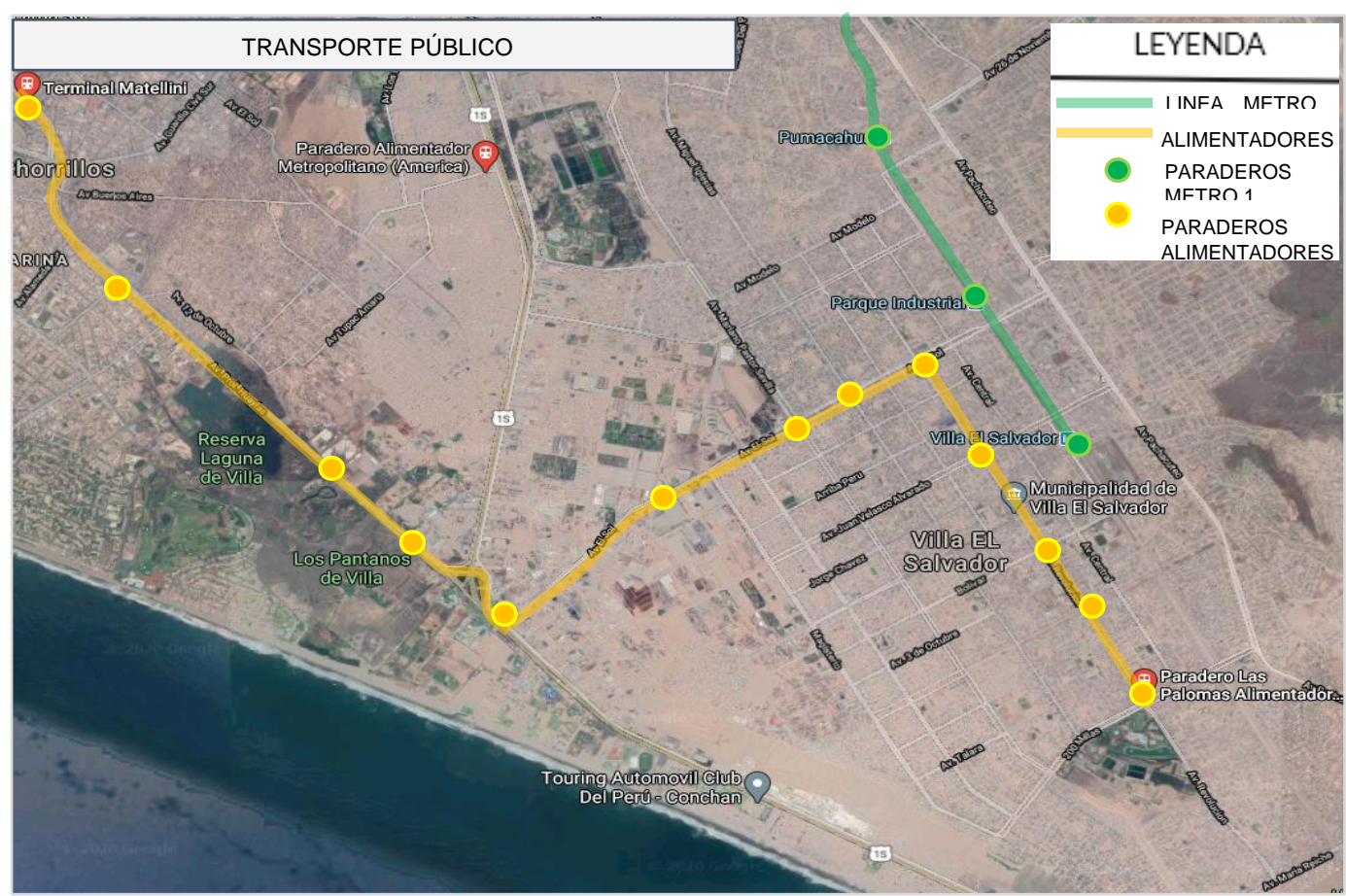

Fuente: Municipalidad de Villa el Salvador, 2016 y Google Earth, 2020. Elaboración Propia.

También, cuenta con una red de ciclovía de $15 \mathrm{~km}$ en la av. Mariano Pastor Sevilla con $5.15 \mathrm{~km}$, av. Cesar Vallejo $3.28 \mathrm{~km}$, av. José Carlos Mariátegui $2.40 \mathrm{~km}$, av. El Sol 2.59, av. 200 Millas $0.56 \mathrm{~km}$ y av. Separadora Industrial 0.99km y en la actualidad está en ejecución la prolongación mariano pastor Sevilla hasta av. Mateo Pumacahua y Pedro Miotta de acuerdo a la Municipalidad de Lima (2018). En cual se observa que planean una implementación de más redes de ciclovías, pero no poseen una proyección de interconectividad en toda la trama de Villa el Salvador lo que sí sería adecuado tomar en cuenta para articular mejor el distrito a continuación, se observa en el gráfico las ciclovías existentes. 
Figura 13. Ruta ciclovía existente, en ejecución y proyectada.

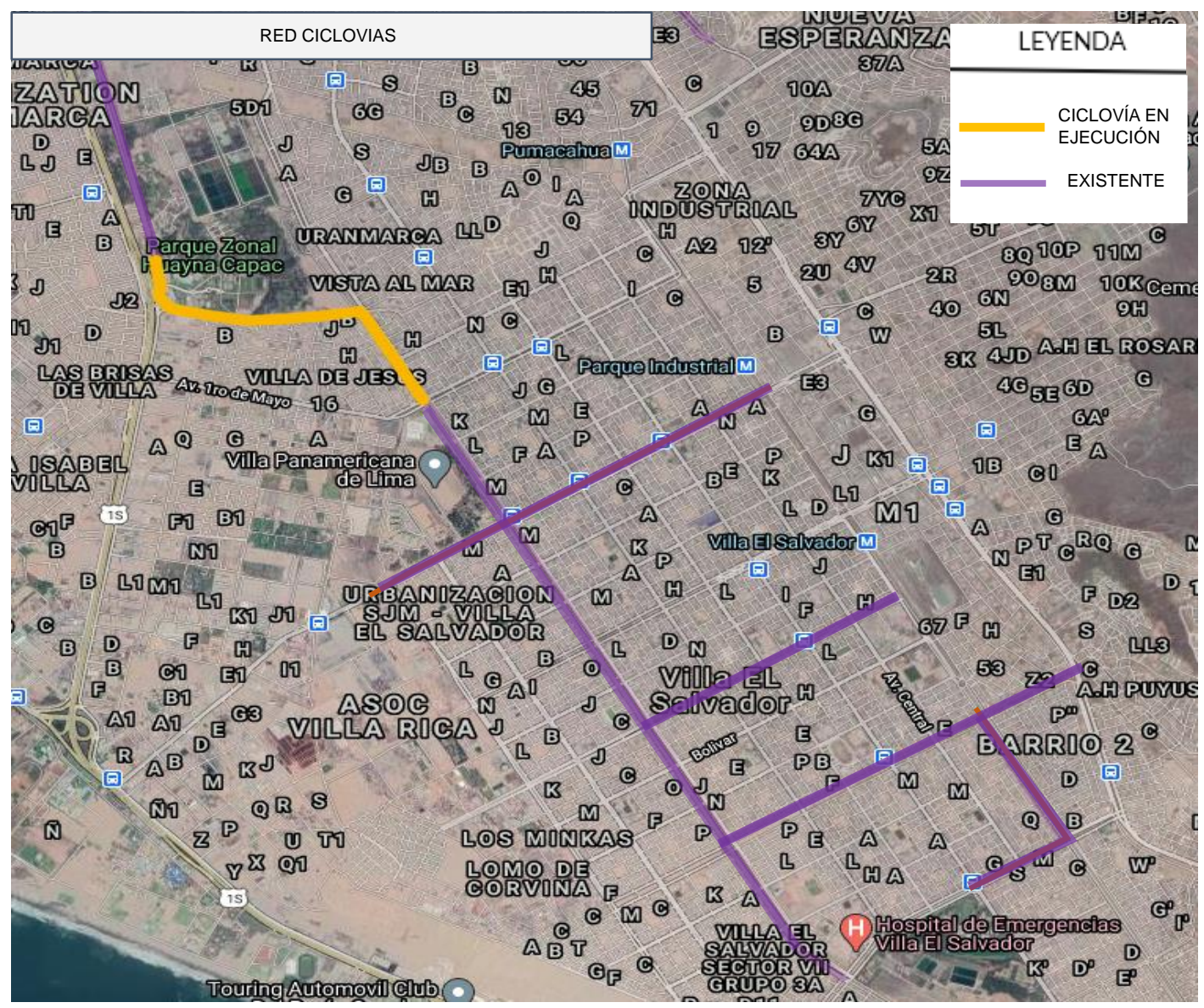

Fuente: Municipalidad de Lima, 2017 y Google Earth, 2020. Elaboración Propia.

Se analiza también la densidad de áreas verdes por habitantes la cual es baja al año 2017 el distrito dispone de 1.83m2 de área verde por habitante según la Municipalidad Metropolitana de Lima (2017). Asimismo, esto se refleja en el deterioro de áreas verdes en las avenidas principales, articuladas con los espacios públicos que se encuentran también descuidados, donde si bien en el plan concertado 2017-2021 de la Municipalidad de Villa el Salvador(2016), se indica la ubicación de las áreas verdes existentes, cuando se realiza una vista aérea del distrito infiere con lo indicado enormemente; ya que, la mayoría de las parcelas poseen poco o nada de los núcleos indicados como áreas verdes, en las parcelas ubicadas en las zonas residenciales, en las alamedas y plazas públicas. 
Figura 14. Núcleos de áreas verdes Villa el Salvador.

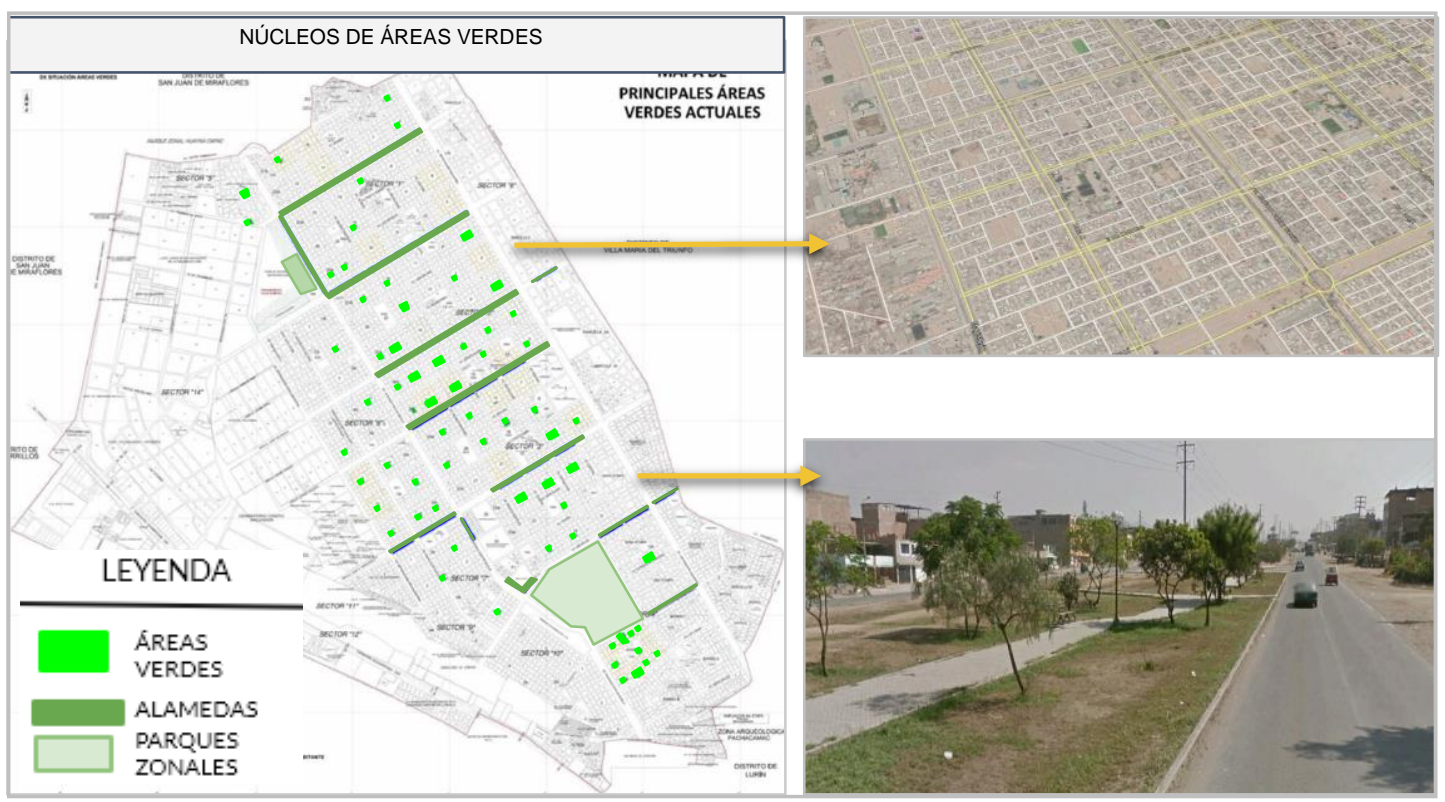

Fuente: Municipalidad Villa el salvador, 2019. Elaboración Propia.

Figura 7. Áreas verdes por distrito en Lima

\begin{tabular}{|rrr|}
\hline \multicolumn{1}{|c}{ Distrito } & $\begin{array}{c}\text { Area verde } \\
\left(\mathrm{m}^{2}\right)\end{array}$ & $\begin{array}{c}\text { Area verde/ } \\
\text { hab }\end{array}$ \\
\hline Surquillo & $246,811.13$ & 2.71 \\
El Agustino & 517.653 .00 & 2.60 \\
La Victoria & $429,427.00$ & 2.47 \\
Ancón & $155,149.53$ & 2.47 \\
Comas & $1227,846.71$ & 2.36 \\
Lurigancho-Chosica & $501,055.68$ & 2.08 \\
Punta Negra & $14,354.40$ & 2.03 \\
San Juan de Miraflores & 694.115 .49 & 1.95 \\
Villa El Salvador & 721.499 .03 & 1.83 \\
\hline
\end{tabular}

Fuente: Municipalidad Metropolitana de Lima, 2017.

Asimismo, desde el año 2008 al 2020 las zonas de parques zonales han disminuido quitando grandes pulmones de Villa el Salvador por cambios de zonificaciones, ya que, la construcción de la Villa de atletas disminuyó gran parte del ex parque 26 complejo biotecnológico y generó más cambios de zonificaciones como se observa en la zonificación actual desfavoreciendo en gran porcentaje las reservas urbanas del distrito. Por ello, preservar gran parte de las áreas verdes en el terreno y también distribuirlo de una mejor forma y adecuada en el distrito es parte de una iniciativa de concientización ambiental en VES. 
Figura 16. Variaciones de zonificación del distrito de Villa el Salvador.

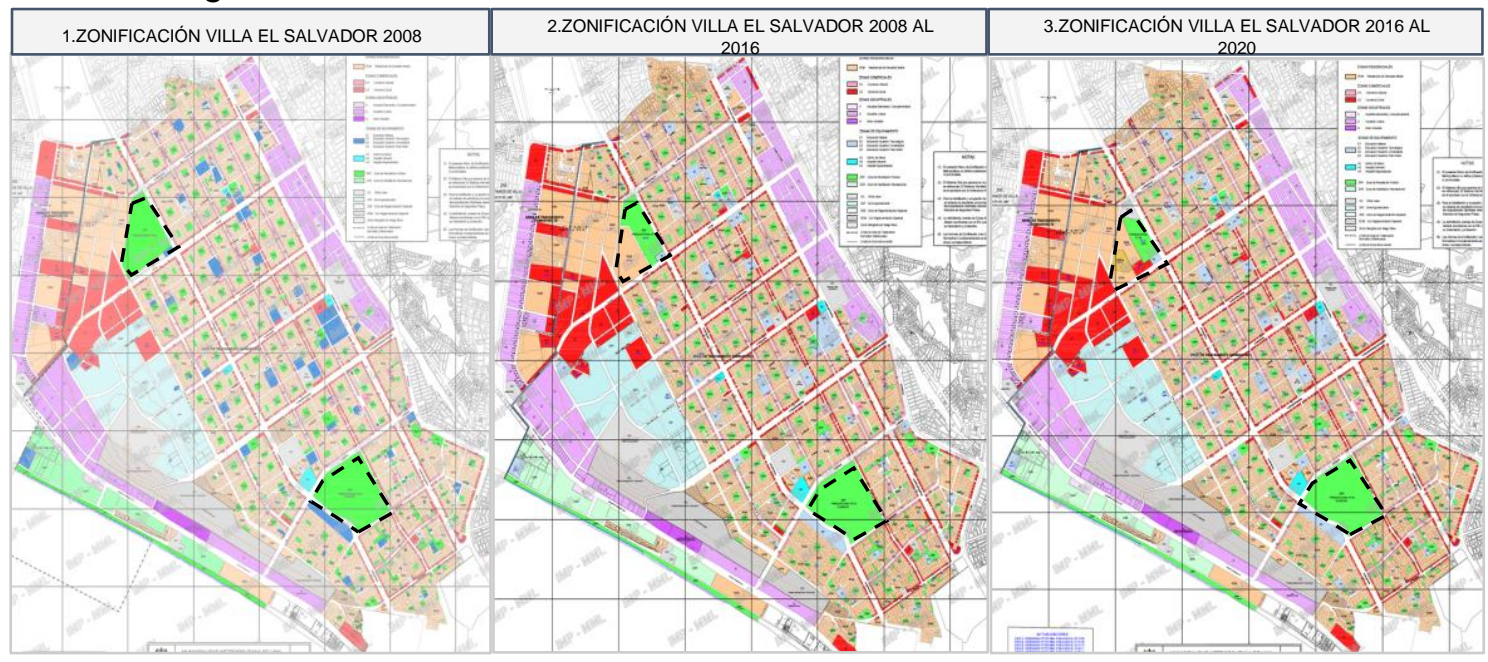

Fuente: Instituto Metropolitano de la planificación, 2019.

Elaboración Propia.

A continuación, se muestra en la siguiente imagen el resumen del análisis del contexto territorial que se basa en conocer tanto las potencialidades que tiene Villa el Salvador y a su vez sobretodo las deficiencias, ya que es muy importante conocer el estado actual de un territorio, donde en este caso se visualiza cuatro aspectos resaltantes en conjunto: las ciclovías existentes, áreas verdes, el alimentador Metropolitano y Metro Linea 1.

Figura 17. Analisis Territorial Villa el Salvador.

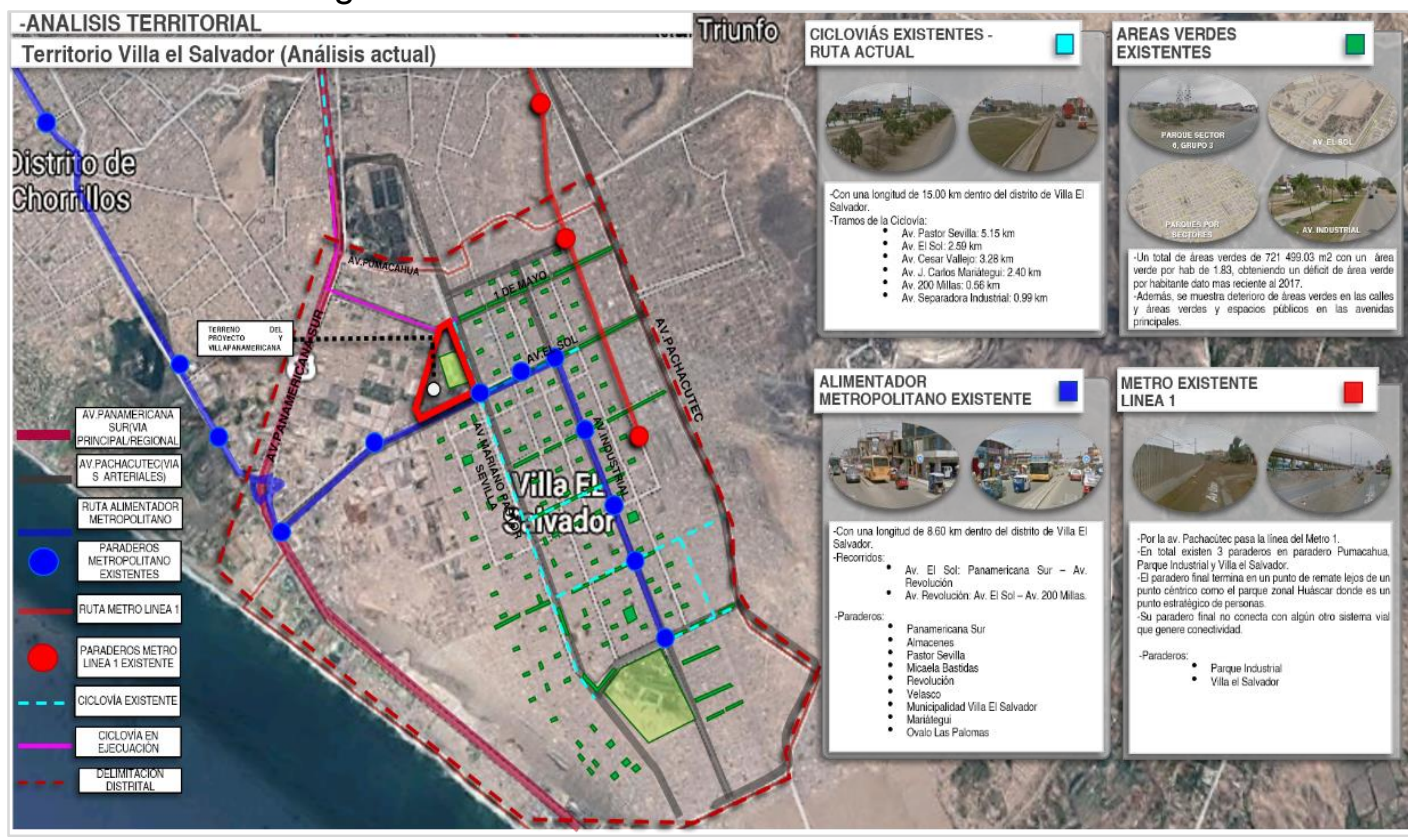

Fuente: Google Maps.

Elaboración Propia. 
Cabe mencionar que según las Estimaciones y Proyecciones de población por departamento, provincia y distrito del Instituto Nacional de Estadística e Informática (2020), Villa del Salvador cuenta con una población de 423,887 habitantes, sin embargo, cuenta con tres centros comerciales (Megaplaza Villa el Salvador, Megaplaza Villa María del Triunfo y Megaplaza Express) que no son a nivel metropolitano, sino de una escala más sectorial (CS) que no cubre la demanda del distrito, teniendo en consideración que la tasa de crecimiento estos últimos años ha sido de 1.9\% que representa al 19\% de Lima provincia, según Apoyo Opinión y Mercado (2018).

Es así como se identifica un déficit de equipamiento comercial a escala zonal, además de que existe un potencial comercial en el territorio debido a las mejoras en la zonificación urbana, crecimiento constante de establecimientos comerciales ya que, en el año 2017 de 9,455 establecimientos ascendió a 11,000 establecimientos, sostenido por la Municipalidad de Villa el Salvador (2016).

Tabla 5. Establecimientos comerciales actuales y proyectados.

\begin{tabular}{|c|c|c|}
\hline Comercio & 2017 & 2020 \\
\hline Establecimientos en Lima & 9,455 & 11,000 \\
\hline
\end{tabular}

Fuente: Municipalidad Villa el Salvador, 2017.

Por otro lado, existe también un déficit habitacional de viviendas en el distrito de Villa el Salvador de 37,826 viviendas (17,589 cuantitativo $2.88 \%$ y 20,237 cualitativo $3.32 \%$ ) correspondiente a un $6.2 \%$ del déficit habitacional de Lima, según el Diario Gestión (2017). En ese sentido, a nivel físico Villa el Salvador alcanzó su máxima extensión urbana según Romero (1992) es por ello que se ve como solución la habilitación de esta Villa Panamericana para cubrir parte de estas carencias con una proyección de disminuir al 3\% al 2020.

Tabla 6. Déficit de viviendas actuales y proyectados.

\begin{tabular}{|l|c|c|}
\hline Déficit viviendas & 2017 & 2020 \\
\hline Villa el Salvador & $6.20 \%$ & $3.00 \%$ \\
\hline
\end{tabular}

Fuente: Planeamiento estratégico para la edificación y vivienda en Lima Metropolitana, Castillo elt, 2018. 
Adicionalmente, se identifica que a pesar que el distrito de Villa el Salvador presenta un potencial comercial porque en él se sitúan diferentes almacenes como el de las cadenas de Ripley y Saga Falabella; parte de este potencial que está establecido en su visión dentro del Plan de Desarrollo Local Concertado 2017-2021 de VES según Municipalidad de Villa el Salvador (2016), tiene un enfoque productivo y comercial, pero actualmente no existe un centro empresarial que pueda complementar las labores comerciales, a pesar de un aumento de empresas en todo el distrito desde el año 2018 de $43,600.00$ a $40,000.00$ al 2020 como indica INEI(2018), no existe un lugar donde se satisfaga la demanda de funcionarios, inversionistas que no tienen oficinas empresariales para desarrollar sus actividades diarias.

Tabla 7. Empresariado actual y proyectado.

\begin{tabular}{|c|c|c|c|}
\hline Empresariado & 2018 & $\begin{array}{c}\text { Densidad empresarial } \\
\text { (Empresas por Km2) }\end{array}$ & 2020 \\
\hline Villa el Salvador & $43,600.00$ & $979,30 \mathrm{emp} . / \mathrm{km} 2$ & $40,000.00$ \\
\hline
\end{tabular}

Fuente: Directorio Central de Empresas y Establecimientos, Instituto Nacional de Estadística e Informática, 2018.

Finalmente, se está desaprovechando muchas potencialidades que posee el distrito de Villa el Salvador en el contexto territorial y por otro lado, no se está considerando la problemática actual y la futura, en cuestiones de demanda de equipamiento, teniendo en cuenta que el crecimiento de la población ya sea por condiciones naturales o por el incremento de la población al habilitar la Villa Panamericana para uso residencial, otro punto importante tampoco en los lotes colindantes de acuerdo a lo que requiere la población después de los Juegos Panamericanos y Parapanamericanos Lima 2019 y post pandemia por COVID19, ya que temporalmente se encuentra como centro de aislamiento temporal para personas infectadas, personas con síntomas de la enfermedad y personal médico.

\subsection{Concepto inicial del proyecto}

La presente tesis apunta a cubrir cuatro grandes necesidades que requiere el distrito de Villa el salvador, la demanda de viviendas dignas con los servicios necesarios para su habitabilidad, parques o áreas verdes, 
áreas de complementos a la actividad empresarial y centros comerciales. Es así como se define el proyecto como "Mejoramiento Urbanístico y Equipamiento Comercial - Empresarial Post Panamericanos entorno de la Villa Panamericana en Villa el Salvador", el cual está compuesto por cuatro grandes sectores de acuerdo a las necesidades identificadas en el análisis previo:

El primer sector denominado BLOQUES RESIDENCIALES, que está destinado a satisfacer la demanda actual de viviendas no solo de Villa el Salvador sino también a nivel metropolitano de carácter social del programa MiVivienda para los estratos socioeconómicos $\mathrm{B}$ y $\mathrm{C}$, es así como se dotará de viviendas dignas con servicios básicos adecuados y espacios eficientes y pensados en las necesidades de los miles de familias quienes carecen una vivienda para conformar su hogar.

Por otro lado, el segundo sector denominado PARQUE TEMÁTICO, que está destinado a cubrir las necesidades relacionadas a las actividades recreativas pasivas y activas, a manera de espacio público que sirva de desfogue para toda la población que se establecerá en los bloques residenciales, en el edificio empresarial y en el centro comercial, además a nivel distrital. Que por su naturaleza será un pulmón de oxígeno para el distrito donde se podrán desarrollar diversas actividades ya sea culturales, con fines comerciales, entre otros.

El tercer sector denominado EDIFICIO EMPRESARIAL, cuya finalidad es que abastezca las actividades empresariales que se desarrollan diariamente debido a la cercanía de los almacenes de distintas empresas como Ripley y Saga, entre otros a los alrededores y en el sur de la metrópoli de Lima, siendo relevante para poder alcanzar la visión del distrito de Villa el Salvador; de esta manera se pretende incorporar oficinas y servicios complementarios como bancos y diversas entidades 0 instituciones que permitan que la actividad empresarial se desarrolle fluidamente y acompañe a las 
necesidades del empresariado que realiza su gestión en el distrito de Villa el Salvador.

Y finalmente, el cuarto sector denominado CENTRO COMERCIAL, como se ha explicado anteriormente es un equipamiento urbano del cual carece el distrito a nivel metropolitano, por lo cual es sumamente necesario para poder satisfacer las necesidades complementarias al uso residencial de la Villa Panamericana y de los bloques residenciales propuestos, además que generará plusvalías al ámbito de estudio.

Es así como, estos sectores van a satisfacer las carencias de las cuales hoy en día el distrito de Villa el Salvador carece y son fundamentales para su desarrollo, mejorando la calidad de vida de las personas para generar no solo desarrollo económico, también social y cultural; y territorial, es decir, un desarrollo sostenible.

Figura 18. Concepto inicial del proyecto.

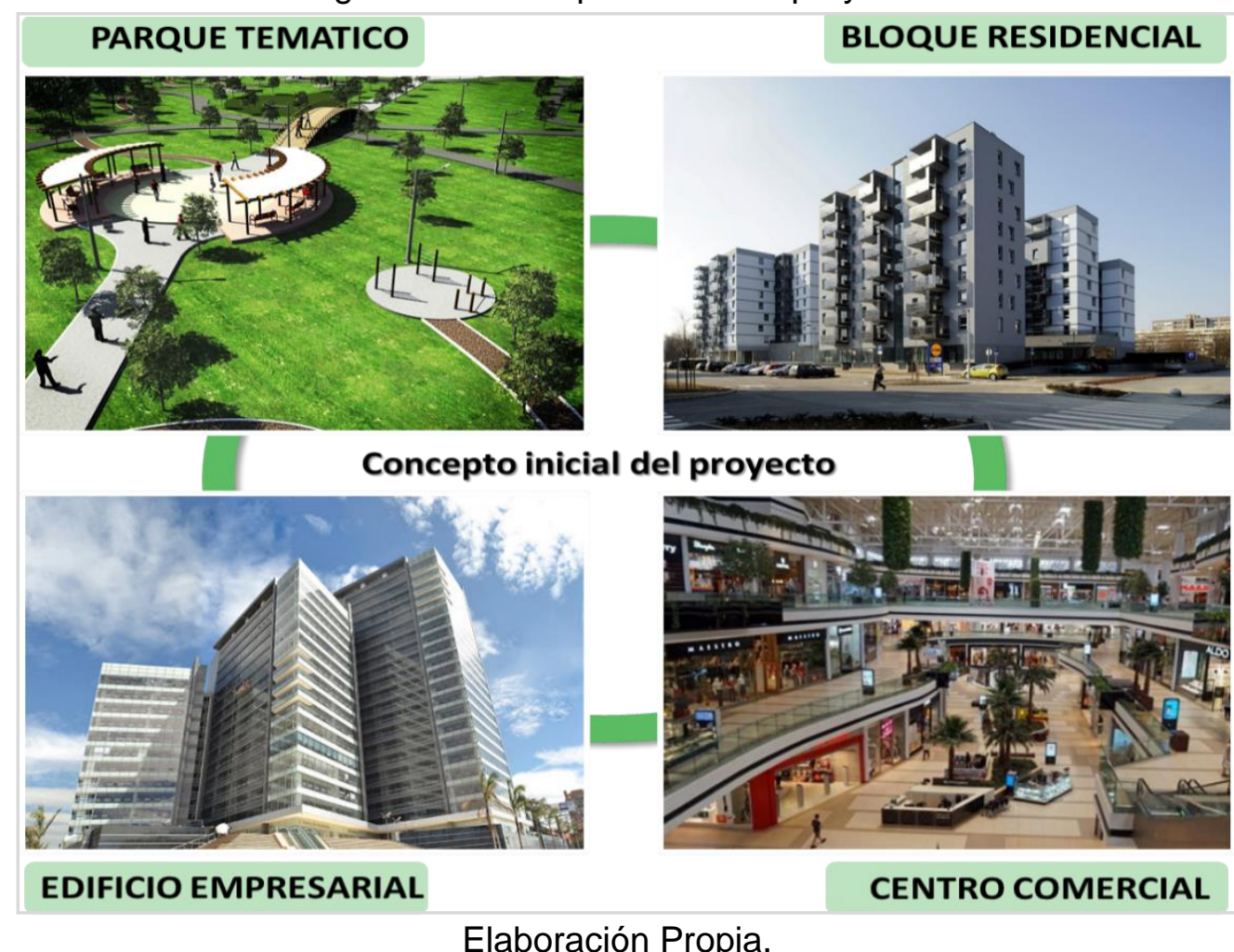

Elaboración Propia. 


\section{Marco teórico y conceptual.}

\subsection{Ejemplos arquitectónicos referenciales.}

A continuación, se describen 3 proyectos nacionales y 2 proyectos internacionales que se consideran referentes para la elaboración de la presente tesis.

\subsubsection{Referentes nacionales.}

Como referentes nacionales tenemos el Centro Comercial Jockey Plaza, el Centro Comercial la Rambla, y el Centro Comercial Mega Plaza, los cuales se ubican en la ciudad de Lima, capital peruana.

\subsubsection{Centro Comercial Jockey Plaza, Lima.}

El jockey plaza fue inaugurado con una extensión de 130 mil metros cuadrados, el 17 de abril de 1997 en los terrenos aquel entonces pertenecientes al Jockey Club del Perú según afirma Patriau (2002), cabe mencionar que este centro comercial fue el primero que se construyó después de la crisis económica de la década de los 90 . Se encuentra ubicado en la Avenida Javier Prado Este, en el distrito de Santiago de Surco, una de las más importantes avenidas a nivel metropolitano.

Figura 19. Ubicación Jockey Plaza, Lima.

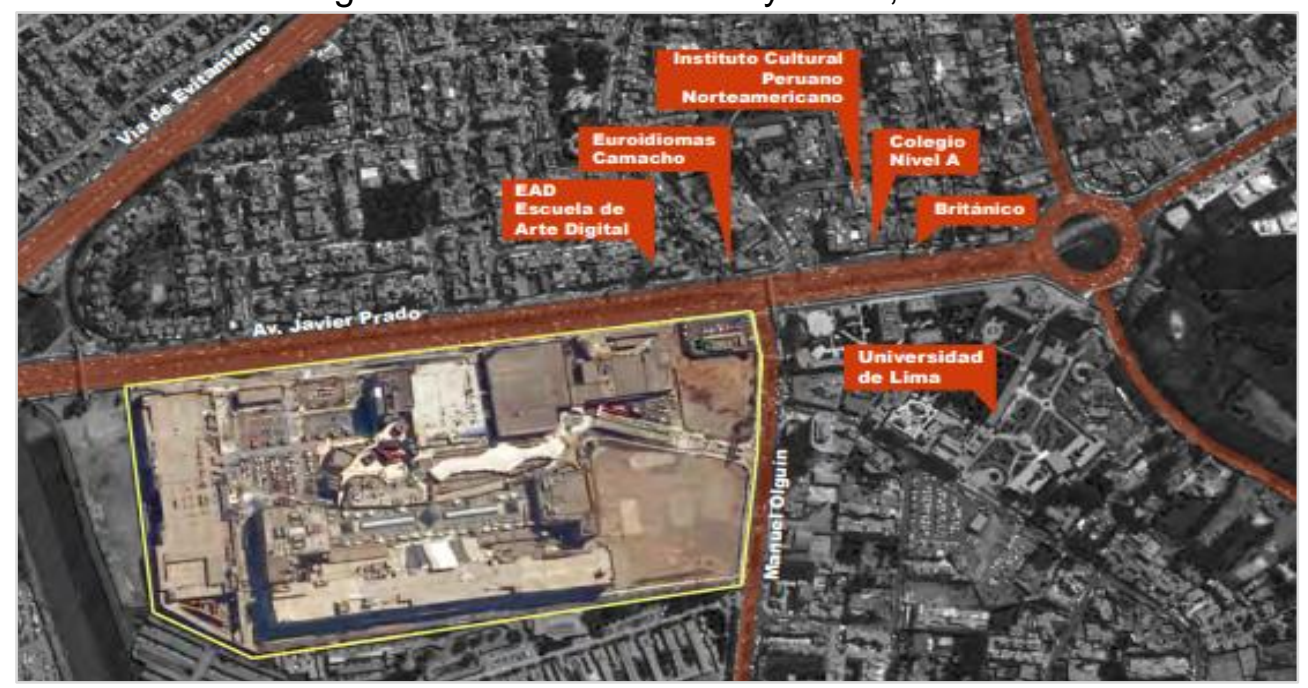

Fuente: ¿Cómo se articula el mall en el espacio urbano desde la experiencia de usuarios jóvenes? CC. Jockey Plaza y Megaplaza en Lima, 2015. 
Este centro comercial ha marcado un hito importante en la historia de los centros comerciales, debido a que generó un paradigma diferente en relación a la administración que los centros comerciales venían ejecutando, y es que fue el pionero en alquilar las tiendas y no venderlas como se venía haciendo hasta ese entonces, según defiende Lampadia Economía (2015).

Esta nueva figura de administración de centros comerciales provocó un crecimiento más constante y sostenido de los centros comerciales, es así como centros comerciales como Plaza San Miguel tuvieron que reinventarse (en términos comerciales, marketing y de gestión) y alinearse a estos nuevos métodos que mostraban indicadores favorables para el crecimiento comercial, según Orrego (2010).

Actualmente, el jockey plaza es el centro comercial más concurrido de la ciudad de Lima, ya que este centro comercial que cuenta con una gran diversidad de tiendas (entre anclas, medianas y pequeñas) respecto a otros centros comerciales de la ciudad. También posee más de 600 locales comerciales y 7 tiendas anclas, en las cuales incluye cadenas nacionales e internacionales como Plaza Vea y Tottus, así como tiendas por departamento como Saga Falabella, Ripley, Oeschle y París, según Carruitero, et al. (2016).

Además, se debe precisar que este centro comercial posee plazas, piletas, alamedas, espejos de agua, circuitos de luces que generan espacios públicos activos, lo cual es otro de los factores por lo que es tan concurrente, ya que deja de ser solo un equipamiento comercial convirtiéndose también en un espacio para el esparcimiento, de encuentros y estancia, que son los factores de éxito. 
Figura 8. Centro Comercial Jockey Plaza.

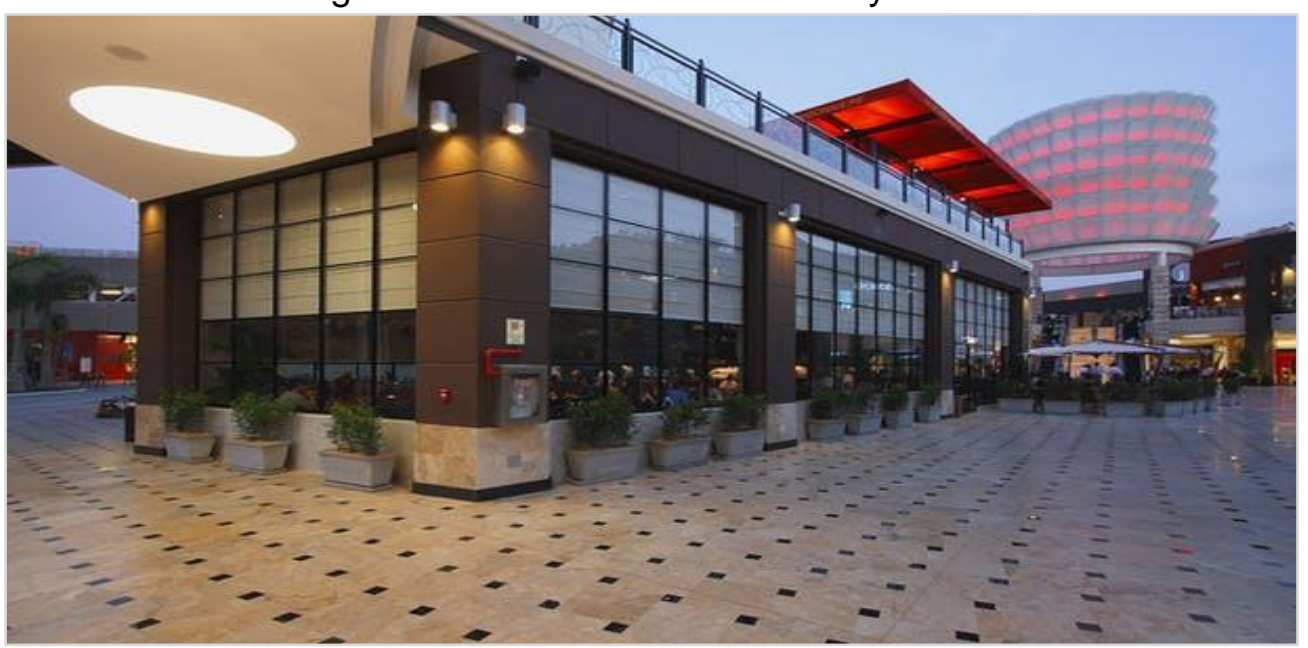

Fuente: Portal Oficial Jockey Plaza, 2020.

En ese sentido, Vega (2013) asegura también que este centro comercial recibe gran diversidad de visitantes que provienen de todas las zonas de Lima metropolitana y de todos los niveles socioeconómicos debido a las diferentes atracciones que ofrece.

La asociación de Centros Comerciales y de Entretenimiento del Perú ACCEP (s.f), indica que el Jockey plaza tiene cerca de 3.5 millones de visitantes, tiene un área rentable de 168,516 m2, además posee 600 tiendas no anclas, 7 tiendas anclas, 12 salas de cine, un gran patio de comidas, un centro de convenciones, un centro médico y 5,100 estacionamientos, tal y como se muestra en el siguiente cuadro.

Tabla 8. Datos estadísticos generales del Jockey Plaza Shopping Center.

\begin{tabular}{|l|c|c|c|c|c|}
\cline { 2 - 6 } \multicolumn{1}{c|}{} & $\mathbf{2 0 1 2}$ & $\mathbf{2 0 1 3}$ & $\mathbf{2 0 1 4}$ & $\mathbf{2 0 1 5}$ & $\mathbf{2 0 1 6}$ \\
\hline Facturación (en millones de s/.) & $2,034.3$ & $2,046.1$ & $2,076.8$ & $2,150.0$ & $2,249.1$ \\
\hline Visitantes por mes (en millones) & 2.5 & 2.5 & 2.5 & 3.0 & 3.5 \\
\hline Área Arrendable (en m2) & 136,834 & 148,514 & 156,105 & 163,956 & 168,516 \\
\hline Tasa de Vacancia & $0 \%$ & $0 \%$ & $0 \%$ & $0 \%$ & $0 \%$ \\
\hline Centros Comerciales & 1 & 1 & 1 & 1 & 1 \\
\hline Número de tiendas no ancla & 377 & 417 & 475 & 523 & 600 \\
\hline Número de tiendas ancla & 5 & 6 & 6 & 6 & 7 \\
\hline Número de salas de cine & 12 & 12 & 12 & 12 & 12 \\
\hline Número de parqueos & 5,060 & 5,060 & 5,100 & 5,100 & 5,100 \\
\hline
\end{tabular}

Fuente: Asociación de Centros Comerciales y de Entretenimiento del Perú ACCEP. (s.f.) 
A nivel de arquitectura, este establecimiento posee patrones de uso urbano que genera grandes espacios públicos de descanso, caminata, espacios para conversar o leer, así mismo posee plazas que marcan un eje marcado de todo el conjunto.

Figura 21. Centro Comercial Jockey Plaza.

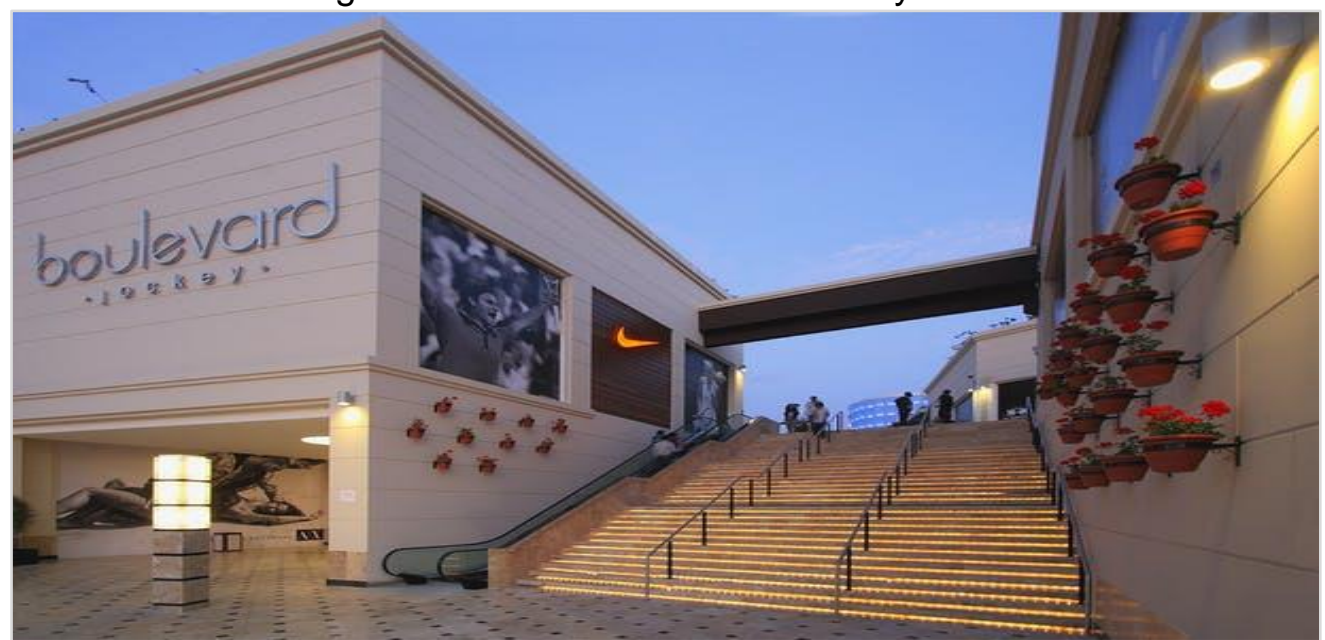

Fuente: Portal Oficial Jockey Plaza, 2020.

Según explica la revista digital Arqa (2016), el desarrollo de las edificaciones es lo que más destaca, gracias a la diversidad y la dependencia de los diseños propuestos; además del desarrollo de las texturas, materiales, códigos, espejos de agua y luces.

Figura 22. Centro Comercial Jockey Plaza.

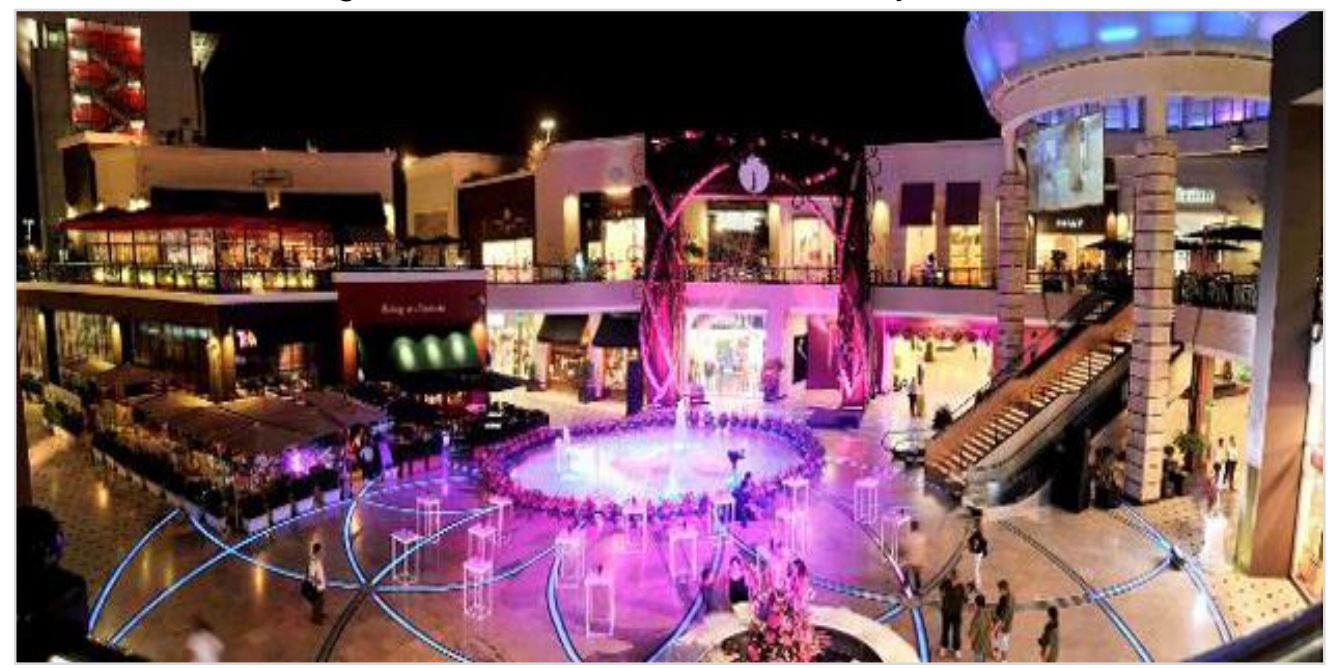

Fuente: Portal Oficial Jockey Plaza, 2020. 


\section{Conclusiones:}

A juicio del autor, este centro comercial representa en términos funcionales lo que se busca lograr con el proyecto, establecer un equipamiento que permita lograr sensaciones más allá del hecho de solo adquirir productos, sino a corresponder también a un lugar de encuentro y estadía. Además, a nivel de historia, representa un hito ya que marcó un antes y un después, gracias a su implementación de nueva gestión para la perdurabilidad del mismo, siendo hoy en día uno de los centros comerciales más concurridos, sobre todo por personas cuya actividad es la empresarial por ubicarse en una zona de lima de esta vocación. La presente tesis busca lograr marcar un hito en la zona, permitiendo a la población contar con la infraestructura necesaria para su desarrollo económico, tal como son los edificios de oficinas y retail.

\subsubsection{Centro Comercial la Rambla San Borja, Lima.}

La Rambla San Borja, es un centro comercial inaugurado en el año 2012 operado por la empresa Urbanova, que está ubicado en la Avenida Javier Prado Este 2050, San Borja en la ciudad de Lima, según afirma Perú Retail (2016).

Figura 23. Ubicación Centro Comercial La Rambla San Borja.

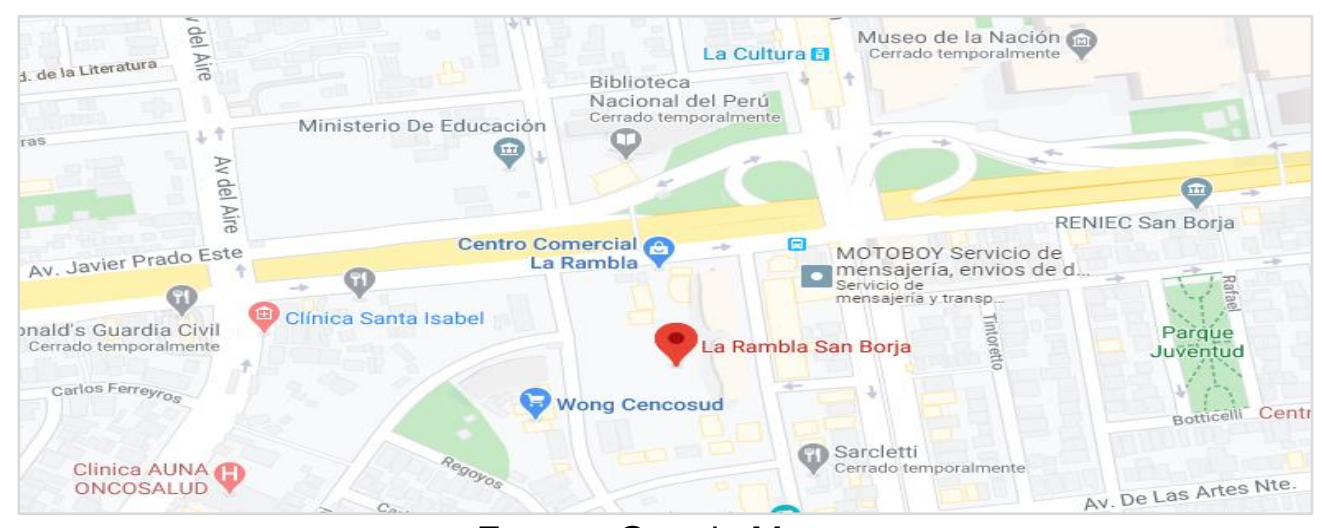

Fuente: Google Maps.

Este centro comercial comprende un área aproximada de 40 mil metros cuadrados, cuenta con 120 tiendas, dos de ellas tiendas anclas actualmente ocupadas por la empresa Ripley, Oeschle y Plaza Vea; 
cuenta con un gran patio de comida, 8 cines, 2 salas prime, 2 mil estacionamientos y cuatro torres de oficinas. Tiene un radio de influencia considerable ya que abastece los distritos de San Borja Surco, San Luis, San Isidro y La Molina.

Figura 24. Centro Comercial La Rambla San Borja.

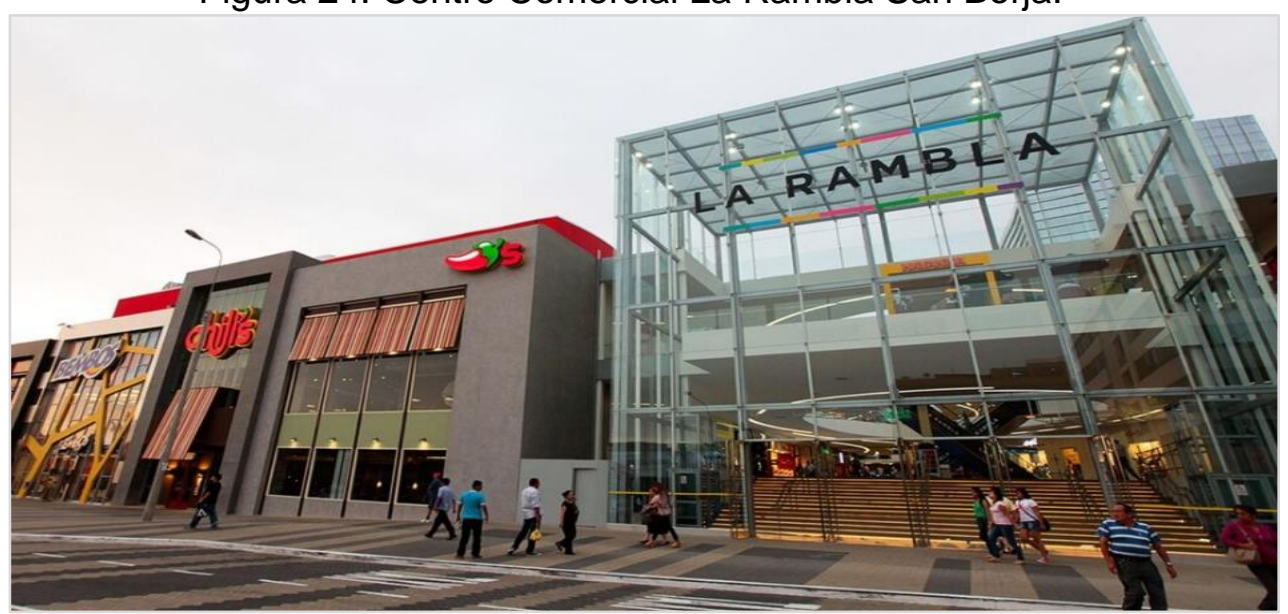

Fuente: Web oficial La Rambla, 2020.

Como se había mencionado, este centro comercial cuenta con cuatro torres de oficinas con certificación LEED - Green building, cuenta con 12 pisos, 8 sótanos y 4 oficinas por pisos; cuenta con recepción, seguridad, salas de conferencia, áreas comunes, un patio de comidas y acceso directo al centro comercial, según A donde Vivir (2019).

Figura 25. Centro Comercial La Rambla San Borja.

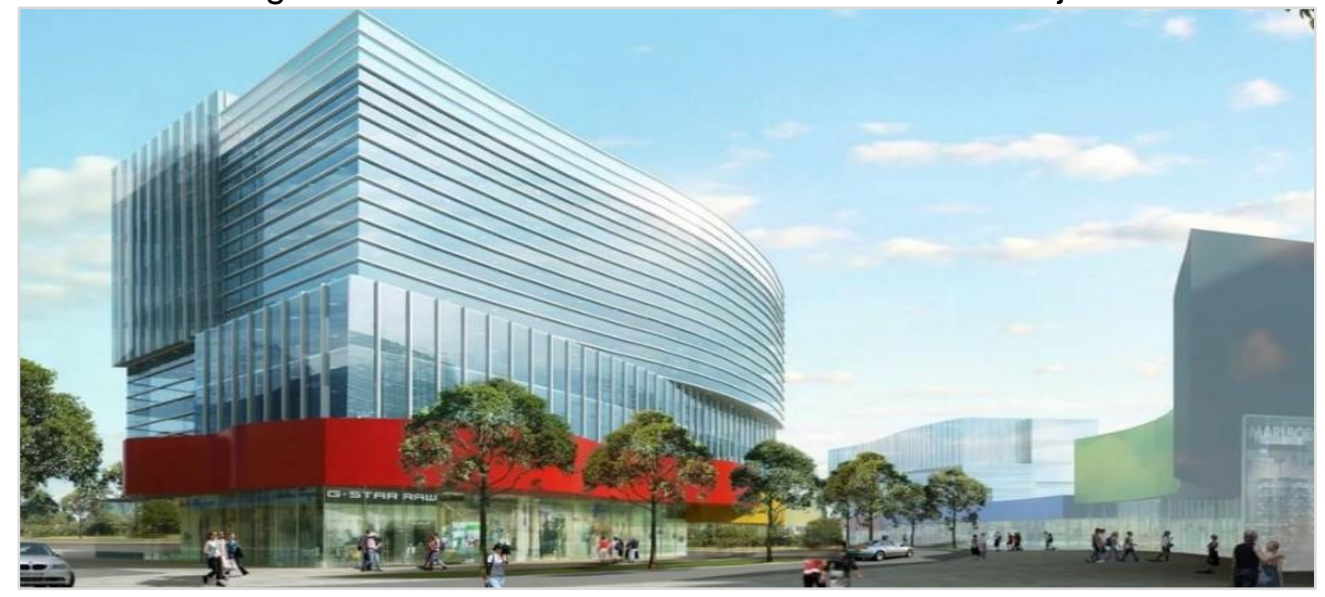

Fuente: Web oficial La Rambla, 2020. 
Es un centro comercial muy concurrido debido a que se encuentra muy cerca al centro de Convenciones de Lima, La Biblioteca Nacional, el Teatro Nacional, el Museo Nacional y a la estación La Cultura del tren de Lima, según el Diario Comercio (2016).

Figura 26. Centro Comercial La Rambla San Borja.

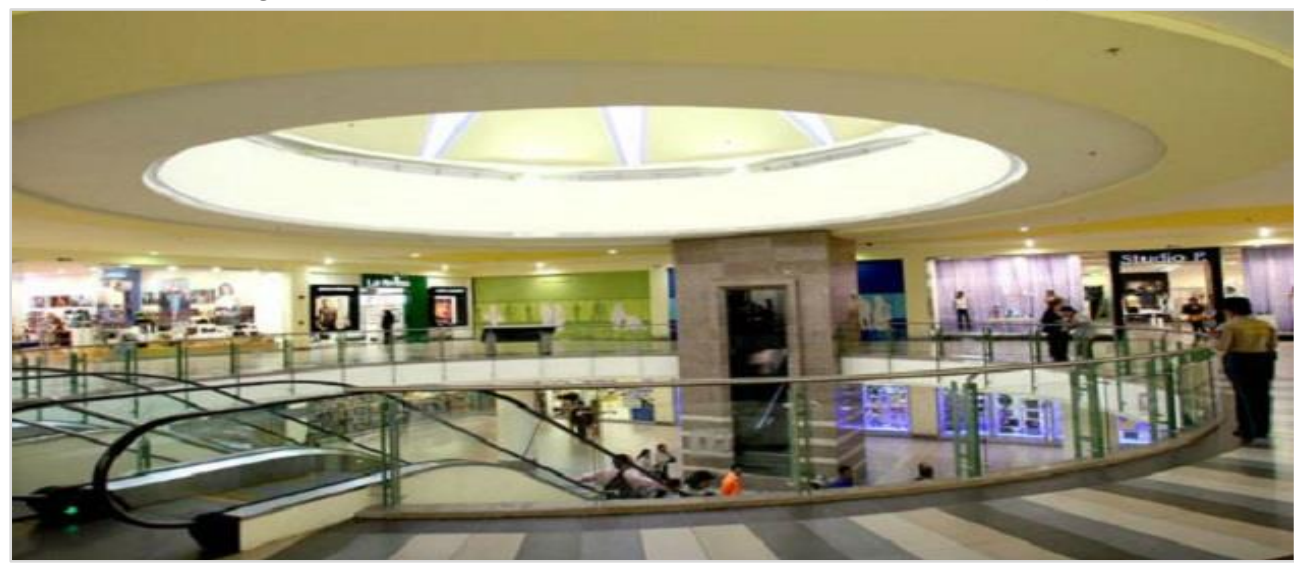

Fuente: Web oficial La Rambla, 2020.

En cuanto a su arquitectura, esta cuenta con tres niveles y con tres ingresos los cuales coinciden con las circulaciones verticales compuestas por dos ejes de escaleras eléctricas y en el centro del edificio por un ascensor panorámico. Además, hacia la Calle Morelli están ubicados los principales bancos, cabe mencionar que toda esta zona es de carácter empresarial y por el lado posterior posee un boulevard íntegramente peatonal, donde se realizan actividades culturales, comerciales, artísticas, etc.

Figura 27. Centro Comercial La Rambla San Borja.

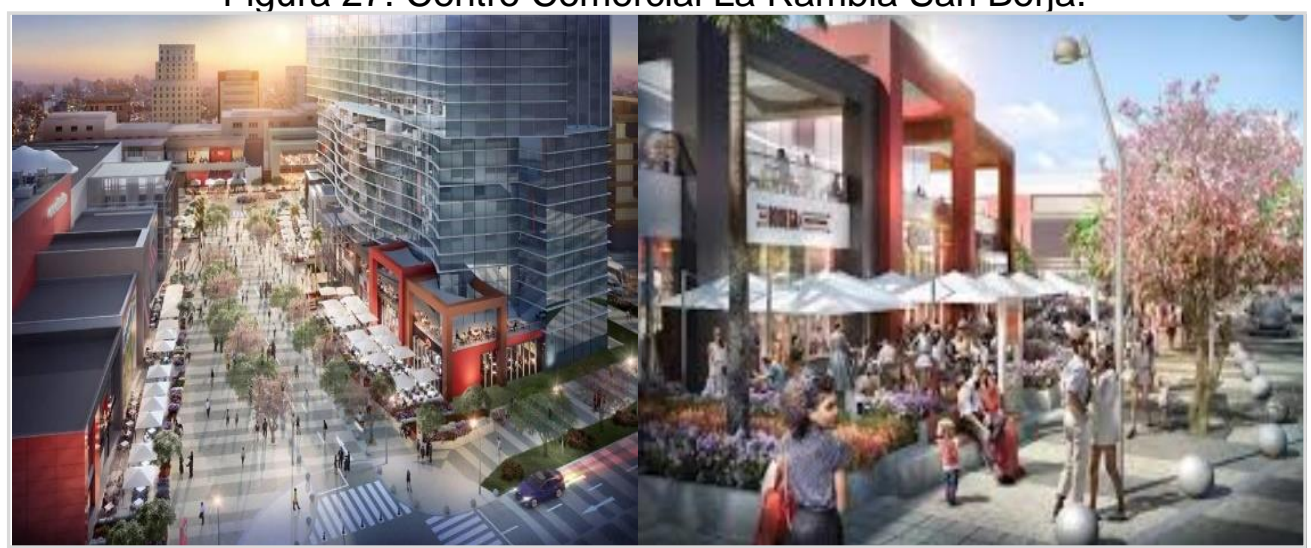

Fuente: Web oficial La Rambla, 2020. 


\section{Conclusiones:}

Se concluye que, este centro comercial es un ejemplo claro de ver los proyectos más allá de su límite predial, ya que como se explico ha generado un eje de uso peatonal, de tal manera que se forma un espacio público entre el centro comercial y las tiendas que están a su alrededor generándose una especie de Street center, donde además se realizan diversas actividades recreativas ya sean eventos musicales al aire libre, venta de productos, ferias, etc. Esta particularidad le da un plus adicional a lo que el centro comercial ofrece naturalmente, y se valora el interés por la mejora del diseño urbano de las áreas anexas.

\subsubsection{Centro Comercial Mega Plaza Lima Norte, Lima.}

El centro comercial Mega Plaza está ubicado en el distrito de Independencia, en la Avenida Alfredo Mendiola 3698, que es vía paralela a la Panamericana Norte la cual tiene gran importancia para la ciudad de Lima por tratarse de una vía interregional, a su vez colinda con la Avenida Industrial, la Calle A y la Avenida Pacifico. Fue inaugurado en el año 2012 y es considerado uno de los centros comerciales con mayores visitas a nivel nacional, según su portal oficial Mega Plaza (2020).

Figura 28. Centro Comercial Mega Plaza Lima Norte, Lima.

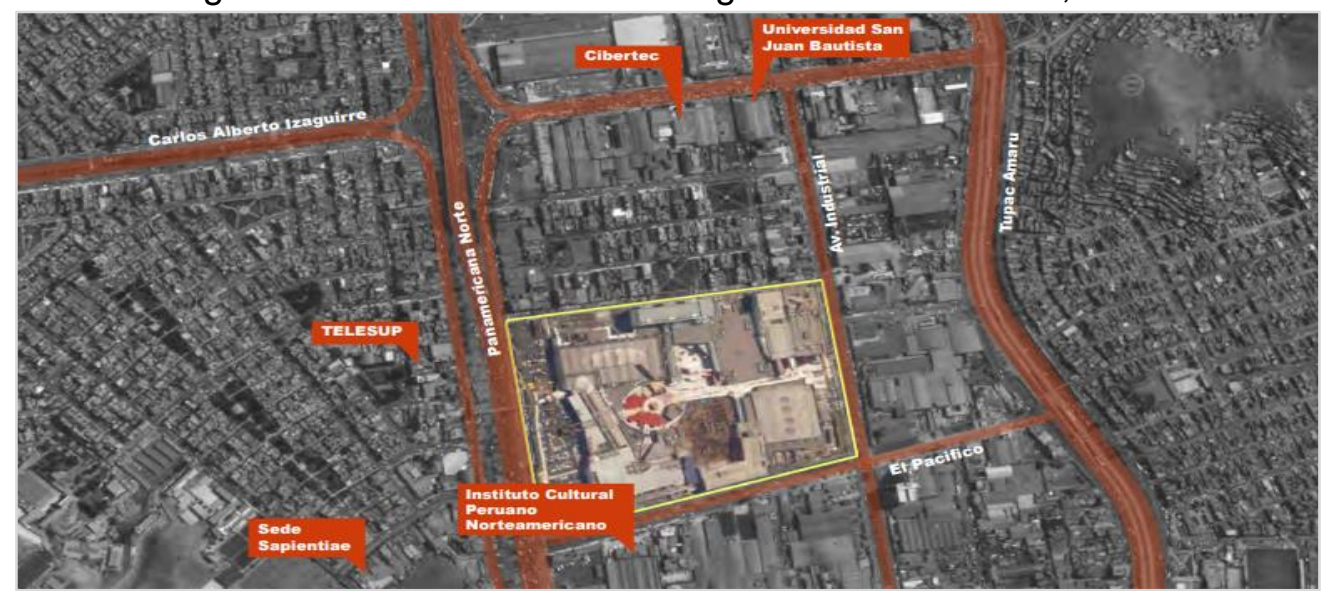

Fuente: ¿Cómo se articula el mall en el espacio urbano desde la experiencia de usuarios jóvenes? CC. Jockey Plaza y Megaplaza en Lima, 2015. 
Según Centeno (2013), es el primer centro comercial que se ubica en una zona pobre en comparación al anteriormente mencionado centro comercial Jockey Plaza que se encuentra en una de las zonas mejor posicionadas de Lima, donde se encuentran los distritos con niveles socioeconómicos altos. Sin embargo, Lima Norte presenta una de las zonas con alto dinamismo comercial

Este centro comercial tiene alrededor de 38 mil metros cuadrados, siendo uno de los centros comerciales más grandes del Perú, y más visitados con un número estimado de 3 millones de visitas al mes según asegura Vigil (2017).

En ese sentido, es preciso mencionar que este centro comercial cuenta con tiendas anclas como supermercados Tottus, Saga Falabella, Paris, Sodimac, Zara, Ripley, Max, complejo de cines con 11 salas y 3500 butacas, como se muestra en la siguiente imagen (Portal Oficial Mega Plaza, 2020).

Figura 29. Centro Comercial Mega Plaza Lima Norte, Lima.

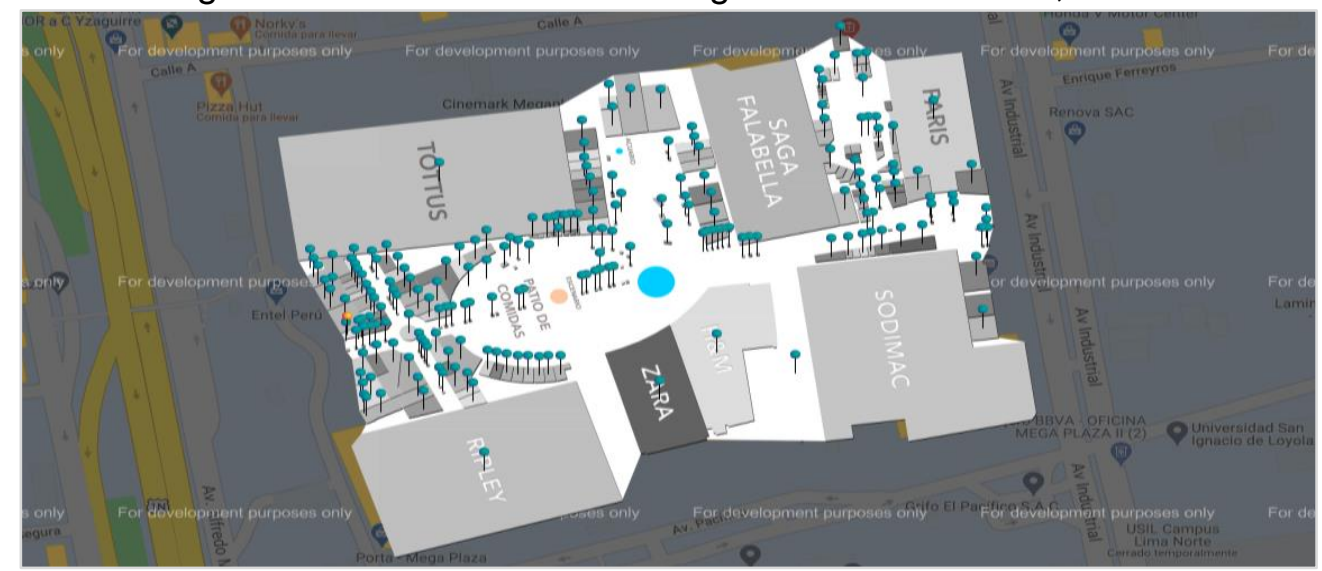

Fuente: Distribución espacial, Portal Oficial Mega Plaza, 2020.

Megaplaza, además de ofrecer una diversidad de tiendas, ofrece espacios urbanos muy bien desarrollados los cuales tienen mucha acogida debido a que, en la zona norte de Lima, existe muy poco espacio público, es así como este centro comercial se vuelve más que un equipamiento comercial, como se muestra en las siguientes 
imágenes, posee una gran plazuela con grandes secciones de vegetación, mobiliario, texturas, espejos de agua, piletas, etc.

Figura 30. Centro Comercial Mega Plaza Lima Norte, Lima.

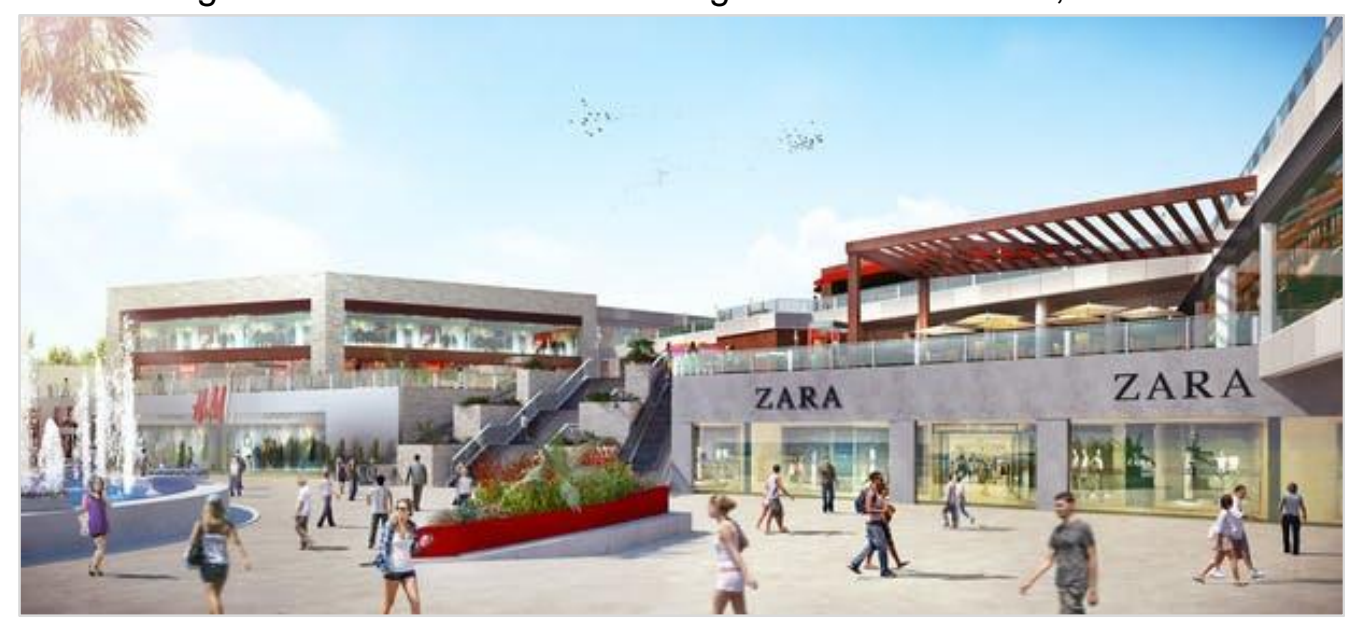

Fuente: Distribución espacial, Portal Oficial Mega Plaza, 2020.

Figura 31. Centro Comercial Mega Plaza Lima Norte, Lima.

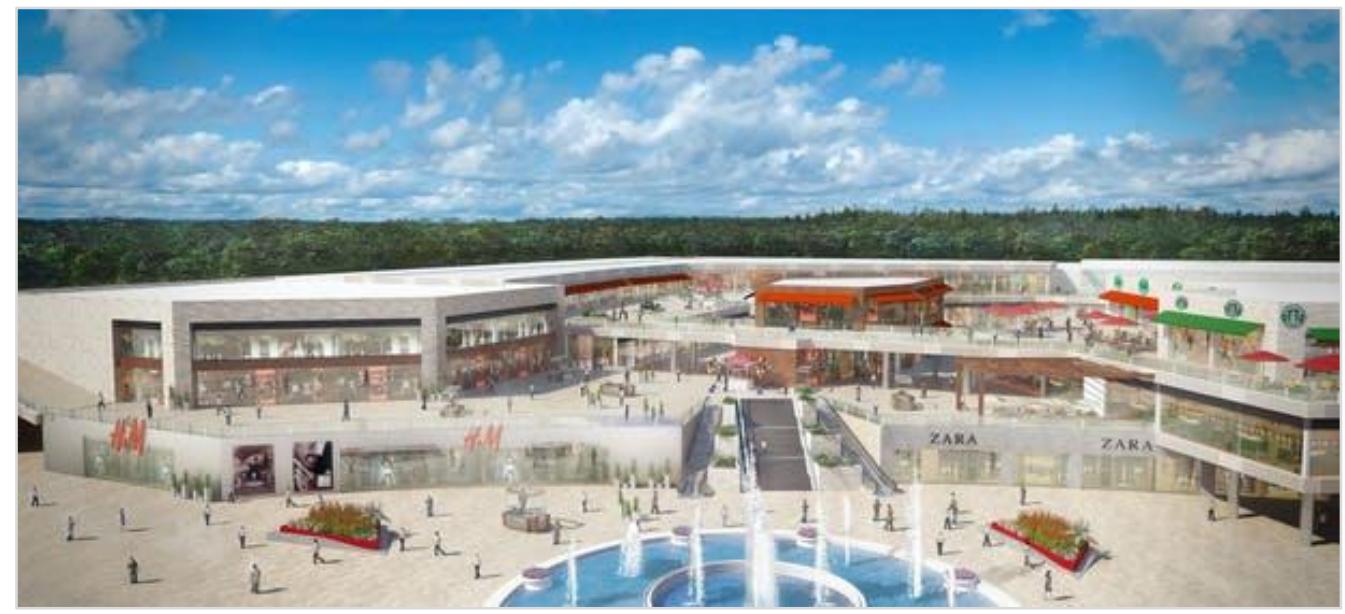

Fuente: Distribución espacial, Portal Oficial Mega Plaza, 2020.

\section{Conclusiones:}

Según a entender del presente autor, este centro comercial es un ejemplo de cómo lograr concebir un proyecto que tenga calidad espacial y en consecuencia que logre ser el centro comercial más visitado de Lima Metropolitana, considerando que a pocas cuadras hay otro centro comercial de considerable tamaño y aun así lograr atraer gran visita. En lo que corresponde a su calidad arquitectónica esta enriquecida de espacios amplios que generan diversas actividades 
(descanso, reencuentros, etc.) y que maneja volúmenes independientes que a su vez están conectados mediante ejes que muestran una visual completa del centro. En ese sentido, la presente tesis busca concebir que el proyecto propuesto sea un hito para Lima Sur, tal como Megaplaza es para Lima Norte, permitiendo de esta manera satisfacer las necesidades existentes y generar desarrollo local.

\subsubsection{Referentes internacionales:}

Los ejemplos arquitectónicos internacionales, han sido seleccionados debido a que son reconocidos a nivel mundial, entre ellos tenemos la Costanera Center y el Boulevard Piedra Roja ambos proyectos ubicados en Santiago de Chile.

\subsubsection{Costanera Center, Santiago de Chile.}

De acuerdo al Diario El Mercurio (2008), Costanera Center es un megaproyecto ubicado en Santiago de Chile, el cual tiene el propósito de ser icono del bicentenario de aquel país, cuenta con la Gran Torre Santiago, que posee una altura de 300 metros, esto la hace considerarse el edificio mal alto de Sudamérica, es llamado también como el "Hito Comercial y arquitectónico más importante de Santiago y del hemisferio sur".

Figura 9. Centro Comercial Mega Plaza Lima Norte, Lima.

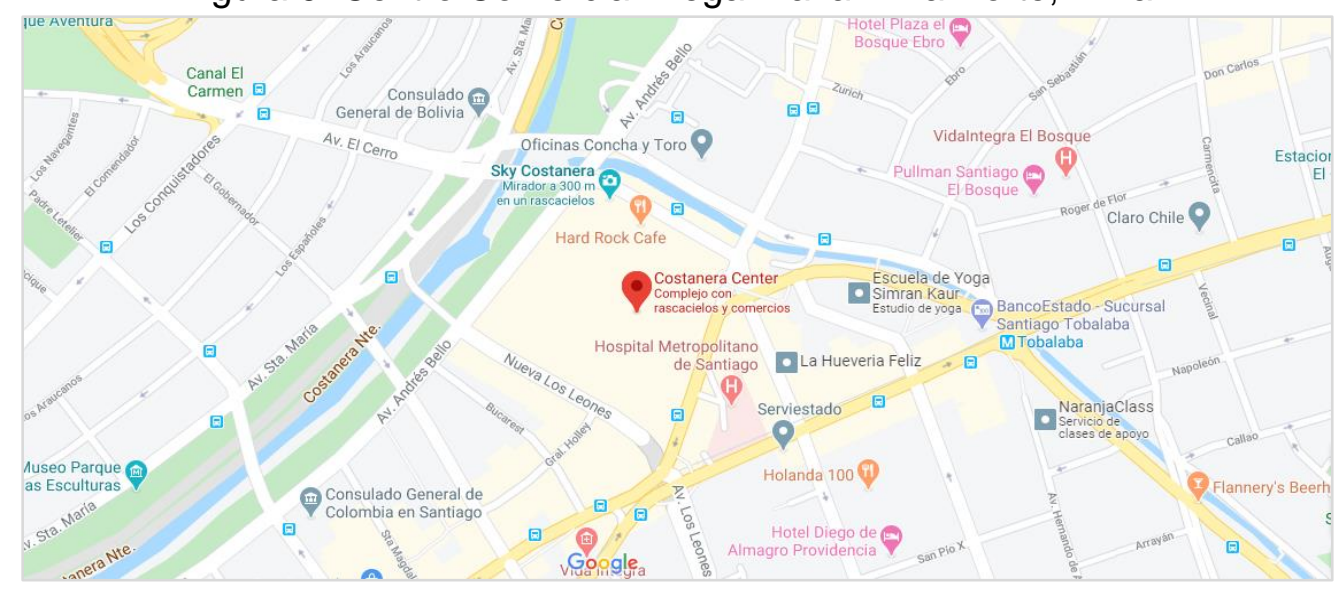

Fuente: Google Maps, 2020. 
Este proyecto de 600 mil metros cuadrados contempla un centro comercial de cuatro niveles con cerca de 200 tiendas, 2 supermercados, 2 hoteles, 14 salas de cine y 5 niveles para estacionamientos. Así mismo, tiene 4 torres como se aprecia en Figura 26, donde la principal alcanza los 57 pisos con una altura de 250 metros donde se encontrarán las principales empresas nacionales y multifuncionales.

De acuerdo a Pavez (2012), el proyecto se conceptualizó partiendo de la premisa de encontrar todo en un solo lugar, motivo por el cual fue ubicado en un lugar estratégico accesible vehicularmente (privado y público) y el cual se habilite priorizando al peatón. Para lograrlo, se construyeron veredas hasta doce metros de ancho y se hicieron pasajes en las calles para facilitar el acceso.

Figura 33. Torres Costanera Center.

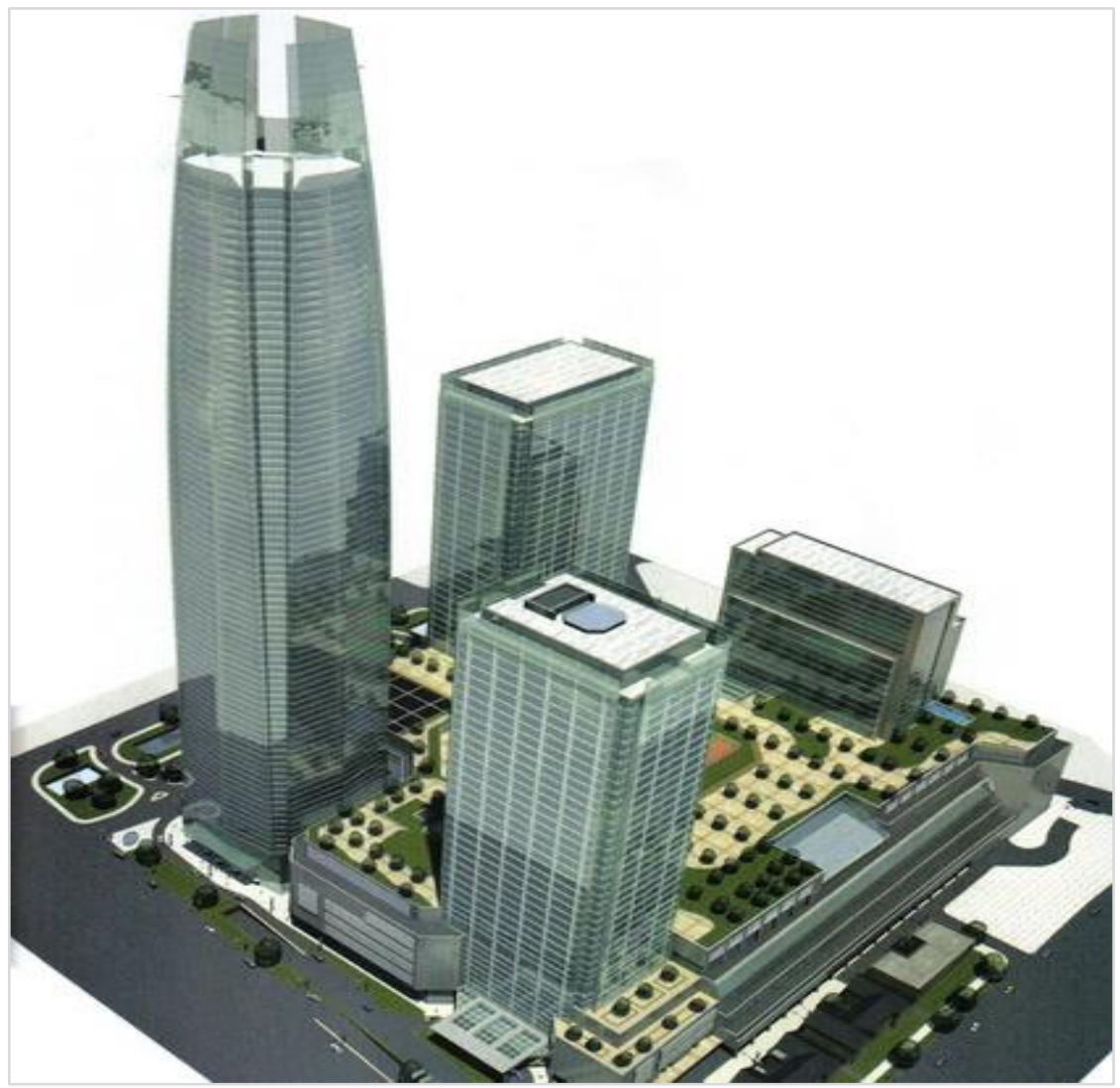

Fuente: Wiki Arquitectura. 
Al ser Chile un país sísmico, se pensó estructuralmente la manera de poder dimensionar la estructura de una edificación de tales dimensiones, para ello se dividió el conjunto en siete volúmenes totalmente independientes, además de aprovechar las circulaciones verticales para la colocación de plazas estructurales que concentran una mayor carga sísmica (Lagos, 2012).

Figura 34. Sistema estructural de la Costanera Center.

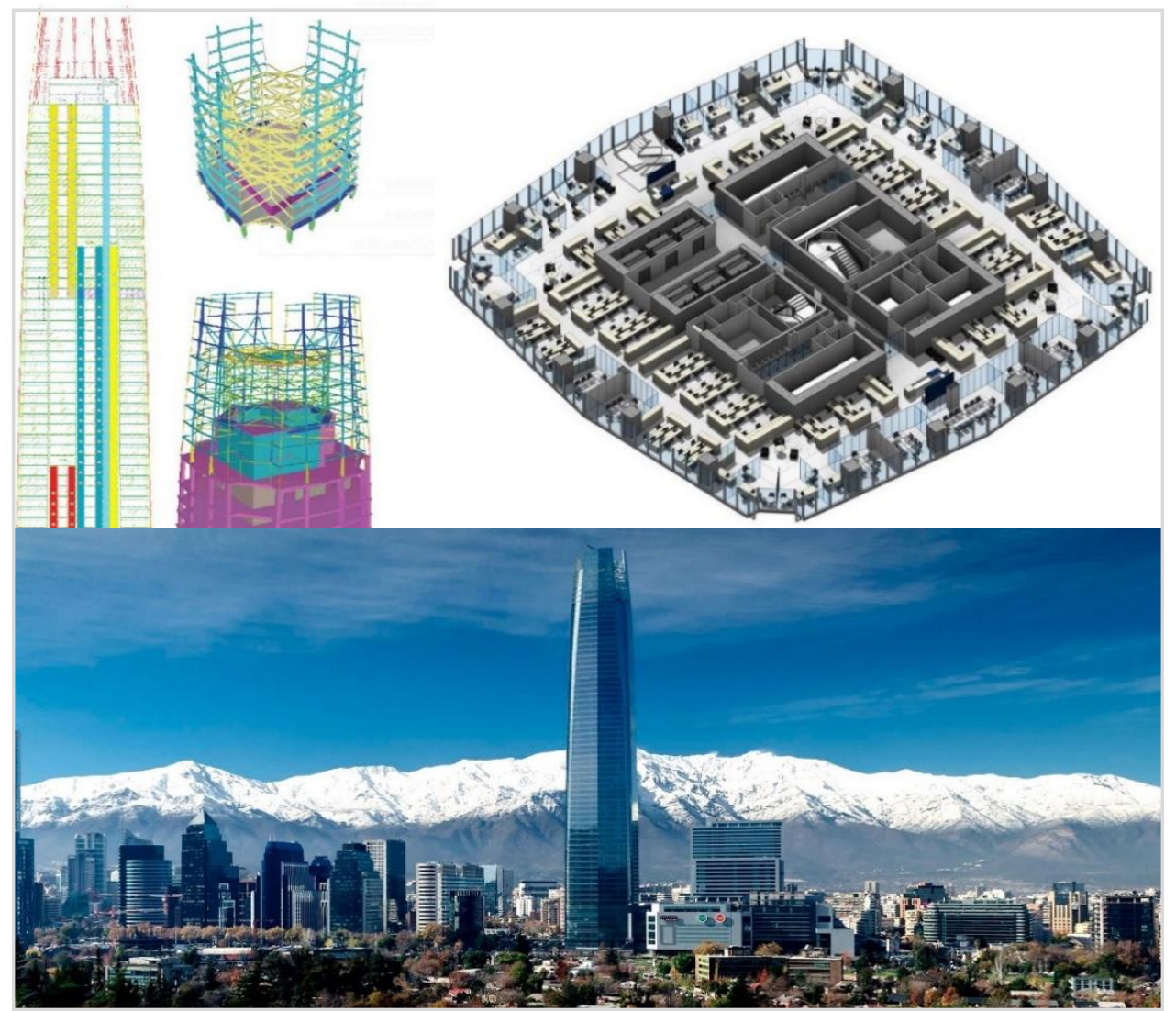

Fuente: Wiki Arquitectura.

El diario El Mercurio (2008) resalta el enfoque sostenible que se le da al proyecto, mediante la elección de materiales de construcción menos contaminantes, estacionamientos para autos híbridos y bicicletas. Entre las características ecológicas que posee el edificio, se disponen de 30 mil m2 de áreas verdes con plantas autóctonas del país de Chile, la cual está implementada para sostenerse mediante agua de lluvias y agua reutilizable. 
Figura 35. Infografía Costanera Center.

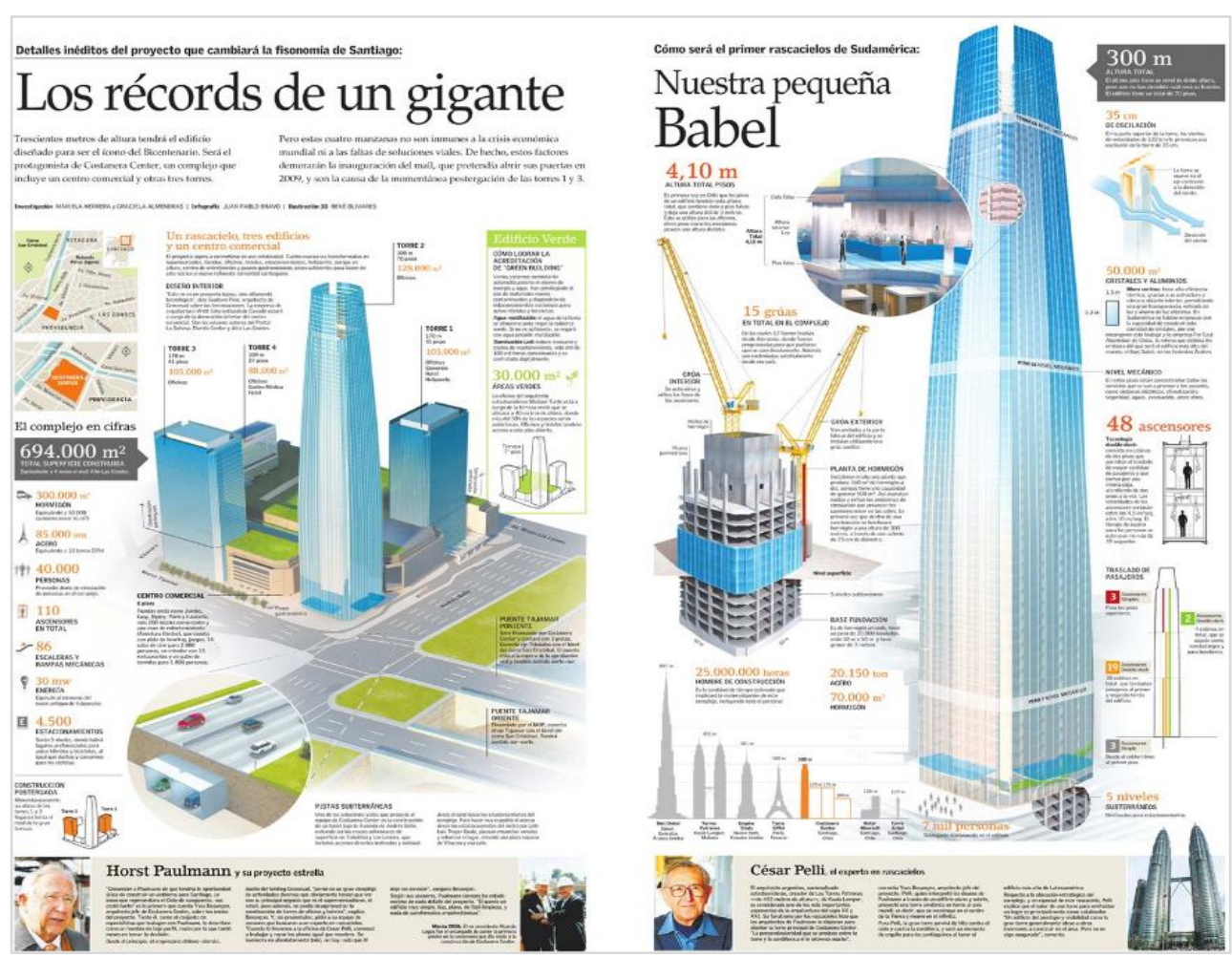

Fuente: Diario el Mercurio, 2008.

\section{Conclusiones:}

Este proyecto es muy importante como referente ya que además de hacer uso de materiales menos contaminantes para su realización, está implementado de forma que se le pueda dar prioridad al transporte ecológico, como autos híbridos y bicicletas. La priorización del peatón y del transporte público, hace que este proyecto sea un aporte urbano a la ciudad. Aparte de ser un edificio con un diseño innovador, se busca que este sea un hito, lo cual se rescata para la presente tesis.

\subsubsection{Boulevard Piedra Roja, Región Metropolitana de Chile.}

Este proyecto fue construido en el año 2018 que tiene un área de $37,749 \mathrm{~m} 2$ por el estudio de arquitectos BL Arquitectos, según Architect África (2019). El centro comercial Boulevard Piedra Roja es una edificación de uso mixto el cual cuenta con un centro comercial más oficinas. Este se encuentra ubicado en el área de la laguna de Piedra Roja, Calama, Antofagasta en Chile. 
Figura 36. Ubicación Boulevard Piedra Roja, Chile.

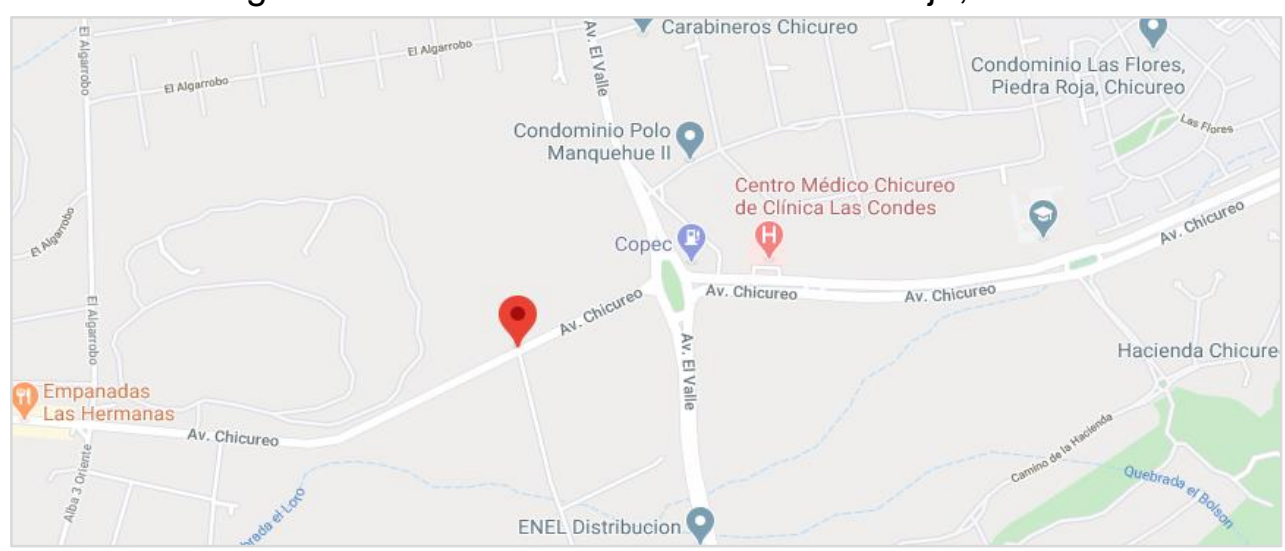

Fuente: Google Maps, 2020.

De acuerdo a la revista chilena EMB Construcción (2016) el proyecto tiene como objetivo entregar a los residentes de la zona equipamiento comercial de calidad, que pueda aumentar los servicios disponibles para todas las familias, así abastecer sus necesidades diarias.

Este proyecto comercial se estimaba completar en 4 o 5 etapas, y así ejecutar la construcción de un hipermercado, 17 tiendas comerciales y un edificio de 4 pisos para oficinas, según afirma EMB Construcción, (2016).

Figura 37. Emplazamiento del Boulevard Piedra Roja, Chile.

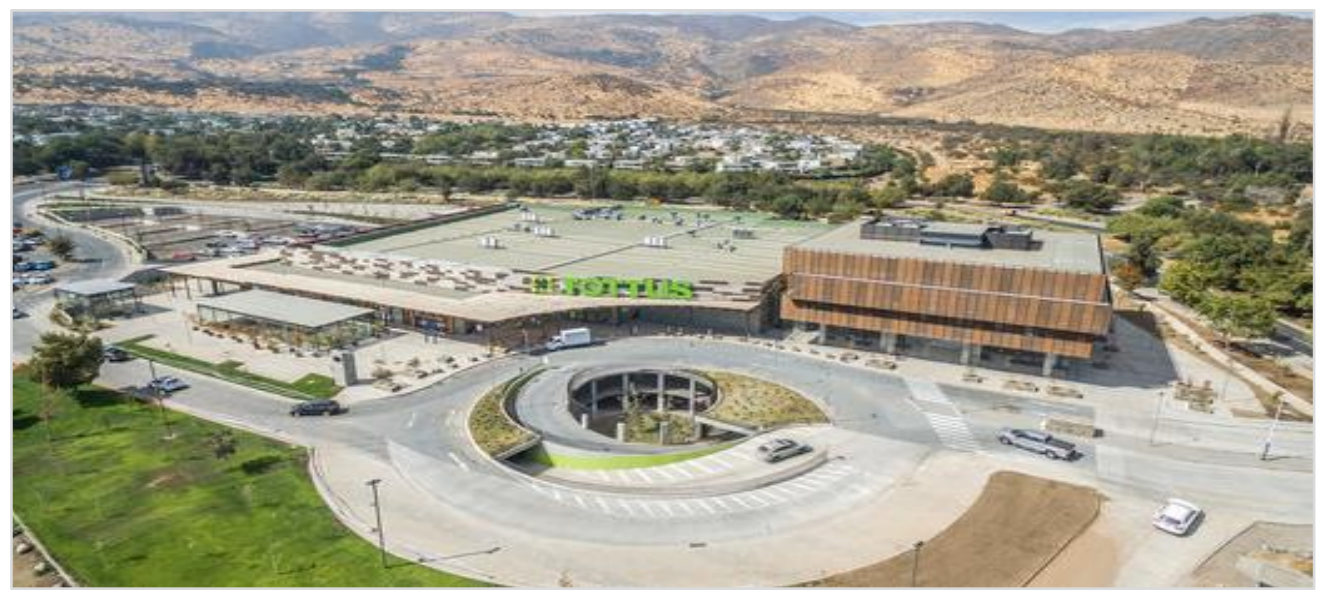

Fuente: Portal Archdaily, 2019.

En la zona donde se ubica el proyecto se caracteriza por usar materiales como madera y piedra por lo que el proyecto contempla estos materiales en el revestimiento de las fachadas, tanto como en las oficinas como en el área comercial. 
Figura 38. Fachada del Boulevard Piedra Roja, Chile.

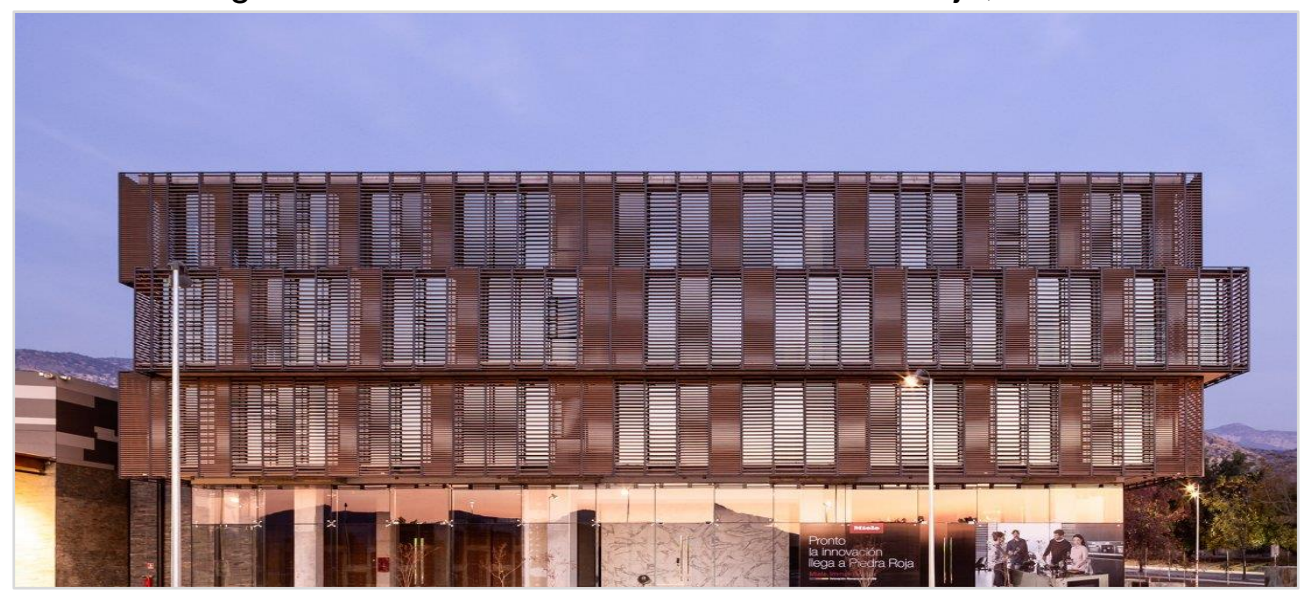

Fuente: Portal Archdaily, 2019.

Internamente tiene perfiles de aluminio en sus tres pisos con láminas de bambú y como segunda piel tiene celosías para controlar la luminosidad interna por lo que es más denso hacia la zona Norte, esta piel hace que sea más armónico con el entorno del lugar.

Figura 39. Boulevard Piedra Roja, Chile.

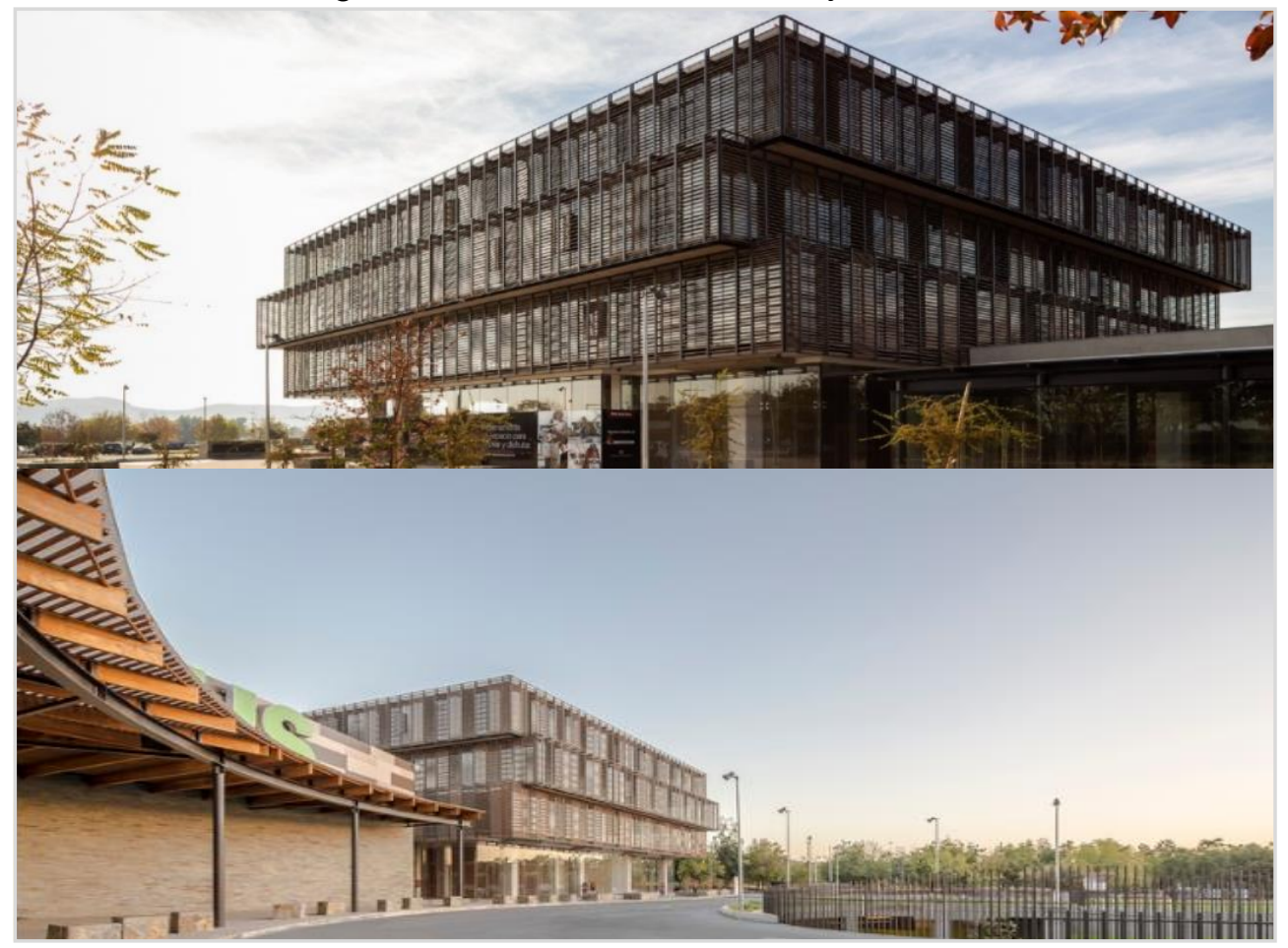

Fuente: Portal Archdaily, 2019.

La ciudad de Calama se caracteriza por poseer un entorno árido, donde en el paisaje dominan las especies cactáceas y los arbustos, debido a esto, el paisajismo del proyecto fue de suma importancia a la hora del 
diseño, por lo cual se decide hacer uso de materiales como piedras y maderas tanto en las fachadas del centro comercial, como las del edificio de oficinas.

Figura 40. Vista detallada de la fachada.

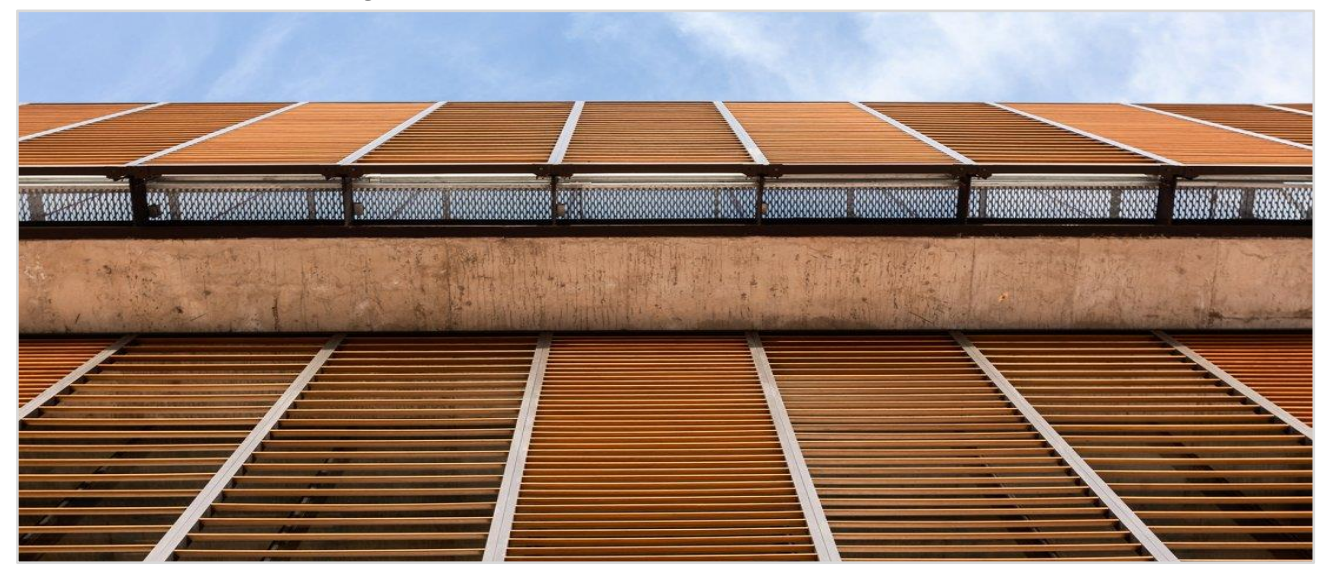

Fuente: Hunter Douglas Architecture, 2019.

\section{Conclusiones:}

De este proyecto se rescata la manera de cómo el desarrollo de la infraestructura está planeado de tal forma que es amigable con el entorno paisajístico de la zona, respetando los patrones que el mismo paisaje brinda tales como el suelo árido y el tipo de vegetación. A pesar de no contar con una gran altura, nos muestra claramente como se pueden realizar proyectos modernos sin irrumpir el entorno.

\subsection{Empresariado.}

\subsubsection{Definición: Empresa y empresariado.}

De acuerdo a Andrade (2006), el empresario se define como aquella persona natural o jurídica que se encuentra a cargo de una unidad de producción o servicio, tomando y asumiendo los riesgos de estas. Según Ferrell et. al. (2004) define al empresario como una persona que arriesga su dinero, tiempo y esfuerzo para desarrollar un producto o forma de hacer algo innovador. 
Una empresa se define como el sistema donde se integran personas y medios con el fin de conseguir diferentes objetivos según McGrawHill Project (s.f).

Figura 41. Elementos de una empresa.

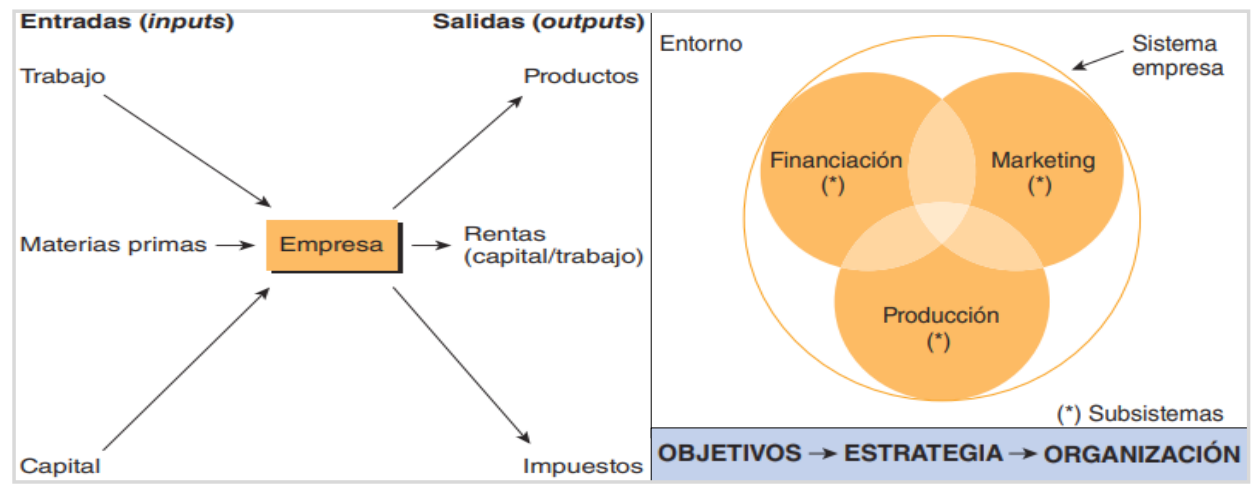

Fuente: La empresa y su organización, McGraw-Hill, 2013.

Asimismo, McGraw-Hill Project (2013) de acuerdo a teorías clásicas sobre el funcionamiento de una empresa, se pueden definir cuatro elementos los cuales son esenciales para la formación de una empresa. Estos son los siguientes:

Factores humanos, se refiere en este punto a las personas que poseen una vinculación directa con la empresa, viene desde los propietarios hasta los empleados según Rojas (2017).

Factores materiales, incluyendo los bienes económicos de la empresa. Estos se dividen en capital fijo (mobiliario, maquinaria, entre otros), y el capital circulante (materias primas, materiales de oficina, etc.).

La organización, la cual es necesaria para obtener los objetivos trazados para la empresa de manera eficiente y eficaz. Para lograrlo, se deben establecer tareas y trabajos desde los rangos más alto hacia los trabajadores de la empresa. Por último y no menos importante se encuentra el entorno, el cual considera todos los factores que condicionan el actuar de la empresa, ya sean leyes, economía, proveedores, cultura, etc., según Rojas (2017). 


\subsubsection{El empresariado en el Perú.}

La actividad empresarial en nuestro país ha sufrido altas y bajas en las últimas décadas, debido a temas de corrupción e inestabilidad económica. De acuerdo con Durand (2004) durante el régimen de Fujimori, el Perú sufrió una corrupción extrema en la cual se vivieron casos de compra de influencias, privatización de empresas estatales, con el fin de satisfacer necesidades de minorías y no del país en general.

Actualmente, ya se cuentan con lineamientos para impulsar el crecimiento económico y empresarial del país, mediante la consolidación del crecimiento económico alto y sostenible con prudencia fiscal (calidad de gasto), el incremento de la productividad del país, para un apuntalamiento del PBI potencial; y por último la mejora del sector público, mediante la toma de medidas para llegar al ciudadano, según Oliva (2018). El Perú, es el único país de la región que mantiene su calificación crediticia, gracias a su sostenibilidad fiscal, de acuerdo a Fitch Ratings (2018):

"La credibilidad y consistencia de la política macroeconómica del Perú ha brindado soporte a la estabilidad macroeconómica y financiera, y ha generado espacio fiscal para realizar políticas contra cíclicas".

Figura 42. Proyección del PBI al 2021.

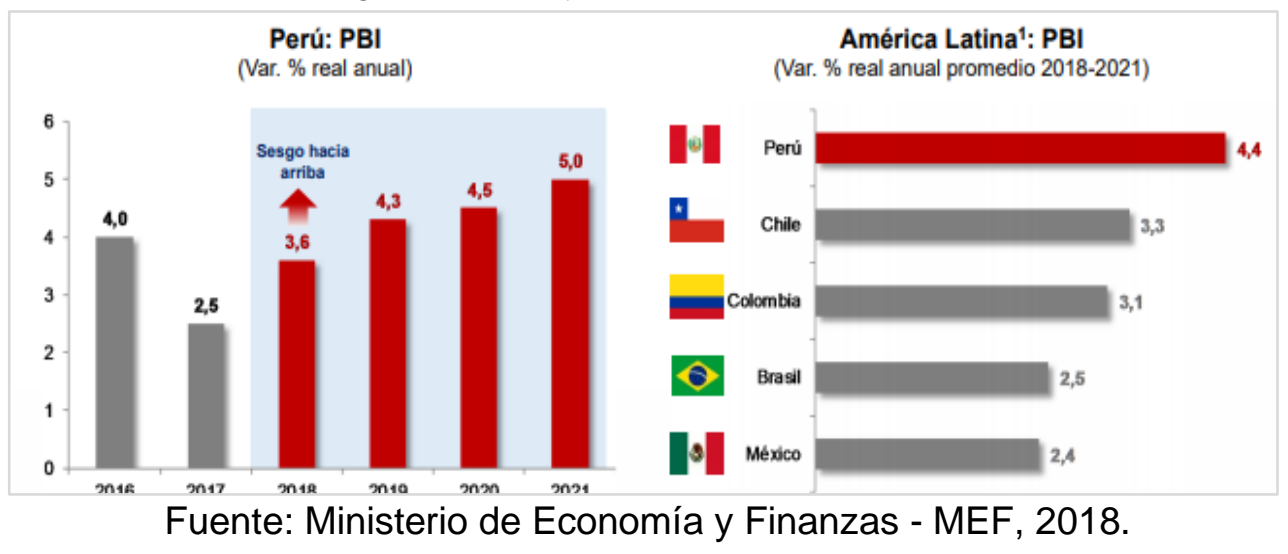


En el Perú más de 1,9 millones de micros, pequeñas y medianas empresas operan formalmente en el mercado peruano, según el Ministerio de la Producción (2017).

Este sector representa cerca del $60 \%$ de la población económicamente activa ocupada, siendo una de las fuentes que más genera empleo en el Perú. Es preciso mencionar que en los últimos años la cantidad de empresas formales ha incrementado exponencialmente con un promedio de $7.2 \%$, según La Superintendencia Nacional de Administración Tributaria - SUNAT (2017).

\subsubsection{El empresariado en Lima Sur.}

La densidad empresarial muestra cuantas empresas existen por cada mil habitantes o por cada kilómetro cuadrado en un determinado lugar. Para el caso de Lima Sur, sectorización en la que está incluido el distrito de Villa el Salvador tiene una densidad empresarial de 73.30 empresas por cada mil habitantes, según Instituto Nacional de Estadística e Informática (2018).

Mientras que la densidad empresarial por kilómetro cuadrado para la zona de Lima Sur es de 145 empresas por kilómetro cuadrado, como se muestra en la siguiente imagen.

Figura 43. Densidad empresarial (empresas / mil hab.), Lima Sur.

\begin{tabular}{|c|c|c|c|c|}
\hline Área interdistrital & Total de empresas & Porcentaje & $\begin{array}{l}\text { Densidad empresarial } \\
\text { (Empresa / mil hab.) }\end{array}$ & $\begin{array}{l}\text { Densidad empresarial } \\
\text { (Empresa por } \mathrm{Km}^{2} \text { ) }\end{array}$ \\
\hline Total & 1106853 & 100,0 & 107,2 & 380,9 \\
\hline Lima Norte & 231545 & 20,9 & 87,3 & 288,8 \\
\hline Lima Centro & 425680 & 38,5 & 236,0 & 2926,0 \\
\hline Lima Este & 225118 & 20,3 & 79,7 & 275,3 \\
\hline ima Sur & 145906 & 13,2 & 73,3 & 171,3 \\
\hline Provincia Constitucional del Calla & 78604 & 7,1 & 74,6 & 271,7 \\
\hline
\end{tabular}

Fuente: Directorio Central de Empresas y Establecimientos, Instituto Nacional de Estadística e Informática, 2018. 
Figura 44. Densidad empresarial (empresas / km2), Lima Sur.

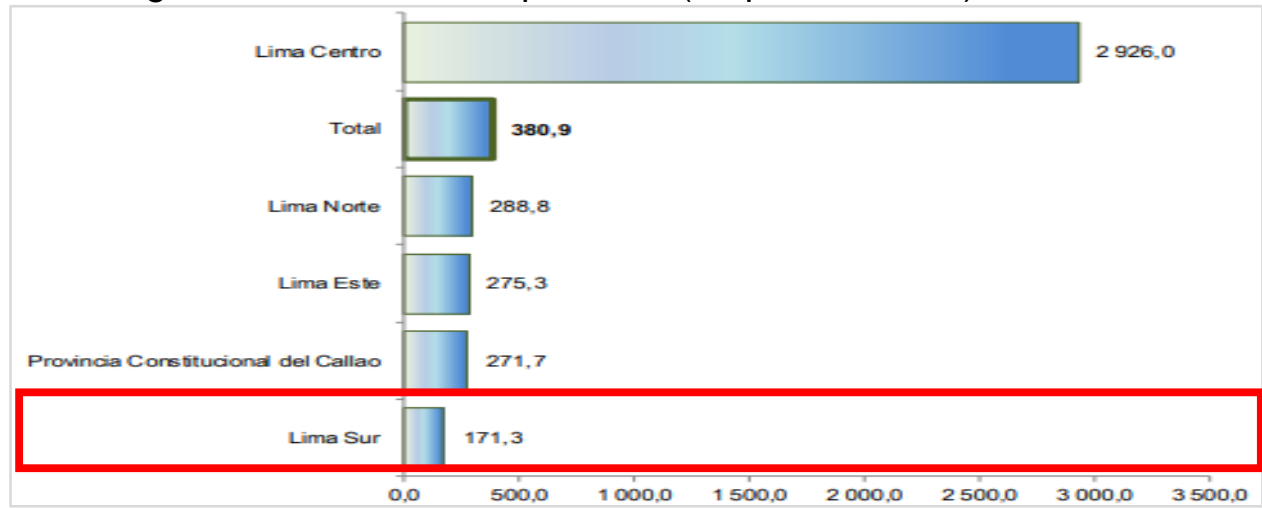

Fuente: Directorio Central de Empresas y Establecimientos, Instituto Nacional de Estadística e Informática, 2018.

Para Villa el Salvador la densidad empresarial de empresas por cada mil habitantes es de 71.00 y la densidad de empresas por cada kilómetro cuadrado es de 979.30, según Instituto Nacional de Estadística e Informática (2018).

Figura 45. Densidad empresarial de Villa el Salvador.

\begin{tabular}{|l|rrrr}
\hline \multirow{2}{*}{ Área interdistrital/Distritos } & Total de empresas & Porcentaje & $\begin{array}{r}\text { Densidad empresarial } \\
\text { (Empresa / mil hab.) }\end{array}$ & $\begin{array}{r}\text { Densidad empresarial } \\
\text { (Empresa por Km²) }\end{array}$ \\
\cline { 2 - 5 } Chorrilos & 28101 & 19,2 & 82,7 & 721,6 \\
Lurín & 8036 & 5,5 & 88,9 & 44,4 \\
Pachacamac & 7317 & 5,0 & 52,9 & 45,7 \\
Pucusana & 986 & 0,7 & 54,2 & 26,1 \\
Punta Hermosa & 835 & 0,6 & 103,6 & 7,0 \\
Punta Negra & 599 & 0,4 & 70,8 & 4,6 \\
San Bartolo & 742 & 0,5 & 91,0 & 16,5 \\
San Juan de Miraflores & 35835 & 24,6 & 85,3 & 1560,1 \\
Santa Maria del Mar & 131 & 0,1 & 76,5 & 13,4 \\
\hline Villa el Salvador & 34600 & 23,7 & 71,0 & 979,3 \\
\hline Villa Maria del Triunfo & 28724 & 19,7 & 61,0 & 407,0 \\
\hline
\end{tabular}

Fuente: Directorio Central de Empresas y Establecimientos, Instituto Nacional de Estadística e Informática, 2018.

Como se ha apreciado, la zona Lima Sur y específicamente el distrito de Villa el Salvador presenta cifras significativas al respecto a su densidad empresarial ya sea empresas por cada mil habitantes o por cada kilómetro cuadrado, siendo esta última muy alta, por lo que una vez más refuerza la necesidad de establecer infraestructuras que den servicios complementarios a esta actividad. 


\subsubsection{Conclusiones.}

El crecimiento y estabilidad económica de nuestro país, es propicia para atraer inversiones, debido al apogeo que posee desde hace mucho tiempo nuestro sector económico. Por otro lado, a nivel local el distrito de Villa el Salvador posee indicadores positivos de crecimiento tendencial del empresariado en Lima, lo que podría constituirse en una futura zona empresarial como lo es hoy en día Lima Norte, es por ello la necesidad de cubrir necesidades actuales y prever las futuras, por lo que el proyecto de la presente tesis está enfocada a cubrir este tipo de necesidades, generando dinamismo en la economía local acorde con las tendencias nacionales.

\subsection{Servicios complementarios a la actividad empresarial.}

De acuerdo a V\&V Grupo Inmobiliario (2019), los negocios enfocados en la satisfacción de las necesidades de sus clientes se manejan y se controlan en espacios de oficinas exclusivas. Es por ello que estas deben ser implementadas y ubicadas estratégicamente dependiendo de la estrategia empresarial del negocio.

Actualmente, la arquitectura tiene una tendencia enfocada en la reducción de distancias de un lugar a otro haciendo uso de espacios y edificaciones mixtas, de tal manera que los usuarios puedan realizar la mayor cantidad de actividades en un mismo lugar (González, 2015).

En ese sentido, a continuación, se establecen algunos de los equipamientos que son complementarios a las actividades empresariales, que estando concentrados en una misma ubicación física generarán facilidades para el sector empresarial y sus actividades diarias.

\subsubsection{Oficinas.}

De acuerdo a la RAE (2014), una oficina se define como el local donde se hace, se ordena o se trabaja algo. El inicio de estos espacios se remonta al siglo $\mathrm{XVI}$, donde se dan los primeros indicios de 
edificaciones relacionadas a usos administrativos, sin embargo, su historia podría darse desde mucho tiempo atrás ya que no hay duda que las grandes civilizaciones del mundo demandaron este tipo de espacios según Hernández (2002).

Los edificios corporativos surgen a partir de que las grandes corporaciones empezaron a encargar a arquitectos, el diseño de sus oficinas, lo cual permitió que se realizarán nuevos planteamientos y esquemas para brindar a los usuarios los espacios más idóneos para el desarrollo de sus actividades (Hernández, 2002).

Figura 46. La oficina en la década de los 90's.

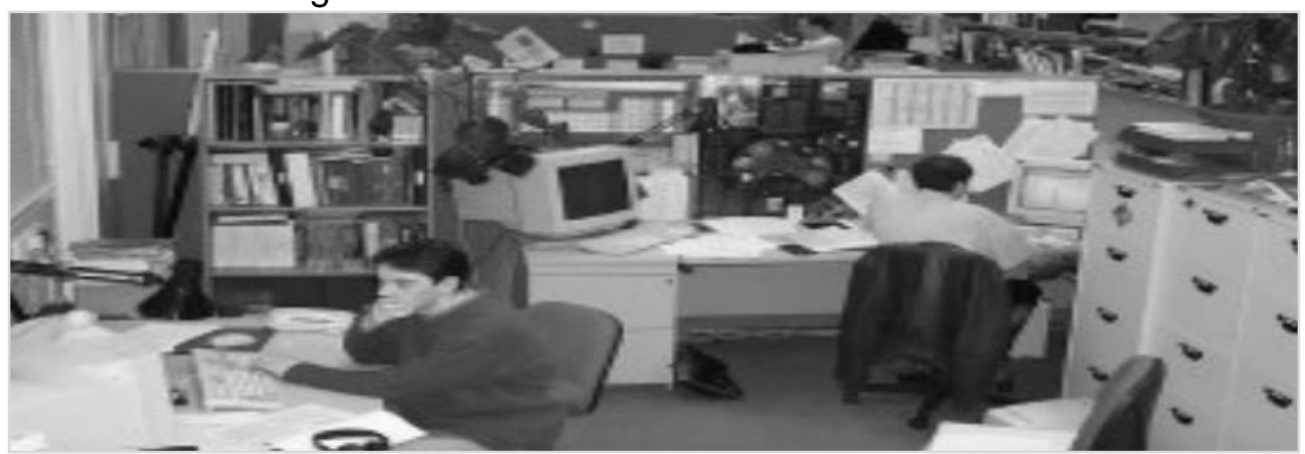

Fuente: University of Leicester, s.f., 2013.

Actualmente, el diseño de oficinas se ha vuelto flexible en cuanto a los espacios de trabajo, fomentado áreas de reuniones informales, con el fin de impulsar la comunicación cara a cara entre personas, así como salas de trabajo concentrado, salas de trabajo confidencial, puestos de trabajo en espacios abiertos, oficinas coworking, entre otros, según la Universidad Nacional de Educación a Distancia - UNED (2014).

Figura 47. La oficina flexible, un lugar de trabajo para la reunión y comunicación.

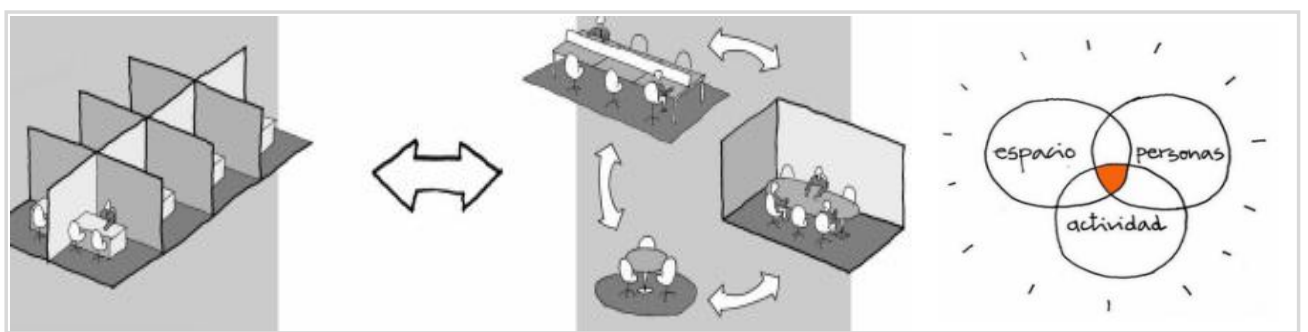

Fuente: Universidad Nacional de Educación a Distancia - UNED, 2014. 
El diseño y creación de espacios de oficinas, si estos se enfocan en tener conceptos modernos e interactivos, producirá que los usuarios que laboren en aquel espacio, posean una mayor productividad, ánimo y capacidad de generar ideas.

Cuando las personas se conectan, se produce un ambiente laboral más armonioso, y el espacio y mobiliario es pieza clave en el desarrollo de esto, es decir, espacios abiertos y áreas para workshops grupales proporcionan un máximo confort en el desarrollo de actividades laborales, según Miller (2013).

Figura 48. Paisaje de Oficina.

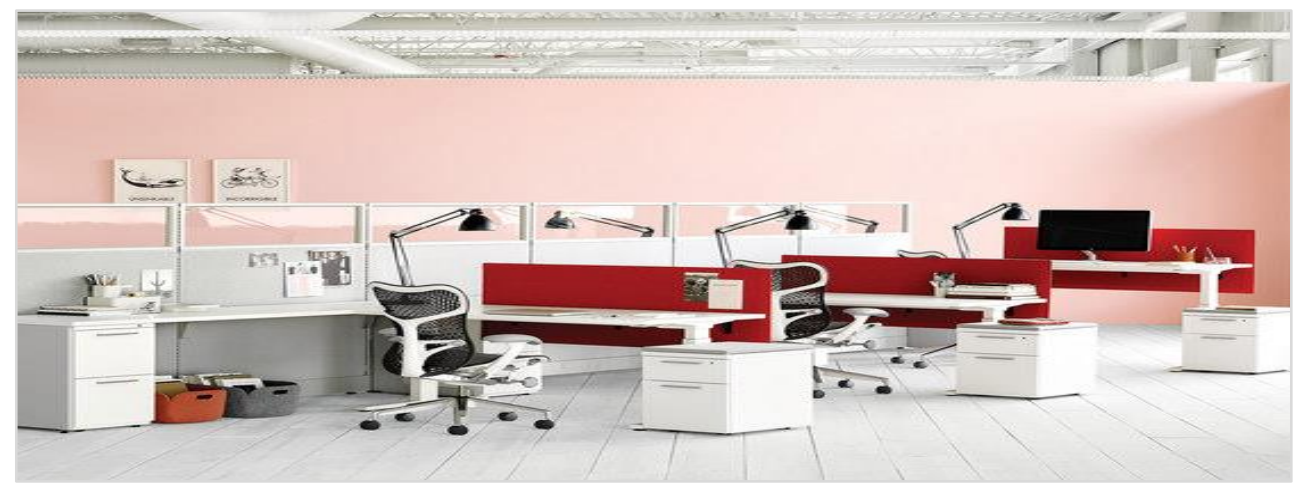

Fuente: Architonic.com, s.f., 2013.

\subsubsection{Centros financieros.}

Los centros financieros se definen como lugares donde se concentran la mayor parte de transacciones financieras y que permiten a los países ganar eficiencia a través del aprovechamiento de la economía de escala, según Cartagena (2002).

Los bancos privados de hoy en día, tienen una amplia gama de servicios que abarcan desde el asesoramiento de inversiones, hasta planificación financiera, gerencial y mobiliaria, como asegura Luthi (s.f).

La historia de los centros financieros remonta a 1929 durante la Gran Depresión de Estados Unidos, debido a que los empresarios tomaban medidas para la reducción de costos, como compartiendo con otros 
profesionales los lugares de trabajo, salas de reuniones y asistentes de oficina según A\&B Services (2001).

En cuanto a otra característica, según Bastie \& Dezert (1980) los centros financieros actualmente se caracterizan por ser edificaciones muy funcionales, con características como acabados en vidrio y concreto, más de siete plantas libres y muchos sótanos de estacionamientos reservados para los trabajadores de las distintas oficinas que albergan ahí.

Figura 49. Centro Empresarial Cronos. Uso de concreto expuesto y vidrios.

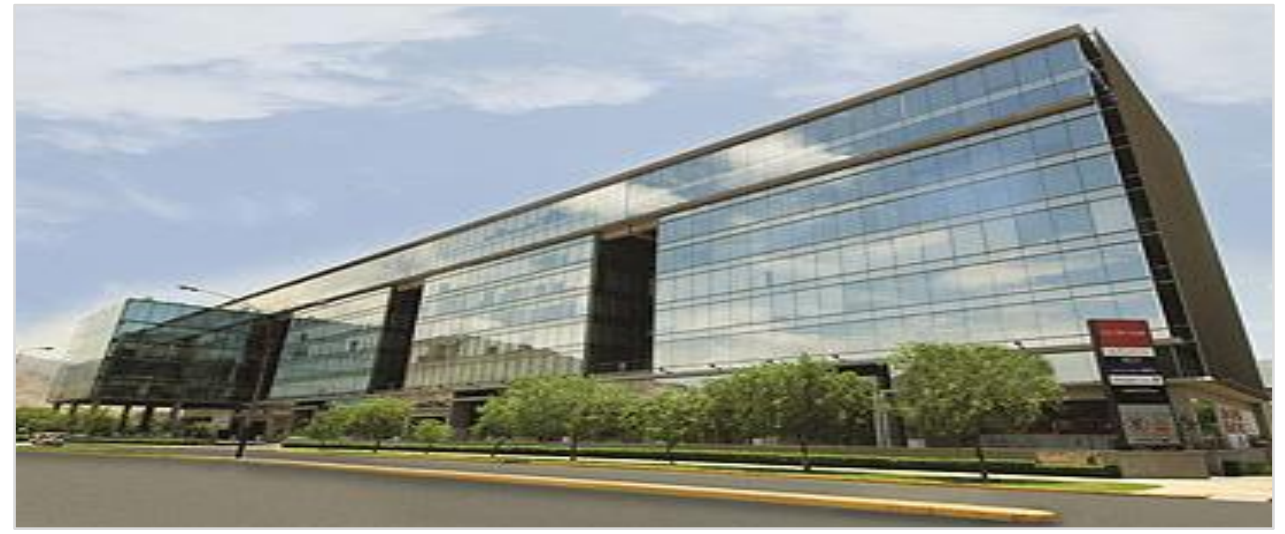

Fuente: Inversiones Centenario, 2018.

A finales del siglo $X X$, la arquitectura corporativa empezó a desarrollarse bajo dos premisas, la primera es la reducción del consumo energético y la segunda la implementación de la tecnología en edificaciones, es por ello que los arquitectos se ven obligados a proponer sistemas constructivos eco amigables y acoplado a esto, la informática, según Hernández (2002).

\subsubsection{Centros comerciales.}

El Consejo Internacional de Centros Comerciales (2010) define un centro comercial como aquel grupo de establecimientos comerciales minoristas que se desarrollan, planifican y cuentan con una sola administración, estos centros comerciales poseen varios formatos, dependiendo de su tamaño y orientación. Estos se clasifican en: super 
regional, regional, comunitario, vecinal y Strip Center. Asimismo, también se pueden segmentar de acuerdo a su especialización, en las cuales puede considerarse power center, lifestyle, fashion mall y outlet.

De acuerdo a Valdés (2009), los centros comerciales en los últimos años se han concentrado en brindar una diversa gama de servicios con el fin de convertirse en los lugares preferidos de convivencia y recreación por las familias. El comercio es hasta el día de hoy uno de los pilares donde se asienta la formación de la ciudad, debido a que estos, han fomentado el crecimiento, el desarrollo y valorización del suelo urbano, por la gran variedad y capacidad de oferta de consumo que demanda (Domenech, 2015).

Asimismo, Domenech (2015) destaca que los centros comerciales actualmente son considerados hitos para la sociedad, ya que funcionan como lugares de socialización urbana. Es así que los espacios comerciales determinan el estilo de vida de la sociedad en la cual se desarrollan, debido a las actividades económicas, sociales y culturales en el espacio público en el cual impactan.

Samper (1989), explica que el concepto de los centros comerciales tiene orígenes en Europa, exactamente en Italia del siglo XIX, donde se desarrollaron grandes galerías comerciales que surgieron de muchas metrópolis europeas y las cuales impactaron por sus audaces construcciones. El primer shopping- center fue inaugurado en 1916 en chicago, y desde aquel entonces su evolución y tipología se han ido mejorando hasta concretar al actual modelo arquitectónico funcional que conocemos hoy en día (Carpio, 2017). 
Figura 50. Markets Square, Chicago.

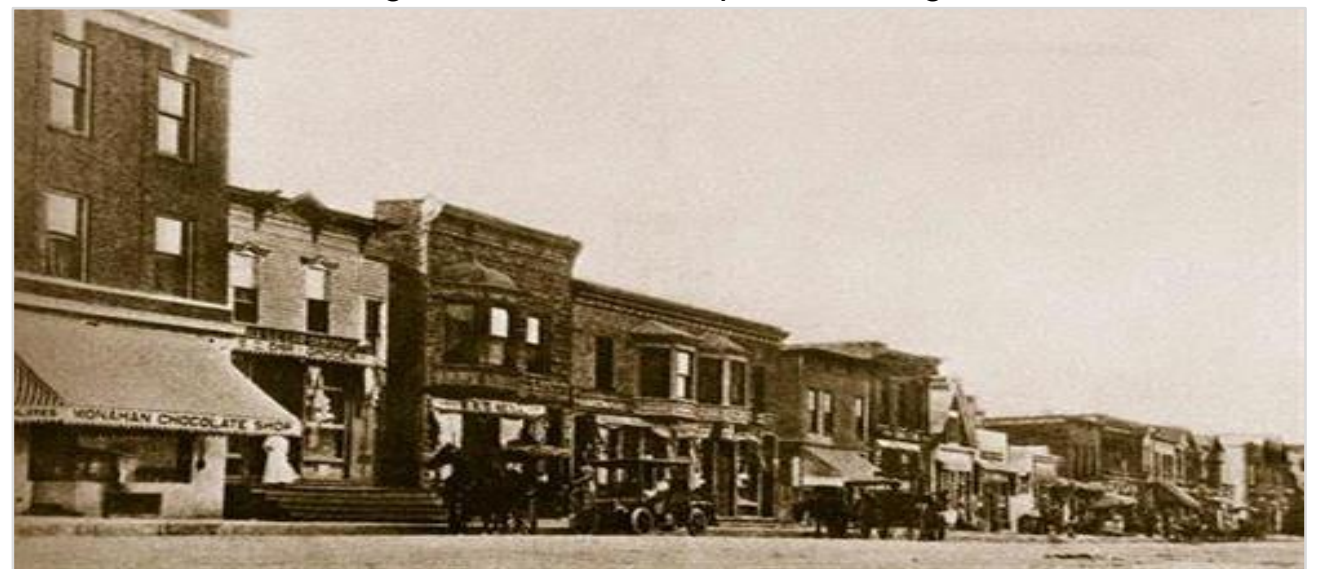

Fuente: Old Chicago Picture - Market Square in Downtown, 2019.

Fasson (2015) indica que el éxito de un centro comercial depende de varios factores tales como la ubicación, las vías de acceso, el rol de las tiendas ancla, el mix de tiendas, la administración centralizada, el diseño arquitectónico exterior e interior, etc.

Actualmente, de acuerdo a Cerda (2013) el sistema de distribución de los centros comerciales se basa en función que parte de dos o tres tiendas anclas, las cuales, dependiendo del tamaño del proyecto, se encuentran a los extremos y son conectadas a través de pasillos rodeados de tiendas menores, con el fin de generar tránsito de personas por toda la edificación en general, siendo esta implementada con zonas de descanso que ordenan el recorrido.

En cuanto a circulación vertical, las escaleras mecánicas son el medio clave para realizar el traslado de una planta a otra, estas también se encuentran ubicadas estratégicamente de tal forma que el cliente se traslade de un extremo a otro sin dejar espacio comercial de lado (Koolhaas, 2001). 
Figura 51. Centro Comercial Larcomar, distrito de Miraflores.

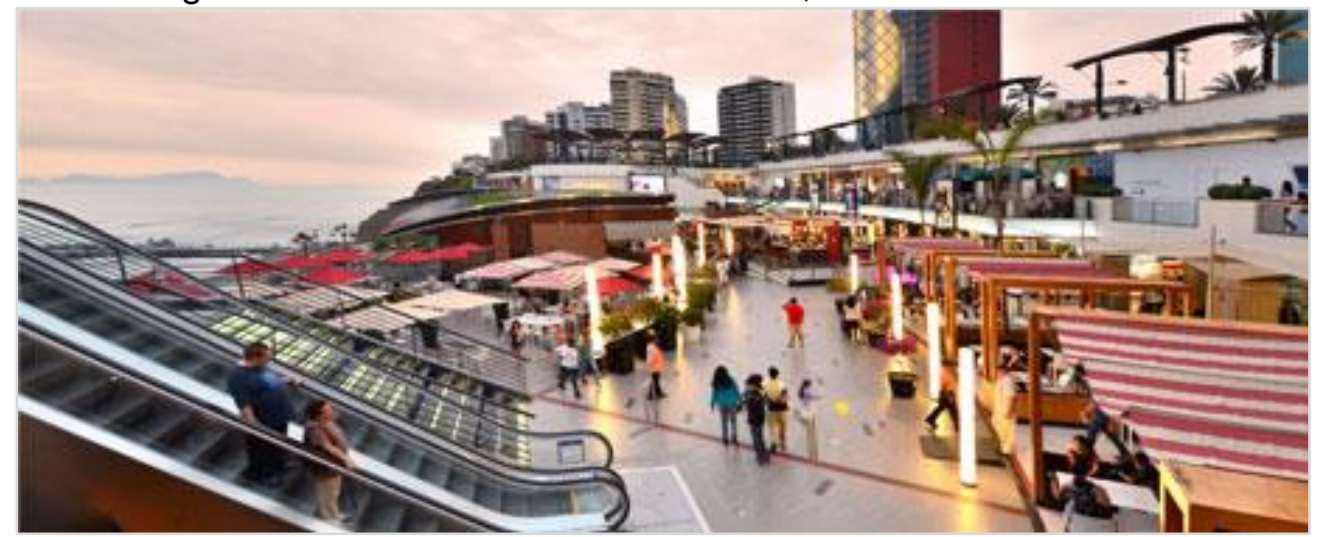

Fuente: Diario Perú 21, 2016.

En el país, el sector construcción y retail son las actividades más dinámicas en la economía nacional, a pesar de la desaceleración, se proyecta la inauguración de más centros comerciales en el país además de un repotenciamiento de los existentes, según Fasson, (2015).

\subsubsection{Conclusiones.}

La implementación de un centro comercial debe considerar una arquitectura funcional y una ubicación geográfica idónea para su éxito en el sector retail. El presente proyecto toma en consideración aspectos como el tipo de usuario de acuerdo a la zona en la que se emplaza la tesis y es por ello que se concluye que su implementación es importante para el desarrollo del distrito, que será una infraestructura que servirá para evitar la centralización de centros comerciales en la capital Limeña. Para que esto se pueda lograr, se deberá proponer una infraestructura moderna e innovadora, que cumpla con los estándares de confort y seguridad que un centro comercial de tal magnitud necesita. 


\subsection{Juegos Panamericanos.}

\subsubsection{Historia.}

La historia de los Juegos Panamericanos remonta a Los Ángeles en 1932, cuando durante los juegos Olímpicos de aquel año, los representantes del Comité Olímpico Internacional - COI en América, sugirieron la posibilidad de celebrar unos Juegos Panamericanos, los cuales sean programados cada cuatro años, en distintos países del continente americano, entre cada celebración de los juegos olímpicos, es así que se propone Dallas como ciudad elegida a realizarse tal evento en 1937; sin embargo, fue tan poca la acogida de los juegos que pasaron desapercibidos por los aficionados, y nunca fue considerada como oficial. Luego de tres años, en 1940 se decide celebrar los Juegos Panamericanos en Buenos Aires, 1942, pero debido al inicio de la Segunda Guerra Mundial, no pudo llevarse a cabo (Barris, 2015).

Según Regalado et. al. (2015), en 1951 se realizan los primeros Juegos Panamericanos oficiales, al desarrollarse en febrero no tuvieron mucha presencia de los países pertenecientes en el hemisferio norte, al ser fechas inusuales para ellos. Este evento se inauguró en Racing y se clausuró en River Plate, teniendo como figuras a Melvin Whitfield (USA), Ferreira da Silva (Brasil), Rafael Fortun (Cuba) y J. Capilla (México).

Figura 52. Primer cartel de los Juegos Panamericanos.

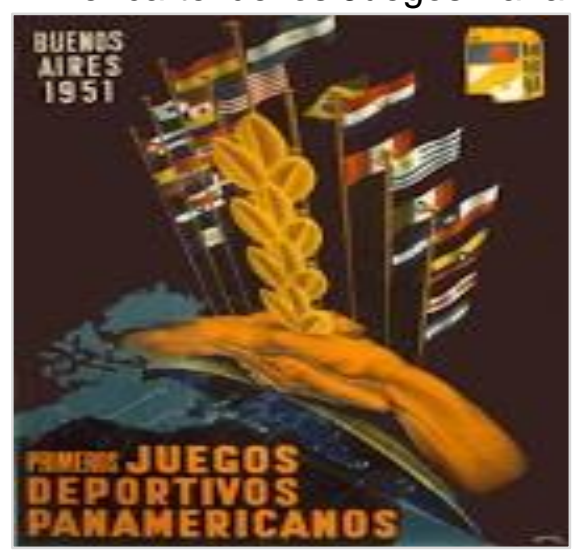

Fuente: Escuela de periodismo deportivo Tea \& Deportes, 2001. 
Actualmente en cada evento de Juegos Panamericanos se desarrollan competiciones de 28 deportes distintos durante los 14 días que dura el torneo, y es considerado una preparación para los juegos olímpicos de verano.

\subsubsection{Impacto de los Juegos Panamericanos en la historia.}

Hasta la actualidad se han realizado 18 ediciones de los Juegos Panamericanos en diversos países y fechas, como se describe a continuación:

- Edición I-1951: Buenos Aires

- Edición II - 1955: México

- Edición III - 1959: Estados Unidos

- Edición IV - 1963: Brasil

- Edición V-1967: Canadá

- Edición VI - 1971: Colombia

- Edición VII - 1975: México

- Edición VIII - 1979: Puerto Rico

- Edición IX - 1983: Venezuela

- Edición X - 1987: Estados Unidos

- Edición XI-1991: Cuba

- Edición XII - 1995: Argentina

- Edición XIII - 1999: Canadá

- Edición XIV - 2003 Republica Dominicana

- Edición XV - 2007: Brasil

- Edición XVI - 2011: México

- Edición XVII - 2015: Canadá

- Edición XVIII - 2019: Perú

Todas estas ediciones de alguna manera han significado gastos tanto en infraestructura como en procesos logísticos para la realización, es ahí donde nos hacemos la interrogante ¿Cómo es posible asegurar que esto sea una inversión y no un gasto?, como asegura la Revista Civilizate (2015) los Panamericanos 2019 son una oportunidad para 
poder transformar una ciudad y hacer cambios significativos luego de estos eventos.

Es así que a pesar de que se han realizado en muchas ciudades estos eventos deportivos solo cuatro han tenido impactos significativos en el territorio a nivel urbano como intervenciones Post Panamericanos, siendo el que más sobresale la edición Toronto 2015 en Canadá, pues dejo como legado en el terreno de la Villa Panamericana un ejemplo de ciudad sostenible dentro de un parque, estableciendo luego de la culminación del evento una ley de construcción de techos verdes, donde cualquier diseño mayor a 2000m2 deberá incluir obligatoriamente los techos verdes. A continuación, se explican algunas ediciones más significativas:

\section{a. Juegos Panamericanos "Cuba” XI edición 1991.}

Los Juegos Panamericanos celebrados en La Habana en agosto de 1991 fueron cuestionados por el pueblo cubano, ya que en medio de una crisis económica y política donde gobernaba Fidel Castro, se hicieron trabajar a medio millón de personas en obras de construcción, sin paga ni descanso (Pérez Chang, 2014).

La infraestructura realizada para dicho evento, sirvió de equipamiento deportivo por pocos años, ya que la falta de mantenimiento y el pasar del tiempo hizo que estas se deterioraron. Cuba ha estado dispuesta a volver a organizar unos juegos olímpicos, sin embargo, no ha sido seleccionada dejando adelante otros países de la región (cubanos por el mundo, 2013). Como consecuencia la ciudad se revalorizo, con un modelo urbano diferente al tradicional, planteado por Roberto Caballero, logrando recuperar la retícula. (Cuadra Manuel, 2018) 
Figura 53. Estadio Panamericano en la actualidad.

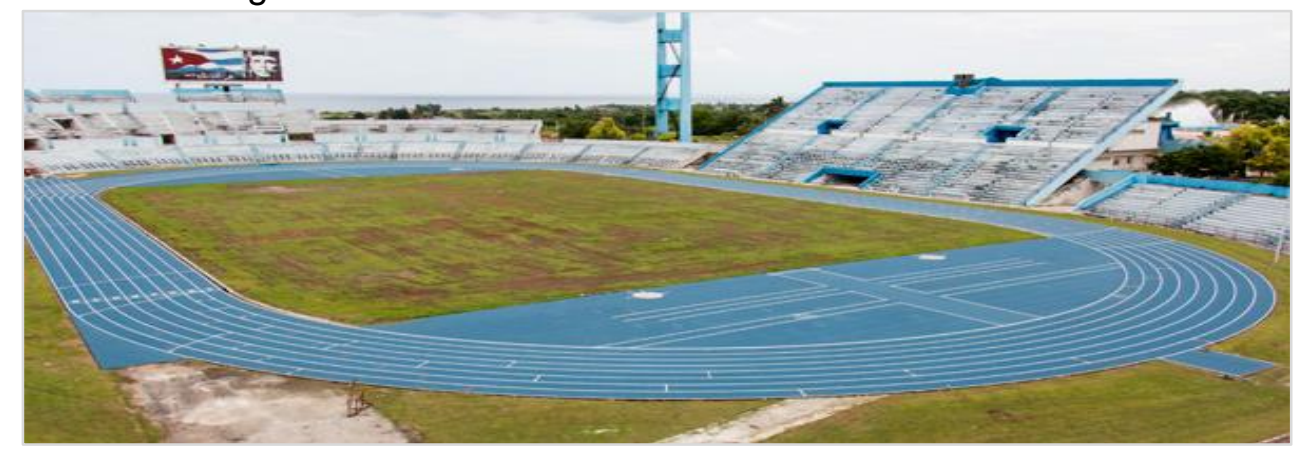

Fuente: Hoy se estrena la pista, Portal deporcuba, 2019.

\section{b. Juegos Panamericanos “Argentina " edición 1995.}

Los Juegos Deportivos Panamericanos №12 se desarrollaron del 11 al 26 de marzo de 1995, en Mar de Plata, Argentina; donde participaron 5,144 atletas de 42 países. En temas de infraestructura se reacondicionó el Parque de los Deportes, incluyendo otras obras nuevas y remodelaciones. Entre las instalaciones construidas se encuentran un Centro de convenciones, un estadio con capacidad de 10,000 personas, un complejo de natación para una capacidad de 8,000 personas, un velódromo para 4,000 espectadores, una pista sintética de atletismo, entre otros; invirtiendo un total de alrededor de 13,3 millones de dólares. El legado de estos juegos para Mar de Plata, fue sin duda su infraestructura deportiva que potenció su desarrollo denominada como la capital del deporte de primer nivel, según el portal de Revista de Urbanismo (2004).

Figura 54. Intervención del Parque de los Deportes en 1995.

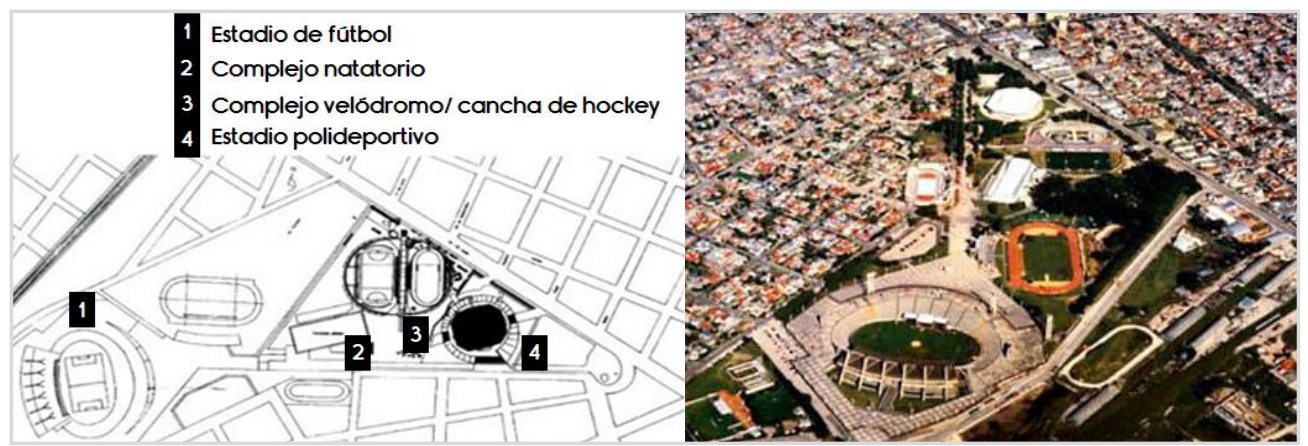

Fuente: Alternativas de Gestión Urbanística: Una mirada reflexiva hacia los últimos diez años, Revista de Urbanismo, 2004. 


\section{c. Juegos Panamericanos "Brasil” edición 2007.}

Esta fue la segunda ocasión que Brasil albergó unos Juegos Panamericanos, siendo la primera vez en Sao Paulo (1963). Tuvo sede en Rio de Janeiro, agrupando a 42 países y un total de 5,633 atletas (Regalado et. al., 2015). En materia de infraestructura, según el portal Notiviajeros (2016) se invirtió en una villa panamericana de hospedaje para los participantes, en el centro acuático María Lenk, arena multiuso de Rio, parque olímpico, campo olímpico de golf, arena olímpica de Río, estadio acuático olímpico, entre otros. Debido a que, en los primeros Juegos Panamericanos realizados en esta locación, la ciudad de Rio de Janeiro ya tenía obras de índole deportiva, lo que sirvió para remodelar las infraestructuras existentes y solo un $26 \%$ necesito construirse.

Figura 55. Infraestructura que dejaron los Juegos Panamericanos en 2003

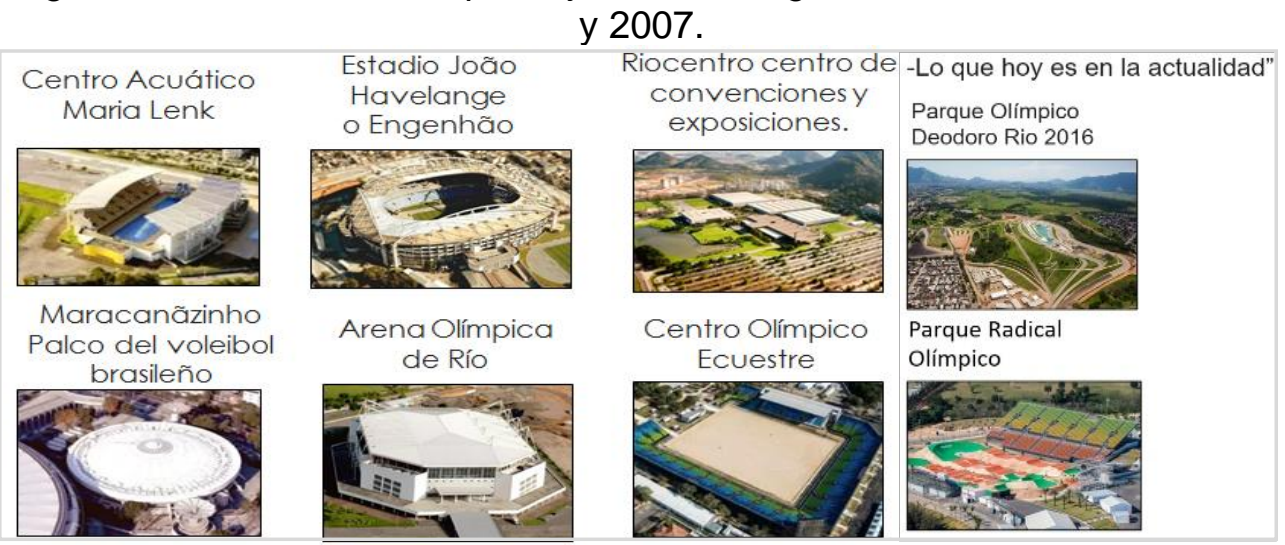

Fuente: Portal Archdaily. Elaboración Propia.

\section{d. Juegos Panamericanos “México” edición 2011.}

Esta fue la tercera ocasión que México realizó unos Juegos Panamericanos. Tuvo sede en Guadalajara, agrupando a 42 países y un total de 6,003 atletas (Regalado et. al., 2015). Para este evento se decidió construir 23 instalaciones deportivas, infraestructura y urbana que sea útil, durante y después de las competencias. Entre las instalaciones construidas se tienen un estadio de atletismo, un complejo de béisbol, un velódromo, una villa panamericana en Parque 
Morelos, un centro acuático Scotiabank, un estadio panamericano de hockey, un complejo de balonmano, un estadio de softball, entre otros. La mayoría de infraestructuras construidas en los juegos olímpicos 2003 permitieron a través de su mejoramiento construir muchas más como infraestructura deportiva de calidad a futuro para su ciudad.

Figura 56. Villa Panamericana en Guadalajara.

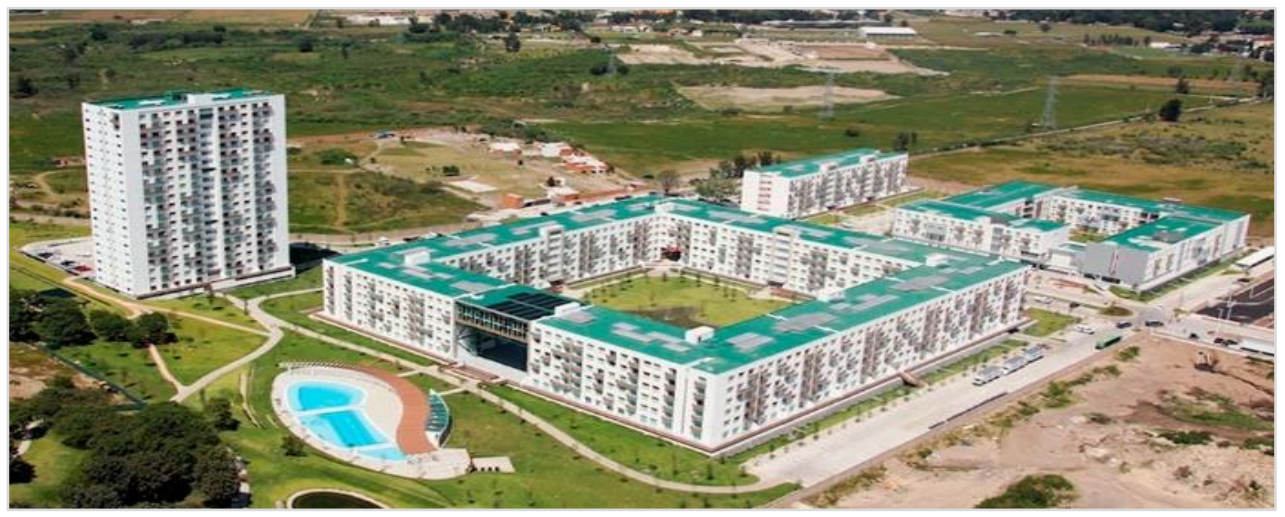

Fuente: Juegos Panamericanos Lima 2019: entre la oportunidad y la incertidumbre, Rodríguez, 2015.

\section{e. Juegos Panamericanos "Canadá" edición 2015.}

Tuvo sede en la ciudad de Toronto, Canadá. Tuvo la participación de 10,000 atletas de 41 países, según el Comité Olímpico de Canadá. (2014). El plan Toronto 2015 se enfocó hacia el uso de nuevos medios, vinculó la sólida infraestructura una significativa experiencia en la difusión de juegos multideportivos. En cuanto a la infraestructura, 10 edificaciones fueron construidas y 15 remodeladas. Entre ellas se encuentran la villa panamericana, el estadio atlético panamericano, el centro acuático Scarborough y complejo deportivo, el centro canadiense de tenis, el centro de bowling, el estadio de atletismo Etobicoke Olympium, el parque panamericano, entre otros. El legado de estos juegos a través de su nueva ley de construcción de techos verdes lo convirtió en los más ecológicos de la historia. 
Figura 57. La Villa de los Atletas en Toronto, Canadá.

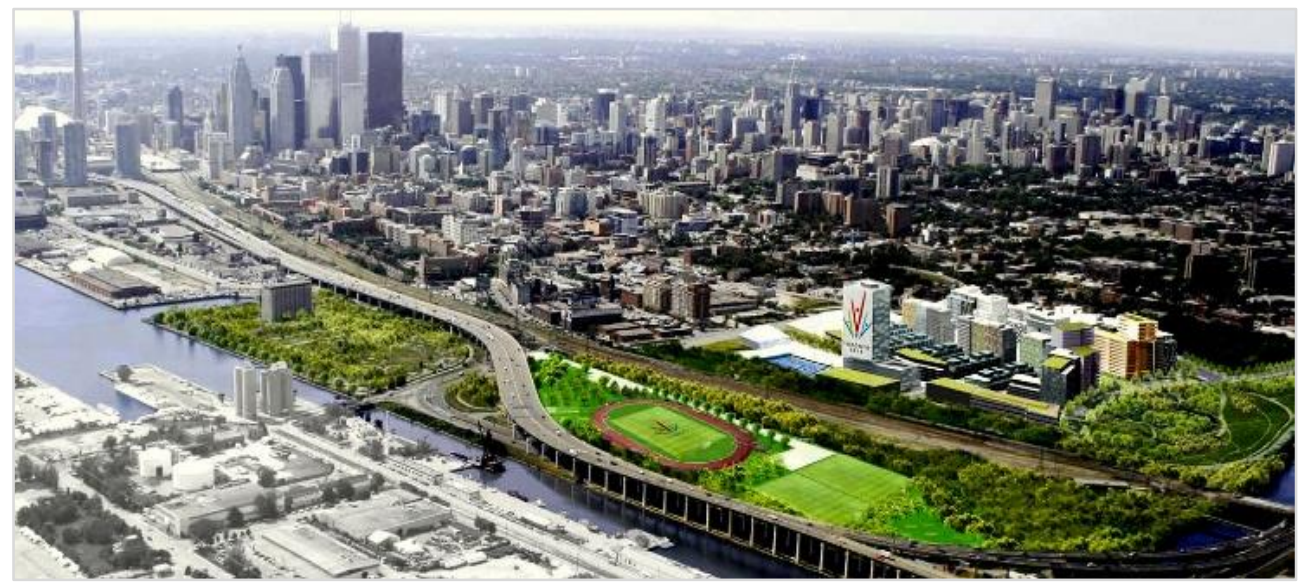

Fuente: Juegos Panamericanos Lima 2019: entre la oportunidad y la incertidumbre, Rodríguez, 2015.

\subsubsection{Lima como sede para los Juegos Panamericanos y Paramericanos 2019.}

Lima fue elegida sede de los Juegos Panamericanos del 2019 el 11 de octubre del 2013, ganando con 31 votos a favor sobre un total de 57 en las cuales participaron las ciudades de Santiago de Chile (9 votos), La Punta Argentina (9 votos), y Ciudad Bolívar de Venezuela (8 votos). La fecha de realización de este evento se tiene planeada desde el 26 de julio al 9 de agosto del 2019 (Diario Gestión, 2013).

En la última década, la ciudad de Lima ha sido participe de eventos internacionales importantes los cuales han aportado a que la capital y el Perú sean reconocidos mundialmente por su capacidad de organización, crecimiento económico, calidad de vida, experiencias culturales y gastronómicas. Asimismo, la organización de eventos deportivos de tal magnitud, se representa como una gran oportunidad al país de reconocimiento, desarrollo educativo, social, cultural y económico en sectores como el turismo, deporte, transporte, infraestructura, entre otros (Regalado, et. al. 2015). 
Figura 58. Distribución de sedes Juegos Panamericanos Lima 2019.

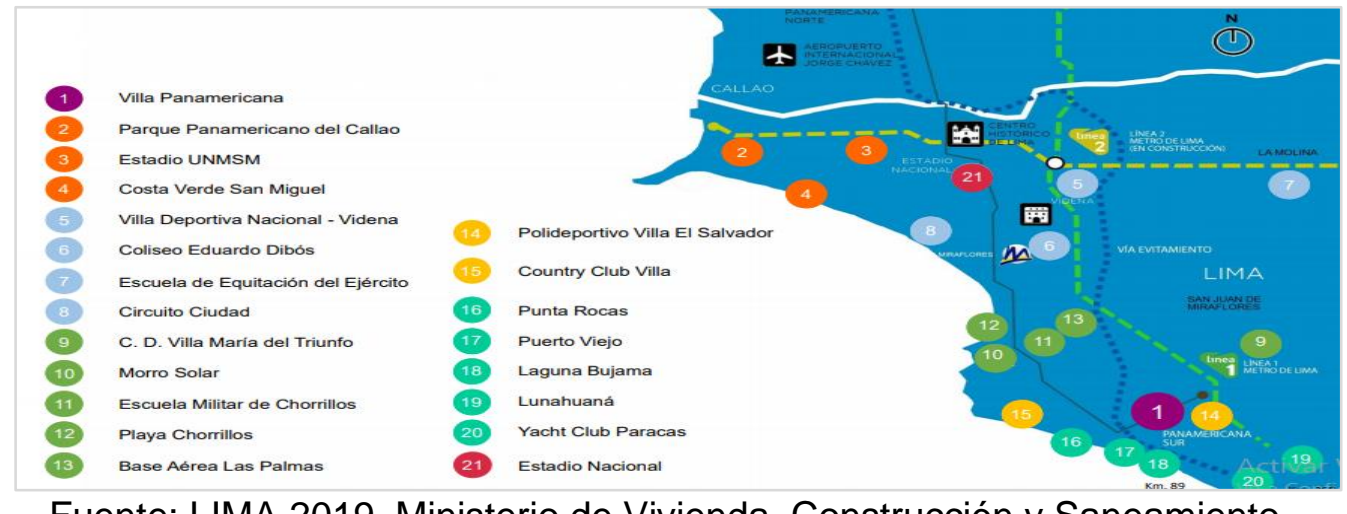

Fuente: LIMA 2019, Ministerio de Vivienda, Construcción y Saneamiento, 2019.

De acuerdo al Ministerio de Vivienda, Construcción y Saneamiento (2019), se prevé que este evento deportivo deje legado positivo en cuanto a desarrollo urbano. Entre las mejoras urbanísticas están la revalorización del terreno aledaño a las sedes a construirse, con un promedio de $7.2 \%$ de los 2, 930,973 m2 ubicados a radio inferior a 400 metros de la Villa Panamericana, tanto como la infraestructura que será destinada a futuros usuarios terminado el evento.

En cuanto a Transporte, el Ministerio de Vivienda, Construcción y Saneamiento (2019) indica que existirá una mejora de conexión entre los distritos limeños y el aeropuerto, así como, se aumentará la capacidad del tren el eléctrico (44 trenes al 2019), y le renovación de buses de los corredores rojo y morado.

De acuerdo a Paz (2019), más de 8500 deportistas de 41 países de América llegaron a la capital de Lima, durante la realización de los Juegos Panamericanos los cuales se ejecutaron en 26 días. A la fecha de abril 2019, se desarrolló la villa panamericana, la cual cuenta con un complejo de 1096 departamentos distribuidos en siete torres ubicadas en Villa el Salvador, esta obra se encuentra finalizada y un polideportivo aledaño. Este polideportivo sirvió como sede principal de los deportes colectivos de Lima 2019. 
Figura 59. Intervenciones viales, Juegos Panamericanos Lima 2019.

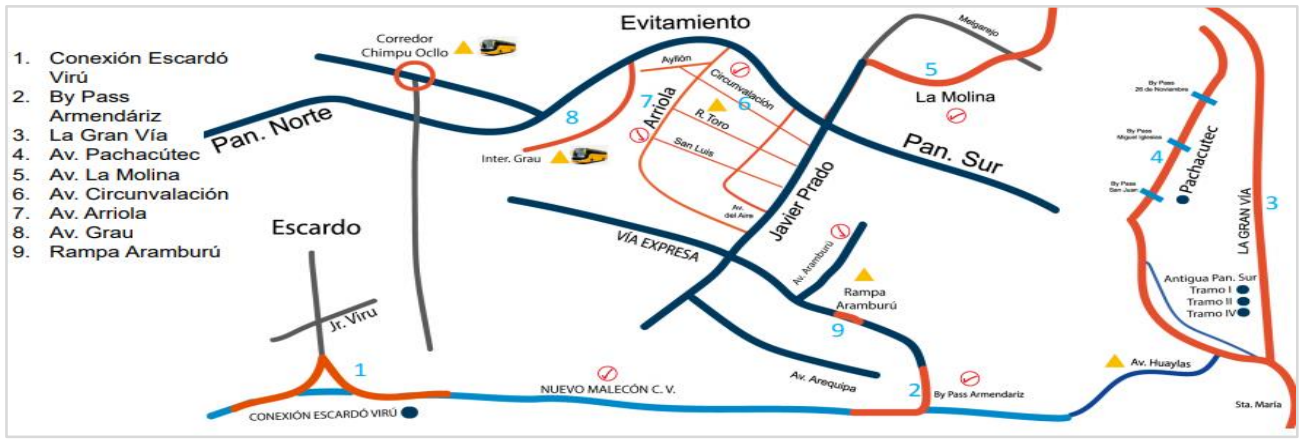

Fuente: LIMA 2019, Ministerio de Vivienda, Construcción y Saneamiento, 2019.

\subsubsection{Conclusiones.}

La realización de los Juegos Panamericanos en Lima ha sido una oportunidad perfecta para poder mejorar al país en muchos aspectos, sobre todo en infraestructura, equipamiento y economía temporal durante su desarrollo. Aquellos proyectos urbanos y arquitectónicos que facilitaron tanto el tránsito y acceso de sedes a otras, no solo aportaron a la realización correcta de los juegos, si no que finalizados estos quedaron como parte de la ciudad para el uso de todos los ciudadanos. Sin embargo, temas como la corrupción y la burocracia que azota al país, ha sido una limitante, ya que han ido retrasando el desarrollo y construcción de los proyectos, creando una amenaza de desaprovechar la oportunidad que un evento de tal magnitud le da a un país y que el legado a nivel de calidad de ciudad no sea la que se hubiera esperado con tales inversiones. Asimismo, teniendo como referencia eventos pasados en países hermanos, se concluye que la infraestructura propuesta para los Juegos Panamericanos deberá demostrar que puede seguir siendo usada por el público y siendo un aporte para la ciudad, en caso de que esto no suceda y las edificaciones realizadas queden en el olvido, el país habrá hecho un gasto más que una inversión.

\subsection{Historia Villa el Salvador}

Como se señaló anteriormente debido a la tragedia del desastre natural de 1970 ocurrido por el terremoto en Yungay, Huaraz; la migración hacia Lima de los sobrevivientes que se quedaron sin hogar más migraciones anteriores 
(Documental VES. Historia de Villa el Salvador), con la ayuda del obispo Luis Bambaren quien bautizo al nuevo asentamiento como Villa el Salvador y la nueva configuración del Arq. Miguel Eugenio Romero Sotelo marcó el principio de este territorio que empezó en un arenal de $3000 \mathrm{Hs}$ aplicando la tecnología urbana que incorpora áreas productivas, industrial, agropecuaria y modulo urbano residencial debido a su tradición, la cual se incorporó a la modernidad, según Romero (2006).

Este distrito refleja un proceso social desde el año 1971 se destaca la fuerte organización de los pobladores, la Comunidad Urbana Autogestionaria de Villa el Salvador (CUAVES) en el año 1973, las mil manzanas tuvieron 5 mil dirigentes y en Villa habitaban 125 mil personas, lo que permitió obtener la capacidad de autogobierno, según Romero (2006). Sin embargo, las áreas sin planificación para la instalación de industrias, no lograban atraer empresas debido a las infraestructuras precarias, falta de apoyo técnico, imagen social inestable, financiero y gubernamental, según Zapata (1996).

En el año 1989 se designa el parque industrial, desarrollándose actividades de carpintería, confecciones, fundición, calzado, artesanías e industrias de alimentos. Para promover el desarrollo económico y social a finales de 1971 se dio inicio a mayor estabilidad social a partir de la elaboración del Plan de Desarrollo Integral de Villa El Salvador, como afirma Romero (2006). De acuerdo a la organización social y estructura territorial Villa el Salvador desde sus inicios se conformó con la filosofía del desarrollo integral con una visión a un enfoque sostenible, el diseño urbano en los comienzos de su conformación permitió que se transforme de un lugar desértico a una ciudad viva y dinámica. El diseño urbano de VES se basa en un modelo de desarrollo socioeconómico, el cual se basa en un planteamiento de diseño de un módulo urbano denominado Grupo Residencial y el modelo de acondicionamiento territorial zonificado por la Junta Nacional de vivienda del Ministerio de Vivienda, ambos en conjunto fueron como soporte físico a la organización comunal, así como para al proyecto de desarrollo integral. 
Se determinó como objetivos del proyecto urbanístico un modelo territorial con estructura modular con tres usos de suelos para el desarrollo de la organización comunal: Industrial - Artesanal, Residencial y AgropecuarioForestal.

Figura 60. Inicio de ocupación en Villa el Salvador.

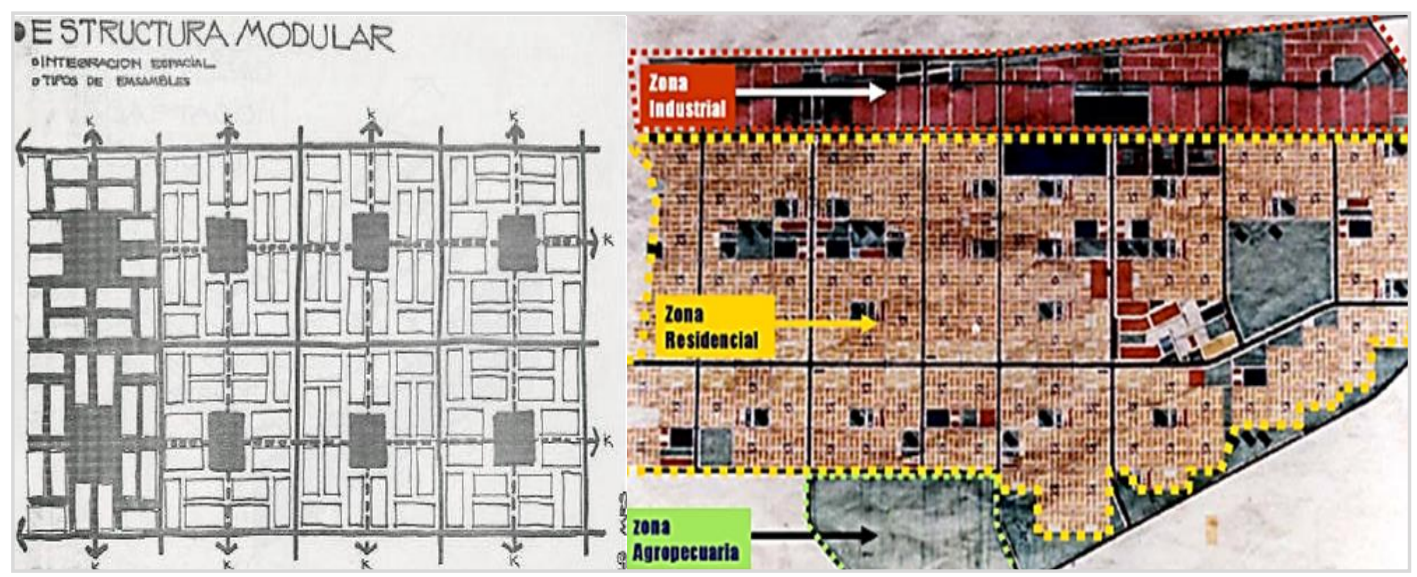

Fuente: Modelo Territorial de Villa el Salvador, Arquitecto Desarrollador, Miguel Romero Sotelo, 2006.

Este módulo se aplicó como base en Villa el Salvador distribuyéndolos en el distrito para su ordenamiento a través de módulos nucleados que constan de 16 manzanas típicos de 24 lotes resultando 120 en total, con un espacio de área verde central para todos, generando un espacio de recreación para los habitantes en cada módulo (Romero, 2006).

Figura 61. Estructura Urbana VES.

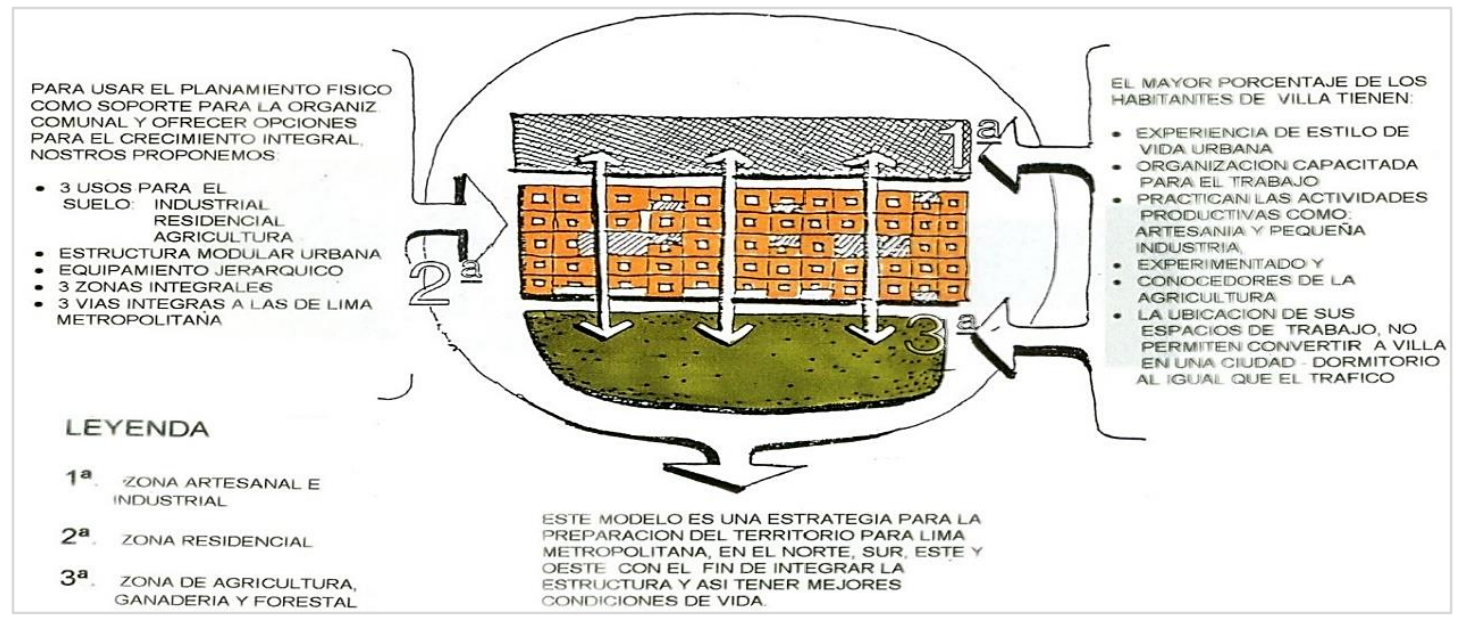

Fuente: Modelo Territorial de Villa el Salvador, Arquitecto Desarrollador, Miguel Romero Sotelo, 2006. 
Figura 62. Estructura Urbana Jerarquizada VES.

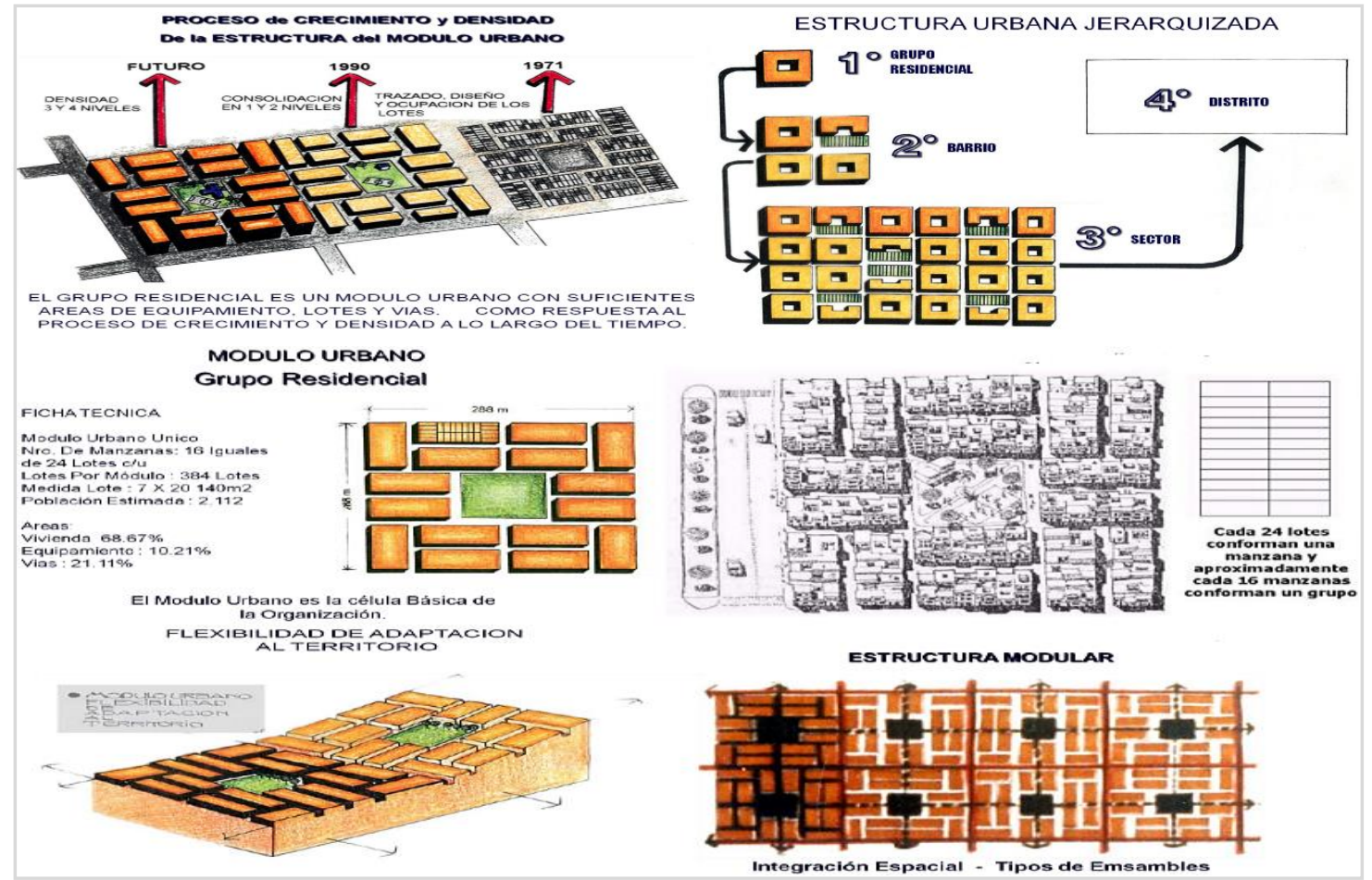

Fuente: Modelo Territorial de Villa el Salvador, Arquitecto Desarrollador, Miguel Romero Sotelo, 2006.

A diferencia de las habilitaciones urbanas tradicionales con el enfoque de ciudad dormitorio, el modelo de ocupación que se propuso fue un contraste a lo anterior más enfocado en lo industrial; asimismo, se formó un planeamiento integral con equipamientos y una red vial coordinada con el Plan Vial de Lima Metropolitana, según Gonzales (2011).

Figura 63. Planeamiento Integral Villa el Salvador.

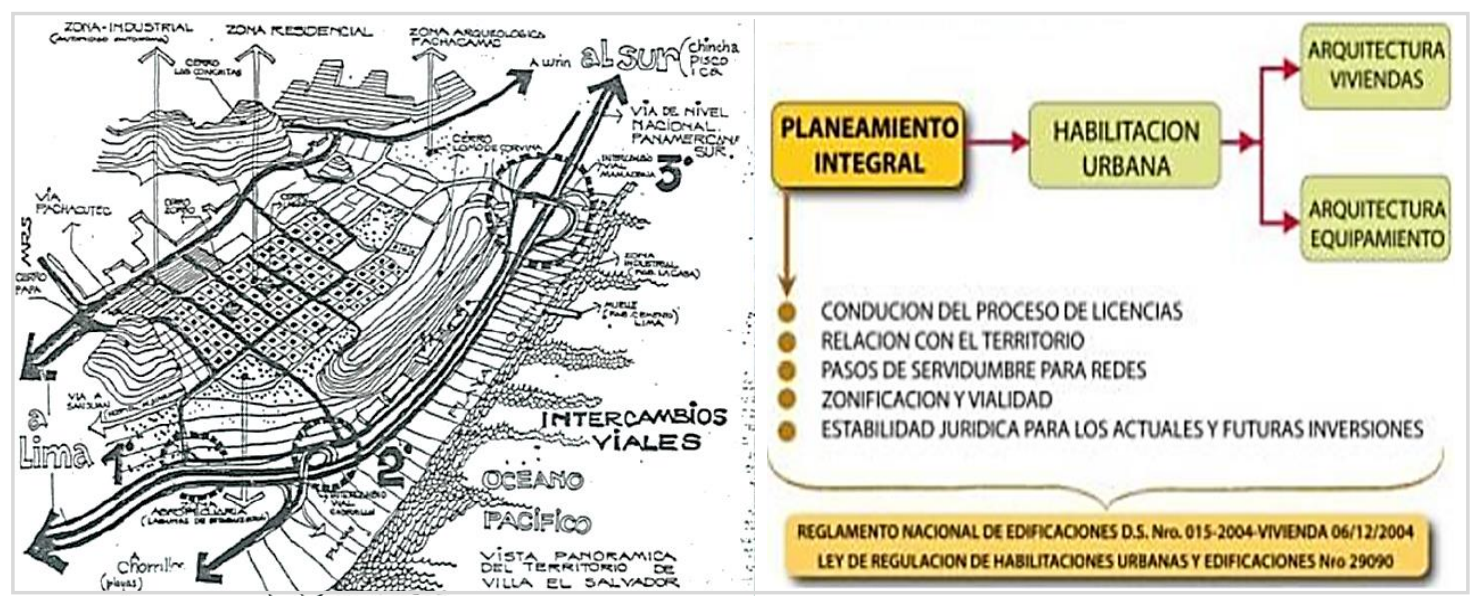

Fuente: Modelo Territorial de Villa el Salvador, Arquitecto Desarrollador, Miguel Romero Sotelo, 2006. 
A través de los años Villa el Salvador a pesar de su ordenamiento territorial en un principio, el crecimiento de su territorio y debido a que se presentaron distorsiones por la ocupación desordenada de los nuevos pobladores que llegaban al distrito. El gobierno local, a pesar de su planificación dentro de sus competencias para obtener un crecimiento ordenado territorialmente, con el pasar del tiempo y de los años las calles alcanzaron un alto rango de inseguridad, vías oscuras y peligrosas; y barriadas, según Castro \& Riofrío (1996).

De acuerdo con el plan de Desarrollo Concertado del distrito de Villa el Salvador (2016), si bien señala buscar crecer y ser un distrito emprendedor la construcción de la Villa Panamericana consiguió un progreso al distrito, pero no de acuerdo a las necesidades que el distrito requiere y aún no logra establecer.

Según Romero (2016), en los últimos 30 años se presenta las siguientes deficiencias en general como procesos constructivos sin calidad arquitectónica y estructural, aglomeración de viviendas, la zona artesanal requiere soluciones de carácter masivos, deficiencia de servicios públicos e inseguridad en espacios públicos, cambio de usos de los espacios del distrito, principalmente todo generado como se mencionó anteriormente por un desorden demográfico lo que comprueba que la visión del diseño planteado al inicialmente puede llegar a no concluirse con el tiempo en su totalidad por cómo se está desarrollando en la actualidad.

Sin embargo, a pesar de sus debilidades el territorio ha mejorado debido a al incrementando las actividades de los establecimientos industriales que ha pasado de 3,523 a 3,500, comerciales de 9,455 a 11,000, servicios de 5,566 a 6000 y el turismo vivencial incremento de 500 a 2000 turistas por mes.

Actualmente, con la construcción de la villa deportiva para los Juegos Panamericanos el nuevo equipamiento residencial y mejoramiento de vías, ha dado como resultado a un desarrollo positivo del distrito. 
Villa el Salvador tiene como visión al 2030 ser un distrito inclusivo, moderno, ordenado, seguro, organizado, productivo, sostenible y la característica más predominante COMERCIAL, un total territorio interconectado y con oportunidades, según el Plan concertado de Villa el Salvador (2016).

El distrito de Villa el Salvador es una ciudad joven que nació en 1971 y recién en 1988 se catalogó como distrito, posee problemas viales de interconexión principalmente con la conectividad con la parte de territorio de las playas y reordenar su desarrollo urbano para reducir la inseguridad ciudadana y mejorar la calidad de vida de sus pobladores. Lo que hace falta es incentivar mayor parte de inversión privada a los empresarios con un gran proyecto, como lo es un gran centro comercial para atraer otros negocios y crear más fuente de trabajo, según el Diario La república (2006).

A continuación, la siguiente imagen muestra como predomina el comercio en todas calles de zona residencial, es decir, no posee un núcleo específico, lo que resulta preocupante ya que hacia la visión 2030 Villa el Salvador se debe de acondicionar adecuadamente como distrito comercial y empresarial.

Figura 64. Ocupación actual Villa el Salvador.

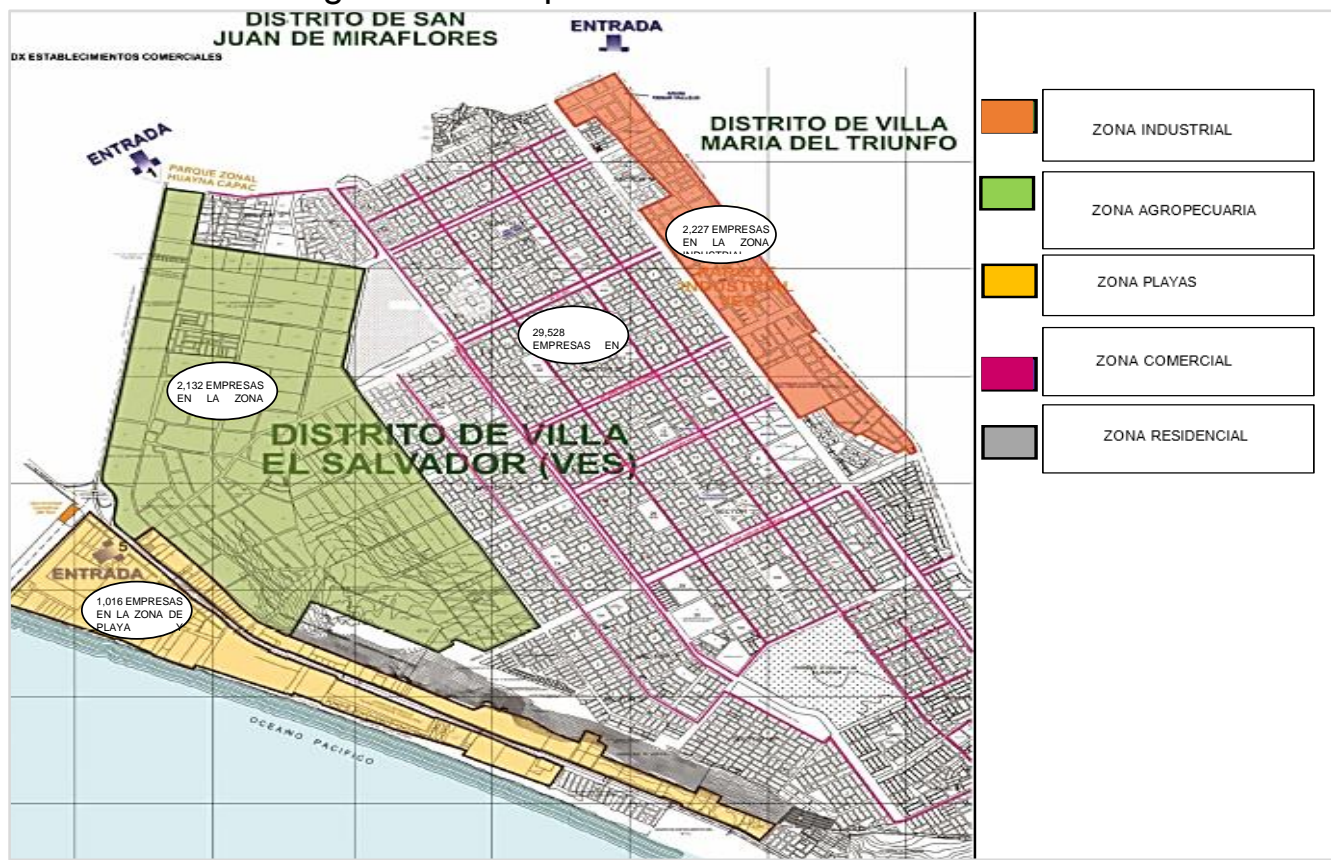

Fuente: Plan desarrollo Concertado del distrito de Villa el Salvador 2017-2021, municipalidad Villa el Salvador, 2016. 
Según Sociedad Peruana de Bienes Raíces (2020), dentro de las actividades que generan plusvalías inmobiliaria y por ende aumento del PBI local son inversiones en centros comerciales. Para que un distrito avance es necesario desarrollar zonas de comercio adecuadamente con un buen emplazamiento no solo implantar viviendas: ya que, este tipo de equipamiento aumenta el valor de las viviendas (Viva anuncios, 2019).

De acuerdo al nuevo plan concertado 2021 se adiciona una nueva zonificación comercial, pero se identifica que hace falta un núcleo comercial y empresarial completo. Se muestra la siguiente imagen, donde se puede observar que las redes viales ya estaban formadas desde los años 1989:

Figura 65. Plan vial 1989 de Villa el Salvador.

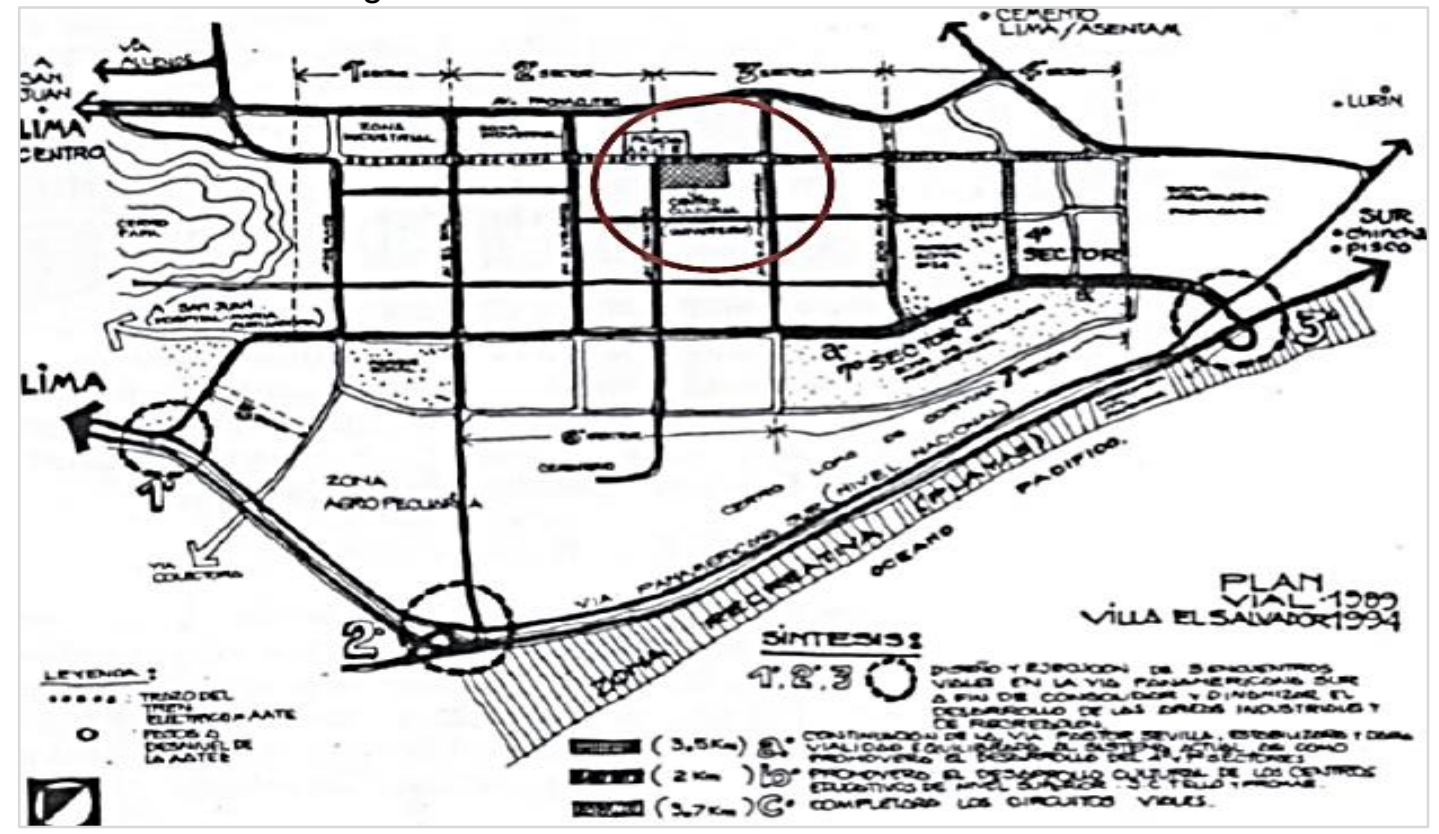

Fuente: Diseño Urbanístico de Villa el Salvador, Arq. Miguel Romero Sotelo, 2006.

Antes de analizar la red vial del distrito de Villa el Salvador se muestra todo el sistema vial de Lima para comprender la conectividad con el distrito, el cual se clasifica en cinco; las vías Regionales, Sub Regionales, vías metropolitanas, vías Arteriales y las vías Colectoras como se observa en el plano vial del Instituto Metropolitano de Lima (2010). 
Figura 66. Sistema Vial Metropolitano de Lima.

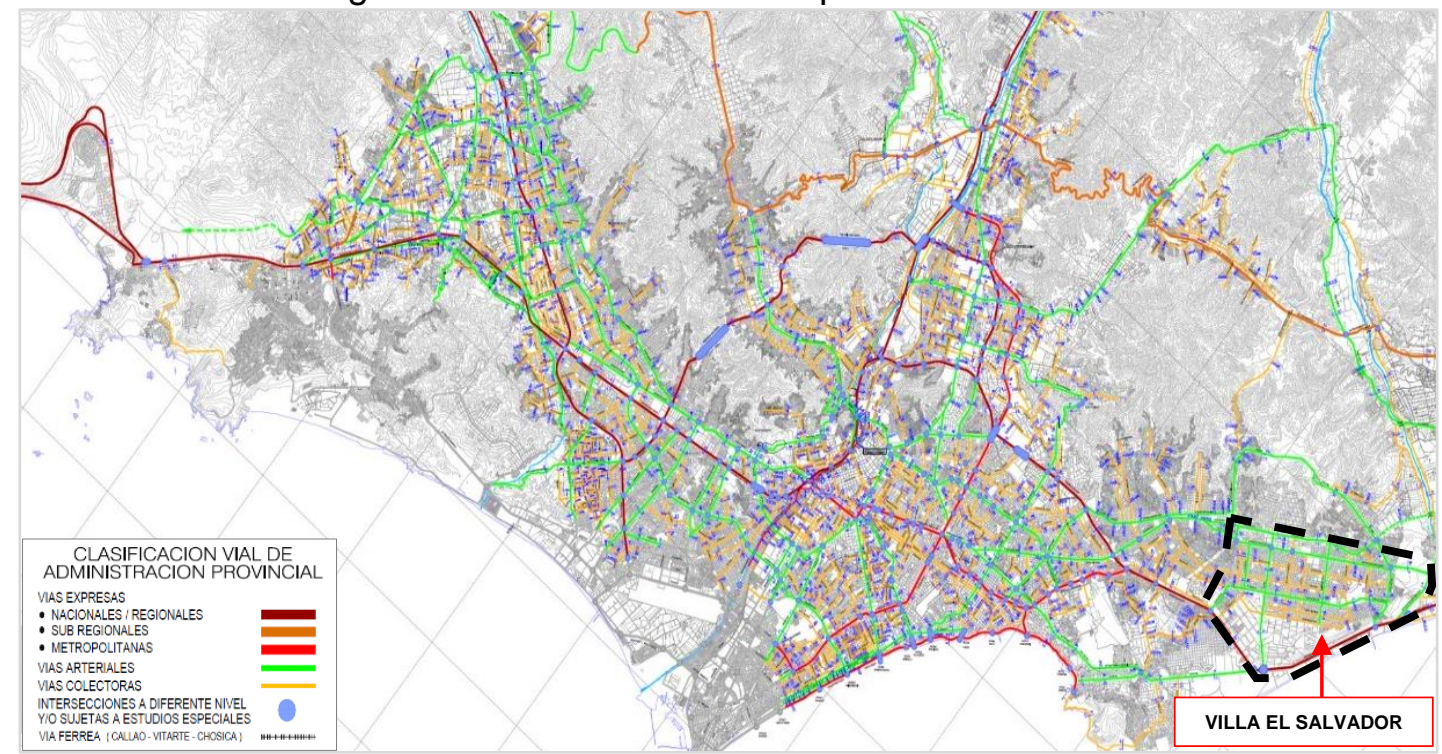

Fuente: Actualización del Sistema Vial Metropolitano, IMP, 2010.

Es necesario resaltar las vías con las que cuenta Villa el Salvador, las vías Regionales y Nacionales de la carretera Panamericana Sur, vías arteriales con la Av. Separadora Industrial por donde pasa el tren línea Metro 1, Av. Pumacahua, Av. El Sol, Av. 1 de mayo, Av. José Carlos Mariátegui y Av. María Reiche importantes, porque interconectan con sistemas de transporte a las regionales con las arteriales y finalmente con las vías colectoras que son todas las demás calles que integran toda la trama urbana del distrito.

Figura 67. Sistema Vial Metropolitano de Lima Sur.

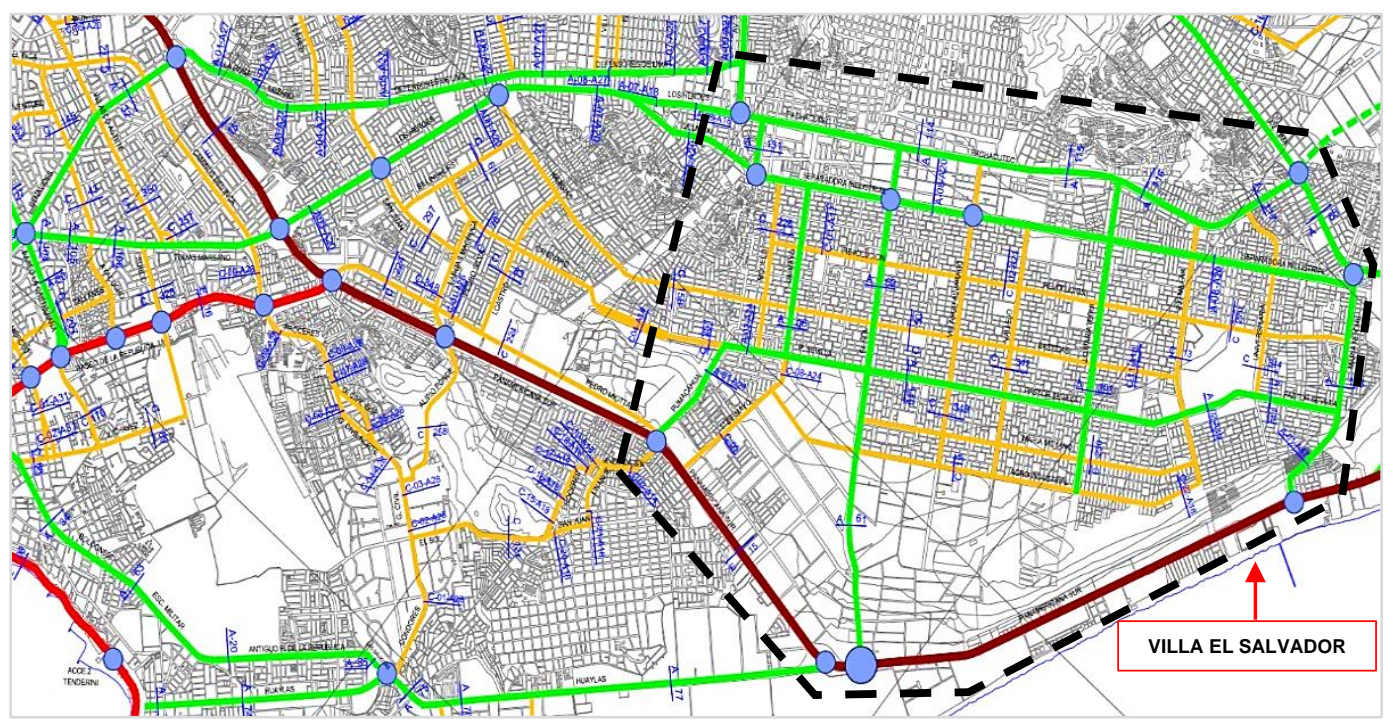

Fuente: Actualización del Sistema Vial Metropolitano, IMP, 2010. 
A continuación, esta otra imagen pertenece a la red vial actual de Villa el Salvador, donde se observa que la trama de acuerdo al primer planteamiento se ha expandido siguiendo el patrón urbano y diseñado. Sin embargo, a pesar de que las calles estén interconectadas, los accesos al distrito por parte de los visitantes no cuentan con el equipamiento suficiente para abastecer el tráfico de la población.

Figura 68. Red vial actual Villa el Salvador.

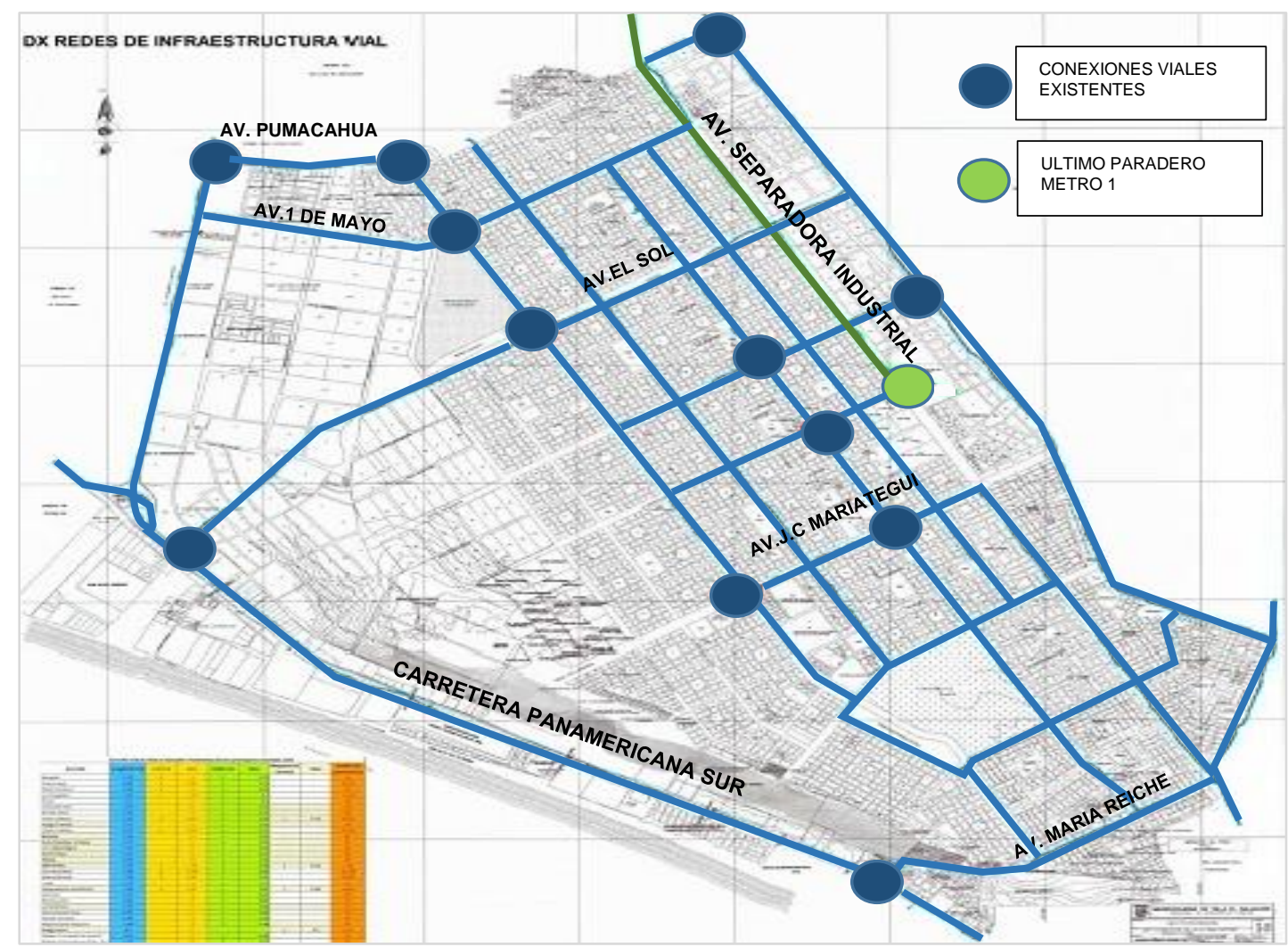

Fuente: Plan desarrollo Concertado del distrito de Villa el Salvador 2017-2021, Municipalidad de Villa el Salvador, 2016. 


\section{Metodología}

\subsection{Cuadro de diseño de la investigación.}

\begin{tabular}{|c|c|c|c|}
\hline $\begin{array}{l}\text { Aspectos a } \\
\text { conocer }\end{array}$ & $\begin{array}{c}\text { Temas de } \\
\text { investigación }\end{array}$ & $\begin{array}{l}\text { Fuentes de } \\
\text { información }\end{array}$ & Instrumento \\
\hline \multirow{5}{*}{$\begin{array}{l}\text { Aspectos } \\
\text { físicos y } \\
\text { territoriales }\end{array}$} & \multicolumn{3}{|c|}{ Revisión Bibliográfica } \\
\hline & $\begin{array}{l}\text { Ubicación del } \\
\text { proyecto }\end{array}$ & $\begin{array}{l}\text { Catastro Urbano de } \\
\text { Villa el Salvador, } \\
\text { Municipalidad de } \\
\text { Villa el Salvador, } \\
2018 .\end{array}$ & $\begin{array}{c}\text { ¿Dónde se } \\
\text { encuentra ubicado } \\
\text { el terreno del } \\
\text { proyecto? }\end{array}$ \\
\hline & $\begin{array}{l}\text { Zonificación del } \\
\text { Distrito de Villa } \\
\text { el Salvador }\end{array}$ & $\begin{array}{c}\text { Plano de zonificación } \\
\text { de Villa el Salvador, } \\
\text { Ordenanza 620- } \\
\text { MML, 2020. }\end{array}$ & $\begin{array}{l}\text { ¿Qué zonificación } \\
\text { tiene el terreno del } \\
\text { proyecto? }\end{array}$ \\
\hline & $\begin{array}{l}\text { Catastro del } \\
\text { Distrito de Villa } \\
\text { el Salvador }\end{array}$ & $\begin{array}{l}\text { Catastro Urbano de } \\
\text { Villa el Salvador, } \\
\text { Municipalidad de } \\
\text { Villa el Salvador, } \\
2017 .\end{array}$ & $\begin{array}{c}\text { ¿Cuáles son las } \\
\text { dimensiones reales } \\
\text { del terreno del } \\
\text { proyecto? }\end{array}$ \\
\hline & Accesibilidad & $\begin{array}{l}\text { Plan del Sistema Vial } \\
\text { Metropolitano, } \\
\text { Ordenanza N } N^{\circ} 341- \\
\text { MML, Municipalidad } \\
\text { Metropolitana de } \\
\text { Lima, 2001. }\end{array}$ & $\begin{array}{l}\text { ¿Cuáles con los } \\
\text { accesos viales con } \\
\text { los que cuenta el } \\
\text { proyecto? }\end{array}$ \\
\hline \multirow[b]{2}{*}{$\begin{array}{l}\text { Aspectos } \\
\text { Climáticos }\end{array}$} & \multicolumn{3}{|c|}{ Revisión Bibliográfica } \\
\hline & $\begin{array}{l}\text { Clima promedio } \\
\text { del Distrito de } \\
\text { Villa el Salvador }\end{array}$ & $\begin{array}{c}\text { Clima distrital Villa el } \\
\text { Salvador, SENAMHI, } \\
2020 .\end{array}$ & $\begin{array}{c}\text { ¿Qué clima } \\
\text { promedio posee el } \\
\text { Distrito de Villa el } \\
\text { Salvador? }\end{array}$ \\
\hline \multirow[b]{2}{*}{$\begin{array}{l}\text { Aspectos } \\
\text { Urbanísticos }\end{array}$} & \multicolumn{3}{|c|}{ Revisión Bibliográfica } \\
\hline & $\begin{array}{l}\text { Parámetros } \\
\text { Urbanos }\end{array}$ & $\begin{array}{l}\text { Plano de zonificación } \\
\text { de Villa el Salvador, } \\
\text { Ordenanza 620- } \\
\text { MML, 2020. }\end{array}$ & $\begin{array}{l}\text { ¿Cuáles son los } \\
\text { parámetros } \\
\text { urbanos del terreno } \\
\text { del proyecto en el } \\
\text { Distrito de Villa el } \\
\text { Salvador? }\end{array}$ \\
\hline \multirow{3}{*}{$\begin{array}{c}\text { Aspectos } \\
\text { Demográficos }\end{array}$} & \multicolumn{3}{|c|}{ Revisión Bibliográfica } \\
\hline & Población & $\begin{array}{c}\text { Censos } 2017 \text { - } \\
\text { Instituto Nacional de } \\
\text { Estadística e } \\
\text { Informática, } 2017 .\end{array}$ & $\begin{array}{c}\text { ¿Cuál es la } \\
\text { población estimada } \\
\text { del Distrito de Villa } \\
\text { el Salvador? }\end{array}$ \\
\hline & $\begin{array}{l}\text { Densidad } \\
\text { Poblacional }\end{array}$ & $\begin{array}{l}\text { Censos } 2017 \text { - } \\
\text { Instituto Nacional de }\end{array}$ & $\begin{array}{l}\text { ¿Cuál es la } \\
\text { densidad } \\
\text { poblacional en el }\end{array}$ \\
\hline
\end{tabular}




\begin{tabular}{|c|c|c|c|}
\hline $\begin{array}{c}\text { Aspectos a } \\
\text { conocer }\end{array}$ & $\begin{array}{c}\text { Temas de } \\
\text { investigación }\end{array}$ & $\begin{array}{l}\text { Fuentes de } \\
\text { información }\end{array}$ & Instrumento \\
\hline & & $\begin{array}{c}\text { Estadística e } \\
\text { Informática, } 2017 .\end{array}$ & $\begin{array}{c}\text { distrito de Villa el } \\
\text { Salvador? }\end{array}$ \\
\hline \multirow{4}{*}{$\begin{array}{l}\text { Aspectos } \\
\text { Socio- } \\
\text { Económicos }\end{array}$} & \multicolumn{3}{|c|}{ Revisión Bibliográfica } \\
\hline & $\begin{array}{l}\text { Índice de } \\
\text { Desarrollo } \\
\text { Humano }\end{array}$ & $\begin{array}{c}\text { Índice de desarrollo } \\
\text { humano- Naciones } \\
\text { Unidas para el } \\
\text { Desarrollo, } 2016 .\end{array}$ & $\begin{array}{l}\text { ¿Cuál es el índice } \\
\text { del desarrollo } \\
\text { humano en el } \\
\text { distrito de Villa el } \\
\text { Salvador? }\end{array}$ \\
\hline & $\begin{array}{c}\text { Déficit } \\
\text { habitacional }\end{array}$ & $\begin{array}{c}\text { Censos } 2017 \text { - } \\
\text { Instituto Nacional de } \\
\text { Estadística e } \\
\text { Informática, } 2017 .\end{array}$ & $\begin{array}{l}\text { ¿Cuál es el déficit } \\
\text { habitacional del } \\
\text { distrito de Villa el } \\
\text { Salvador? }\end{array}$ \\
\hline & $\begin{array}{l}\text { Nivel Socio } \\
\text { Económico }\end{array}$ & $\begin{array}{c}\text { NSE Lima } \\
\text { Metropolitana, Ipsos } \\
\text { Apoyo, } 2018 .\end{array}$ & $\begin{array}{l}\text { ¿Cuál es el nivel } \\
\text { socio económico de } \\
\text { la población del } \\
\text { distrito de Villa el } \\
\text { Salvador? }\end{array}$ \\
\hline \multirow{4}{*}{$\begin{array}{l}\text { Aspectos } \\
\text { Normativos y } \\
\text { Legales }\end{array}$} & \multicolumn{3}{|c|}{ Revisión Bibliográfica } \\
\hline & Oficinas & $\begin{array}{c}\text { Reglamento } \\
\text { Nacional de } \\
\text { edificaciones Norma } \\
\text { A.080 - Ministerio de } \\
\text { Vivienda, } \\
\text { Construcción y } \\
\text { Saneamiento y } \\
\text { SENCICO, 2015. }\end{array}$ & $\begin{array}{c}\text { ¿Qué criterios } \\
\text { deben tomarse en } \\
\text { cuenta para el } \\
\text { diseño de oficinas? }\end{array}$ \\
\hline & Comercio & $\begin{array}{c}\text { Reglamento } \\
\text { Nacional de } \\
\text { edificaciones Norma } \\
\text { A.070 - Ministerio de } \\
\text { Vivienda, } \\
\text { Construcción y } \\
\text { Saneamiento y } \\
\text { SENCICO, 2015. }\end{array}$ & $\begin{array}{l}\text { ¿Qué criterios } \\
\text { deben tomarse en } \\
\text { cuenta para el } \\
\text { diseño de } \\
\text { establecimientos } \\
\text { comerciales? }\end{array}$ \\
\hline & Vivienda & $\begin{array}{c}\text { Reglamento } \\
\text { Nacional de } \\
\text { edificaciones Norma } \\
\text { A.020 - Ministerio de } \\
\text { Vivienda, } \\
\text { Construcción y } \\
\text { Saneamiento y } \\
\text { SENCICO, } 2015 .\end{array}$ & $\begin{array}{l}\text { ¿Qué criterios } \\
\text { deben tomarse en } \\
\text { cuenta para el } \\
\text { diseño de } \\
\text { viviendas? }\end{array}$ \\
\hline
\end{tabular}




\subsection{Diseño de los instrumentos}

\subsubsection{Aspectos Físicos y Territoriales:}

- ¿Dónde se encuentra ubicado el terreno del proyecto?

- ¿Qué zonificación tiene el terreno del proyecto?

- ¿Cuáles son las dimensiones reales del terreno del proyecto?

- ¿Cuáles con los accesos viales con los que cuenta el proyecto?

\subsubsection{Aspectos Climáticos:}

- ¿Qué clima promedio posee el Distrito de Villa el Salvador?

\subsubsection{Aspectos Urbanísticos:}

- ¿Cuáles son los parámetros urbanos del terreno del proyecto en el Distrito de Villa el Salvador?

\subsubsection{Aspectos Demográficos:}

- ¿Cuál es la población estimada del Distrito de Villa el Salvador?

- ¿Cuál es la densidad poblacional en el distrito de Villa el Salvador?

\subsubsection{Aspectos Socio-Económicos:}

- ¿Cuál es el índice del desarrollo humano en el distrito de Villa el Salvador?

- ¿Cuál es el déficit habitacional del distrito de Villa el Salvador?

- ¿Cuál es el nivel socio económico de la población del distrito de Villa el Salvador?

\subsubsection{Aspectos Normativos y Legales:}

- ¿Qué criterios deben tomarse en cuenta para el diseño de oficinas?

- ¿Qué criterios deben tomarse en cuenta para el diseño de establecimientos comerciales?

- ¿Qué criterios deben tomarse en cuenta para el diseño de viviendas? 


\section{Factores condicionantes del proyecto.}

\subsection{Aspectos Físicos y Territoriales}

\section{¿Dónde está ubicado el terreno del proyecto?}

El proyecto está ubicado en el distrito de Villa el Salvador, distrito con 35,460 km2 en la Costa Central del departamento de Lima, a 20km al sur del centro histórico. Conforma parte de uno de los distritos de Lima Metropolitana parte de área Sur de Lima, en la sentada del desierto de la tablada de Lurín en la zona intercuenca de Lurín y Rímac. Comprende de las coordinadas geográficas con latitud Sur $12^{\circ} 12^{\prime} 34^{\prime \prime}$, longitud Oeste $76^{\circ} 56^{\prime} 08^{\prime \prime}$ y altitud, y a $175 \mathrm{msnm}$. Colinda con los siguientes distritos:

-Norte : Distrito San Juan de Miraflores y Villa María del Triunfo.

-Sur : Distrito Lurín

-Este : Distrito Villa María del Triunfo

-Oeste: Chorrillos y el Océano Pacífico.

Figura 69. Mapa distrital de Lima Metropolitana.

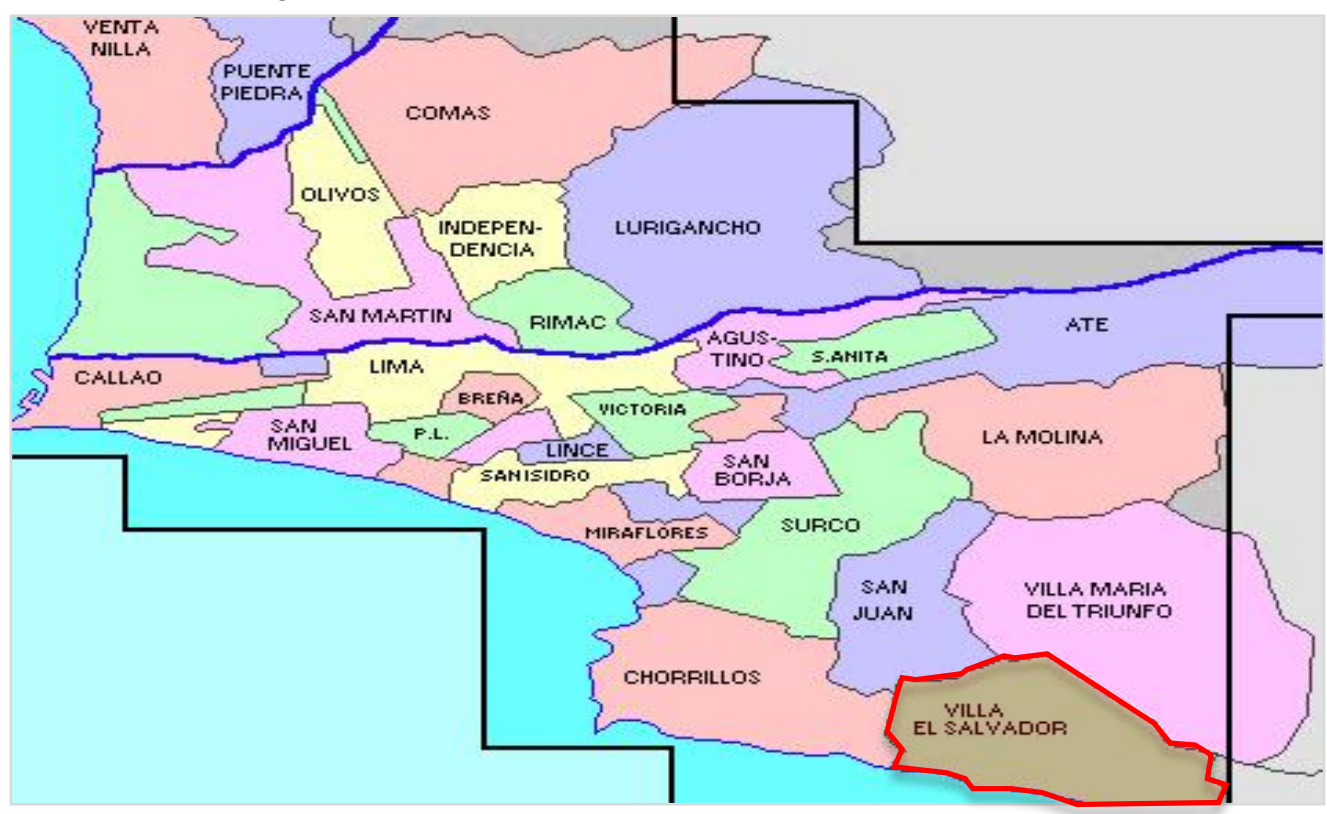

Fuente: Plano de Lima. Portal terra-inca, 2018. 
Conforma parte del Lima Sur nuevo nodo de centralidad en Lima Metropolitana zona que posee el 19,2\% de habitantes según el Instituto Estadística e Informática (2017).

Figura 70. Mapa áreas interdistritales de Lima Metropolitana y Callao.

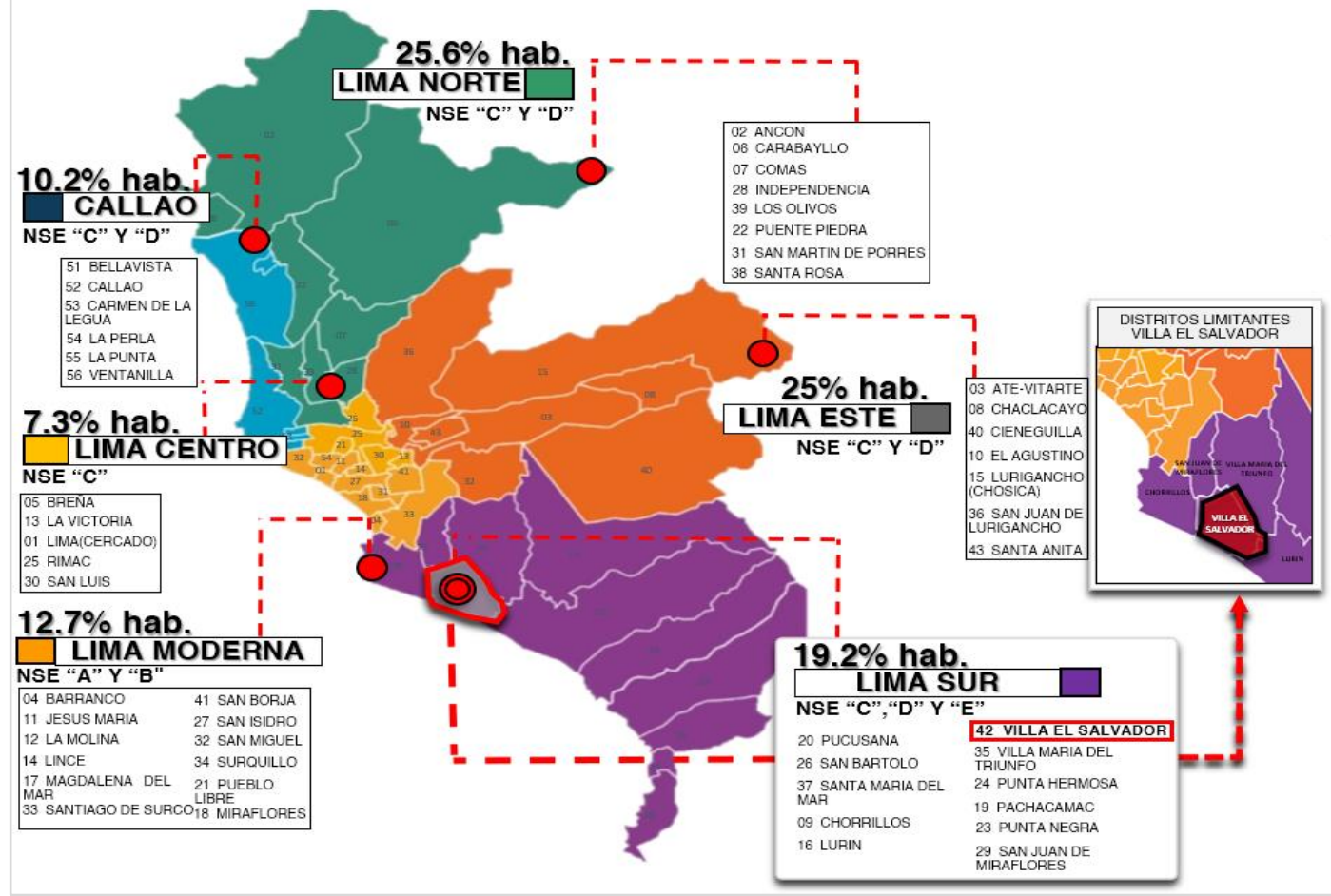

Fuente: Instituto Nacional de Estadística e Informática, 2017. Elaboración Propia.

Villa el Salvador está dividido en 9 sectores designado por la Municipalidad de VES; el territorio I que comprende los Sectores 1 y 8 , territorio II que comprende el Sector 2, territorio III comprende el Sector 3, territorio IV comprende la Urbanización Pachacamac, territorio $\mathrm{V}$ donde se encuentra el terreno del proyecto comprende de la zona de playas, agropecuaria y asociaciones de vivienda del Sector 5, territorio VI Sector 6 y Asociaciones de vivienda, territorio VII sectores 7, 9, 10 y AA.HH del Cerro Loma de Corvina, territorio VIII el AA.HH del parque Metropolitano y el territorio IX el parque industrial, también ha designado una zonificación actual a Villa el Salvador, los usos de suelo en todo el distrito difieren de estos lineamientos, se muestra continuación en las siguiente figura .... 
Figura 71. Identificación de los sectores de VES.

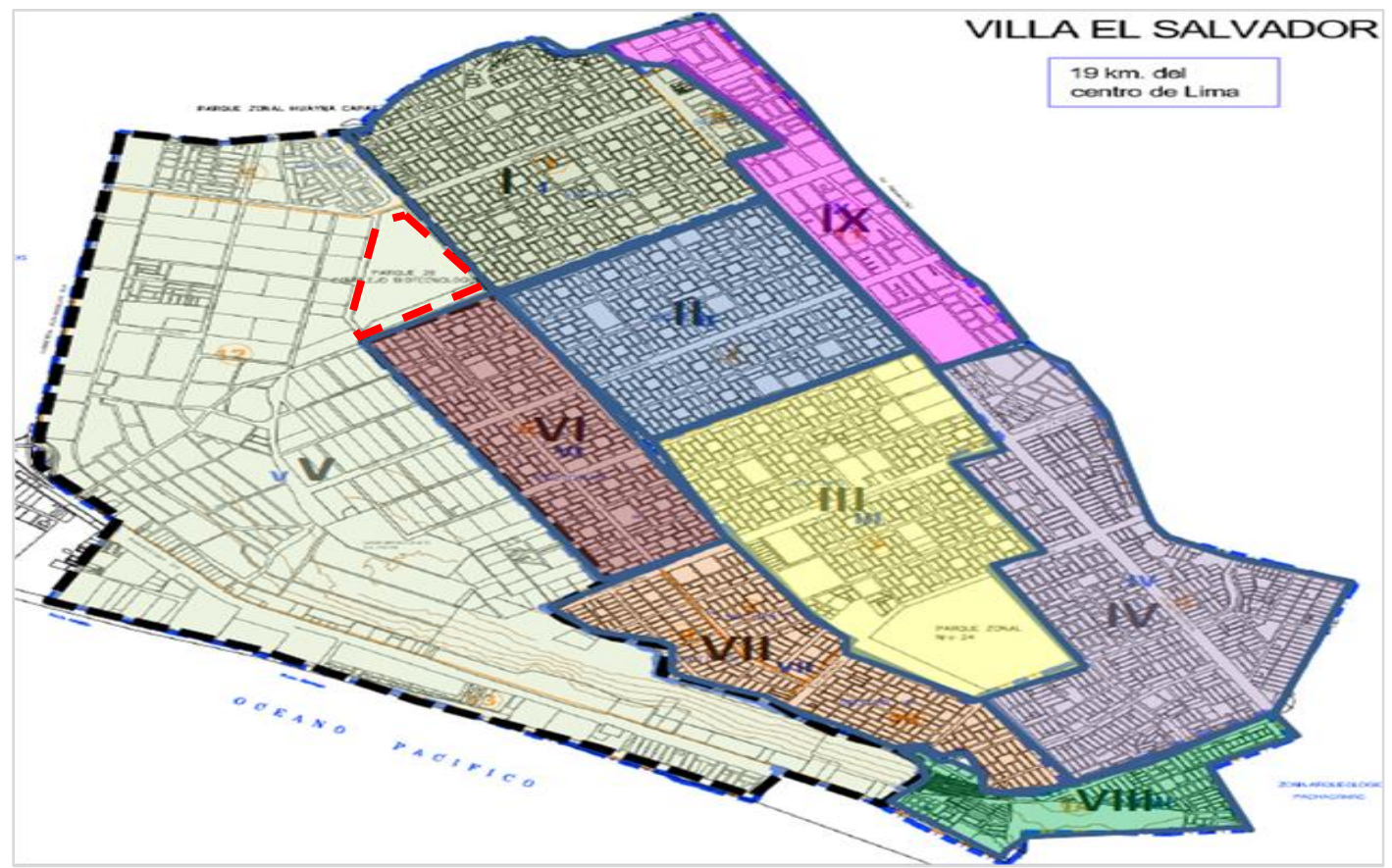

Fuente: Reajuste Integral Zonificación del V territorio de Villa el Salvador, Ministerio de transporte y comunicaciones, 2017.

El proyecto se localiza puntualmente en un terreno del sector $\mathrm{V}$ antes totalmente un parque zonal denominado Parque Zonal $N^{\circ} 26$ Complejo Biotecnológico, terreno que cambio de zonificación por la resolución Suprema $N^{\circ}$ 002-2016-VIVIENDA al construirse la actual Villa Panamericana. Los terrenos de intervención son los lotes colindantes de la Villa Deportiva Panamericana o Villa de atletas, definido en el Plan de desarrollo concertado del distrito de Villa El Salvador 2017-2021.

Figura 72. Villa deportiva Panamericana en el distrito Villa el Salvador.

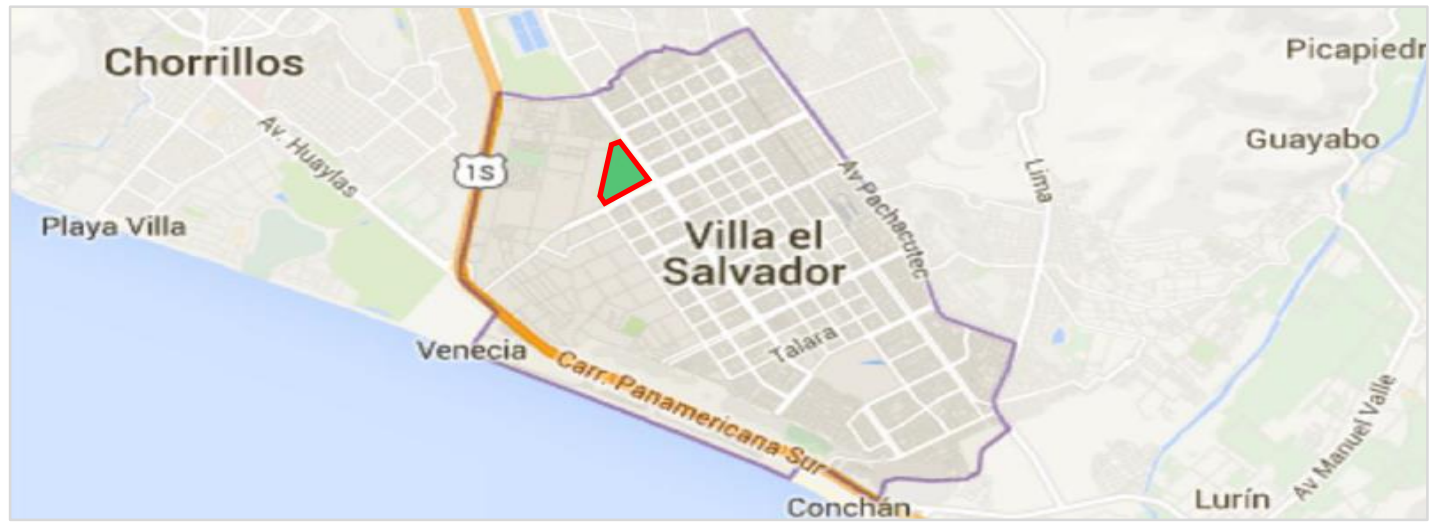

Fuente: Google Maps, 2020. 
Figura 73. Villa deportiva Panamericana en el terreno

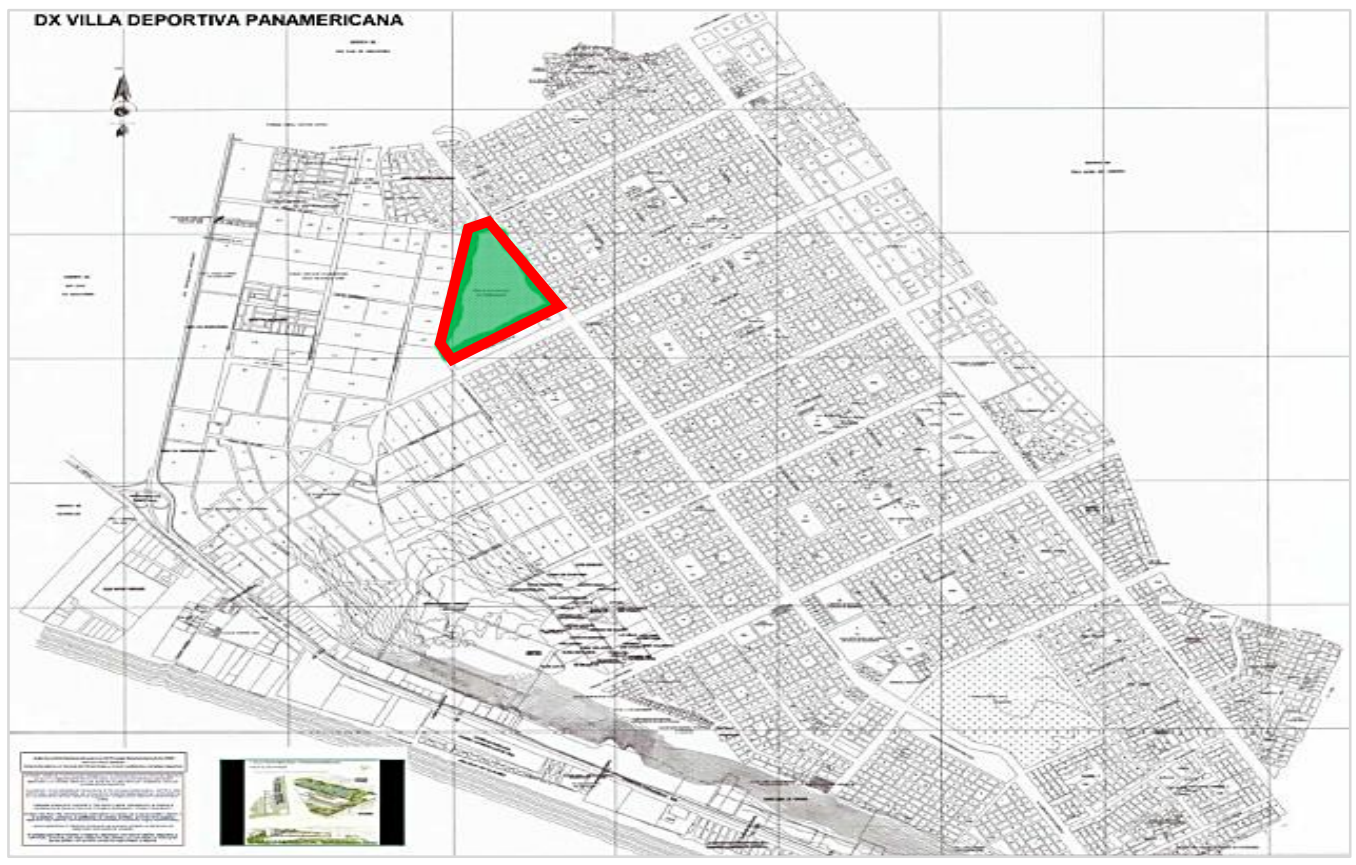

Fuente: Municipalidad de Villa El Salvador. Plan de desarrollo concertado del distrito de Villa el Salvador, 2016.

\section{¿Qué tipo de zonificación tiene el terreno del proyecto?}

El terreno en suma agrupa varios tipos de zonificación; entre los que están Zona de Recreación Pública (ZRP), Otros Usos (OU), Residencial de Densidad Media (RDM), Residencial de Densidad Media (RDM-E), Comercio Zonal (CZ) y Educación Básica (E1).

Figura 74. Plano de Zonificación del terreno ubicado en Villa el Salvador.

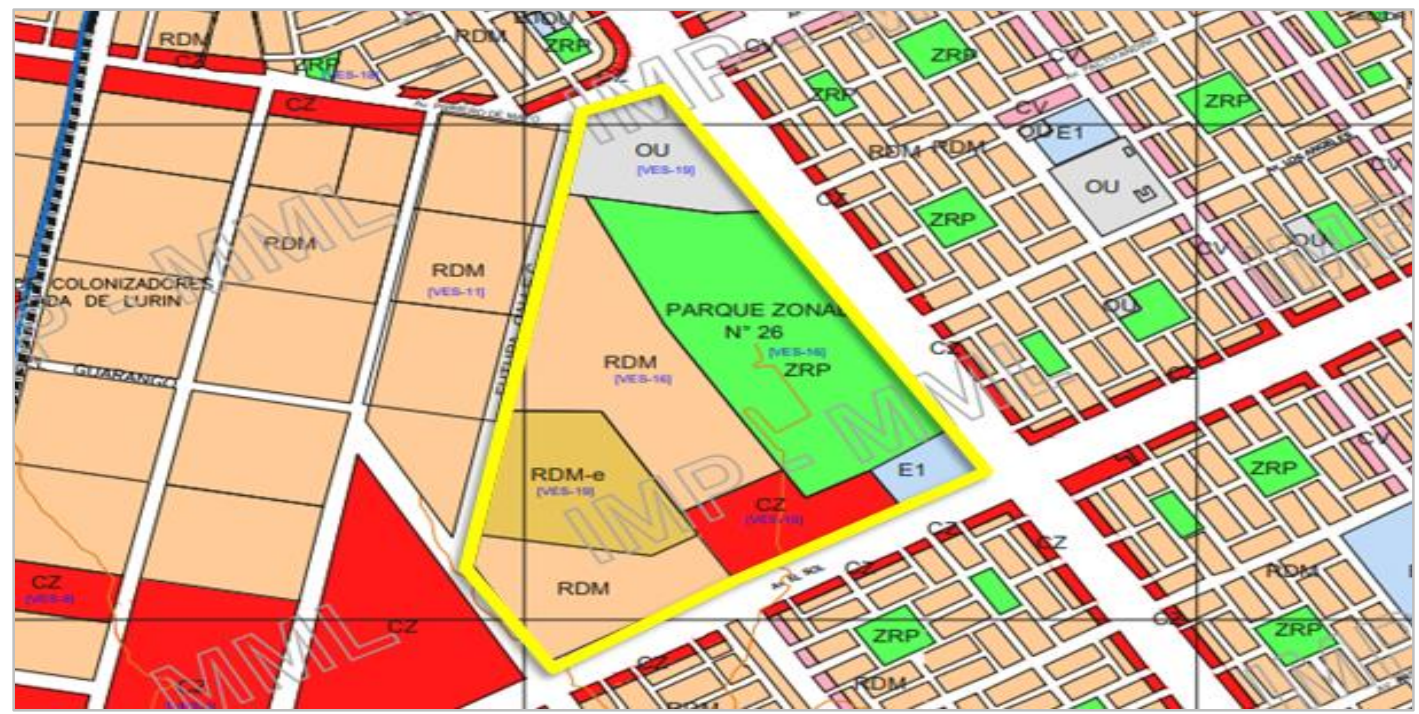

Fuente: Instituto Metropolitano de Planificación. Plano de Zonificación de Lima Metropolitana Villa EI Salvador. MVES, 2020. 


\section{¿Cuáles son las dimensiones del terreno del proyecto?}

El terreno tiene un área total de $449227,80 \mathrm{~m} 2$ o $44.9 \mathrm{Ha}$, y un perímetro de $3.215,37 \mathrm{ml}$. Sus linderos se detallan a continuación:

$\checkmark$ Norte: Colinda con TERCEROS con línea continua del tramo 12-13 con $130.35 \mathrm{ml}$.

$\checkmark$ Sur: Colinda con TERCEROS con línea quebrada de 7 tramos del tramo 1-2 con $149.93 \mathrm{ml}$, del tramo 2-3 con 88.05, del tramo $3-4$ con $373.57 \mathrm{ml}$,, del tramo 4-5 con $333.36 \mathrm{ml}$., del tramo 5-6 con $19.42 \mathrm{ml}$., del tramo 6-7 con $207.30 \mathrm{ml}$., del tramo 7-8 con $135.29 \mathrm{ml}$.

$\checkmark$ Este: Colinda con TERCEROS con línea continua del tramo 13-1 con $798.81 \mathrm{ml}$.

$\checkmark$ Oeste: Colinda con AVENIDA con línea quebrada de 5 tramos del tramo 8-9 con $111.12 \mathrm{ml}$, del tramo 9-10 con 230.47, del tramo 10-11 con 208.20 $\mathrm{ml}$., del tramo $11-12$ con $400.70 \mathrm{ml}$.

\section{¿Cuáles con los accesos viales con los que cuenta el proyecto?}

Tiene acceso mediante la red vial distrital y de la provincia de Lima, se accede por la Av. Mariano Pastor Sevilla, y se ubica entre la intersección con la Av. El Sol la cual será la vía más importante, ya que será la entrada principal.

Figura 75. Vías y accesos del terreno.

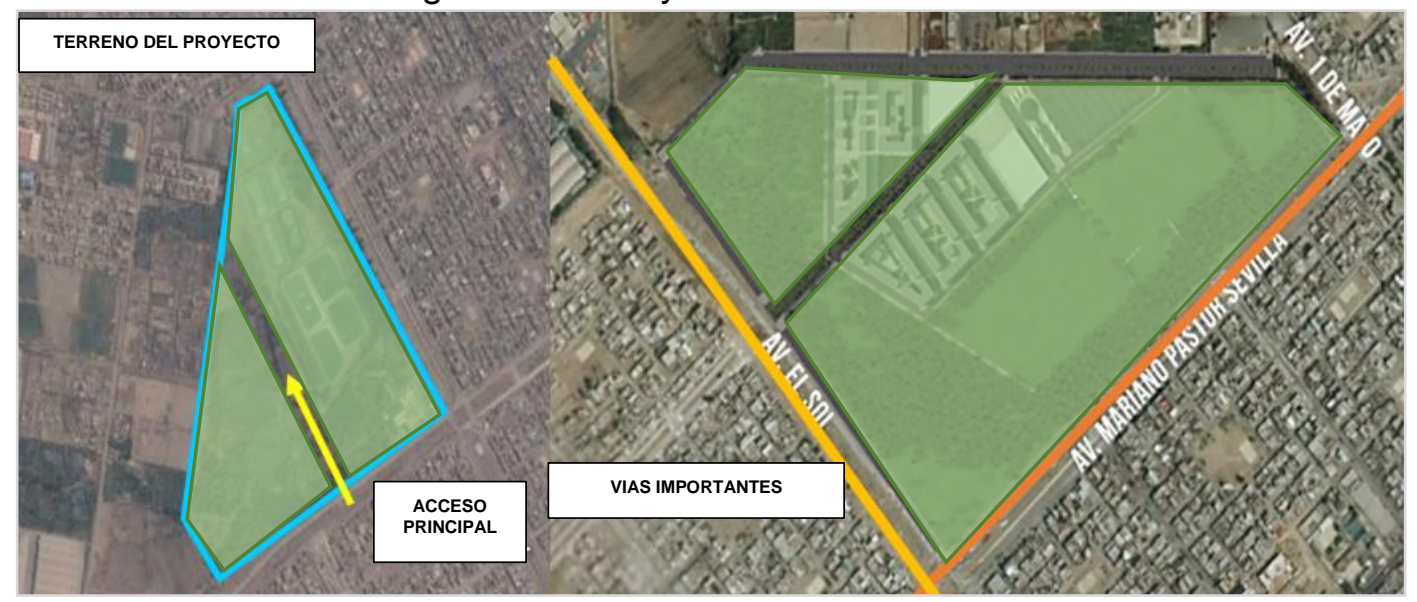

Elaboración Propia. 


\subsection{Aspectos Climáticos}

\section{¿Qué clima posee el Distrito de Villa el Salvador?}

Villa el Salvador, al pertenecer al Departamento de Lima, tiene un clima mayormente subtropical semi-desértico, con poca precipitación de lluvias (con excepción de los años de donde se tiene el Fenómeno del Niño), y condiciones de humedad elevadas, según SENAMHI (2020). Posee temperaturas anuales de $18^{\circ} \mathrm{C}$ a $19^{\circ} \mathrm{C}$ a lo largo del litoral costero. Asimismo, tiene alto nivel de nubosidad, con mayor presencia en otoño e invierno.

\section{Figura 76. Mapa Climático Nacional.}

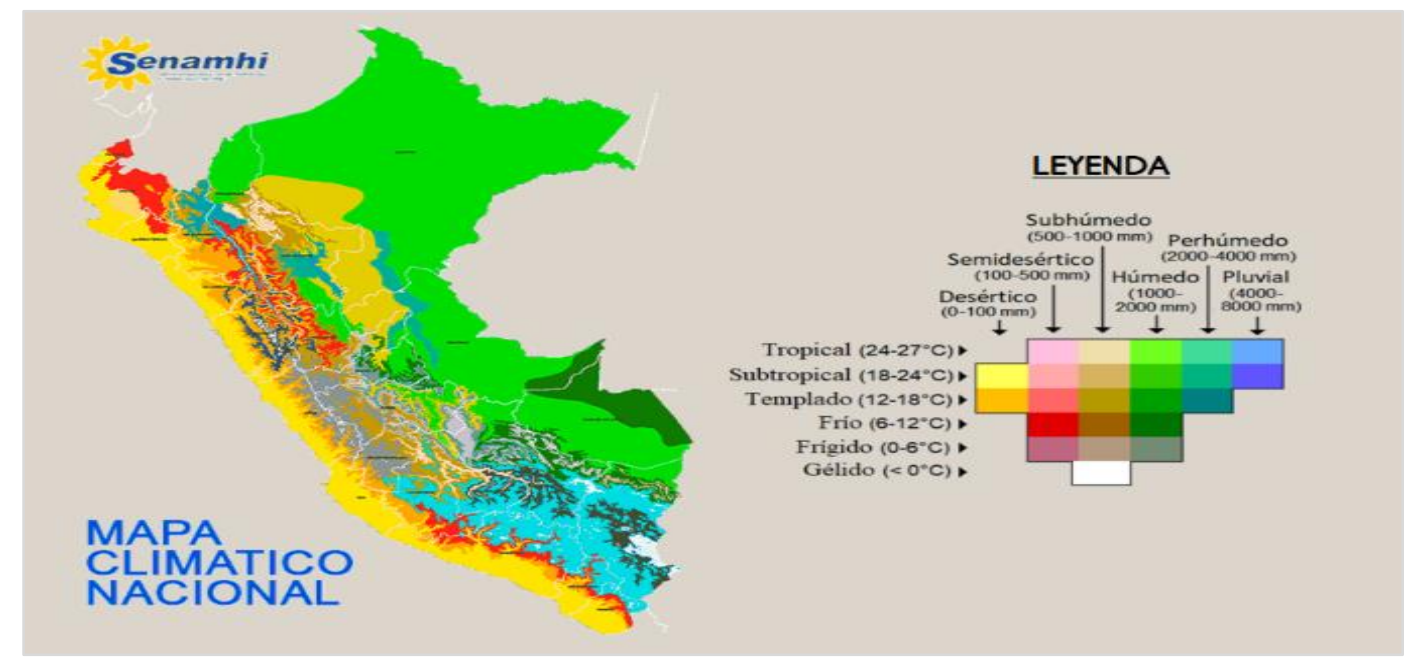

Fuente: Clima en el Perú, Mapa Climático Nacional. SENAMHI, 2020.

\subsection{Aspectos Demográficos}

\section{¿A nivel distrital cual es la principal actividad económica del Distrito de Villa el Salvador? \\ Actualmente, Villa El Salvador se caracteriza por ser el punto de gran industria y comercio, como producción de muebles, artesanías, etc. Como es de evidenciarse de acuerdo con el informe de la Municipalidad Distrital de Villa El Salvador (2006), donde predominan las actividades del Sector Terciario, con el $84,31 \%$, seguido por el Sector Secundario con $14,72 \%$ y finalmente, el Sector Primario con $0.97 \%$.}


Figura 77. Unidades Económicas según rama de actividades económicas.

\begin{tabular}{|l|l|l|}
\hline RAMAS DE ACTIVIDAD ECONOMICA & Cantidad & \multicolumn{1}{c}{$\%$} \\
\hline I. SECTOR PRIMARIO & $\mathbf{1 5 1}$ & $\mathbf{0 , 9 7 \%}$ \\
\hline Agricultura, ganadería & 147 & $0.95 \%$ \\
Explotación, minas y canteras & 4 & $0.03 \%$ \\
\hline II. SECTOR SECUNDARIO & $\mathbf{2 2 8 7}$ & $\mathbf{1 4 . 7 2 \%}$ \\
\hline Industrias Manufactureras & 2050 & $13.20 \%$ \\
Suministro de Electricidad, Gas y Agua & 2 & $1.29 \%$ \\
Construcción & 235 & $151 \%$ \\
\hline III. SECTOR TERCIARIO & $\mathbf{1 3 0 9 6}$ & $\mathbf{8 4 . 3 1 \%}$ \\
\hline Comercio & 10384 & $66.85 \%$ \\
Comercio, Reparación de Vehiculares Automotores, Motocicletas & 1125 & $7.24 \%$ \\
Hoteles y Restaurantes & 50 & $0.32 \%$ \\
Intermediación Financiera & 382 & $2.46 \%$ \\
Actividades Inmobiliarias, Empresariales y de Alquileres & & \\
Servicios & 144 & $0.93 \%$ \\
Transporte Almacenamiento y Comunicaciones & 10 & $0.06 \%$ \\
Adm. Púb. y Defensa, Planes de Seg. Social de Afiliación Obligatoria & 131 & $0.84 \%$ \\
Actividades de Enseñanza & 184 & $1.18 \%$ \\
Servicios Sociales y de Salud & 686 & $4.42 \%$ \\
\hline Otras Actividades de Serv. Comunitarios Sociales y Personales & & \\
\hline IV. NO ESPECIFICADO & $\mathbf{1}$ & $\mathbf{0 . 0 1 \%}$ \\
\hline (No especificado) & $\mathbf{1 5 5 3 4}$ & $\mathbf{1 0 0 . 0 0 \%}$ \\
\hline TOTAL & 1 & \\
\hline
\end{tabular}

Fuente: Diagnóstico Local Participativo del Consumo de Drogas en el Distrito de Villa EI Salvador. MVES, Villanueva, 2006.

\section{¿Cuál es la población estimada del Distrito de Villa el Salvador?}

De acuerdo a datos de XII Censo de Población y VII de Vivienda y III de Comunidades Indígenas (2017), la población de Villa El Salvador es de 393,254 habitantes, además, la población estimada de acuerdo a las Estimaciones y Proyecciones de población por departamento, provincia y distrito del Instituto Nacional de Estadística e Informática (2020) en Villa El Salvador es de 423,887 habitantes, siendo el distrito con mayor población en Lima Sur, 216,183 son mujeres representando al 51\% y 207,704 hombres el 49 por ciento de la población.

Figura 78. Situación poblacional de los distritos de Lima Sur.

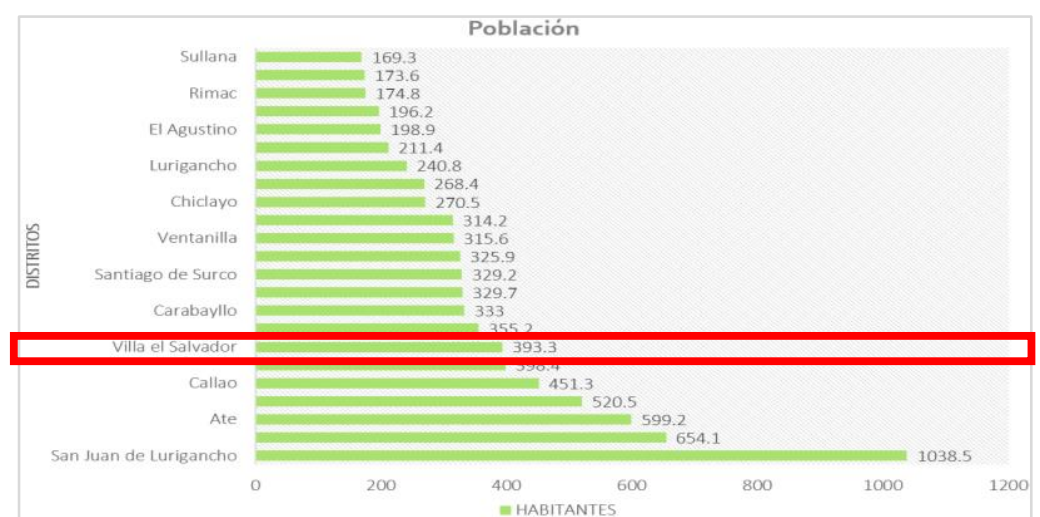

Fuente: Censos Nacionales primeros resultados, INEI, 2017. Elaboración Propia. 
Por último, se obtienen datos que para el año 2025 existe una proyección de 506,664 de habitantes de acuerdo a la publicación del boletín de estadísticas vitales del Instituto Nacional de Estadística e Informática (1995).

Tabla 9. Población actual y proyectado.

\begin{tabular}{|l|c|c|}
\hline \multicolumn{1}{|c|}{ Población } & Hab. 2020 & Proyección 2025 \\
\hline Villa el Salvador & $423,887(4,6) \%$ & $506,664.00$ \\
\hline
\end{tabular}

Fuente: Estimaciones y Proyecciones de población por departamento, provincia y distrito del Instituto Nacional de Estadística e Informática - INEI, 2020.

\section{¿Cuál es la densidad poblacional en el distrito de Villa el Salvador?}

El distrito de Villa El Salvador 13,043 habitantes por $\mathrm{Km}^{2}$, de acuerdo con Lima Como Vamos (2015). Obteniendo el puesto 16 de los distritos con más $\mathrm{Hab} . / \mathrm{Km}^{2}$ a nivel de Lima Metropolitana.

Figura 79. Densidad Poblacional en distritos de Lima Metropolitana.

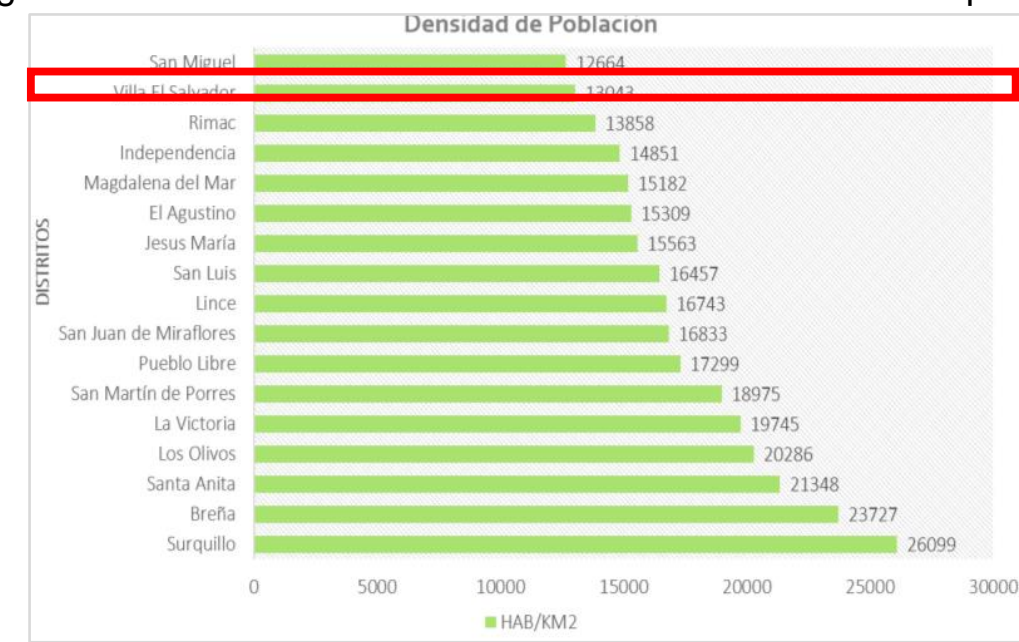

Fuente: Cómo vamos en demografía, Lima Como Vamos, 2015. Elaboración Propia.

\subsection{Aspectos Urbanísticos}

¿Cuáles son los parámetros urbanos del terreno del proyecto en el Distrito de Villa el Salvador?

La ORDENANZA №2211-MML PUBLICADA EL 29-12-19, define la modificación del plano de zonificación del distrito de Villa El Salvador, aprobado por la ordenanza № 933. Esto a partir del reajuste integral, según la ORDENANZA № 620-MML, de la zonificación de los usos del suelo de Lima Metropolitana. 
Dentro de este nuevo esquema se definen los siguientes términos de zonificación en el proyecto:

$\checkmark$ Otros Usos (OU)

$\checkmark$ Zona de Recreación Pública (ZRP)

$\checkmark$ Residencial de Densidad Media (RDM)

$\checkmark$ Residencial de Densidad Media (RDM-E)

$\checkmark$ Comercio Zonal (CZ)

$\checkmark$ Educación Básica (E1)

Figura 80. Modificación el Plano de Zonificación del distrito de Villa El Salvador.
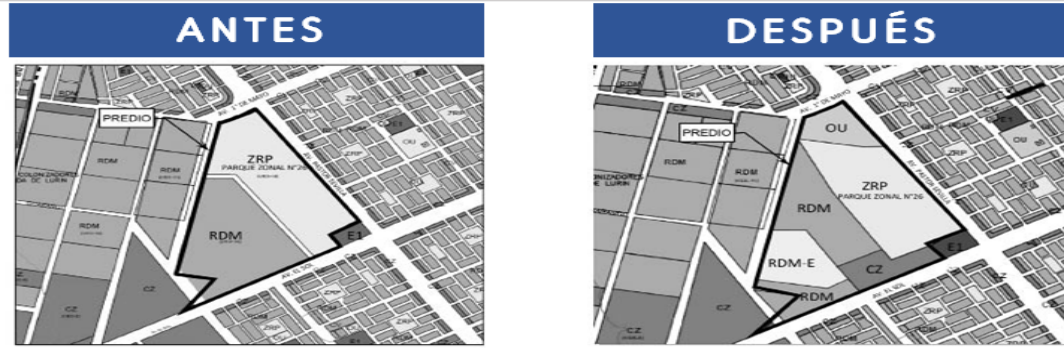

\begin{tabular}{|c|c|c|c|c|c|c|}
\hline ZONIFICACION & USOS PERMITIDOS & $\begin{array}{c}\text { LOTE } \\
\text { MINIIIMO }\end{array}$ & $\begin{array}{l}\begin{array}{l}\text { FRENTE } \\
\text { MENMIO }\end{array} \\
\end{array}$ & $\begin{array}{l}\text { ALTURA DE } \\
\text { EDIFICACION }\end{array}$ & $\begin{array}{c}\text { AREALIBRE } \\
\text { MANIIIAA } \\
\end{array}$ & \begin{tabular}{|l|} 
ESTACIO \\
NAMIENTO
\end{tabular} \\
\hline \multirow{4}{*}{ RESIDENCIAL DE DENSIDAD MEDIA (RDMa) } & UNIFAMILIAR & $90(6)$ & $\frac{6}{6}$ & 3 & $30 \%$ & 1 cada viv \\
\hline & MULTIFAMILIAR & 120 & 6 & 3 & $30 \%$ & 1 cada 2 \\
\hline & MULTIFAMILIAR & 150 & 8 & $4(5)$ & $30 \%$ & 1 cada 2 \\
\hline & $\begin{array}{c}\text { CONJUNTO } \\
\text { RESIDENCIAL }\end{array}$ & 2500 & 10 & 8 & $30 \%$ & $\begin{array}{c}1 \text { cas } \\
\text { vive } 2\end{array}$ \\
\hline $\begin{array}{l}\text { RESIDENCIAL DE DENSIDAD MEDIA CON REGLAMENTACION ESPECIAL (R) } \\
\text { E) }\end{array}$ & $\begin{array}{l}\text { CONJUNTO } \\
\text { RESIDENCIAL }\end{array}$ & 10000 & 30 & $1.5 \mathrm{a}+(7)$ & $60 \%$ & $\begin{array}{c}2 \text { cada } 3 \\
\text { vix }\end{array}$ \\
\hline
\end{tabular}

1. En áreas de asentamientos humanos ubicados en terrenos de pendiente pronunciada solo se permitirá uso residencial Unifamiliar y Bifamiliar y una altura máxima de 3 pisos.

2. En las zonas de RDM se podrá construir vivienda unifamiliar en cualquier lote superior a $90 \mathrm{~m} 2$

3. En las zonas residenciales RDM se permitirá en primer piso el uso complementario de c omercio a pequeña escala y talleres artesanales hasta un área máxima igual al $35 \%$ del área de lote, según señalado en el Índice de Usos para la Ubicación de Actividades Urb anas.

4. . Municipalidad Distrital podrá proponer requerimientos de estacionamiento distintos a los señalados en el presente cuadro, para su ratificación por la MML.

5. Para edificaciones con alturas mayores a 3 pisos se requerirá obligatoriamente la pres entación de un Estudio Geotécnico.

6. Solo se admitirán los lotes existentes menores de $90 \mathrm{~m} 2$ los cuales deberán cumplir las r ecomendaciones señaladas en el Artículo $2^{\circ}$ de la Ordenanza N ${ }^{\circ}$ 593-MML.

7. Normativa exclusiva para aplicación de la Villa Panamericana.

\begin{tabular}{|c|c|c|c|c|c|c|}
\hline \multicolumn{2}{|r|}{ ZONA } & ALTURA DE EDIFICACION & USO COMPATIBLE & TAMAAÑO DE LOTE & AREA LIBRE & ESTACIONAMAIENTO \\
\hline \multirow[b]{2}{*}{ ou } & \multirow[b]{2}{*}{ OTROS USOS } & \multirow[b]{2}{*}{ Según proyecto } & INSTITUCIONALES & \multirow[b]{2}{*}{ Existente } & \multirow[b]{2}{*}{ Según Proyecto } & \multirow[b]{2}{*}{ Según Proyecto } \\
\hline & & & \begin{tabular}{|c|} 
CENTROS DEPORTIVOS \\
TERMINALES TERRESTRES
\end{tabular} & & & \\
\hline
\end{tabular}

Fuente: Modifican el Plano de Zonificación del distrito de Villa El Salvador aprobado por Ordenanza N 620, El Peruano, 2019.

\subsection{Aspectos Socio-Económicos}

¿Cuál es el indicador del Desarrollo Humano en el distrito de Villa el Salvador?

De acuerdo con PNUD (2019), el distrito de Villa El Salvador tiene un Índice de Desarrollo Humano de 0.69. Este último agrupa una Esperanza de Vida 
(79.73 años), una población con el $74.31 \%$ de población con Educación Secundaria Completa, 9.72 años en promedio total de educación y un ingreso familiar per cápita de $\mathrm{S} / .1,441.8$.

Figura 81. Segmentos distritales en Lima Metropolitana según IDH 2019.

\begin{tabular}{|c|c|c|c|c|c|c|c|}
\hline \multirow[t]{2}{*}{ AREA } & \multicolumn{2}{|c|}{ Poblacion } & \multirow{2}{*}{$\begin{array}{c}\text { Tndice do } \\
\text { Oesarrollo } \\
\text { Humano }\end{array}$} & \multirow{2}{*}{ 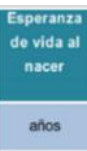 } & \multirow{2}{*}{$\begin{array}{c}\text { Con Educacion } \\
\text { socundaria } \\
\text { completa } \\
\text { (Poblac. 18 años) } \\
\%\end{array}$} & \multirow{2}{*}{$\begin{array}{l}\text { Anos do } \\
\text { educación } \\
\text { (Poblac. 25 } \\
\text { y mass) } \\
\text { anos }\end{array}$} & \multirow{2}{*}{$\begin{array}{c}\begin{array}{c}\text { Ingreso } \\
\text { tamiliar per } \\
\text { capita }\end{array} \\
\text { N.S. mes }\end{array}$} \\
\hline & habitantes & \begin{tabular}{|c|} 
\%ole Lima \\
Metopolitana
\end{tabular} & & & & & \\
\hline LIMA METROPOLITANA $1 /$ & $10,233,002$ & 100.0 & 0.7221 & 80.37 & 75.86 & 10.71 & $1,493.0$ \\
\hline LIMA & $9,188,545$ & 89.8 & 0.7255 & 79.97 & 75.96 & 10.62 & $1,530.5$ \\
\hline $\begin{array}{l}\text { Jesús Maria, Puebio Libre, Magdalena del Mar, } \\
\text { Lince, San Borja, Miratores, San Miguel, Surquilio, } \\
\text { Barranco, Santago de Surco, La Molina, San Isidro }\end{array}$ & $1,269,227$ & 12.6 & 0.8213 & 80.45 & 78.94 & 13.33 & $1,883.8$ \\
\hline $\begin{array}{l}\text { Breña, Chaclacayo, Chorrillos, Comas, El Agustino, } \\
\text { La Victoria, Lima, Los Olivos, Punta Negra, Rimac, } \\
\text { San Bartolo, San Juan de Mirantores, San Luis, San } \\
\text { Martin de Porres, Santa Anita, Santa Maria Del Mar }\end{array}$ & $3,541,074$ & 34.6 & 0.7397 & 80.34 & 77.49 & 11.00 & $1,564.0$ \\
\hline $\begin{array}{l}\text { Ato, Independencia, Lurin, San Juan de Lurigancho, } \\
\text { Villa El Salvador, Villa Maria Del Triunto }\end{array}$ & $3,060,114$ & 29.9 & 0.6945 & 79.73 & 74.31 & 9.72 & $1,441.8$ \\
\hline $\begin{array}{l}\text { Ancon, Caradady lo, Crenegunla, Lungancrio, } \\
\text { Pachacamac, Pucusana, Puentio Piedra, Punta } \\
\text { Hermosa, Santa Rosa }\end{array}$ & $1,298,130$ & 12.7 & 0.6602 & 78.56 & 73.01 & 9.52 & $1,297.4$ \\
\hline
\end{tabular}

Fuente: El reto de la igualdad, PNUD, 2019.

\section{¿Cuál es el nivel socio económico de la población del distrito de Villa el Salvador?}

Según La Asociación Peruana de Empresas de Inteligencia de MercadosAPEIM (2016), el distrito de Villa el Salvador se encuentra en la Zona 9, en conjunto con Villa María del Triunfo, Lurín y Pachacamac. Esta zona agrupa mayoritariamente al nivel socio-económico "C" con un $45.7 \%$, seguido del "D" con un $36.6 \%$, el "E" con un $11.4 \%$ y el "B" con un $6.3 \%$.

Figura 82. Distribución de Niveles Socioeconómicos en Lima.

\begin{tabular}{|c|c|c|c|c|c|c|}
\hline \multirow{2}{*}{ Zona } & \multirow[b]{2}{*}{ TOTAL } & \multicolumn{5}{|c|}{ Niveles Socioeconómicos } \\
\hline & & NSE A & NSE B & NSE C & NSE D & NSE E \\
\hline Total & 100 & 4.8 & 21.7 & 42.4 & 23.8 & 7.3 \\
\hline Zona 1 (Puente Piedra, Comas, Carabayllo) & 100 & 0.5 & 10.9 & 46.6 & 29.8 & 12.2 \\
\hline Zona 2 (Independencia, Los Olivos, San Martin de Porras) & 100 & 2.0 & 23.7 & 52.1 & 19.8 & 2.4 \\
\hline Zona 3 (San Juan de Lurigancho) & 100 & 0.0 & 19.1 & 44.2 & 26.7 & 10.0 \\
\hline Zona 4 (Cercado, Rimac, Breña, La Victoria) & 100 & 4.3 & 27.1 & 44.6 & 20.2 & 3.8 \\
\hline $\begin{array}{l}\text { Zona } 5 \text { (Ate, Chadacayo, Lurigancho, Santa Anita, San Luis, EI } \\
\text { Agustino) }\end{array}$ & 100 & 2.1 & 12.3 & 42.6 & 34.0 & 8.9 \\
\hline Zona 6 (Jesús Maria, Lince, Pueblo Libre, Magdalena, San Miguel) & 100 & 13.7 & 58.0 & 22.2 & 5.4 & 0.8 \\
\hline Zona 7 (Miraflores, San Isidro, San Borja, Surco, La Molina) & 100 & 35.9 & 43.2 & 14.9 & 4.5 & 1.4 \\
\hline Zona 8 (Surquillo, Barranco, Chorrillos, San Juan de Miraflores) & 100 & 3.9 & 26.6 & 44.5 & 20.5 & 4.4 \\
\hline Zona 9 (Villa El Salvador, Villa Maria del Triunfo, Lurín, Pachacamác) & 100 & 0.0 & 6.3 & 45.7 & 36.6 & 11.4 \\
\hline $\begin{array}{l}\text { Zona } 10 \text { (Callao, Bellavista, La Perla, La Punta, Carmen de la Legua, } \\
\text { Ventanilla) }\end{array}$ & 100 & 1.2 & 19.7 & 44.3 & 23.8 & 11.1 \\
\hline Otros & 100 & 0.0 & 8.1 & 47.6 & 25.4 & 18.9 \\
\hline
\end{tabular}

Fuente: APEIM (2016). Niveles Socio-económicos 2016. APEIM. 


\subsection{Aspectos Normativos y Legales}

¿Qué requerimientos deben cumplir los establecimientos para ser accesibles para toda la población?

Se deben tomar en cuenta las consideraciones dictadas por Reglamento Nacional de Edificaciones (2016), aprobado con Decreto Supremo № 011 VIVIENDA-2006 y actualizado con Decreto Supremo 006-2014-VIVIENDA es la Norma A.120 Accesibilidad para personas con discapacidad y de las personas adultas mayores, donde se definen criterios que proporcionan a la arquitectura el porcentaje adecuado de rampas, los anchos mínimos en los pasadizos, entre otros.

\section{¿Qué criterios deben tomarse en cuenta para el diseño bajo el enfoque de la seguridad?}

Para proporcionar seguridad en las edificaciones, se debe considerar la Norma A.130 del Reglamento Nacional de Edificaciones (2016), aprobado con Decreto Supremo № 011 VIVIENDA-2006, aquí se dictan los requisitos de seguridad y prevención de siniestros, además de la preservación del patrimonio y la continuidad edificatoria. En esta norma se agrupan los sistemas de evacuación, señalización, protección anti-incendios, entre otros.

\section{¿Qué criterios deben tomarse en cuenta para el diseño de oficinas?}

En el caso de oficinas, se debe considerar la Norma A.080 Oficinas, presente en el Reglamento Nacional de Edificaciones (2016), aprobado con Decreto Supremo Nº11 VIVIENDA-2006. En este inciso, se provee la información sobre los criterios a considerar como las condiciones de habitabilidad y funcionalidad, dotación de servicios, estacionamientos, entre otros.

\section{¿Qué criterios deben tomarse en cuenta para el diseño de establecimientos comerciales?}

En relación a espacios comerciales, se debe emplear la Norma A.070, presente en el Reglamento Nacional de Edificaciones (2016), aprobado con Decreto Supremo No 011 VIVIENDA-2006 y actualizado con Decreto Supremo 006-2014-VIVIENDA. En este, se establecen los lineamientos para 
los distintos tipos de locales comerciales, ya sean individuales 0 conglomerados.

\section{Equipamiento Comercial y Empresarial entorno a la Villa Panamericana en} Villa el Salvador.

\subsection{Introducción.}

El proyecto está ubicado en el distrito de Villa el Salvador, en la provincia de Lima, departamento de Lima, Perú. Se encuentra en un área urbana consolidada, aledaño a la Villa Panamericana, terminada de construir en el año 2019. En primera instancia, se ha realizado un análisis urbano, identificando las principales vías de acceso y transporte público; así también, los puntos urbanos de interés a nivel distrital y metropolitano. Con dicha información se concibió una propuesta de Planteamiento Integral, que sustente la viabilidad del proyecto, en relación a los factores logístico, social, territorial y urbano.

Si bien, la trama urbana de Villa el Salvador actualmente refleja el legado de la planificación diseñada por el arquitecto Miguel Eugenio Romero Sotelo, con el paso de los años, la población ha crecido en cantidad y, en paralelo, en necesidades. En ese contexto, el masterplan urbano propuesto promueve el mejoramiento de la infraestructura de recreación, el equipamiento comercial y empresarial; a fin de beneficiar las actividades económicas y sociales; asimismo, promover la participación ciudadana que no solo impactan como beneficio a un nivel distrital, sino también metropolitano.

\subsection{Planeamiento Integral.}

\subsubsection{Antecedentes.}

Villa El Salvador remonta su formación a inicios de 1970, cuando habitantes de Pamplona, se trasladaron hasta allí, para terminar, estableciéndose informalmente. Fue hasta 1971, que su planificación urbana llegaría, de las manos del Arq. Miguel Romero Sotelo, volviéndose un modelo de urbe y de autogestión, a nivel latinoamericano y mundial. 
Asimismo, Villa El Salvador es un distrito que pertenece a la unidad de Lima Sur, siendo un punto que mantiene gran conectividad vial y con acceso al Tren Eléctrico, siendo aspectos a favor de su desarrollo actual y futuro, a nivel metropolitano.

A la actualidad, Villa El Salvador, es un distrito de gran crecimiento poblacional y donde recientemente, se inauguró la Villa Panamericana, en 2019, que sirvió de hospedaje para los atletas de los Juegos Panamericanos y Parapanamericanos. Si bien la Villa Panamericana consiguió un progreso positivo para el distrito, su impacto urbano pudo haber sido mayor, si se identificaba óptimamente las necesidades de vivienda en función al costo habitacional por metro cuadrado que requieren.

A nivel distrital, con mayor inversión en equipamiento urbano de carácter comercial y empresarial, podría ayudar evitar un posible futuro como ciudad dormitorio, el rumbo de la temática del proyecto integral es alinearse a una ciudad compacta y mixta. Tomando en consideración el PLAN 2035 Villa EI Salvador se considera uno de los nodos de Centralidad a Nivel De Lima Metropolitana integrándose a los Nodos de Lima Centro; Lima Norte, Callao y Lima Este.

\subsubsection{Características del área de estudio.}

\subsubsection{Característica de Lima Metropolitana PLAM 2035}

La ciudad de Lima hasta los años 80 se expandió desde el casco urbano hasta las periferias debido a las diversas migraciones de provincias, estas zonas crecieron con muchas deficiencias de habitabilidad y servicios básicos, alejadas de Lima Centro se les denomino los "conos" (norte, sur y este).

Desde los años 90 la población de los conos se incrementó de manera desordenada, asimismo, los centros comerciales empezaron a construirse (Jockey Plaza, Lima Norte, Plaza San Miguel, Larcomar, 
Plaza Lima Sur, etc). Esto implico en parte la descentralización del comercio que antes se centralizo en el Lima Centro.

A través de los años Lima mantuvo casi dos décadas una estructura monocéntrica, pero la misma dinámica de la población ha reestructurado el ámbito espacial, social y político del territorio convirtiéndolo en una ciudad policéntrica es decir una Lima con distintas centralidades y diferentes funciones según Pensando Lima (2009).

Figura 83. La nueva Lima policéntrica.

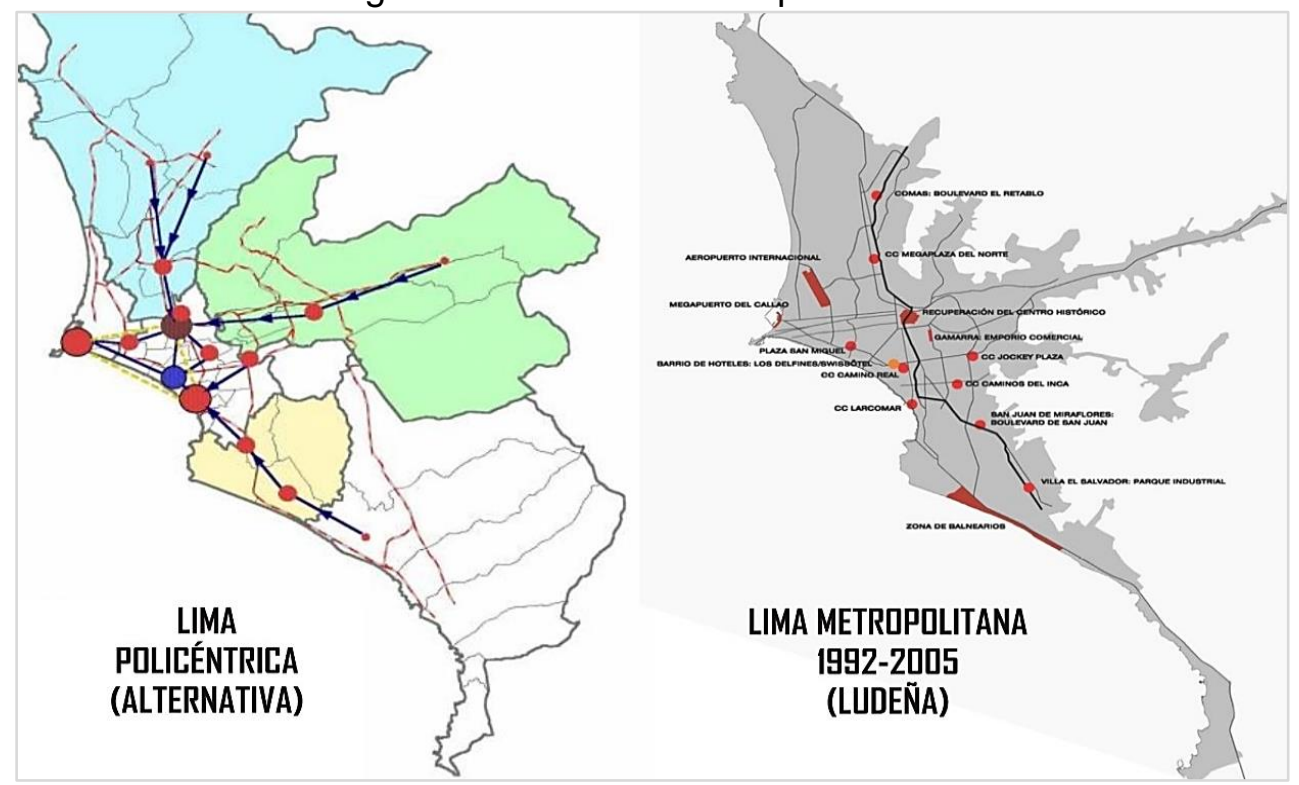

Fuente: Las Limas (y “los conos). Miguel Ludeña, 2005.

A partir del año 2000 el aumento poblacional en corredores viales desborda crecimiento de la ciudad. Aparecen nuevas centralidades. La mayor parte de las centralidades existentes de comercio o industria han surgido espontáneamente, con excepción de Ventanilla, San Luis, Santa Anita, Infantas, Naranjal y VES de acuerdo al Instituto Metropolitano de Planificación (2013).

El desarrollo de las nuevas centralidades en el cual se incluye Villa el Salvador se dio por la red vial de articulación territorial, demanda de nuevas áreas de poblaciones insatisfechas y nuevos impulsos de inversiones de entes privados o mixtos. 
A continuación, se muestran las nuevas centralidades como puntos estratégicos para población en la siguiente figura.

Figura 84. Nuevas centralidades en el área Metropolitana.

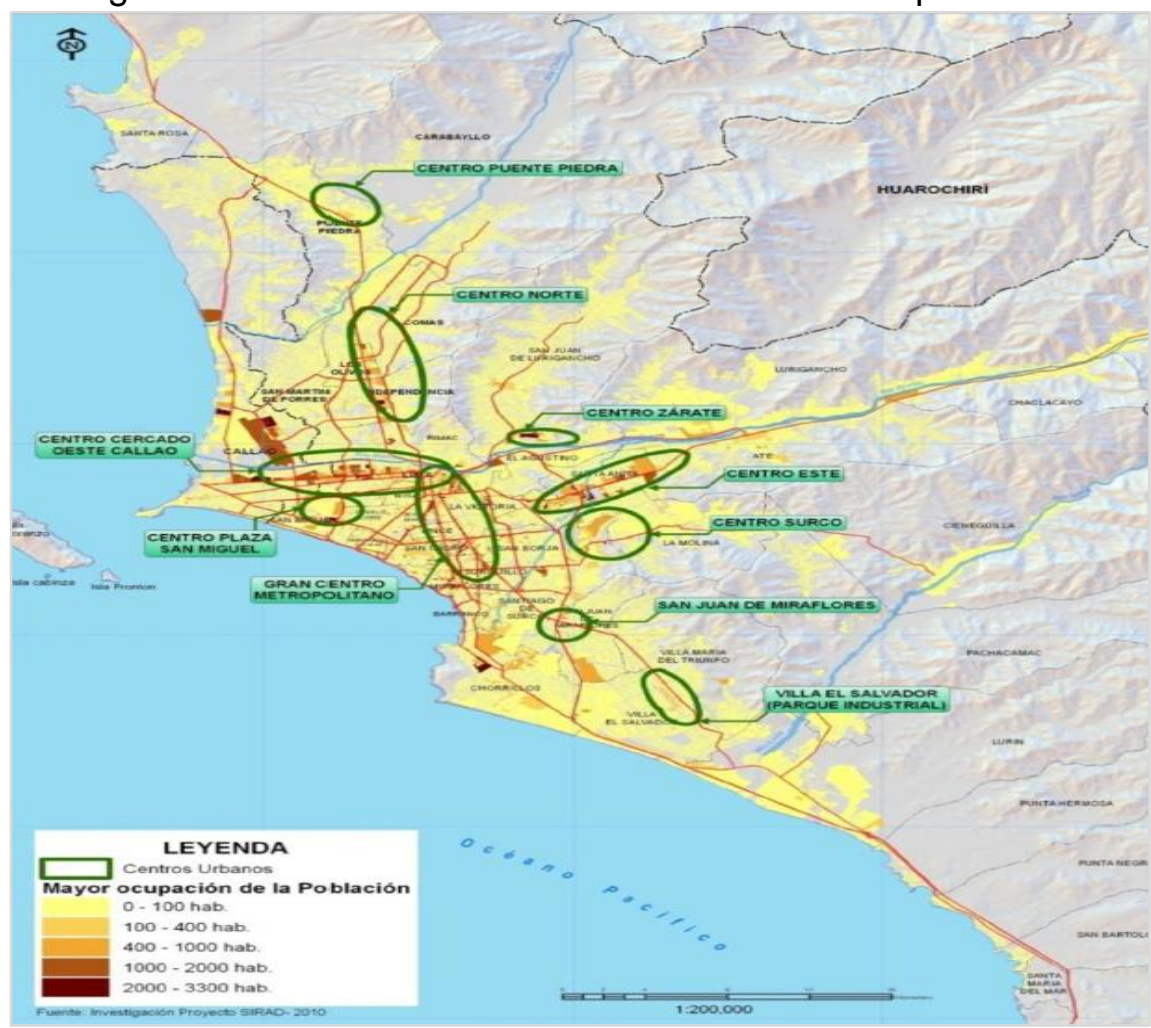

Fuente: Investigación Proyecto SIRAD e Instituto Metropolitano de Planificación, 2013.

Por ello, se analiza que Lima Metropolitana denominada ahora Lima policéntrica, da lugar a una nueva visión de reestructurarla con un planteamiento integral a largo plazo desde el año 2005 al 2035 PLAM 2035.

EI PLAM 2035 se basa en una propuesta de ordenamiento territorial y urbano para el desarrollo de Lima Metropolitana-Callao, generando la integración de los distritos que llama centralidades (Norte, sur, este), lugares que en su mayoría son poblaciones de bajos recursos. Busca las mejoras con planes estratégicos en el ámbito socio económico, vivienda, educativo, salud, servicios básicos, comercio e industria, preservando el medio ambiente con implementación y mejora de las áreas verdes de acuerdo a unos lineamientos importantes, ciudad 
justa e incluyente, ciudad patrimonial y creativa, ciudad sostenible y resiliente, ciudad compacta, integrada y policéntrica, ciudad región, ciudad competitiva y ciudad planificada y gobernable.

Asimismo, uno de los planes más importantes es la intervención en red vial que se planifico una articulación vial de líneas férreas, metros, buses Metropolitano y alimentadores, transporte del sector privado y ciclovías para una mejor conectividad disminuyendo el tiempo de viaje, es decir, un sistema vial capaz de integrar de manera óptima y funcional a las centralidades, dentro de las cuales se encuentra Villa el Salvador.

Lo que permite analizar la factibilidad del proyecto "Mejoramiento urbanístico y equipamiento comercial - empresarial Post Panamericanos entorno de la Villa panamericana en Villa el Salvador" como parte del desarrollo de la nueva centralidad de Lima Sur asimilándose al desarrollo comercial que posee Lima Norte.

Figura 85. Desarrollo de centralidades PLAM 2035.

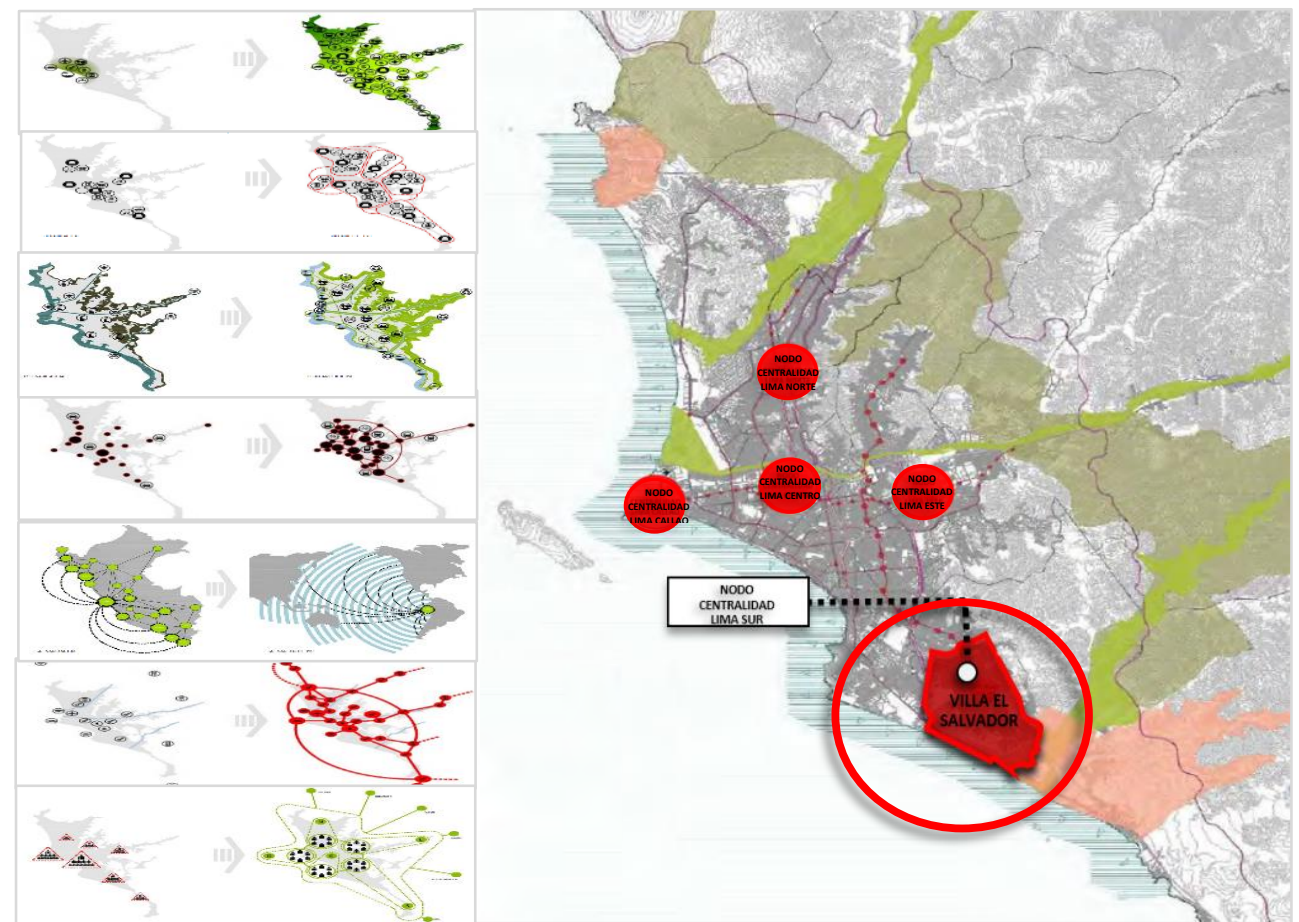

Fuente: Instituto Metropolitano de Planificación, 2014. Banco Interamericano de Desarrollo,2018. Elaboración Propia. 


\subsubsection{Característica de territorio Villa el Salvador al 2021}

El presente proyecto tiene un área de estudio a escala metropolitana y un área de intervención distrital de 44.9 hectáreas, correspondiente al Planeamiento Integral.

El concepto como distrito que en un principio fue enfocarlo a características agropecuarias, pues a pesar de ser un espacio árido disponía también espacios de áreas verdes en sus inicios incluso antes de conformase como distrito, pero no terminó con esa finalidad, todos los cambios de interacción social, nuevas actividades económicas y necesidades de la población lo determinaron actualmente como un distrito comercial que ha topado su extensión horizontal territorial y ha descuidado sus reservas de áreas verdes que poseía, a continuación se muestra Villa el Salvador a través de los años incluso antes de denominarse distrito y hasta la actualidad:

Figura 86. Proceso del suelo urbano en Villa el Salvador 1969.

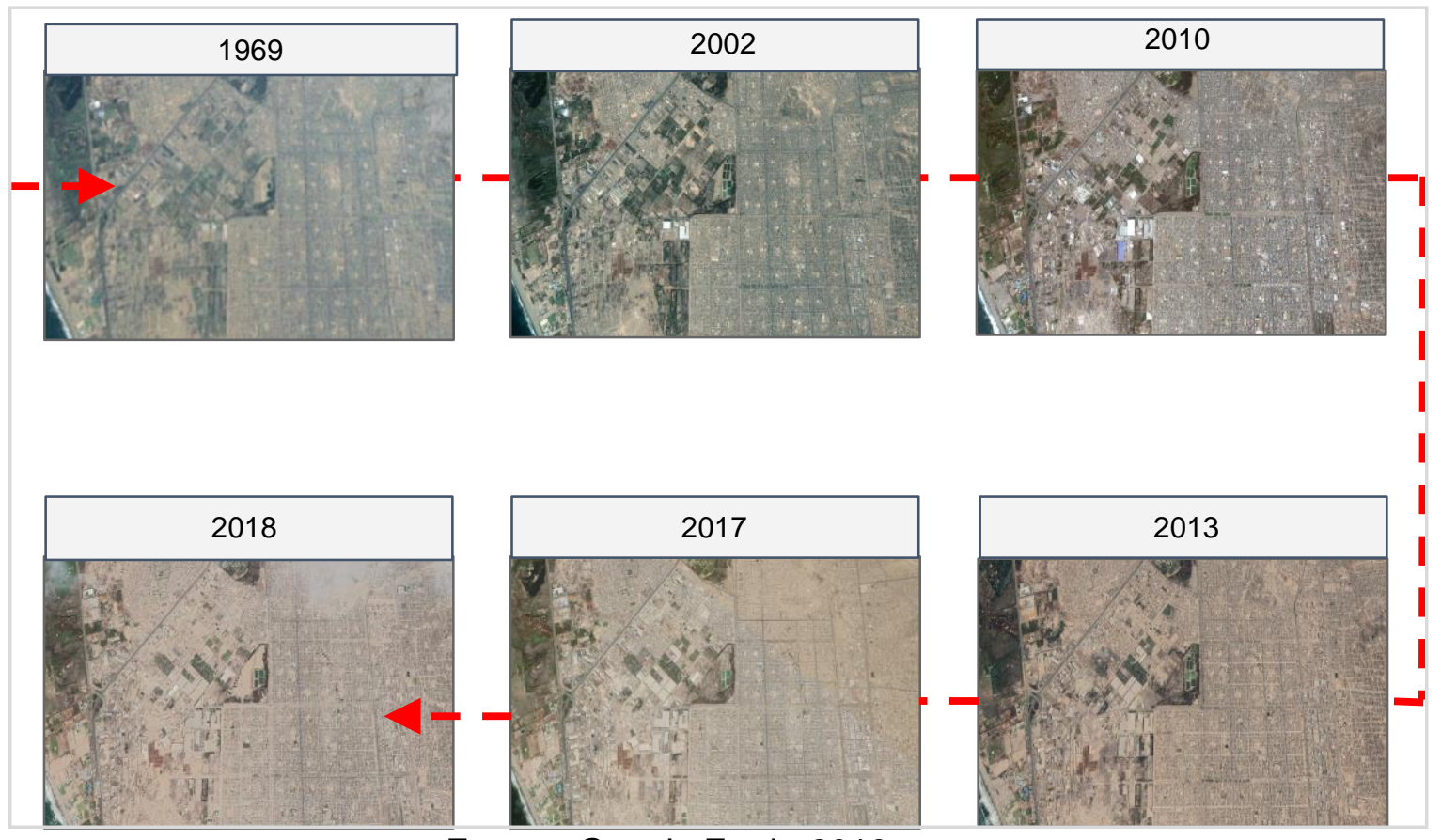

Fuente: Google Earth, 2019.

Elaboración Propia 
Cuando Villa El Salvador fue lotizado en 1971, pasó de ser de un terreno árido a un modelo de urbanismo sostenible; ya explicado anteriormente se agrupaba en 120 zonas residenciales de 16 manzanas iguales de 24 lotes cada una, con vías de secciones extensas de acceso y áreas de recreación bien definidas, siendo el grupo residencial la célula básica de su organización comunal y territorial. Esto puede verse en la siguiente figura.

Figura 87. Evolución de la zonificación de Villa El Salvador.

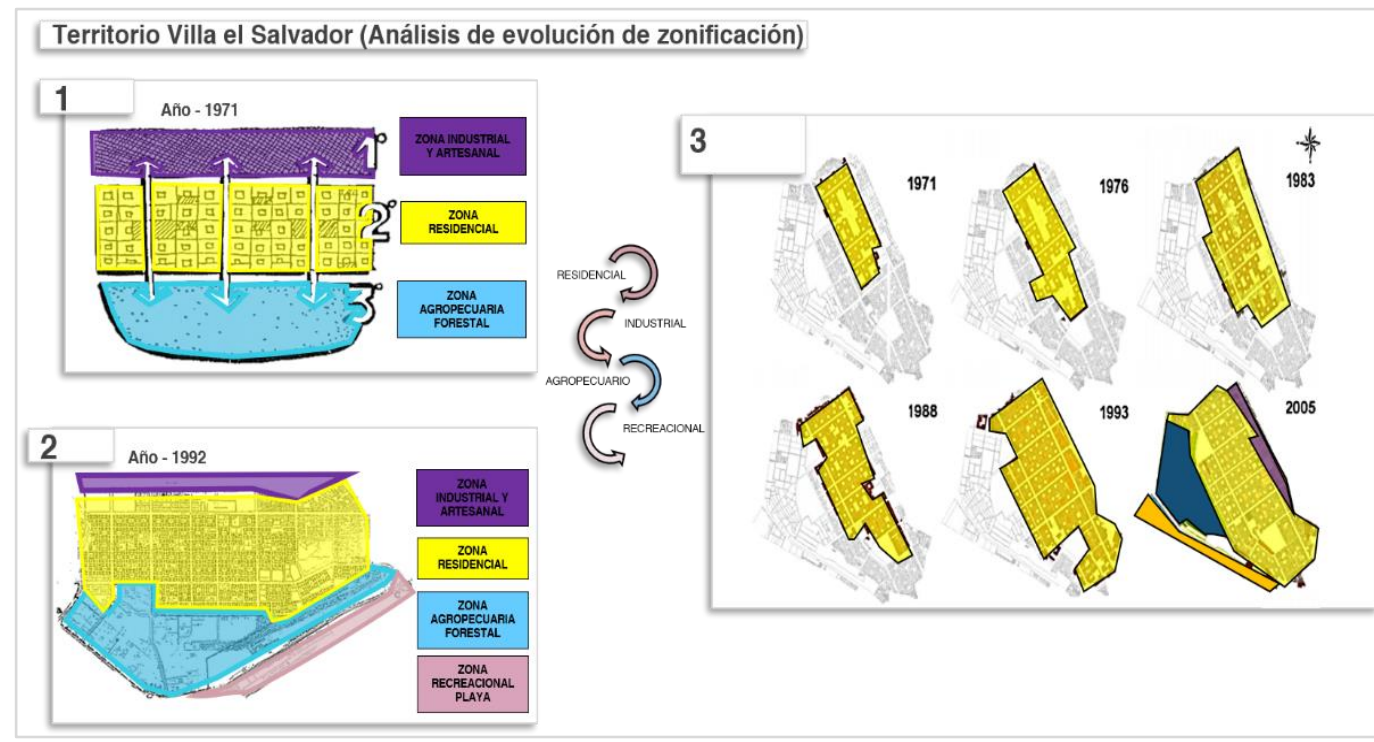

Fuente: Hábitat popular: un camino propio, Miguel Romero Sotelo 1992. $\mathrm{n}$ el paso de los años, este modelo urbano característico del distrito se consolidó con zona de industria y artesanal, zona agropecuaria forestal, residencial de densidad media con dirección a un rubro como distrito más comercial y de producción, debido a su incremento de locales comerciales en sus ejes viales.

Esta nueva característica comercial emergente del mismo distrito y también de acuerdo a la nueva visión del Plan de desarrollo local Concertado de acuerdo Municipalidad de Villa el Salvador (2016), donde fundamenta que es la característica más importante actualmente de la visión del distrito, factor importante de oportunidad para desarrollar un eje comercial en lima aumentando las plusvalías del territorio y como nuevo nodo de centralidad de acuerdo al PLAM 2035 potencialmente se 
integra a todas las redes comerciales de Lima Metropolitana, se observa en la siguiente figura la evolución del territorio:

Figura 88. Zonificación de Villa El Salvador a la actualidad.

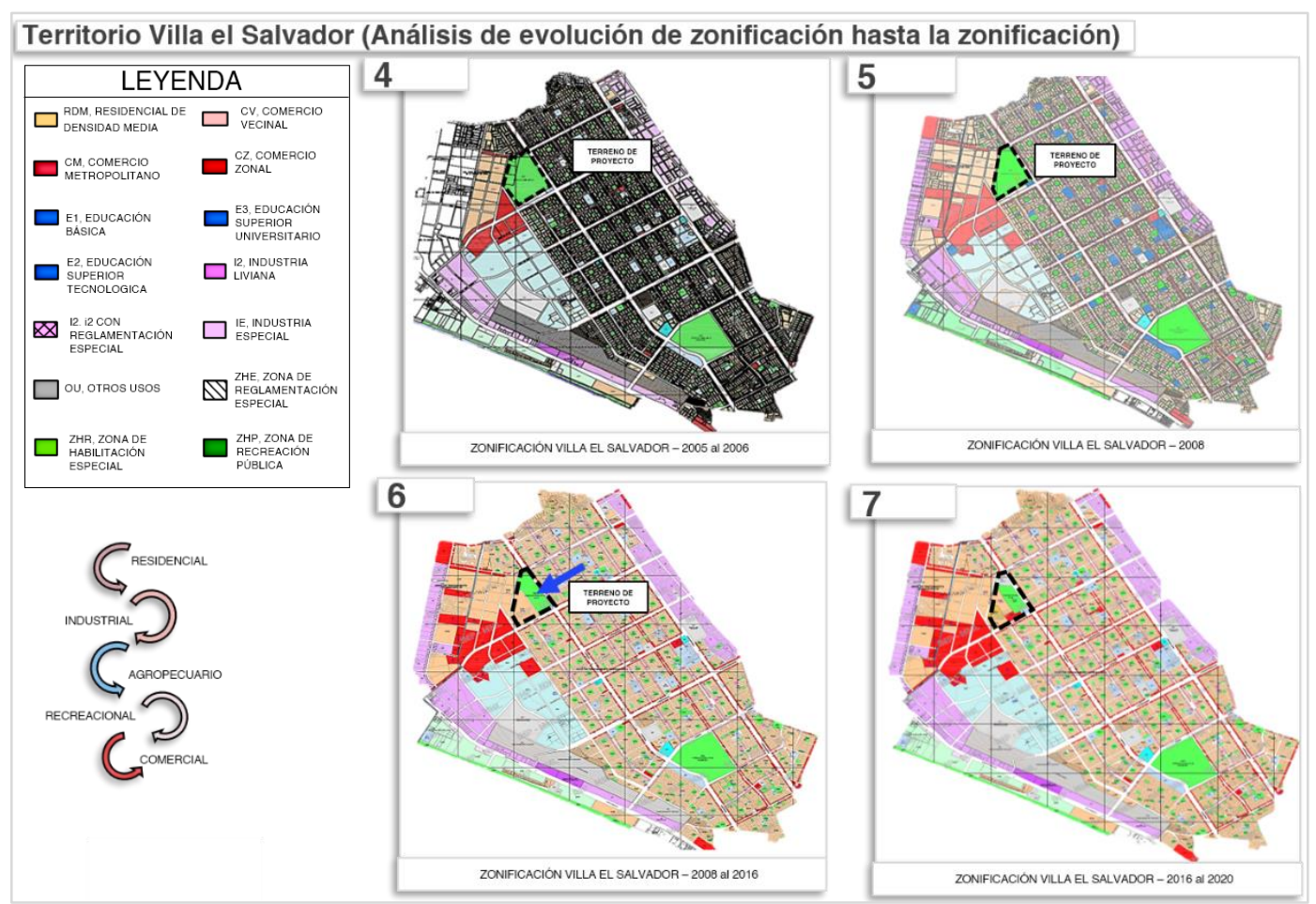

Fuente: Plan de Desarrollo Local Concertado de Villa El Salvador 20172021. Municipalidad de Villa El Salvador, 2016. Elaboración Propia.

\subsubsection{Propuesta de Planeamiento Integral.}

La propuesta evalúa las condiciones actuales de accesibilidad, primeramente, teniendo conocimiento que el distrito forma parte del nodo de conectividad Lima Sur dentro del PLAM 2035; asimismo es accesible a las redes de vías importantes existentes de todo Lima, como la Carretera Panamericana sur (vía Nacional), vías arteriales y colectoras que se integran a Lima metropolitana; además a las vías rápidas del Metropolitano y el Metro Línea 1.

El distrito que se conecta con la Línea 1 del Metro de Lima, cuenta con paraderos en el distrito con la estación Pumacahua, estación de Parque Industrial y estación Villa El Salvador, también se conectan con la estación Bayóvar (San Juan de Lurigancho), asimismo pasa por los núcleos de Lima 
Sur hasta Lima Este, y en dicha ruta igualmente por Lima Moderna. De la misma forma, posee vías alimentadoras que lo conectan a la red del Metropolitano desde el Terminal Matellini (Chorrillos) hasta el Terminal Naranjal (Los Olivos), es decir Lima Sur y Lima Norte respectivamente, pasando por Lima Centro en la misma ruta.

Se considera que el distrito se interconectará con más sistemas viales rápidos, con las líneas de metro 2 que está en ejecución y las líneas 3, 4, 5 y 6 a construirse a futuro. (Autoridad Autónoma del Sistema eléctrico de Transporte Masivo de Lima y Callao - AATE, 2020); a continuación, se muestra en la Figura 72.

Figura 89. Accesibilidad vial actual y a futuro.

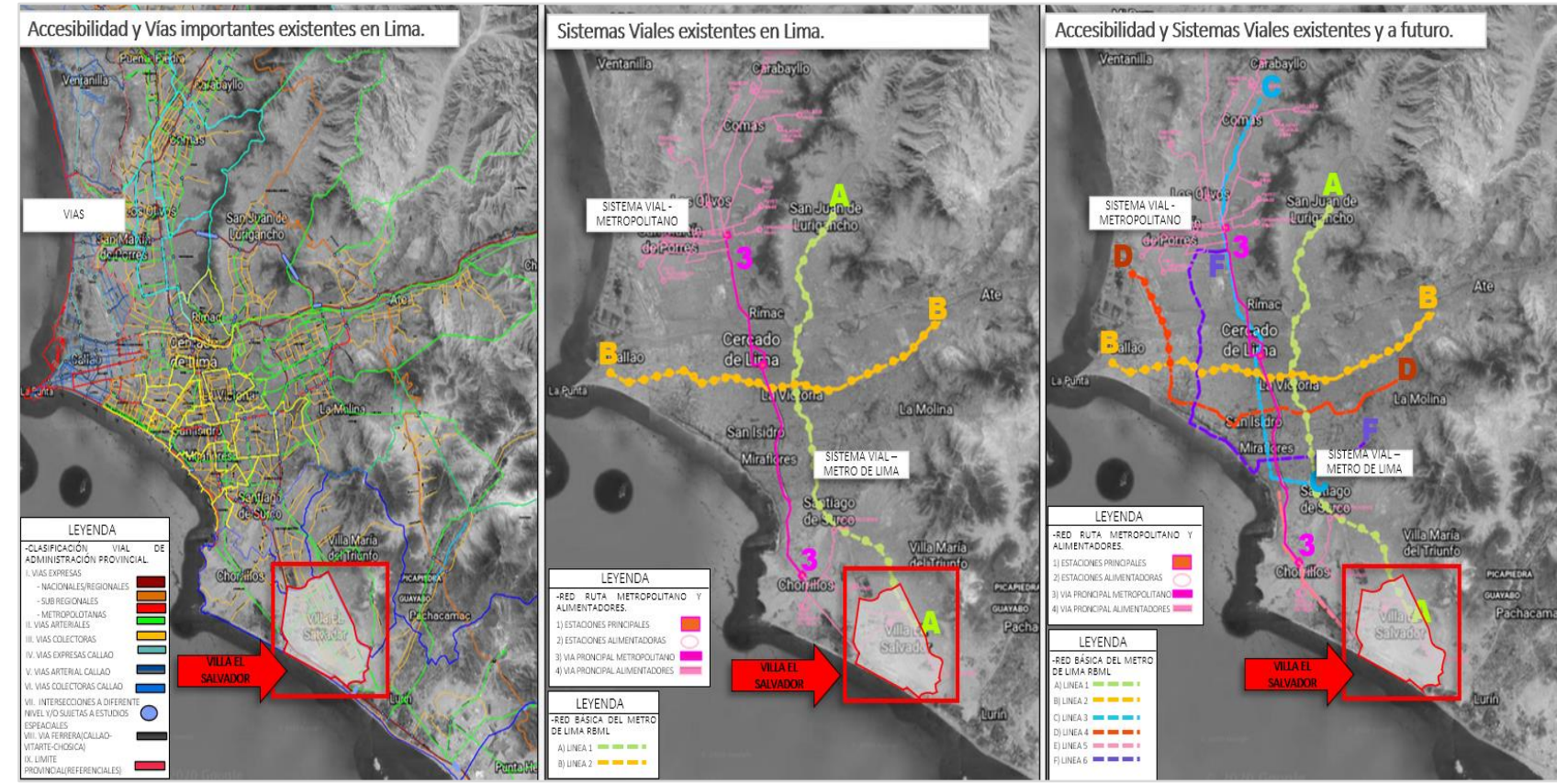

Fuente: Municipalidad Metropolitana de Lima y Autoridad Autónoma del Sistema eléctrico de Transporte Masivo de Lima y Callao, 2020. Elaboración Propia.

La propuesta de mejoramiento vial urbano partirá luego de la extensión del metropolitano por parte de la municipalidad de Lima que viene desde la vía expresa hasta intersección de Paseo de la República con República de Panamá. El punto de partida de esta intervención será la continuación de aquella extensión, que se denominará la nueva ruta que se ampliará hasta la carretera Panamericana Sur que llegará a una estación propuesta como 
estación "Pantanos de Villa" y de ese punto se conectarán con alimentadores existentes que vienen desde la estación Mantellini, y así generar mayor conectividad con Villa el Salvador con la av. El Sol, una de las avenidas más importantes del distrito que posee amplia sección vial, la misma que llega al proyecto.

Todas estas intervenciones viales se plantean como propuestas para dar mayor viabilidad y accesibilidad al proyecto de tesis, asimismo para generar un mejoramiento a nivel distrital permitiendo conexiones con otros distritos, vías que tendrán mayor soporte para los grandes flujos vehiculares actuales y del futuro, propuestas viales que servirán a todo el distrito de Villa el Salvador y también potenciará las vías importantes de lima sur, se muestra en la siguiente imagen:

Figura 90. Accesibilidad vial actual y a futuro.

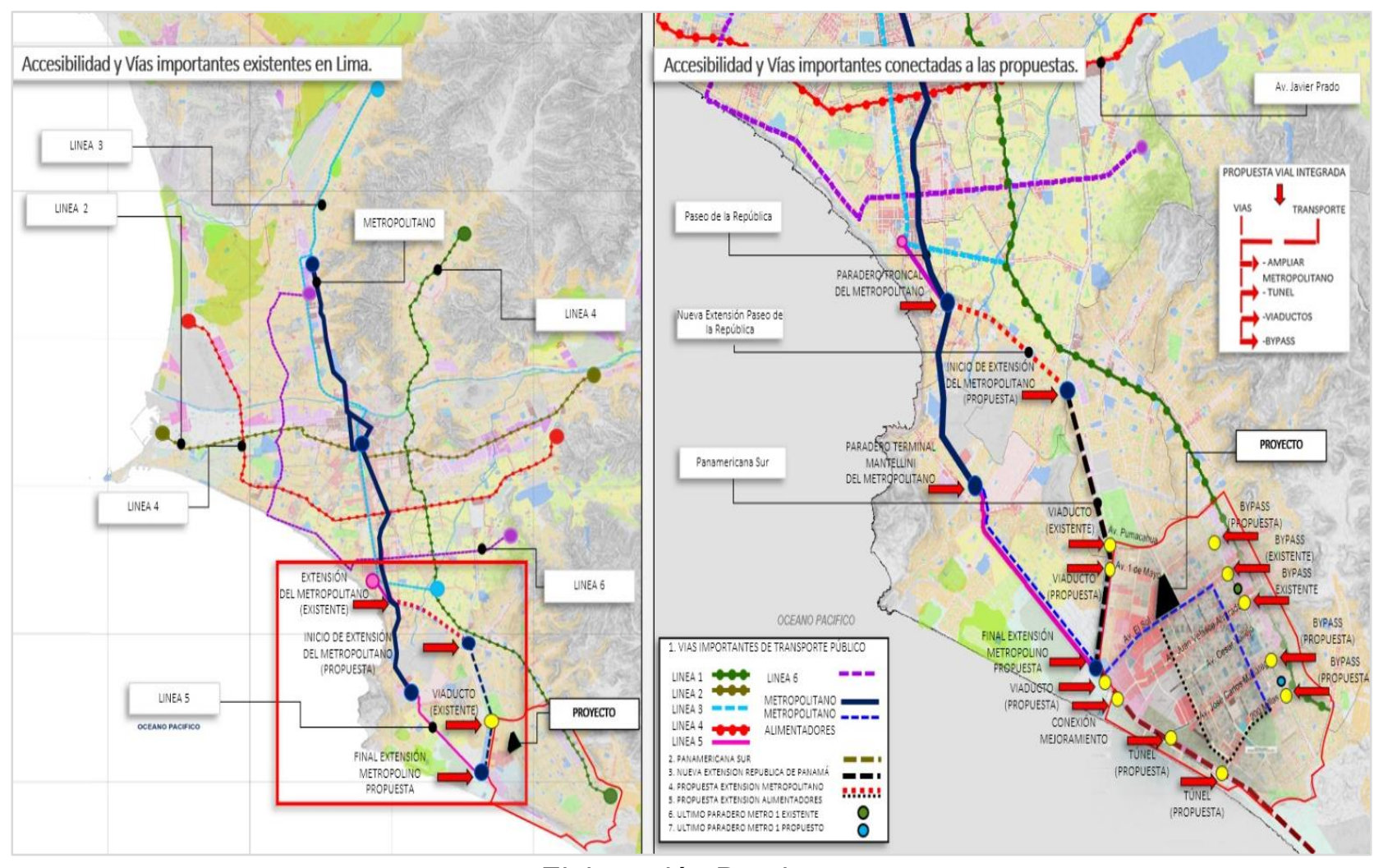

Elaboración Propia. 
Para aportar con un mejoramiento del transporte público en Villa el Salvador teniendo el previo conocimiento de la ruta del alimentador del Metropolitano y sus paraderos, se propone extender rutas adicionales en av. 200 Millas y av. Mariano Pastor Sevilla e implementar más paraderos para todos los ciudadanos que viven en Villa el Salvador y así dar mayor facilitad de conectividad al proyecto tal como se muestra en la figura....

Figura 91. Plano Sistema de transporte público (propuesta integral).

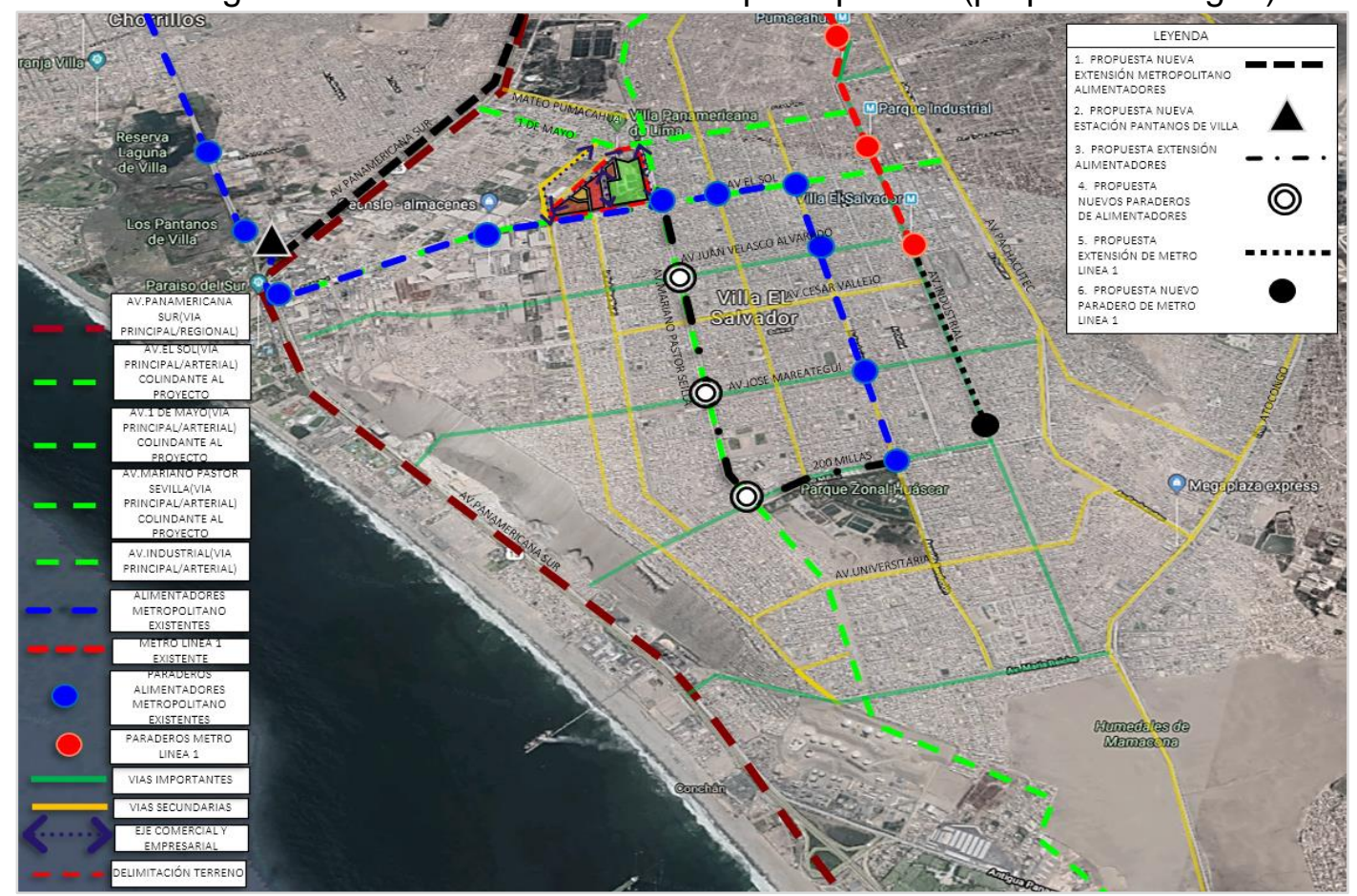

Elaboración Propia.

Asimismo, estas propuestas viales se complementan con otras que existen de movilidad sostenible urbana por temas anteriormente indicados de interconectividad. Se propone una ruta de ciclovías en Villa el Salvador con puntos de acopio y estacionamientos estratégicos, debido a que la ciclovía existente no posee una conectividad fluida en toda la trama del distrito la nueva implementación con más rutas con una totalidad de $23.6 \mathrm{~km}$ en las av. Mariano Pastor Sevilla, María Reiche, 200 Millas, Juan Velasco Alvarado y Mateo Pumacahua. Las cuales se conectarán con las ciclovías propuestas en el proyecto que detallan más adelante, se muestra en la siguiente imagen. 
Figura 92. Plano Ciclovías y propuesta (propuesta integral).

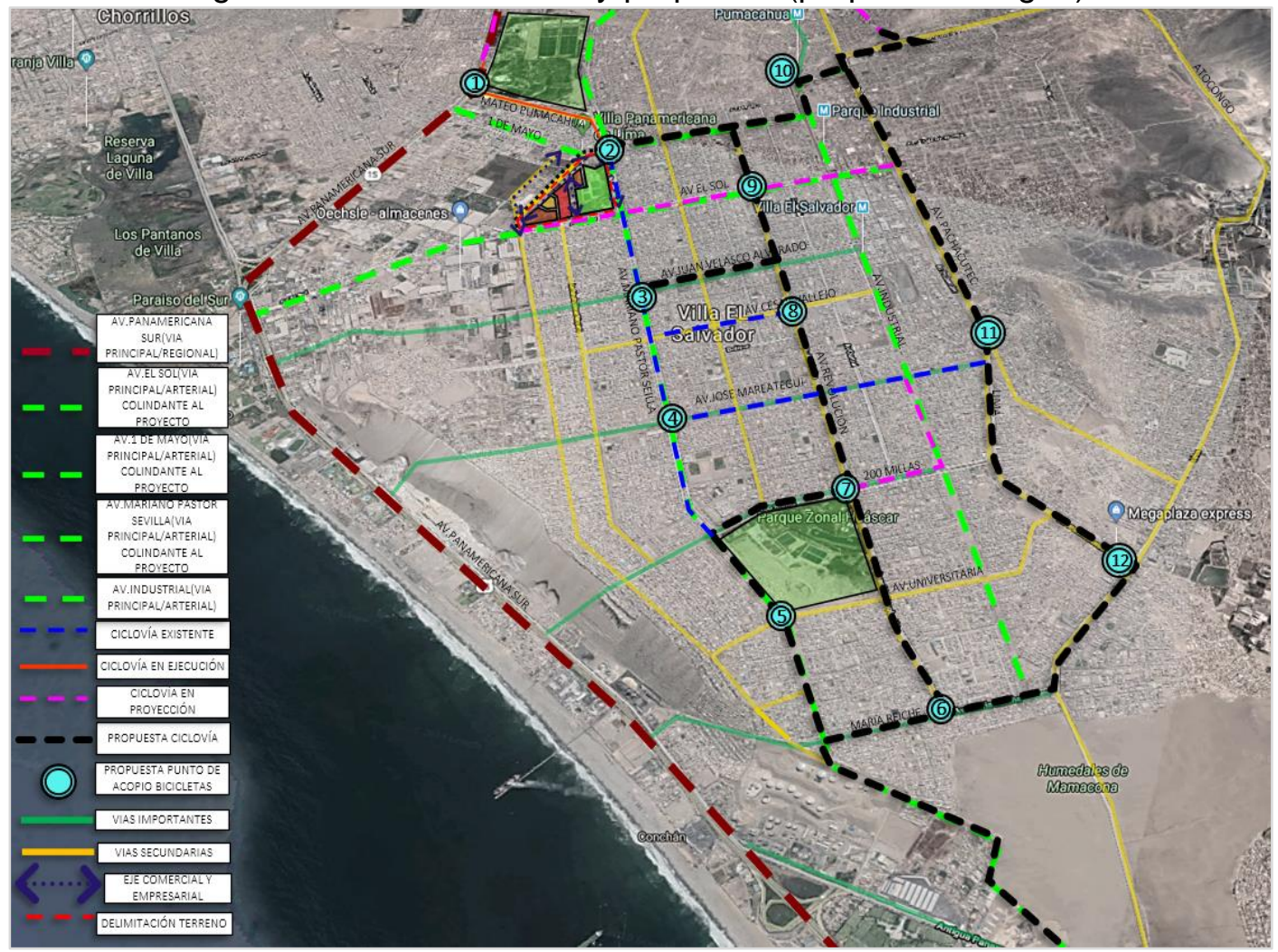

Elaboración Propia.

Teniendo en cuenta el déficit de áreas verdes por habitante existentes en Villa el Salvador es necesario mejorarlas, para incrementar la calidad ambiental del distrito y asi directamente aumentar la calidad de vida de las personas. Parte de la propuesta del planteamiento integral implementa corredores verdes de $32.81 \mathrm{~km} 2$ en las vías Juan Velasco Alvarado, Cesar Vallejo, Av. Pachacútec, Av. 200 millas, María Reiche y Pumacahua; y las vías principales que contienen al nuevo núcleo urbano propuesto con la Av. El Sol, Av. 1 de Mayo y la Av. Mariano Pastor Sevilla; siendo esta última la avenida de conexión eje a eje, entre la Villa Panamericana y el parque Zonal Huáscar, pudiendo llegar también a los humedales de Mamacona y al Santuario de Pachacamac. Se recuperará las áreas verdes en deterioro identificadas previamente para que todo el distrito se encuentre alineado a la sostenibidad con mayor porcentaje de áreas verdes, mejor calidad de aire, mayor asombramiento en las calles por el arbolado, además, de esta manera aumentar la seguridad en las calles, como se observa en la siguiente imagen. 
Figura 93. Plano Corredores Verdes (propuesta integral).

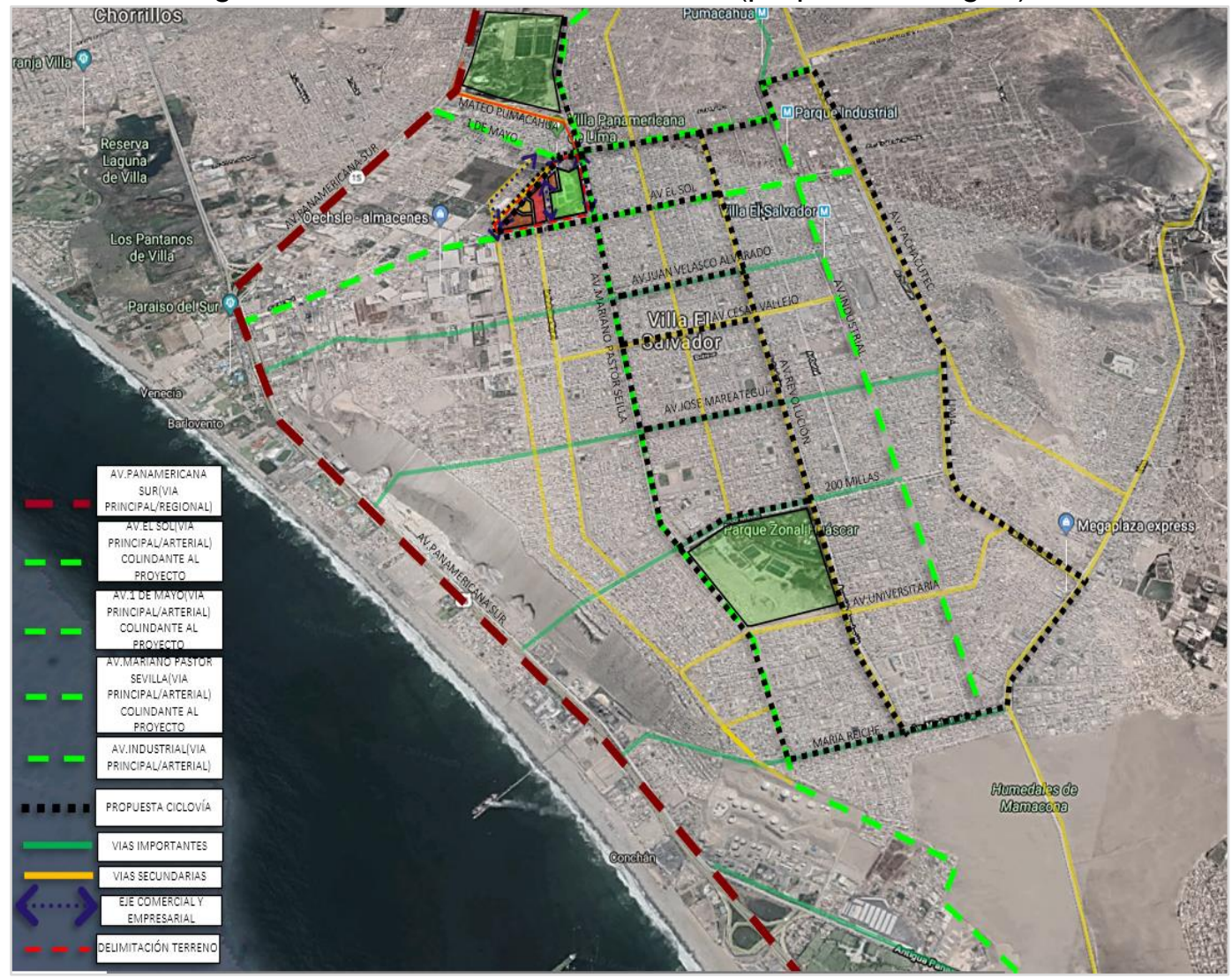

Elaboración Propia.

Para este nuevo planteamiento integral de acuerdo a las necesidades del distrito se propone una nueva zonificación teniendo en cuenta la importancia de la característica comercial que posee el distrito, la cual generará un ordenamiento territorial y plusvalías. Esta zonificación es necesaria debido a que el comercio actual que están ubicados en vías principales y secundarias se encuentran difusos y desordenados con uso de comercio vecinal. Por ello, con la nueva propuesta las vías principales pasarán a uso comercio zonal, y también se busca ordenar en el terreno del proyecto un núcleo de comercio al alcance de todos con uso de comercio Metropolitano.

Con este cambio se permitirá ordenar los ejes comerciales de todo el distrito con el propósito de dar mayor formalidad a los locales comerciales en Villa el Salvador, más valorización a los terrenos, brindando oportunidad de inversión a nuevos empresarios con el objetivo de elevar el nivel socioeconómico y laboral de la población. 
Figura 94. Plano de Nueva Zonificación Propuesta.

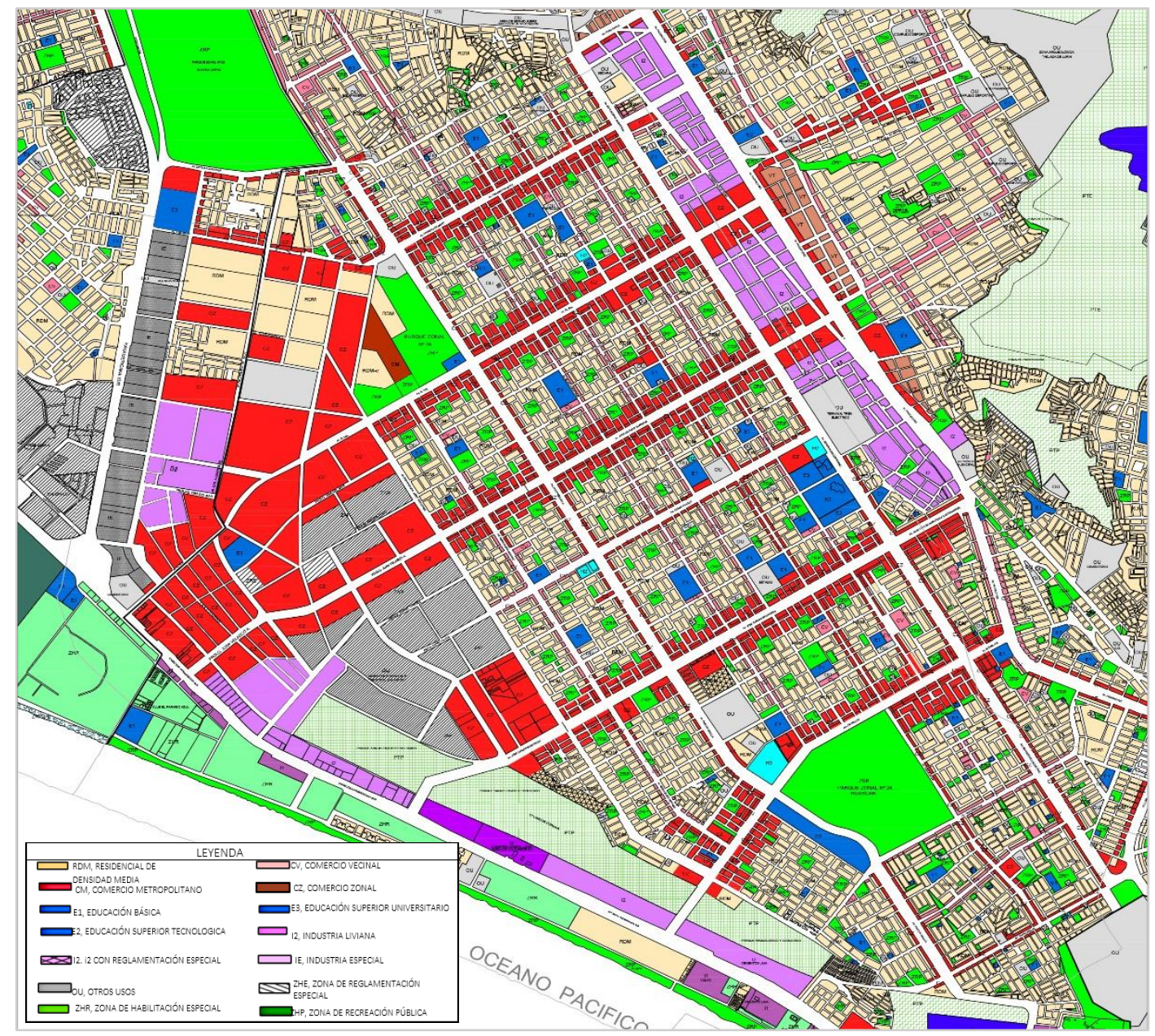

Elaboración Propia.

De acuerdo a ello, se realiza en primer lugar el desarrollo de la propuesta del Master Plan Urbano, que toma en consideración el cambio en la zonificación existente, para generar corredores comerciales a lo largo de las avenidas 1 de Mayo, EI Sol, Juan Velasco Alvarado, José Carlos Mariátegui y 200 millas.

Luego, como complemento importante propuestas de intervenciones viales que van desde viaductos, túneles, bypasses, sistema de transporte público rápidos (Metropolitano y Metros), corredores verdes, rutas para ciclistas y peatones. Con la finalidad de mejorar la trama urbana y fluidez vial en Villa el Salvador, esta propuesta dará mayor interconectividad de la trama urbana con el proyecto para potenciar aún más el territorio con la ventaja de pertenecer al nuevo nodo de centralidad Lima Sur, a continuación, se muestra en la siguiente figura: 
Figura 95. Master Plan Urbano (propuesta integral).

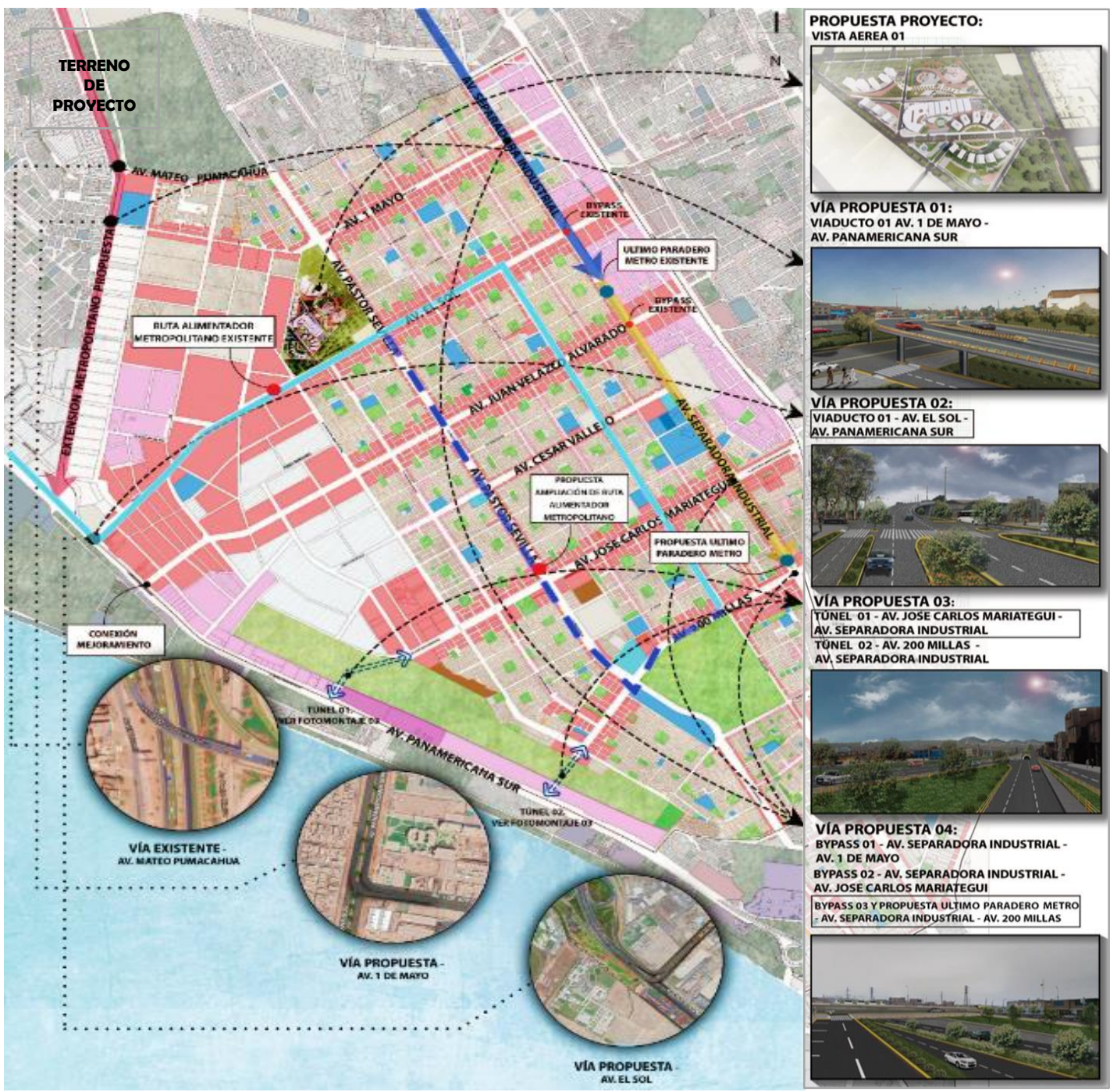

Elaboración Propia.

\subsection{Equipamiento Comercial y Empresarial entorno a la Villa} Panamericana, en Villa en Salvador.

\subsubsection{Planificación de la propuesta.}

La ubicación del proyecto de arquitectura con la denominación de "Mejoramiento Urbanístico y Equipamiento Comercial-Empresarial Post Panamericanos Entorno de la Villa Panamericana en Villa el Salvador" se encuentra donde antes fue en su totalidad como terreno el parque zonal 26 Biotecnológico. Específicamente se ubica en los lotes colindantes del nuevo edificio existente denominado Villa Panamericana, los 
cuales, una vez acabados los Juegos Panamericanos del 2019, no tienen un planteamiento de integración urbanística muy específico.

Por ello, fue viable proponer un proyecto a nivel urbano aprovechando la nueva importancia que tiene ahora Villa el Salvador luego de este gran evento a nivel mundial y considerándolo como nuevo nodo del sur de centralidad del PLAM 2035.

Figura 96. Ubicación del terreno.

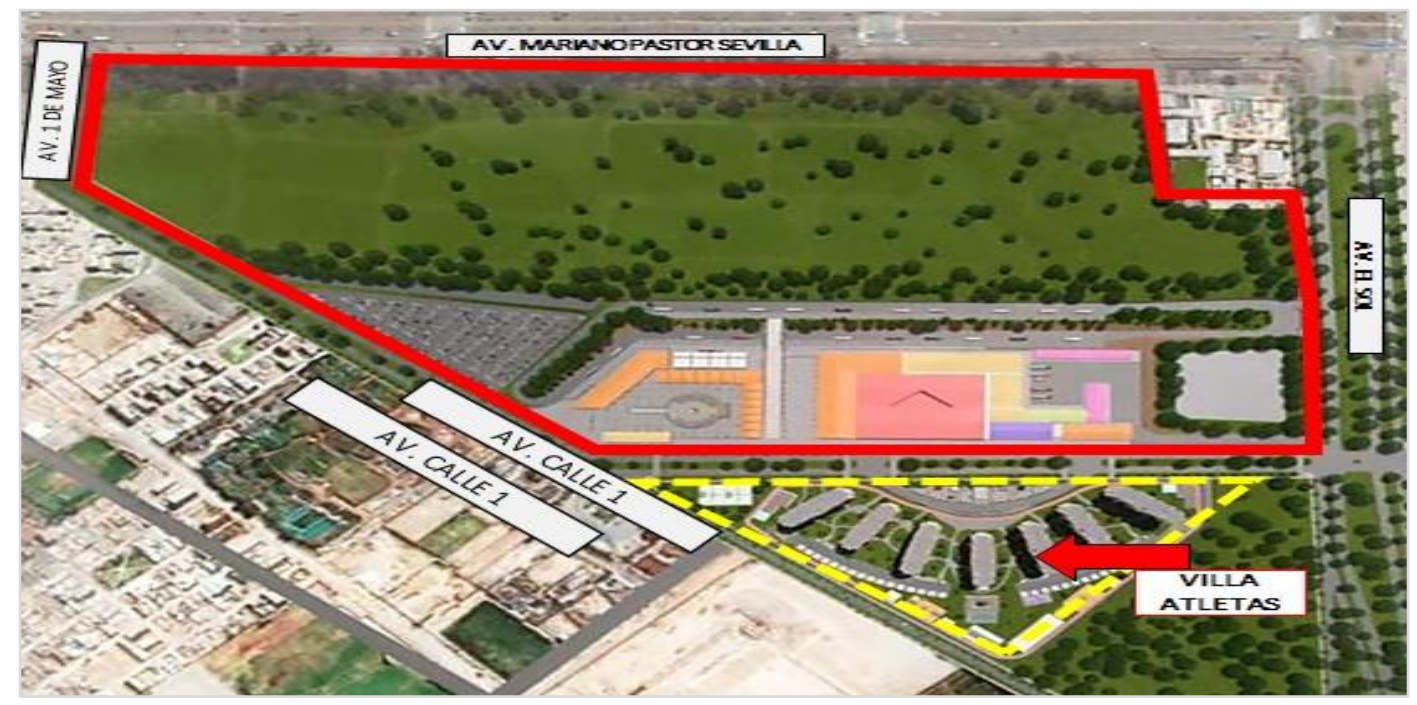

Elaboración Propia.

Asimismo, teniendo en cuenta el acondicionamiento y dinámica territorial del distrito a través de los años ha derivado en ejes comerciales difusos, esta propuesta busca ser un punto de remate y encuentro social, donde el uso propuesto que tendrá el terreno se enfoca en un centro comercial a nivel metropolitano como núcleo cubriendo el déficit comercial con un establecimiento a escala Metropolitana donde asistirán 12681 personas por día, el cual contará con 65 tiendas, tiendas anclas y espacios de esparcimiento, todos ellos integrados en un solo sitio comercial para brindar una mayor oportunidad de diversificación adquisitiva y de entretenimiento, cubriendo un $0.60 \%$ de este déficit. 
La parte complementaria correspondiente del proyecto integral destinado para el tema empresarial se cubrirá con un bloque de edificio empresarial para resolver la inexistencia de una zona empresarial que se requiere en Villa el Salvador, se resolverá un $0.35 \%$ de déficit total de empresariado con la implementación de 156 oficinas para diversos usos a disposición de muchas empresas. Además, cabe mencionar también que el proyecto se integra a los 7 bloques existentes de edificios que poseen 1096 departamentos para viviendas de la Villa Panamericana, donde se propone continuar con la propuesta de más viviendas la construcción de la segunda y tercera etapa de la Villa Panamericana de 10 bloques de 1216 departamentos de vivienda social, donde ambos en conjunto cubren con 2312 viviendas el $0.4 \%$ de este déficit.

También, en la parte de la propuesta de recreación y paisajismo se complementa con la intervención de una red de ciclovías para mejorar la conectividad de todos los equipamientos propuestos con las vías principales de av. El Sol, av. Mariano Pastor Sevilla y av. 1 de mayo; asimismo, un Parque temático, como área de recreación para el entretenimiento a nivel local y de lima sur.

En las áreas de reserva (bosques) se proponen huertos urbanos para incentivar la participación ciudadana en complemento con las plazas públicas para mayor integración con la ciudad, un espacio de encuentro de los pobladores accesible para todos, reducir niveles de inseguridad y contaminación, mejor conexión con la naturaleza y aumentar la biodiversidad, generar espacios verdes autogestionarios, educación ambiental y compromiso para generar una ciudad sostenible. 
Figura 97. Vista Aérea de la Propuesta.

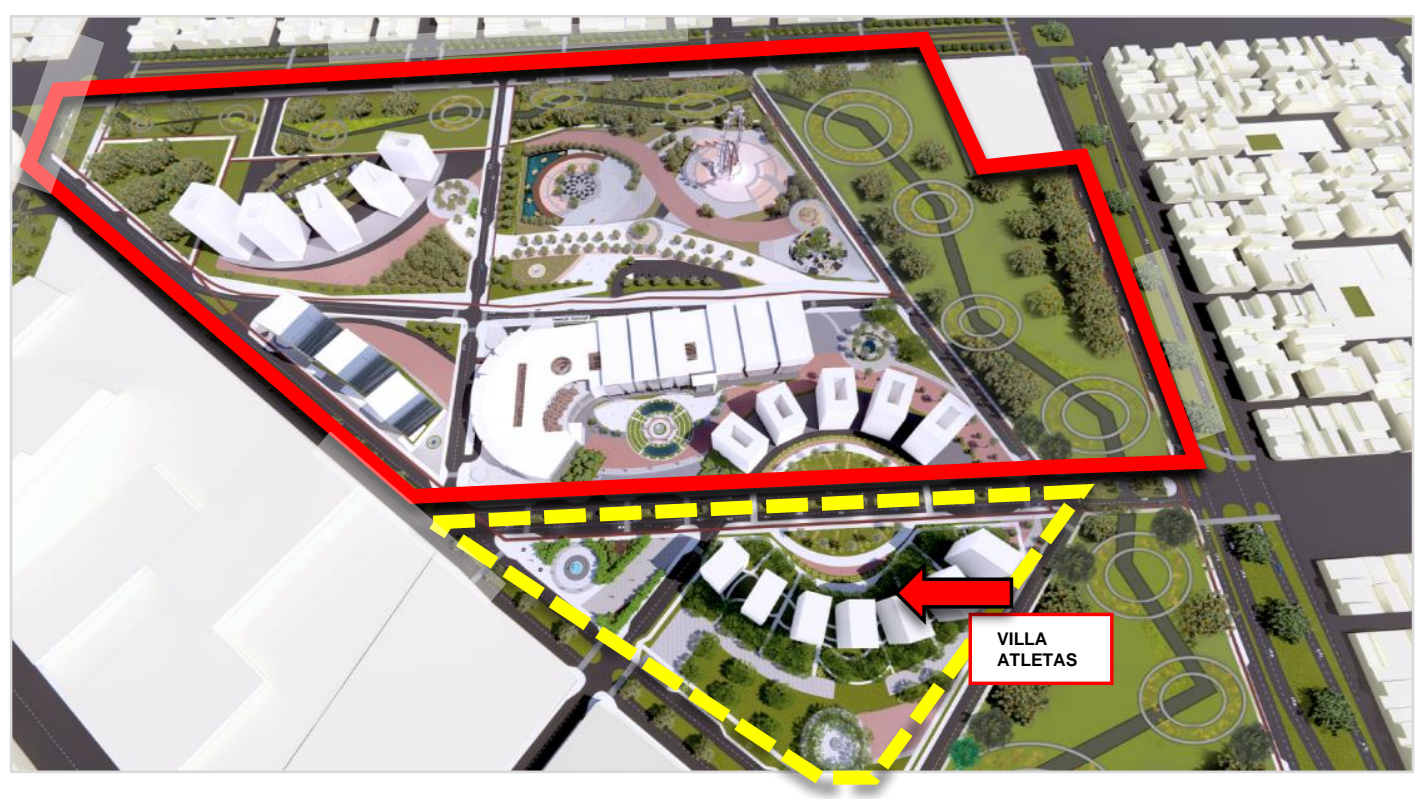

Elaboración Propia.

Todo lo mencionado está dividido dentro de 5 manzanas, que constan de varias zonificaciones existentes de acuerdo a la municipalidad de Villa el Salvador Zona de Densidad Media (RDM), Densidad Media Especial (RDMe), Comercio Zonal (CZ), Otros Usos (OU) y Recreación Pública (ZRP).

Con el fin de ser viable al máximo, además de las nuevas intervenciones viales anteriormente explicadas, se propone una nueva zonificación en el terreno del proyecto, sin modificar las zonificaciones donde existen ya proyectos construidos. Sin embargo, las zonas del terreno del proyecto sin equipamiento definido a nivel urbano serán las modificadas en base a Densidad Media (RDM-E), Otros Usos (OU), Recreación Pública (ZRP) para recuperar el porcentaje de áreas verdes, Comercio Metropolitano $(\mathrm{CM})$ y más predominancia de comercio zonal (CZ) en todos los ejes de calles y avenidas principales de Villa el Salvador potenciando la característica principal que tiene Villa el Salvador como distrito comercial, esto se muestra en la siguiente figura: 
Figura 98. Zonificación actual y propuesta.

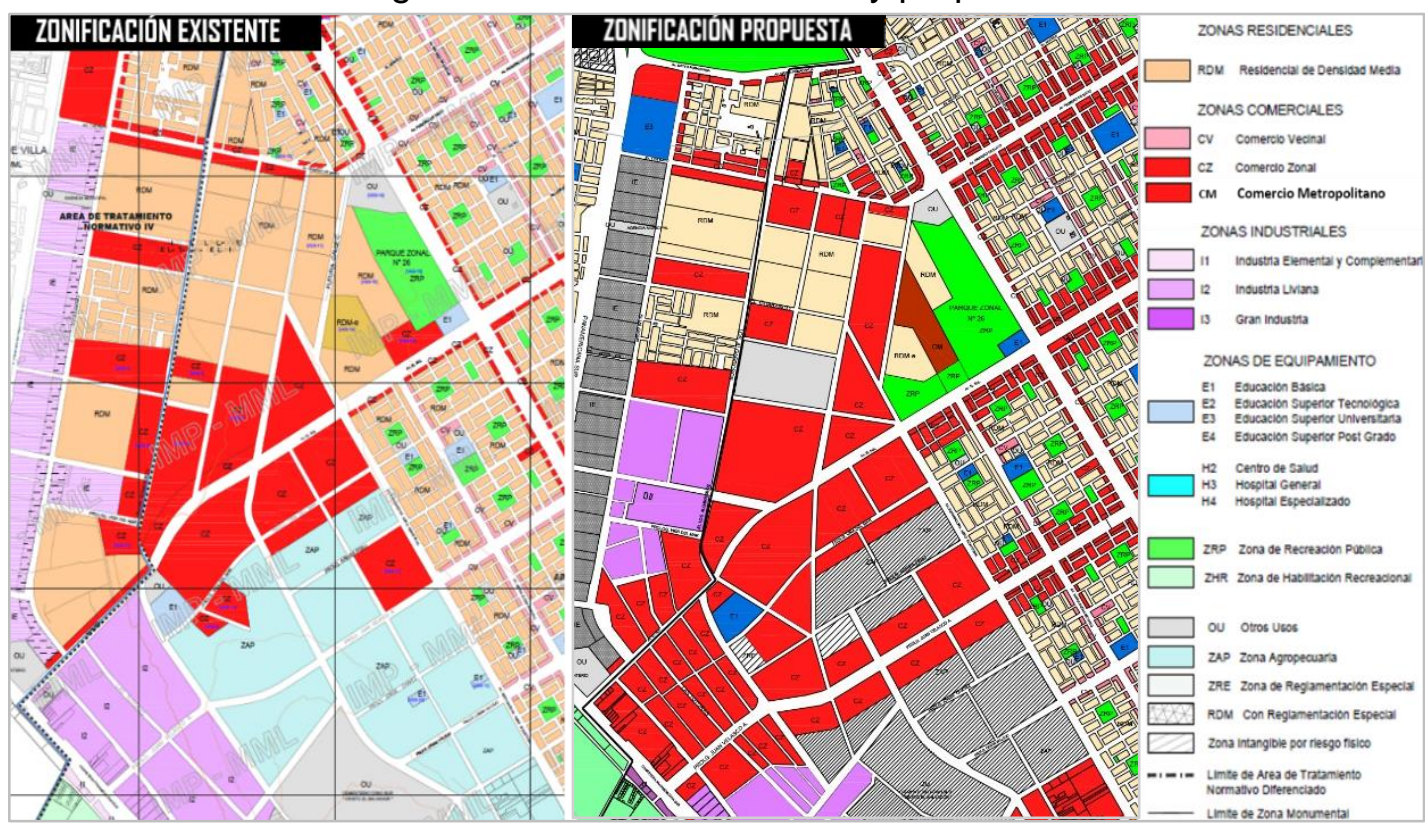

Elaboración Propia.

Las secciones de vías colindantes al terreno son: la Av. Mariano Pastor Sevilla de 76.45 metros lineales, la Av. El Sol de 80 metros lineales, la Av. Calle 1 de 60 metros lineales; la Av. 1 de Mayo de 60 metros lineales; y la Av. María Elena Moyano de 40 metros lineales, tal y como se muestra a continuación:

Figura 99. Secciones de vías del proyecto.

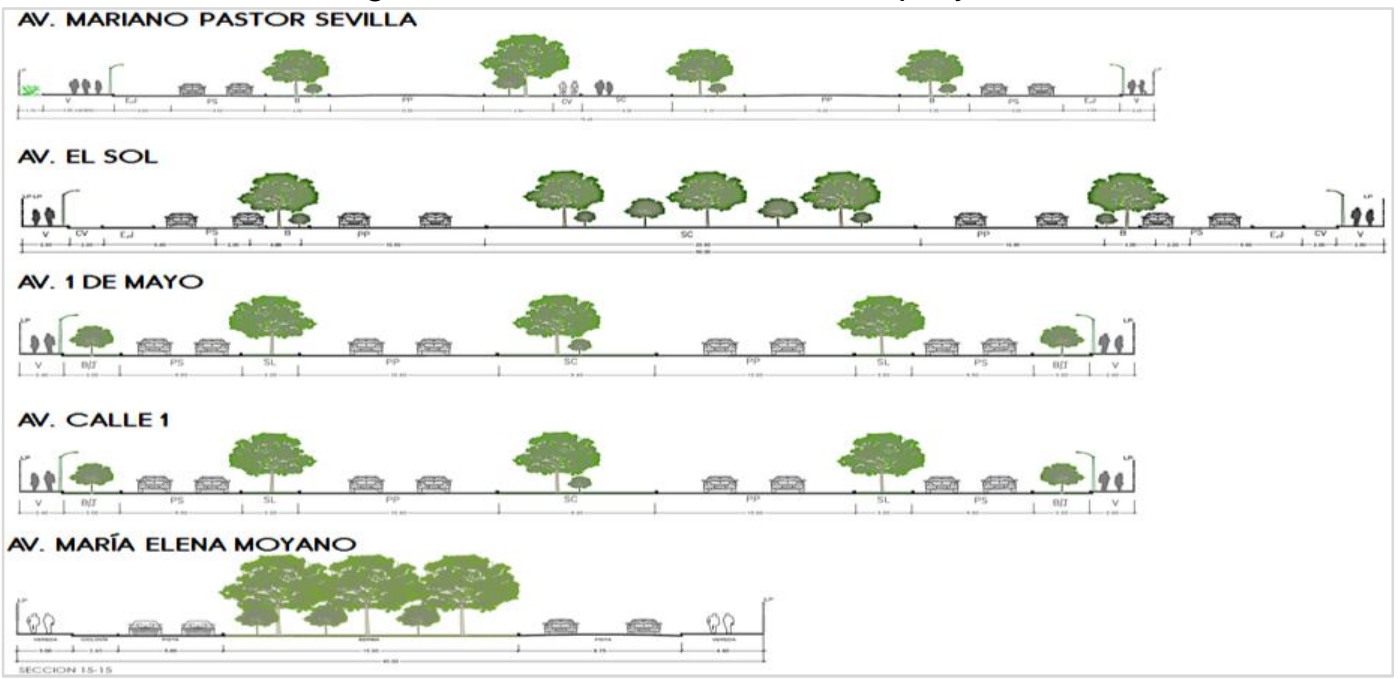

Elaboración Propia. 
El proyecto se caracteriza principalmente, por albergar usos empresariales y comerciales, siendo este último, el punto principal de interés arquitectónico. El cuadro técnico del proyecto, se resume en los siguientes datos:

$\checkmark$ Zonificación: Zona de Reglamentación de Densidad Media (RDM), Densidad Media Especial (RDM-e), Comercio Zonal (CZ), Otros Usos (OU) y Recreación Pública (ZRP).

$\checkmark$ Usos permitidos: Variable

$\checkmark$ Área total bruta: 449 227, 82 M2

$\checkmark$ Área bosques: 150 200,15 M2

$\checkmark$ Área a ceder de vías: 142 033,61M2

$\checkmark$ Área recreativa y veredas: 105 329,75 M2

\subsubsection{Visión del Proyecto.}

"Mejoramiento Urbanístico y Equipamiento Comercial-Empresarial Post Panamericanos Entorno de la Villa Panamericana en Villa el Salvador, será un proyecto que servirá de plataforma para el desarrollo de las actividades de intercambio comercial. A nivel metropolitano, será un hito arquitectónico donde se promueva una identidad comercial $y$ empresarial, que dé soporte a los negocios de la población de Villa El Salvador y que incentive a las empresas a invertir por el crecimiento de Lima Sur."

Figura 100. Vista aérea del centro comercial.

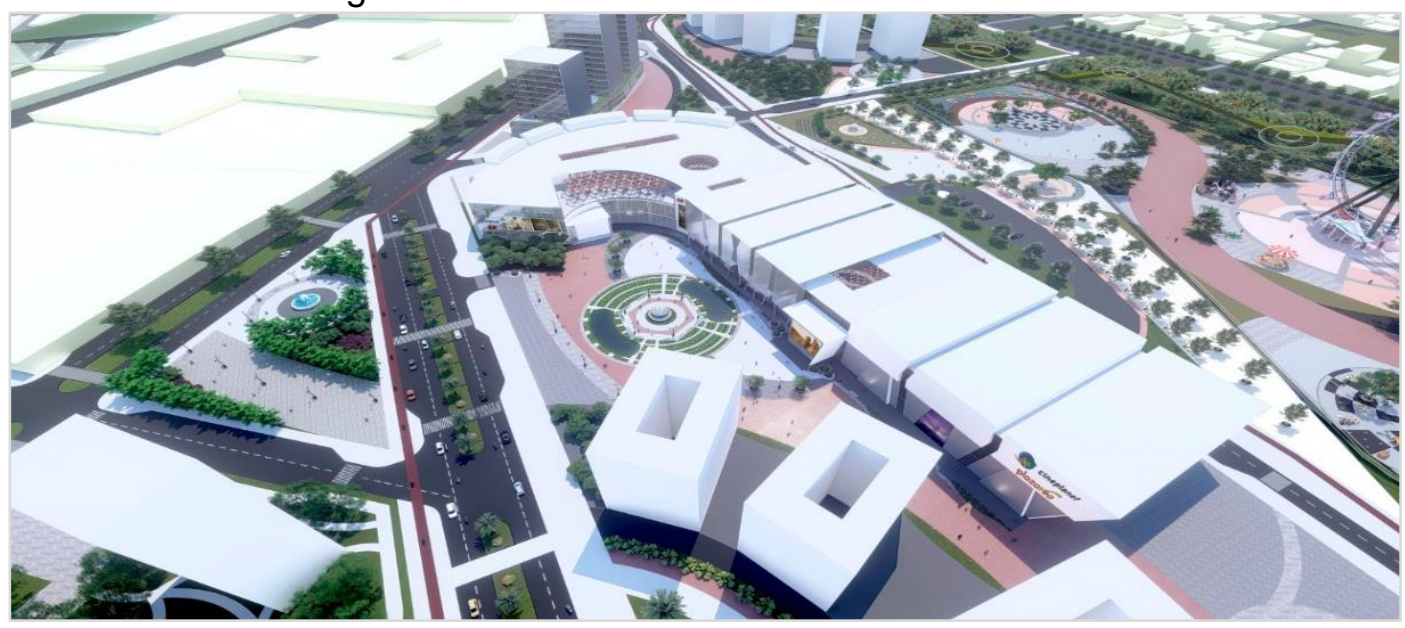

Elaboración Propia. 


\subsubsection{Conceptos de Diseño.}

Según Astuhuamán (2004), al recorrer parte de Perú y Ecuador en 1802, Alexander Von Humboldt definió que la arquitectura inca sigue los conceptos de solidez, simetría y sencillez: la solidez se presentaba en los muros construidos finamente tallados y apilados; la simetría se relacionaba con la disposición de sus elementos como pórticos y ventanas debidamente alineados y manteniendo un orden, los cuales muchas veces tenían formas trapezoidales; la sencillez, por último, se expresaba en sus edificaciones, ya que no llevaban mucha ornamentación o decoración intrincada, y empleaba formas poligonales simples.

El proyecto se plantea en base de estos 3 conceptos, haciendo la analogía entre el pasado y el presente, donde cada una, supone de diversos materiales según su época y realidad constructiva. La base de la volumetría representa una forma uniforme, de la cual se extraen piezas y se va jugando con el sólido, de tal manera que se forman espacios entre ellos y ritmos en la arquitectura, que son trazados mediante formas trapezoidales, como se muestra en la siguiente figura.

Figura 101. Analogía entre la arquitectura incaica de Ollantaytambo y la del proyecto.

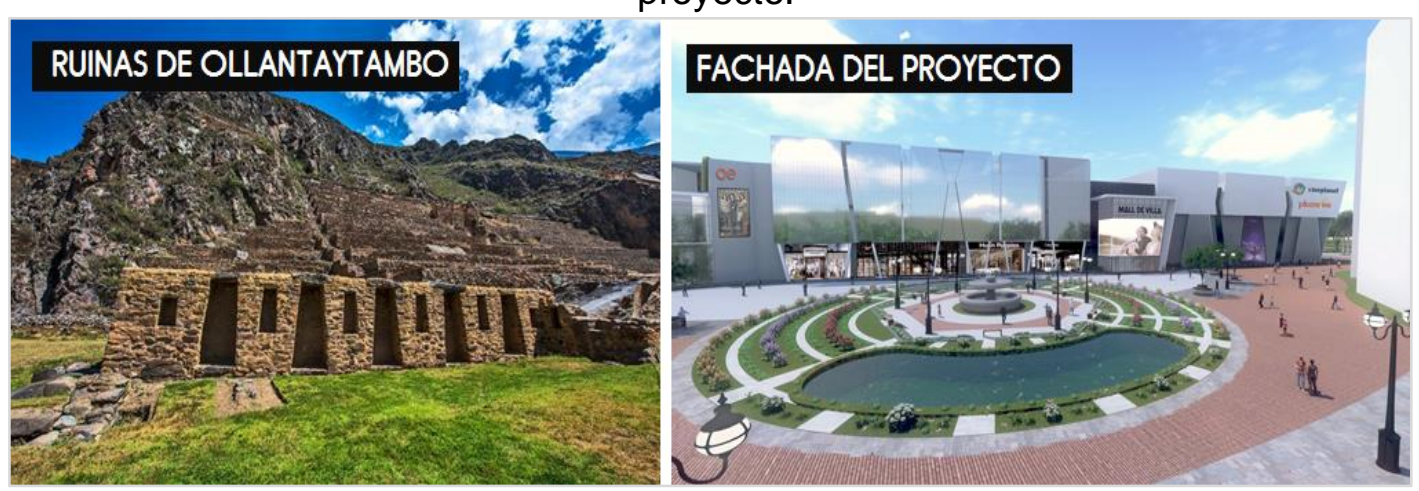

Fuente: Ollantaytambo, construcción inca de sorprendente perfección. El Peruano, 2019. Elaboración Propia.

En segunda instancia, el tratamiento de las áreas recreativas del proyecto responde a una geometría con curvas y rectilínea oblicua, muy presente en el paisajismo orgánico. De acuerdo, con Pérez (2016) la geometría curvilínea tiene como fuerzas generadoras al punto, el arco, el radio y el ángulo. Bajo 
ese criterio se delineo un lineamiento organizado por líneas sinuosas, que van por los espacios. El lenguaje de esta geometría fomenta el recorrido peatonal, y remata con los encuentros de las edificaciones, como se aprecia en la Figura 78, representa una propuesta lúdica, frente a la rigidez de las formas en la volumetría arquitectónica.

Figura 102. Paisajismo orgánico en el proyecto.

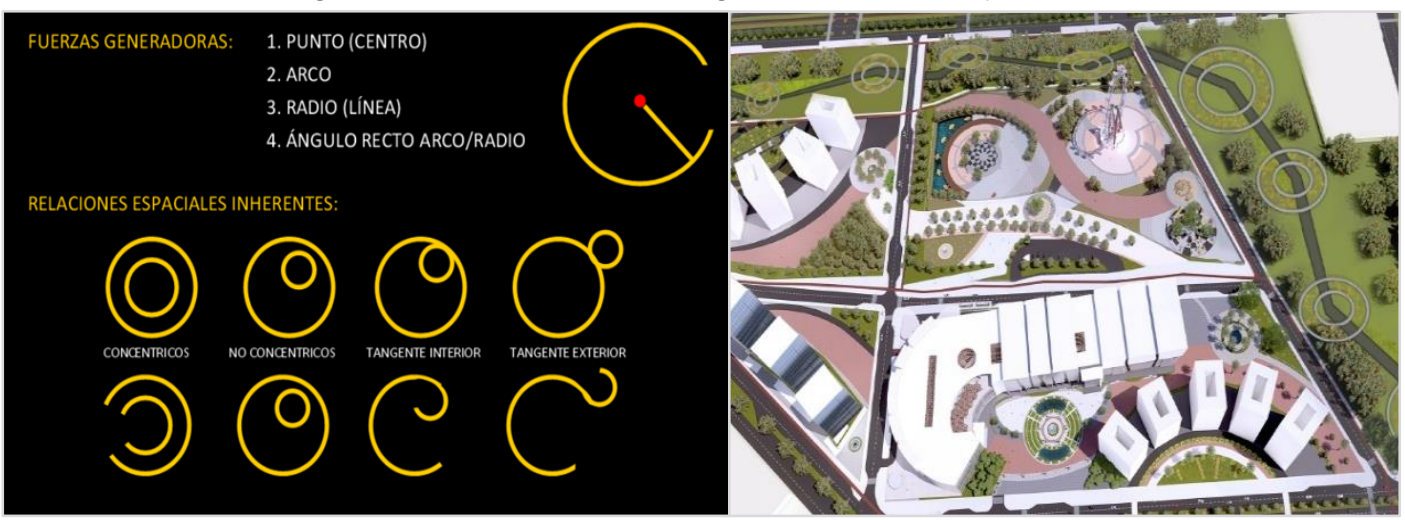

Fuente: Arquitectura del paisaje: forma y materia, Pérez Igualada, 2016. Elaboración propia

\subsubsection{Programa Arquitectónico}

El presente proyecto arquitectónico divide a las intervenciones en 4 manzanas, con las siguientes zonas: comercial, empresarial, residencial (vivienda social) y recreativo, tal y como se observa en la figura siguiente.

Figura 103. División del programa arquitectónico.

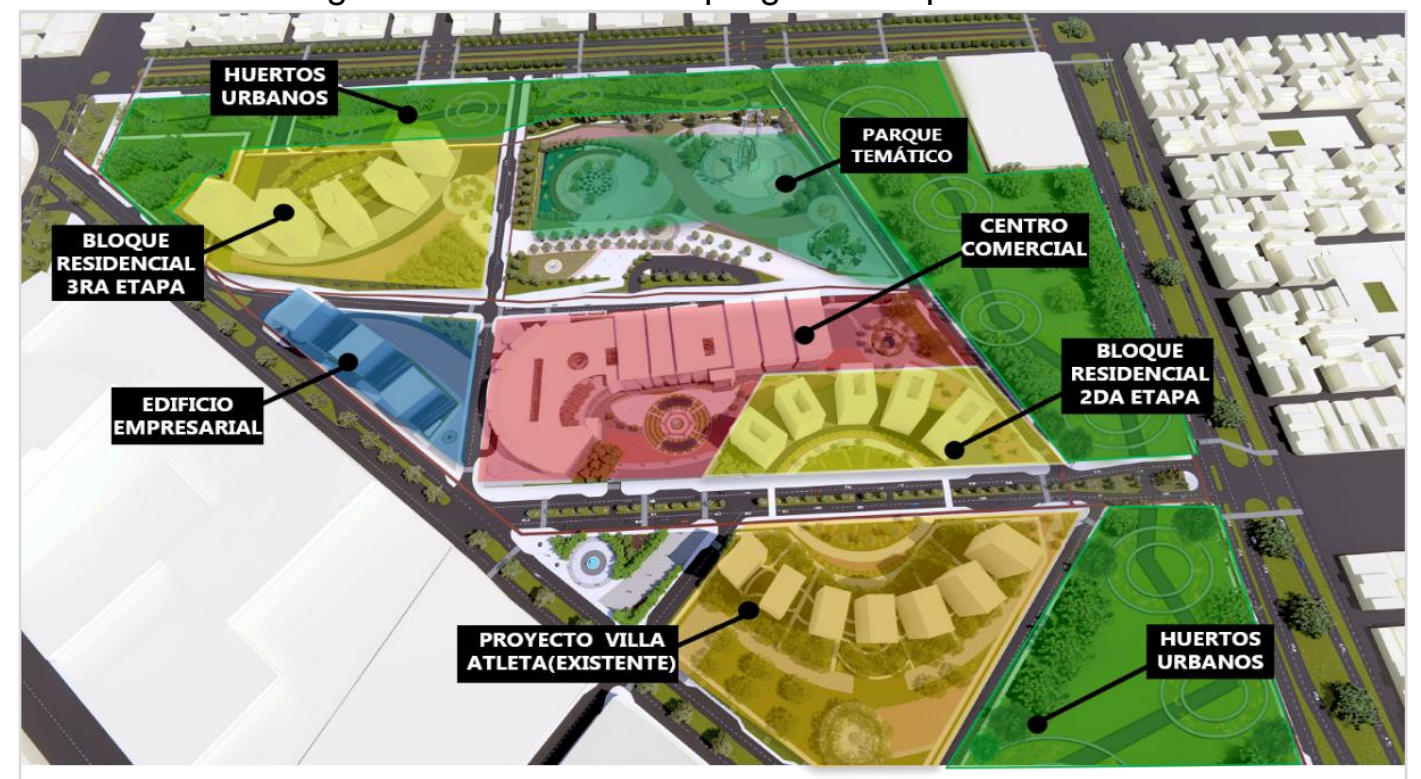

Elaboración Propia. 
La "Zona Comercial" tiene a la propuesta del Centro Comercial llamado "Mall de Villa", que agrupa tiendas anclas (3 niveles), tiendas intermedias (dos de 1 nivel y otros 2 niveles), supermercado, gimnasio, cine, local de entretenimiento, locales comerciales, locales bancarios, áreas administrativas, recepción, restaurantes, baños, patio de comidas, locales de comida rápida, estacionamientos y áreas de servicio complementario. Véase la siguiente figura.

Figura 104. Vista de la zona comercial.

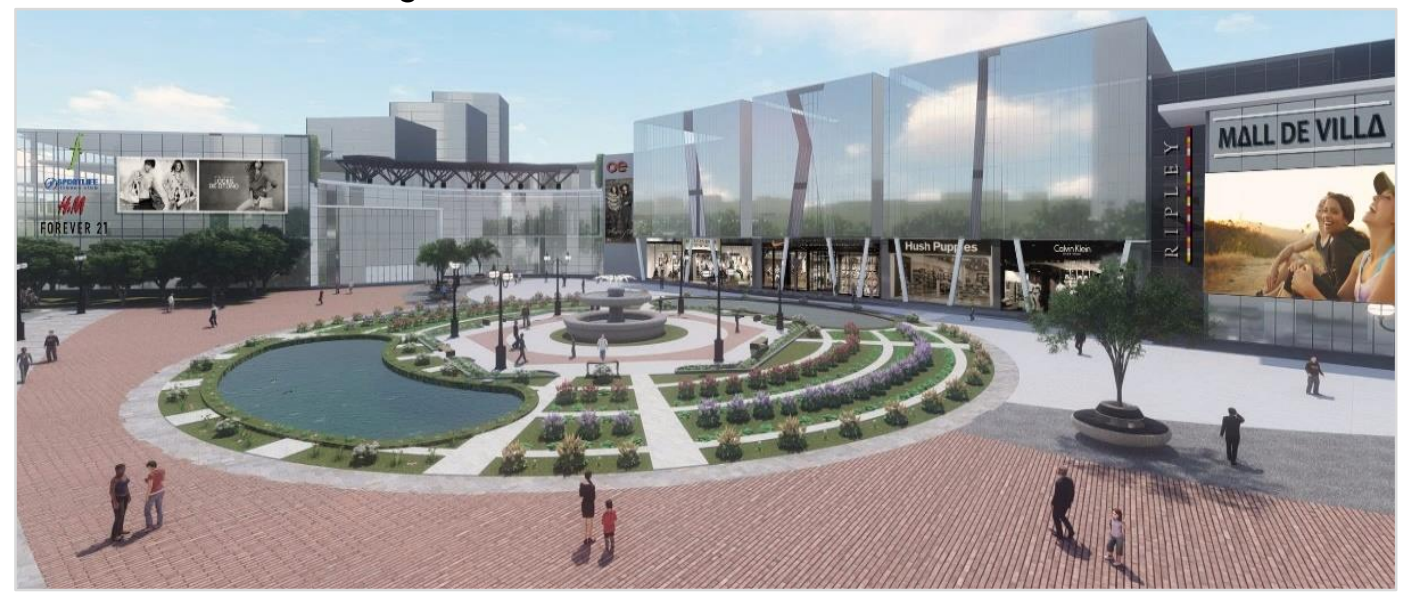

Elaboración Propia.

La "Zona Empresarial" consta de 1 edificación de 3 torres, que han sido agrupadas consecutivamente y a diferentes cantidades de pisos, con conexión en las primeras plantas. Estas contienen áreas de lobby, hall de ascensores, baños, oficinas (a partir del tercer piso) y estacionamientos. Véase en la siguiente figura.

Figura 105. Vista aérea de la zona empresarial.

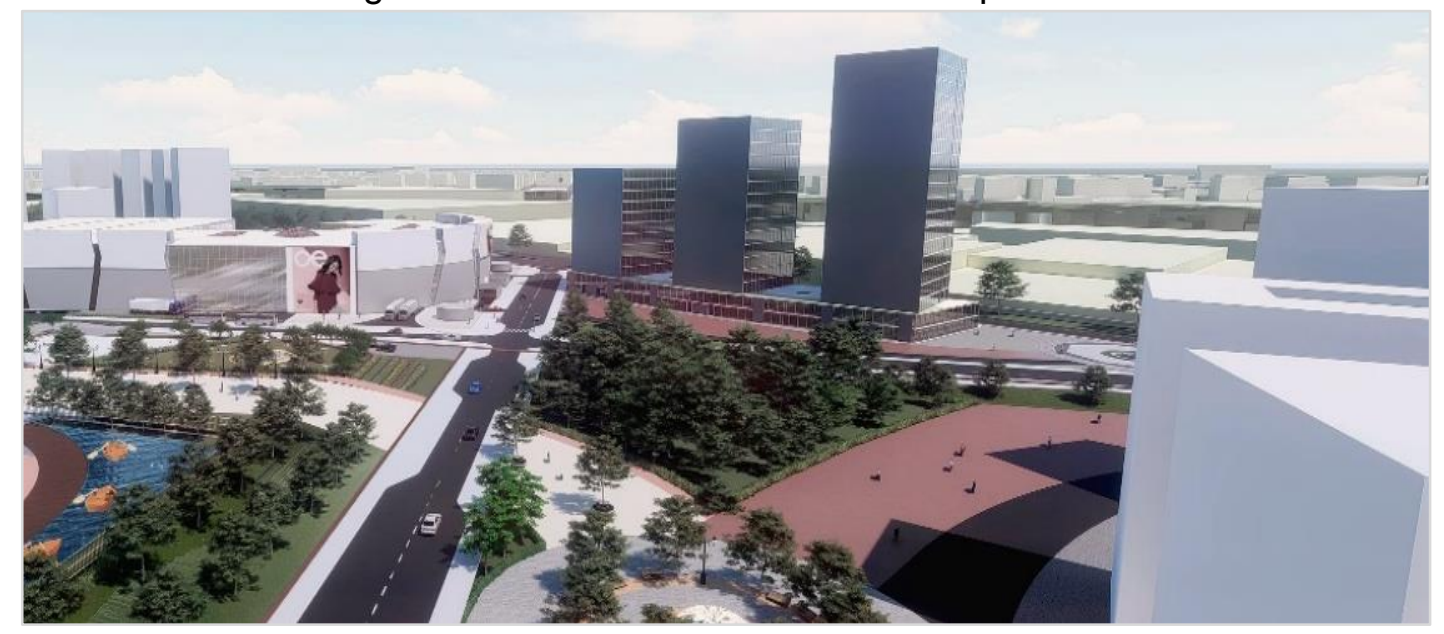

Elaboración Propia. 
La "Zona Residencial" agrupa a las edificaciones corresponden a la segunda y tercera etapa de la Villa Panamericana como propuesta, cada una cuenta con 5 bloques, dispuestos con orientación radial hacia un mismo punto de la circunferencia con alturas escalonadas, pero siguiendo el mismo manejo arquitectónico de la primera etapa, ya construida. Véase en la figura siguiente.

Figura 106. Vista aérea de la zona residencial.

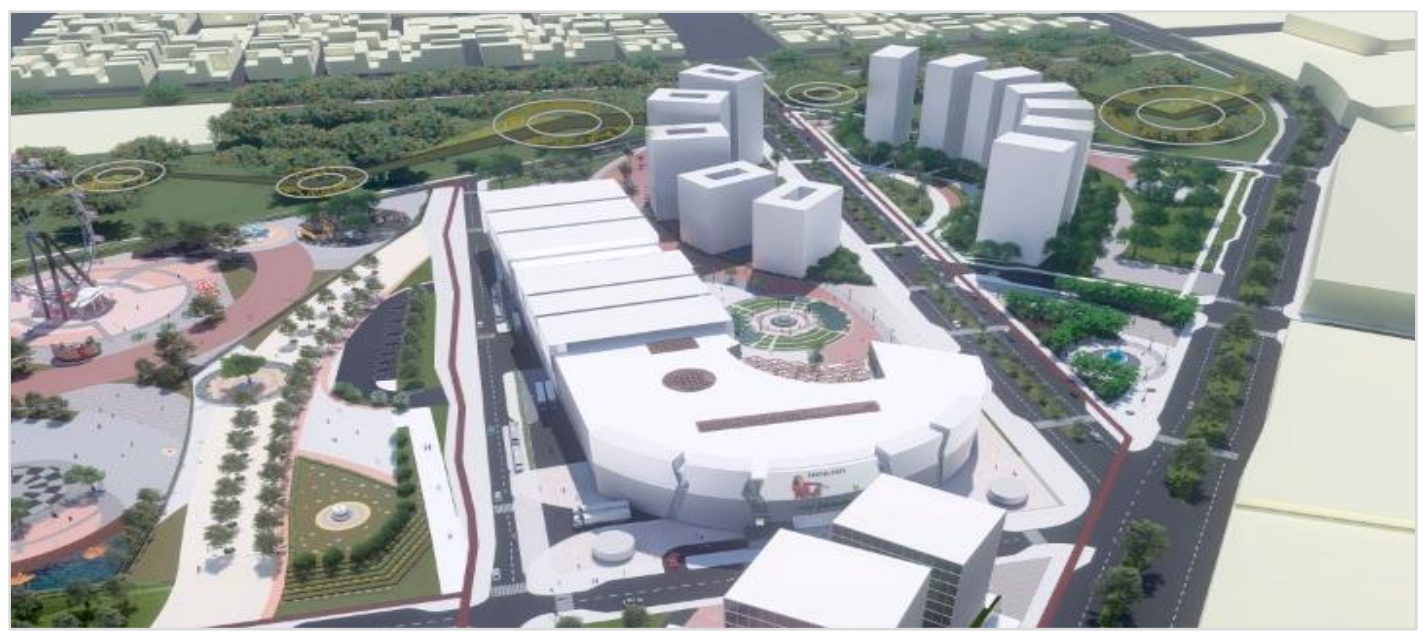

Elaboración Propia.

La "Zona Recreativa”, por último, comprende un parque temático con áreas pasivas y activas, zonas de juegos, laguna artificial, piletas ornamentales y zona de juegos de diversiones mecánica entre otros. Véase en la siguiente figura.

Figura 107. Vista aérea de la zona recreativa.

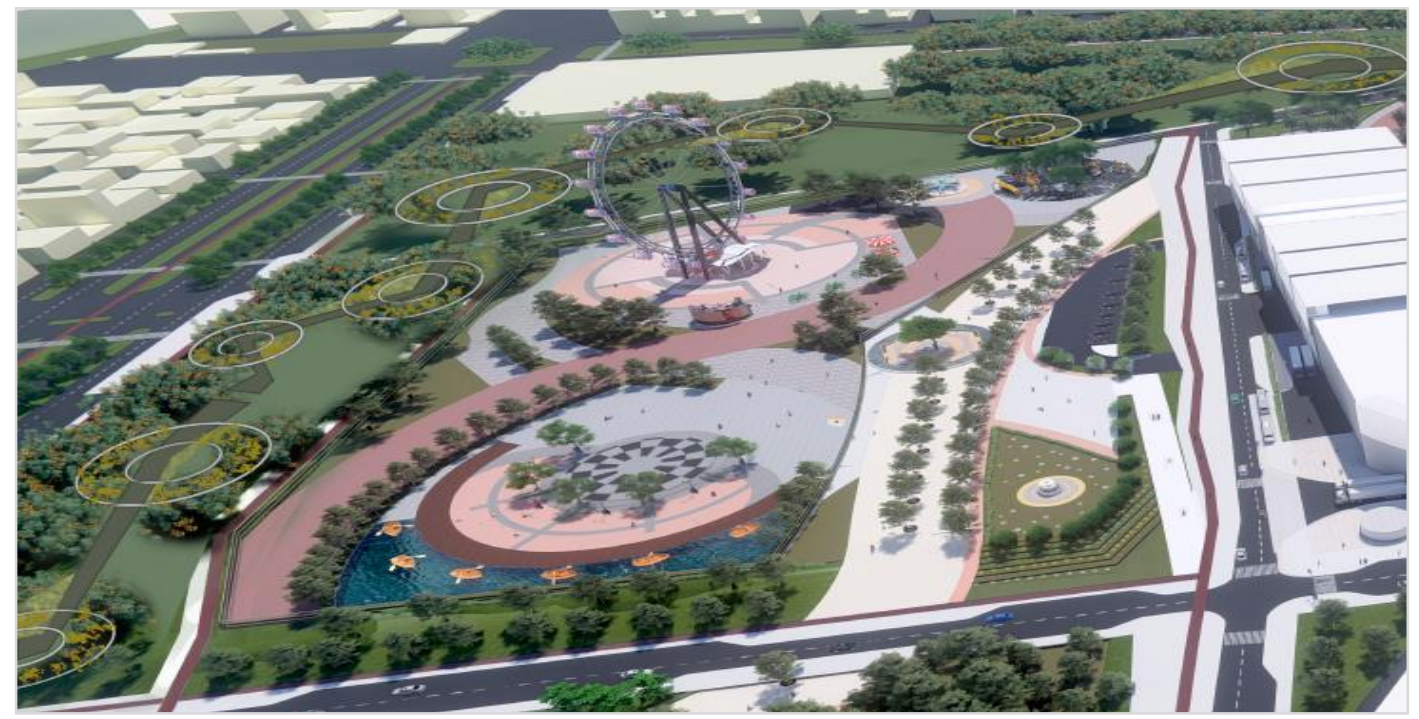

Elaboración Propia. 


\subsubsection{Descripción de Áreas del Proyect o}

\section{- ZONA COMERCIAL}

Esta zona tiene de ingreso principal a la Av. María Elena Moyano, la cual está frente a la primera etapa de la Villa Panamericana. Esta zona tiene un área total construida de $70,989.51 \mathrm{~m}^{2}$. Consta de 3 niveles, aquí se encuentran las tiendas anclas que son las 3 tiendas por departamento (cada una de 3 niveles), 3 tiendas intermedias (dos de 1 nivel y otra con 2 niveles), un supermercado, un cine, un local de entretenimiento, un gimnasio, 21 locales comerciales grandes, 10 locales comerciales pequeños, zona de carga, descarga y patio de maniobra, montacargas, almacenes, cuarto de control, cuartos técnicos, cisternas, hall de ascensores, escaleras eléctricas, núcleo de baños y capacidad para 544 estacionamientos distribuidos en dos sótanos.

Este edificio comercial tiene tres ingresos definidos, uno pasa por la tienda por departamento 1 , dos de ellos conducen a un hall de recepción y el principal con doble altura. A su vez, estos últimos se conectan a la alameda interna que conduce a las diferentes tiendas.

Figura 108. Plano del primer piso del centro comercial.

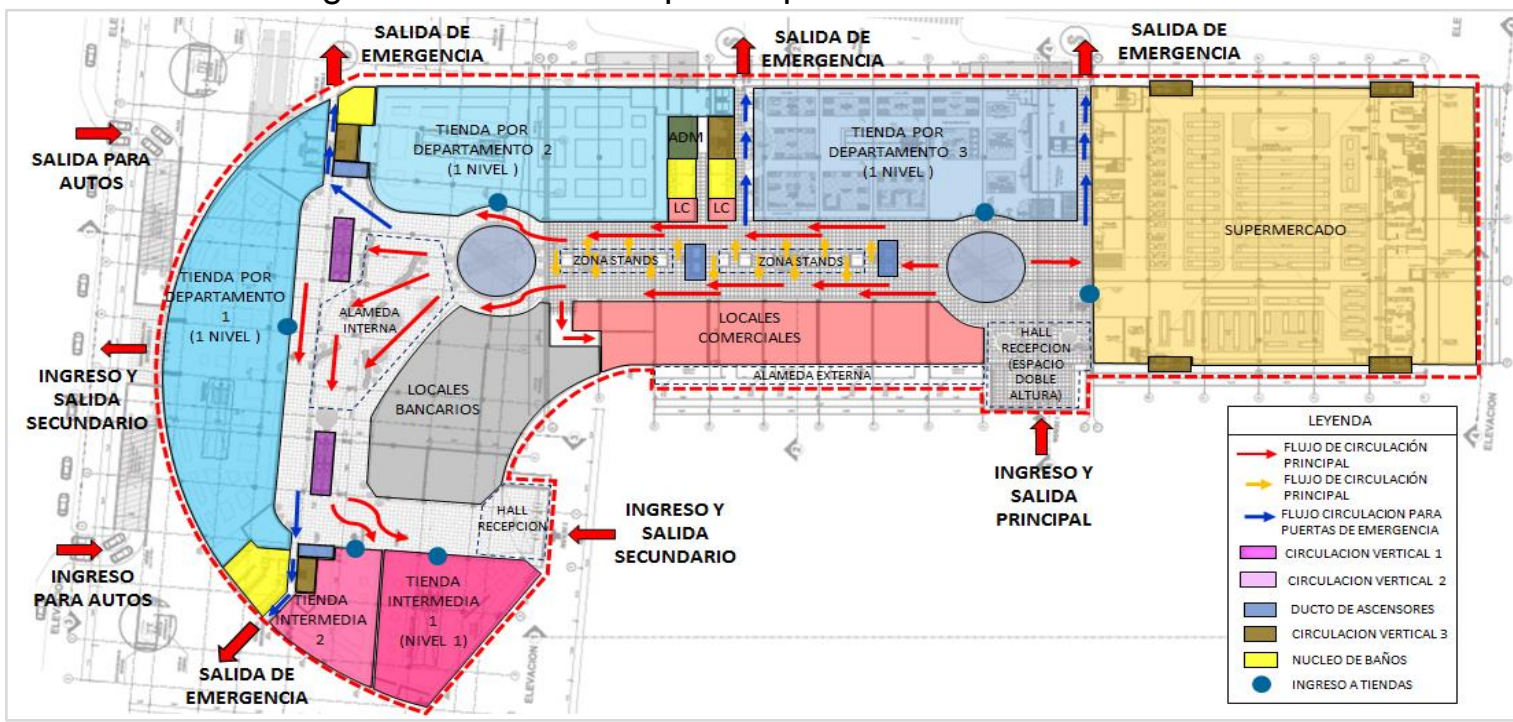

Elaboración Propia. 
Asimismo, hay una alameda exterior que genera un paseo por los locales comerciales que incentiva a bordear todo el exterior del centro comercial creando una función del espacio social con agradable vista a una gran pileta, con mobiliarios urbanos y áreas verdes. Respecto a la seguridad y defensa civil, el interior del centro comercial posee 4 salidas de emergencia, 3 de las cuales tienen el núcleo de escaleras cercanas.

Figura 109. Plano del segundo piso del centro comercial.

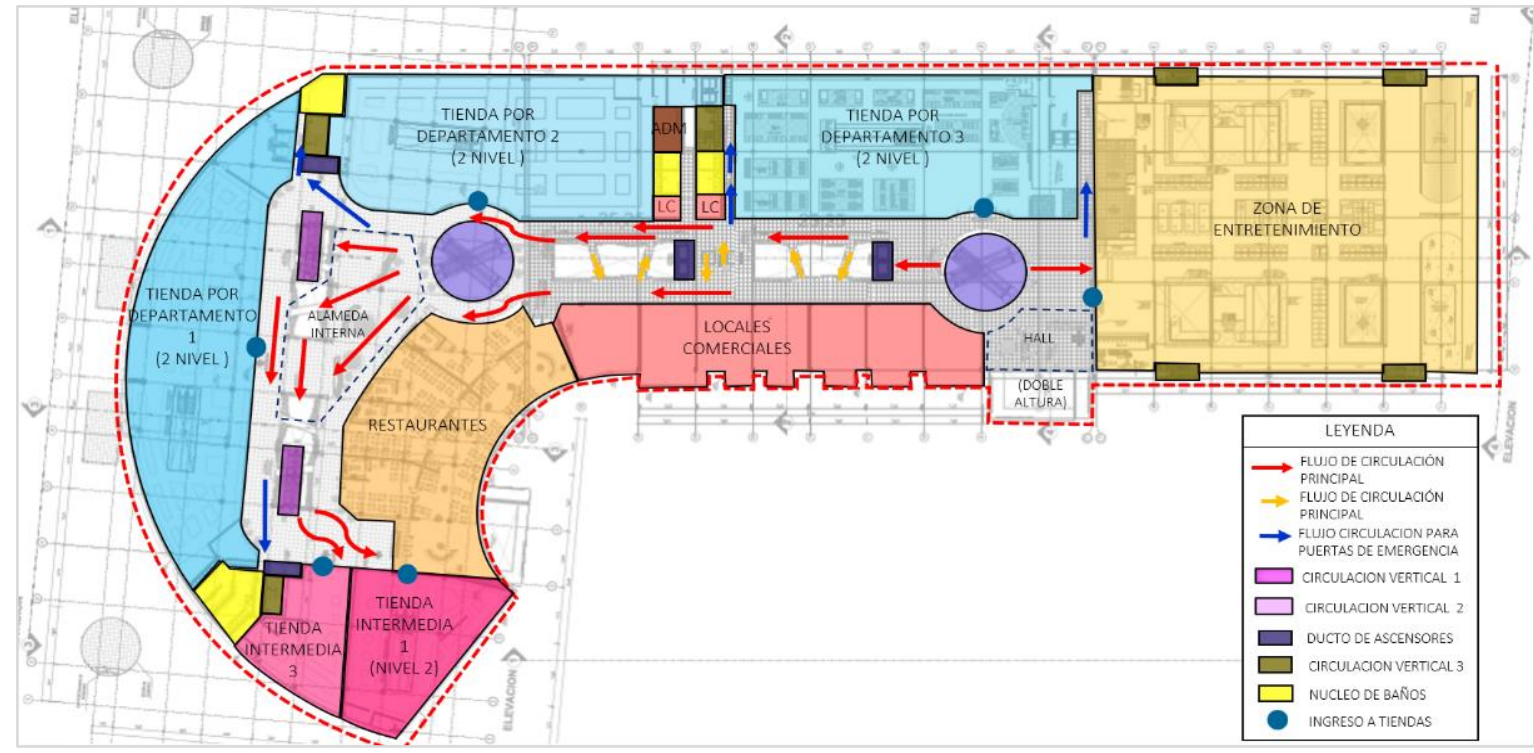

Elaboración Propia.

Figura 110. Plano del tercer piso del centro comercial.

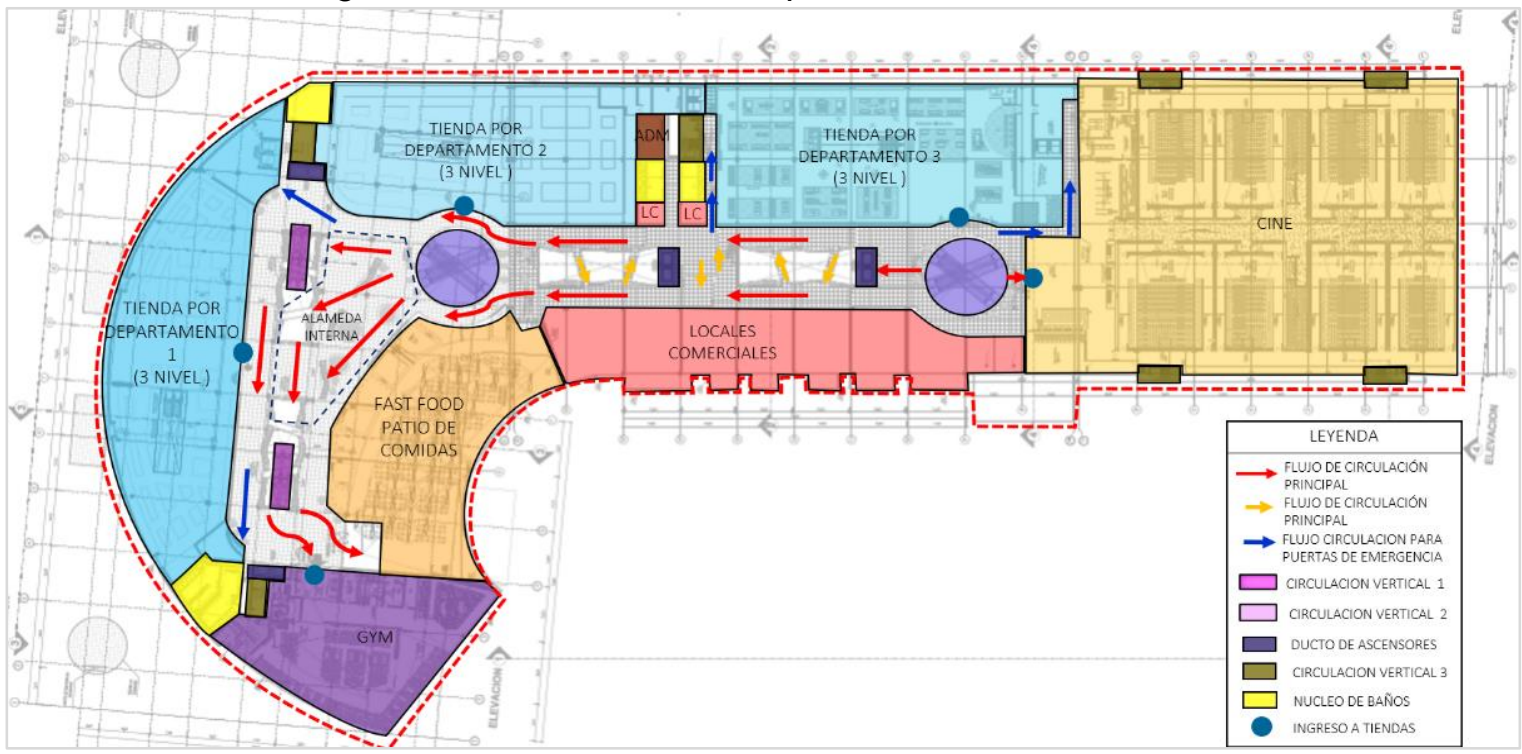

Elaboración Propia. 
La circulación interna se da de manera lineal, variando su flujo cuando se llega a las zonas pasivas dentro de la alameda, ya que tiene áreas de asientos y pueden usarse para diversas actividades de entretenimiento. Cada piso cuenta con sets de escaleras eléctricas de subida y bajada, distribuidas en sitios clave de circulación. En promedio general, la altura de cada piso es de 6.5 metros, contando los $0.6 \mathrm{~m}$ de viga peraltada.

Figura 111. Elevación y corte longitudinal del centro comercial.

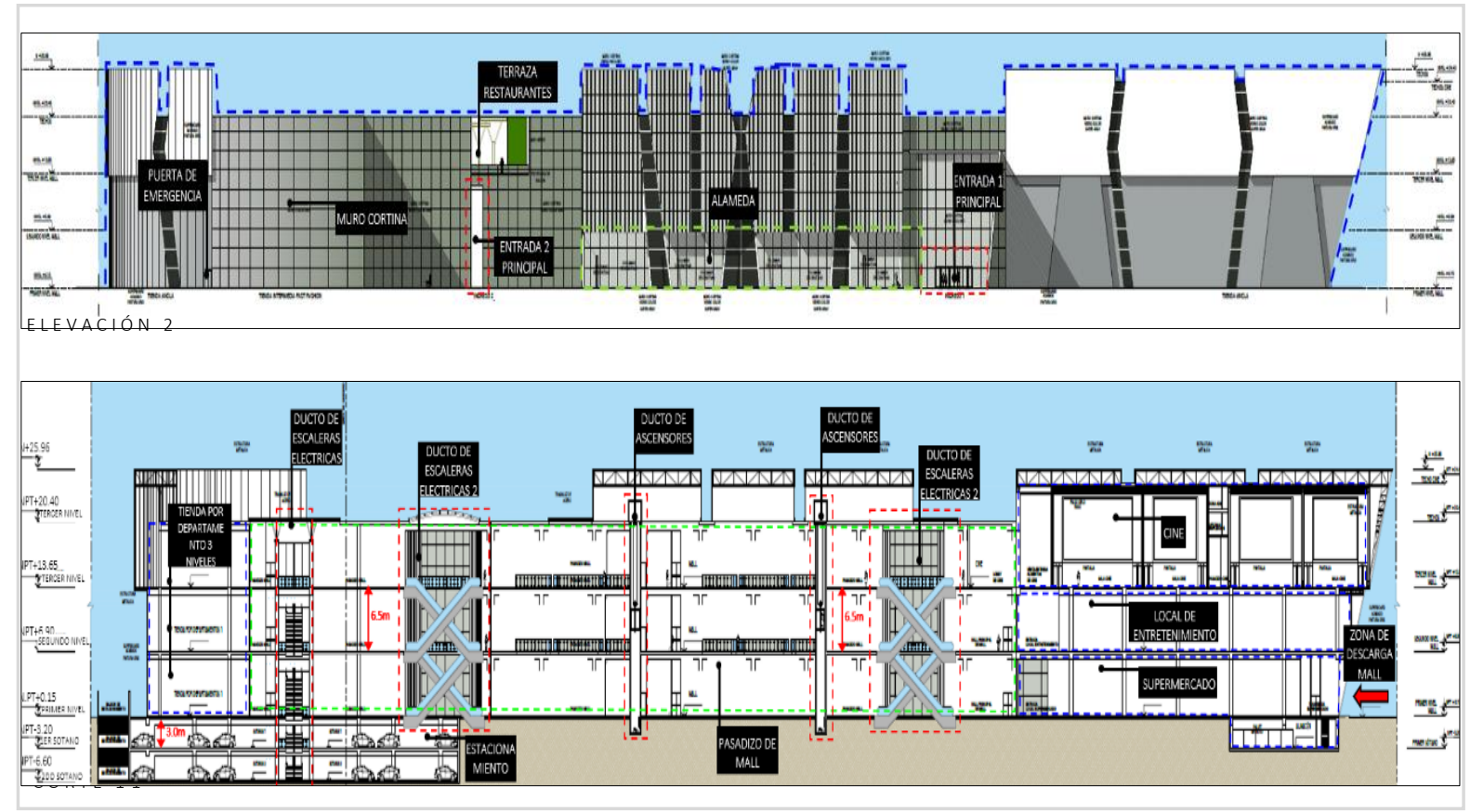

Elaboración Propia.

Algunos de los espacios interiores están compuestos con tramas geométricas en el piso y en la estructura de techos, relacionándolo con la propuesta poligonal de la arquitectura en el exterior. Posee gran apertura espacial y permeabilidad visual, acompañado de integración ecológica, presente mediante algunos jardines verticales y macetas, como parte de la decoración. Algunas áreas de descanso presentan fuentes de agua, como parte de la ornamentación, cerca de donde también yacen stands de venta para una experiencia relajante a las personas al momento de realizar sus compras. 
Figura 112. Hall de ingreso, tiendas comerciales y supermercado en el primer piso.

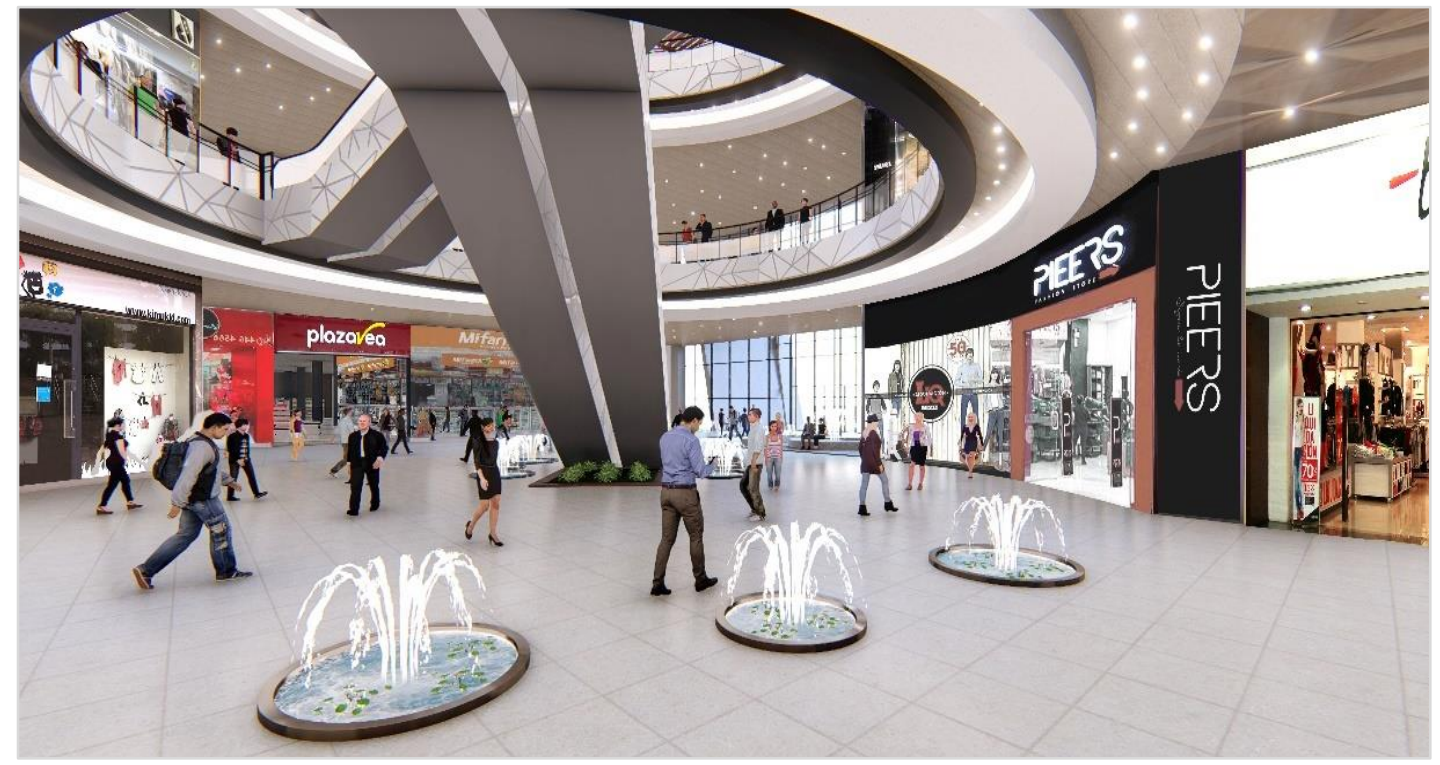

Elaboración Propia.

Figura 113. Pasadizo típico y zona de stands en el primer piso.

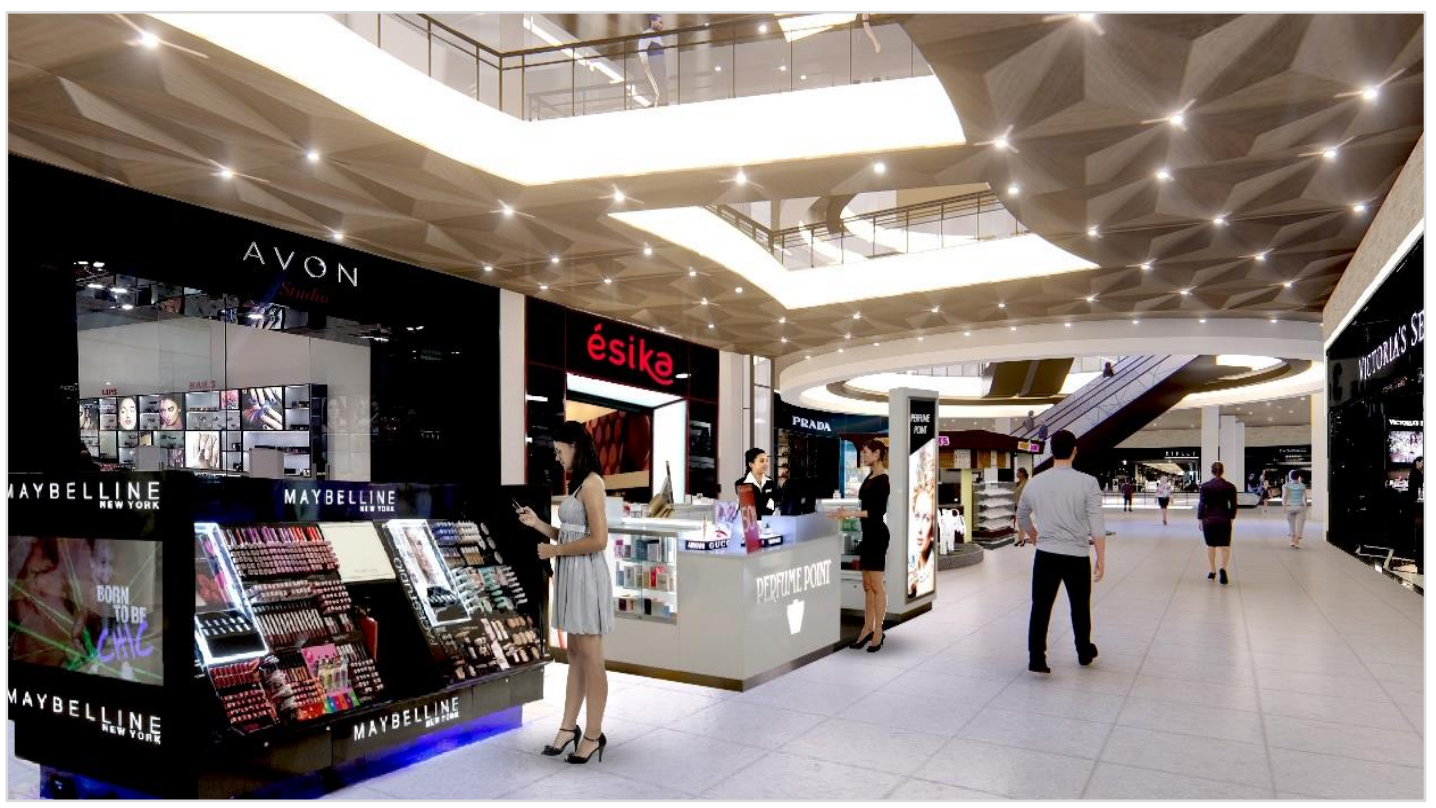

Elaboración Propia.

Entre lugares de esparcimiento y de actividades afines, se tiene un cine con $4,021 \mathrm{~m}^{2}$; un gimnasio con $954 \mathrm{~m}^{2}$; restaurantes con 1,346 $\mathrm{m}^{2}$; patio de comidas con 1,125 m²; zona de comida rápida con $310 \mathrm{~m}^{2}$; estas últimas al aire libre con algunas paredes verdes ecológicas, y zonas de entretenimiento de $3,583 \mathrm{~m}^{2}$. 
Figura 114. Zona de restaurantes en el segundo piso.

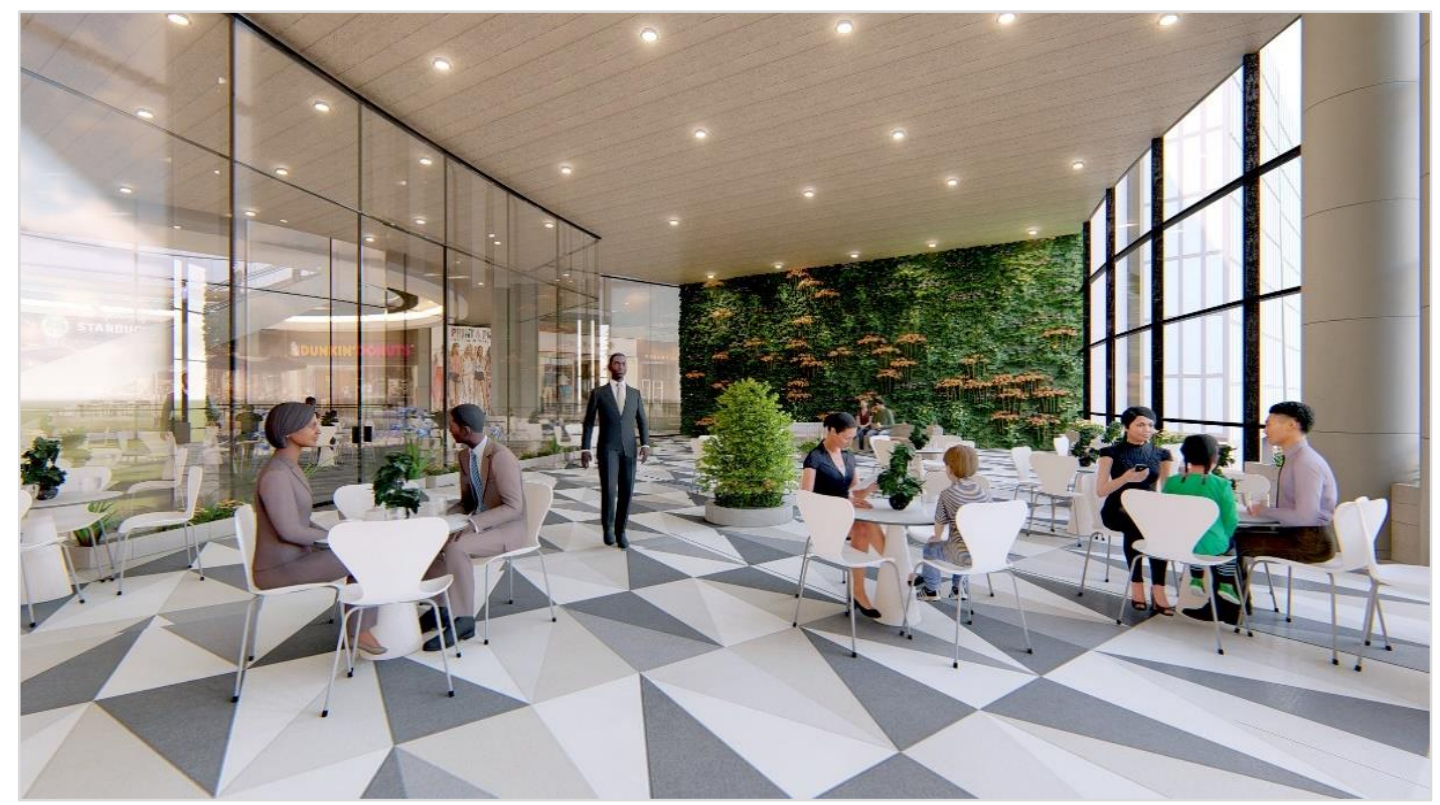

Elaboración Propia.

Figura 115. Hall común en tercer piso.

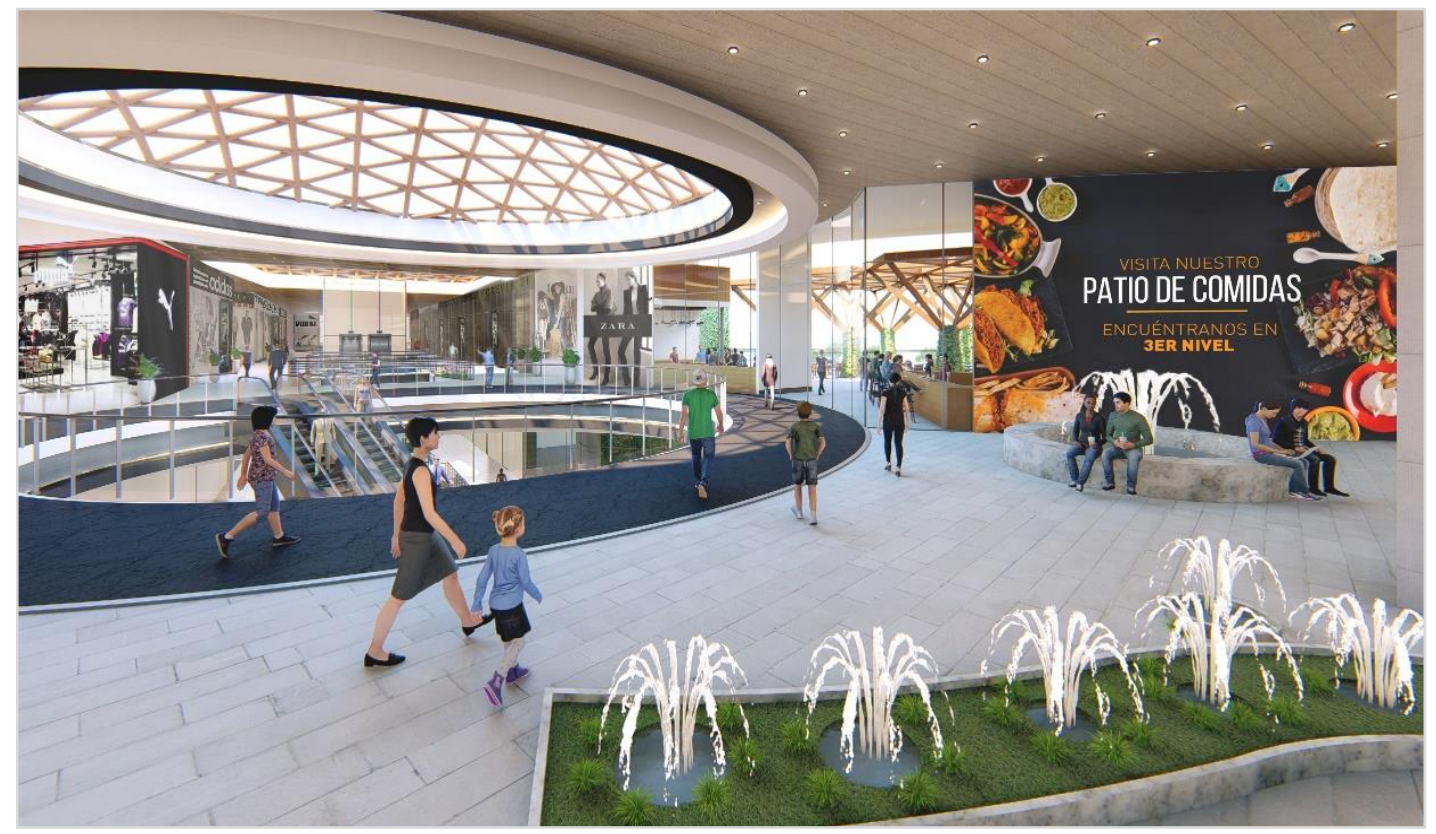

Elaboración Propia. 
Figura 116. Patio de comidas en el tercer piso.

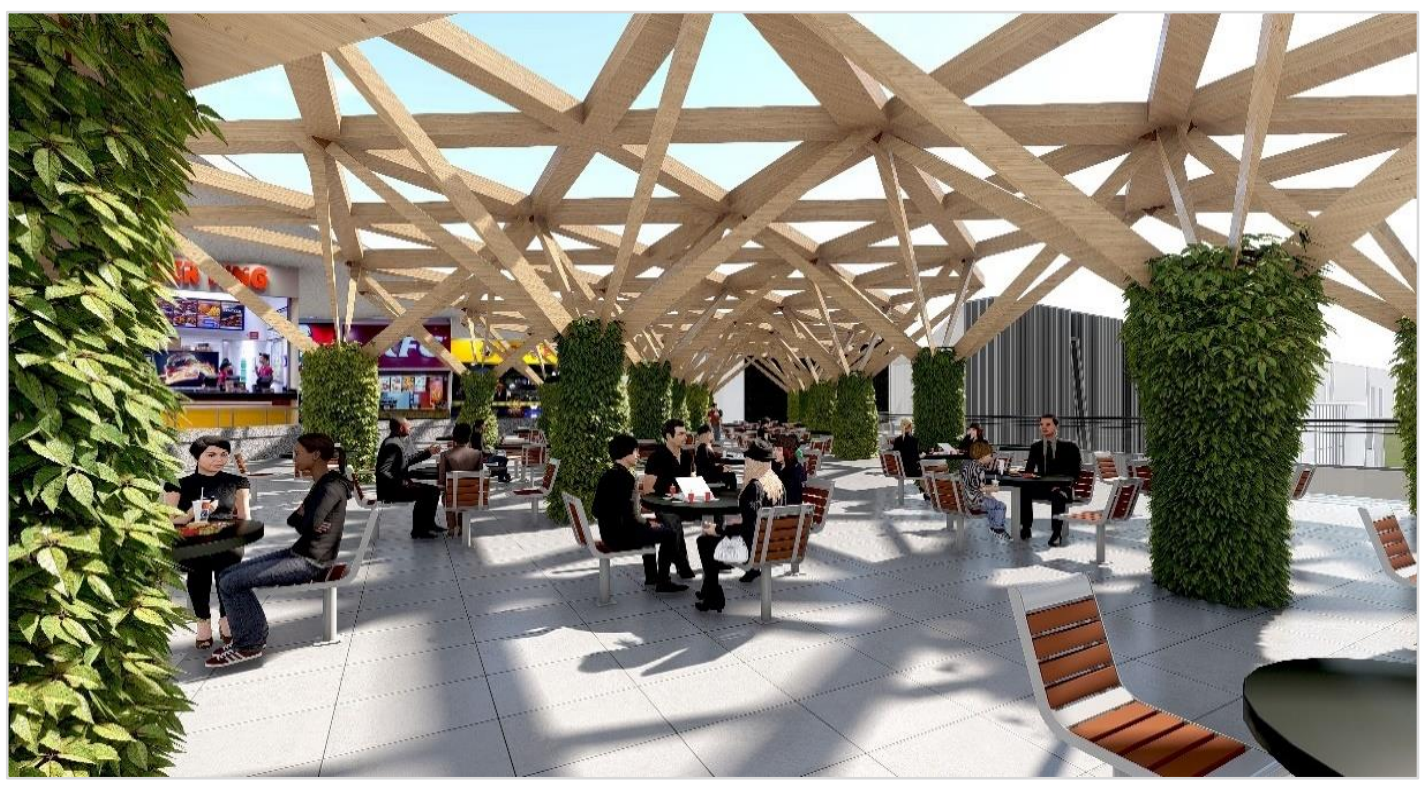

Elaboración Propia.

Las tiendas por departamento que son las tiendas anclas tienen un área construida de 1,633 $\mathrm{m}^{2}$, distribuidas en los 3 niveles e interconectadas. El supermercado tiene un área de 3,494 $\mathrm{m}^{2}$. Los locales comerciales son 31 en total, 21 de los grandes con 3,164 $\mathrm{m}^{2}$ y 10 de los pequeños con $317 \mathrm{~m}^{2}$. El área de los locales bancarios tiene un área de 1,227 $\mathrm{m}^{2}$ que se distribuyen en 6 unidades.

Figura 117. Tienda por departamento típica en el primer piso.

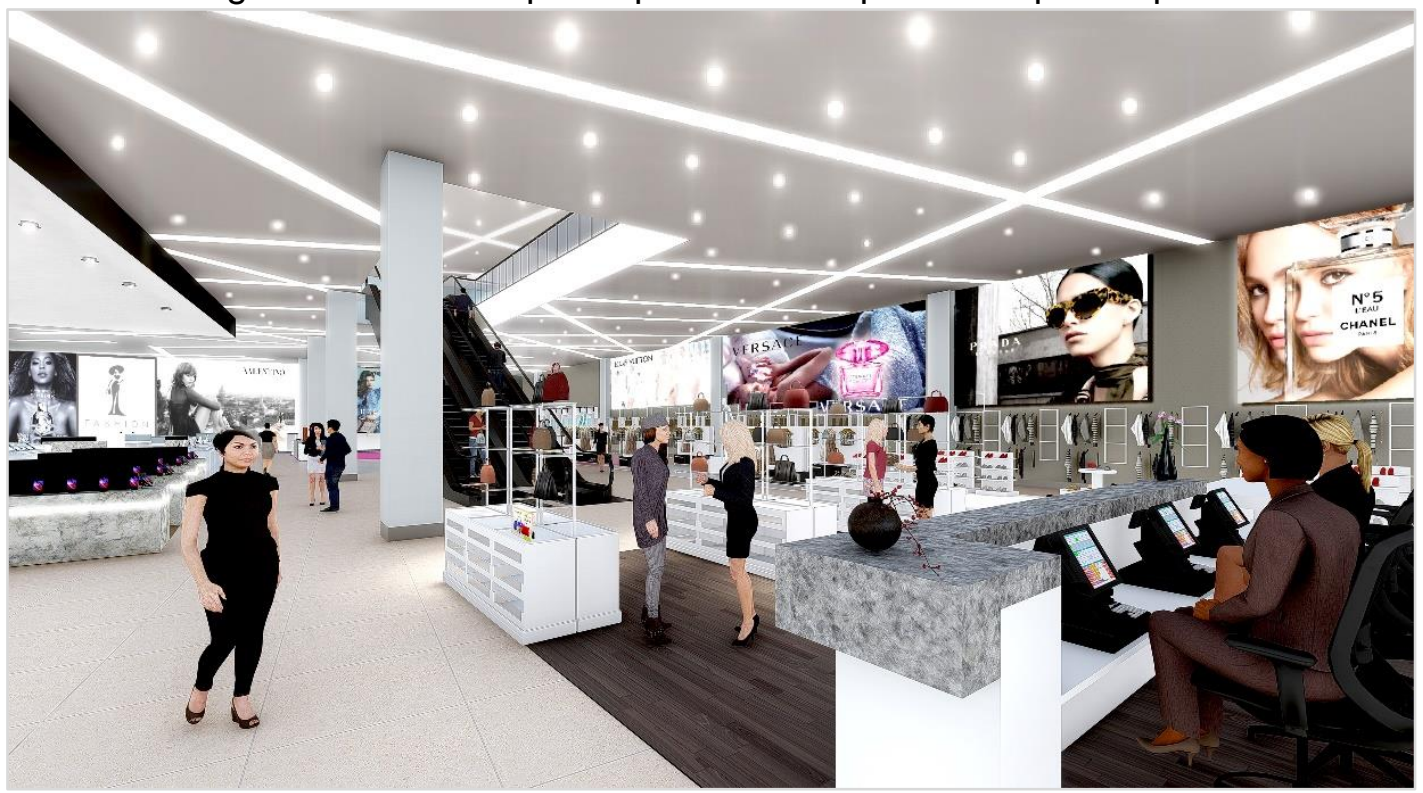

Elaboración Propia. 
Figura 118. Local de entretenimiento en el segundo piso.

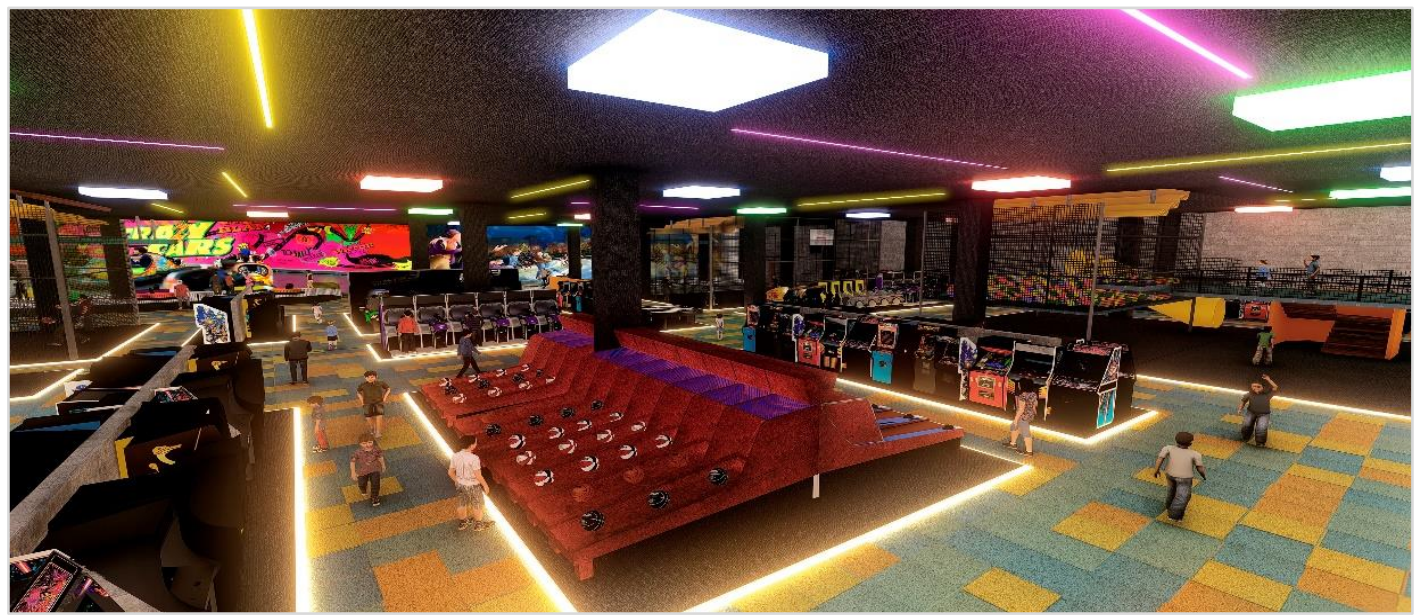

Elaboración Propia.

Figura 119. Hall entrada de cine y boletería.

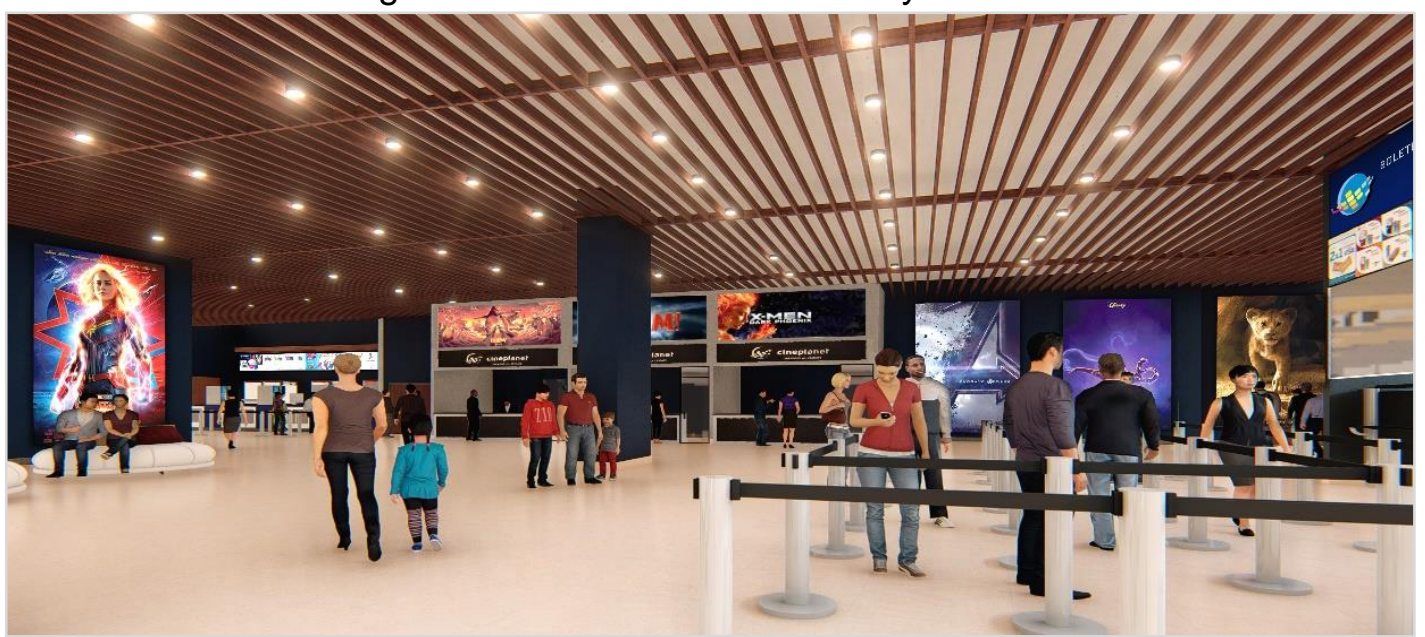

Elaboración Propia.

Figura 120. Sala de cines.

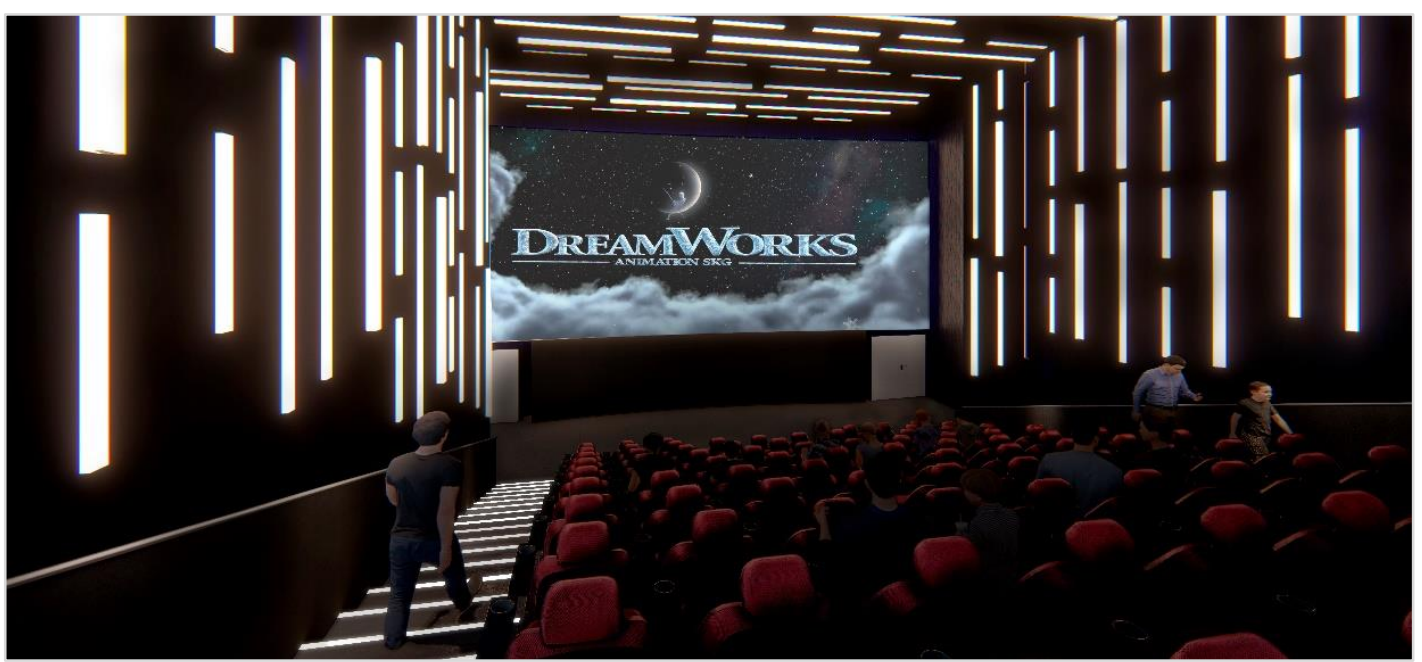

Elaboración Propia. 
El gimnasio que es un establecimiento destinado para la práctica de deporte y diversas actividades físicas/entrenamientos, mediante máquinas e implementos deportivos a disposición de quienes asistan. Mencionado anteriormente el gimnasio cuenta con $954 \mathrm{~m} 2$, se configura en 1 nivel y 1 mezanine y, la distribución de sus ambientes es la siguiente: Administración, Counter de atención, Hall de atención, Núcleos de baños de hombres y mujeres (con sauna), Baños para discapacitados, Tienda de ropa, Sala de evaluación y nutrición, Almacenes, Cuarto de control, Zona de funcional, Zona de máquinas, Zona de musculación, Karate y boxing, Salón de baile, Salón de cycling y Zona de abdominales. El gimnasio tiene una altura total de $20.40 \mathrm{~m}$ entre el primer piso y el mezanine, donde se contempla una doble altura, dando una mayor amplitud y ventilación al espacio como se muestra en la figura 105.

Figura 121. Planta del primer piso y mezanine del gimnasio.

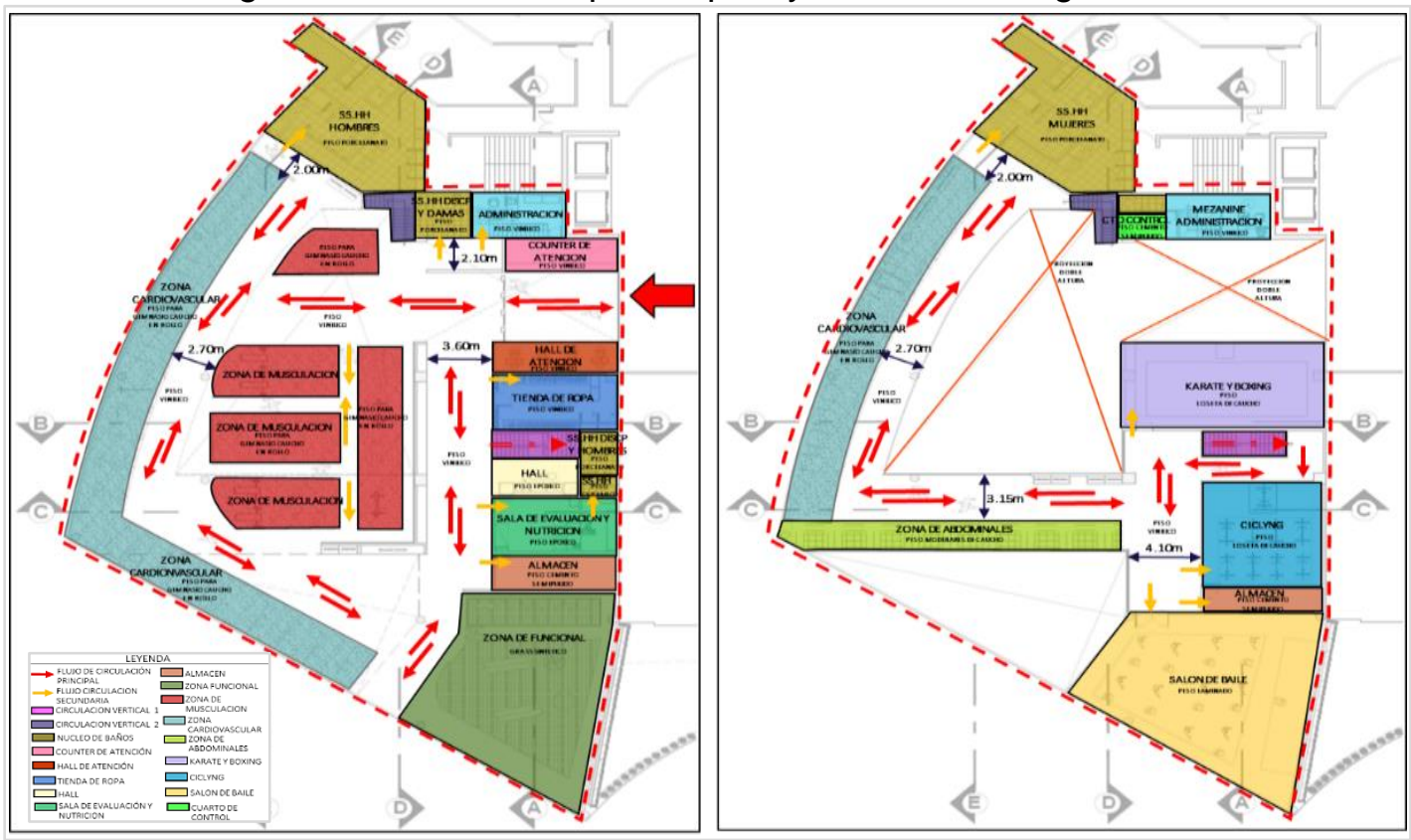

Elaboración Propia.

La arquitectura interior del gimnasio, posee un diseño muy contemporáneo con bastante iluminación a nivel artificial mediante luces LED y natural beneficio de su acabado constructivo del muro cortina para que las actividades deportivas se puedan desarrollar de forma óptima, complementando los espacios amplios. Los acabados son elegantes y 
adecuados para los entrenamientos con pisos laminados, pisos de corcho de caucho en la zona de entrenamientos integrándose con la iluminación cálida de los techos cubiertos por el cielo raso que en la mayoría son de espuma de aluminio estabilizada y otras de cielo raso modular suspendido donde en conjunto le dan calidad a la arquitectura buscando lo más importante de todos los proyectos una experiencia única del lugar.

Figura 122. Cortes arquitectónicos del gimnasio.

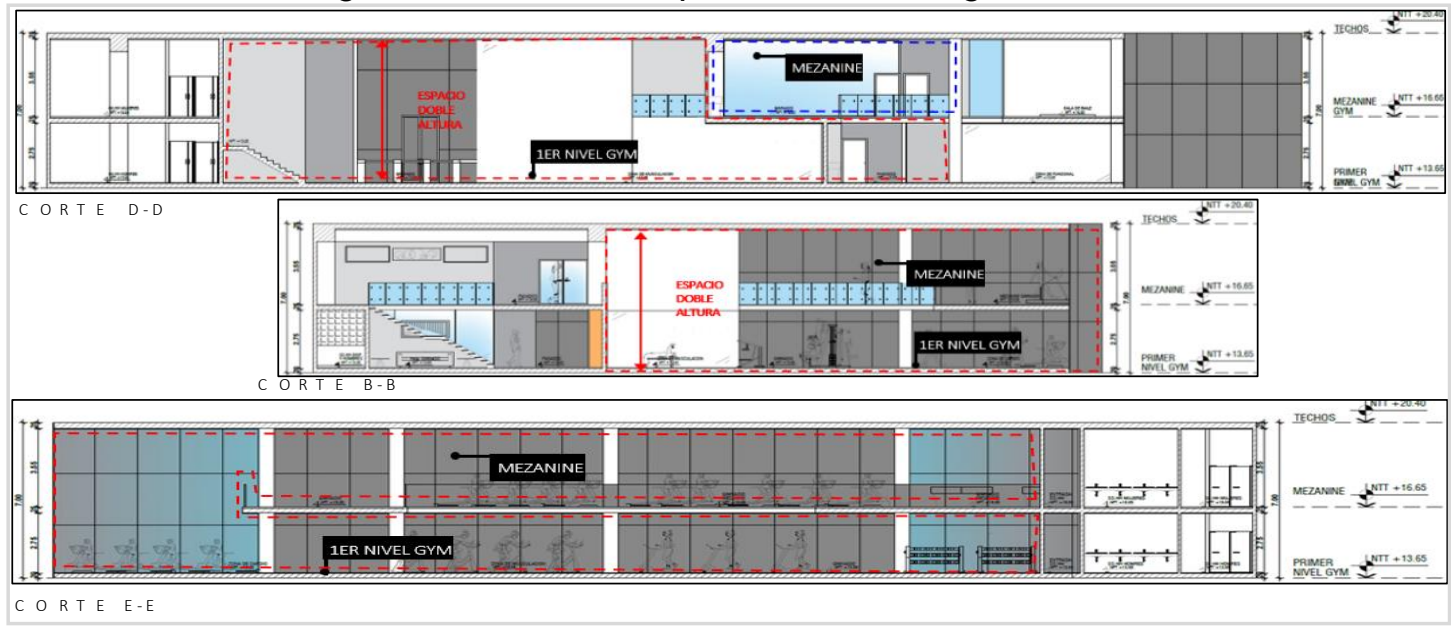

\section{Elaboración Propia.}

Los acabados de los baños en general para todos los tipos existentes en el establecimiento contienen pisos de porcelanato, contrazócalos de porcelanato, paredes de pepelma y cerámico, puertas contraplacadas y cielo raso modular suspendido. $\mathrm{Y}$ en la zona de sauna ubicadas en el interior contiene su acabado con planchas de madera con puertas de vidrio templado.

Figura 123. Vistas interiores del gimnasio.

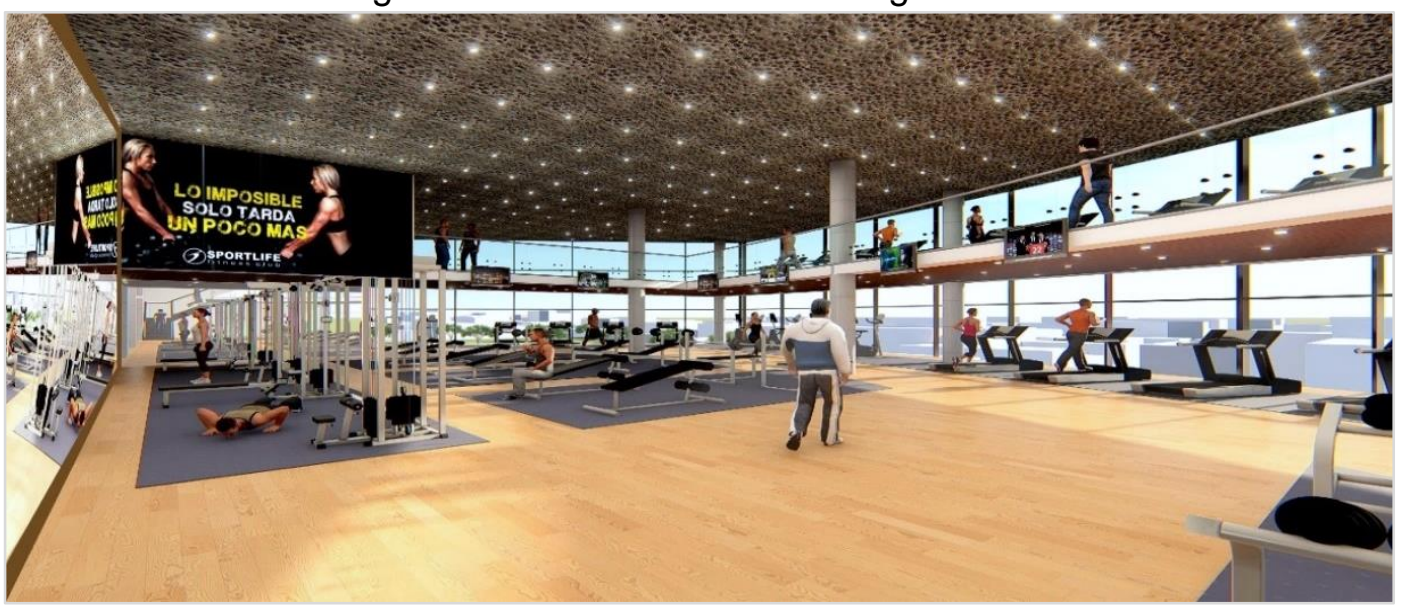

Elaboración Propia. 
Figura 124. Vistas interiores del gimnasio.

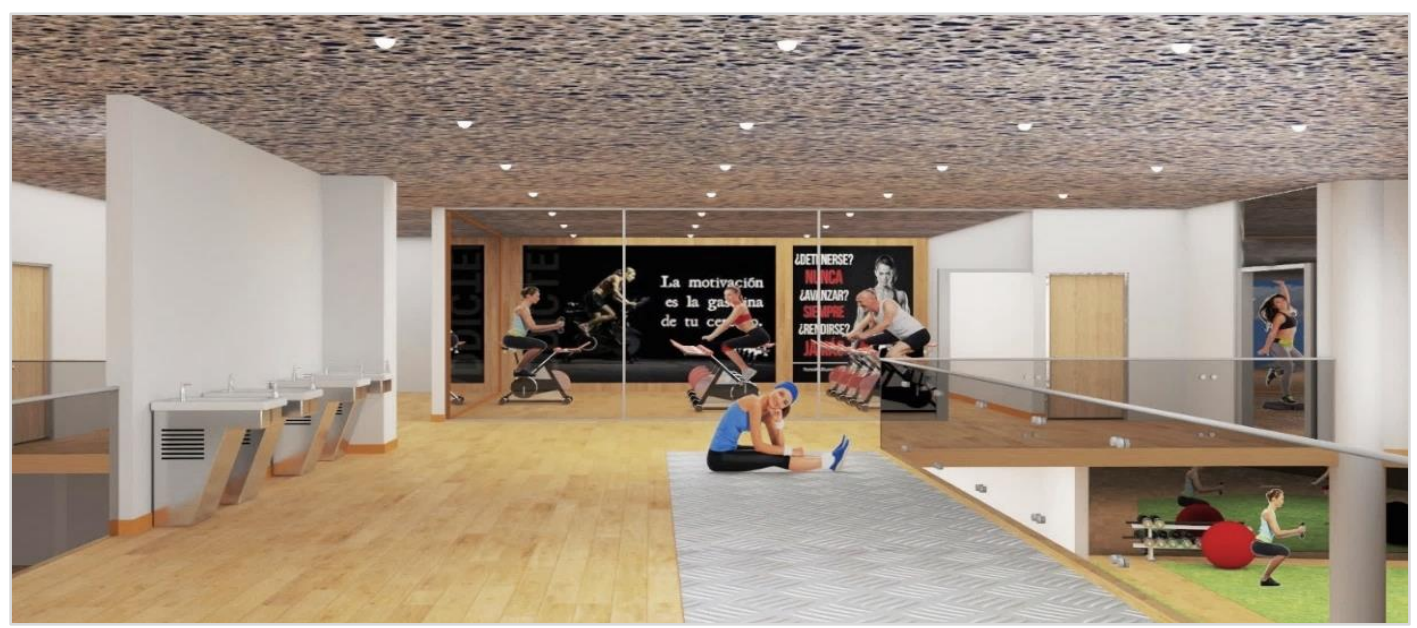

Elaboración Propia.

Figura 125. Vistas interiores del gimnasio.

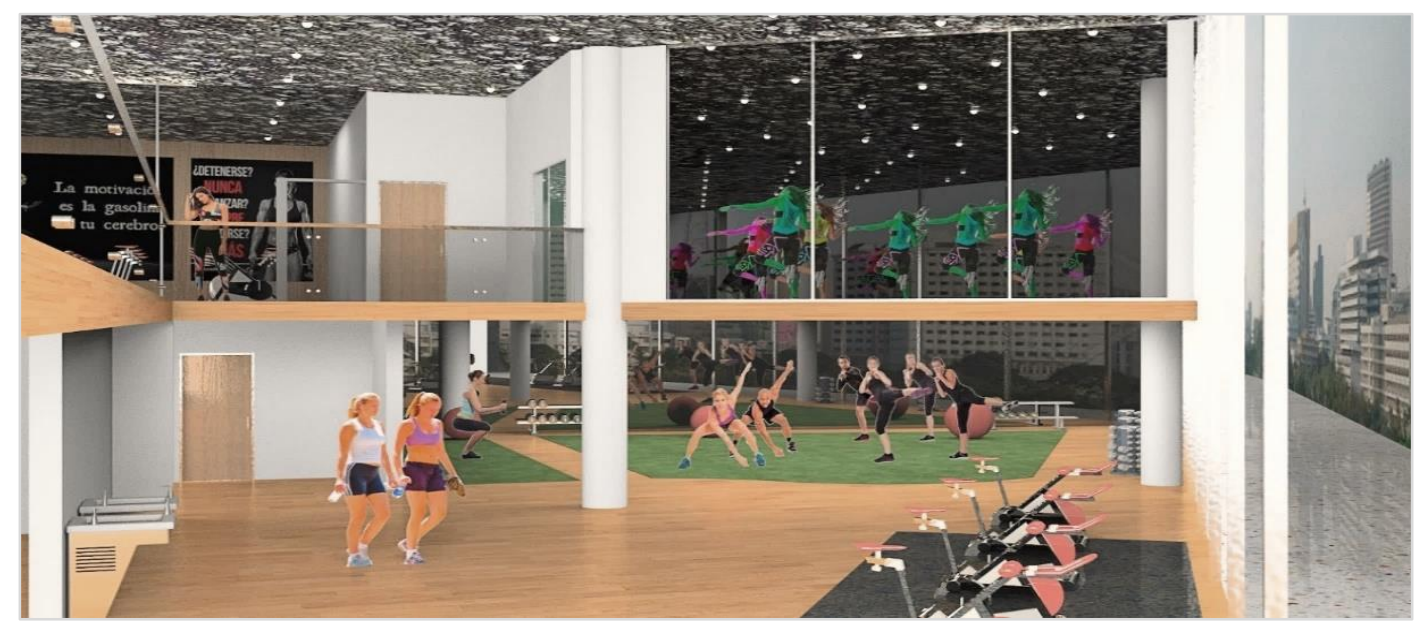

Elaboración Propia.

Figura 126. Vistas interiores baño típico del gimnasio.

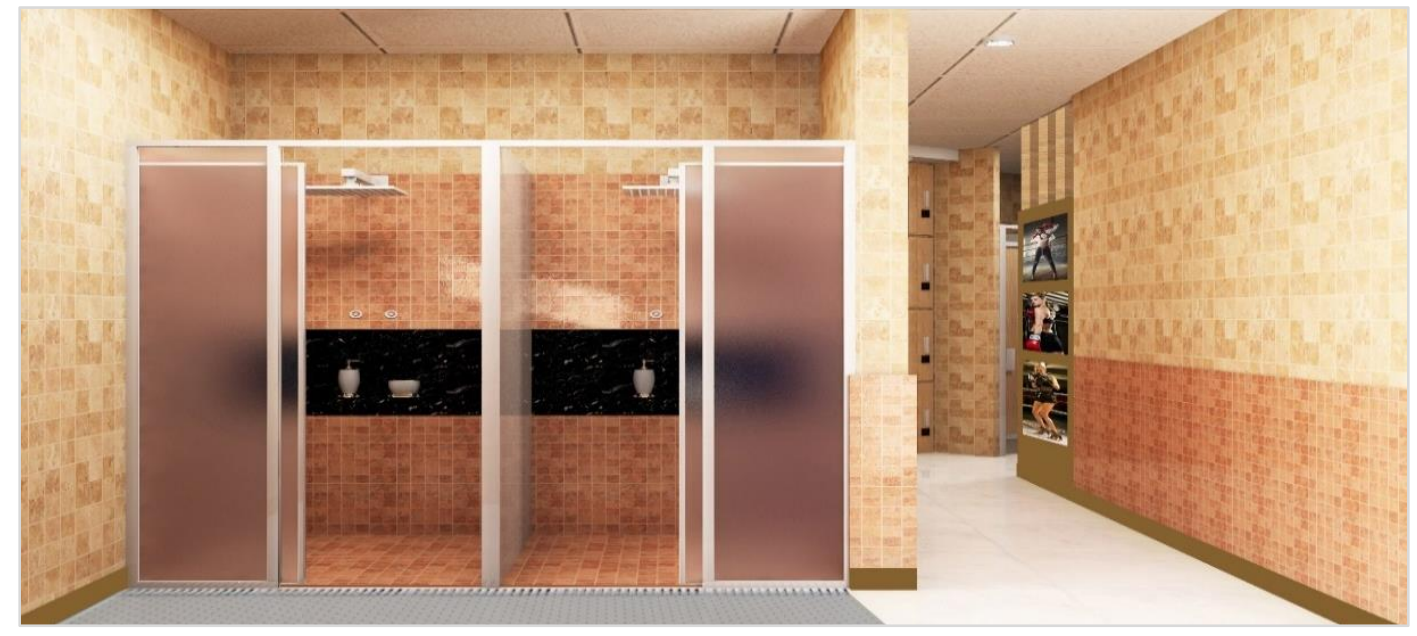

Elaboración Propia. 
Por ello, en cada espacio y zonas del Centro Comercial propuesto tanto en la arquitectura exterior e interior, funcionalidad, y la iluminación son muy importantes para generar un valor diferenciado en el diseño integral. La iluminación sobretodo juega un papel fundamental. En interiores la iluminación se hace presente en los techos, influenciando y guiando el recorrido del peatón, mediante líneas disruptivas, que conjugan con el diseño presentes en muchos detalles de la arquitectura. En exteriores, el punto radial está enfocado hacia la pileta dentro de la plaza, donde se tiene un juego de luces que irradian del piso, de igual manera la volumetría del edificio desprende luminosidad desde su fachada.

Figura 127. Hall típico del centro comercial.

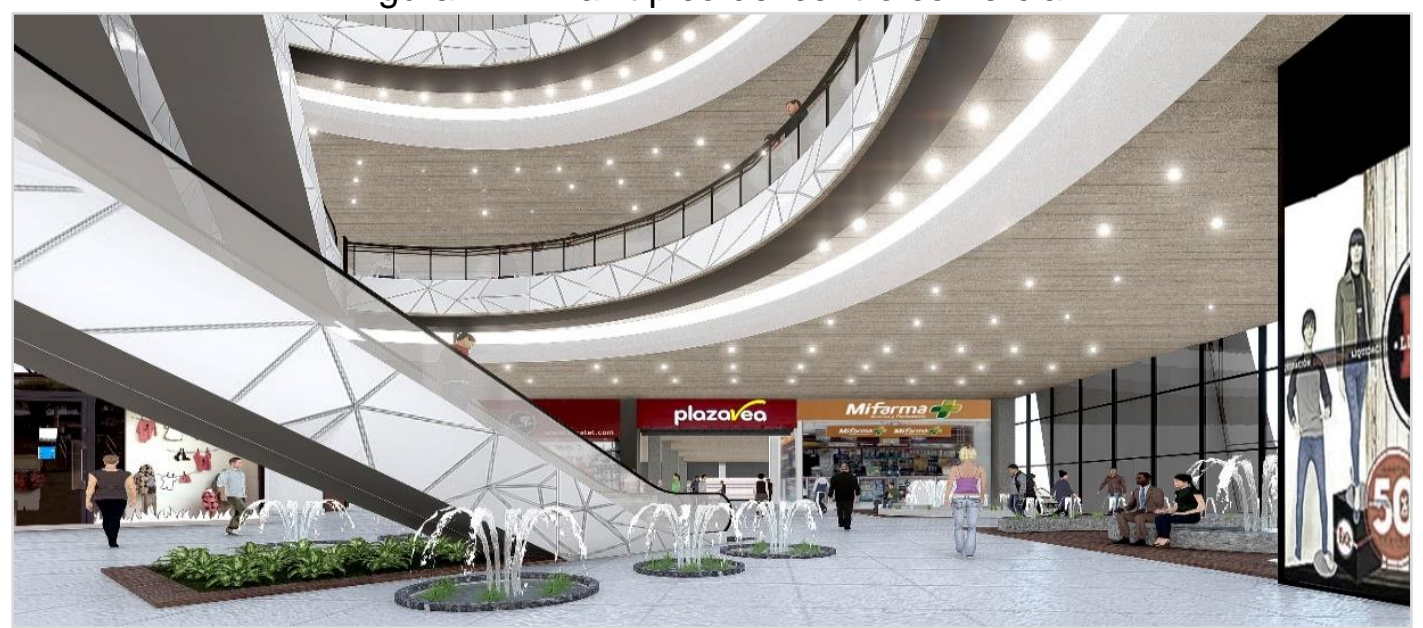

Elaboración Propia.

Figura 128. Vista exterior del centro comercial.

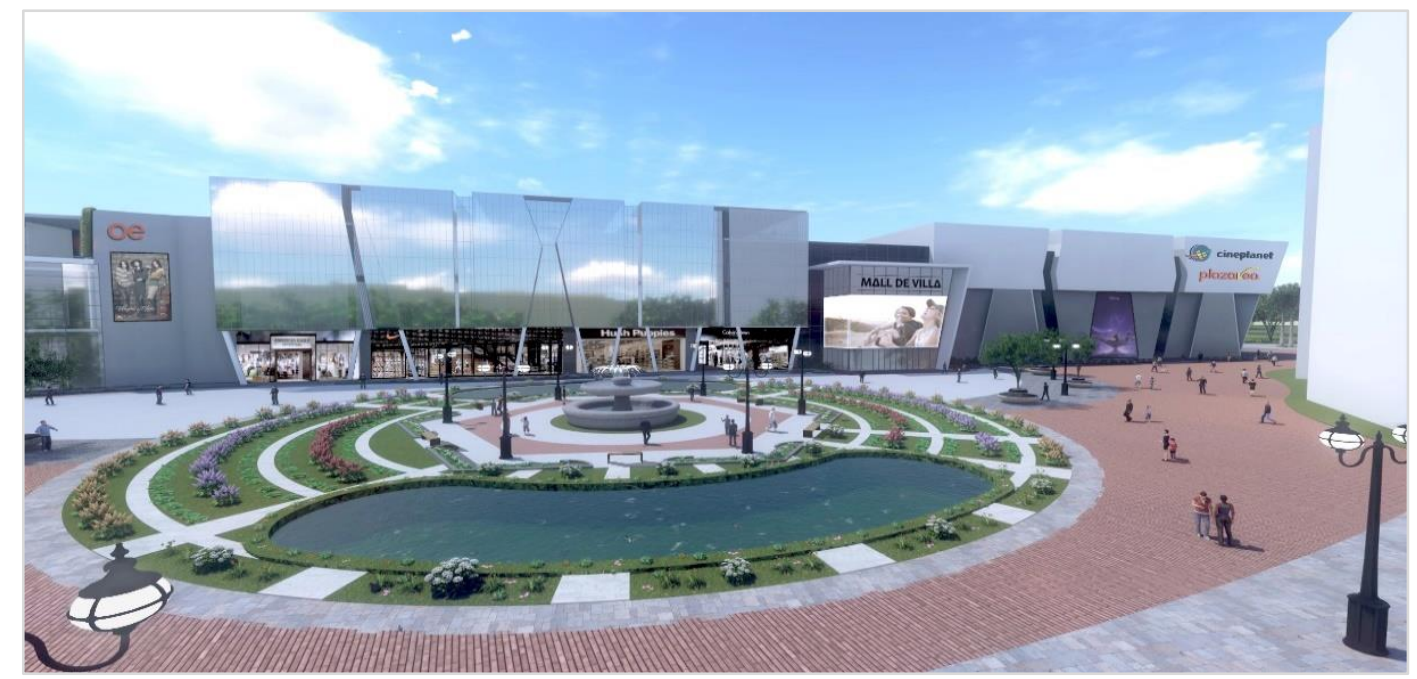

Elaboración Propia. 
Figura 129. Vista nocturna del centro comercial.

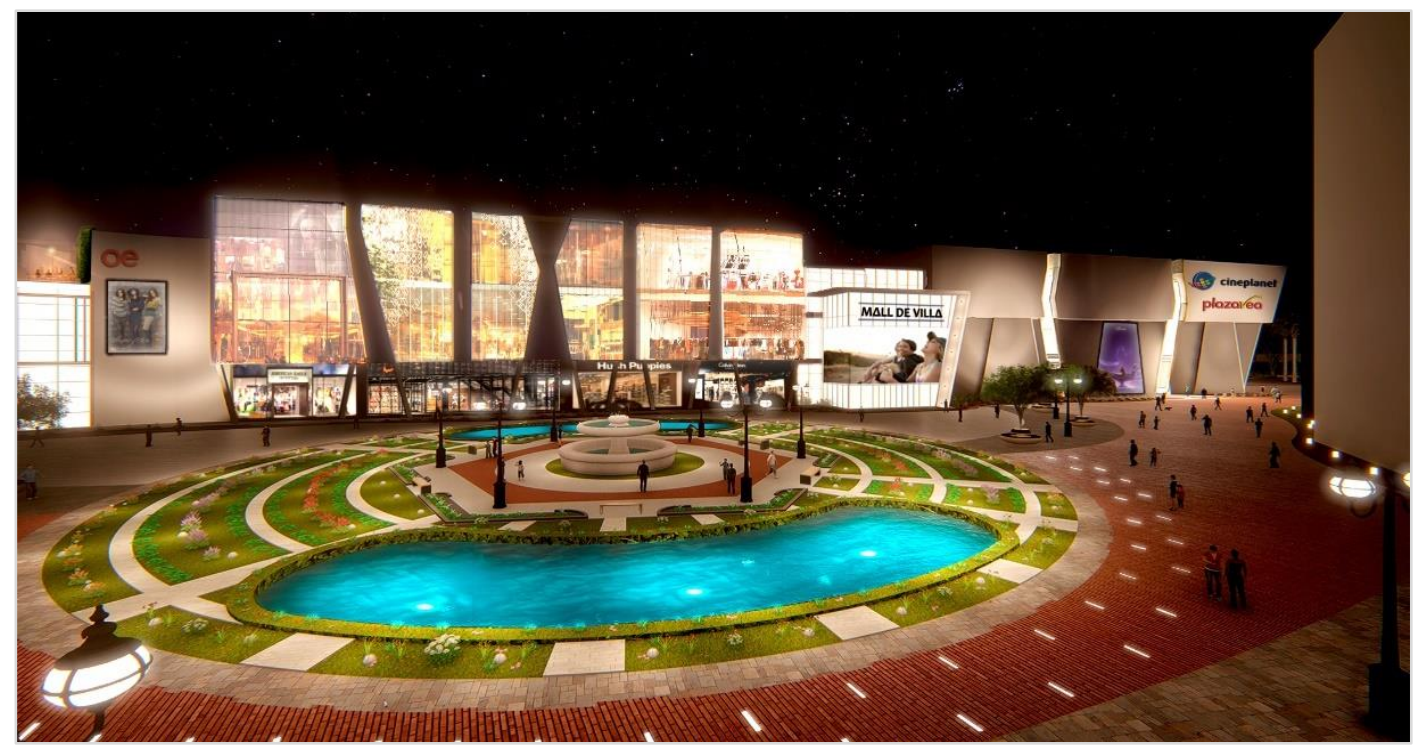

Elaboración Propia.

Finalmente, el muro cortina elemento constructivo en la fachada de gran importancia en casi todo el Centro Comercial, gran factor de la iluminación interior y exterior lo que genera ya sea en el día mediante iluminación natural permitiendo que la luz solar ilumine toda la edificación y en la noche todos los juegos de luces interiores que traspasan la transparencia del muro cortina, generan que las tiendas sean visibles y atractivas visualmente, el contraste con el acabado de superboard más iluminación de los exteriores de las plazas y las diferencias de alturas de los techos muestran la belleza arquitectónica del Centro Comercial en su totalidad.

\section{- ZONA EMPRESARIAL}

La zona empresarial tiene un área total construida de $48,684.49 \mathrm{~m}^{2}$. Al estar en una manzana triangular, tiene 3 accesos viales, donde el principal se da a través de la Av. Calle 1. Sus áreas internas se dividen en: un lobby con un área de $873 \mathrm{~m}^{2}$; tres halls de ascensores con área de $13 \mathrm{~m}^{2}$ cada uno; 96 baños con un total de $22 \mathrm{~m}^{2}$ cada uno. Además, presenta 4 tipos de oficinas: 4 unidades del tipo 1 con $354 \mathrm{~m}^{2}$ cada una; 8 unidades del tipo 2 con $406 \mathrm{~m}^{2}$ cada una, 48 unidades del tipo 3 con $206 \mathrm{~m}^{2}$ cada una; y 96 unidades del tipo 4 con $151 \mathrm{~m}^{2}$ cada una. Asimismo, tiene capacidad para 206 estacionamientos en un área de $12,500 \mathrm{~m}^{2}$ ubicados en sótanos de dos niveles. 
Figura 130. Planta del primer piso de la zona empresarial.

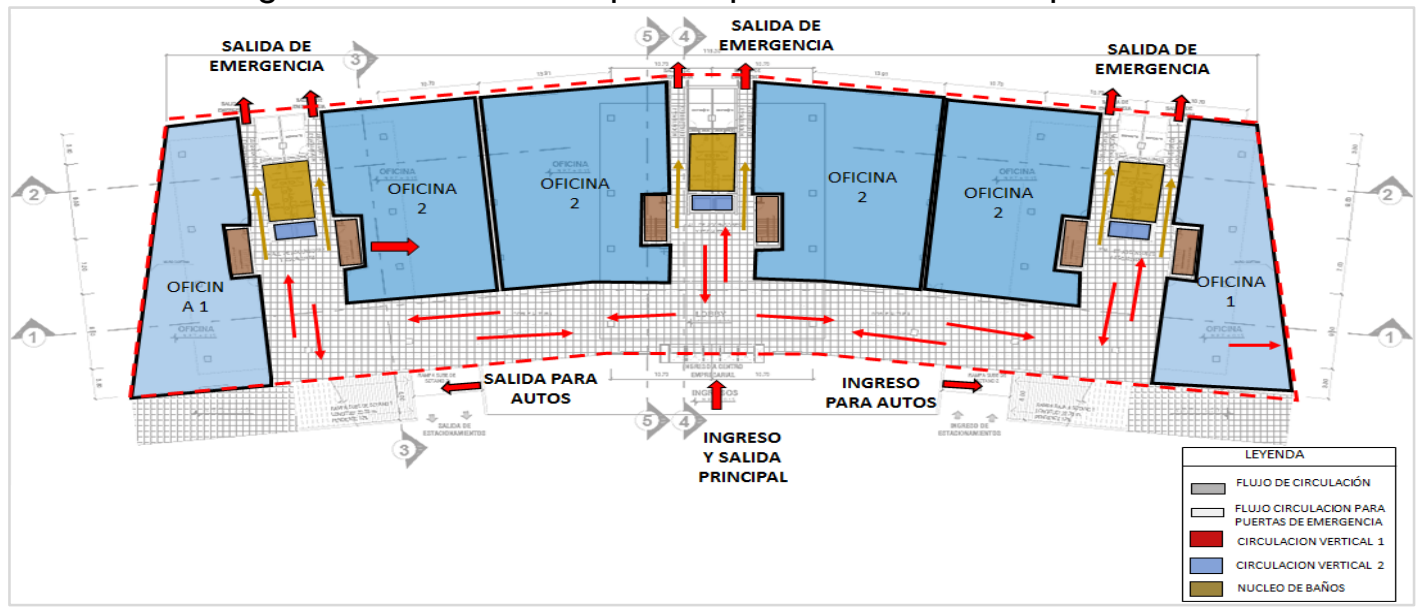

Elaboración Propia.

Arquitectónicamente, emplaza a 3 bloques de torres de 10, 14 y 18 niveles respectivamente, unidos a una platea de base que le suma 2 pisos más a cada uno. Su composición busca crear solidez y a la vez dinamismo, por lo que tiene un orden escalonado; que además ayuda a ampliar las visuales en cada torre y su iluminación. El tipo de construcción que se utiliza en este edificio principalmente son los muros cortina y el concreto expuesto. Estructuralmente, todos los núcleos de ascensores, escaleras y S.S.H.H. rigen debidamente alineados, asegurando su estabilidad y seguridad.

Figura 131. Cortes y planta típica de edificio empresarial.

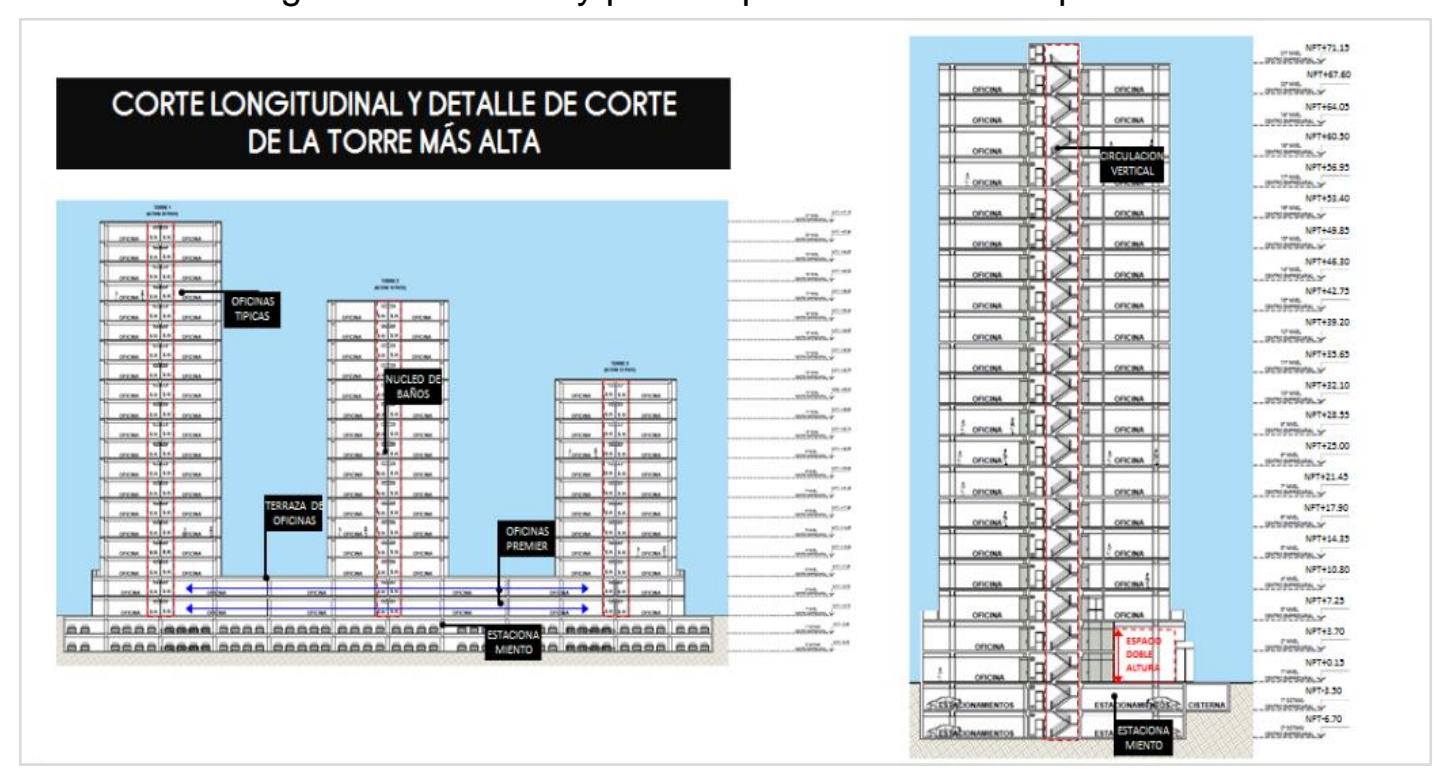

Elaboración Propia. 
Figura 132. Cortes y planta típica de edificio empresarial.

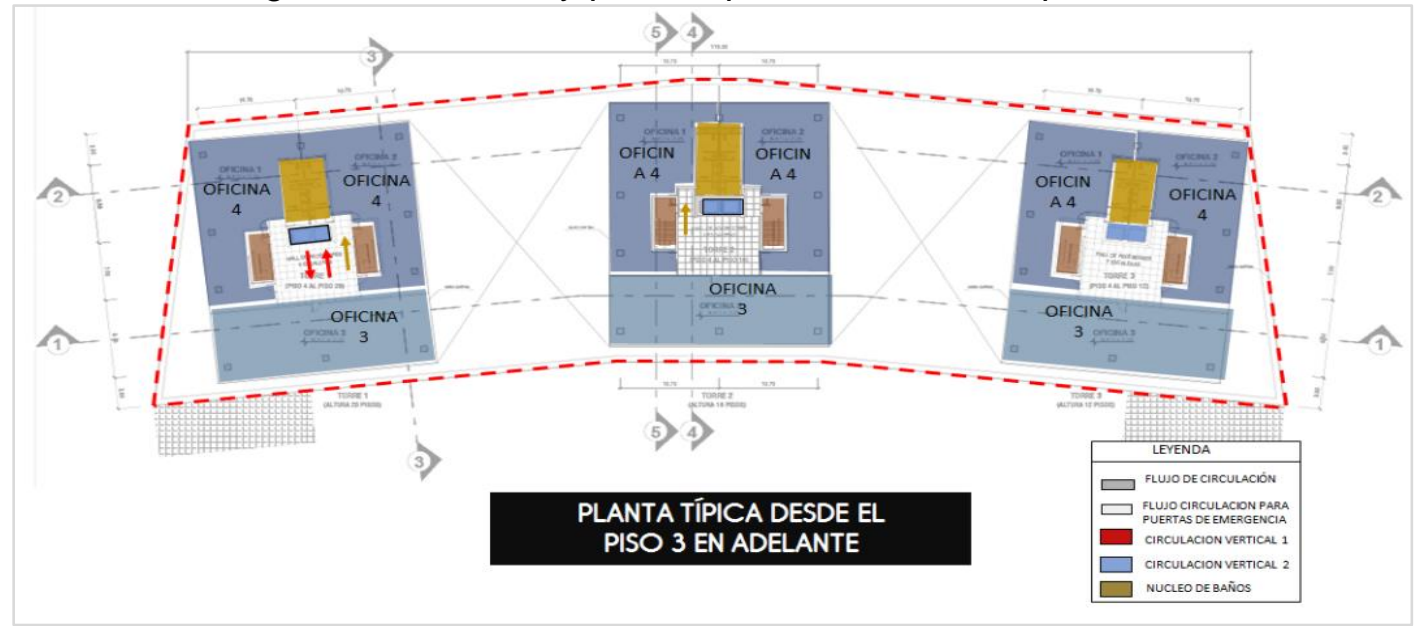

Elaboración Propia.

\section{- ZONA RESIDENCIAL}

La zona residencial de las etapas 2 y 3 , tiene un área total construida de $133,387.76 \mathrm{~m}^{2}$. Las etapas 1 y 2 , tienen acceso principal a través de la Av. María Elena Moyano, mientras que la etapa 3 accede por calles S/N. Tanto la etapa 2 y la 3, tienen 5 bloques de edificios residenciales; a diferencia de la etapa 1, que tiene 7 bloques. Tiene por característica, continuar el lenguaje escalonado de la zona empresarial; de esta forma, los bloques 1 y 2 , tienen 12 pisos, el bloque 3 tiene 15 pisos, el bloque 4 tiene 17 pisos, y finalmente, el bloque 5 tiene 20 pisos.

Figura 133. Relación de pisos en bloques residenciales.

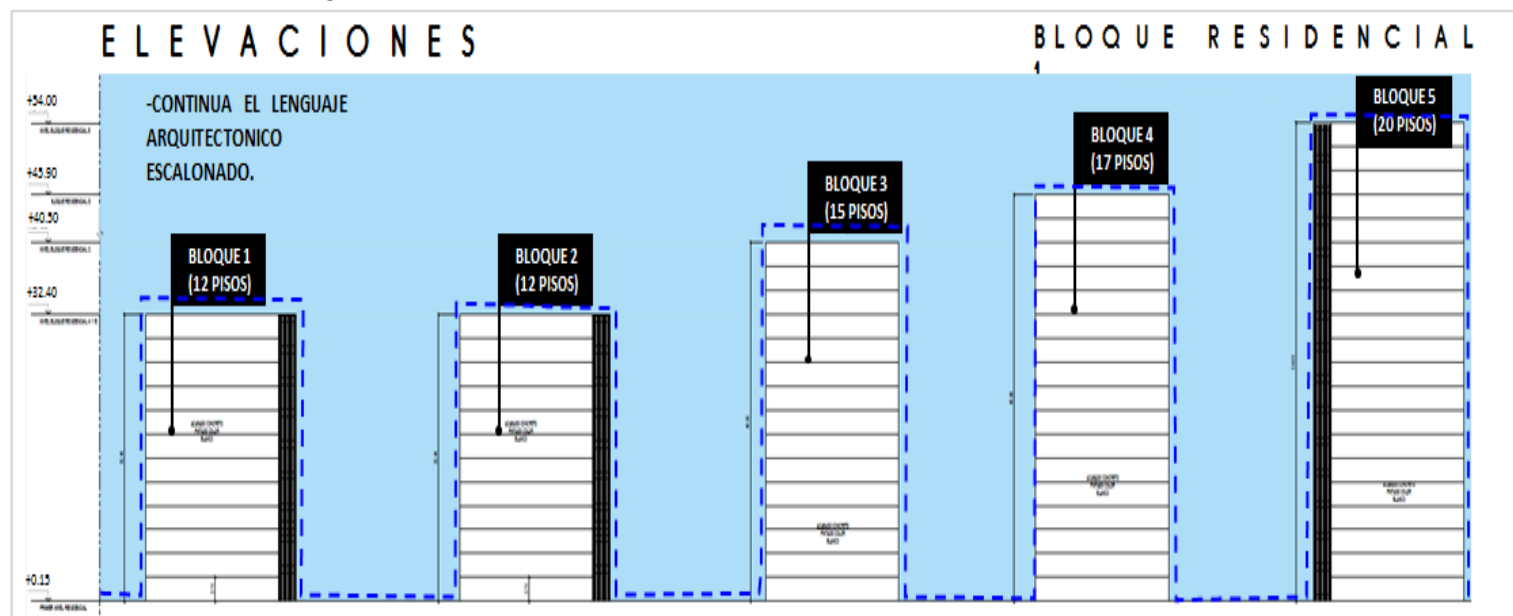

Elaboración Propia. 


\section{- ZONA RECREATIVA}

La zona recreativa tiene un área total de 288,033.12 $\mathrm{m}^{2}$. Su acceso principal es por calles $\mathrm{S} / \mathrm{N}$. Esta área tiene concordancia espacial con el centro comercial, el centro empresarial y los bloques residenciales de la etapa 3. Se hizo esta propuesta para liberar visualmente el espacio y generar equilibrio entre llenos y vacíos, e igualmente funciona perfectamente como área de recreación y ocio, para las demás zonas.

Figura 134. Planta del Parque Temático en el proyecto.

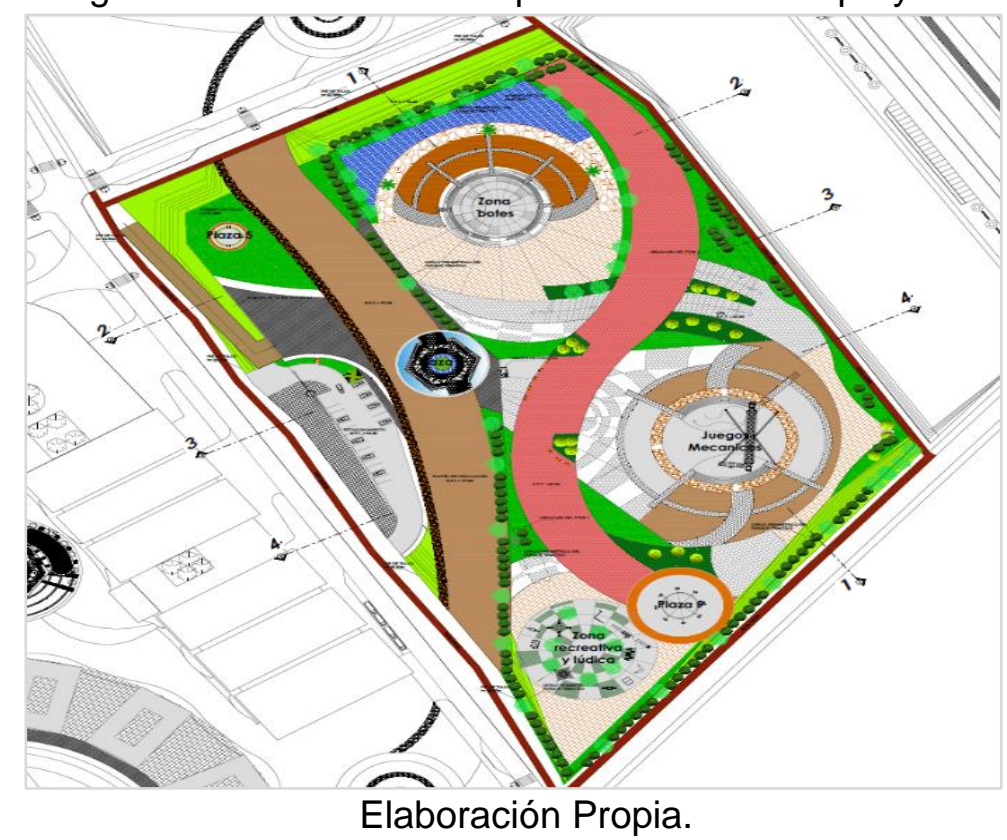

Figura 135. Cortes de parque temático.

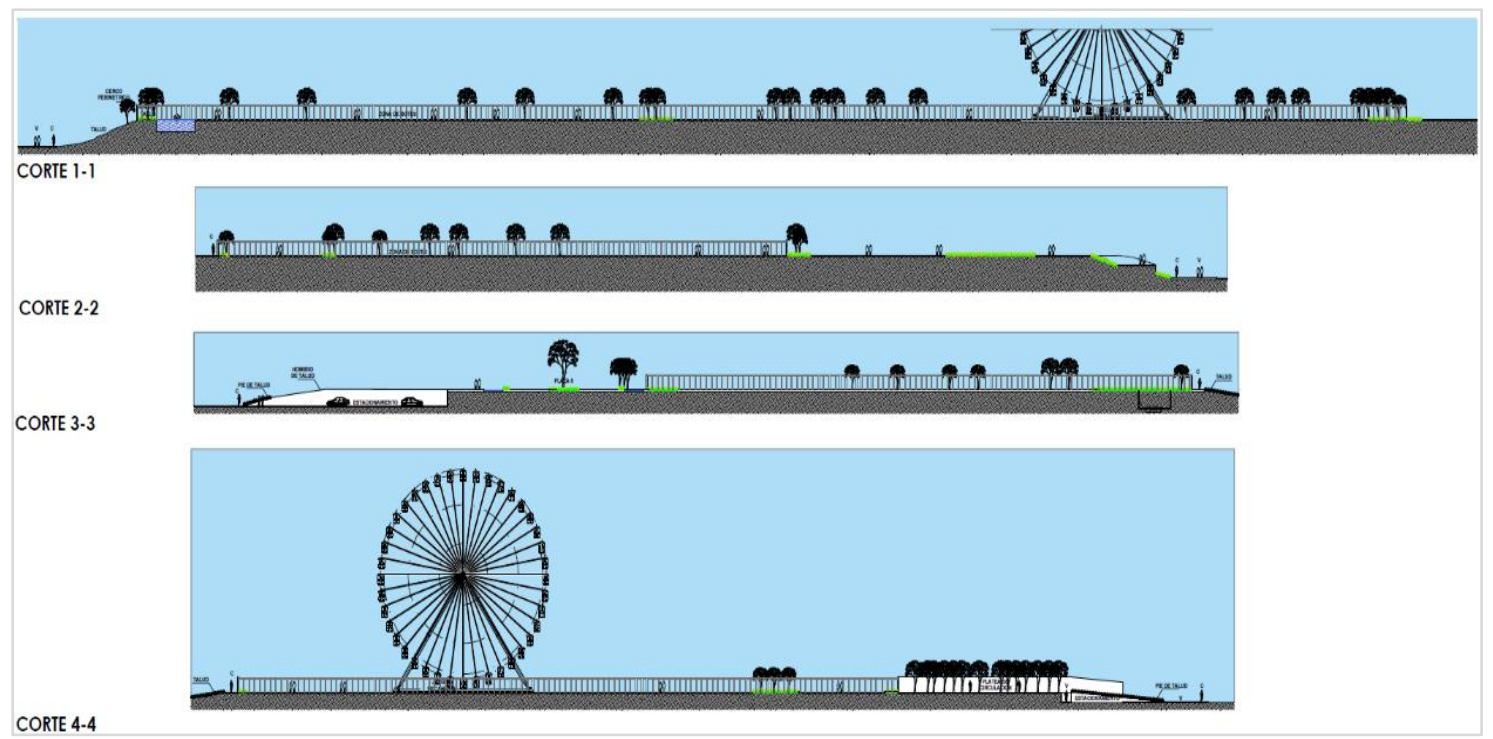

Elaboración Propia. 
Finalmente, se muestra el proyecto integral que consta de los volúmenes del centro comercial, centro empresarial, los bloques de vivienda de 2da y 3era etapa de la Villa Panamericana, el parque temático, las plazas y piletas distribuidas en todo el proyecto propuesto, la red de ciclovía y las áreas verdes, las vías secundarias, principales, las peatonales y los ingresos en toda el área de intervención que permite la interconexión con las demás calles de Villa el Salvador.

Figura 136. Vistas de proyecto integral.

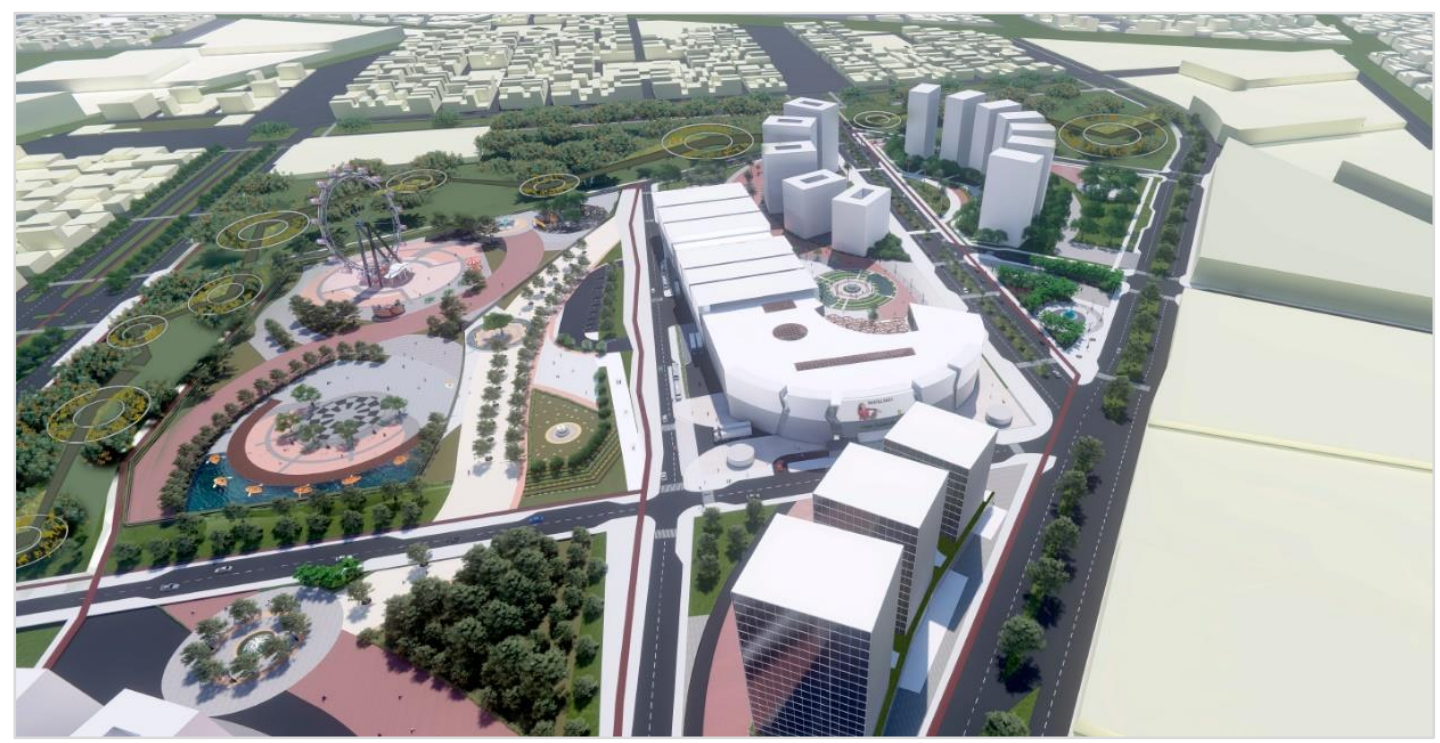

Elaboración Propia.

Figura 137. Vistas de proyecto integral.

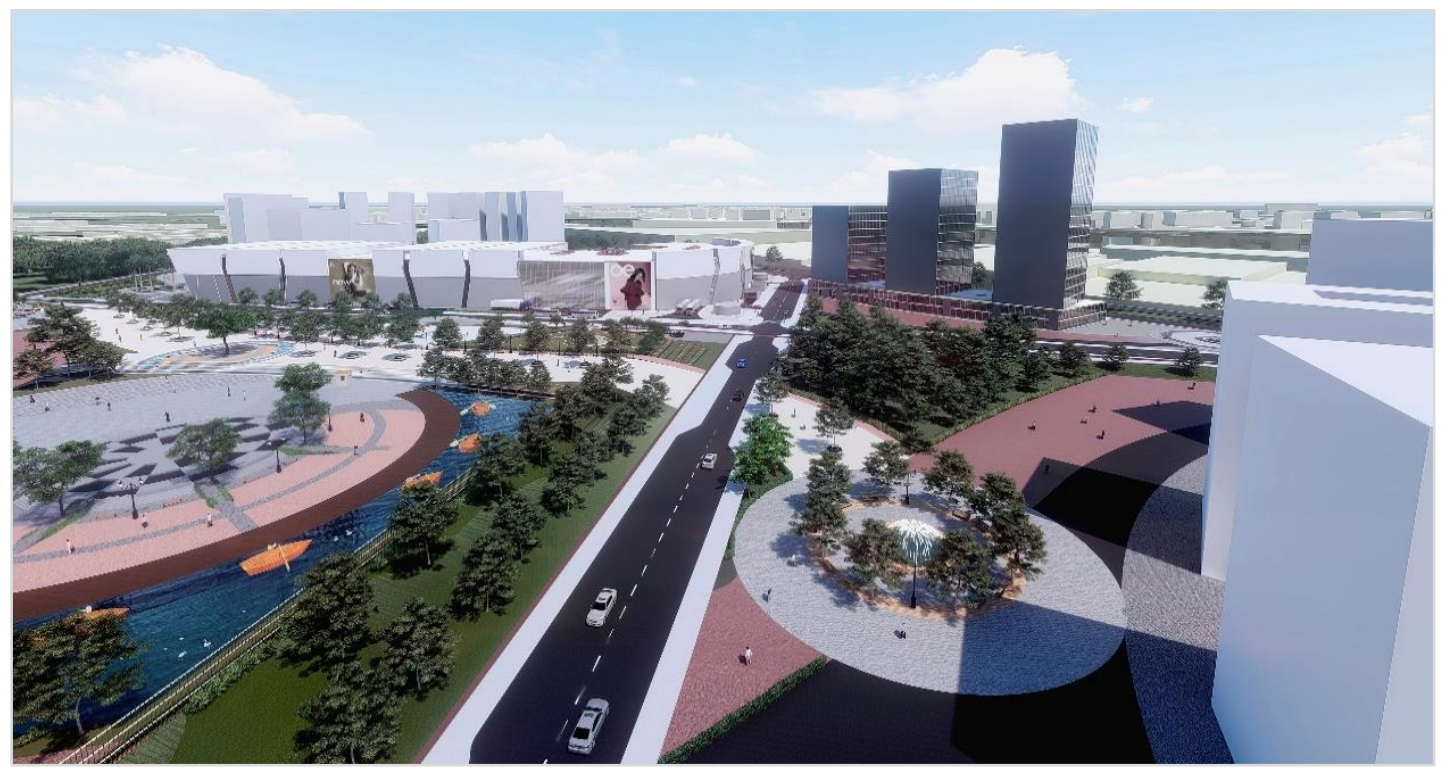

Elaboración Propia. 


\subsubsection{Cuadro de Áreas del Proyecto}

Tabla 10. Áreas conjuntas del proyecto.

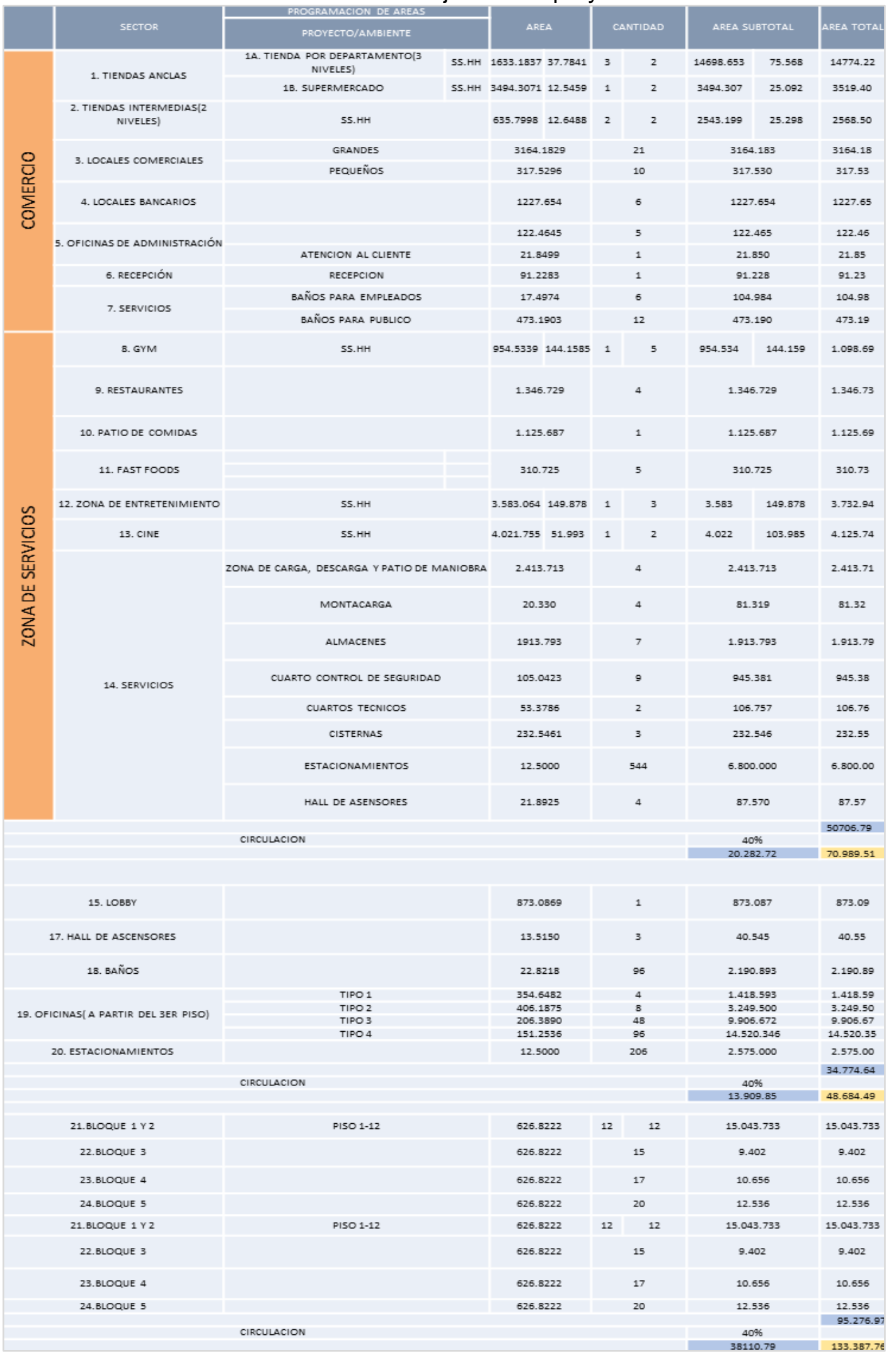

\section{Elaboración Propia.}


5.3.7. Acabados.

Tabla 11. Acabados presentes en el diseño.

\begin{tabular}{|c|c|c|c|}
\hline \multirow{2}{*}{ INFRAESTRUCTURA } & \multicolumn{3}{|c|}{ CUADRO DE ACABADOS GENERAL EXTERIORES } \\
\hline & COD. & DESCEIPCION & ACABADO O ITEM \\
\hline \multirow{4}{*}{ 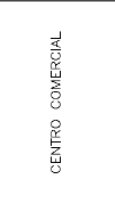 } & 1 & $\begin{array}{l}\text { FACHADA } \\
\text { INGRESO } \\
Y_{2}\end{array}$ & $\begin{array}{l}\text { MURO CORTINA MDEIO COLOR GFIS O } \\
\text { INCOLORO SEGÚN INOICACION. }\end{array}$ \\
\hline & 2 & $\begin{array}{ll}\text { FACHADA } \\
\text { INGRESO } 3 \\
\end{array}$ & $\begin{array}{l}\text { SUPERBDARD ACABADO PINTURA } \\
\text { ECOLOGICA GRIS }\end{array}$ \\
\hline & 3 & PAREDES & $\begin{array}{l}\text { SUPERBOARD ACABADO FINTURA } \\
\text { ECOLOGICA GRIS }\end{array}$ \\
\hline & 4 & TECHOS & B-MORPH RECUERIMAIENTO \\
\hline \multirow{3}{*}{ 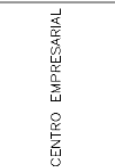 } & \multirow[t]{2}{*}{1} & \multirow{2}{*}{ PAREDES } & $\begin{array}{l}\text { MURO CORTINA YDRIO COLOR GRIS O } \\
\text { INCOLORO SEGÚN INDICACIÓN. }\end{array}$ \\
\hline & & & B-MORPH RECUERIMIIENTO \\
\hline & 2 & TECHOS & B-MORPH RECUBRIMIENTO \\
\hline \multirow{2}{*}{ 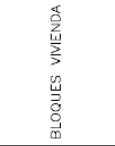 } & 1 & PAREDES & $\begin{array}{l}\text { CONCRETO PRUACADOR DE AIRE INGENA } \\
\text { CONCRETCS PINTADO COLOR BLANCO }\end{array}$ \\
\hline & 2 & TECHOS & $\begin{array}{l}\text { CONCRETO PRUFICADOR DE, ARE INGENIA } \\
\text { CONCRETOS PINTADO CLLOR BLANCO }\end{array}$ \\
\hline
\end{tabular}

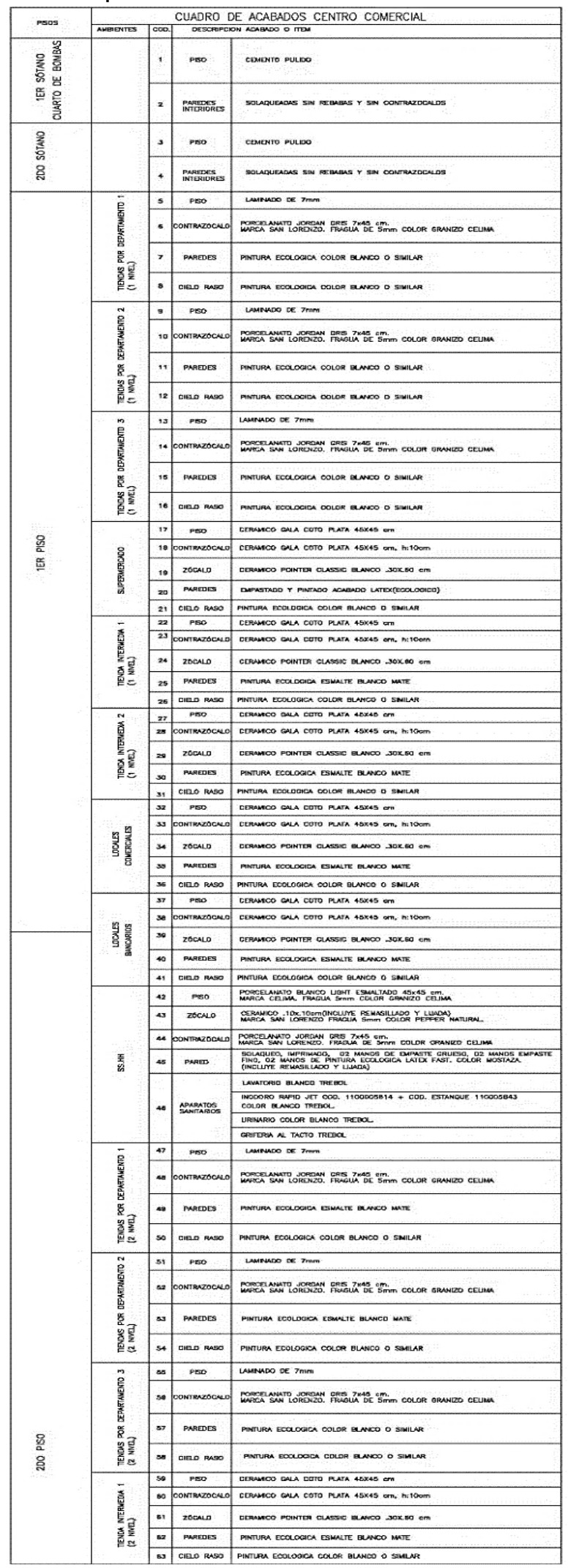

Elaboración Propia. 


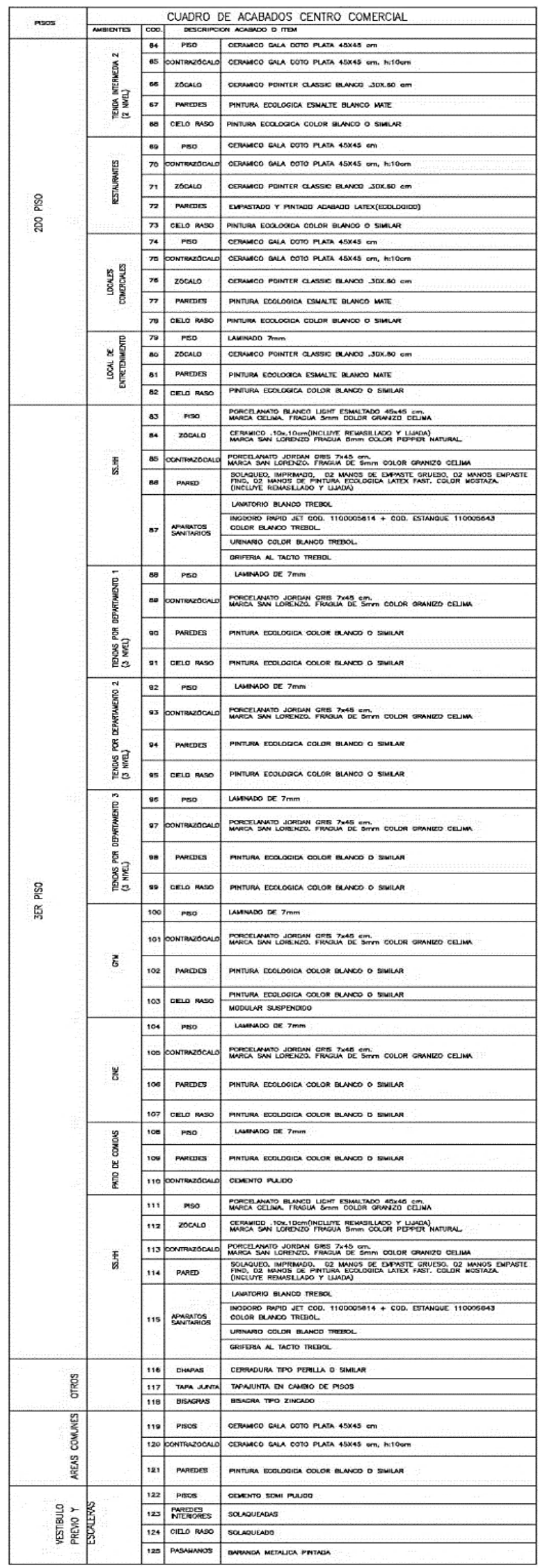

Elaboración Propia. 


\subsubsection{Sostenibilidad.}

Hay diversos términos de arquitectura ecológica o sostenible y una forma de lograrlo es también mediante su sistema constructivo al utilizar opciones con un menor impacto medio ambiental. Por ello, el proyecto es de esencia sostenible primero, porque a la larga reducirá costos contemplando algunos sistemas sostenibles, además de materiales constructivos ecológicos y reciclados para que sea ambientalmente amigable, de esta manera logra grandes beneficios para el medio ambiente, principalmente la mitigación de los efectos de los cambios climáticos, mejora la calidad del aire, la optimización de aguas mediante pozos residuales, absorción del $\mathrm{CO} 2$, disminución de huella de carbono, el ahorro de energía. A continuación, se detallan las opciones y materiales constructivos sostenibles:

Figura 138. Conceptualización de proyecto sostenible.

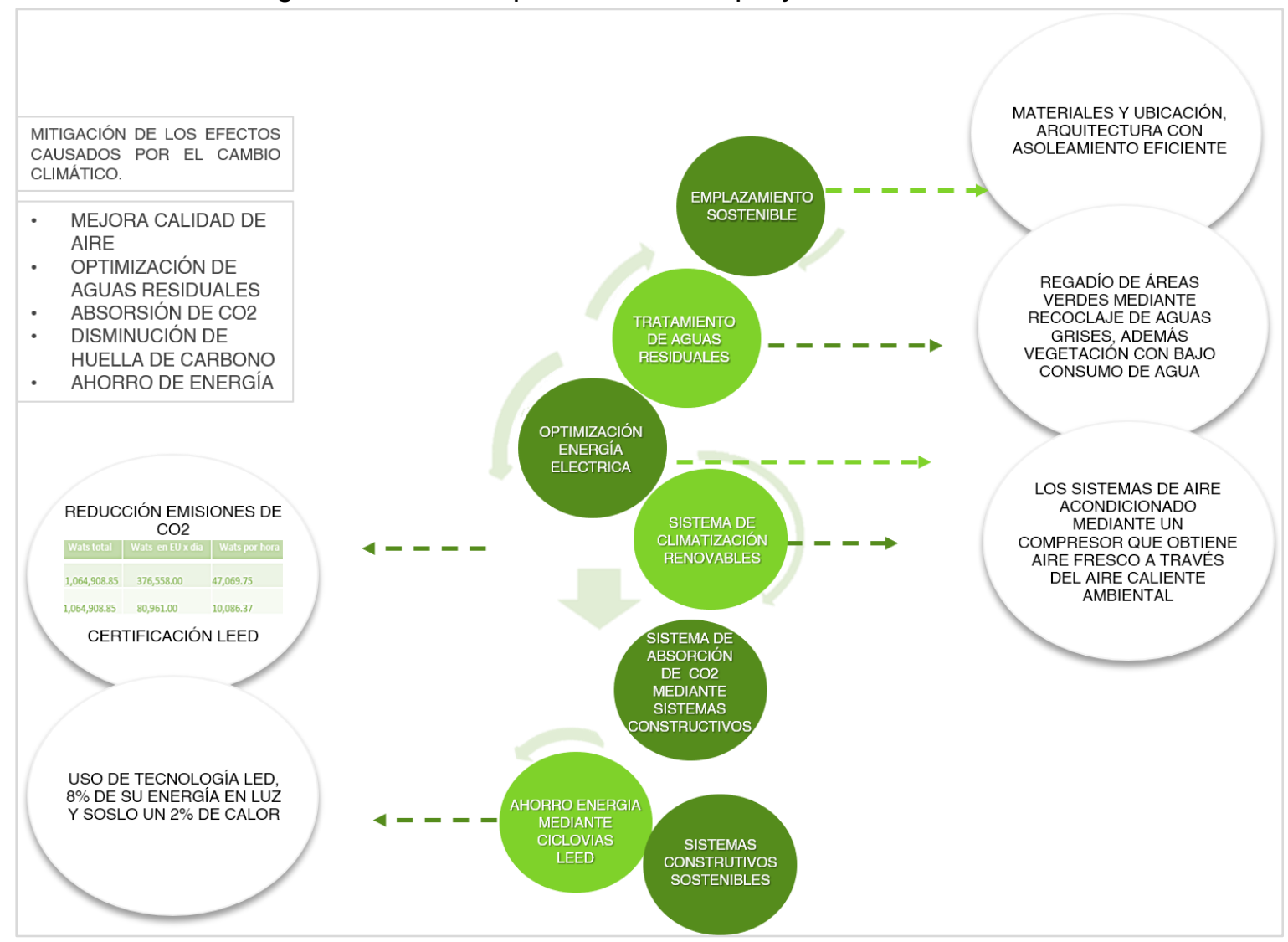

Elaboración Propia. 


\section{- Cemento Ecológico}

- Material que se utilizará en todas las construcciones del proyecto propuesto principal material eco amigable de la intervención.

- Su principal característica es que se usa para cualquier tipo de construcción.

- Reduce hasta un $50 \%$ de emisiones de gas por su proceso de fabricación.

- Es más ligera que el convencional y da un mejor acabado.

- Soportan agentes externos como hidrocarburos, los álcalis, las sales y aceites minerales, empresas como de la marca INKA poseen este producto de cementos ecológicos.

Figura 139. Cemento en fachadas.

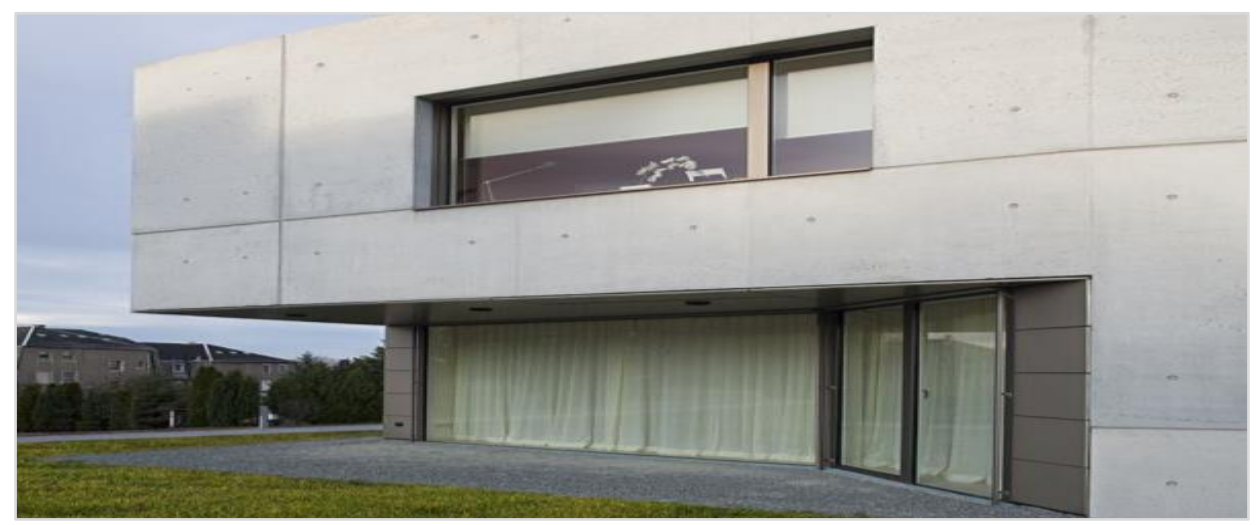

Fuente: Casa minimalista con fachada en cemento, Portal fachadas de casas, 2013.

\section{- Adoquines Reciclados marca CICLO}

- Se utilizará en todos los espacios exteriores de recreación y plazas del proyecto.

- Producto obtenido de reciclaje RCD sostenible, porque en su fabricación de materiales convencionales reducen la explotación de los recursos naturales.

- Medidas 4cm (altura) x 10cm (ancho) x $20 \mathrm{~cm}$ (largo).

- NTP.399.611

- Resistencia a la compresión: $290 \mathrm{~kg} / \mathrm{cm} 2$

- Color gris, rojo, anaranjado y otras variedades. 
Figura 140. Adoquín rojo y grises.

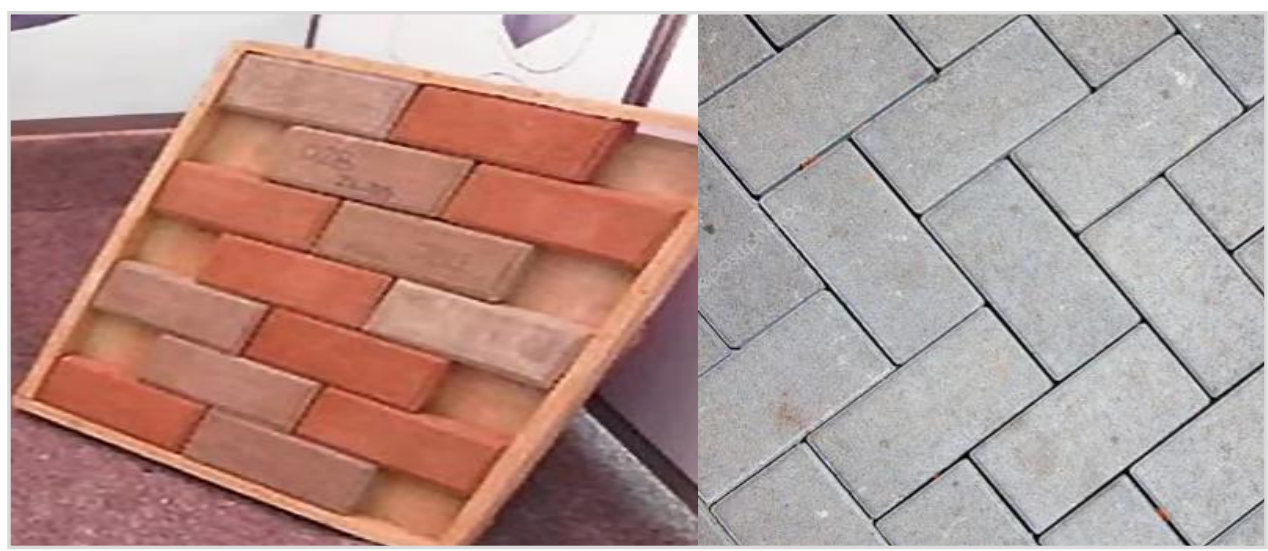

Fuente: Adoquines eco amigables, Productos marca Ciclo, 2020.

\section{- Ladrillos Reciclados marca CICLO}

- Producto de construcción que se utilizará en todas las tabiquerías de todas las infraestructuras del proyecto.

- Opción de material constructivo mediante el reciclaje RCD que transforma los residuos en nuevos materiales eco amigables.

- Medidas: 9cm (altura)X13cm (ancho)x 23 cm(largo)

- Resistencia a la compresión 130 kg/cm2

Figura 141. Ladrillo ecológico.

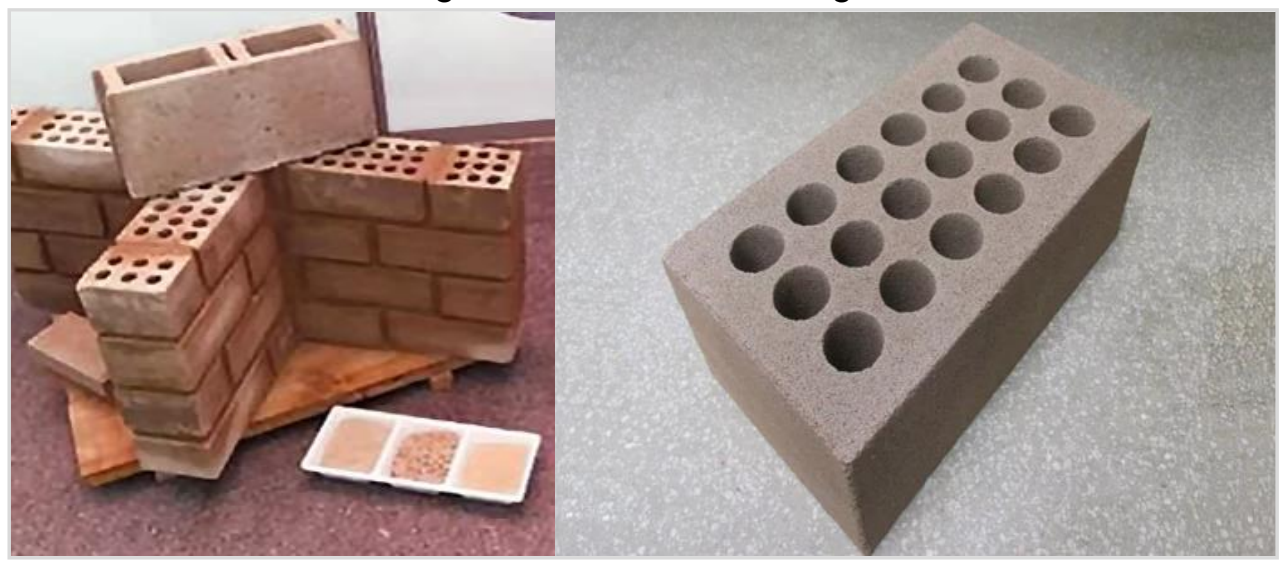

Fuente: ladrillos eco amigables, Productos marca Ciclo, 2020. 


\section{- Revestimiento tecnología B-MORPH}

- Material principal que se utilizará en gran parte del Centro Comercial en conjunto con el superboard.

- Hecho en base de plástico reciclado con nanotecnología que degrada gases contaminantes en su superficie B-Tile que neutraliza los gases contaminantes.

- Diseños geométricos de plegado flexibles y personalizados con losetas.

- Medidas $0.45 \mathrm{~cm} \times 0.45 \mathrm{~cm}$.

- Revestimiento exterior de fachadas que neutraliza los gases contaminantes, mediante un proceso de nanotecnología.

Figura 142. Revestimiento B-Morph.

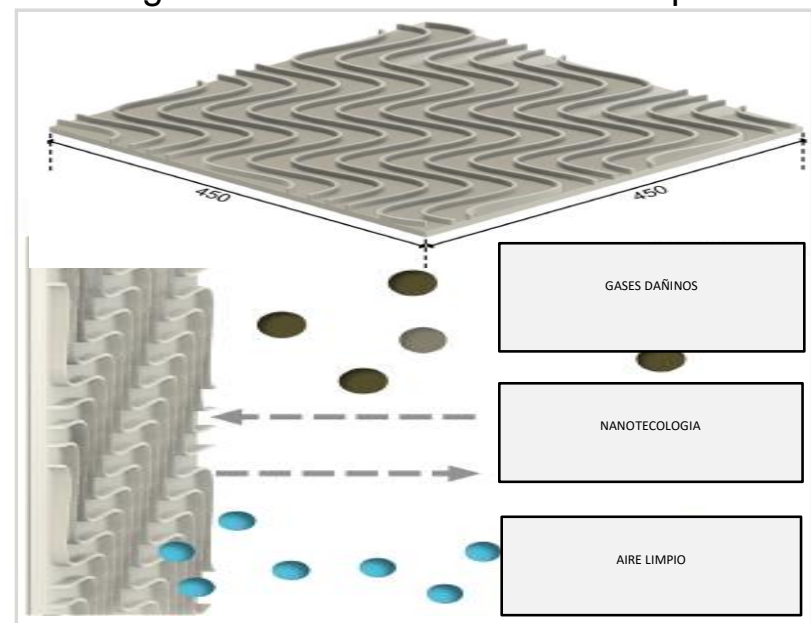

Fuente: ¿Ciudades que se comen el smog?, Publimetro, Arce G, 2019.

\section{- Concreto purificador de aire marca INGENIA CONCRETOS}

- Este material se utilizará en las fachadas del Centro Empresarial y 2do y 3 er bloque bloques de viviendas del proyecto.

- Las placas de concreto absorben gases de efecto invernadero, y los transforman en nitratos, sustancias que funcionan como fertilizante en las plantas.

- Hechas de fibras orgánicas y caucho de llantas materiales que al reaccionar con la luz solar y contaminantes del aire actúan como la fotosíntesis.

- Se utiliza para acabados de edificios y fachadas arquitectónicas. 
Figura 143. Concreto purificador.

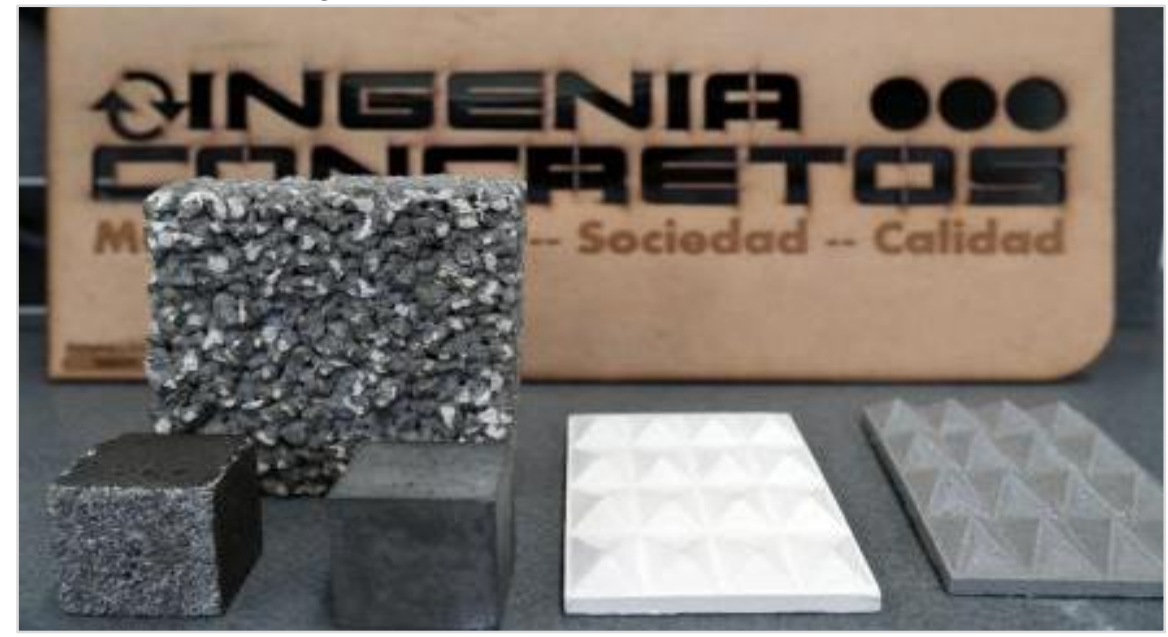

Fuente: Jóvenes de la UNAM crean un concreto que purifica el aire, Ángeles B, 2018.

\section{- Pavimento solar}

- Este nuevo de diseño se utilizará en toda la red de ciclovía planteada en el proyecto.

- Ciclovías hechas con revestimiento con piedras LED para que puedan cargarse con la luz del sol, que se libere por la noche, iluminando los caminos hasta por 10 horas seguidas. (Este sistema ya se utiliza en Polonia y Holanda).

Figura 144. Ciclovía con aplicación de pavimento solar.

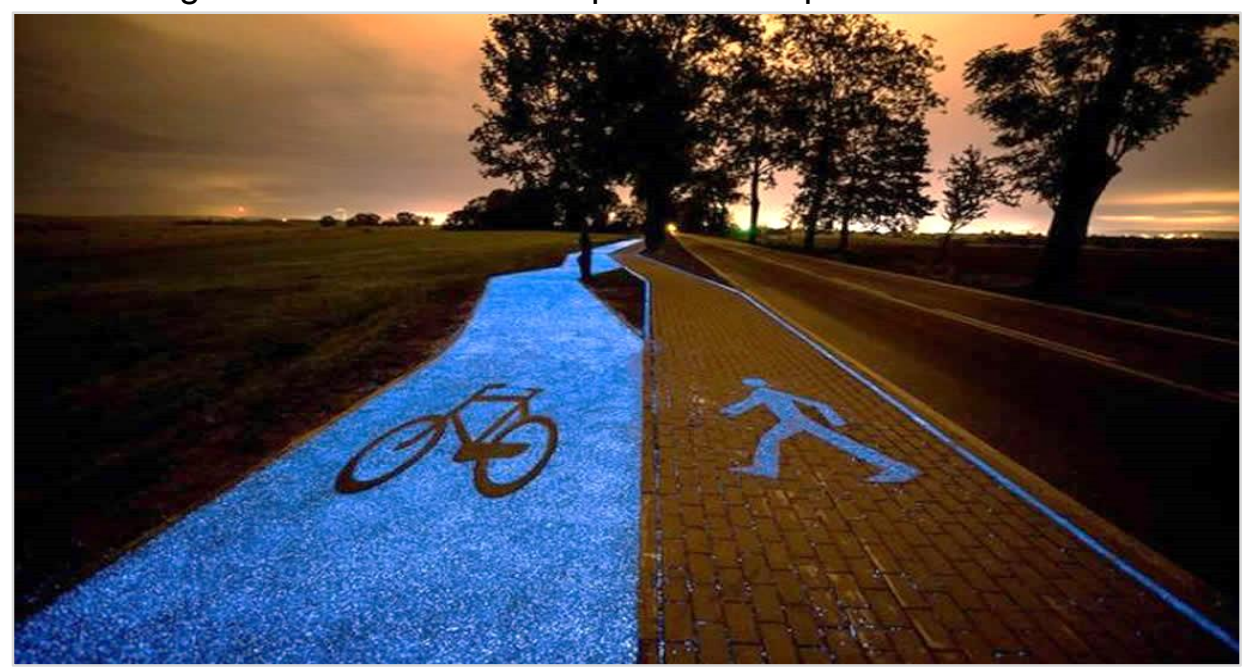

Fuente: Holanda estrena la primera ciclovía solar del mundo que le da energía a una ciudad, Intriper, 2015. 


\section{- Pintura ecológica}

- Pintura para aplicar en los acabados de las edificaciones del proyecto.

- Esta pintura para aplicar a interiores y exteriores.

- Opción de material eco amigable de larga duración.

- Se puede aplicar en todo tipo de construcciones.

- Tiene acabado mate.

Figura 145. Pintura ECO de American Colors.

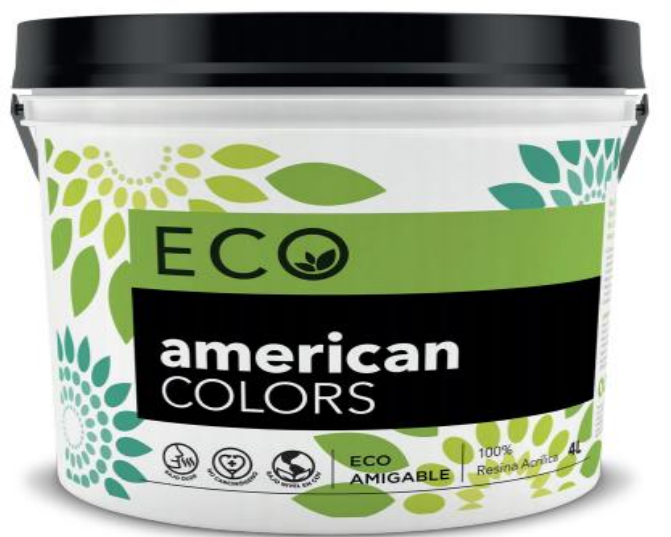

Fuente: Pintura ECO Productos - Pinturas a base de agua, Portal, 2020.

\section{- Luminaria LED}

- Luminaria para interiores y exteriores.

- A comparación de la luminaria convencional, la luminaria LED tiene mayor vida útil.

- Escaso consumo, propone hasta $85 \%$ de ahorro energético para fuentes incandescentes y 50\% para fluorescentes y lámparas.

- Contempla $80 \%$ de su energía en luz y solo $2 \%$ en calor.

- Reducción de calor, que evita sobre calentamiento y posibles riesgos inflamables. 
Figura 146. Luces LED.

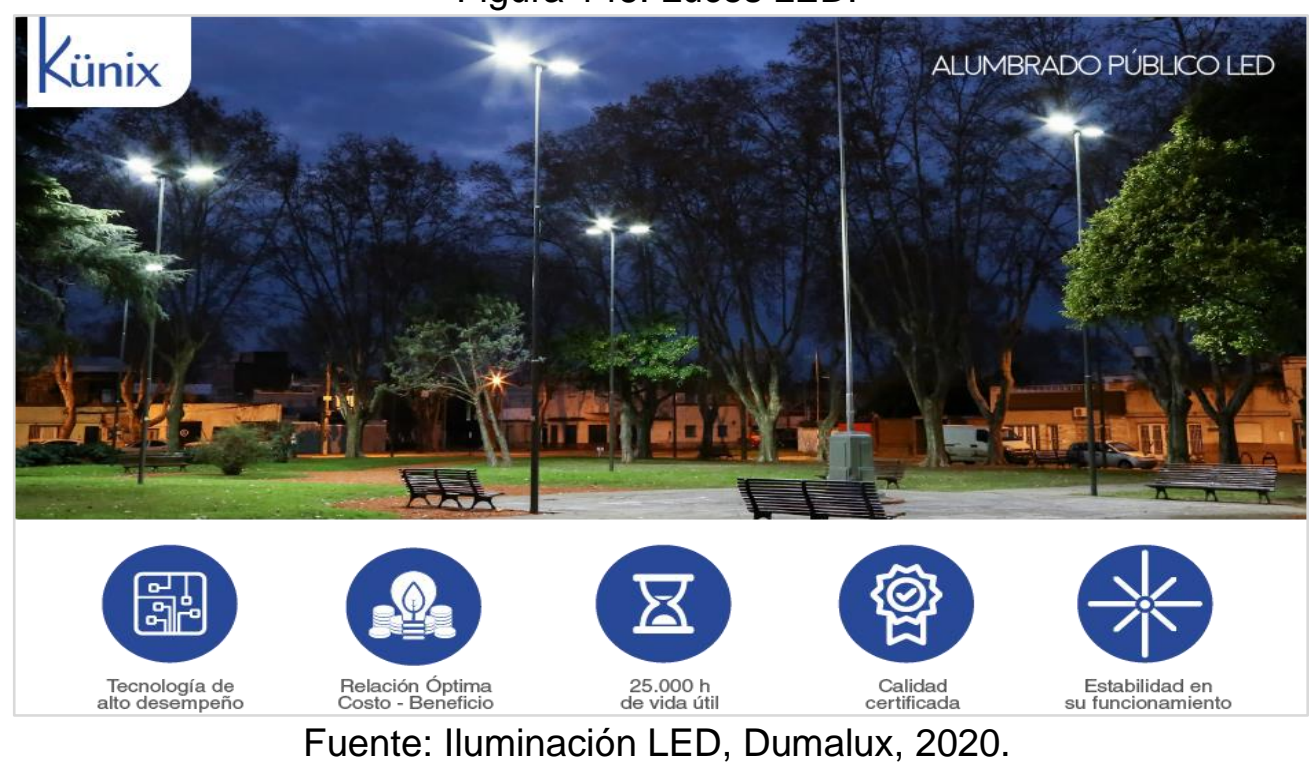

\section{- Planta de tratamiento de agua residual}

- Esta planta de tratamiento se colocará en dos puntos del parque temático.

- Limpieza de las aguas residuales para su reutilización de forma segura.

- Uso de lagunas anaeróbicas, lagunas facultativas y laguna de maduración como almacén previo a su reutilización.

- Uso de aguas residuales para el mantenimiento y regadío de áreas verdes.

Figura 147. Planta de tratamiento de agua residual.

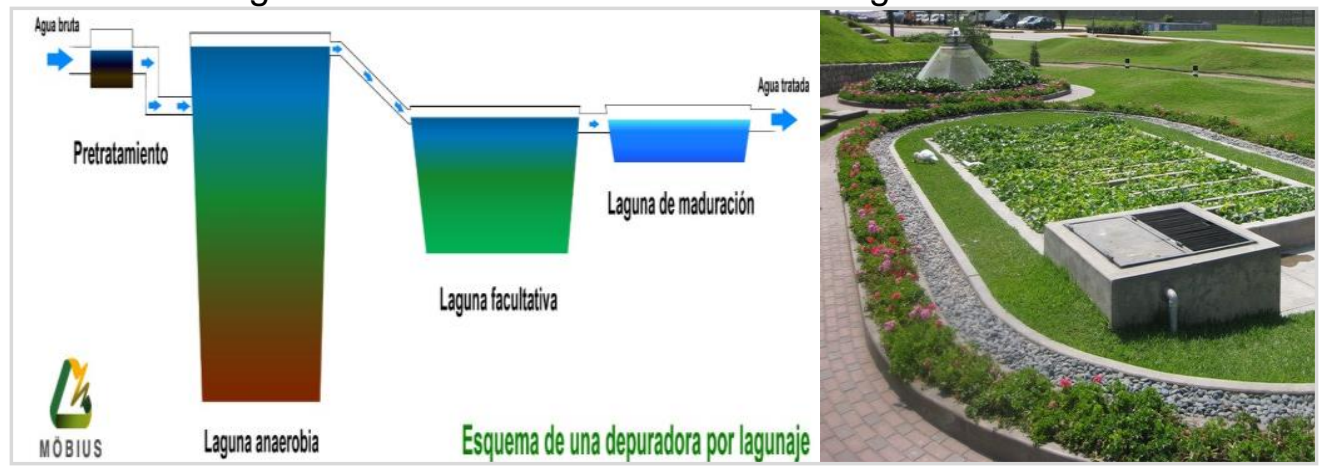

Fuente: Biomasa Residual, Mobius, 2020. 


\subsubsection{Sistema constructivo}

\section{1) Centro comercial}

\section{- Sótanos:}

- Todo el perímetro del sótano está conformado por muros de concreto armado.

- El sistema estructural es dual (aporticado y muros estructurales)

- Losa de los techos son losas macizas de concreto armado en 2 sentidos

- Primer y segundo piso:

- El sistema estructural de ambos pisos es aporticado

- Losa del entre piso 1 y 2 se propone losas aligeradas de concreto armado con viguetas y planchas colaborantes.

\section{- Tercer piso:}

- El sistema estructural de ambos pisos es aporticado

- En el techo se propone una parte losas aligeradas de concreto armado con viguetas y planchas colaborantes, y otro sector con estructuras metálicas.

Figura 148. Corte longitudinal del Mejoramiento Urbanístico y Equipamiento Comercial - Empresarial Post Panamericanos entorno de la Villa Panamericana en Villa el Salvador.

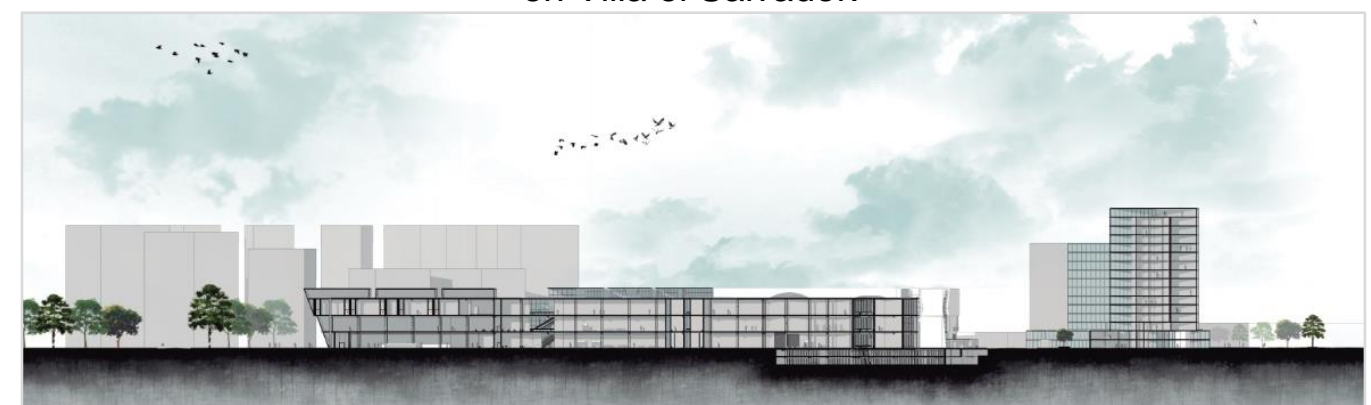

Elaboración Propia.

\section{2) Centro empresarial}

\section{- Sótanos:}

- Todo el perímetro del sótano está conformado por muros de concreto armado.

- El sistema estructural es aporticado (columnas y vigas de concreto armado). 
- Losa de los techos son losas macizas de concreto armado en 2 sentidos.

- Primer y segundo piso:

- El sistema estructural es dual (aporticado y muros estructurales)

- Losa del entre piso 1 y 2 se propone losas aligeradas de concreto armado con viguetas y planchas colaborantes.

\section{- Tercer piso y pisos típicos:}

- El sistema estructural es dual (aporticado y muros estructurales)

- Losa de entre pisos se propone losas aligeradas de concreto armado con viguetas y planchas colaborantes.

\section{3) Viviendas (2da y 3ra etapa)}

- Sótanos:

- Todo el perímetro del sótano está conformado por muros de concreto armado.

- El sistema estructural es aporticado (columnas y vigas de concreto armado).

- Losa de los techos son losas macizas de concreto armado en 2 sentidos.

\section{- Pisos típicos:}

- El sistema estructural es dual (aporticado y muros estructurales)

- Losa de los techos son losas aligeras de concreto armado en 2 sentidos.

Figura 149. Corte trasversal del Mejoramiento Urbanístico y Equipamiento Comercial - Empresarial Post Panamericanos entorno de la Villa Panamericana en Villa el Salvador.

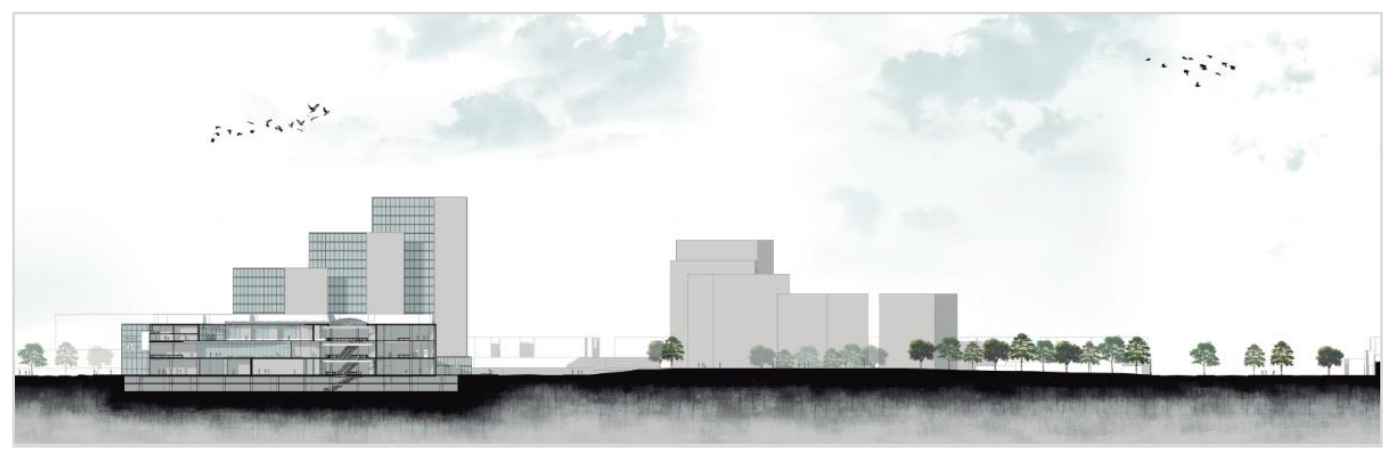

Elaboración Propia. 


\section{Relación de Laminas.}

Tabla 12. Relación de Láminas proyecto de Tesis.

\begin{tabular}{|c|c|c|c|c|}
\hline \multicolumn{5}{|c|}{$\begin{array}{c}\text { Relación de Laminas: "Proyecto Mejoramiento Urbanístico y Equipamientos } \\
\text { Comercial-Empresarial Post Panamericanos Entorno de la Villa Panamericana en } \\
\text { Villa el Salvador" }\end{array}$} \\
\hline \multirow{5}{*}{ 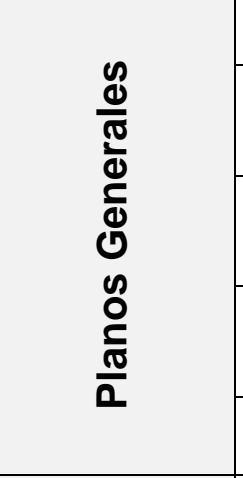 } & $\mathbf{N}^{\circ}$ & Nombre de Lamina & Escala & Formato \\
\hline & ANT-01 & $\begin{array}{l}\text { Anteproyecto: Plano de conjunto (Master } \\
\text { Plan) }\end{array}$ & $1 / 1250$ & $\mathrm{~A} 0$ \\
\hline & ANT-02 & $\begin{array}{l}\text { Anteproyecto: Plano de conjunto (Plot } \\
\text { Plan) }\end{array}$ & $1 / 1250$ & A0 \\
\hline & ANT-03 & $\begin{array}{l}\text { Anteproyecto: Plano de perfiles } \\
\text { transversales }\end{array}$ & $1 / 1500$ & A0 \\
\hline & ANT-04 & Anteproyecto: Vistas 3D & - & A1 \\
\hline \multirow{4}{*}{ 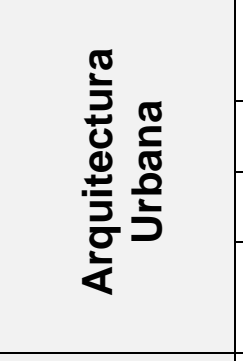 } & U-01 & $\begin{array}{l}\text { Plano de Ubicación, normatividad y } \\
\text { cuadro de áreas }\end{array}$ & Indicada & $\mathrm{A} 1$ \\
\hline & $\mathrm{U}-02$ & Plano de Habilitación Urbana & $1 / 1250$ & $\mathrm{~A} 1$ \\
\hline & U-03 & Plano Propuesta Vial & $1 / 1500$ & A1 \\
\hline & U-04 & $\begin{array}{l}\text { Plano Propuesta Integral Urbana con } \\
\text { secciones viales }\end{array}$ & $1 / 1500$ & A1 \\
\hline \multirow{12}{*}{ 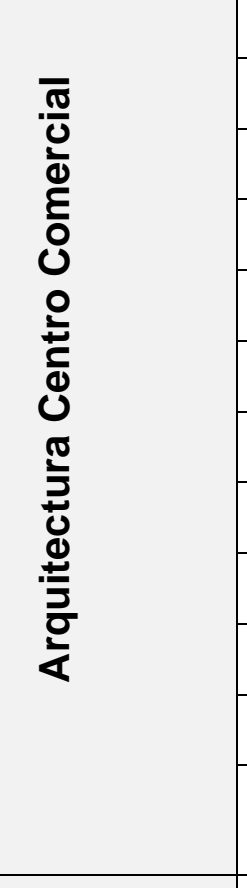 } & CC-01 & Planta $2^{\circ}$ sótano & $1 / 250$ & A1 \\
\hline & CC-02 & Planta $1^{\circ}$ sótano & $1 / 125$ & $\mathrm{~A} 1$ \\
\hline & $\mathrm{CC}-03$ & Planta $1^{\circ}$ piso & $1 / 125$ & $\mathrm{~A} 1$ \\
\hline & CC-04 & Planta $2^{\circ}$ piso & $1 / 125$ & A1 \\
\hline & CC-05 & Planta 3ํo piso & $1 / 125$ & A1 \\
\hline & CC-06 & Plano Techos & $1 / 125$ & A1 \\
\hline & CC-07 & Cortes $1-1,2-2,3-3,4-4,5-5$ y $7-7$ & $1 / 125$ & \\
\hline & CC-08 & Elevaciones 1, 2, 3 y 4 & $1 / 125$ & $\mathrm{~A} 1$ \\
\hline & CC-09 & Planta Supermercado sótano & $1 / 125$ & A1 \\
\hline & CC-10 & Planta Supermercado $1^{\circ}$ piso & $1 / 125$ & $\mathrm{~A} 1$ \\
\hline & CC-11 & Planta Supermercado Mezanine & $1 / 125$ & A1 \\
\hline & $\mathrm{CC}-12$ & $\begin{array}{l}\text { Cortes sección Supermercado 1-1, } \\
\text { sección Supermercado 2-2 }\end{array}$ & $1 / 125$ & $\mathrm{~A} 1$ \\
\hline \multirow{2}{*}{ 层事 을 产 } & CC-13 & Planta Zona de Entretenimiento $1^{\circ}$ piso & $1 / 125$ & A1 \\
\hline & CC-14 & Planta Zona de Entretenimiento Mezanine & $1 / 125$ & $\mathrm{~A} 1$ \\
\hline
\end{tabular}




\begin{tabular}{|c|c|c|c|c|}
\hline \multicolumn{5}{|c|}{$\begin{array}{c}\text { Relación de Laminas: "Proyecto Mejoramiento Urbanístico y Equipamientos } \\
\text { Comercial-Empresarial Post Panamericanos Entorno de la Villa Panamericana en } \\
\text { Villa el Salvador" }\end{array}$} \\
\hline & CC-15 & $\begin{array}{l}\text { Cortes sección Zona de Entretenimiento } \\
1-1 \text { y } 2-2\end{array}$ & $1 / 125$ & $\mathrm{~A} 1$ \\
\hline \multirow{11}{*}{ 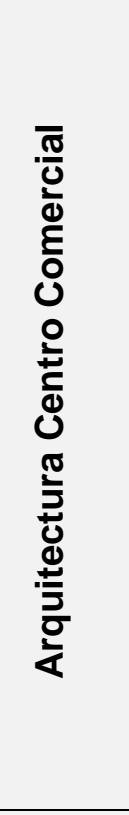 } & CC-16 & Planta Cine $1^{\circ}$ piso & $1 / 125$ & $\mathrm{~A} 1$ \\
\hline & CC-17 & Planta Cine Mezanine 1 & $1 / 125$ & A1 \\
\hline & CC-18 & Planta Cine Mezanine 2 & $1 / 125$ & $\mathrm{~A} 1$ \\
\hline & CC-19 & Cortes sección Cine 1-1 y 2-2 & $1 / 125$ & A1 \\
\hline & CC-20 & Planta Tienda por departamentos sótano & $1 / 125$ & A1 \\
\hline & CC-21 & Planta Tienda por departamentos $1^{\circ} \mathrm{piso}$ & $1 / 125$ & $\mathrm{~A} 1$ \\
\hline & CC-22 & Planta Tienda por departamentos $2^{\circ}$ piso & $1 / 125$ & A1 \\
\hline & CC-23 & $\begin{array}{l}\text { Cortes sección Zona Tienda por } \\
\text { departamento } 1-1 \text { y } 2-2\end{array}$ & $1 / 125$ & $\mathrm{~A} 1$ \\
\hline & CC-24 & Planta Gimnasio $1^{\circ}$ piso & $1 / 125$ & A1 \\
\hline & CC-25 & Planta Gimnasio Mezanine & $1 / 125$ & $\mathrm{~A} 1$ \\
\hline & CC-26 & Cortes sección Gimnasio 1-1 y 2-2 & $1 / 125$ & A1 \\
\hline \multirow{6}{*}{ 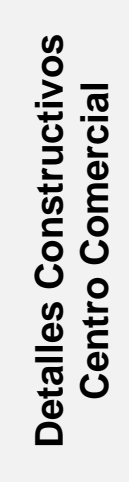 } & CC-27 & $\begin{array}{l}\text { Sistema Constructivo de Centro } \\
\text { Comercial y Cuadro de acabados }\end{array}$ & $1 / 100$ & A1 \\
\hline & CC-28 & Detalles de Ascensores C.C & $1 / 25$ & A1 \\
\hline & CC-29 & Detalles de Escaleras C.C & $1 / 25$ & A1 \\
\hline & CC-30 & Detalles de Muro Cortina 1 & $1 / 25$ & A1 \\
\hline & CC-31 & Detalles de Muro Cortina 2 & $1 / 25$ & A1 \\
\hline & CC-32 & Detalles de Muro verde & $1 / 25$ & $\mathrm{~A} 1$ \\
\hline \multirow{7}{*}{ 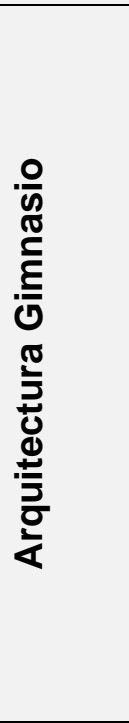 } & CC-33 & Planta Gimnasio $1^{\circ}$ piso & $1 / 75$ & $\mathrm{~A} 1$ \\
\hline & CC-34 & Planta Gimnasio Mezanine & $1 / 75$ & $\mathrm{~A} 1$ \\
\hline & CC-35 & $\begin{array}{l}\text { Cortes A-A, B-B, C-C - Cuadro de } \\
\text { acabados y vanos }\end{array}$ & $1 / 50$ & $\mathrm{~A} 1$ \\
\hline & CC-36 & $\begin{array}{l}\text { Cortes D-D, E-E - Cuadro de acabados y } \\
\text { vanos }\end{array}$ & $1 / 50$ & $\mathrm{~A} 1$ \\
\hline & CC-37 & $\begin{array}{l}\text { Detalles Constructivos de escaleras } 1 \text { - } \\
\text { Gym }\end{array}$ & $1 / 25$ & $\mathrm{~A} 1$ \\
\hline & CC-38 & $\begin{array}{l}\text { Detalles Constructivos de escaleras } 2 \text { - } \\
\text { Gym }\end{array}$ & $1 / 25$ & $\mathrm{~A} 1$ \\
\hline & CC-39 & $\begin{array}{l}\text { Detalles Constructivos de escaleras } 3 \text { - } \\
\text { Gym }\end{array}$ & $1 / 25$ & $\mathrm{~A} 1$ \\
\hline
\end{tabular}




\begin{tabular}{|c|c|c|c|c|}
\hline \multicolumn{5}{|c|}{$\begin{array}{c}\text { Relación de Laminas: "Proyecto Mejoramiento Urbanístico y Equipamientos } \\
\text { Comercial-Empresarial Post Panamericanos Entorno de la Villa Panamericana en } \\
\text { Villa el Salvador" }\end{array}$} \\
\hline & CC-40 & $\begin{array}{l}\text { Detalles Puertas y Carpintería } 1 \text { - Baños } \\
\text { hombres y mujeres Gym }\end{array}$ & $1 / 25$ & $\mathrm{~A} 1$ \\
\hline \multirow{14}{*}{ 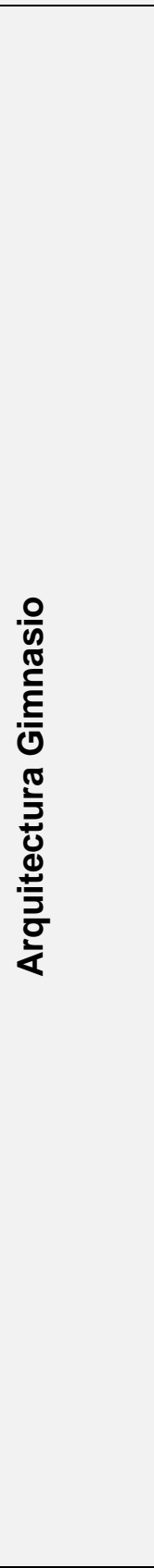 } & CC-41 & $\begin{array}{l}\text { Detalles Puertas y Carpintería } 2 \text { - Baños } \\
\text { hombres y mujeres Gym }\end{array}$ & $1 / 25$ & $\mathrm{~A} 1$ \\
\hline & CC-42 & Detalles Ventanas y Mamparas 1 - Gym & $1 / 25$ & $\mathrm{~A} 1$ \\
\hline & CC-43 & Detalles Ventanas y Mamparas 2 - Gym & $1 / 25$ & $\mathrm{~A} 1$ \\
\hline & CC-44 & $\begin{array}{l}\text { Planta de Baños general hombres y } \\
\text { mujeres, cuadro de acabados y vanos } \\
\text { Gym }\end{array}$ & $1 / 25$ & $\mathrm{~A} 1$ \\
\hline & CC-45 & $\begin{array}{l}\text { Detalles Planta Servicios higiénicos, Corte } \\
\text { A-A, B-B, C-C y E-E - Baños hombres } \\
\text { Gym }\end{array}$ & $1 / 25$ & $\mathrm{~A} 1$ \\
\hline & CC-46 & $\begin{array}{l}\text { Detalles Planta Duchas y sauna, Corte A- } \\
\text { A, B-B, C-C y E-E - Baños hombres Gym }\end{array}$ & $1 / 25$ & A1 \\
\hline & CC-47 & $\begin{array}{l}\text { Detalles Planta Vestidores y lockers, } \\
\text { Corte A-A, B-B, C-C y E-E - Baños } \\
\text { hombres Gym }\end{array}$ & $1 / 25$ & $\mathrm{~A} 1$ \\
\hline & CC-48 & $\begin{array}{l}\text { Detalles Planta Servicios higiénicos, Corte } \\
\text { A-A, B-B, C-C y E-E - Baños mujeres } \\
\text { Gym }\end{array}$ & $1 / 25$ & A1 \\
\hline & CC-49 & $\begin{array}{l}\text { Detalles Planta Duchas y sauna, Corte A- } \\
\text { A, B-B, C-C y E-E - Baños mujeres Gym }\end{array}$ & $1 / 25$ & $\mathrm{~A} 1$ \\
\hline & CC-50 & $\begin{array}{l}\text { Detalles Planta Vestidores y lockers, } \\
\text { Corte A-A, B-B, C-C y E-E - Baños } \\
\text { mujeres Gym }\end{array}$ & $1 / 25$ & $\mathrm{~A} 1$ \\
\hline & CC-51 & $\begin{array}{l}\text { Detalles Planta Baño de Evaluación y } \\
\text { Nutrición - Baños adicionales Gym }\end{array}$ & $1 / 25$ & $\mathrm{~A} 1$ \\
\hline & CC-52 & $\begin{array}{l}\text { Detalles Planta Baño de Administración - } \\
\text { Baños adicionales Gym }\end{array}$ & $1 / 25$ & $\mathrm{~A} 1$ \\
\hline & CC-53 & $\begin{array}{l}\text { Detalles Planta Baño de Discapacitados y } \\
\text { Mujeres - Baños discapacitados Gym }\end{array}$ & $1 / 25$ & A1 \\
\hline & CC-54 & $\begin{array}{l}\text { Detalles Planta Baño de Discapacitados y } \\
\text { Hombres - Baños discapacitados Gym }\end{array}$ & $1 / 25$ & A1 \\
\hline \multirow{5}{*}{ 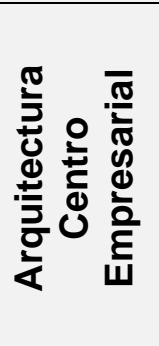 } & CE-1 & Planta $1^{\circ}$ Sótano 1 y Sótano 2 & $1 / 250$ & A1 \\
\hline & CE-2 & Planta $1^{\circ}$ piso & $1 / 250$ & A1 \\
\hline & CE-3 & Planta $2^{\circ}$ piso & $1 / 250$ & $\mathrm{~A} 1$ \\
\hline & CE-4 & Planta $3^{\circ}$ piso & $1 / 250$ & A1 \\
\hline & CE-5 & Planta $4^{\circ}$ piso(típico) & $1 / 250$ & $\mathrm{~A} 1$ \\
\hline
\end{tabular}




\begin{tabular}{|c|c|c|c|c|}
\hline \multicolumn{5}{|c|}{$\begin{array}{c}\text { Relación de Laminas: "Proyecto Mejoramiento Urbanístico y Equipamientos } \\
\text { Comercial-Empresarial Post Panamericanos Entorno de la Villa Panamericana en } \\
\text { Villa el Salvador" }\end{array}$} \\
\hline & CE-6 & Planta Techos & $1 / 250$ & $\mathrm{~A} 1$ \\
\hline & CE-7 & Cortes $1-1$ y $2-2$ & $1 / 250$ & A1 \\
\hline \multirow{2}{*}{ 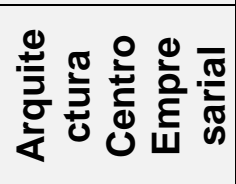 } & CE-8 & Cortes $3-3,4-4$ y $5-5$ & $1 / 250$ & A1 \\
\hline & CE-9 & $\begin{array}{l}\text { Elevaciones Frontal, Posterior, Lateral } \\
\text { izquierda y Lateral derecha }\end{array}$ & $1 / 250$ & $\mathrm{~A} 1$ \\
\hline 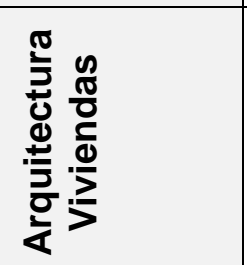 & V-1 & Volumetría & $\mathrm{s} / \mathrm{e}$ & $\mathrm{A} 1$ \\
\hline \multirow{6}{*}{ 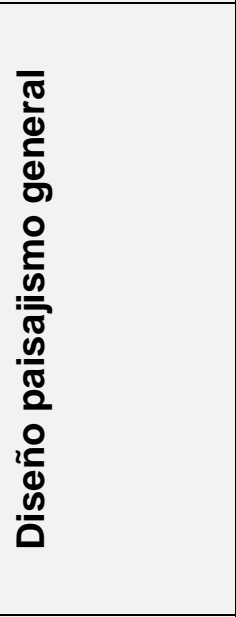 } & G-1 & $\begin{array}{l}\text { Planta Espacio (Parque Temático), Cortes } \\
\text { y Paisajismo. }\end{array}$ & $\mathrm{s} / \mathrm{e}$ & $\mathrm{A} 1$ \\
\hline & G-2 & Diseño de Plazas & $1 / 500$ & $\mathrm{~A} 1$ \\
\hline & G-3 & Diseño Terraza 1 & $1 / 250$ & $\mathrm{~A} 1$ \\
\hline & G-4 & Diseño Terraza 2 & $1 / 250$ & $\mathrm{~A} 1$ \\
\hline & G-5 & Detalles de Sardineles 1 & $1 / 20$ & $\mathrm{~A} 1$ \\
\hline & G-6 & Detalles de Sardineles 2 & $1 / 20$ & A1 \\
\hline \multirow{2}{*}{ 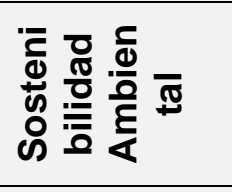 } & G-7 & Ciclovía en Intervención & $\mathrm{s} / \mathrm{e}$ & $\mathrm{A} 1$ \\
\hline & G-8 & $\begin{array}{l}\text { Áreas Verdes: en parques, jardines y } \\
\text { reserva urbana }\end{array}$ & $1 / 2500$ & $\mathrm{~A} 1$ \\
\hline \multirow{4}{*}{ 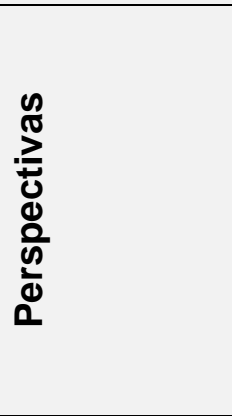 } & G-9 & $\begin{array}{l}\text { Vistas 3D de conjunto Centro Comercial, } \\
\text { Viviendas }\end{array}$ & - & $\mathrm{A} 1$ \\
\hline & G-10 & Vistas 3D Centro Comercial & - & A1 \\
\hline & $\mathrm{G}-11$ & $\begin{array}{l}\text { Vistas 3D Supermercado, Zona de } \\
\text { Entretenimiento, Cine, Tienda por } \\
\text { departamento }\end{array}$ & - & A1 \\
\hline & $\mathrm{G}-12$ & Vistas 3D Gimnasio & - & $\mathrm{A} 1$ \\
\hline
\end{tabular}

Elaboración: Elaboración propia. 


\section{CONCLUSIONES}

$\checkmark$ El distrito de Villa el Salvador es el único distrito que ha sido planificado en su totalidad. En la actualidad se han presentado algunos problemas y necesidades; en ese sentido la presente tesis apunta a cubrir cuatro grandes necesidades que requiere el distrito de Villa el salvador, la demanda de viviendas dignas con servicios necesarios para su habitabilidad, parques 0 áreas verdes, áreas de complementos a la actividad empresarial y centros comerciales.

$\checkmark$ Es así como el distrito de Villa el Salvador podrá contar con un eje comercial y empresarial, además de mejorar el equipamiento residencial y recreativo. Ofreciendo intervenciones en el circuito vial para el distrito, el proyecto urbano genera nuevas pautas de recorrido para el peatón, haciendo que sea más interesante, diverso y seguro.

$\checkmark$ El proyecto existente de la "Villa Panamericana" mejoraría su composición dentro del entorno urbano con este nuevo proyecto, se podrá fomentar la integración social y urbana, además del surgimiento de mayor empleo para la población de Lima Sur, una región que muchas veces depende de otras para realizar sus actividades laborales.

Se generará un nuevo polo potencial en Lima Sur de desarrollo comercialempresarial que servirá también para toda la población de Lima como una forma de descentralización de los ejes de comercio existentes. Y como el lugar de intervención ha pasado por eventos importantes como los Juegos Panamericanos 2019 y actualmente cobertura de COVID es ideal considerarlo un espacio de hito con los equipamientos necesarios para la ciudad.

$\checkmark$ Este proyecto se pensó además que era necesario que sea de carácter sostenible mediante sus características arquitectónicas y opciones de construcción. Una propuesta modelo hacia una ciudad sostenible y sobretodo una ciudad justa para todos mediante su ordenamiento urbano que servirá de beneficio para toda la población actual y la de las próximas generaciones. 


\section{BIBLIOGRAFÍA}

\section{-Referencias de artículos, libros, revistas y periódicos.}

Ministerio de Vivienda, Saneamiento y Construcción. (2015). Arquitectura A.0320 Hospedaje. Perú: Faro. Recuperado el 03 de junio de 2020 de Recuperado el 03 de junio de 2020 de https://www3.vivienda.gob.pe/dgprvu/titulo03edificaciones.html

Ministerio de Vivienda, Saneamiento y Construcción. (2019). Arquitectura A.070 Comercio. Perú: Faro. Recuperado el 03 de junio de 2020 de Recuperado el 03 de junio de 2020 de https://www3.vivienda.gob.pe/dgprvu/titulo03edificaciones.html

Ministerio de Vivienda, Saneamiento y Construcción. (2019). Arquitectura A.070 Comercio. Perú: Faro. Recuperado el 03 de junio de 2020 de Recuperado el 03 de junio de 2020 de https://www3.vivienda.gob.pe/dgprvu/titulo03edificaciones.html

Ministerio de Vivienda, Saneamiento y Construcción. (2019). Arquitectura A.080 Oficinas. Perú: Faro. Recuperado el 03 de junio de 2020 de Recuperado el 03 de junio de 2020 de https://www3.vivienda.gob.pe/dgprvu/titulo03edificaciones.html

Ministerio de Vivienda, Saneamiento y Construcción. (2020). Decreto Supremo Nº 002-2020 Vivienda. Perú: El Peruano. Recuperado el 03 de junio de 2020 de Recuperado el 03 de junio de 2020 de https://busquedas.elperuano.pe/normaslegales/decreto-supremo-que-aprueba-lamodificacion-del-reglamento-e-decreto-supremo-n-002-2020-vivienda-1848002-4/

Ministerio de Vivienda, Saneamiento y Construcción. (2016). Decreto Supremo Nº 022-2016 Vivienda. Perú: El Peruano. Recuperado el 03 de junio de 2020 de Recuperado el 03 de junio de 2020 de http://www3.vivienda.gob.pe/DGPRVU/docs/DUDU/01\%20RATDUS\%20\%20DS\%20022-2016-Viviend.pdf

Instituto Nacional de Estadística e Informática - INEI. (2017). Censo Nacional 2017: XII Población y VII de Vivienda. Recuperado el 03 de junio de 2020 de https://www.inei.gob.pe/media/MenuRecursivo/publicaciones digitales/Est/Lib1539 libro.pdf

Instituto Nacional de Estadística e Informática - INEI. (2018). VI Análisis de la Densidad Empresarial. Recuperado el 03 de junio de 2020 de https://www.inei.gob.pe/media/MenuRecursivo/publicaciones digitales/Est/Lib1703 lcap06.pdf

Instituto Nacional de Estadística e Informática - INEI. (2020). PERÚ: Estimaciones y Proyecciones de Población por Departamento, Provincia y Distrito, 2018 2020. Boletín Especial N²6. Recuperado el 06 de junio de 2020 de 
https://www.inei.gob.pe/media/MenuRecursivo/publicaciones digitales/Est/Lib1715 /libro.pdf

Instituto Nacional de Estadística e Informática - INEI. (1995). Boletín de Estadísticas Vitales 1994-95. CAP.VII: ANEXOS. LIMA METROPOLITANA: Población Proyectada, según Distritos 1995 - 2025. Recuperado el 06 de junio de 2020 de file://C:/Users/USER/Desktop/INEI\%20\%20LIMA\%20METROPOLITANA \%20PO BLACION\%20PROYECTADA,\%20SEGUN\%20DISTRITOS\%201995\%20\%202025.html

Regalado et al. (2015). Juegos Panamericanos Lima 2019 Factores críticos para su organización. Recuperado el 06 de junio de 2020 de https://www.esan.edu.pe/publicaciones/2015/06/15/juegos-panamericanos.pdf

Asociación Peruana de Empresas de Investigación de Mercado - APEIM. (2016). Niveles Socioeconómicos 2016. Recuperado el 06 de junio de 2020 de http://apeim.com.pe/wp-content/uploads/2019/11/APEIM-NSE-2016.pdf

SENAMHI (s.f.). Mapa climático del Perú. Lima 2020. Recuperado el 06 de junio de 2020 de https://senamhi.gob.pe/?\&p=mapa-climatico-del-peru

Comité Olímpico de Canadá. (2014). Toronto 2015. Recuperado el 06 de junio de $2020 \mathrm{de}$ http://images.toronto2015.org/system/asset pdfs/906/original/bid-ook.pdf

Programa de las Naciones Unidas para el Desarrollo - PNUD. (2019). El reto de la igualdad, una lectura de las dinámicas territoriales en el Perú. Recuperado el 06 de junio de 2020 de https://www.undp.org/content/dam/peru/docs/Publicaciones\%20pobreza/PNUD\%2 0Peru\%20-\%20El\%20Reto\%20de\%20la\%20lgualdad.pdf

Instituto Nacional de Estadística e Informática - INEI. (2014). Una mirada a Lima Metropolitana. Recuperado el 06 de junio de 2020 de https://www.inei.gob.pe/media/MenuRecursivo/publicaciones digitales/Est/Lib1168 libro.pdf

Lima Como Vamos. (2015). Cómo vamos en Demografía, Sexto informe de resultados sobre calidad de vida. Recuperado el 06 de junio de 2020 de http://www.limacomovamos.org/cm/wpcontent/uploads/2016/07/Demografia2015final.pdf

Villanueva, S. (2006). Diagnóstico Local Participativo del consumo de drogas en el distrito de Villa El Salvador. Municipalidad Distrital de Villa El Salvador. Recuperado el 06 de junio de 2020 de http://www.cicad.oas.org/fortalecimiento institucional/savia/PDF/diagnosticofinal/D iagnostico Final VillaEISalvador.pdf

Instituto Metropolitano de Planificación - IMP. (2006). Plano de zonificación de Lima Metropolitana - Villa El Salvador. Recuperado el 06 de junio de 2020 de https://www.imp.gob.pe/images/Planos\%20de\%20Zonif\%20Febrero\%202020/2 Vi lla el Salvador 2211.pdf 
Municipalidad de Lima. (2020). Ordenanza Municipal № 2211 20-12-2019. Recuperado el 06 de junio de 2020 de http://www.transparencia.munlima.gob.pe/gobierno-abiertomunicipal/transparencia/mml/datos-generales/disposiciones-emitidas1/ordenanzas-municipales/cat view/14-documentos-mml/1-disposicionesemitidas/77-resoluciones-ordenanzas/135-ordenanzas-municipales/1354ordenanzas-municipales-2019

El Peruano. (2019). Modifican el Plano de Zonificación del distrito de Villa El Salvador aprobado por Ordenanza № 933 - Ordenanza № 2165. Lima 2020. Recuperado el 06 de junio de 2020 de https://busquedas.elperuano.pe/normaslegales/modifican-el-plano-de-zonificaciondel-distrito-de-villa-el-ordenanza-no-2165-1791960-1/

Notiviajeros. (Julio, 2016). Conoce la impresionante infraestructura olímpica y turística de Río de Janeiro. Recuperado el 06 de junio de 2020 de https://www.notiviajeros.com/2016/07/17/conoce-la-impresionante-infraestructuraolimpica-y-turistica-de-rio-de-janeiro/

Revista de Urbanismo. (2014). Alternativas de Gestión Urbanística: Una mirada reflexiva hacia los últimos diez años. Lima 2020. Recuperado el 06 de junio de 2020 de https://web.uchile.cl/vignette/revistaurbanismo/CDA/urb simple/0,1310,SCID\%253 D6977\%2526ISID\%253D315\%2526IDG\%253D2\%2526ACT\%253D0\%2526PRT\% 253D6967,00.html

Revista Perú Construye. (2018). Villa de atletas - Lima 2019. Unión de ingeniería, planeamiento y productividad. Edición 55.

https://peruconstruye.net/edicion-55/

Rodríguez, F. (2015). Juegos Panamericanos Lima 2019: entre la oportunidad y la incertidumbre. Lima 2020. Recuperado el 06 de junio de 2020 de https://www.archdaily.co/co/772376/juegos-panamericanos-lima-2019-entre-laoportunidad-y-la-incertidumbre

(2020, junio 13) De: Diario El Peruano. [Mensaje de Blog]. Disponible en https://beta.elperuano.pe/noticia-ollantaytambo-construccion-inca-sorprendenteperfeccion-87526.aspx

Astuhuamán, C. (2004). La arquitectura inca. Recuperado el 06 de junio de 2020 de https://www.researchgate.net/publication/301204752 La Arquitectura Inca

Pérez. (2016). Arquitectura del paisaje: forma y materia. Recuperado el 06 de junio de 2020

de https://gdocu.upv.es/alfresco/service/api/node/content/workspace/SpacesStore/c6 b957ab-d3ae-4130-83d3-5a7c32f0b676/TOC 033403 01.pdf?guest=true

Municipalidad Distrital de Villa el Salvador. (2006). Diagnóstico local participativo del consumo de drogas en el distrito de Villa el Salvador 2006. Recuperado el 5 de mayo de 2020 de 
http://www.cicad.oas.org/fortalecimiento institucional/savia/PDF/diagnosticofinal/D iagnostico Final VillaEISalvador.pdf

Municipalidad Distrital de Villa el Salvador. (2012). Plan Urbano de Villa el Salvador. Recuperado el 5 de mayo de 2020 de http://www.munives.gob.pe/WebSite/Transparencia/PlanDesarrolloUrbano/PUVES-VOL1.pdf

Romero, M (2006). Arquitecto Desarrollador. Recuperado el 5 de mayo del 2020 de https://docplayer.es/8361500-El-arquitecto-desarrollador.html

Suyo Urbanistas. (2012). Creando Ciudades. Recuperado el 5 de mayo del 2020 de 2020 de http://www.suyourbanistas.com/deutsch/wpcontent/uploads/2012/04/PROYECTA-Urbanismo-Santa-Mar\%C3\%ADa-de-VillaClub1.pdf

Chong, G. (2009). Patrones de densificación en Villa el Salvador - I. Recuperado el 5 de mayo de 2020 de https://issuu.com/residente/docs/ves-1

(2019, marzo 16) De: Diario RPP Noticias. [Mensaje de Blog]. Disponible en https://rpp.pe/lima/actualidad/lima-2019-la-villa-panamericana-quedo-lista-y-estascon-20-fotos-de-sus-instalaciones-noticia-1186355

Ministerio de Educación. (2016). Reglamento de los Juegos Panamericanos. Recuperado el 5 de mayo de 2020 de https://fay.org/2018/12/05/reglamentoselectivo-para-los-juegos-panamericanos-lima-19-slima19/

Ministerio de Educación. (2016). Creación de los servicios de la Villa Panamericana en el distrito de Villa el Salvador, Unidad formuladora, Proyecto Especial para se muestra la preparación y desarrollo de los XVIII Juegos Panamericanos del año 2019. Recuperado el 5 de mayo de 2020 de http://ofi4.mef.gob.pe/bp/ConsultarPIP/frmConsultarPIP.asp?accion=consultar\&txt $\underline{\text { Codigo }=378239}$

(2019, agosto 28) De: Diario Gestión [Mensaje de Blog]. Disponible en https://gestion.pe/economia/villa-panamericana-valor-de-departamentos-seriamuy-caro-para-la-zona-noticia/

Del Río, M. (2019). Villa Panamericana: Valor de departamentos sería muy caro para la zona. Recuperado el 8 de mayo de 2020 de https://gestion.pe/economia/villa-panamericana-valor-de-departamentos-seriamuy-caro-para-la-zona-noticia/

Instituto Nacional de Estadística e Informática - INEI (2017). Proyecciones de población al 2023. Recuperado el 8 de mayo de 2020 de https://gestion.pe/economia/inei-lima-tendria-9-millones-111-mil-habitantes$\underline{126802-\text { noticia/?ref=gesr }}$

Regalado et alt. (2015). Juegos Panamericanos Lima 2019. Factores críticos para su organización. Recuperado el 8 de mayo de 2020 de https://repositorio.esan.edu.pe/bitstream/handle/ESAN/110/Gerencia para el des arrollo 50.pdf 
Ministerio de Educación. (2015). Supremo № 022-2015-MINEDU. Recuperado el 8 de mayo de 2020 de https://cdn.www.gob.pe/uploads/document/file/105023/ 002-2015-MINEDU - 0503-2015 121251 -DS N 002-2015-MINEDU.pdf

Lima 2019. (2019). Acta de la Cuadragésima Novena Sesión de COPAL - Lima Perú. Recuperado el 8 de mayo de 2020 de https://www.lima2019.pe/documentos-institucionales

La Contraloría General de la Republica. (2017). Oficio No 00019-2017-CG/DC. Recuperado el 8 de mayo de 2020 de http://fweb.contraloria.gob.pe/BuscadorInformes/0/edoc/4068498/Informe Control 00007-2017-CG\%20GCIP.pdf

(2018, diciembre 14) De: América Noticias [Mensaje de Blog]. Disponible de Recuperado el 8 de mayo de 2020 de https://www.americatv.com.pe/noticias/actualidad/juegos-panamericanoscontraloria-advierte-retrasos-dos-proyectos-n351032

(2019, febrero 04) De: Diario Gestión. Contraloría alerta retrasos en culminación de la Villa Panamericana, ¿qué halló? [Mensaje de Blog]. Recuperado el 8 de mayo de 2020 de https://gestion.pe/economia/contraloria-alerta-retrasosculminacion-villa-panamericana-hallo-257697-noticial

(2018, diciembre 13) De: Diario El Comercio. Panamericanos: Contraloría advierte retrasos en sedes de Callao y Punta Negra [Mensaje de Blog]. Recuperado el 8 de mayo de 2020 de https://elcomercio.pe/lima/obras/juegos-panamericanoscontraloria-advierte-retrasos-sedes-callao-punta-negra-noticia-587459-noticial

Municipalidad Distrital de Villa el Salvador. (2016). Plan de Desarrollo Local Concertado 2017-2021. Recuperado el 8 de mayo de 2020 de http://www.munives.gob.pe/WebSite/municipalidad/PlandeDesarrolloLocalConcert ado/PDLC2017-2021MVES.pdf

Asociación de Centros Comerciales del Perú. (2016). Los centros comerciales en el Perú. Recuperado el 12 de mayo de 2020 de http://preciso.pe/wpcontent/uploads/2016/06/ACCEP.pdf

Organización Mundial de la Salud. (2020). La OMS caracteriza a COVID-19 como una pandemia. Recuperado el 12 de mayo de 2020 de https://www.paho.org/hq/index. php?option=com content\&view=article\&id=1 5756: who-characterizes-covid-19-as-a-pandemic\&ltemid=1926\&lang=es

Instituto Geográfico Nacional del Perú. (2018). Población Lima Metropolitana. Recuperado el 12 de mayo de 2020 de https://www.ign.gob.pe/

Apoyo Opinión y Mercado. (2018). Centros comerciales. Recuperado el 12 de mayo de https://www.ipsos.com/es-pe/apoyo-opinion-y-mercado

(2017, enero 25) De: Diario Gestión. Déficit habitacional en Lima Metropolitana es de 612,464 viviendas al 2016 [Mensaje de Blog]. Recuperado el 12 de mayo 
https://gestion.pe/economia/deficit-habitacional-lima-metropolitana-612-464viviendas-2016-127350-noticia/

Romero, M. (1992). Hábitat popular: Un camino propio. Recuperado el 12 de mayo de 2020 de http://biblioteca.cae.org.ec/cgi-bin/koha/opacdetail.pl?biblionumber=263\&query desc=au\%3A\%22Romero\%20Sotelo\%2C $\% 20$ Miguel\%22

Romero, M. (1994). Ciudad y Territorio. Estudios Territoriales. Recuperado el 12 de mayo de 2020 de https://dialnet.unirioja.es/servlet/articulo?codigo=177305

Romero, M. (2006). El Arquitecto Desarrollador. Recuperado el 12 de mayo de 2020 de https://docplayer.es/8361500-El-arquitecto-desarrollador.html

Patriau. (2002). Jockey Plaza, millonario problema. Recuperado el 15 de mayo de 2020 de https://larepublica.pe/archivo/333410-jockey-plaza-millonario-problema/

Arqa. (2016). Instituto Metropolitano de Diseño. [Mensaje de Blog]. Disponible de https://arqa.com/arquitectura/instituto-metropolitano-diseno.html

Orrego. (2010). Boulevard Jockey Plaza. Recuperado el 15 de mayo de 2020 de https://archinect.com/jose.orrego.peru/project/boulevard-jockey-plaza-2010

Carruitero et. al. (2016). Jockey Plaza. Recuperado el 18 de mayo de 2020 de https://pirhua.udep.edu.pe/handle/11042/2945

Instituto Metropolitano de Planificación - IMP (2010). Sistema Vial Metropolitano de Lima. Recuperado el 12 de mayo de https://www.imp.gob.pe/images/Sistema\%20Vial/SVM\%201999\%20\%20ADENDA\%2057\%20(PLANO\%20GENERAL).pdf

Vega. (2013). ¿Dónde somos limeños? Recuperado el 18 de mayo de 2020 de https://www.pucp.edu.pe/profesor/pablo-vega-centeno-sara-

lafosse/publicaciones/?x\&pagina=2

Retail. (2016). Desarrollo de los centros comerciales La Rambla en Perú. Recuperado el 18 de mayo de 2020 de https://www.peruretail.com/especial/desarrollo-centros-comerciales-la-rambla-peru/

A donde vivir. (2019). Edificio de oficinas en San Borja - La Rambla. Recuperado el 20 de mayo de 2020 de https://www.adondevivir.com/propiedades/torre-del-arte:edificio-de-oficinas-en-san-boria-la-51596308.html

Mega Plaza. (2020). Tiendas Megaplaza. Recuperado el 20 de mayo de 2020 de https://www.megaplaza.com.pe/tienda/informes/

Vigil. (2017). Crecimiento de Mega Plaza en Lima Norte. Recuperado el 30 de mayo de 2020 de https://www.peru-retail.com/crecimiento-megaplaza-lima-norte/

(2008, mayo 2020). De: Diario Mercurio [Mensaje de Blog]. Disponible de https://digital.elmercurio.com/2020/06/13/A 
Pavez. (2012). Proyectos Costanera Center - Altos desafíos. Recuperado el 30 de mayo de 2020 de http://biblioteca.cchc.cl/datafiles/27229-2.pdf

Lagos. (2012). Cultura Valdiviana. Recuperado el 30 de mayo de 2020 de https://books.google.com.pe/books?id=Hw56RRPCIVwC\&pg=PA10\&lpg=PA10\&d $\mathrm{q}=$ costanera+lagos+2012\&source=bl\&ots=xOQ9pBV9wl\&sig=ACfU3U0TIMmsFFC BQVsCt9QW8h 3fWtNUA\&hl=es419\&sa=X\&ved=2ahUKEwila D86N7pAhUkVt8KHafiCZcQ6AEwAXoECBAQAQ\# $\mathrm{v}=$ onepage \&q=costanera\%20lagos\%202012\&f=false

Architect Africa. (2019). Boulevard Piedra Roja. Recuperado el 30 de mayo de 2020 de https://www.architectafrica.com/node/3832

Construcción. (2016). Mall Vivo de Piedra Roja actualiza su oferta. Recuperado el 30 de mayo de 2020 de http://www.emb.cl/construccion/noticia.mvc?nid=20160801w8

Andrade. (2006). Empresario. Recuperado el 30 de mayo de 2020 de http://agnitio.pe/articulo/la-naturaleza-juridica-de-la-empresa/

Ferrell et. al. (2004). Definición de empresario. Recuperado el 30 de mayo de 2020 de $\quad$ https://www.promonegocios.net/empresa/definicionempresarios.html\#: : :text=Definici\%C3\%B3n\%20de\%20Empresario\%20Desde\%2 0Distintos\%20Puntos\%20de\%20Vista\%3A\&text=Para\%20Ferrell\%2C\%20Hirt\%2C \%20Adriaens \%C3\%A9ns\%2C, algo\%20innovador\%22\%20\%5B3\%5D

McGraw-Hill. (2013). La empresa y su organización. Recuperado el 30 de mayo de 2020

file:///C:/Users/USER/Downloads/La\%20organizaci\%C3\%B3n\%20en\%20la\%20em presa\%20-\%20McGraw-Hill.pdf

Rojas. (2017). La Empresa y El Entorno. Recuperado el 30 de mayo de 2020 de https://riuma.uma.es/xmlui/bitstream/handle/10630/13602/Temas\%20Econom\%C3 \%ADa\%20de\%20la\%20Empresa.pdf? sequence $=1$ \&isAllowed $=\mathrm{y}$

Durand. (2004). Cleptocracia y empresariado en el Perú. Recuperado el 30 de mayo de 2020 de https://nuso.org/media/articles/downloads/3233 1.pdf

Oliva. (2018). Informe de actualización de proyecciones macroeconómicas 20192022. Recuperado el 30 de mayo de 2020 de https://www.mef.gob.pe/contenidos/pol econ/marco macro/IAPM 2019 2022.pdf

Fitch Rating. (2018). Fitch ratifica calificación crediticia del Perú en BBB+. Recuperado el 30 de mayo de 2020 de http://www.elperuano.pe/noticia-fitchratifica-calificacion-crediticia-del-peru-bbb-64952.aspx

Ministerio de la Producción. (2017). Estadística MYIPYME. Recuperado el 01 de junio de 2020 de http://ogeiee.produce.gob.pe/index.php/shortcode/estadisticaoee/estadisticas-mipyme 
La Superintendencia Nacional de Administración Tributaria - SUNAT. (2017). Empresas Formales. Recuperado el 01 de junio de 2020 de http://www.sunat.gob.pe/

V\&V Grupo Inmobiliario. (2019). Actividad empresarial. Recuperado el 01 de junio de 2020 de https://vyv.pe/proyectosventa/vivienda/mood $/$ ?utm source=google next\&utm medium=mood\&utm term $=$ cpa\&utm content=text ad\&gclid=CjwKCAjwq832BRA5EiwACvCWsQ-vCcdBRZWZvc1001G3r06iTpUg9Zbt5aXzjOVspXKPGy0IRmNxRoCRZQQAvD BwE

González Couret, Dania. (2015). Tendencias actuales de la Arquitectura y el Urbanismo en América Latina. 1990-2014. Arquitectura y Urbanismo, 36(2), 128-138. Recuperado en 13 de agosto de 2020, de http://scielo.sld.cu/scielo.php?script=sci arttext\&pid=S1815-

58982015000200009\&lng=es\&tlng=es

RAE (2014). Definición de Oficinas. Recuperado el 01 de junio de 2020 de https://dle.rae.es/oficina

Hernández. (2002). La Habitabilidad Energética en Edificios de Oficinas. Recuperado el 01 de junio de 2020 de http://www.mastesis.com/tesis/la+habitabilidad+energ-C3A9tica+en+edificios+de+oficinas: 98741

Universidad Nacional de Educación a Distancia - UNED (2014). Concepción del entorno de trabajo. Recuperado el 01 de junio de 2020 de http://portal.uned.es/pls/portal/docs/PAGE/UNED MAIN/LAUNIVERSIDAD/VICER RECTORADOS/EVALUACIONCALIDAD/INFRAESTRUCTURA/06GUIA\%20DE\%20CRITERIOS\%20DE\%20DISE\%C3\%910 251010.PDF

Miller. (2013). El mobiliario de oficina como clave para un nuevo espacio de trabajo flexible, eficiente y conectado. Recuperado el 01 de junio de 2020 de http://www.fadu.edu.uy/sepep/files/2019/04/A KAC Tesina DEPM FADU Udelar Oficina-3.0 2018 T MNieto.pdf

Cartagena. (2002). Centros Financieros: naturaleza, factores de éxito y experiencias. Recuperado el 01 de junio de 2020 de https://www.bcr.gob.sv/bcrsite/uploaded/content/category/1864911547.pdf

A\&B Services. (2001). Centros financieros. Recuperado el 01 de junio de 2020 de http://abservices.rul

Bastie \& Dezert. (1980). Características de los distritos financieros en el espacio urbano. Recuperado el 01 de junio de 2020 de https://rua.ua.es/dspace/bitstream/10045/20231/1/Mej\%c3\%adas.pdf

América Retail. (2010). Consejo Internacional de Centros Comerciales. Recuperado el 01 de junio de 2020 de https://www.americaretail.com/tag/consejo-internacional-de-centros-comerciales/ 
Valdés (2009). Las bolsas llenas, centros comerciales. Recuperado el 01 de junio de 2020 de http://www.obrasweb.mx/arquitectura/2009/03/18/las-bolsas-llenascentros-comerciales.

Doménech. (2015). Espacio público y comercio en la ciudad contemporánea. Recuperado el 01 de junio de 2020 de https://revistas.uniandes.edu.co/doi/pdf/10.18389/dearq17.2015.02

Samper. (1989). Historia de los centros comerciales. Recuperado el 01 de junio de 2020 de file:///C:/Users/1.61 architects/Downloads/42143-107991-1-PB.pd

Carpio. (2017). Historia de los centros comerciales. Recuperado el 01 de junio de 2020 de file:///C:/Users/1.61architects/Downloads/RGN-V5N8-2017-3\%20(1).pdf

Fasson. (2015). Fashion Law o Derecho de la Moda. Recuperado el 01 de junio de 2020 de http://www.parthenon.pe/columnas/derecho-de-la-moda-retail/fashionlaw-o-derecho-de-la-moda-una-nueva-especializacion/

Cerda. (2013). De-Malling, una oportunidad para la integración del mall a la ciudad. Recuperado el 01 de junio de 2020 de http://repositorio.uchile.cl/bitstream/handle/2250/141681/nuevos-espacioscomerciales-urbanos.pdf? sequence $=1$ \&isAllowed $=y$

Higa. (2015). ¿Cómo se articula el mall en el espacio urbano desde la experiencia de usuarios jóvenes) Loa C. C. Jockey Plaza y Megaplaza e Lima Metropolitana? Revista Investiga Territorios. http://repositorio.uchile.cl/bitstream/handle/2250/141681/nuevos-espacioscomerciales-urbanos. pdf? sequence $=1$ \&isAllowed $=y$

Koolhaas. (2001). Escuela Técnica Superior de Arquitectura de Madrid. Recuperado el 01 de junio de 2020 de http://ocs.editorial.upv.es/index.php/LC2015/LC2015/paper/viewFile/792/1298

Regalado et. al. (2015). Juegos Panamericanos Lima 2019: factores críticos para su organización. Recuperado el 01 de junio de 2020 de https://www.esan.edu.pe/publicaciones/serie-gerencia-para-eldesarrollo/2015/juegos-panamericanos-lima-2019-factores-criticos-para-suorganizacion/

Cuadra, Manuel. (2018). La arquitectura de la revolución cubana 1959-2018. Recuperado el 01 de junio de 2020 de https://books.google.com.pe/books?id=qDdYDwAAQBAJ\&printsec=frontcover\&hl= es\&source=gbs ge summary $r \& c a d=0 \# v=0$ onepage $\& q \& f=$ false

Revista Civilízate. (2015). ¿Está preparada Lima para los Juegos Panamericanos? Recuperado el 01 de junio de 2020 de http://revistas.pucp.edu.pe/index.php/civilizate/article/view/15273/15738

(2013, octubre 11) De: Diario Gestión. Histórico: Lima fue elegida como sede de los Juegos Panamericanos 2019 [Mensaje de Blog]. Disponible de https://gestion.pe/tendencias/historico-lima-elegida-sede-juegos-panamericanos2019-50228-noticial 
Ministerio de Vivienda, Construcción y Saneamiento (2019). Juegos Panamericanos y Parapanamericanos. Recuperado el 01 de junio de 2020 de http://ww3.vivienda.gob.pe/DGPRVU/eventos/Lima\%202019\%20Juegos\%20pana mericanos\%20y\%20parapanamericanos\%20-\%20Carlos\%20Neuhaus.pdf

Romero, M. (2016). Villa el Salvador. Recuperado el 01 de junio de 2020 de https://suyourbanistas.com/pdf/Brochure-Comercial-de-Corporacion-Suyo.pdf

Zapata. (1996). Sociedad y poder local: la comunidad de villa el salvador 19711996. Recuperado el 01 de junio de 2020 de https://www.academia.edu/9000146/SOCIEDAD Y PODER LOCAL LA COMUN IDAD DE VILLA EL SALVADOR 1971-

1996 Antonio Zapata. TESTIMONIO Y REFLEXIONES DE UN ACTOR Mich el Azcueta

Gonzales. (2011). Modelo de gestión urbana mixta como estrategia de desarrollo para comunidades industriales autogestionarias, Recuperado el 01 de junio de 2020

de https://upcommons.upc.edu/bitstream/2117/117635/1/TVYGG1de1.pdf

Castro \& Riofrío. (1996). La regularización de las barriadas: el caso de Villa el Salvador (Perú). Recuperado el 03 de junio de 2020 de https://books.openedition.org/cemca/922?lang=es

Municipalidad de Villa el Salvador. (2016). Plan de Desarrollo Local Concertado del Distrito de Villa el Salvador 2017-2021. Recuperado el 03 de junio de 2020 de

http://www.munives.gob.pe/WebSite/municipalidad/PlandeDesarrolloLocalConcert ado/PDLC2017-2021MVES.pdf

(2006, enero 14). De: Diario La República. Turismo El Salvador [Mensaje de Blog]. Recuperado el 03 de junio de 2020 de Disponible de https://larepublica.pe/archivo/289246-turismo-el-salvador/

(2020, mayo 29). De: OtraMirada. Perú, el terremoto de mayo del 70 y 50 años de solidaridad médica cubana [Mensaje de Blog]. Recuperado el 03 de junio de 2020 de http://www.otramirada.pe/per\%C3\%BA-el-terremoto-de-mayo-del-70-y50-a\%C3\%B1os-de-solidaridad-m\%C3\%A9dica-cubana

YouTube. (2013) Documental VES, Historia de Villa el Salvador. Recuperado el 03 de junio de 2020 de https://www.youtube.com/watch?v=jSuwZRZkunk

Municipalidad Metropolitana de Lima. (2012). Plan Regional de Desarrollo Concertado de Lima 2012-2025. Recuperado el 03 de junio de 2020 de https://sinia.minam.gob.pe/documentos/plan-regional-desarrollo-concertado-lima2012-2025

Municipalidad Metropolitana de Lima. (2012). Plan Regional de Desarrollo Concertado de Lima 2012-2025. Recuperado el 03 de junio de 2020 de 
https://sinia.minam.gob.pe/documentos/plan-regional-desarrollo-concertado-lima$\underline{2012-2025}$

Municipalidad Metropolitana de Lima. (2018). PLAM 2035. Plan Metropolitano de Desarrollo Urbano de Lima y Callao 2035. Recuperado el 03 de junio de 2020 de https://transitemos.org/publicaciones-3/plan-lima-y-callao-2035/

Banco Interamericano de Desarrollo. (2018). Propuestas de Ordenamiento Urbano Territorial en Lima, Perú. Recuperado el 03 de junio de 2020 de https://publications.iadb.org/publications/spanish/document/Propuestas-deordenamiento-urbano-territorial-en-Lima-Peru-2018.pdf

(2009, enero 13). De: Pensando Lima. Crecimiento y expansión de Lima [Mensaje de Blog]. Recuperado el 03 de junio de 2020 de https://pensandolima.wordpress.com/2009/09/13/crecimiento-y-expansionde-lima/?blogsub=confirming\#subscribe-blog

(2011, agosto 04). De: Limamalalima. Las limas y Los conos [Mensaje de Blog]. Recuperado el 03 de junio de 2020 de https://limamalalima.wordpress.com/2011/08/04/las-limas-y-losconos/?blogsub=confirming\#subscribe-blog

(2015, enero 24). De: Arquitectura y empresa. PLAM Lima y Callao 2035 [Mensaje de Blog]. Recuperado el 03 de junio de 2020 de https://www.arquitecturayempresa.es/noticia/plam-lima-y-callao-2035

Municipalidad Distrital Villa el Salvador. (2020). Datos Generales. Recuperado el 03 de junio de 2020 de http://www.munives.gob.pe/distrito.php\#Zonificacion

(2014, diciembre 27). De: LaMula.pe. Lima, la ciudad policéntrica [Mensaje de Blog]. Recuperado el 03 de junio de 2020 de https://redaccion.lamula.pe/2014/12/27/lima-la-ciudad-policentrica/albertoniquen/

Lima Como Vamos. (2017). Evaluando la Gestión en Lima y Callao. VIII Informe de resultados sobre calidad de vida. Recuperado el 03 de junio de 2020 de http://www.limacomovamos.org/cm/wpcontent/uploads/2018/11/InformeGestion2017.pdf

Autoridad Autónoma del Sistema Eléctrico de Transporte masivo de Lima y Callao - AATE. (2020). Mapa de Análisis. Recuperado el 03 de junio de 2020 de http://bigdata.aate.gob.pe:3009/bigdata

Rizo Patrón, L. (2017). Proyecto de Vivienda - Comercio en el distrito de San Miguel. Tesis de grado. Recuperado el 03 de junio de 2020 de http://repositorio.urp.edu.pe/bitstream/handle/urp/1023/rizo I.pdf?sequence=1\&isA $\underline{\text { llowed }=\mathrm{y}}$

(2014, septiembre 17). De: ConNuestroPeru.com. Importancia de las áreas verdes en Lima [Mensaje de Blog]. Recuperado el 03 de junio de 2020 de https://www.connuestroperu.com/actualidad/punto-de-vista/43662-importancia-delas-areas-verdes-de-lima 
(2020, mayo 11). De: Diario el Comercio. Pedalear contra la pandemia Lima [Mensaje de Blog]. Recuperado el 03 de junio de 2020 de https://especiales.elcomercio.pe/?q=especiales/pedalear-contra-la-pandemiaecpm/index.html

Google Maps. (2020). Ciclovías de Lima y Callao. Recuperado el 03 de junio de 2020 de https://www.google.com/maps/d/viewer?msa=0\&mid=12PUI4VbbO3IBWRSaXrCM HHOU NI\&\&ll=-12.220335046686476\%2C-76.93224095434428\&Z=15

Municipalidad de Lima. (2020). MML Inaugura moderna ciclovía en villa el salvador en el día internacional de la bicicleta. Recuperado el 03 de junio de 2020 de http://www.munlima.gob.pe/noticias/item/35936-mml-inaugura-moderna-cicloviaen-villa-el-salvador-en-el-d\%C3\%ADa-internacional-de-la-bicicleta

Instituto Metropolitano PROTRANSPORTE. (2020). Rutas Alimentadoras. Recuperado el 03 de junio de 2020 de http://www.metropolitano.com.pe/conocenos/rutas/ruta-alimentadora/

Moovit. (2020). Metropolitano - Alimentadores. Recuperado el 03 de junio de 2020 de https://moovitapp.com/index/es-419/transporte p\%C3\%BAblico-line-AS04Lima-1102-1110949-690210-0

Moovit. (2020). Metropolitano - Alimentadores. Recuperado el 03 de junio de 2020 de https://moovitapp.com/index/es-419/transporte p\%C3\%BAblico-line-AS04Lima-1102-1110949-690210-0

Huamán, L., Huayta, J., Orihuela, L. \& Quiroz, L. (2017). Propuesta de aplicación de Línea 4 del Metro de Lima-Callao Tramo Av. Ovalo Gambetta Panamericana Norte. Tesis de maestría. Recuperado el 03 de junio de 2020 de

http://repositorio.urp.edu.pe/bitstream/handle/urp/1023/rizo l.pdf?sequence=1\&isA llowed=y

(2018, noviembre 16). De: Peruconstruye.net. Inauguran moderna ciclovía de más de 2 kilómetros en Villa el Salvador [Mensaje de Blog]. Recuperado el 03 de junio de 2020 de https://peruconstruye.net/2018/11/16/inauguran-modernaciclovia-de-mas-de-2-kilometros-en-villa-el-salvador/

(2020, enero 27). De: Sociedad peruana de Bienes Raíces. Plusvalía Inmobiliaria (es el incremento de valor del suelo) [Mensaje de Blog]. Recuperado el 03 de junio de 2020 de https://bienesraicess.com/blogs/plusvalia-inmobiliariaincremento-valor-del-suelo/

(2019, febrero 28). De: Vivanuncios. ¿Qué tipo de establecimientos aumentan el valor de un inmueble? [Mensaje de Blog]. Recuperado el 03 de junio de 2020 de https://blog.vivanuncios.com.mx/bienes-raices/comprar-casa/plusvalia-de-uninmueble/ 
8. ANEXOS

- PROPUESTA DE INTERVENCIÓNES VIALES CON VIAS EXISTENTES:

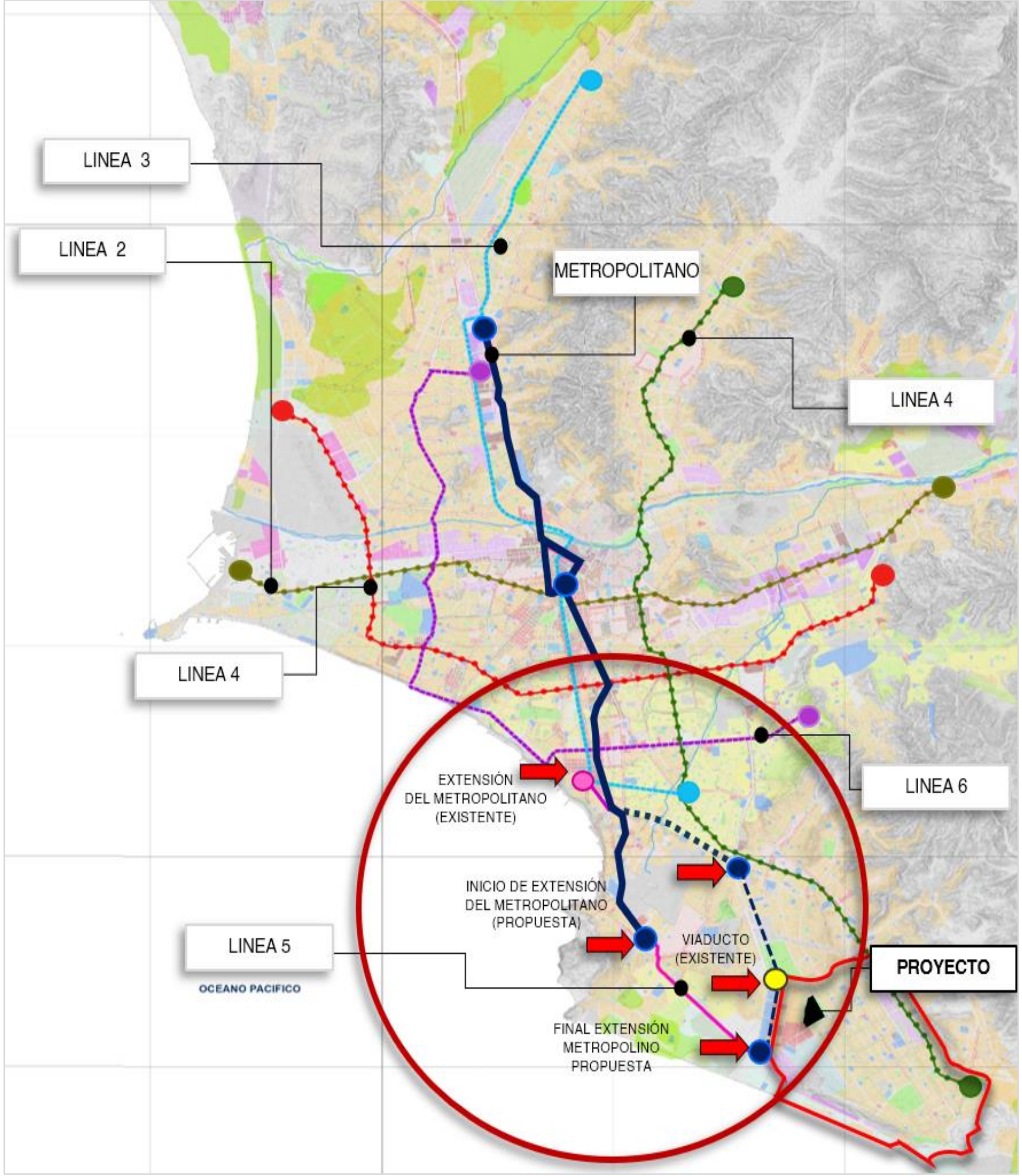




\section{- PROPUESTA DE INTERVENCIÓNES VIALES:}

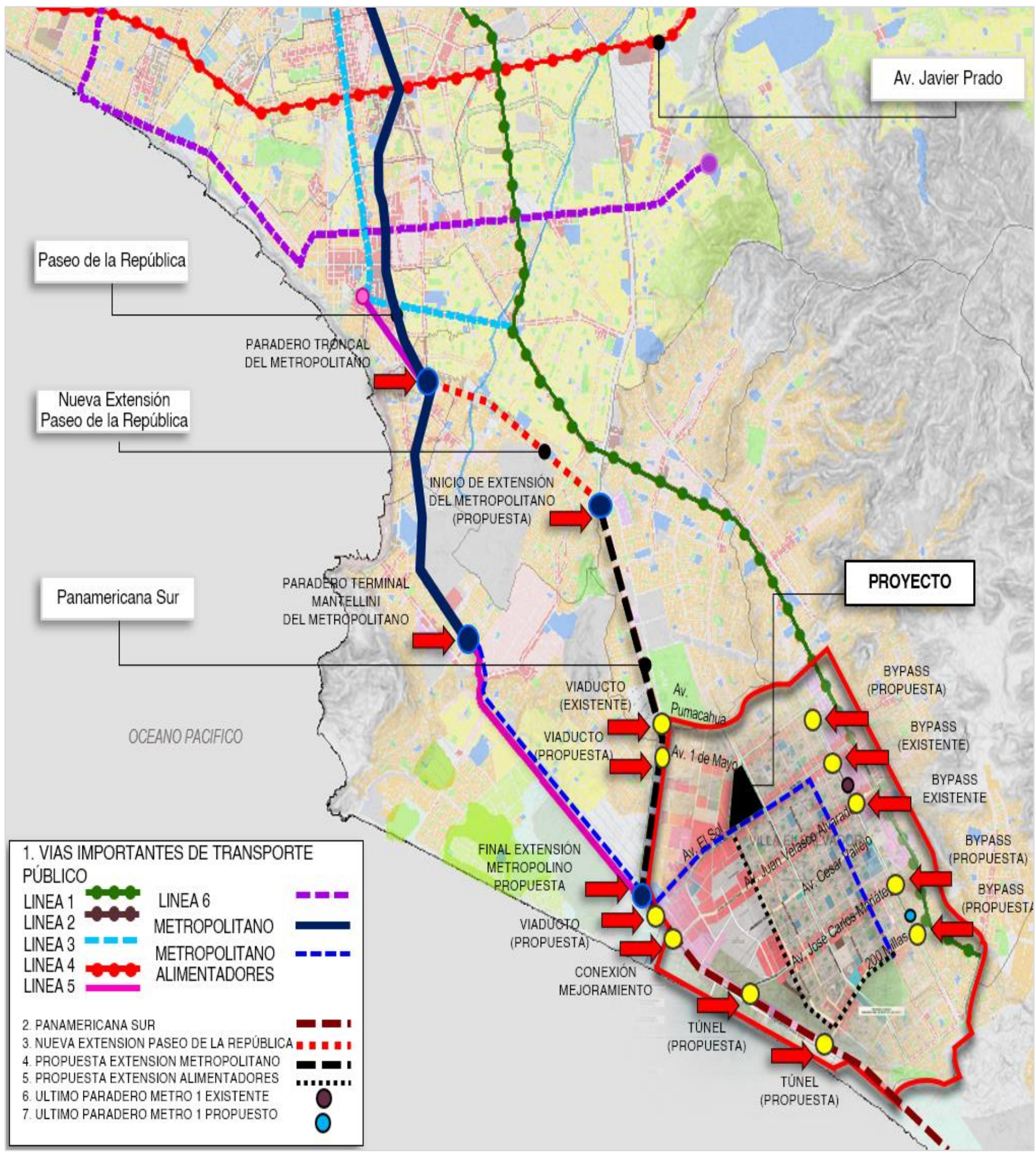




\section{- ZONIFICACIÓN PROPUESTA PARA VILLA EL SALVADOR:}

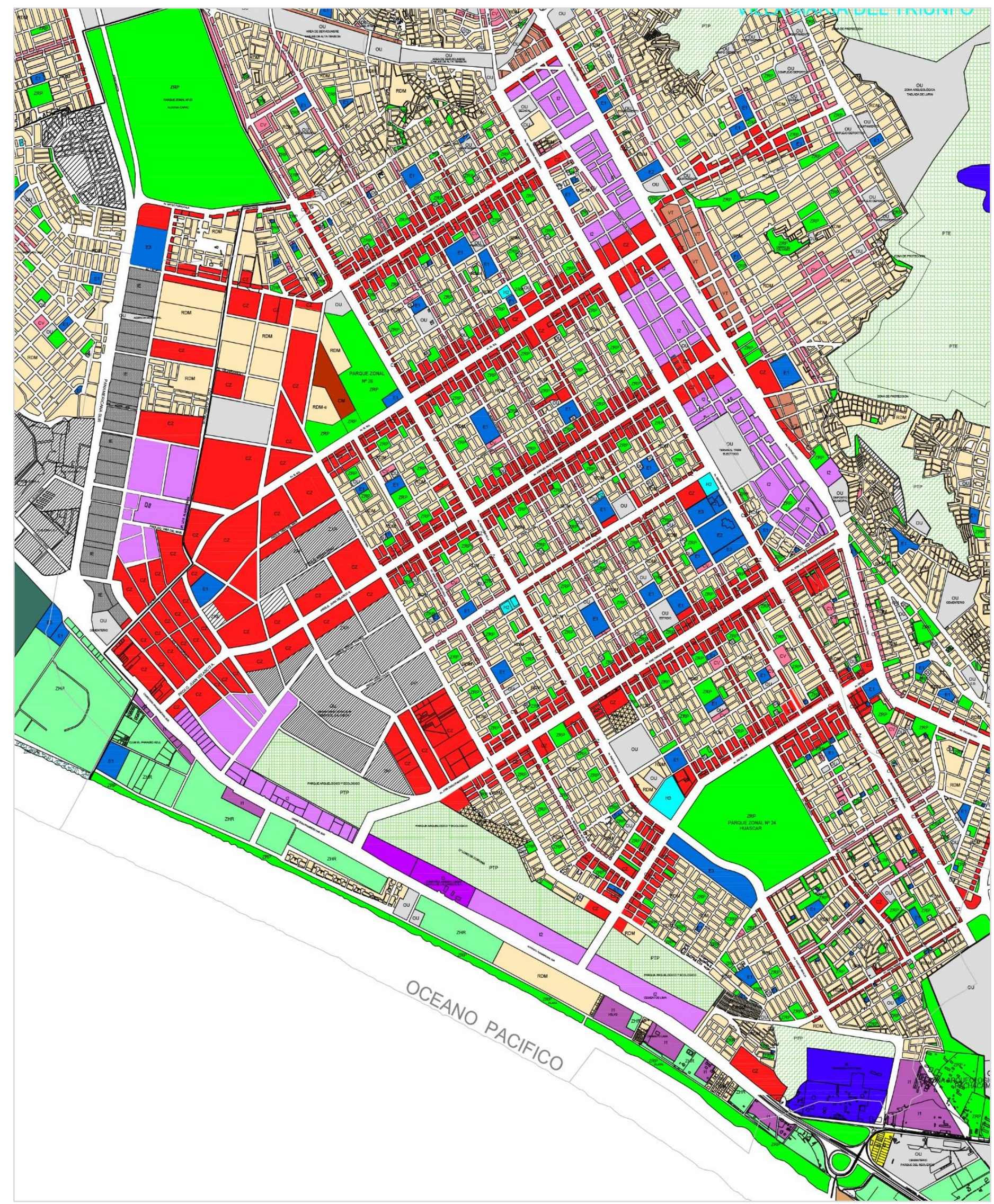


- PROPUESTA URBANA INTEGRAL:
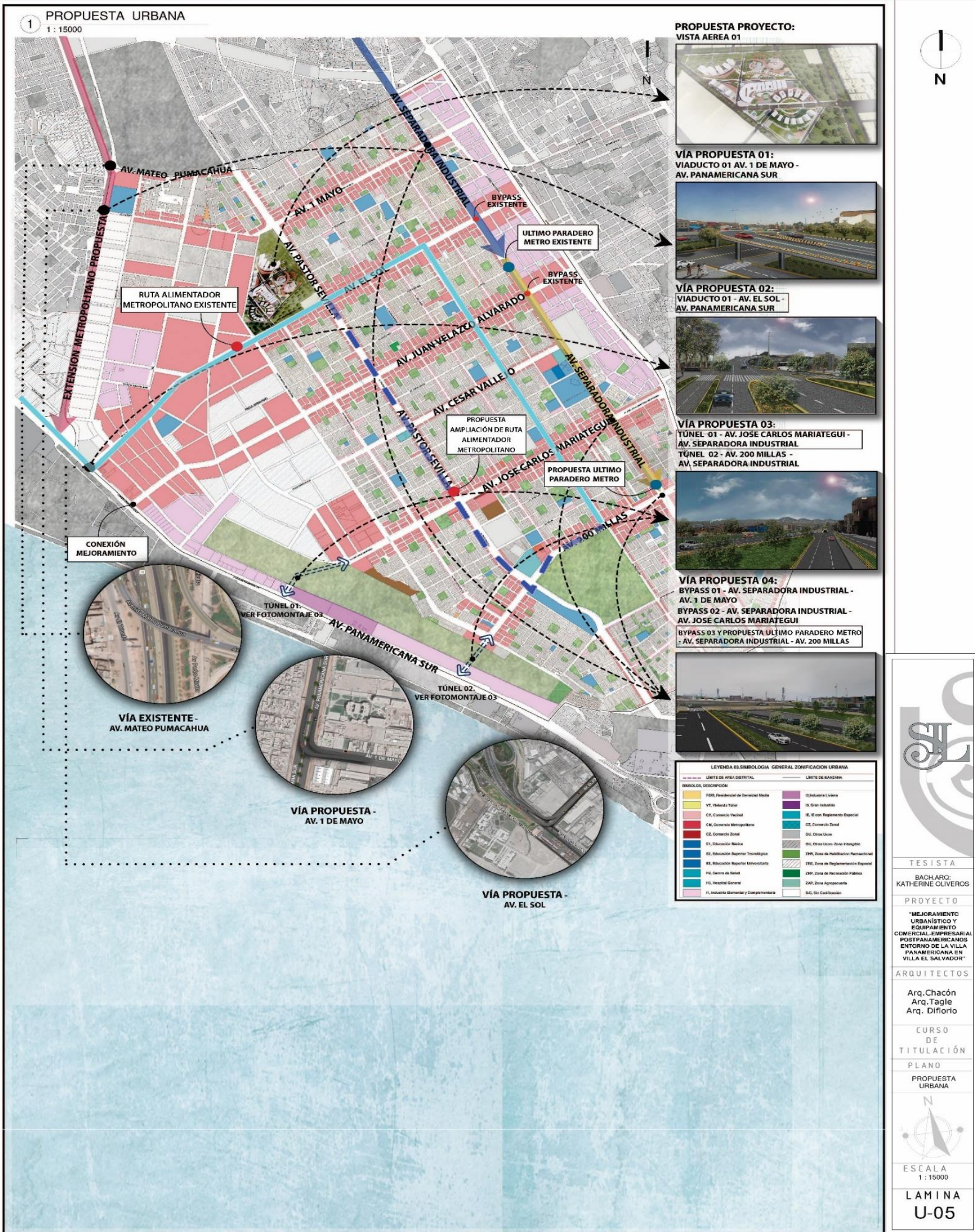
- MODELO VIADUCTO - VIA PROPUESTA 01 DE PROPUESTA URBANA INTEGRAL:

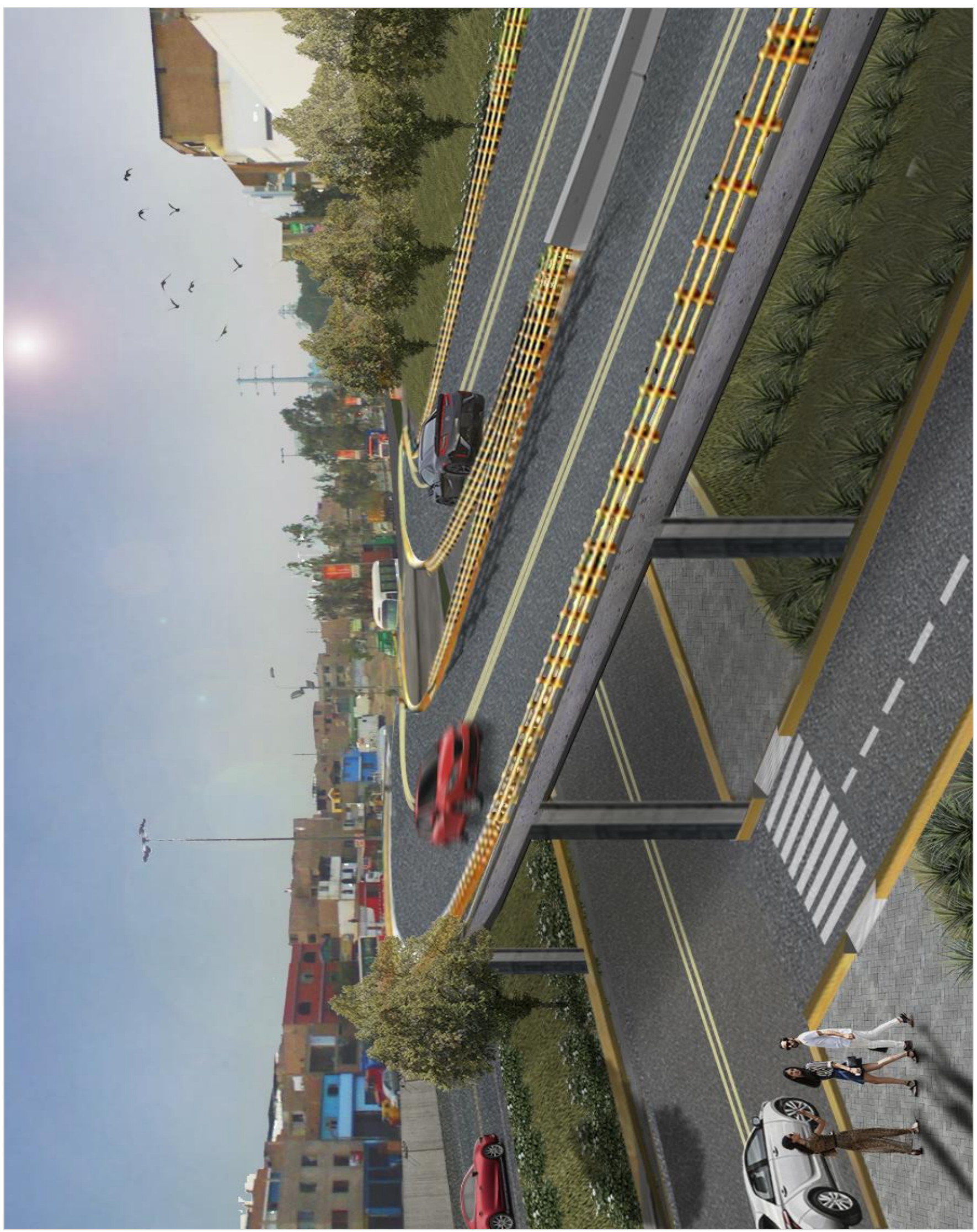


- MODELO VIADUCTO - VIA PROPUESTA 02 DE PROPUESTA URBANA INTEGRAL:

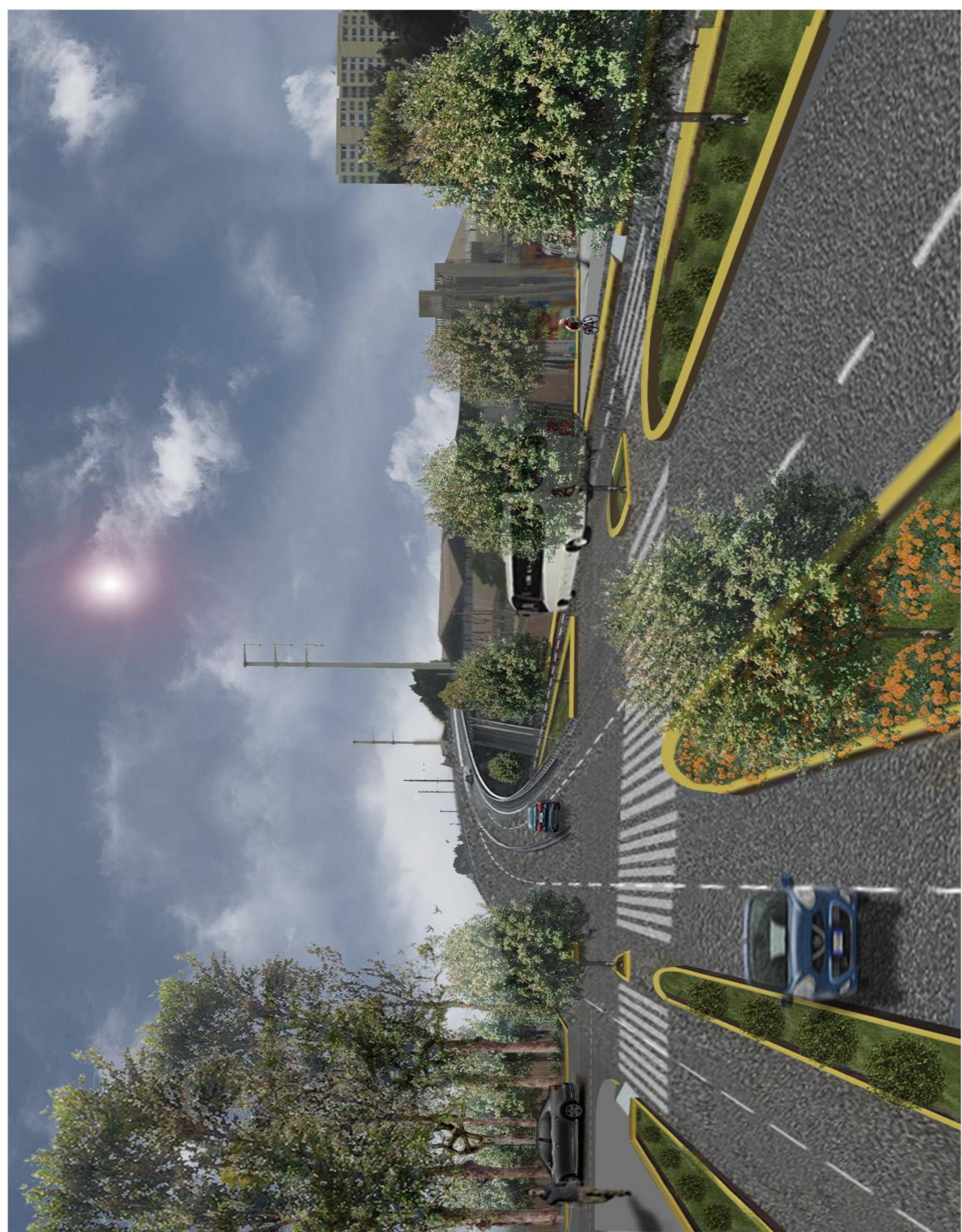


- MODELO TÚNEL - VIA PROPUESTA 03 DE PROPUESTA URBANA INTEGRAL:

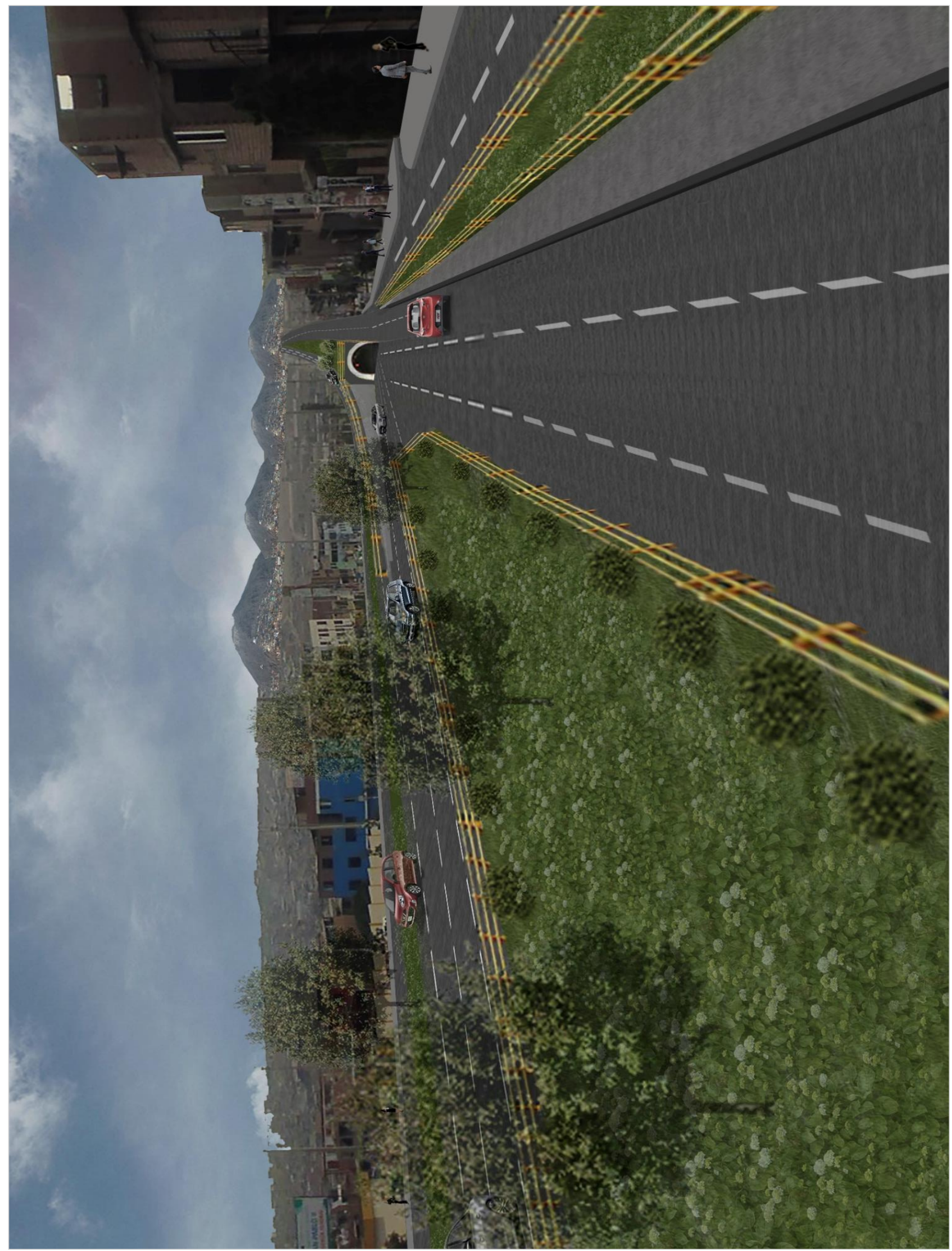


- MODELO BYPASS - VIA PROPUESTA 04 DE PROPUESTA URBANA INTEGRAL:

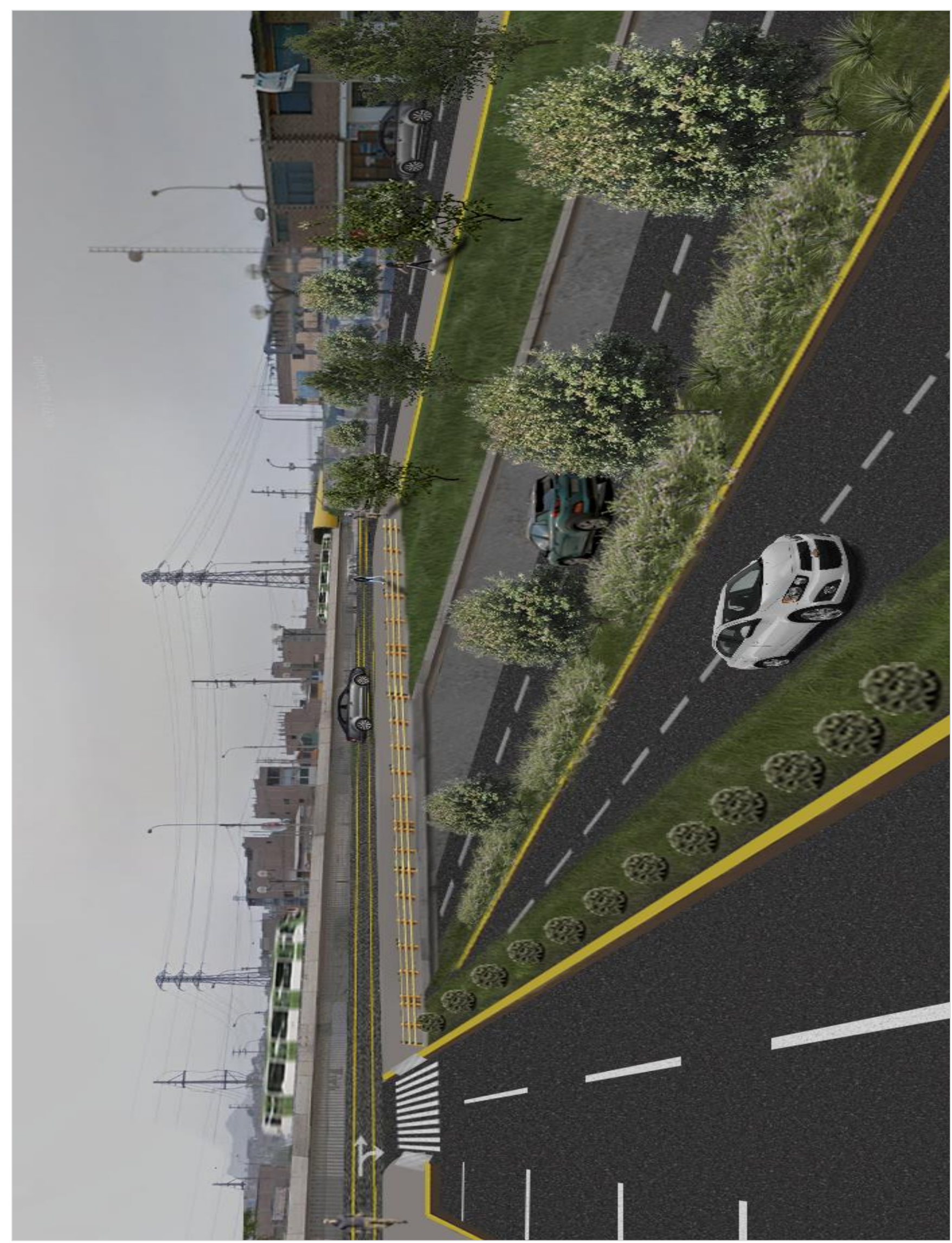


- MASTER PLAN DE PROYECTO ARQUITECTÓNICO:

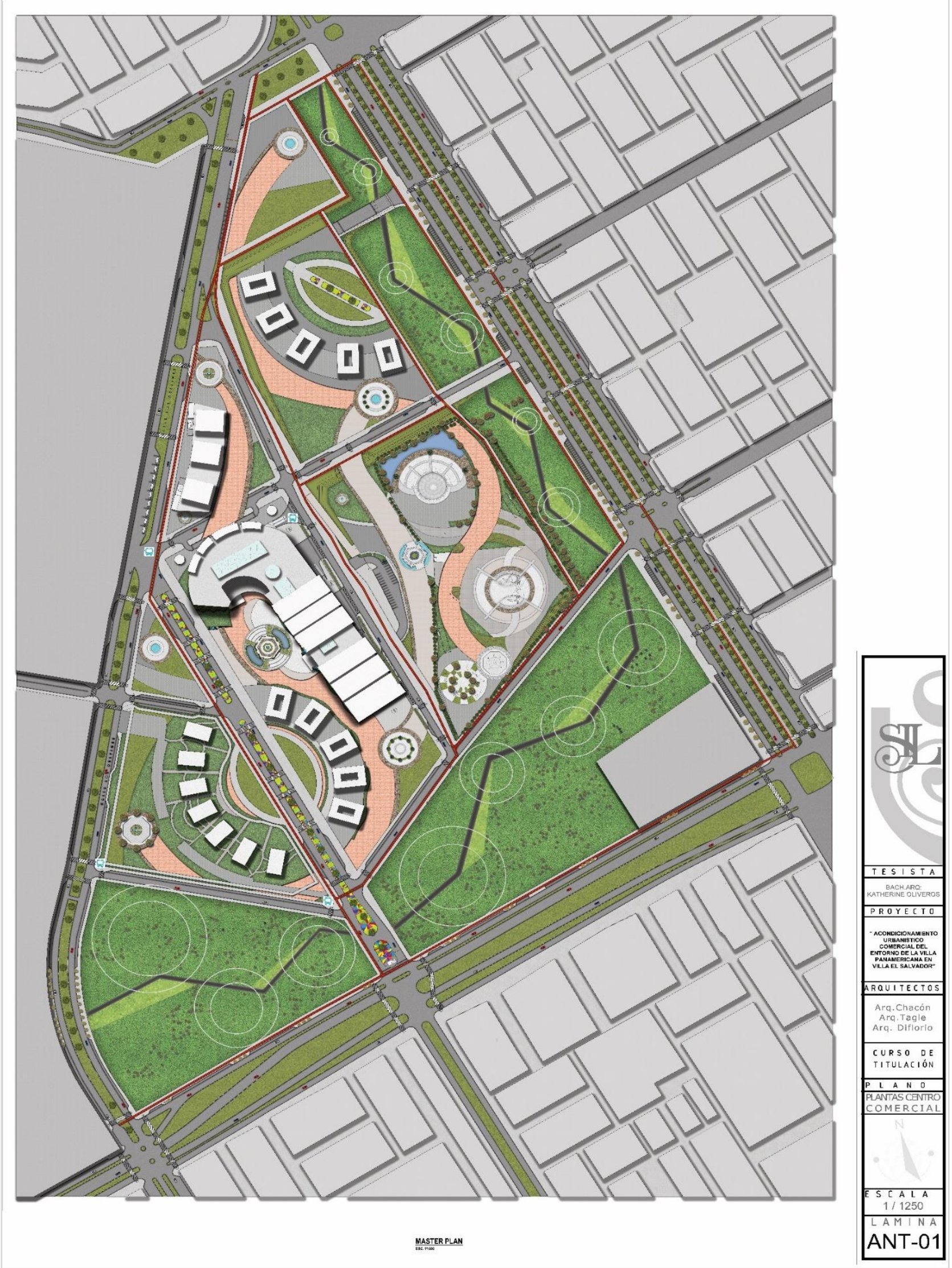


- PERFILES URBANOS DEL PROYECTO ARQUITECTÓNICO:

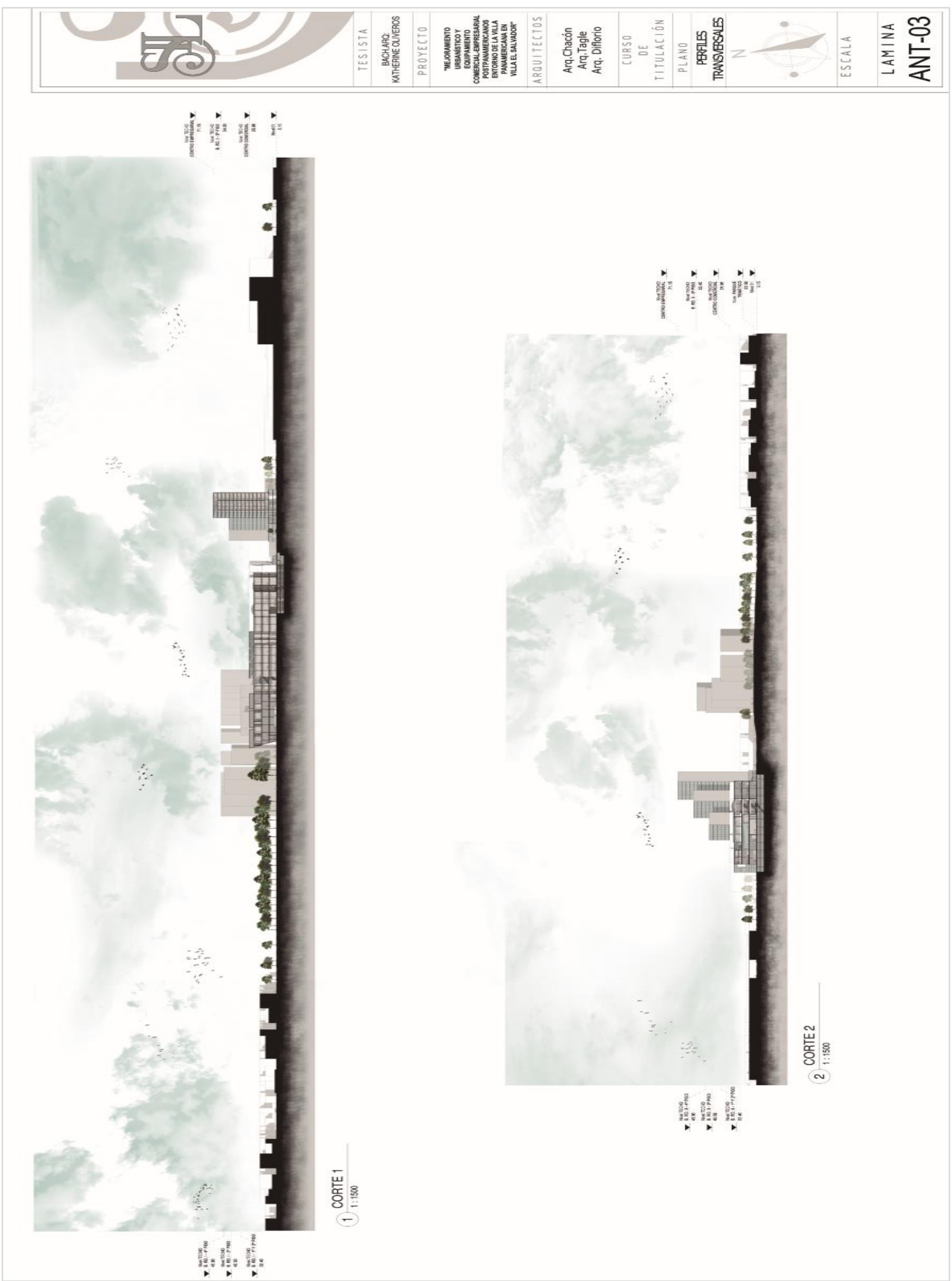


- PLANOS CENTRO COMERCIAL - PRIMER SÓTANO:

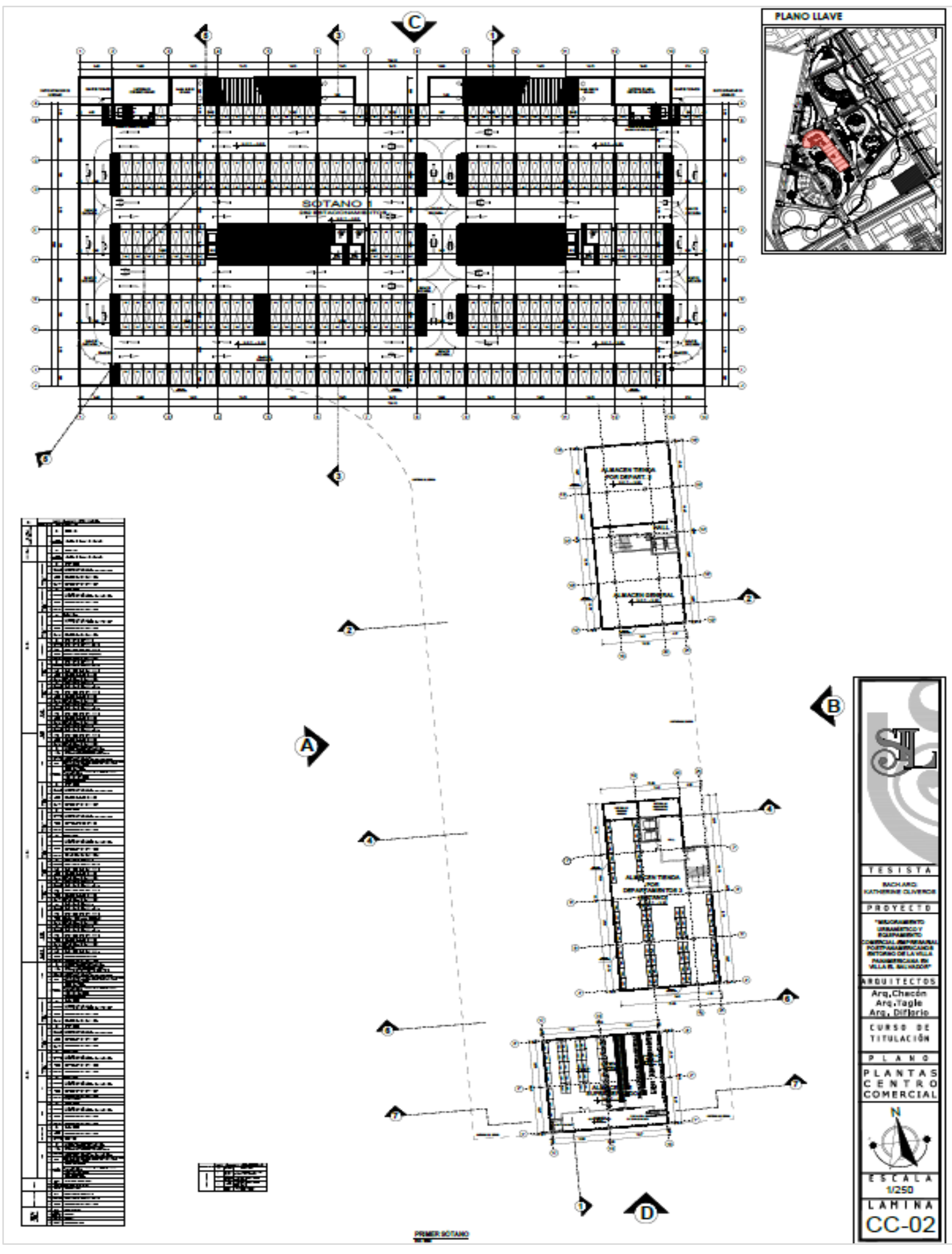


- PLANOS CENTRO COMERCIAL - SEGUNDO SÓTANO:
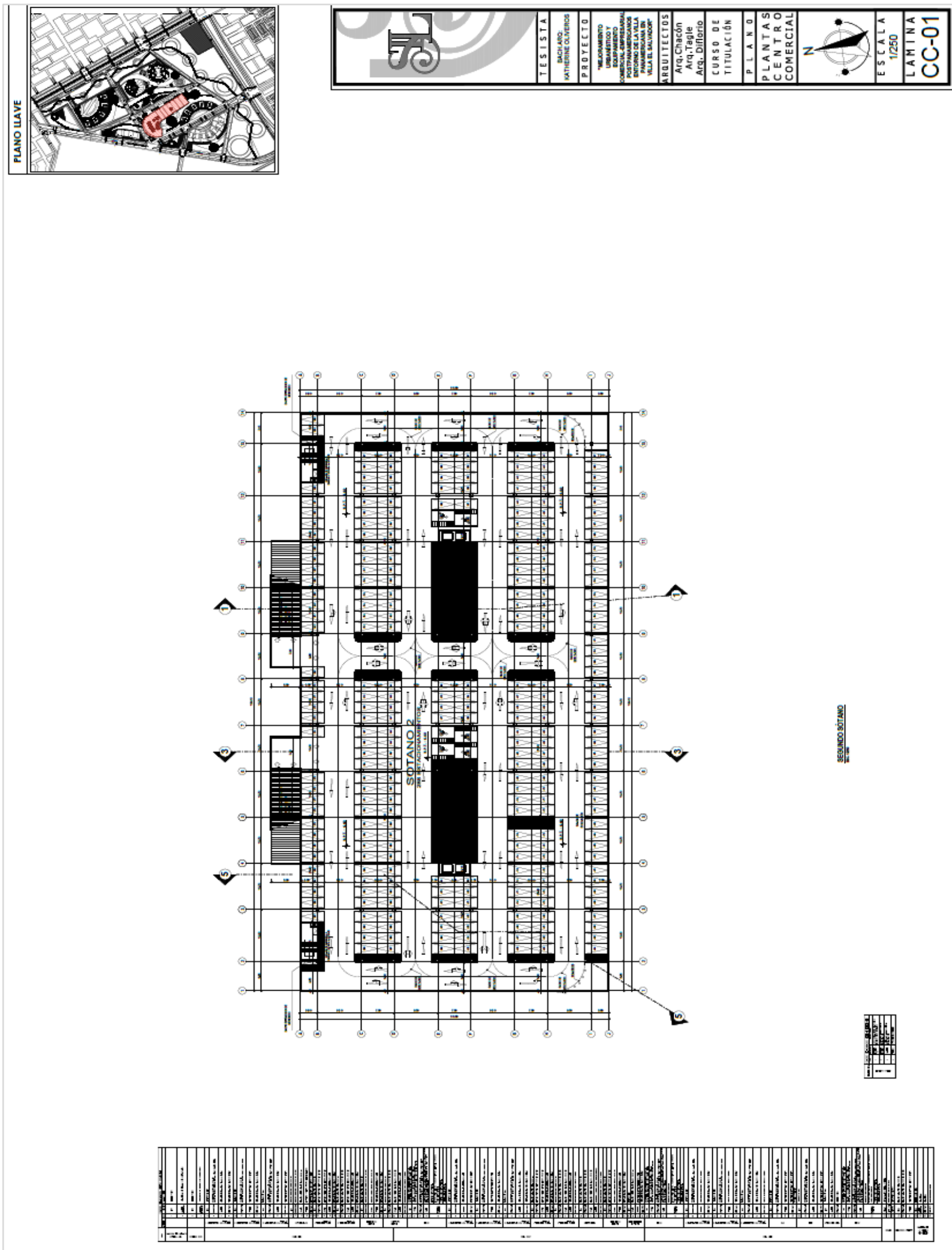
- CENTRO COMERCIAL - PRIMER PISO:

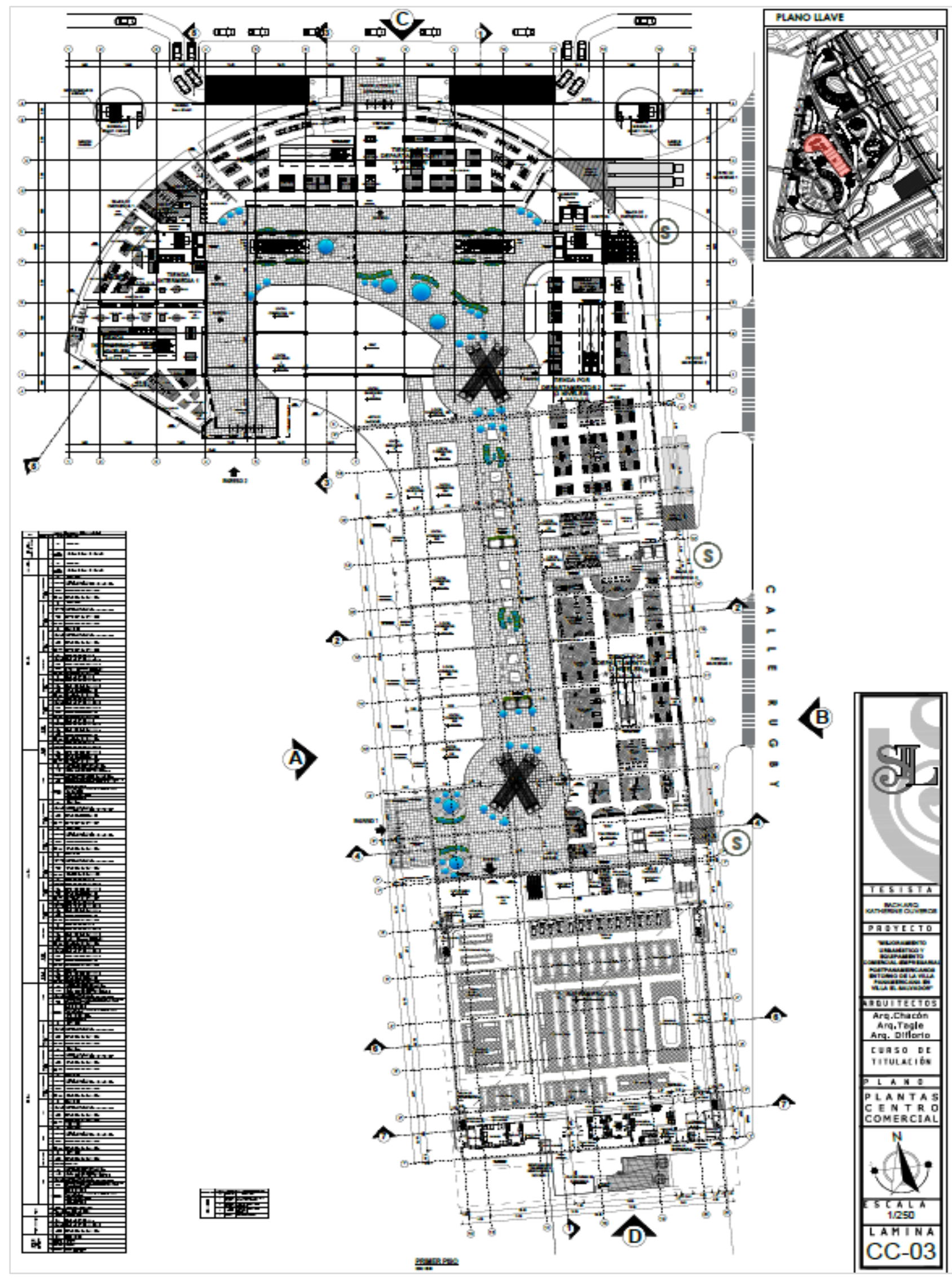


- CENTRO COMERCIAL - SEGUNDO PISO:

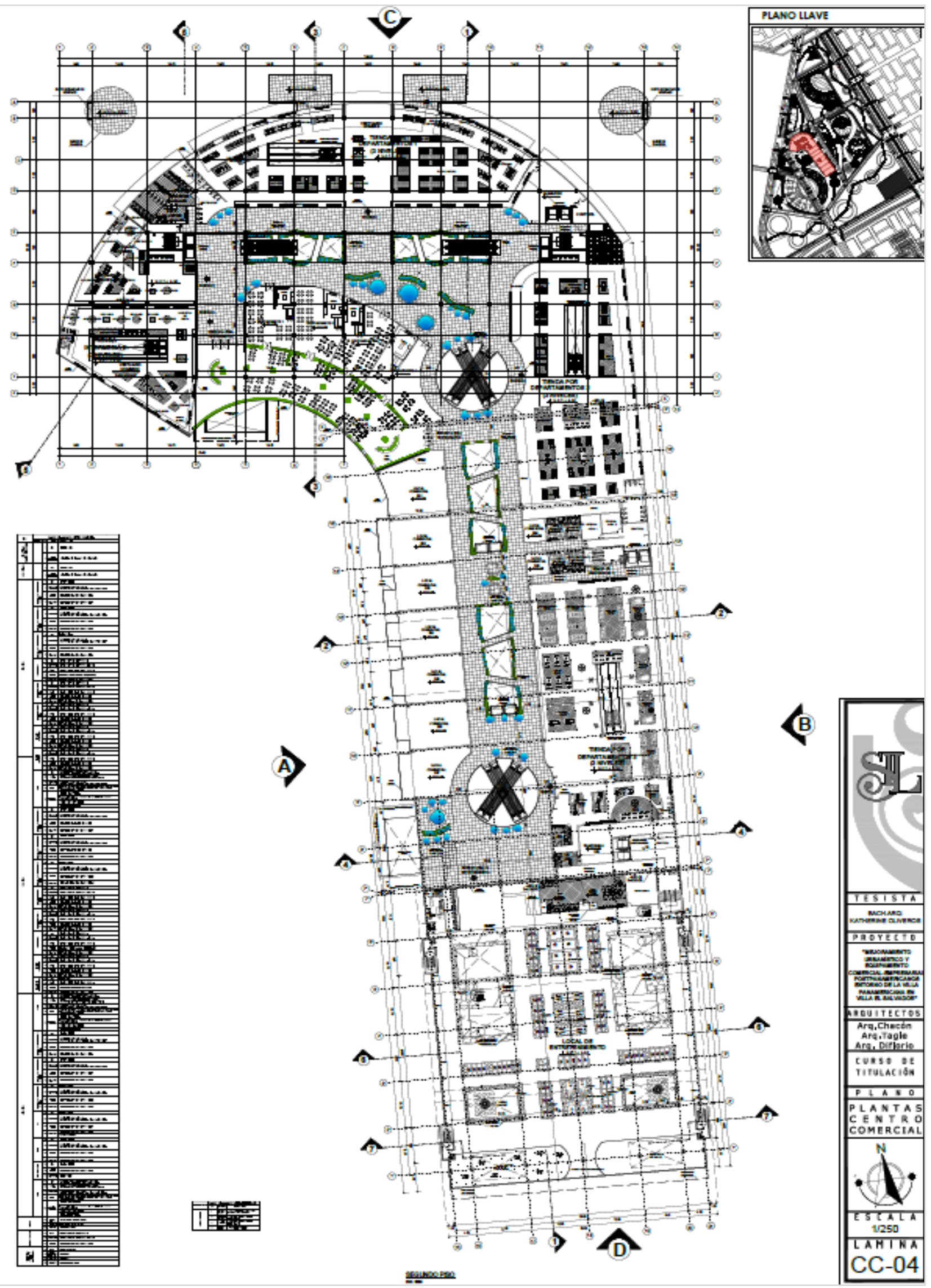


- CENTRO COMERCIAL - TERCER PISO:

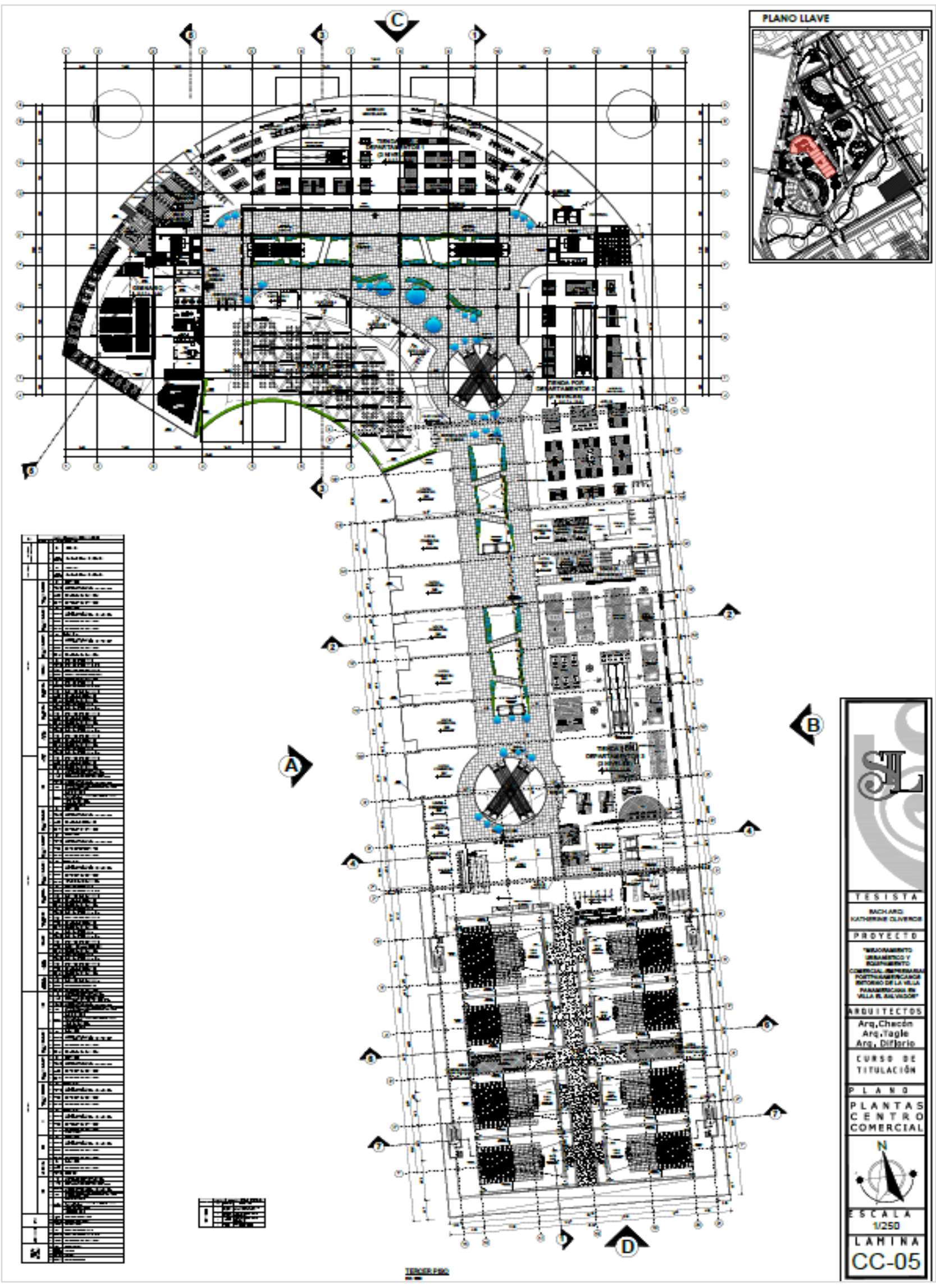


- CENTRO COMERCIAL - TECHOS:

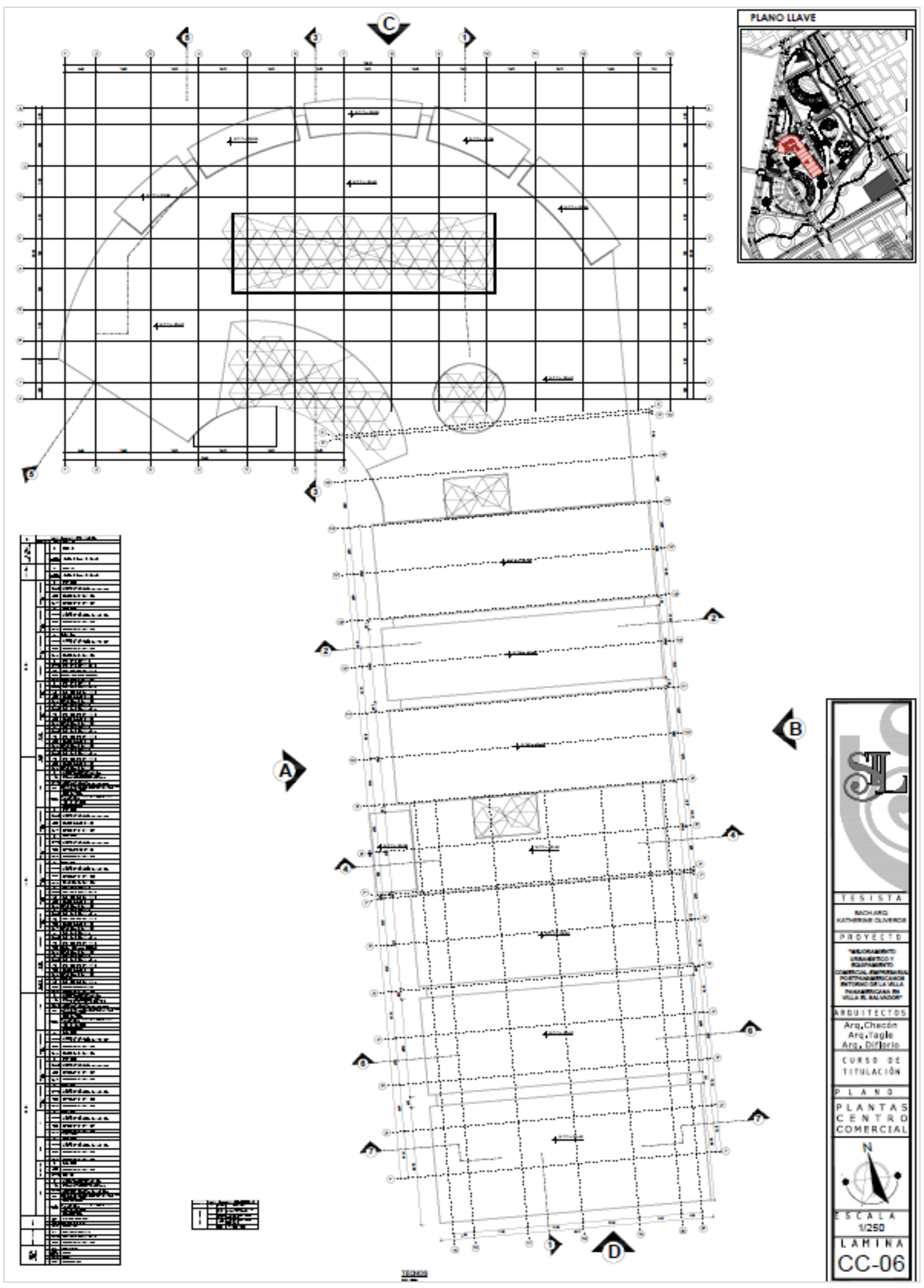


- CENTRO COMERCIAL - CORTES:

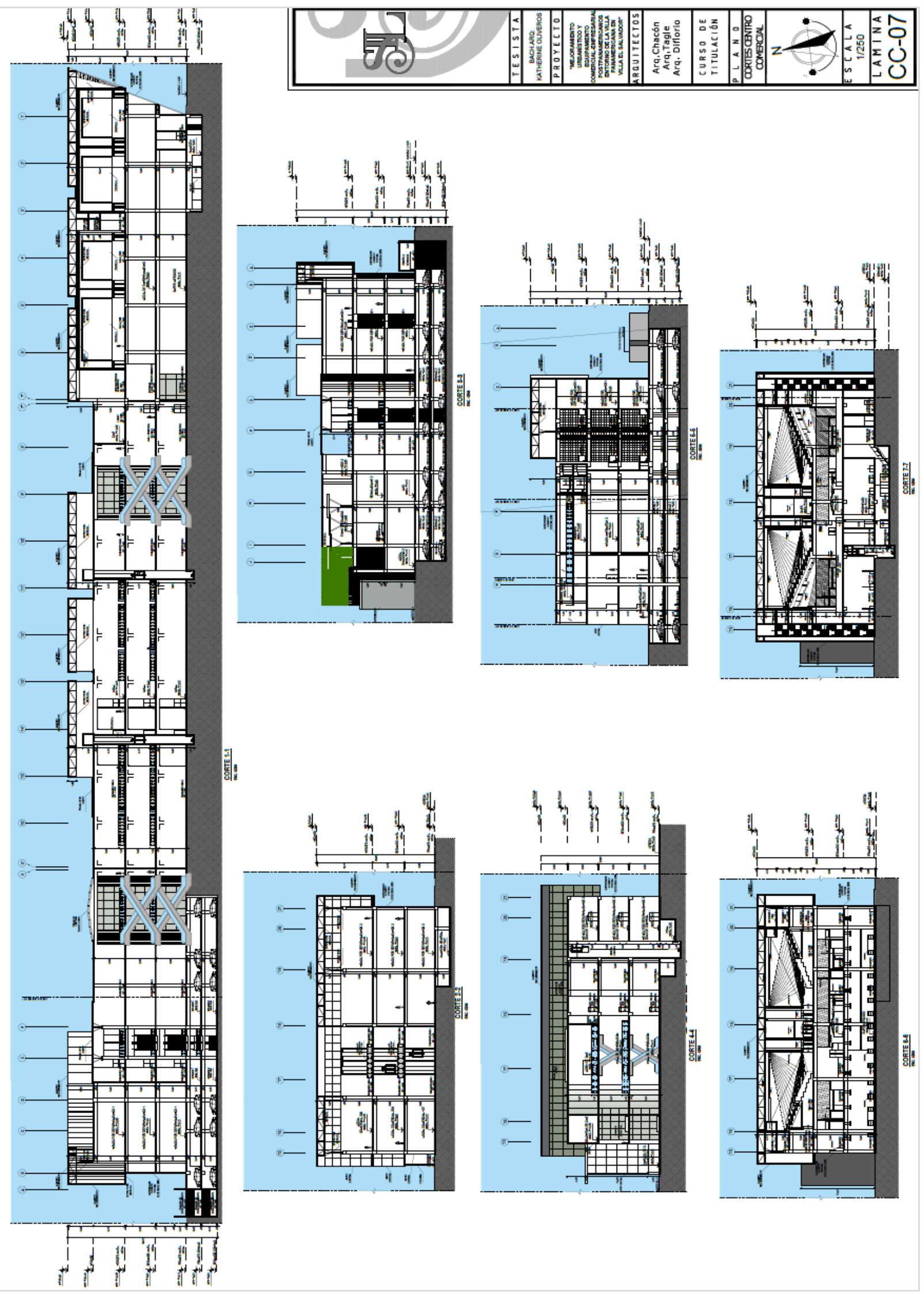


- CENTRO COMERCIAL - ELEVACIONES:

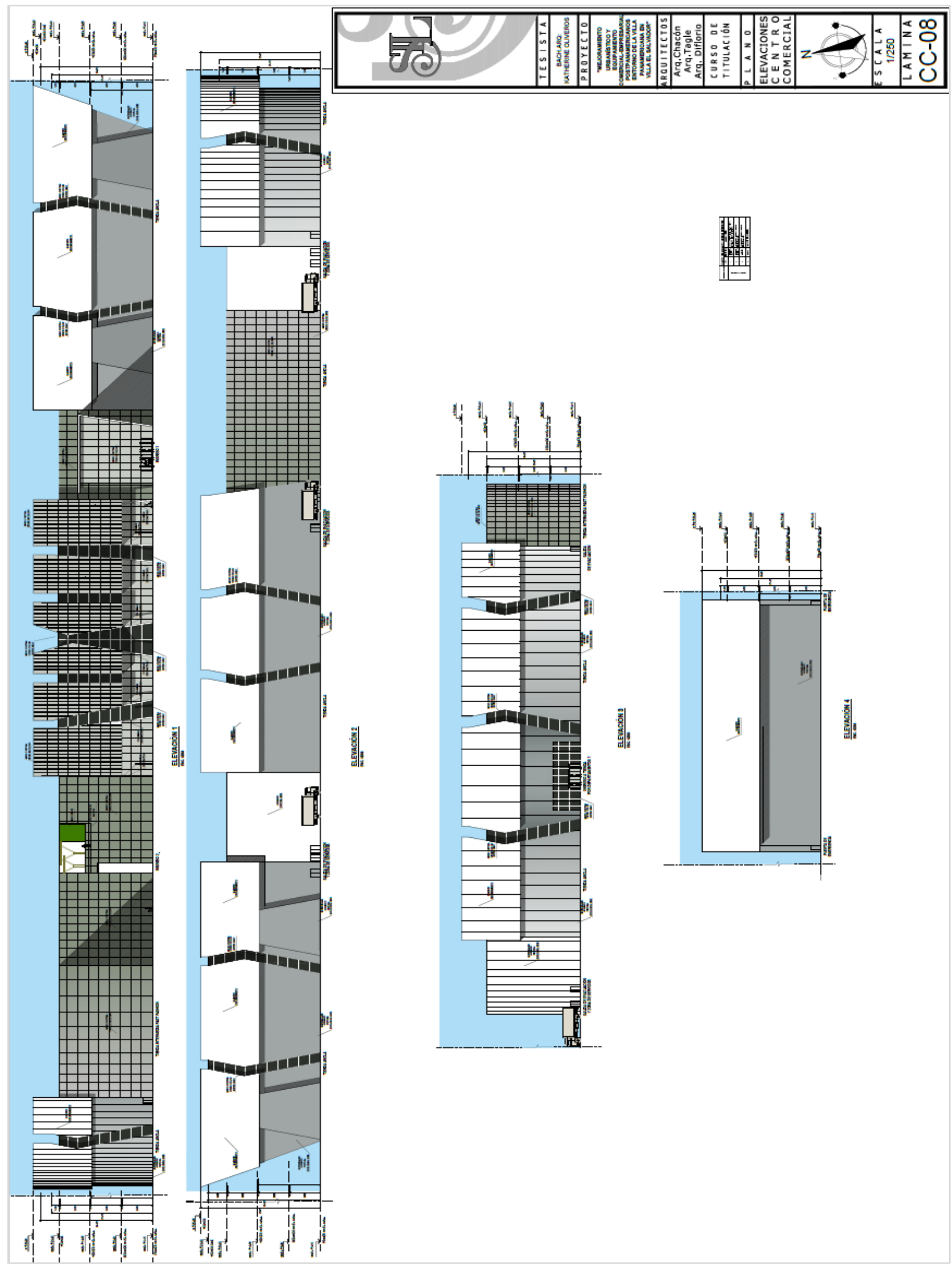


- DETALLES CENTRO COMERCIAL - ACSENSOR:

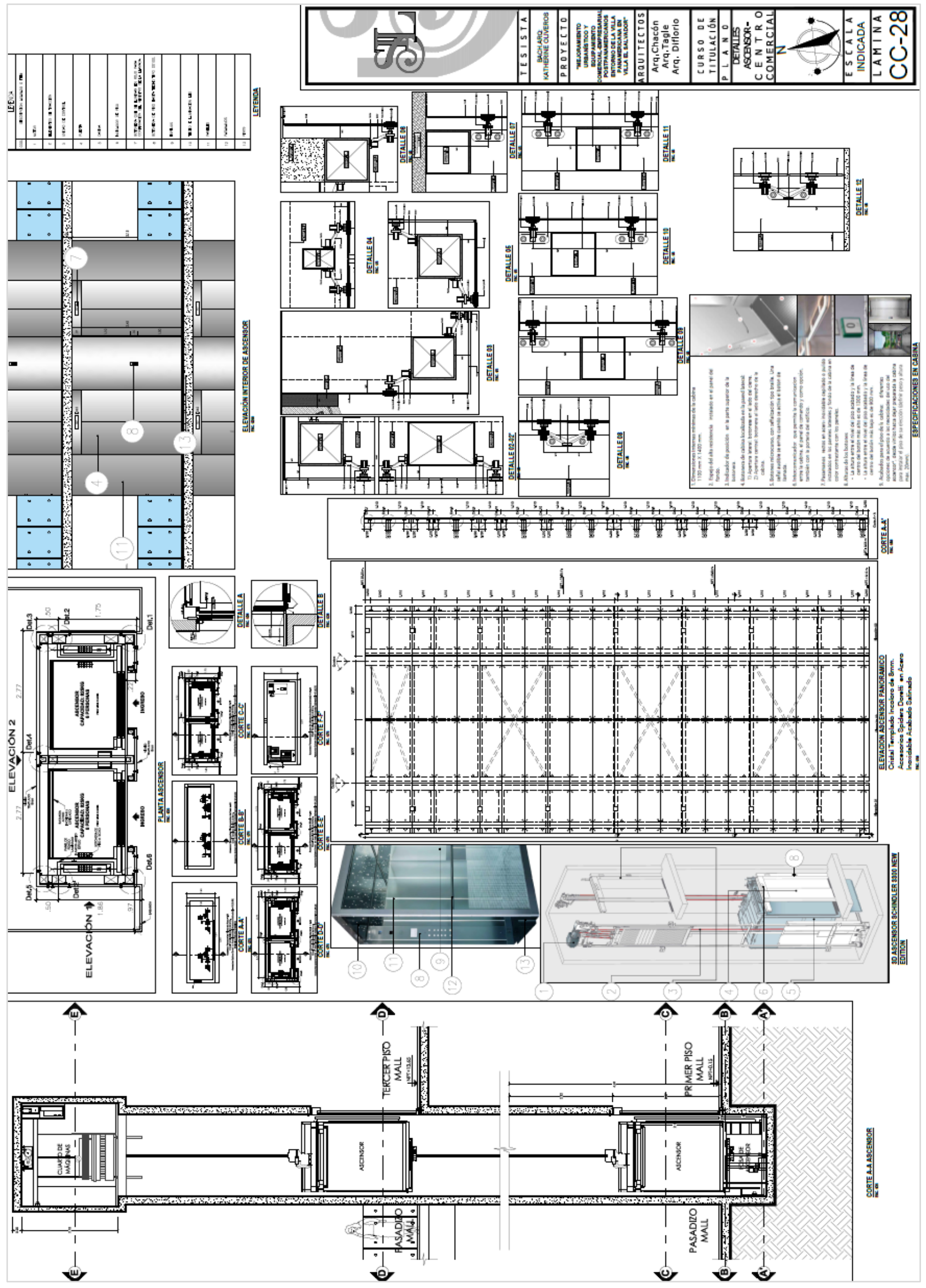


- DETALLES CENTRO COMERCIAL - ESCALERAS:

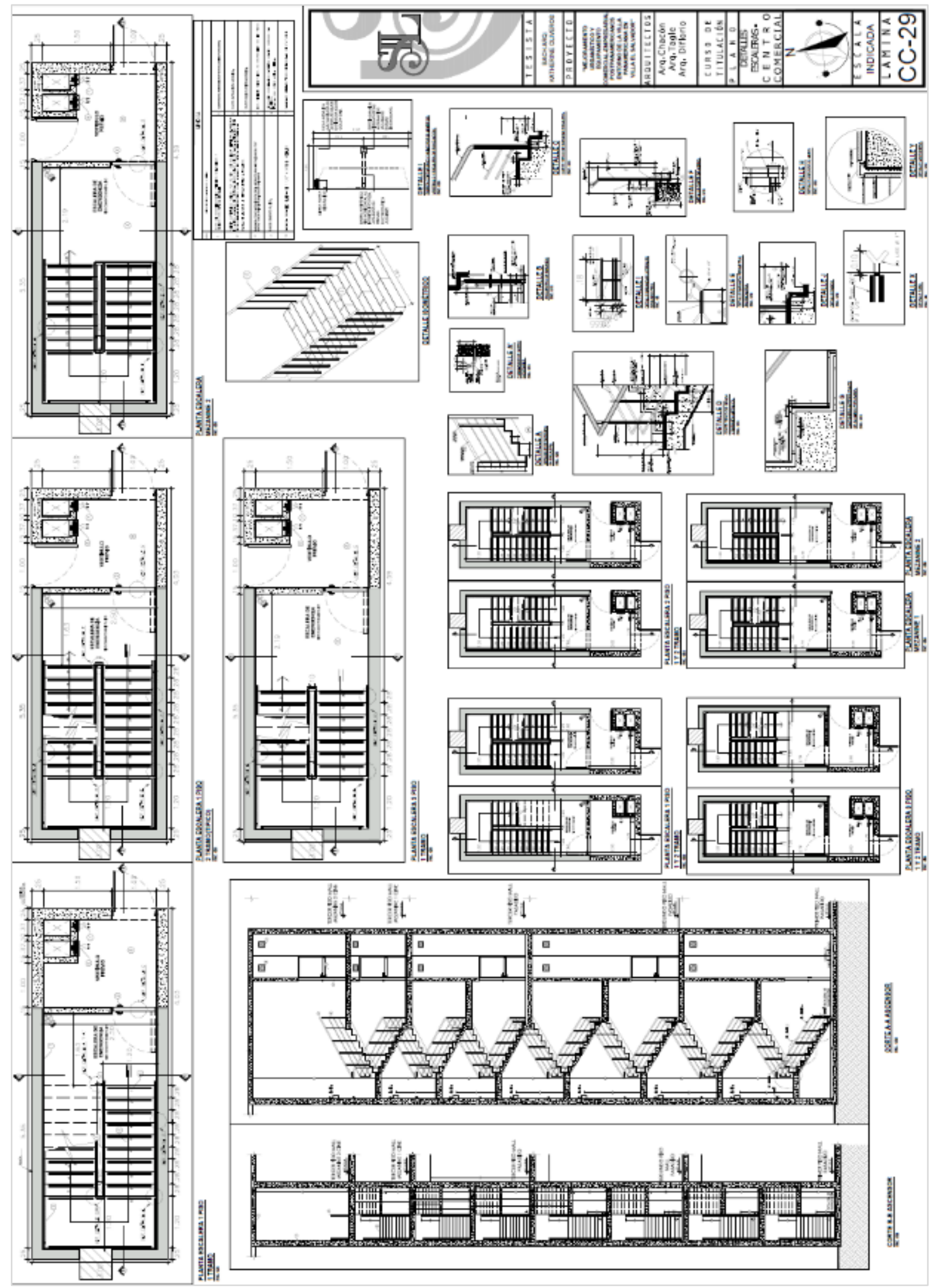


- DETALLES CENTRO COMERCIAL - MURO CORTINA:

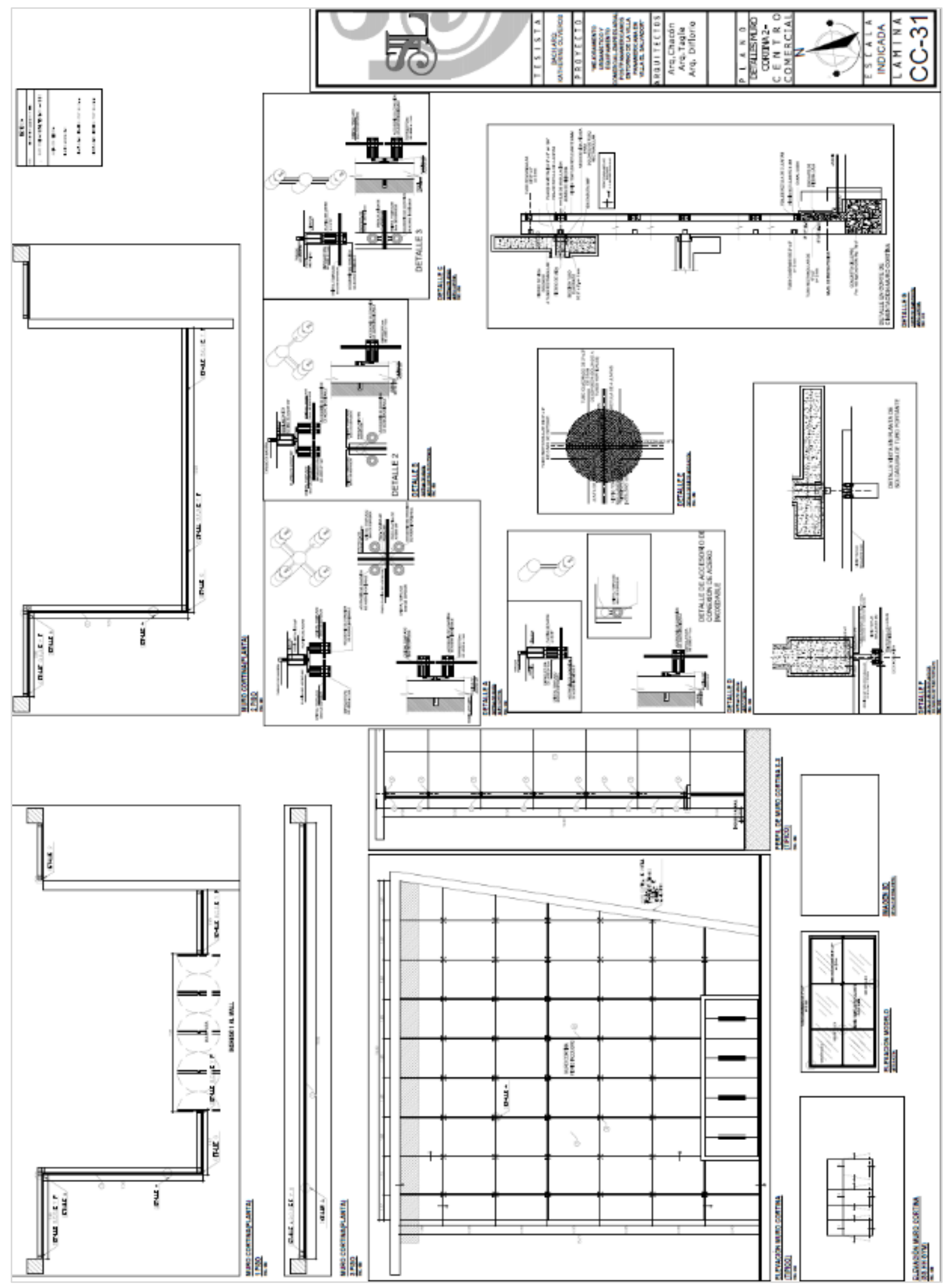


- DETALLES CENTRO COMERCIAL - SUPERBOARD:
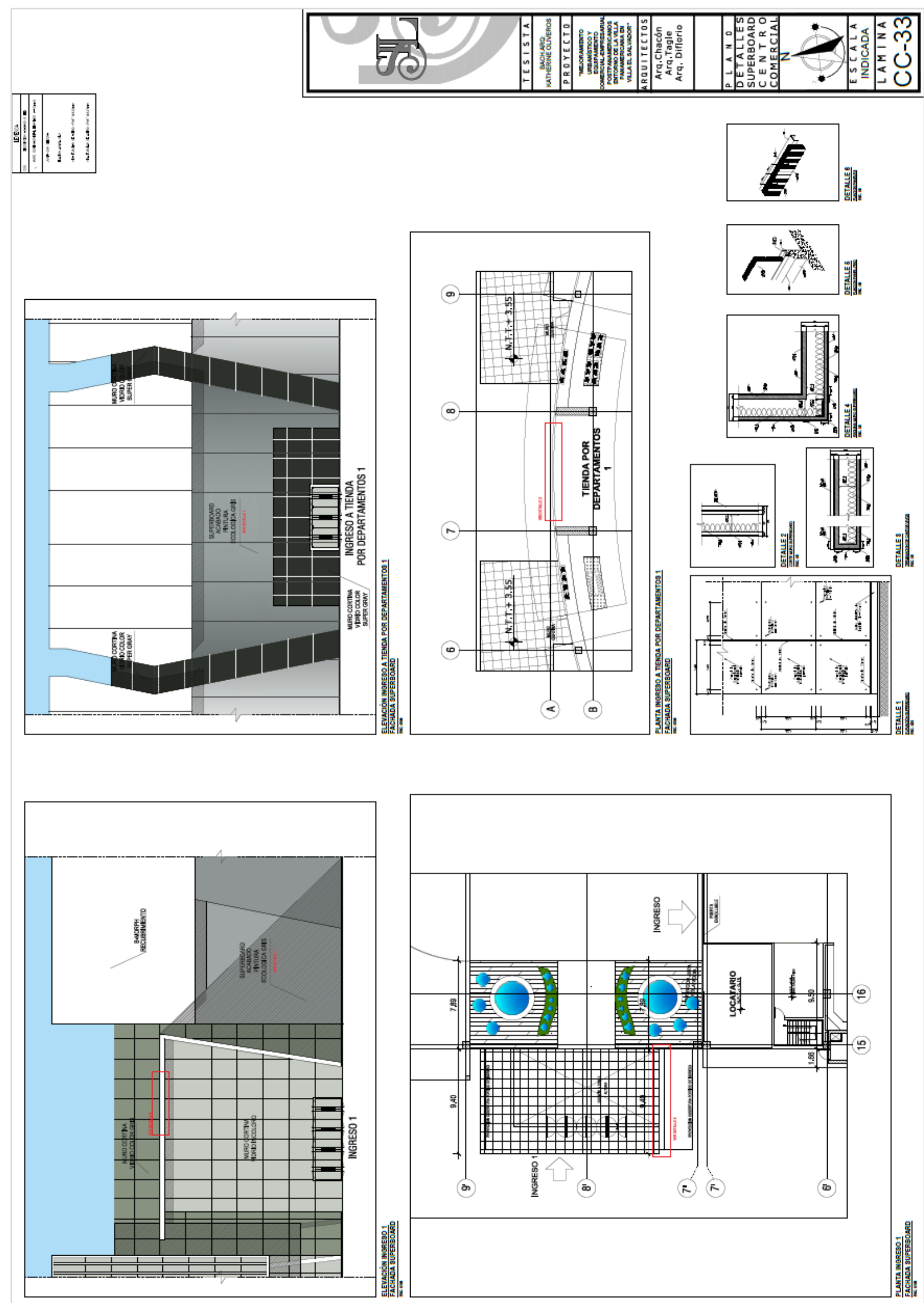
- DETALLES CENTRO COMERCIAL - MURO VERDE:

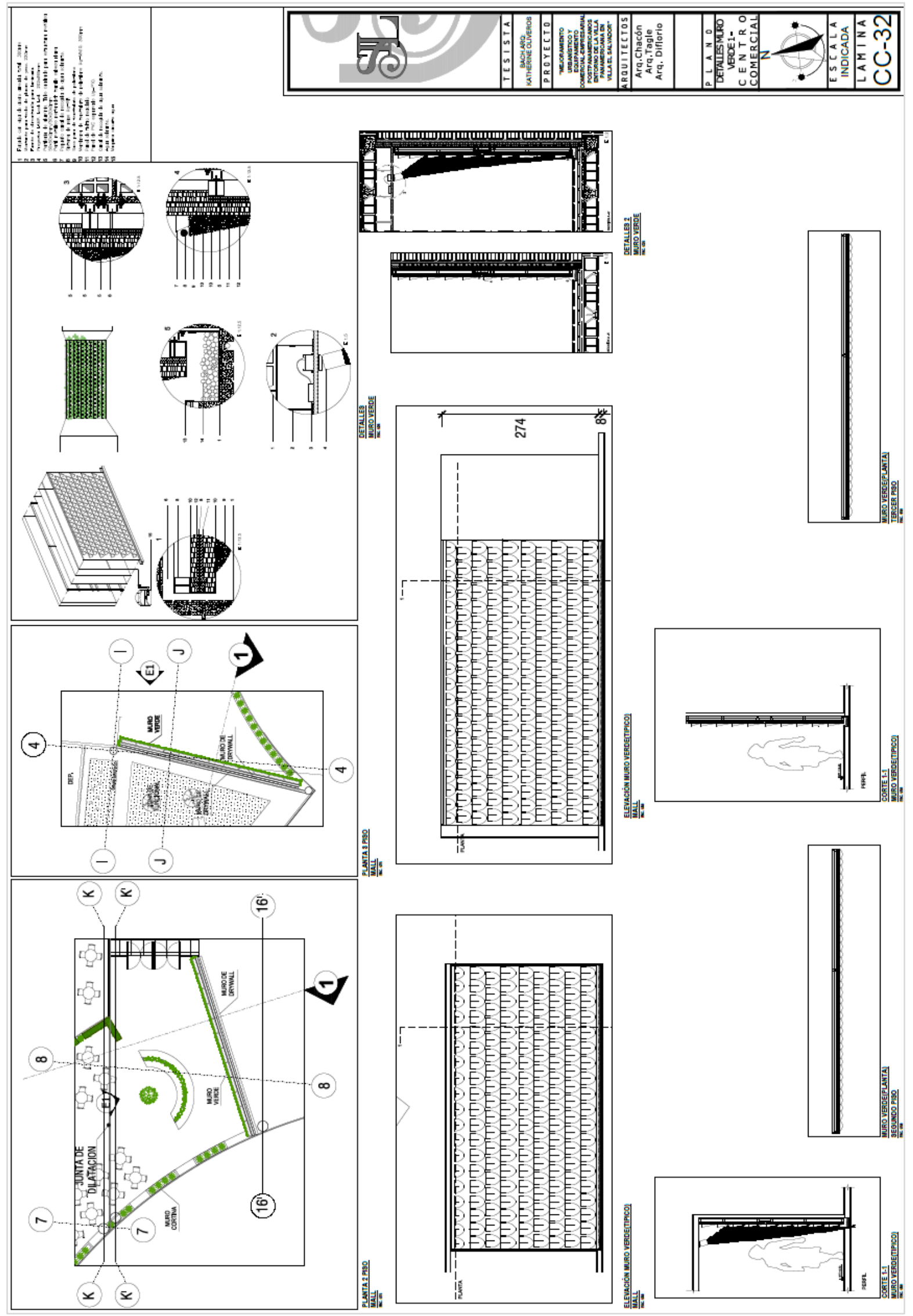


- GYMNASIO ARQUITECTURA DETALLE - PRIMER PISO ESC 1/75:

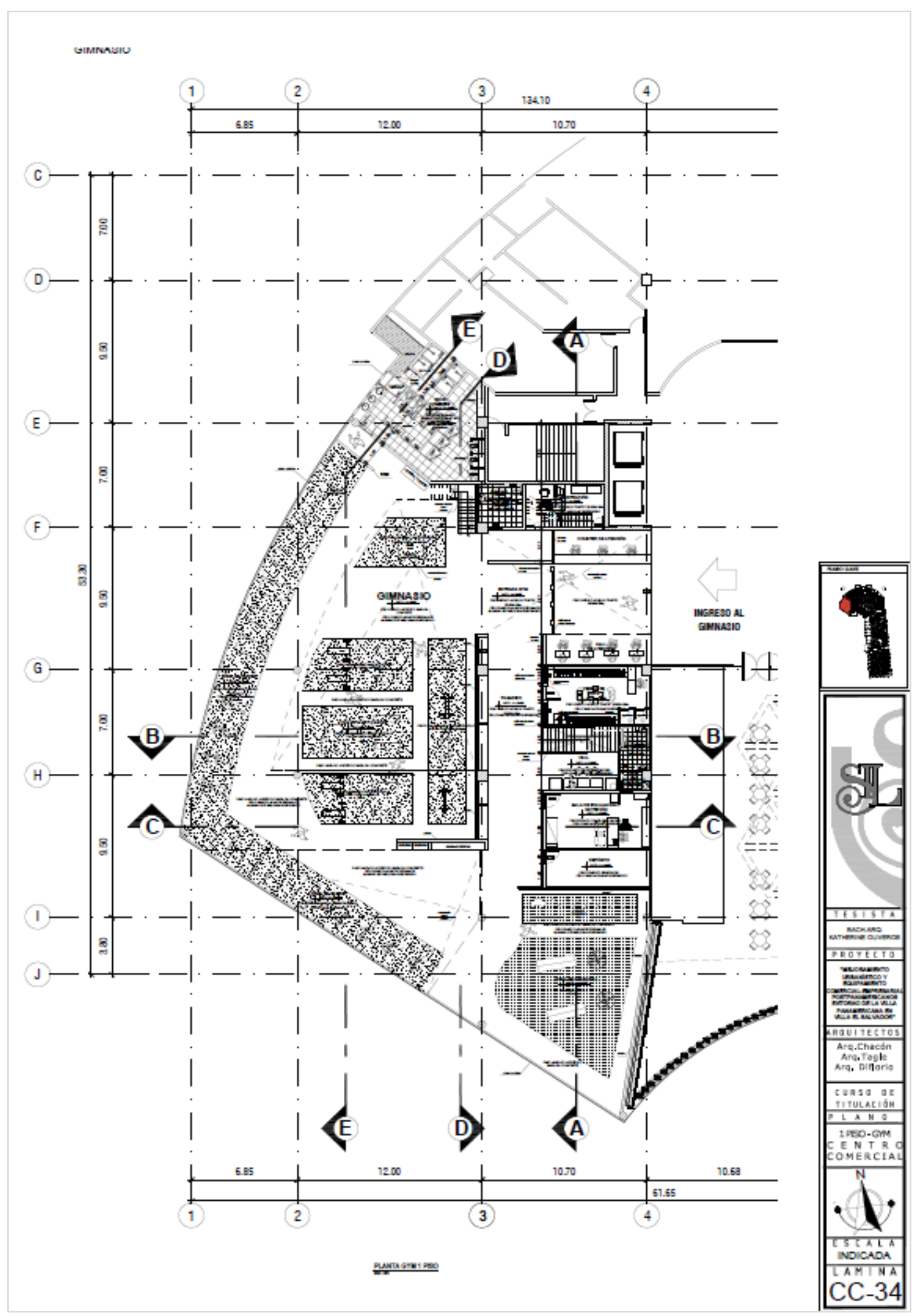


- GYMNASIO ARQUITECTURA DETALLE - MEZANINE ESC 1/75:

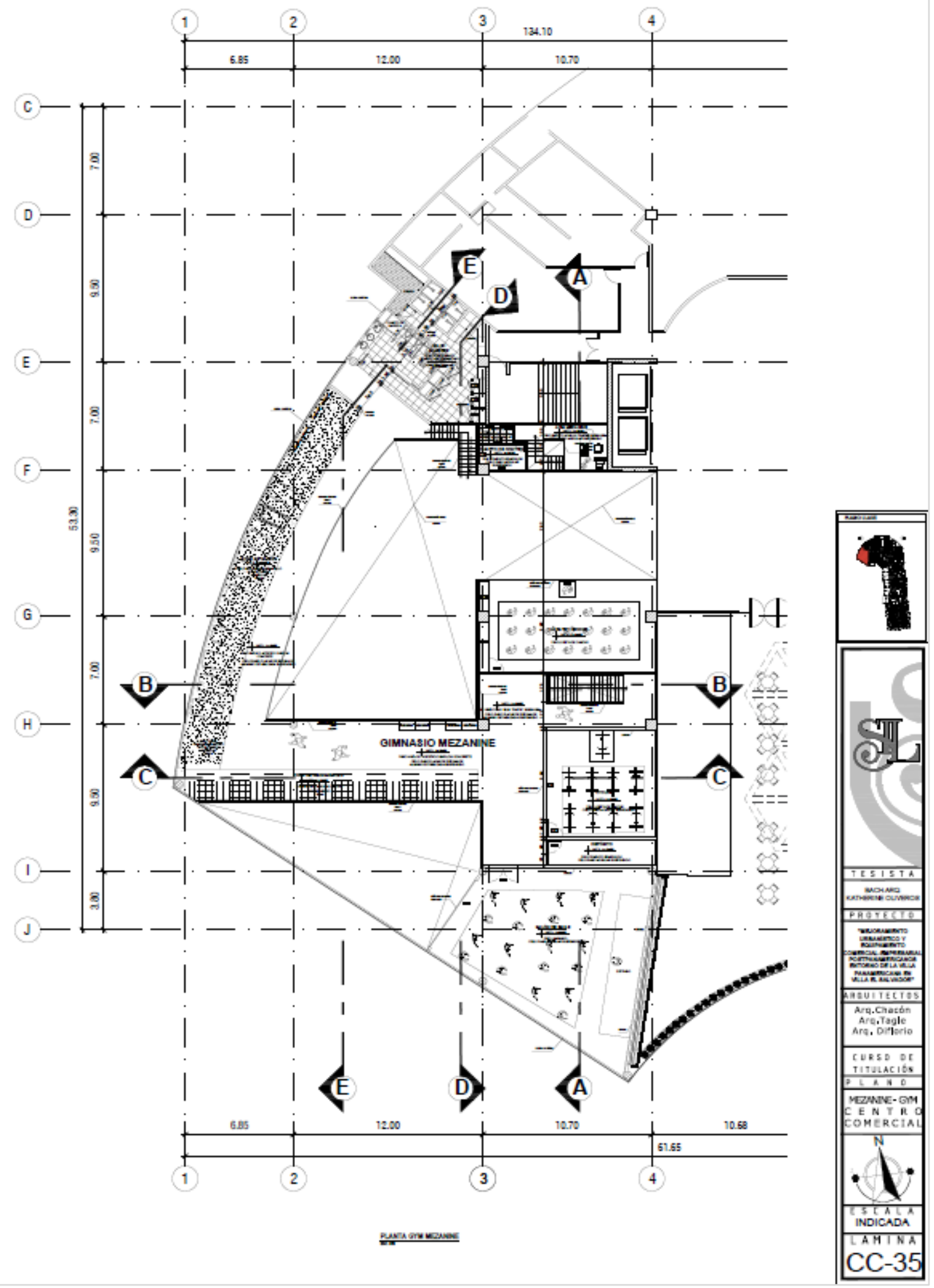


- CORTES GYMNASIO 1/50:

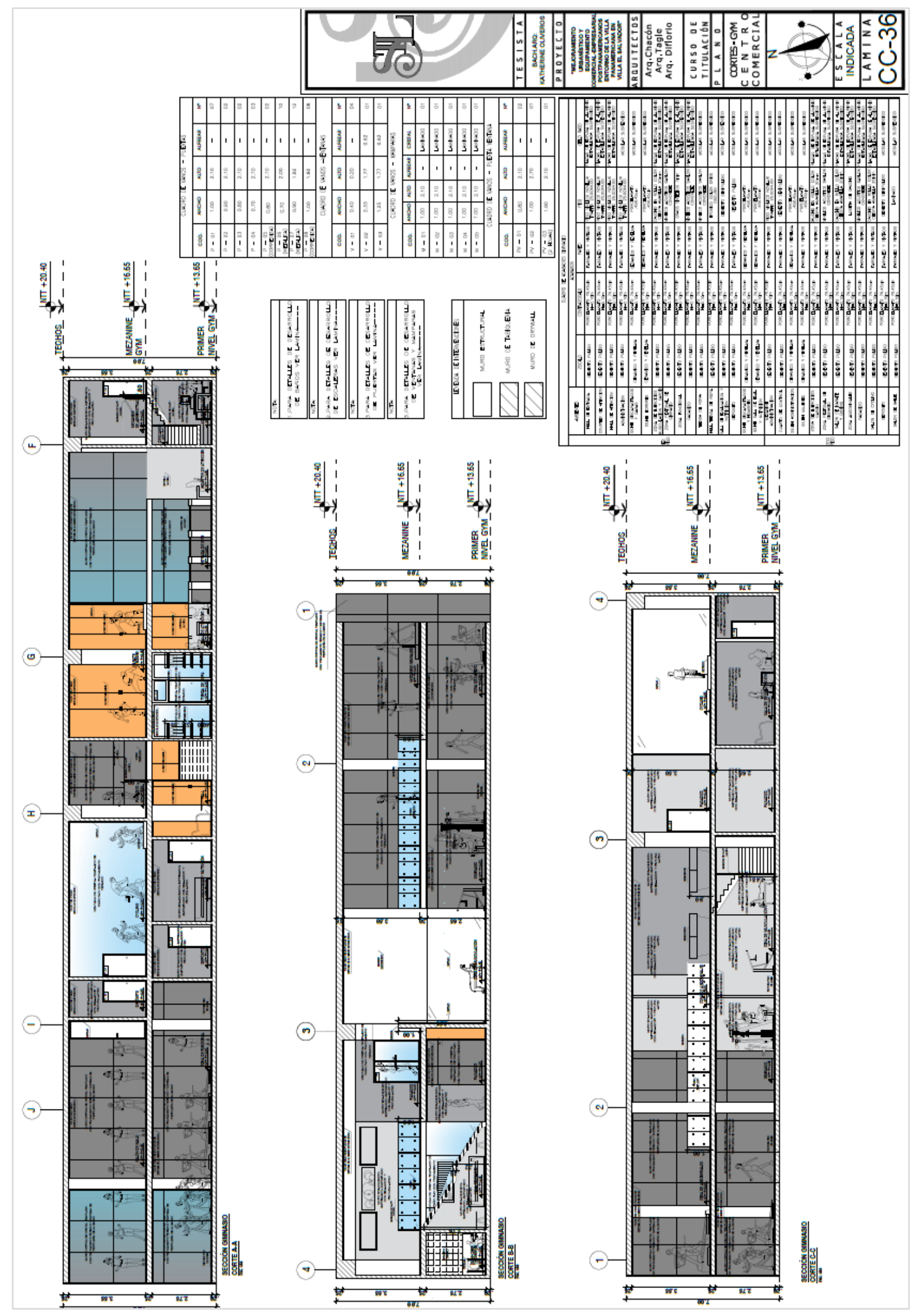


- CORTES GIMNASIO 1/50:

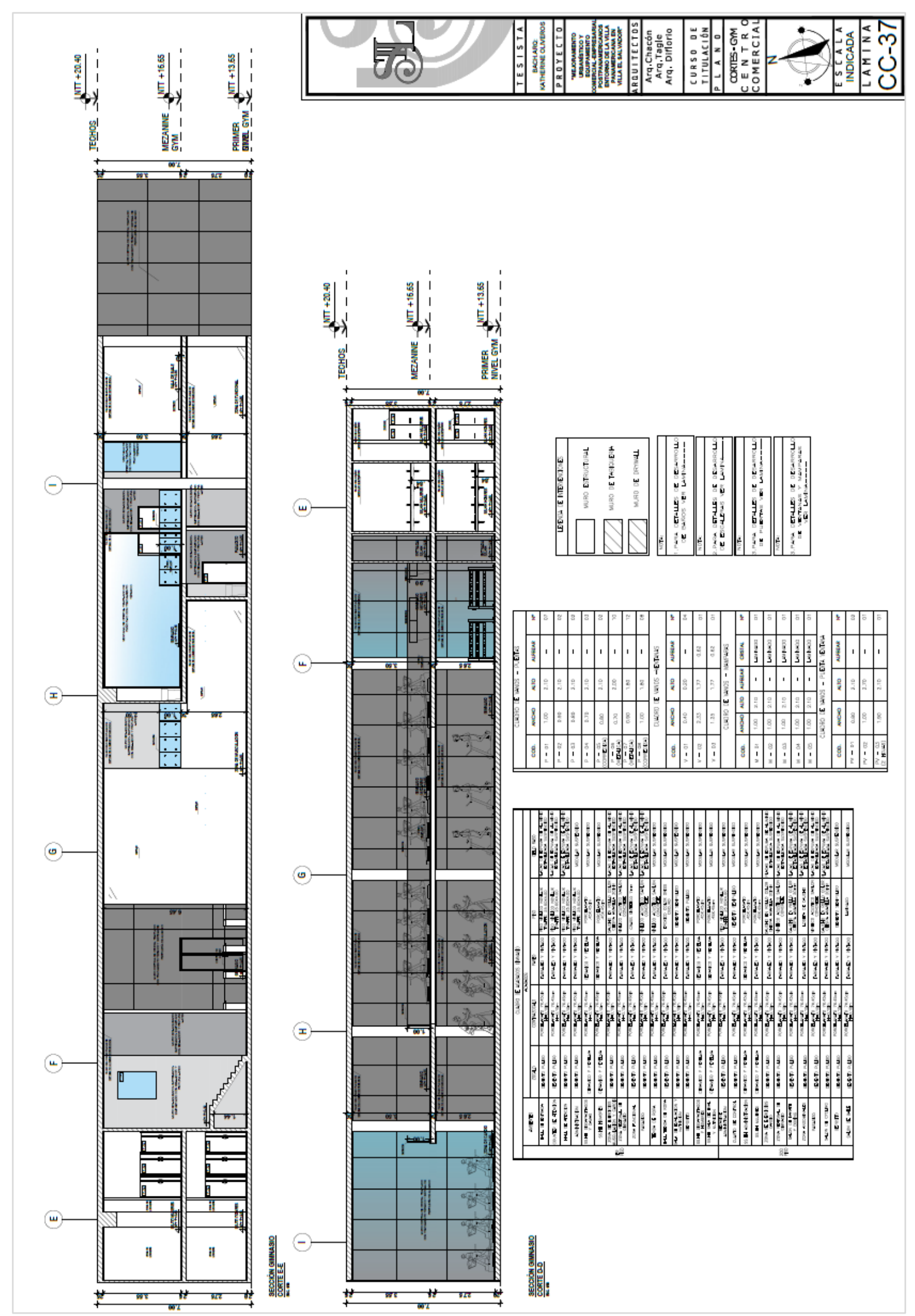


- DETALLES GYMNASIO 1/25:

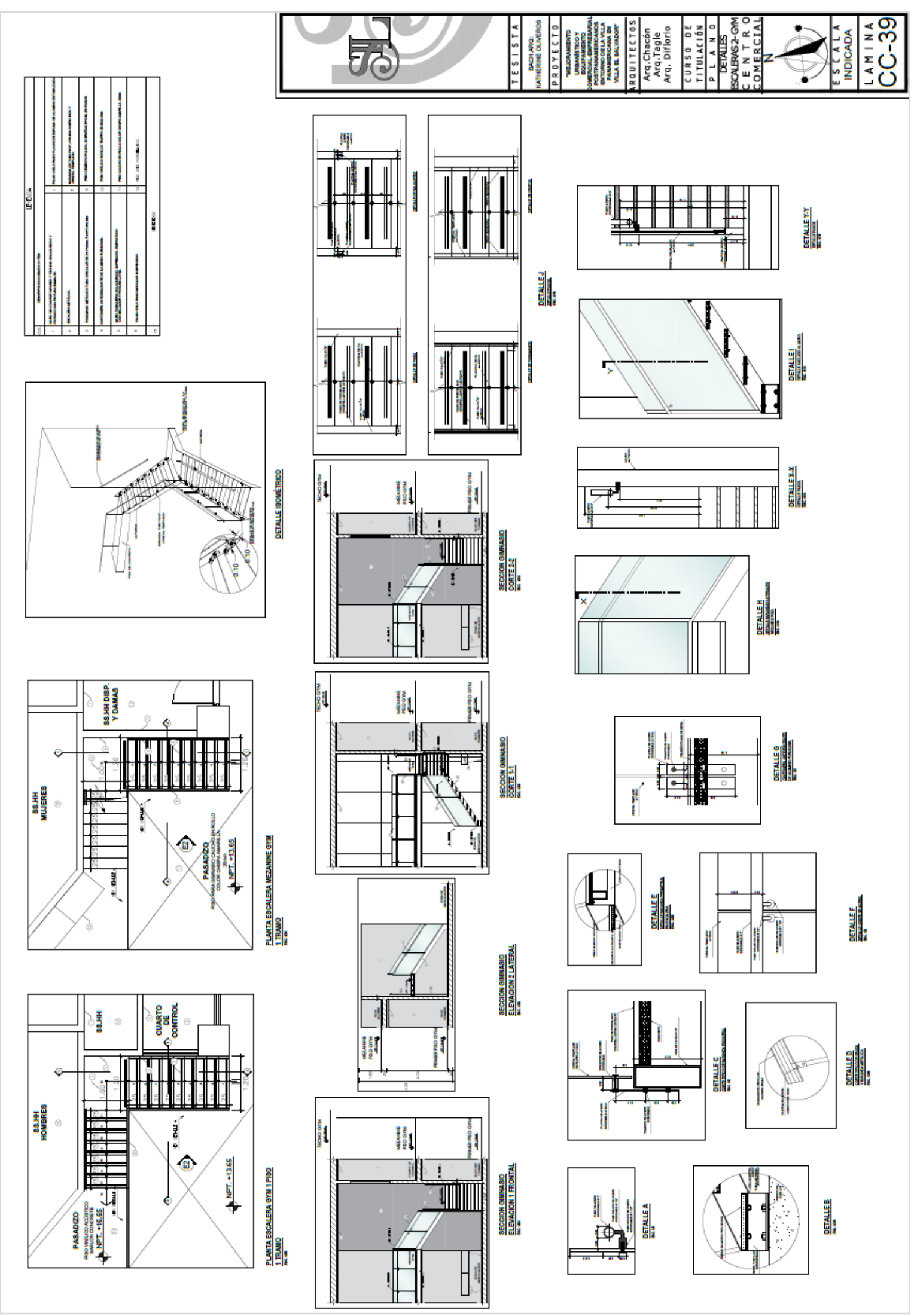


- DETALLES GYMNASIO 1/25:

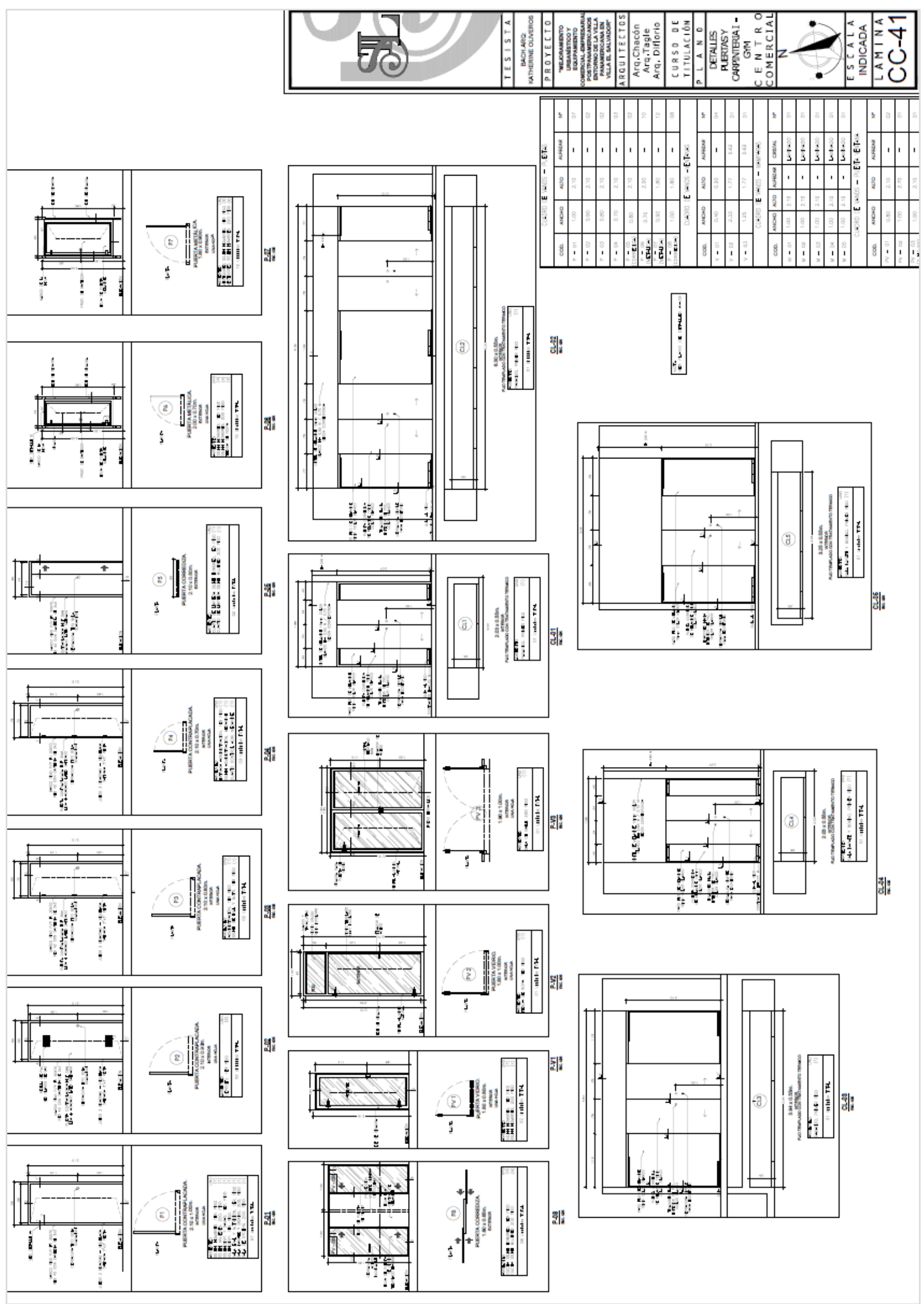


- DETALLES GYMNASIO 1/25:

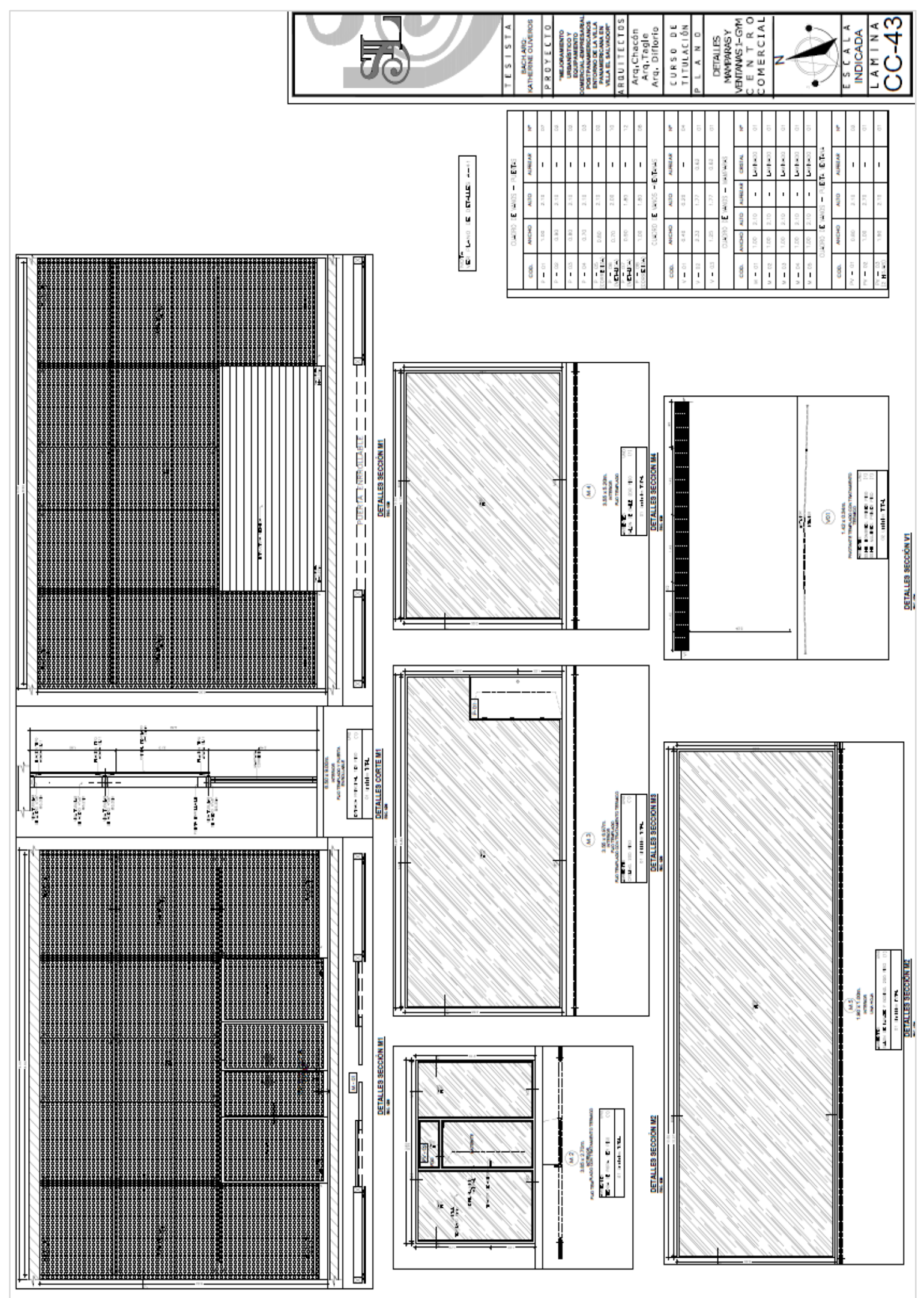


- PLANO PAISAMISMO GENERAL:

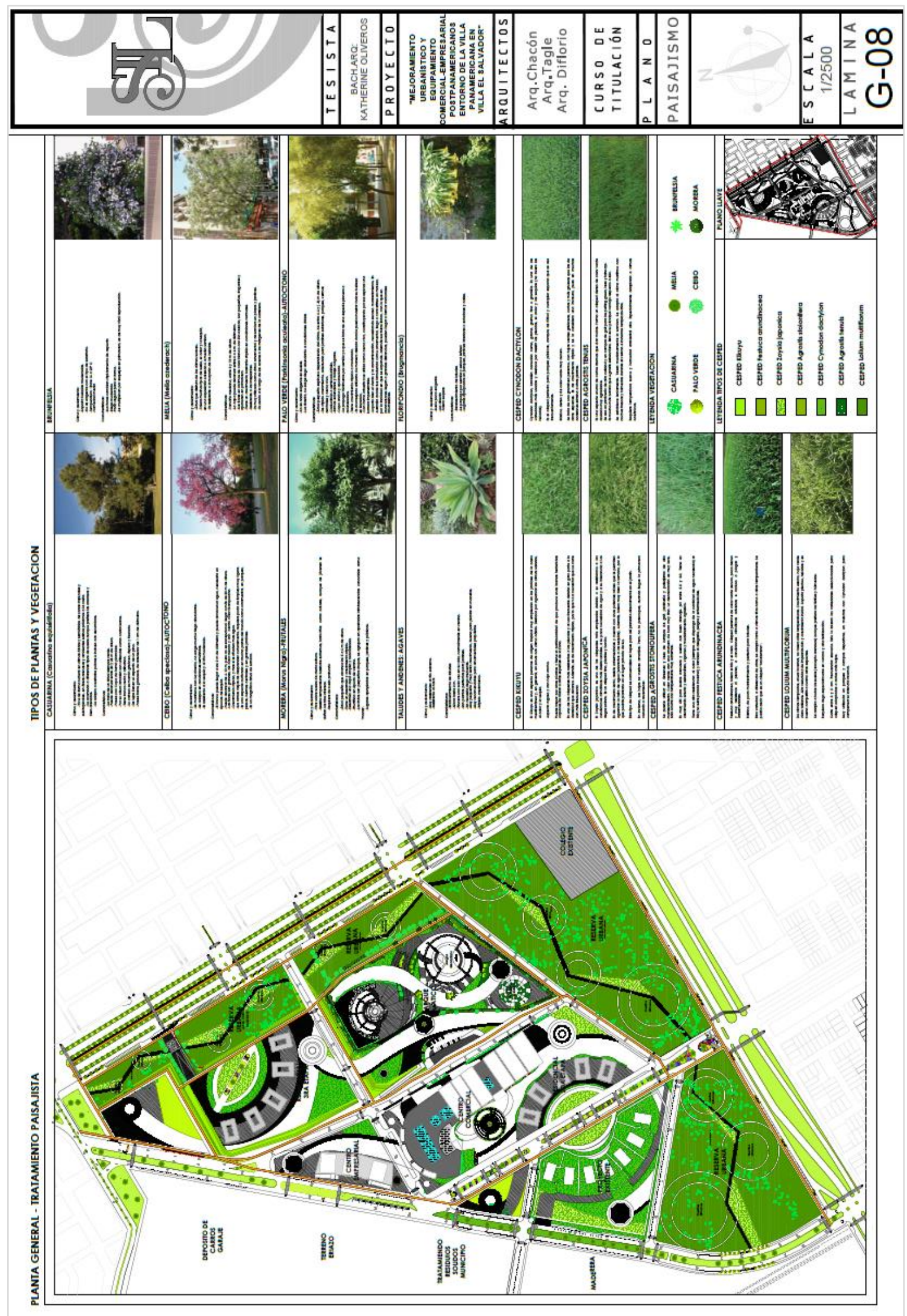


- PLANO Ciclovía General:

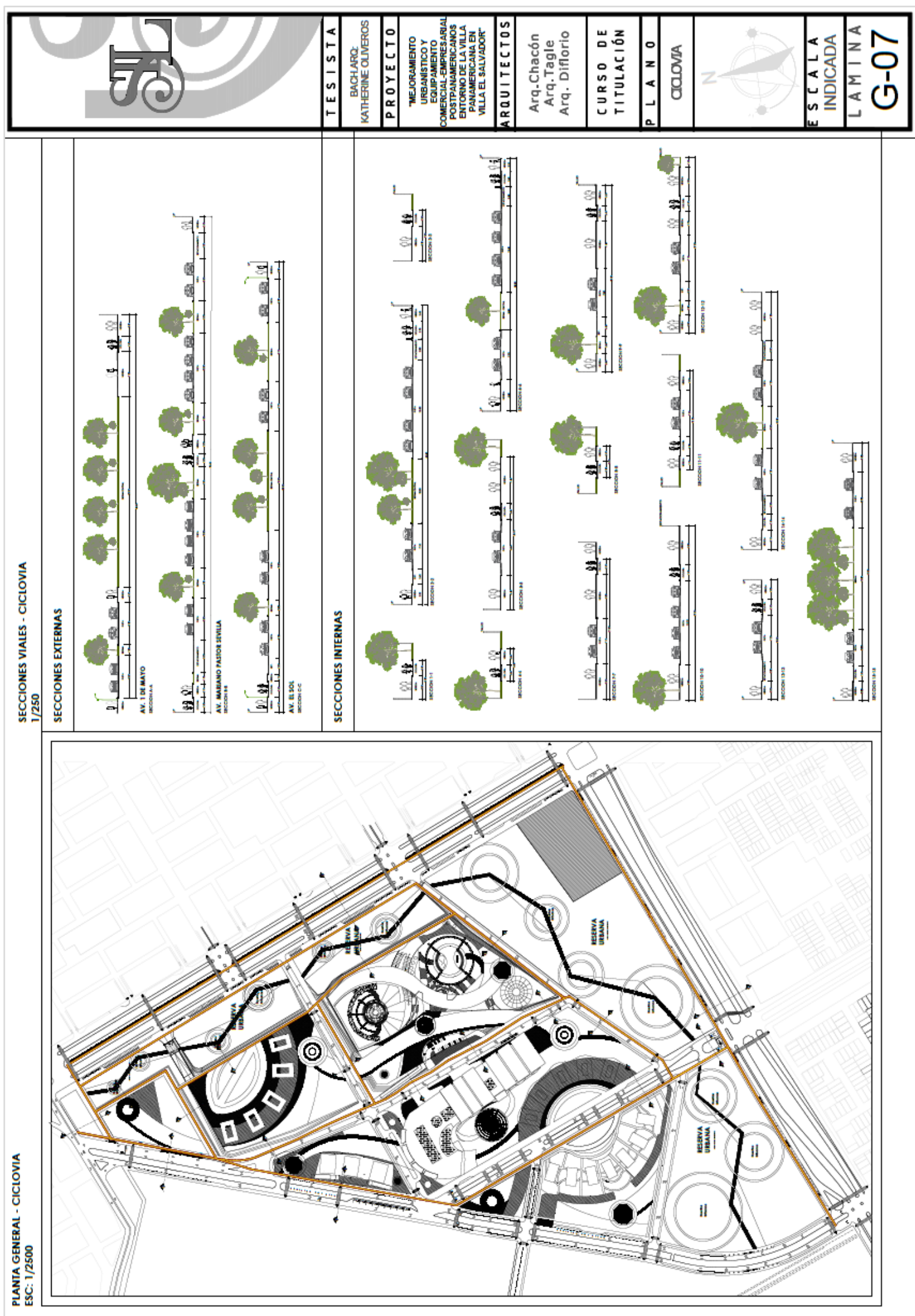


- PANEL 1 - ANALISIS MACRO URBANO:

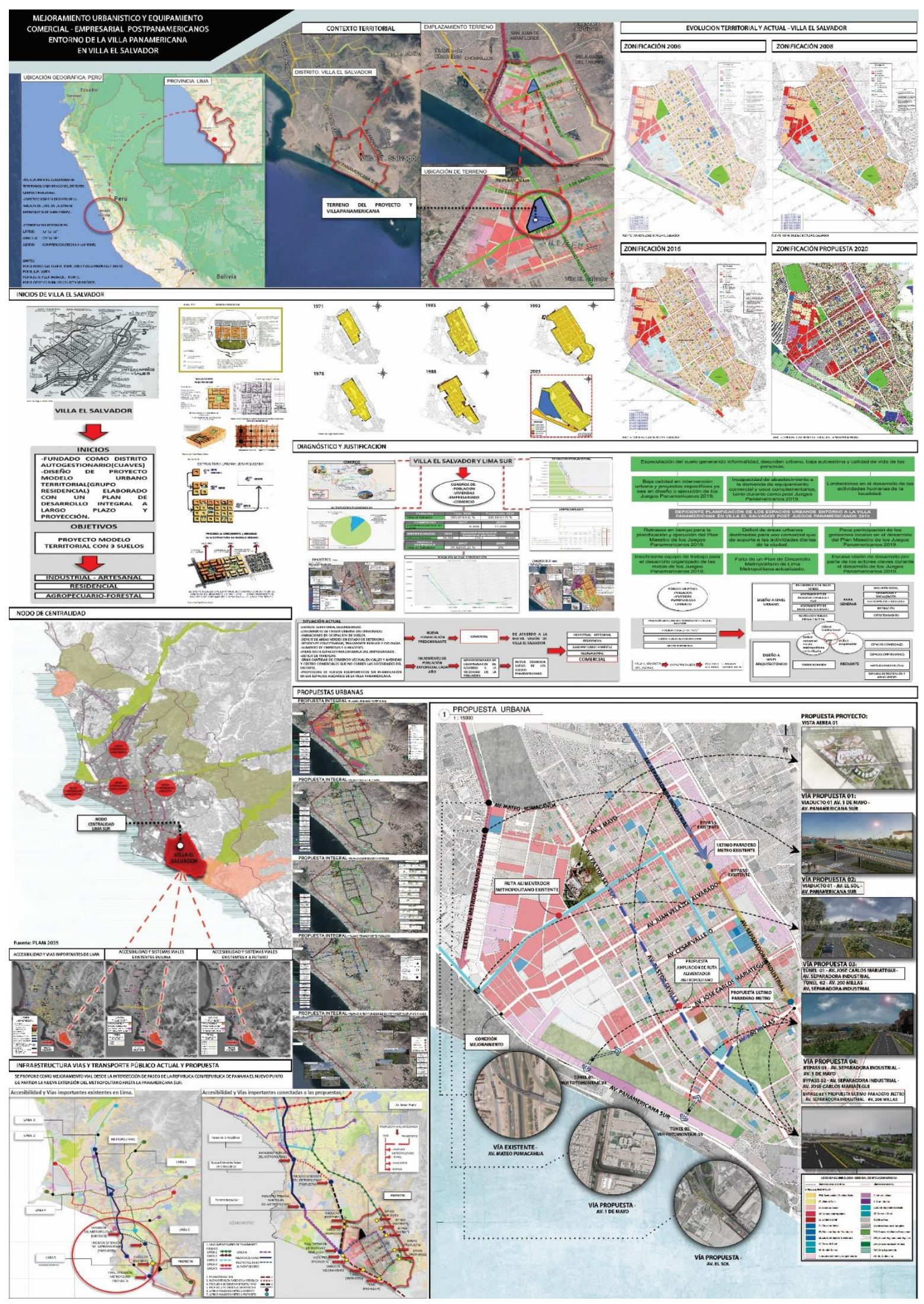


- PANEL 2 - PROYECTO INTEGRAL:

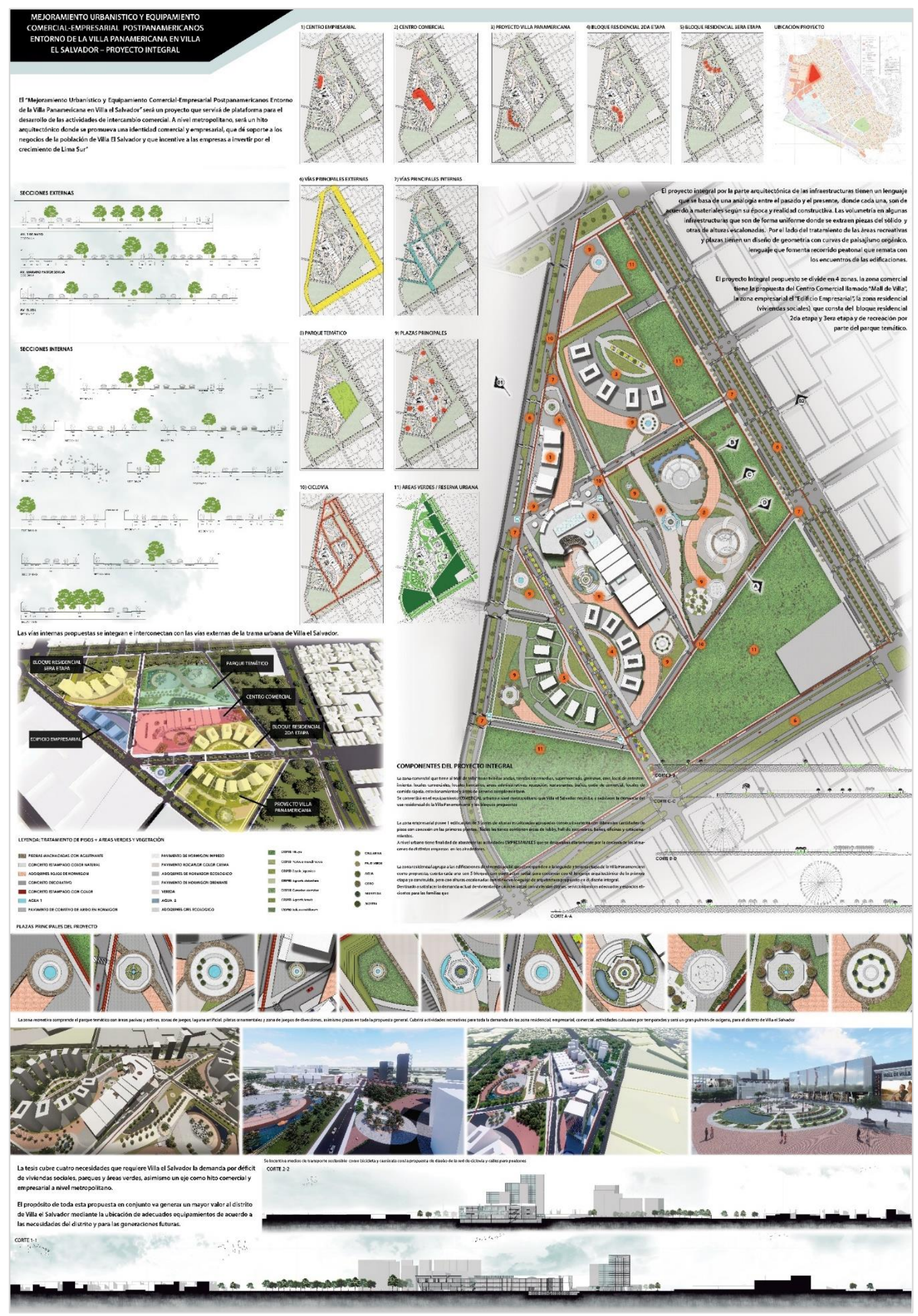


- PANEL 3 - PROYECTO CENTRO COMERCIAL:

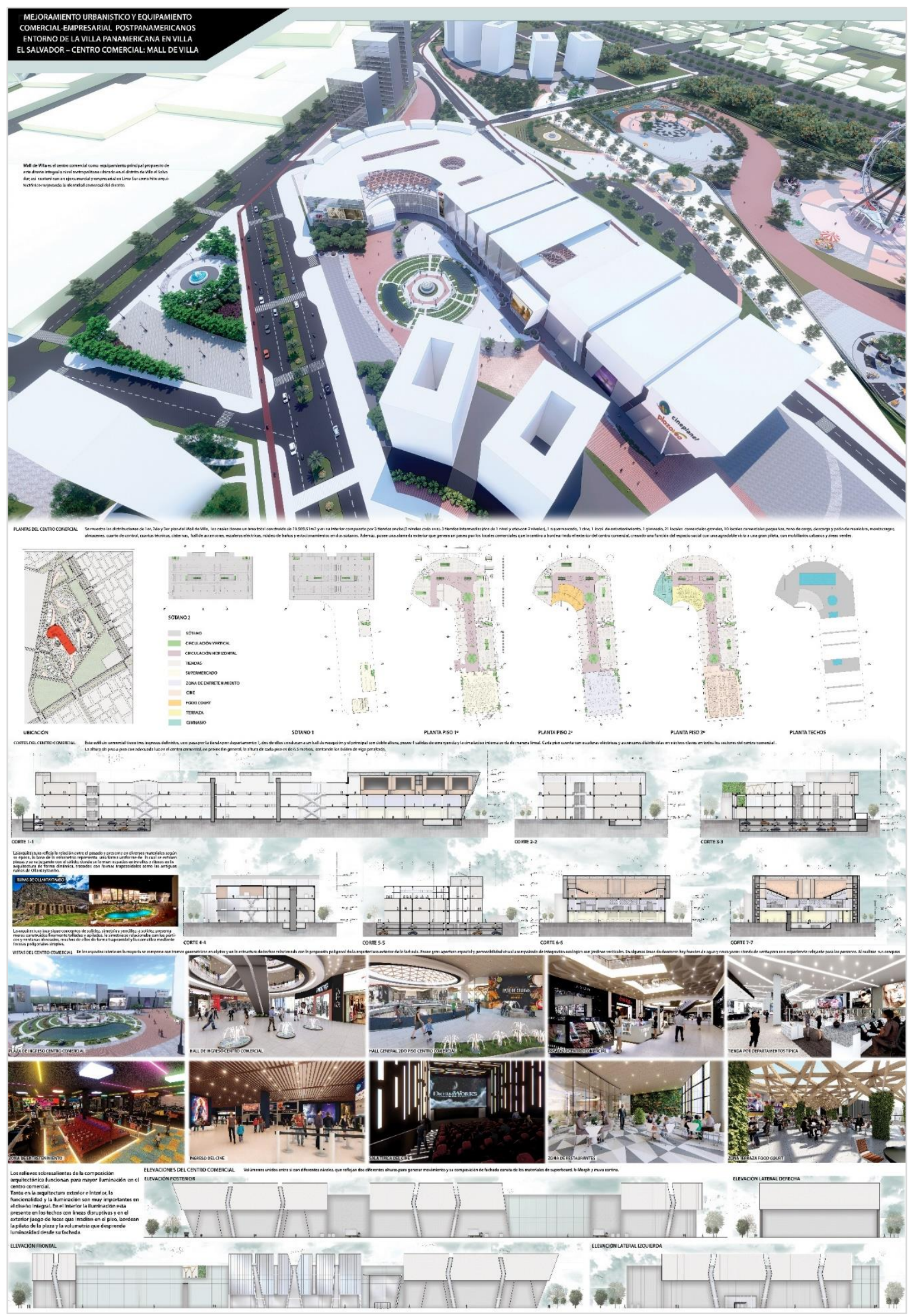


- PANEL 4 - GIMNASIO:

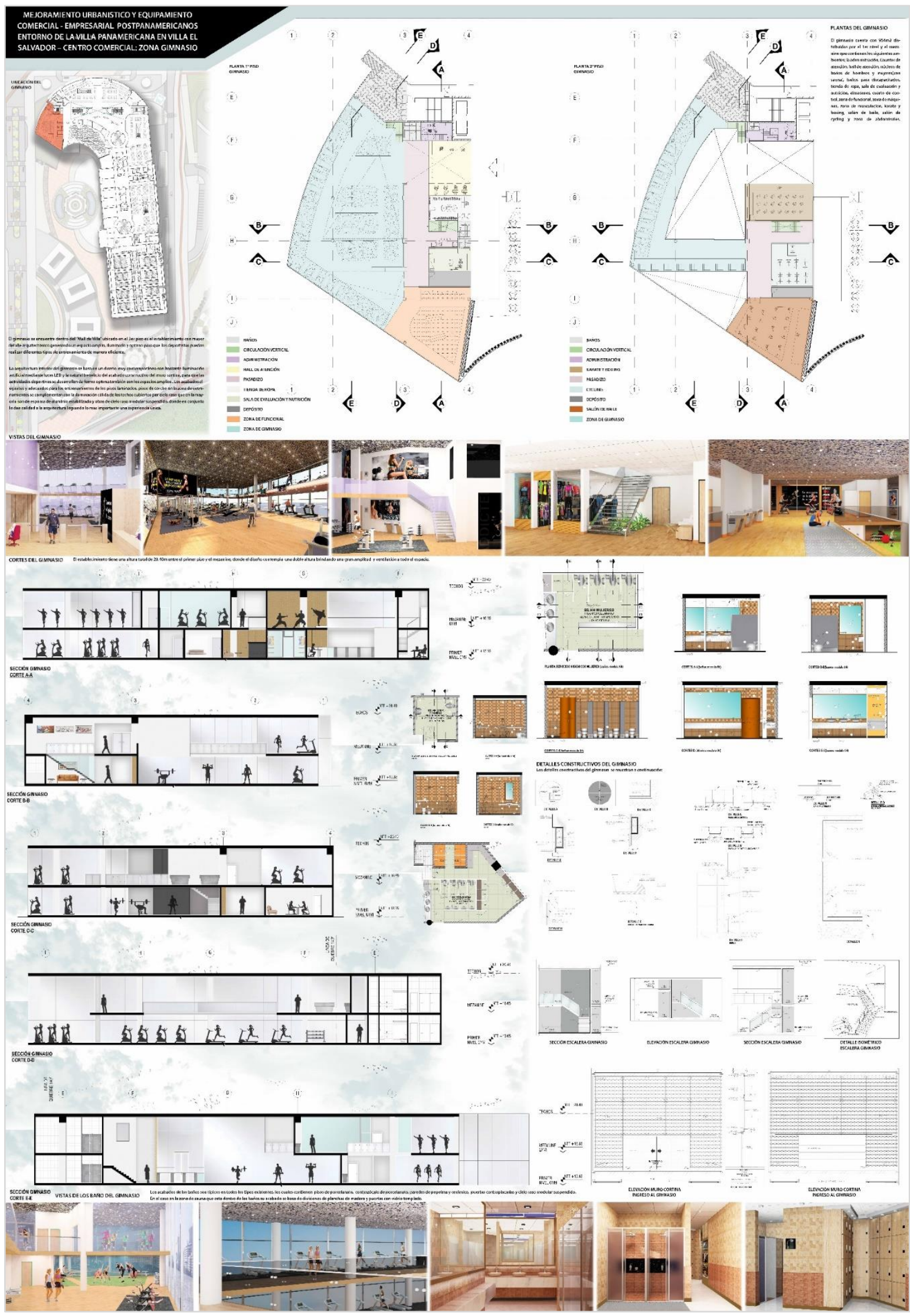


- VISTAS 3D - PROYECTO INTEGRAL:

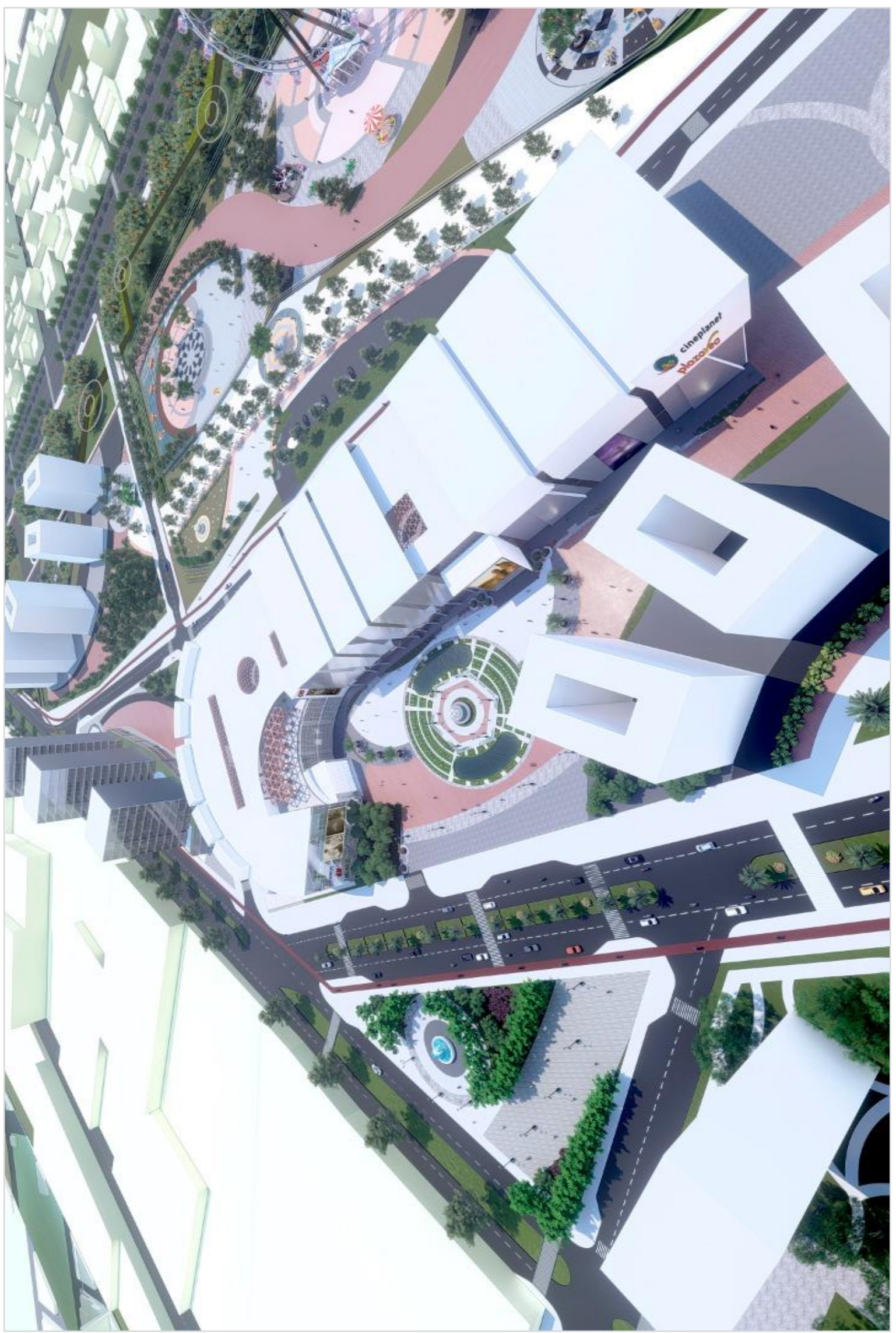


- VISTAS 3D - PROYECTO INTEGRAL:

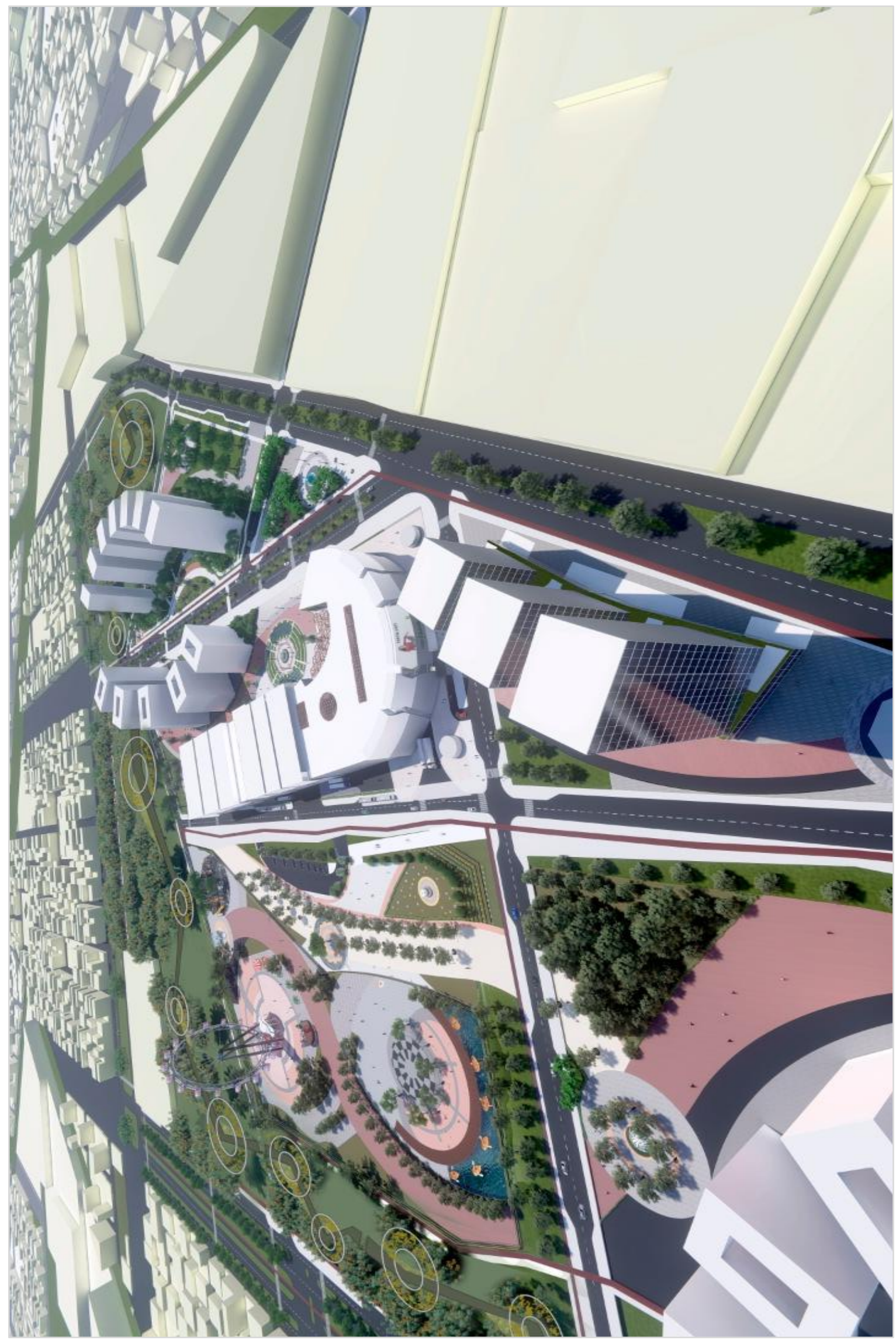


- VISTAS 3D - PROYECTO INTEGRAL:

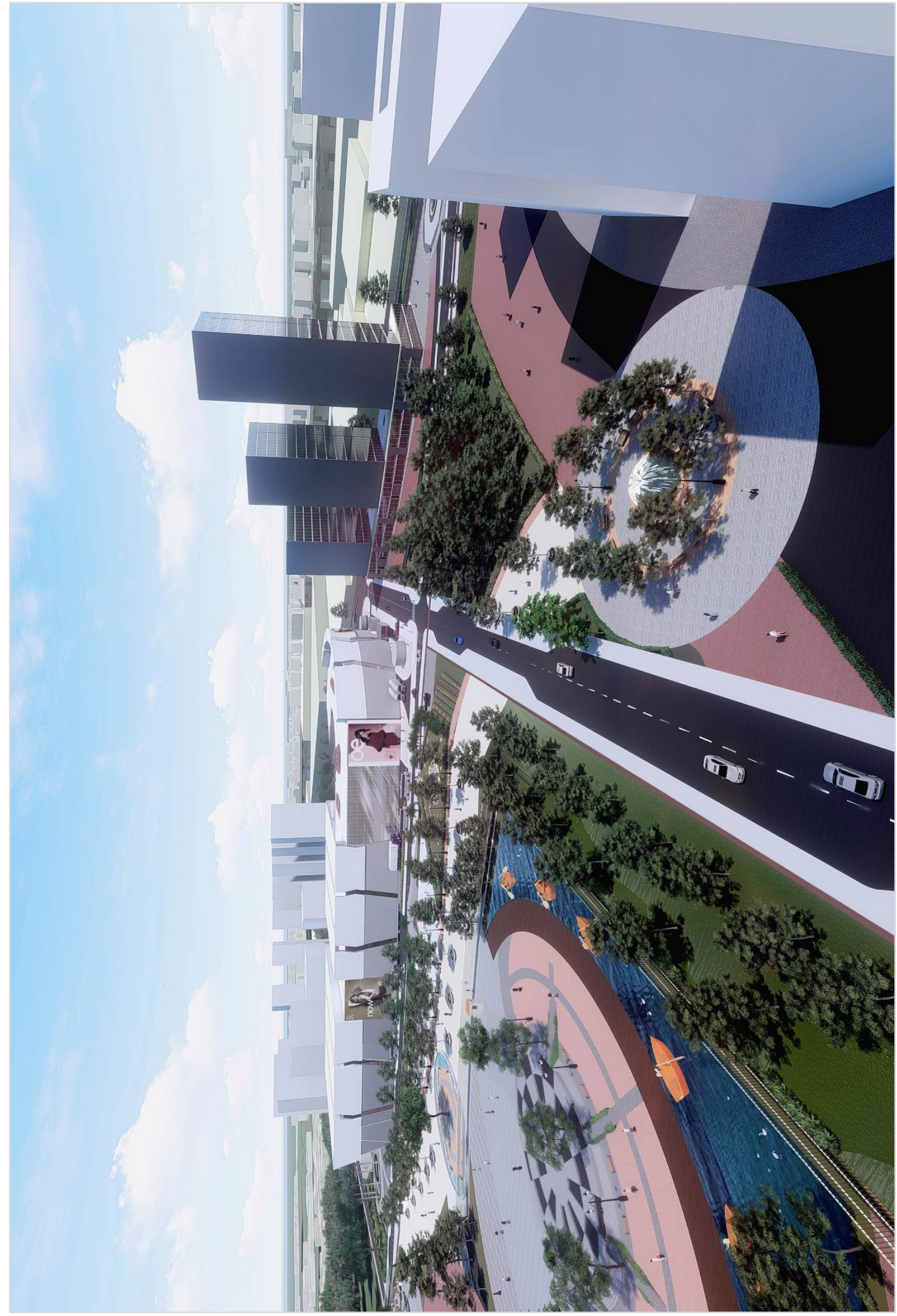


- VISTAS 3D - FACHADA CENTRO COMERCIAL "MALL DE VILLA":

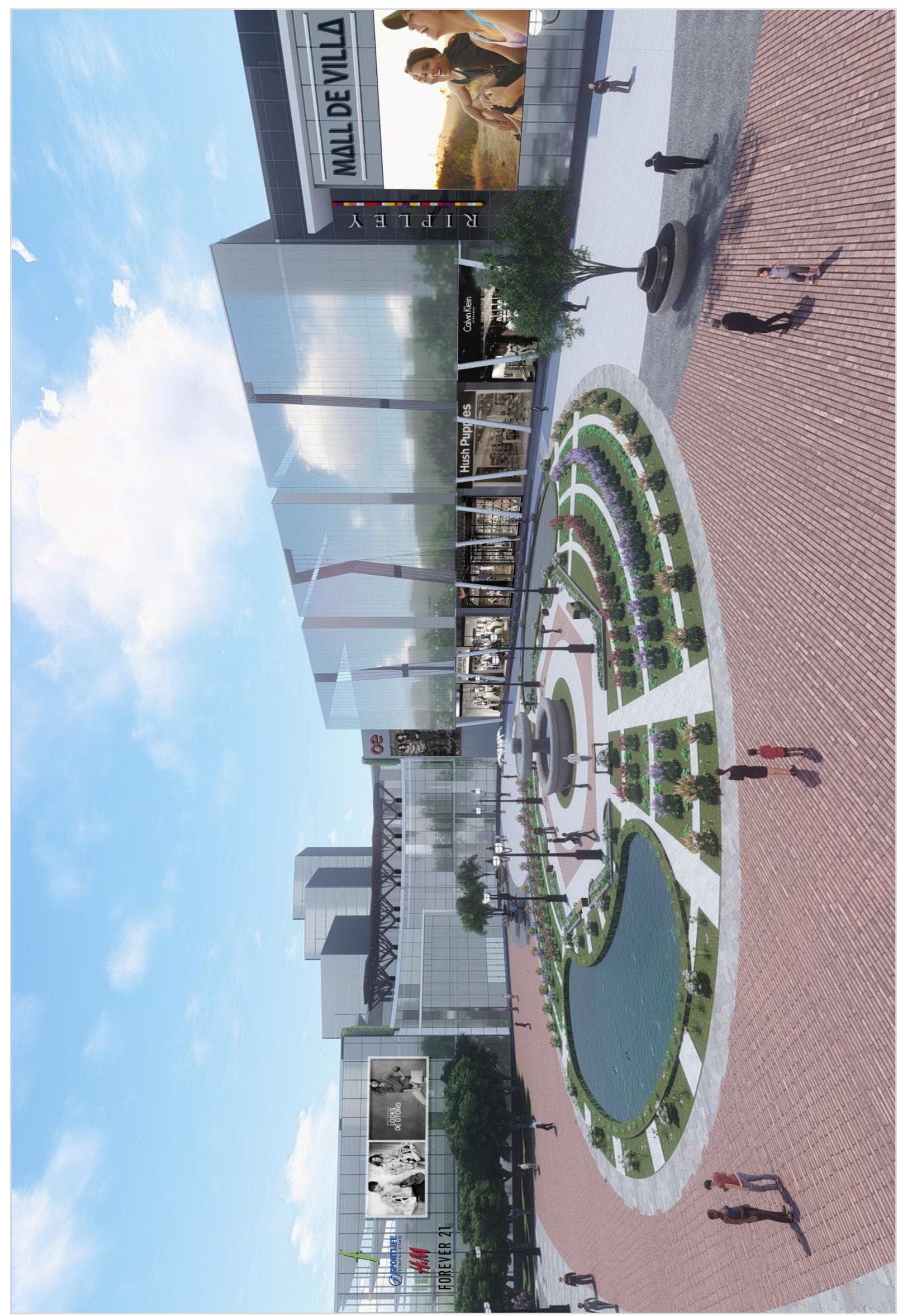


- VISTAS 3D - FACHADA CENTRO COMERCIAL "MALL DE VILLA":

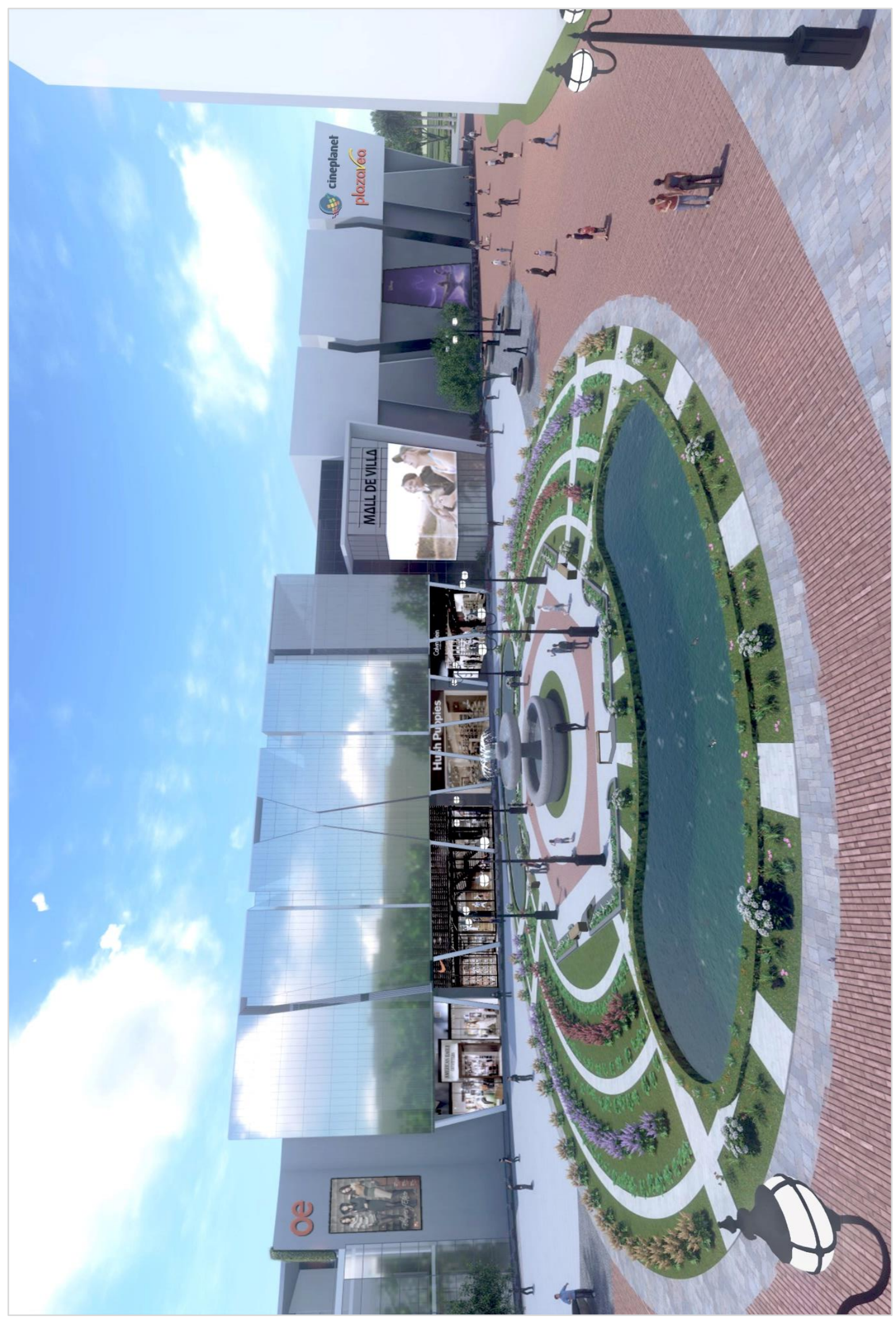


- VISTAS 3D - FACHADA CENTRO COMERCIAL “ MALL DE VILLA “ DE NOCHE:

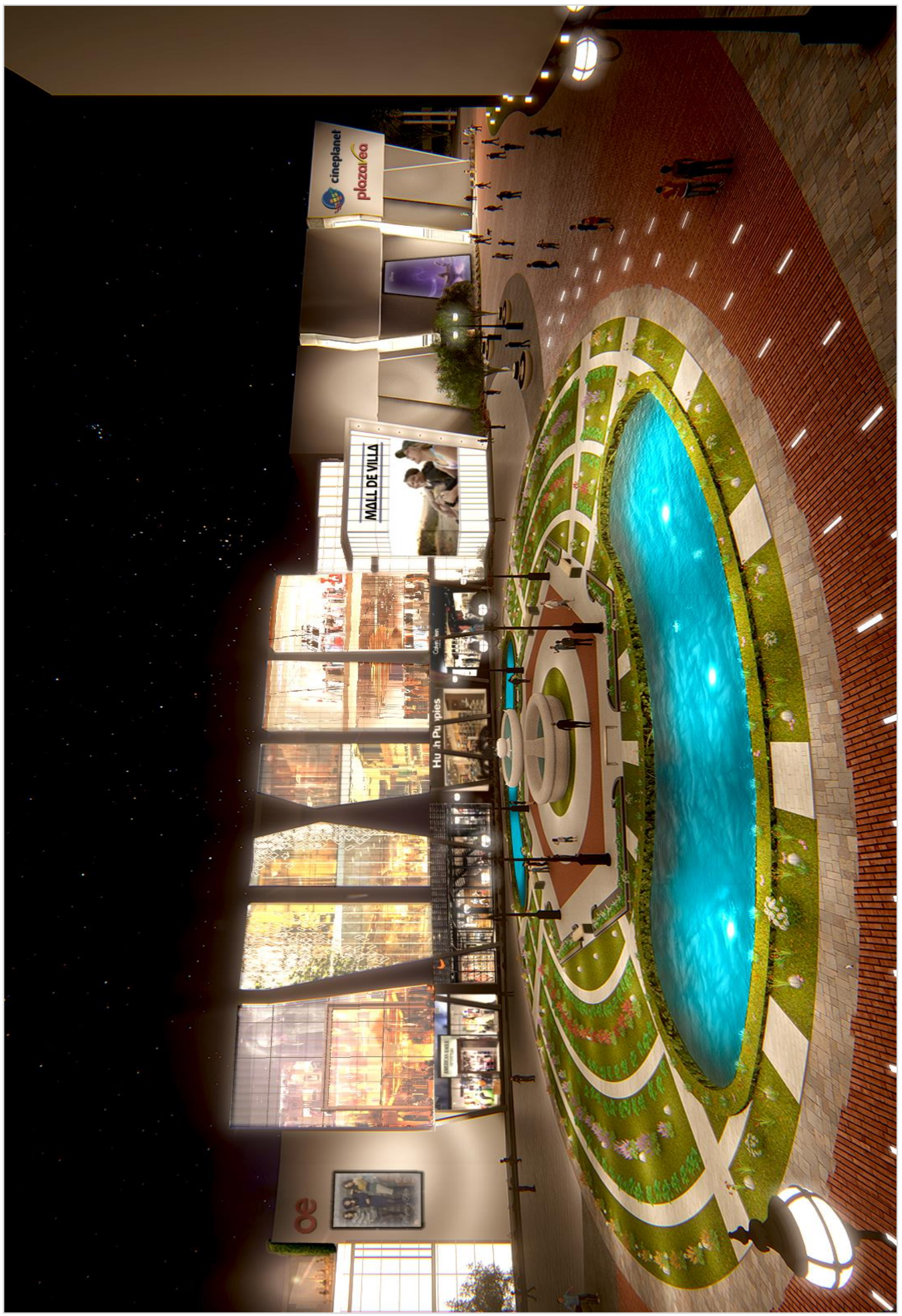


VISTAS 3D - INTERIOR PRIMER PISO CENTRO COMERCIAL "MALL DE VILLA":

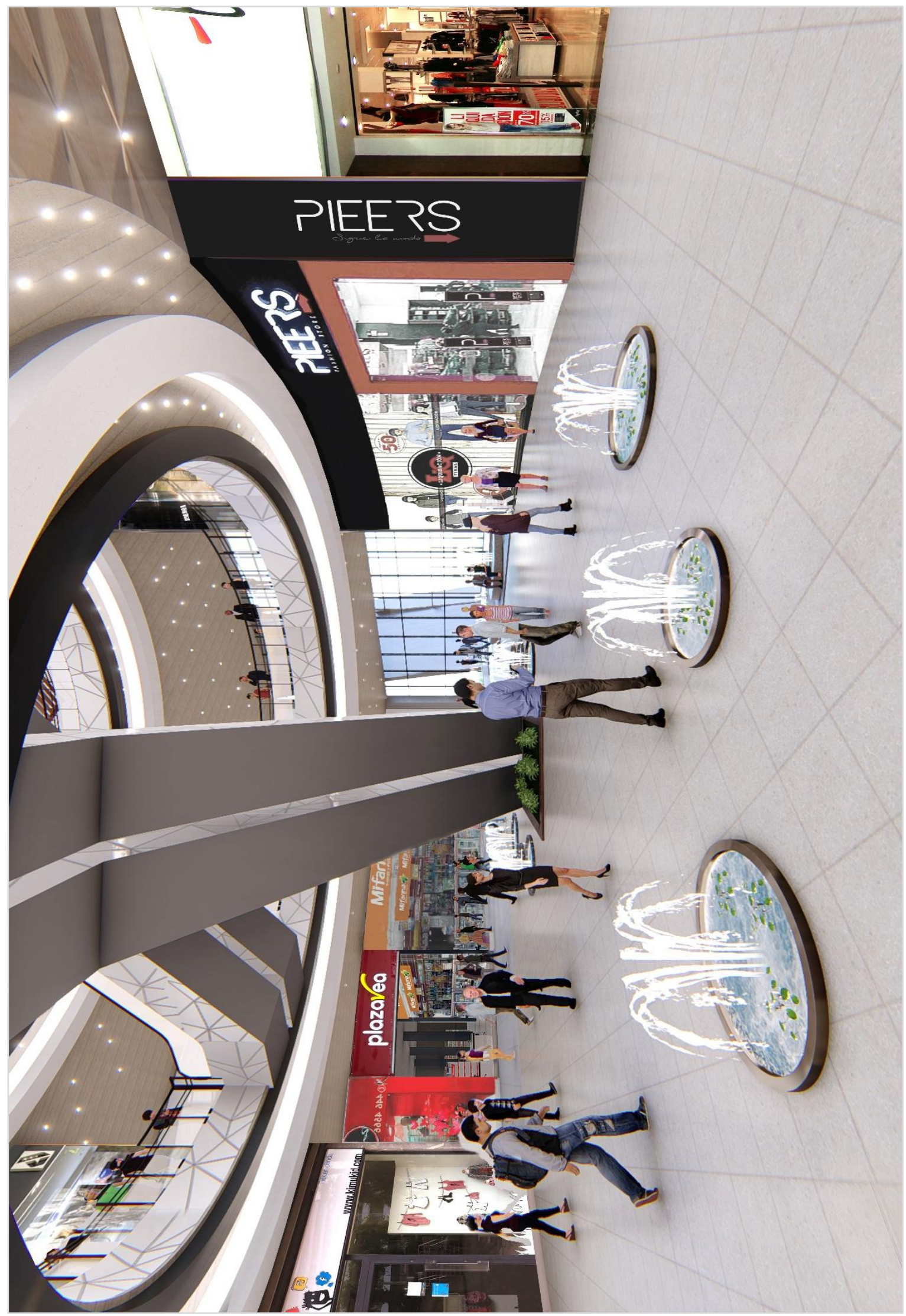


- VISTAS 3D - PASADIZO PRIMER PISO CENTRO COMERCIAL "MALL DE VILLA":

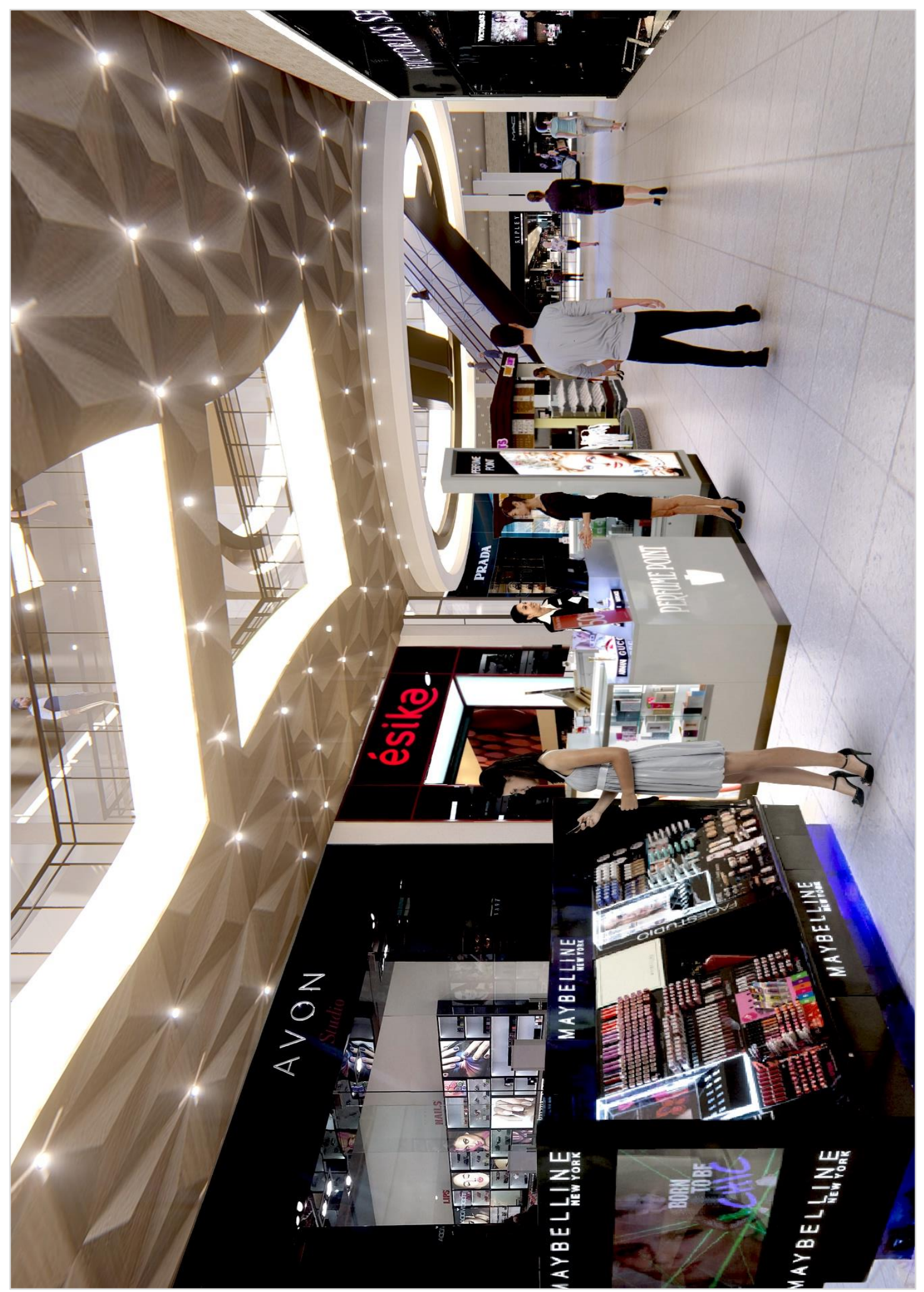


- VISTAS 3D - 3ER PISO CENTRO COMERCIAL "MALL DE VILLA":

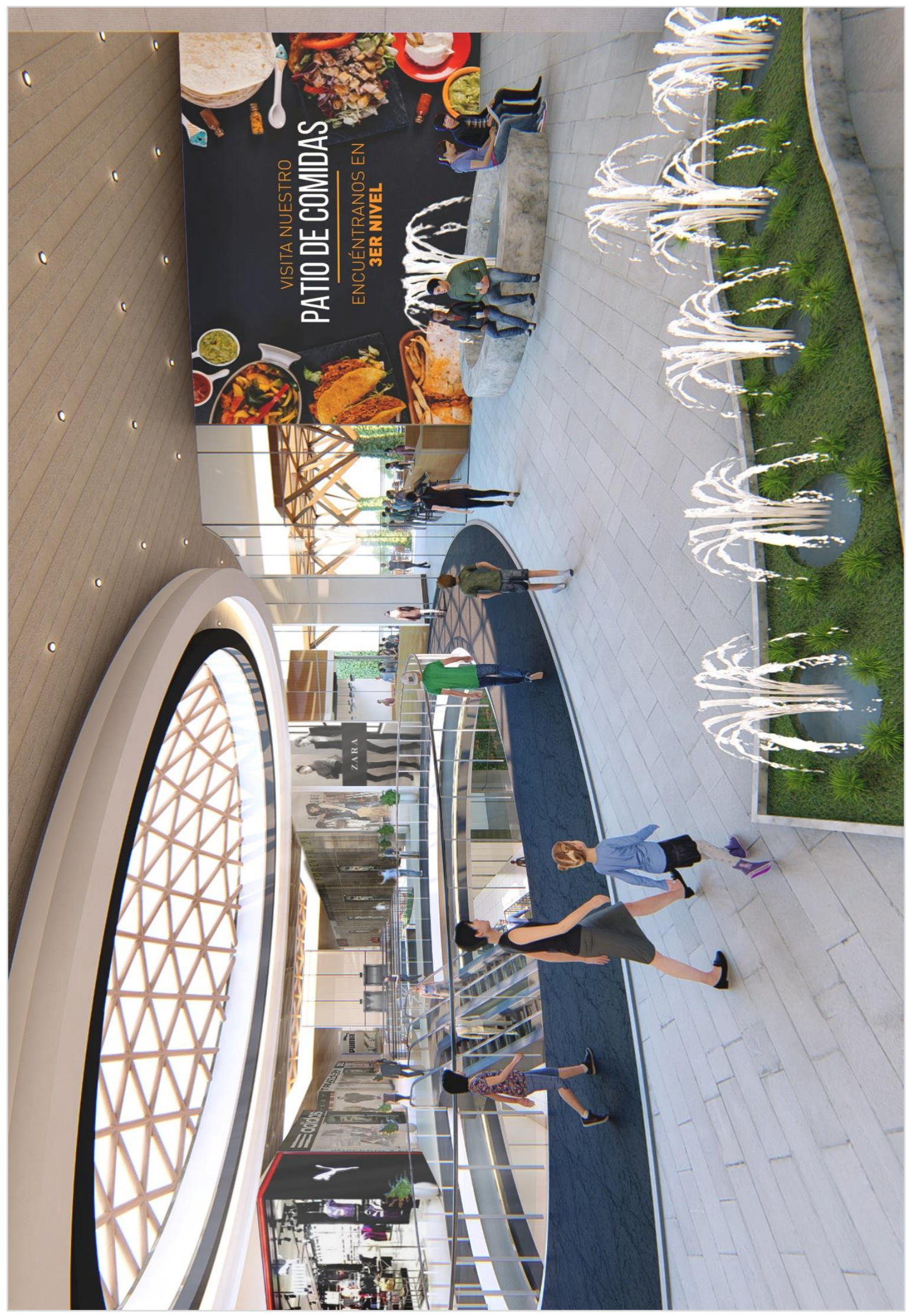

